\title{
Kiwi Prefab:
}

\section{Prefabricated Housing in New Zealand}

An historical and contemporary overview

with recommendations for the future

By Pamela Bell

A thesis submitted to the Victoria University of Wellington

in fulfilment of the requirements for the Degree of Master of Architecture.

School of Architecture and Design

Victoria University of Wellington, 2009 
KIWI PREFAB 


\section{Abstract}

If architecture could adapt itself to... succeed in the prefabricated house business, then it might recover some of the influence that it has lost in the last thirty years and begin to make a real difference to the quality of the built environment (Davies 10).

The role of the architect has been eroded from that of master architect to a coordinator of consultants (Kieran and Timberlake 29). The prefabricated house offers lessons in popularity, accessibility, and industrial production. Therefore, the challenge of the prefabricated house to the architecture profession is to reconcile artistic expression with commercial realities and reengage with the construction industry and public (Davies 10).

This thesis sets out to discover a future kiwi prefab, by investigating an unrealised potential for architect-designed prefabricated housing in New Zealand. It takes a holistic view of prefabricated housing products, systems and businesses in order to determine practical recommendations to move the industry forward towards greater uptake of prefabrication. This aim responds to a critique of the history of architect-designed prefabricated housing as, "a long continuum of noble failures" (Davies 9). Contrastingly, non-architect-designed prefabricated housing has experienced commercial success. This is evident in New Zealand's established transportable housing industry, the worldwide use of pre-nailed components in traditional construction, and the United States-based modular and manufactured housing industries.

This research starts with an introduction to prefabrication, its typologies and terminology, and its established relationships with architecture and sustainability. The previously little-known stories of prefabricated housing in New Zealand to 2009 are documented through interviews and case studies. This process of exploring and recording historical and contemporary exemplars reveals specific attitudes and approaches to issues which are then summarised and discussed. The resulting lessons reveal a need to focus on challenges and opportunities in two key areas of research and development, and marketing and communication.

The significant outcome of this research is recommendations for prefabricated housing strategies in New Zealand in 2010 and beyond. An argument is made that implemented strategic actions will lead to increased understanding of prefabrication's merits and greater uptake. Three key outcomes are a potential for a hybrid module-plus-panel typology, the need for industry cooperation and consolidation, and the formation of a marketing association to facilitate communication. The recommended strategies are then assessed in the context of New Zealand's forecast housing industry, with resulting predictions and suggestions for further research and action steps in the near future. An important finding from this investigation is the role of prefabricated housing in innovation, research and marketing for the wider architecture profession and construction industry. 
KIWI PREFAB 


\section{Contents}

\section{BACKGROUND SECTION}

\section{Chapter 1 What is Prefab?}

A Background to Prefabricated Housing 23

- Prefabrication Terminology 25

- Merits of Prefabrication 35

- Challenges of Prefabrication 39

- Prefabrication and Architecture 43

- Prefabrication and Sustainability 47

- A Theoretical Context for Prefabrication 51

\section{Chapter 2 Past Prefabs:}

A Short History of Prefabricated Housing $\quad 57$

- International Historical Overview 59

- New Zealand's History of Prefabricated Housing 71

- Historical Issues 93

\section{CASE STUDIES SECTION}

\section{Chapter 3 Kiwi Prefabs Today:}

Contemporary New Zealand Case Studies $\quad 99$

- Contemporary Case Studies 101

- Component-based Prefab - Carters Manufacturing, 101 Timber Construction Solutions, bachkit by Replica

Architects, Lockwood Group

- Panelised Prefab - Triboard by Juken New Zealand, 115

Durapanel Systems

- Modular Prefab - De Geest Construction 123

- Hybrid Prefab 129

- Complete Building Prefab - Laing Homes, McRaeway 131 Homes

- Contemporary Issues

\section{Chapter 4 Prefab Precedents:}


- Introduction to Contemporary International Prefab 149

- California Case Studies - Marmol Radziner Prefab, Michelle 163 Kaufmann Designs, Office of Mobile Design, LivingHomes, Dwell Homes by Empyrean

- International Issues

Chapter 5 New Kiwi Prefabs:

Recent New Zealand Case Studies $\quad 189$

- Recent Case Studies 191

- Component-based Prefab - Pinespan by Pinecone 191 Timber Buildings

- Panelised Prefab - Drop-Loc Building System by 193 Bay Property Care

- Modular Prefab 197

○ Hybrid Prefab 197

- Complete Building Prefab - ipad by Architex, 199 Habode and i-houz, port-a-bach by Atelier Workshop, Koastline Beachouses by Kodesign Builders

\section{SYNTHESIS SECTION}

\section{Chapter 6 Challenges and Opportunities:}

Summary of Lessons Learnt

- Lessons Learnt

- Key Challenges and Opportunities

\section{Chapter 7 Strategies:}

Key Opportunities, Solutions and Recommendations

- Marketing and Communication

- Research and Development

- Recommendations

- Proposed Marketing and Communication Strategies

- $\quad$ Strategy Summary

\section{Chapter 8 What Now?}

The Future of Prefabricated Housing in New Zealand

- New Zealand Housing in the Near Future

- $\quad$ Future Potential of Prefabricated Housing

- Future Predictions, Suggested Research, and Action Plan 


\section{Chapter 9 Conclusions:}

Evaluation, Reflection and Implications

- Addressing the Aim

- Scope of the Investigation

- Reflection on Key Findings

\section{Appendices}

A. Interview Questions $\quad 335$

B. List of Industry Participants 336

C. Sample Interview Transcript: Keith Clark 340

D. Sample Case Study: Industrialised Building Systems 343

E. Table of Findings 352

F. Chronological Index 359

Glossary 
KIWI PREFAB 


\section{Acknowledgements}

I would like to acknowledge the contributions of the following assistance in terms of financial support, professional support and personal support for the two years that this research took place (mid-2007 to mid-2009).

Financial support was gratefully received from a twice-awarded Victoria University of Wellington Masters by Thesis Scholarship (2008 and 2009), a New Zealand Postgraduate Study Abroad Award (2008), a Porirua City Council Waste Minimisation Scholarship (2008) and a Todd Foundation Award for Excellence (2008). These scholarships enabled numerous first-hand site visits to be made to New Zealand prefabricated housing businesses, as well as research trips to Los Angeles and New York for conferences, exhibitions, interviews and site visits.

Professional support was provided by supervisor, senior lecturer and practicing architect Mark Southcombe. His positive encouragement and detailed focus ensured that the research programme was adhered to and a structured thesis outcome was achieved. Valuable guidance was provided by proof-readers and Victoria University's School of Architecture staff members Guy Marriage, Christine McCarthy, Michael Dudding and Robin Skinner. Professional writer Charlotte Hurley and librarian Robyn East gave valuable advice on grammar and editing. The School of Architecture librarians were very helpful and their resourcefulness was a key reason for choosing to undertake this Masters at Victoria.

Further thanks go to the long list of industry participants who volunteered time, energy and enthusiasm to respond to interviews, site visits and follow-up queries. This thesis relies on firsthand research so their input was vital. A full list of these people is attached in Appendix B.

Final thanks go to my wider family group for personal support, and in particular my husband Tim Park and my daughter Sophie Park for helping to keep life in perspective during the demands of this research period. 


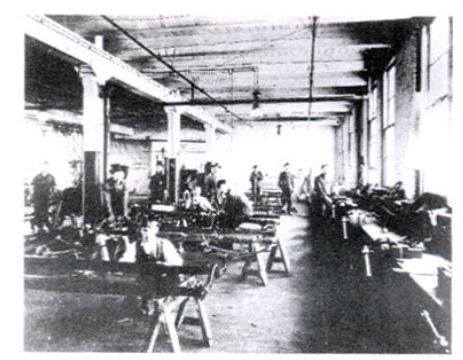

SINGULAR CRAFT 1900

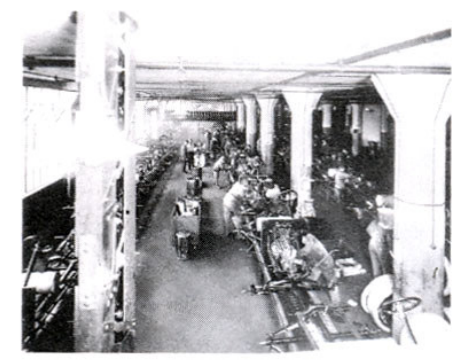

ASSEMBLY LINE 1920

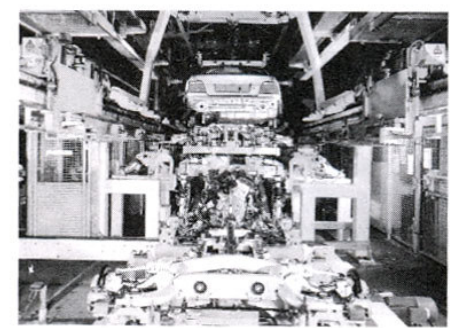

MODULARIZED 2003

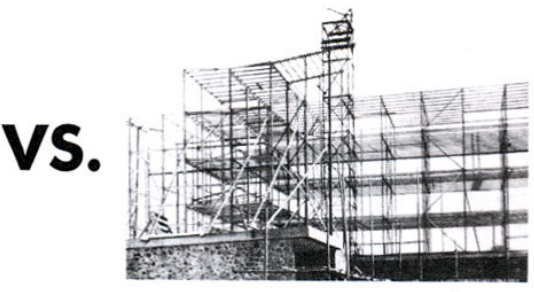

SINGULAR CRAFT 1900-2003

Figure 1: Changing car manufacture methods, compared with singular craft-based assembly in construction over the last century. Source: S. Kieran and J. Timberlake, Refabricating Architecture, New York: McGraw-Hill, 2004: 84. 


\section{Introduction}

This thesis will examine prefabricated housing in New Zealand, in order to document its status in 2009 and propose ways to increase the uptake of architect-designed products and systems for 2010 and beyond. This investigation responds to an identified issue:

The way architects design and contractors build is hopelessly broken (Kieran and Timberlake, Loblolly House 158). ${ }^{1}$

Today, housing construction processes vary little from that of a hundred years ago (1). ${ }^{2}$ According to industry expertise, they are out-moded, out-dated, and out-of-touch. The New Zealand construction industry follows an identified worldwide pattern based on a lack of research, wasteful processes and uncertainty (Gann 6). Historically, architects have expressed motivation to dream, explore and design new methods of construction for the housing industry in an effort to address these issues. They have produced prototypes, experiments and exemplars of housing delivery alternatives. Part of that design process has been to look more closely at ways to improve construction quality and regain control over the final housing product outcome.

Innovative residential construction is an ongoing focus of United States architects, academics and researchers Stephen Kieran and James Timberlake. They express their frustration with design and construction processes that often extend beyond forecast timeframes and budgets:

Why are we consistently forced to make design decisions on the basis of cost that result in less choice, less customisation, more standardisation, and less quality? Why are we faced with numerous quality issues at the end of the construction process, solved only by reams of paper and countless hours of time? ...As architects we find it difficult to stop designing and not involve ourselves in the construction process (Kieran and Timberlake, Refabricating Architecture 135).

This sentiment is echoed by other architecture professionals around the world, several of whom have resolved to address quality control issues, and their stories form the case studies in this thesis. They have responded with collaborative software networks, by taking on the role of general contractor, or have set up their own factory production. These initiatives have provided exemplars for improving construction quality through increasing communication, taking more control, and moving production away from the building site.

Construction processes that occur away from the building site are known as prefabrication, or prefab (2). ${ }^{3}$ Prefabrication is an amalgam of design and business. It presents an opportunity for architects to recognise "commodity as an equal partner to art", and potentially make architecture "as accessible, affordable, and sustainable as the most technically sophisticated consumer products available today" (Kieran and Timberlake, Refabricating Architecture xii). Prefabricated

\footnotetext{
1 This thesis uses the Modern Language Association (MLA) system of in-text citations, with a list of works cited at the end of this document. Book and journal citations include a page reference or 'np' where no page number is given. Electronic articles, website pages and personal communication is non-paginated so the in-text citation does not include a page reference. Figures are sourced according to MLA guidelines. All web-based images were sourced in June 2009

2 Figures (illustrations, charts, diagrams and photographs) are referred to in text by their number in bold.

${ }^{3}$ Prefab is a widely-used abbreviation of prefabrication which indicates either the process or the end-product. Refer to Chapter 1 and Glossary for further explanation of terms.
} 

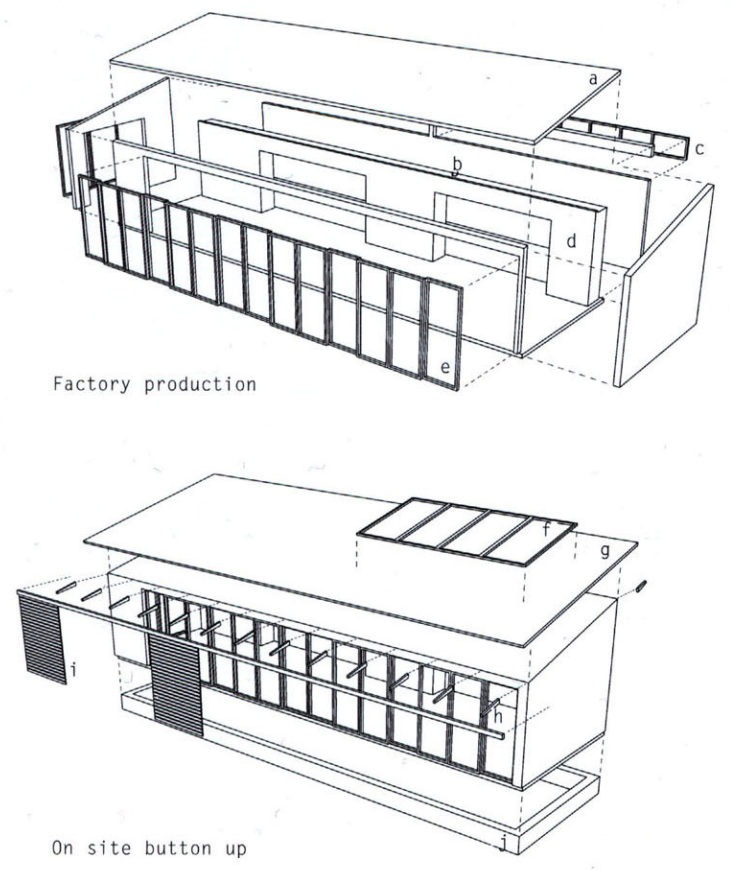

a. Roof structure

b. Hidden up-lighting

c. Clerestory windows

d. Storage bar

e. Siding glass wall

f. Site installed solar panels

g. Site installed standing seam metal roofing

h. Roof brackets

i. Siding wood screens

j. Site built foundation

k. Site built deck

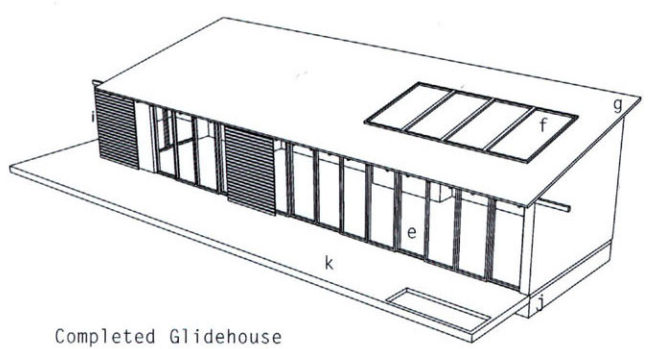

Figure 2: Prefabricated factory production combines with site-based finishing, in Michelle Kaufmann's Glidehouse. Source: S. Costa Duran, Green Homes, New York: Collins Design, 2007: 68. 
housing has formally existed since the turn of the nineteenth century and is commonly referred to by its typology: kitset, panelised, modular and transportable.

Historically, many architect-designed prefabricated housing systems have not made the leap from innovative prototype to commercial success. This begs the question of why business triumph has been elusive. It has given architect-designed prefabricated housing the reputation of signifying an unobtainable 'holy grail' (Gardyne). This status makes the subject of prefabrication even more intriguing.

The dream of packaged kit houses purchased via mail-order catalogue or off-the-shelf has always been...the holy grail of Modern architecture (Ebong 12).

The dream that Ima Ebong refers to is a potential for prefabricated housing. Over the following chapters this dream will be investigated towards discovering a potential for architect-designed prefabricated housing in New Zealand.

\section{Aim and Scope}

An unrealised potential for architect-designed prefabricated housing in New Zealand will be investigated in this thesis. The specific research objective is to formulate proposed key strategies for the prefabricated housing industry, in order to increase the uptake of prefabrication. ${ }^{4}$ Several other objectives will be achieved during this process. A new clarity of understanding about prefabrication definitions, typologies and merits will be established. The little-known stories of prefabrication pioneers in the last century of New Zealand's history will be documented for the first time through primary research interviews and site visits. Case studies of contemporary and emerging housing products will be similarly documented. Key prefabricated housing industry participants' attitudes and approaches to issues will be summarised for the first time. These issues will be grouped and analysed to form valuable lessons, which will then be discussed to inform the proposed strategies for the near future.

The scope of the investigation is limited to detached prefabricated housing products and systems in New Zealand since the mid-nineteenth century; the kiwi prefab. ${ }^{5}$ This research scope excludes recycled container architecture, temporary post-disaster structures, mobile chassis-based dwellings and multi-unit housing. ${ }^{6}$ It will draw on in-depth literature surveys and first-hand case studies to determine issues faced by New Zealand's prefabricated housing businesses. These will form a basis for a critical appraisal of the key areas of challenges and opportunities, and design of recommended strategies for the future.

${ }^{4}$ The term 'industry' is used to refer to all prefabricated housing businesses in New Zealand. This is despite a cohesive industry presence, structure or association.

${ }^{5}$ According to the New Zealand Department of Immigration's Glossary "Kiwis is a colloquial term for New Zealand people, and a Kiwi is a New Zealander or something that is New Zealand. It is also one of New Zealand's national symbols because of the kiwi bird which is unique to New Zealand."

${ }^{6}$ Further, this research is not a definitive worldwide history of prefabrication; for this refer to writings by Colin Davies or Barry Bergdoll and Peter Christensen. It is not an illustrated book of contemporary prefabs; for these refer to books by Allison Arieff and Bryan Burkhart or Jill Herbers. It is not a treatise such as those by Stephen Kieran and James Timberlake or Burnham Kelly. 


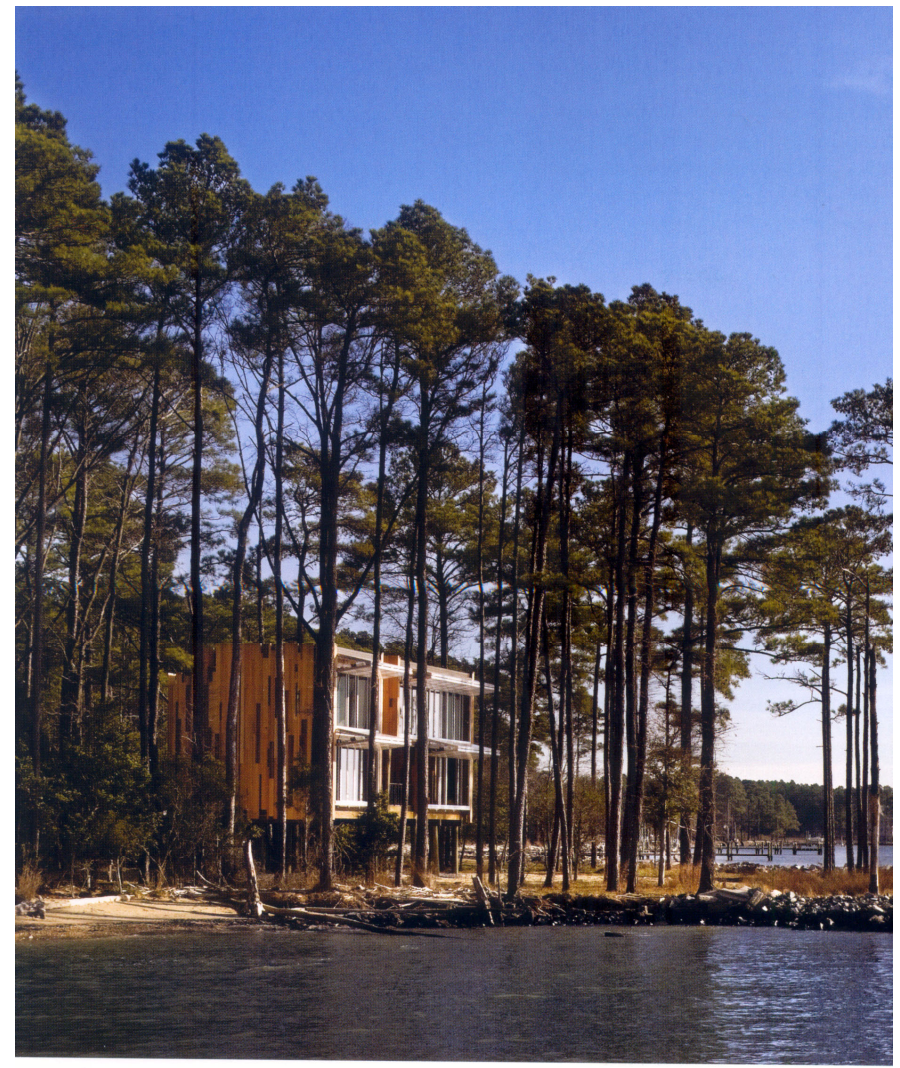

Figure 3: An exemplar for prefabrication's potential: Loblolly House by KieranTimberlake, 2006. Source: S. Kieran and J. Timberlake, Loblolly House, New York: Princeton AP, 2008: 16 
New Zealand's prefabricated housing industry could apply and benefit from the research findings. A potential for architect-designed prefabricated housing in New Zealand will be both documented and argued for, in the hope to inspire action towards the future uptake of these systems, products and technologies (3). It is hoped that implementing the proposed strategies will inspire a change in the way prefabrication is understood and experienced in New Zealand by the government, construction industry and wider public.

\section{Research Context}

Prefabrication is one approach to construction. However, it differs from traditional construction in that it takes much of the process away from the building site in order to improve efficiencies through factory-based systems. Prefabricated technologies are largely misunderstood and as a result they have met with historical resistance from government, industry and the public alike (Laing, Craig and Edge 81). This means that prefabrication methods are not widely utilised today. In 2005, architecture critic Colin Davies commented:

The history of prefabrication can be seen from some perspectives as a long continuum of noble failures (Davies 9).

Many other critics consider architect-designed prefabricated housing to have been plagued by failure (Arieff and Burkhart 10; Bergdoll and Christensen 9; Kieran and Timberlake,

Refabricating Architecture 105). ${ }^{7}$ However, there are examples of prefabricated housing such as the United States manufactured home industry and the United Kingdom post-war prefab programme which are seen as commercially successful and enduring (Davies 78; Vale 1). Architectural history continues to celebrate architect-designed prefabs for their experimental successes despite their commercial failures (Davies 9).

The case for architect-designed innovative prefabrication is captured by Barry Bergdoll and Peter Christensen:

The exploration of prefabricated housing continues to be one of architecture's most purposeful and enterprising pursuits. Attempts to reconcile singular artistic creation with mass production reflect on the role of the prefabricated dwelling as a critical agent in invention in architecture, formal and material research, and sustainability (Bergdoll and Christensen 'Home Delivery' exhibition text).

Prefabrication's role as "a critical agent in invention" is reiterated by Karrie Jacobs in her observation that, "the most significant accomplishment of the prefab architects is not how many houses they have built, but how they have transformed the culture of architecture" (97). Prefabricated housing prototypes provide innovation and inspiration, as Davies notes, "in a demonstration house the idea matters more than the reality" (36). Prototypes are tangible metaphors, demonstrating experimental ideas and testing concepts. The prototype sometimes becomes the end product, effectively advertising for related housing products and making the

${ }^{7}$ There are few texts on architect-designed prefabricated housing. Key texts referred to in this thesis include Colin Davies' The Prefabricated $\underline{\text { Home}}$, Stephen Kieran and James Timberlake's Refabricating Architecture, Barry Bergdoll and Peter Christensen's $\underline{\text { Home Delivery, and Allison }}$ $\overline{\text { Arieff }}$ and Bryan Burkhart's Prefab. Refer to Chapter 1 for theoretical context. 

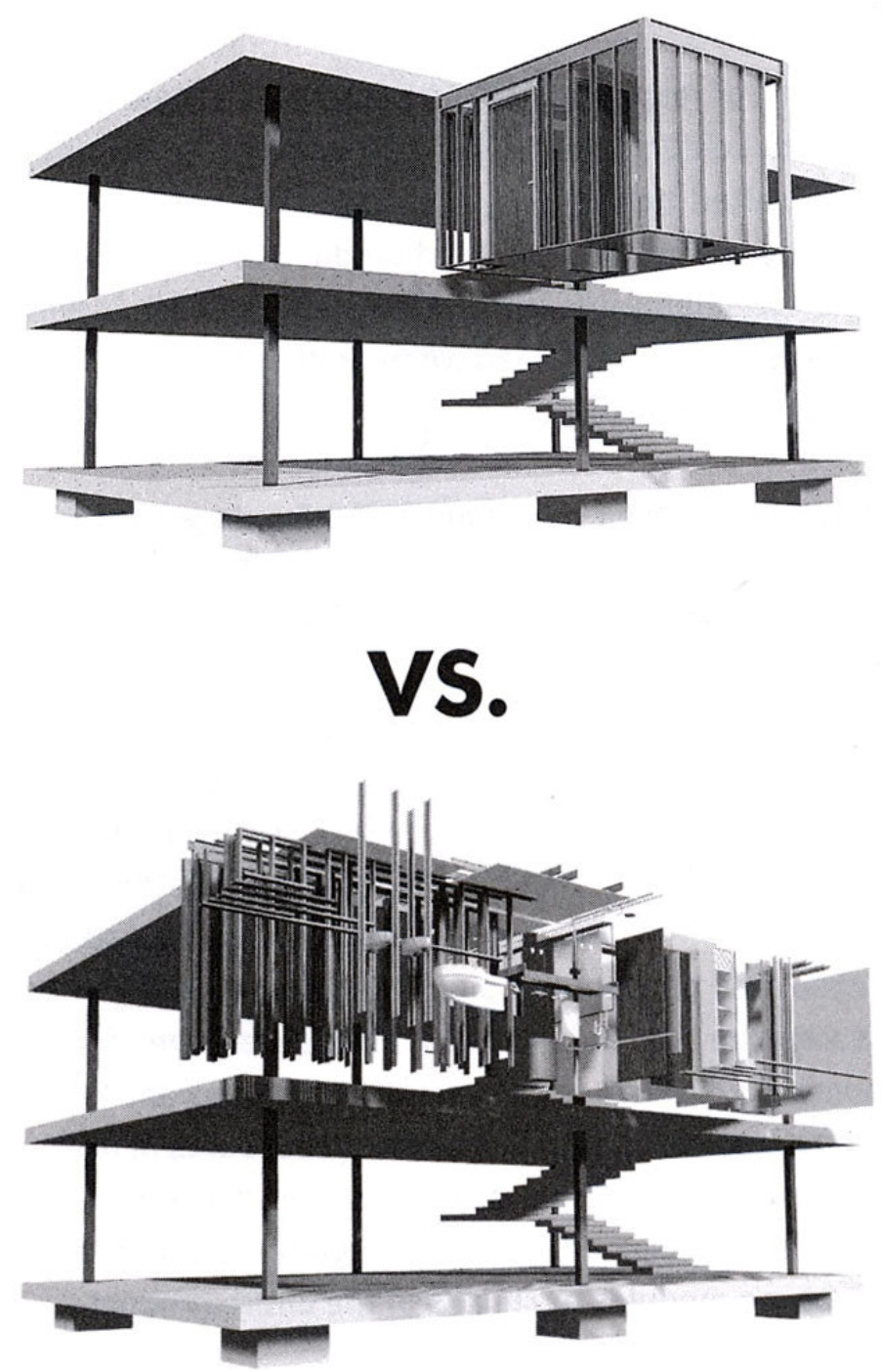

Figure 4: Prefabrication's benefits of pre-packaged component assemblies, a single trip to site, versus traditional construction demonstrated in Le Corbusier's Dom-ino structure.

Source: S. Kieran and J. Timberlake, Refabricating Architecture, New York: McGraw-Hill, 2004: 46. 
move into repeated manufactured units unnecessary as it is already successfully generating a market demand.

Historically, prefabrication has been held up as an answer to housing affordability, yet "the problem remains essentially unchanged" (Kelly 96). Prefabrication has potential merits to offer in terms of predictable quality, costs and timeframes (4). It may enable material waste minimisation, reduction of transport to site and safer working conditions, which all contribute to more sustainable outcomes. Despite these merits, there have been overwhelming challenges in a number of instances, which means that traditional housing construction practices are favoured today.

A close look at prefabrication in New Zealand is timely for a number of reasons; worldwide economic recession is forcing consolidation and efficiencies in the building industry, the government has identified prefabrication for starter homes, the international contemporary prefab movement is gaining momentum, and several new prefabricated housing products are entering the local market. This thesis expands on these key happenings. ${ }^{8}$ Furthermore, the slowing of New Zealand's housing construction industry means that the consumer market is demanding more dwellings than are currently being supplied. On this basis, it is predicted that a critical housing shortage will occur in late 2009 (Alexander qtd. in Gibson 2). The forecast conditions could be suitable for prefabrication technologies to be utilised in the near future.

This is also an opportunity to document the country's history of prefabricated housing for the first time as there is a relative absence of literature on the subject. ${ }^{9}$ This research considers prefabricated housing systems, products and businesses together for the first time as a holistic industry, despite an absence of a recognised industry structure. These are some of the challenges and opportunities that an investigation into prefabricated housing can address.

${ }^{8}$ Refer to Chapter 4 for international precedents, Chapter 5 for recent New Zealand prefabricated housing products and Chapter 7 for the government's 'Starter Home Design' competition.

9 There has been no formal research into this topic since the mid-1980s. Refer to undergraduate report by Peter Wong on "Industrialised Building Systems" (1980) and Allan Mitchener's Master of Architecture thesis "Towards Industrialised Housing" (1984). 


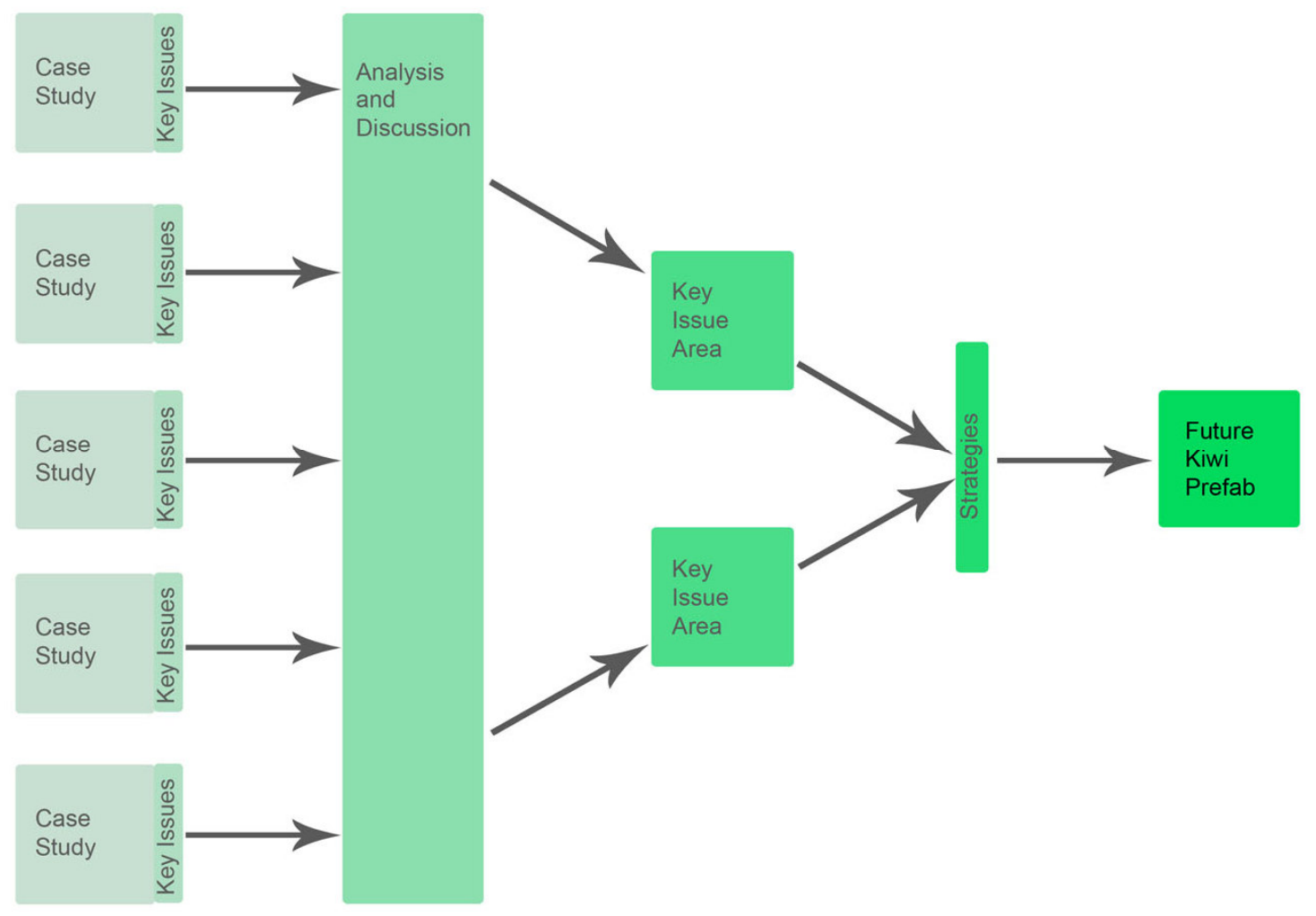

Figure 5: Research Methodology Diagram: strategy development. Source: Author's Diagram. 


\section{Research Structure}

This thesis is intentionally written in an accessible style to be as widely useful to the broader prefabricated housing industry as possible. The research structure is based on the premise that it is necessary to look back and learn from history in order to identify issues and approaches for the future. In the case of prefabrication, history provides us with a litany of mistakes and still relevant issues. Before the process of historical review can take place, however, it is necessary to define key terms and provide background information. There are three sections to this thesis:

\section{Background}

The introductory chapter explains prefabrication typologies, associated terms, merits and challenges. It provides the context of prefabrication's relationships with architecture and sustainability. In this way it sets the scene for the following case study chapters. The second chapter provides a historical background for prefabricated housing. It summarises highlights from the international history of prefabricated housing prior to a short history of New Zealand's own exemplars. Issues to be addressed are drawn from both sections for further discussion.

\section{Case Studies}

The third chapter documents case studies of contemporary established prefabricated housing businesses in New Zealand. Interview questions focus on motivation for prefabrication, explanation of system typology, past achievements, current challenges and future outlooks. Key issues are identified for further discussion. The fourth chapter looks outside New Zealand to contemporary international exemplars. A brief worldwide overview precedes first-hand case studies of Californian contemporary architect-designed prefabricated housing. Issues are similarly derived. The fifth chapter examines recent New Zealand prefabricated housing products in production or pre-production in 2009. Issues and opportunities emerging from the case studies are noted for further analysis. A table of case study findings occurs in appendix $E$ and a chronological index is laid out in appendix $F$.

\section{Synthesis}

The sixth chapter compiles, summarises and analyses issues emerging from the four previous case study chapters into lessons that can be learnt from. Key challenges and opportunities are identified here before being further investigated in the following chapter. The seventh chapter draws on local and international examples to propose strategies for New Zealand prefabricated housing in 2010 and beyond. The final two chapters look towards the near future and evaluate key findings in this context. The eighth chapter outlines the future context of New Zealand housing and the prefabricated housing industry worldwide. It uses this basis to make informed predictions for emerging housing products, suggestions for further research areas, and recommendations for action steps. The final, and ninth, chapter discusses the thesis investigation, its limitations, key findings and conclusions for a Kiwi prefab in 2010 and beyond. 


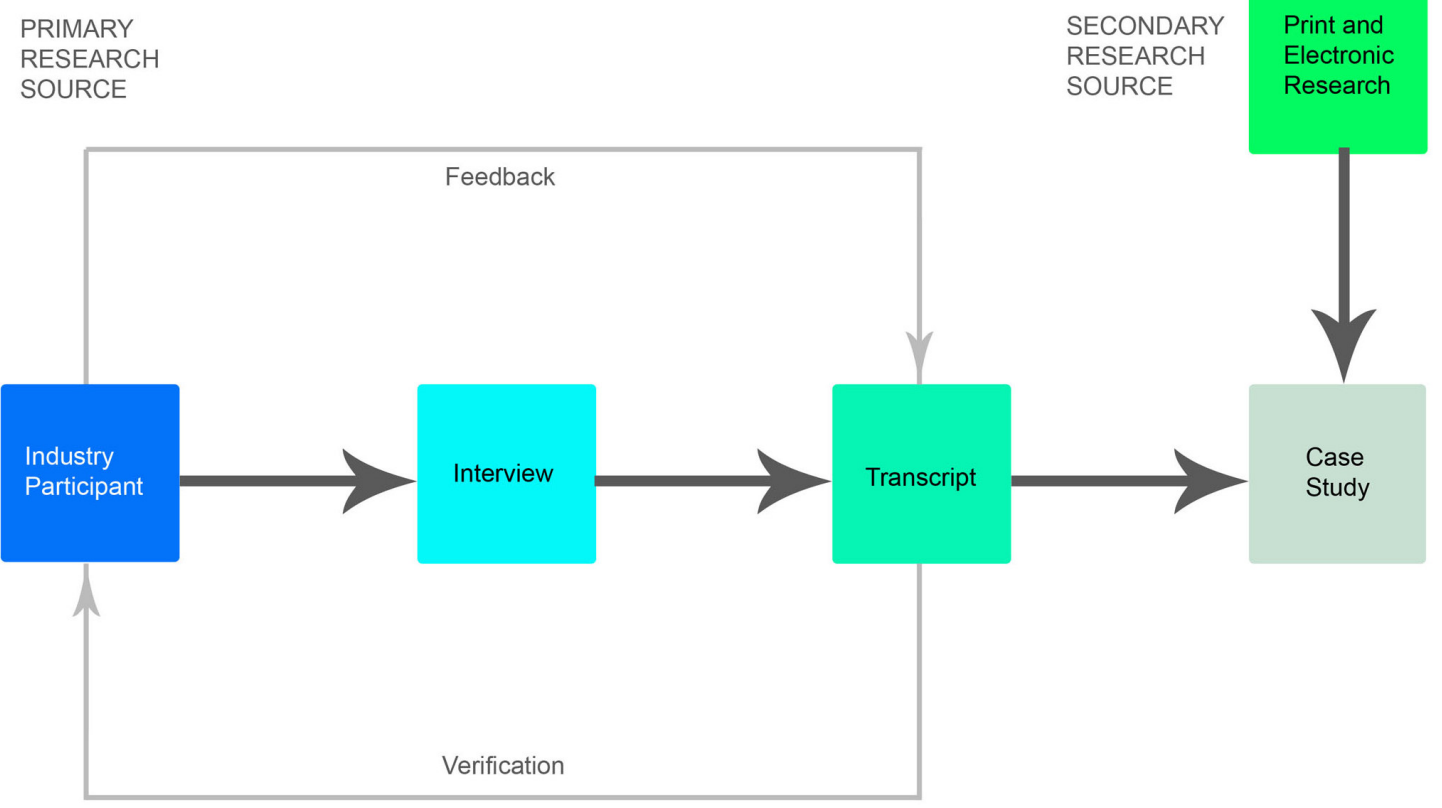

Figure 6: Research Process Diagram: case study development. Source: Author's Diagram. 


\section{Research Design}

A series of qualitative case studies are the research method used to record stories of $\mathrm{New}$ Zealand prefabricated housing businesses from the past and present (5). The process to develop these case studies involves in-depth research, as well as interviews and site visits where possible (6). Resulting interview transcripts are verified by participants via e-mail or postal mail. Follow-up phone-calls and e-mails determine further facts and confirm accuracy. Supporting literature is derived from relevant books, magazines, reports, journals, websites, web-based articles, newspapers, television programmes, exhibitions and conferences. Two research trips to the United States occurred in 2008: one to the 'Dwell on Design' conference and exhibition in Los Angeles, and the other to the 'Home Delivery' exhibition at the Museum of Modern Art in New York (MoMA). Both trips involved extensive interviews and site visits with prefabrication businesses and experts. Examples of research instruments follow the thesis body in the appendices: interview questions in appendix A, list of industry participants in appendix B, sample interview transcript in appendix $C$, and sample case study in appendix $D .{ }^{10}$

New Zealand's small prefabricated housing industry is only connected by word-of-mouth so new contacts, opportunities and information unfold through the network of prefabrication expertise uncovered by the research process. ${ }^{11}$ Discussion and analysis of the qualitative case studies will identify recurring factors which can be directly compared, summarised and analysed. Discussion of the outcomes will form the basis for the recommended strategies which will then be tested against the current housing industry context and evaluated. Findings, predictions and action steps will be suggested for the near future. The evaluation of this investigation and limitations discovered will be discussed in the final chapter.

10 The author can be contacted for access to original interview transcripts.

11 The author invites new information, contacts and updates. 


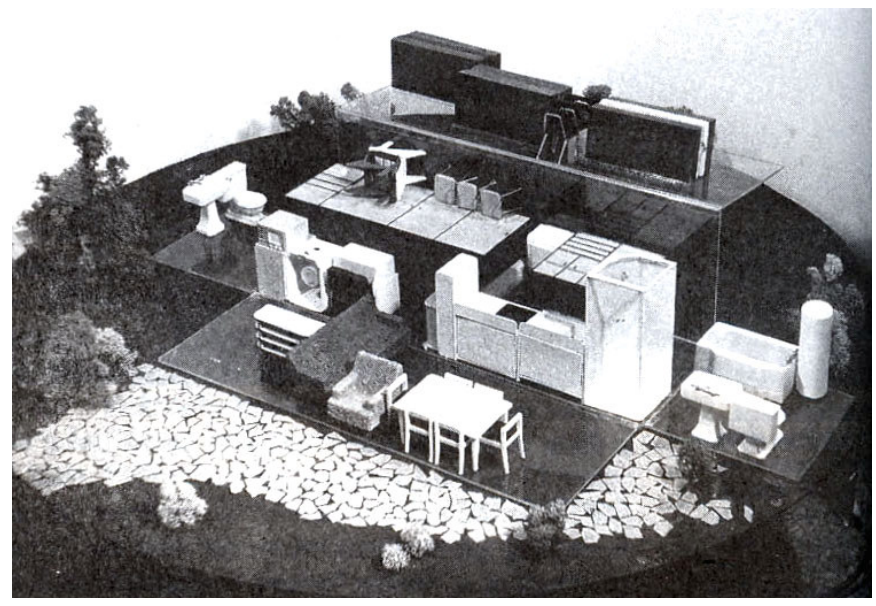

Figure 7: An historical international exemplar: Buckminster Fuller's intriguing and inventive Autonomous Living Unit ,1949. Source: M. Pawley, Design Heroes: Buckminster Fuller, London: HarperCollins, 1990: 118. 


\section{What is Prefab?}

\section{A Background to Prefabricated Housing}

Prefabrication as an "agent in invention" may potentially address the problem of a "broken" contemporary design and construction process (Bergdoll and Christensen; Kieran and Timberlake Loblolly House 158). Prefabricated housing has been identified as a key lesson and opportunity for the architecture profession (Davies 206). Architect-designed prefabricated housing's historical struggle with commercial success reinforces its intriguing 'holy grail' reputation. An outline of the theoretical context and problem framework has been set.

This chapter will introduce prefabrication, also referred to as its abbreviated form, prefab. It will clarify terms, outline merits and challenges, and touch on the contexts of architecture and sustainability, before providing a theoretical background. ${ }^{12}$ The purpose is to set the scene for the following case study chapters that will look into the past, present and emerging future of New Zealand prefabricated housing and international exemplars (7).

12 Formatting conventions used in this thesis are as follows. Italics are used to indicate a brand, product or system name. Single quotation marks are used to indicate a temporary scheme, exhibition, conference or series. Capital letters are used to indicate business or organisation names. 

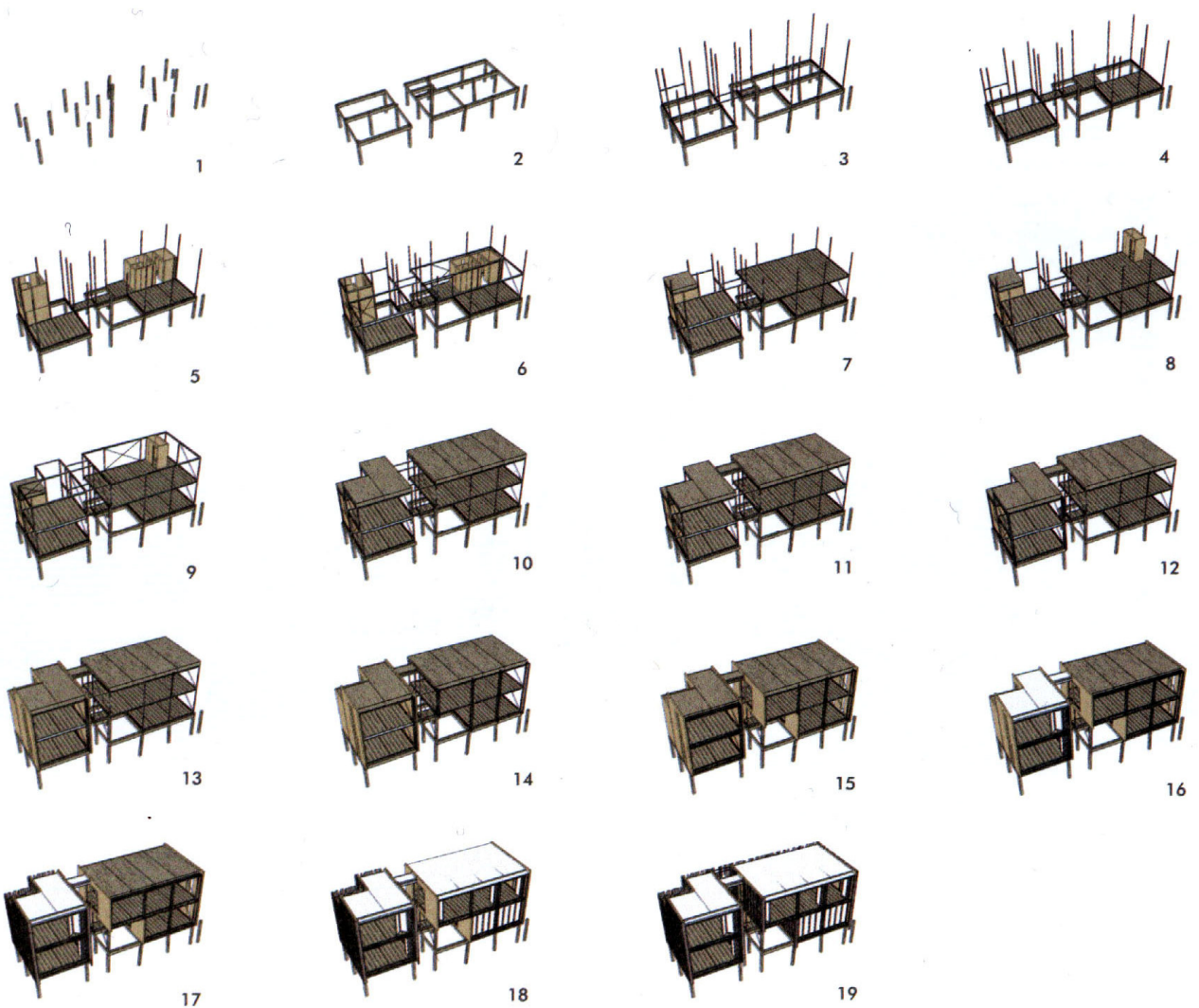

Visual schedule

Figure 8: Prefabricated stick components, panels and modules assembled at site in KieranTimberlake Loblolly House. Source: S. Costa Duran, Green Homes, New York: Collins Design, 2007: 110. 


\section{Prefabrication Terminology}

There is significant confusion and misinformation surrounding the nomenclature of prefabrication which is why it is important to define the term early in this thesis. The prefabrication spectrum is extensive and the industry is diverse and fragmented. Industry reports use differing terms which can lead to confusion (Gibb and Pendlebury). For the sake of clarity, the prefabrication term is used throughout this investigation, in preference to other industry terms such as 'offsite', 'modern methods of construction', 'non-traditional construction' and 'innovative construction'. ${ }^{13}$

In 1965, R.B. White described the nebulous nature of prefabrication:

Prefabrication could not be treated as a science; it is neither a single process nor a combination of known processes identifiable and measurable. It may sometimes be viewed in abstract and subjective terms, but it does not of itself provide a philosophy of design (White 298).

The prefabrication term is commonly misconstrued and suffers from historical misperceptions such as low-quality, flimsy and one-size-fits-all (Hart 123). These misperceptions have been a major historical impediment to consumer acceptance and subsequent commercial success (Laing, Craig and Edge 81). Prefabrication is often confused with its associated terms, such as mobile, portable, standardised or industrialised. These terms are explained below and listed in the Glossary section.

Prefabrication has come to describe any manufacturing process that takes place within a factory-controlled environment. It particularly refers to any part of a building made away from the building site that is later assembled at the site (Brown). Other interchangeable historical terms include "ready-made" and "pre-assembly" (Marcel Duchamp qtd. in Colomina 68; Gibb). Kieran and Timberlake's 2004 treatise Refabricating Architecture refers to prefabrication as both componentised and offsite construction. The latter term was taken up in the United Kingdom by the industry-wide campaigning organisation, Buildoffsite. The United Kingdom's industry has adopted the non-hyphenated offsite term in an effort to disengage from historical negative misperceptions. ${ }^{14}$ Today many terms abound, including pre-built, pre-configured, pre-designed, pre-planned and the abbreviation prefab. All indicate that work is done before reaching the final site. In this thesis, the definition of prefabrication is any component constructed away from the site and the abbreviated prefab term is used interchangeably.

Prefabricated housing can be categorised according to materials, technologies, market sector or extent of prefabrication. The extent, types, typologies or methodologies of prefabrication are described here. Prefab proponent and architectural historian Colin Davies sets the scene:

13 The 'innovative construction' term is particularly confusing as prefabrication methods have been used in construction for over two-hundred years. The use of the innovative term refers to particular systems, products and technologies.

${ }^{14} \mathrm{It}$ is used in a number of terms such as offsite production (OSP), offsite manufacture (OSM) and offsite fabrication (Gorgolewski 121; Gibb). This is as a direct result of United Kingdom government reports suggesting innovative methods of construction should be adopted by the building industry (Construction Taskforce 28). 

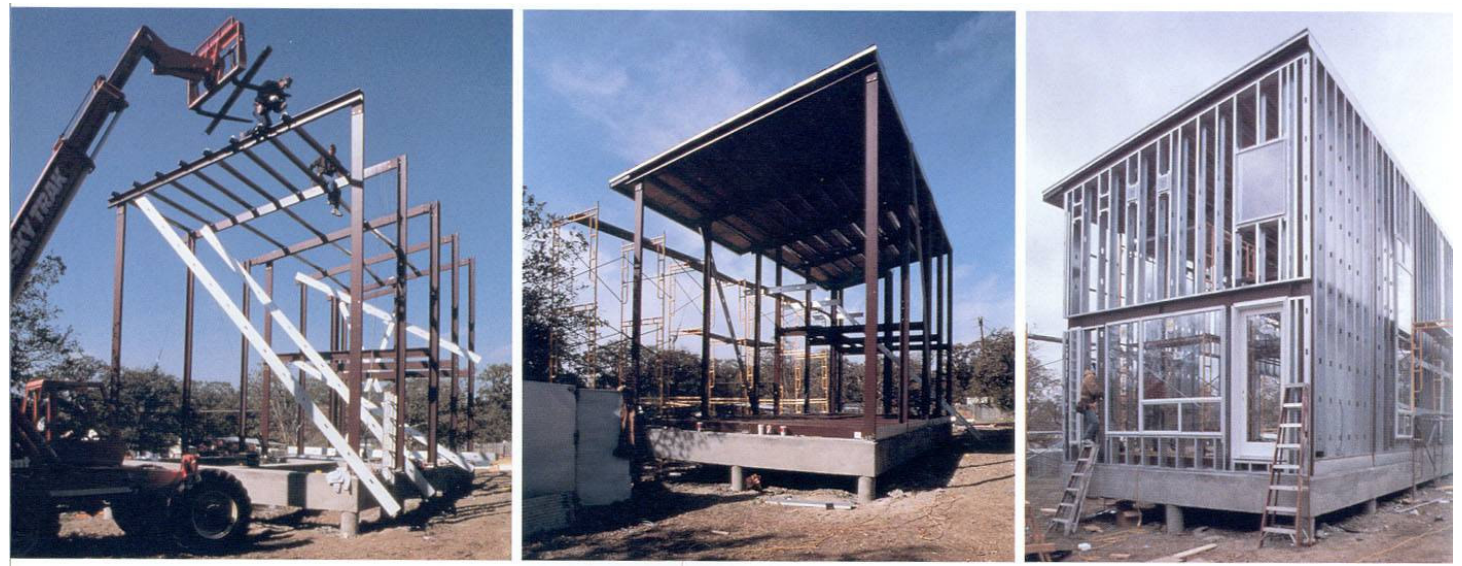

Figure 9: Stick component-based construction: steel framing elements.

Source: A. Arieff and B. Burkhart, Prefab, Layton: Gibbs Smith, 2002: 126.

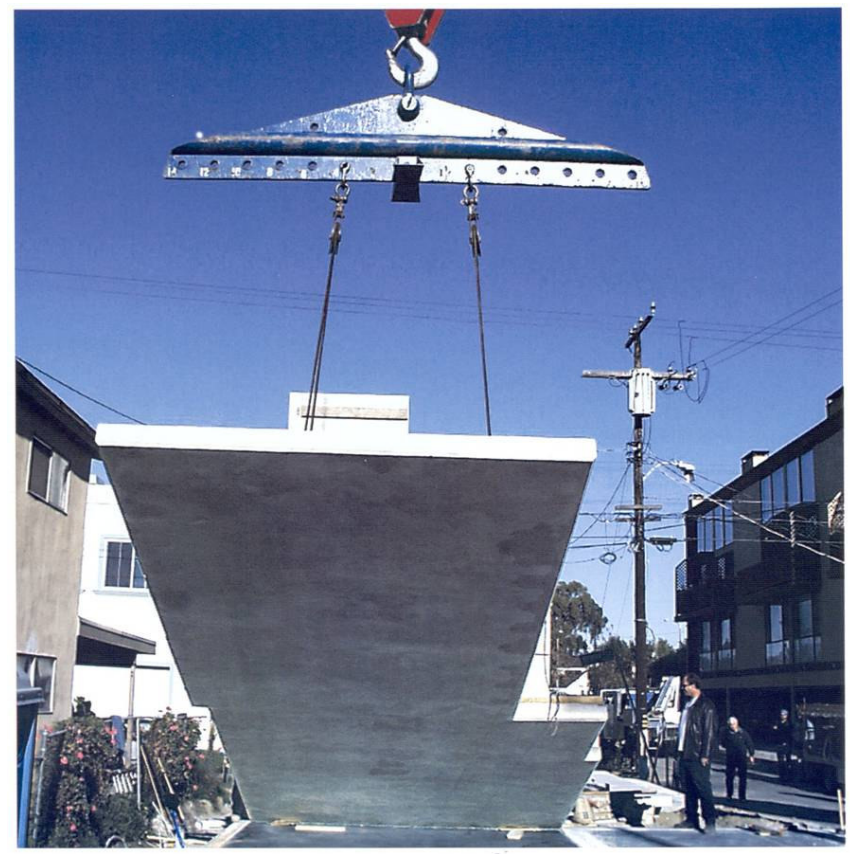

Figure 10: Panelised construction: precast concrete panels.

Source: A. Arieff and B. Burkhart, Prefab, Layton: Gibbs Smith, 2002: 128. 
Prefabricated buildings can be temporary or permanent, cheap or expensive, all the same or all different, small or large, traditional or Modern, well designed or badly designed (Davies 206).

Davies' comment challenges the perception that prefabrication is synonymous with low-quality. Both United States and United Kingdom experts agree that prefabrication can be divided into four main types, or levels of extent. In the United States these are referred to as stick, panel, module or box-form (Arieff and Burkhart; Buchanan; Kelly). ${ }^{15}$ Leading British researcher Alistair Gibb defines these four primary categories as component sub-assembly, non-volumetric preassembly, volumetric pre-assembly and complete buildings. This thesis concurs with recent classifications that a fifth category of hybrid prefabrication is needed to describe systems that combine volumetric and panelised typologies (Alter "Acorn House"; Gaze et al). The five typologies of prefabrication referred to in this thesis are component (stick and sub-assembly), panel (non-volumetric), module (volumetric), hybrid (module-plus-panel) and complete buildings (box-form) (8).

\section{Component}

Component-based prefabrication includes stick and sub-assembly prefabrication. Stick refers to lengths of timber or steel that are pre-cut, pre-sized or pre-shaped puzzle-type pieces brought to site where they are assembled by a builder, as opposed to the traditional construction process which cuts timber to size at site (9). Sub-assemblies include windows and doors which are assembled away from the site and installed into other elements once at the building site. This includes fixtures and fittings, and structural members such as pre-nailed roof trusses and wall frames. The use of pre-nailed components has become an accepted part of the traditional construction process by the full range of home building companies in New Zealand. A common form of component-based construction is known as kitset housing.

\section{Panel}

Panelised or non-volumetric prefabrication comprises manufactured panels that may include integrated building services, and may be transported as a flat-pack (10). Panels can be classified as closed, complete with doors, windows, services and cladding or lining, or open as framing. ${ }^{16}$ Some architects refer to closed panel systems as cartridges or cassettes (Kieran and Timberlake, Loblolly House 83; Birkbeck and Scoones 40).Other elements include preinsulated foundations and structurally insulated panels (SIPs). While panelised elements can be stacked flat for efficient transportation to site, they require more work for assembly at site than modular units.

15 Where a page number is not given, the typology discussion is not confined to a single page, but evident throughout the book. 


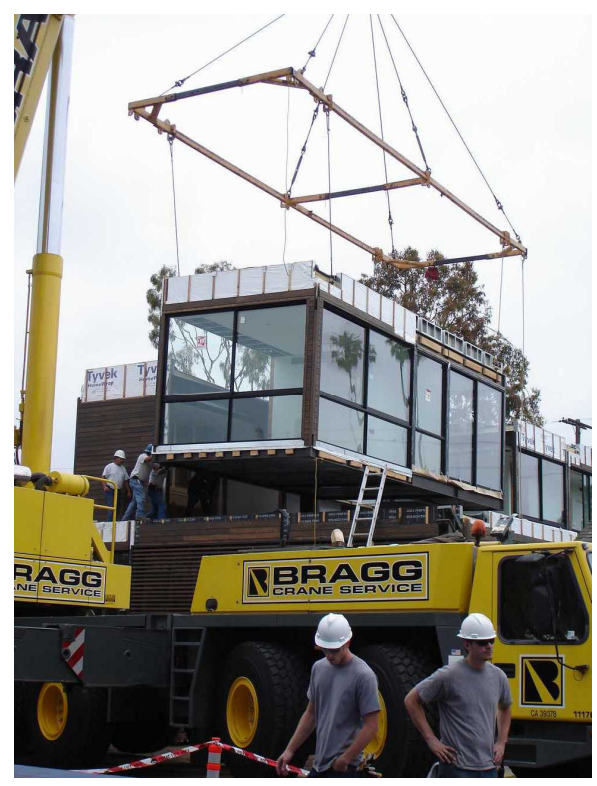

Figure 11: Modular prefabrication assembled at site. Source: Author's photograph, 2008.
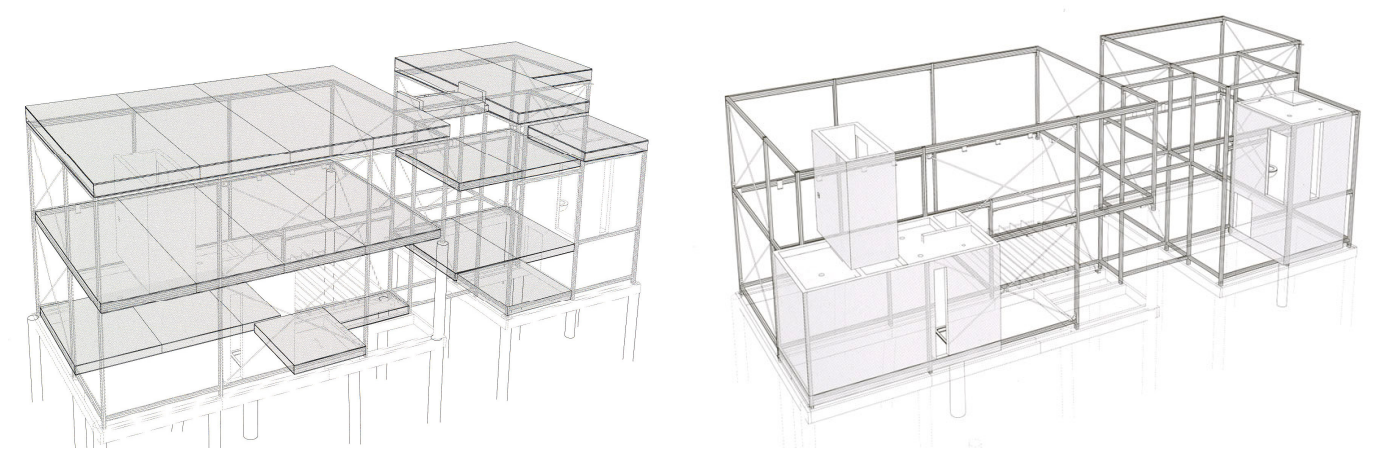

Figure 12 and 13: Hybrid prefabrication in Loblolly House: floor and ceiling panels (also used for walls), and utility modules. Source: S. Kieran and J. Timberlake, Loblolly House, New York: Princeton AP, 2008:82 and 102.

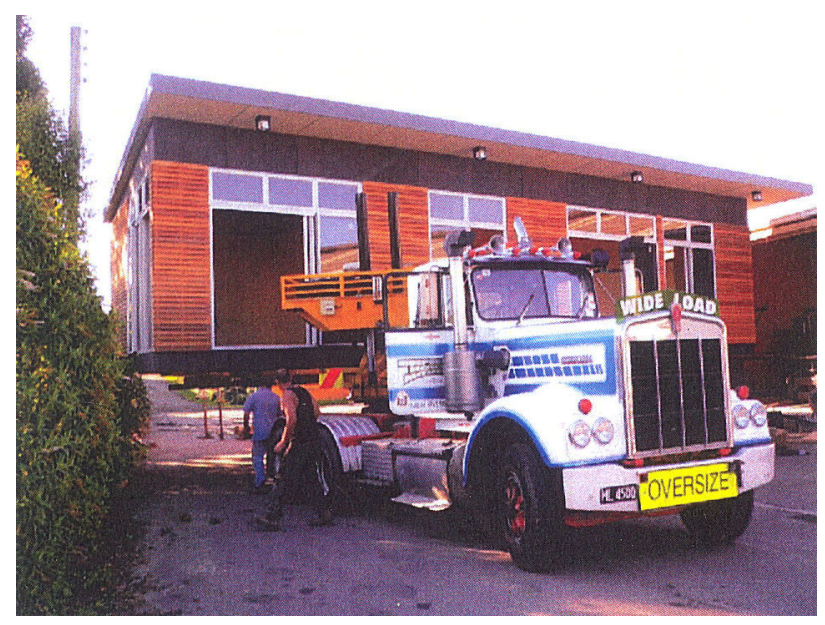

Figure 14: Complete building or box-form prefabrication in transit to site. Source: Image courtesy of Studio Pacific Architecture. 


\section{Module}

Modular, sectional or volumetric prefabrication refers to a three-dimensional structural unit being constructed away from the site and transported to site where it is combined with other units or systems to create a whole dwelling (11). In most cases, "a number of volumetric units are combined with additional on site works such as an external...skin" (Cook 51). The threedimensional object of prefabrication can be referred to as a volume, module, or section. Cores and pods are references to non-structural units used inside conventional buildings or modules (Birkbeck and Scoones 9). M.T. Gorgolewski offers this explanation of modular construction and its suitability:

Three-dimensional units are manufactured in the factory with a high degree of services, internal finishes and fit-out installed in controlled, factory conditions prior to transportation to site... This approach is particularly suited to highly serviced areas such as kitchens, bathrooms and plant rooms, which have a high added value, and cause disruption and delays on site, but may be less appropriate for other rooms which have less internal fit-out (Gorgolewski 122).

The term modular home was brought into common usage in the 1970 s by the United States modular housing industry. It is a type of building that meets building codes, is factory assembled in full-dimensional units and then fixed onto a permanent foundation at site (Reidelbach Jr. 5). It is a more permanent type of building than the mobile or manufactured homes which also gained popularity during that era (refer to Associated Terms following).

\section{Hybrid}

Hybrid prefabrication will be used to refer to hybrid module-plus-panel or semi-volumetric systems (12-13). These systems use "volumetric units for the highly serviced areas such as kitchens and bathrooms and construct the remainder of the building using panels or by another means" (Gorgolewski 124). Hybrid prefabrication systems are regarded as combining the benefits of two prefabricated construction systems, while allowing for more flexibility and consumer choice. They can be used for additions and alterations in order to extend buildings with minimal disruption (Ross et al 1).

\section{Complete Buildings}

Box-form or complete buildings are commonly known as portable, relocatable or transportable dwellings in New Zealand (14). ${ }^{17}$ They are a type of volumetric prefabrication where entire buildings are constructed in a factory or yard and then moved to site where they are attached to permanent foundations. These buildings may or may not incorporate prefabricated components, and standardised framing and sheet elements.

${ }^{17}$ Relocated houses are also known colloquially by the abbreviated term 'relocs'. 


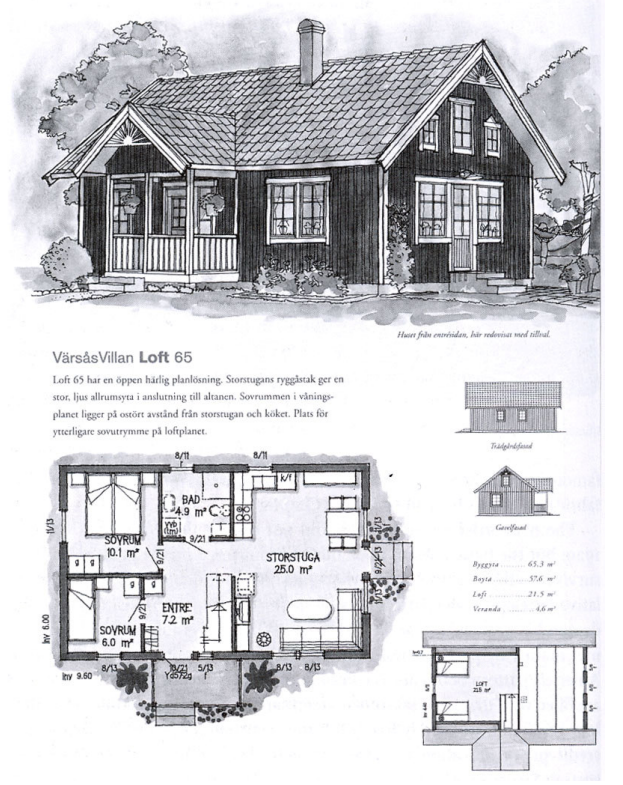

Figure 15: Page from a typical Swedish pattern-book.

Source: C. Davies, The Prefabricated Home, London: Reaktion, 2005: 122.

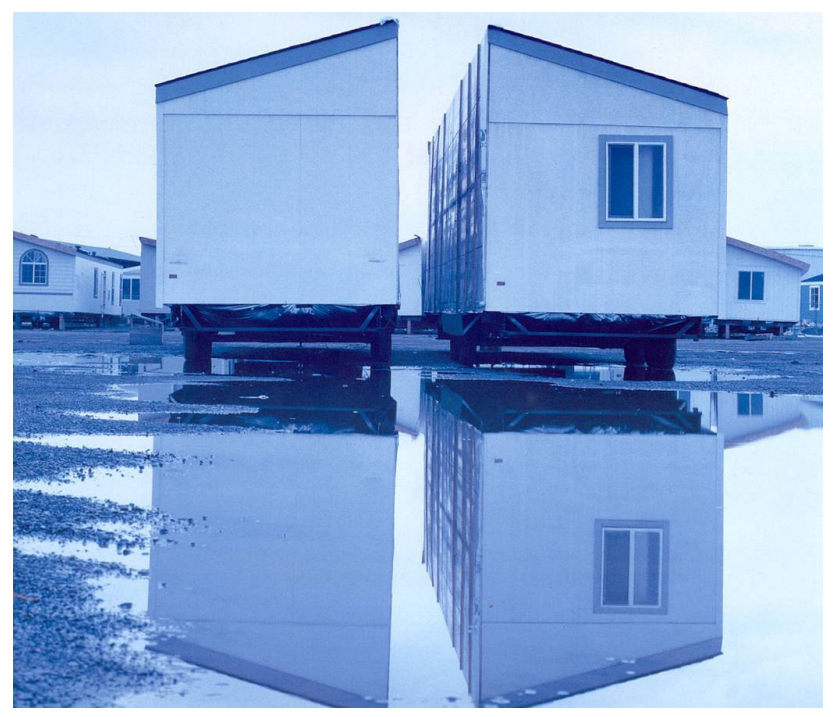

Figure 16: Manufactured home sections or modules. Source: A. Arieff and B. Burkhart, Prefab, Layton: Gibbs Smith, 2002: 9. 


\section{Associated Terms}

Prefabrication is a system or process, not a product. This distinction is where much of the confusion and misperception about prefabrication lies. Prefabrication describes a way of construction rather than an aesthetic outcome. It can be viewed as an approach, a methodology, a mind-set, a tool, a pattern, or a philosophy. Non-physical elements such as services can also be clustered as David Gann points out:

The growing demand for packaged products and service delivery is blurring the traditional boundaries between manufacturing, design, construction and service sectors (Gann 14).

In this way, prefabrication can be viewed as a system to bundle products and services and prepackage them for delivery to clients. It can be interpreted as both a literal construction process and as a systems-based approach for delivering housing.

The term prefabrication is often used interchangeably with associated terms such as mobile or portable, standardised or industrialised, pre-planned or pattern-book. These can be mistakenly substituted for prefabrication, so for clarity the following section identifies these terms. A dwelling may have one of these attributes without being able to be described as prefabricated.

Historically, standardised or pre-configured plans were compiled into pattern-books (15). While not technically prefabrication, concepts of efficiency are evident through the use of repetition, convenience for customers is offered in terms of communicated housing-plan options, and product reliability is enforced in using a singular brand name to deliver the housing system.

In America, the term mobile home has become displaced by manufactured home since 1974 , due to a marketing effort by the United States Department of Housing and Urban Development (HUD) to dispel unattractive connotations of the trailer-home term (Mau and Institute without Boundaries 34). Formerly described as a travel-trailer or house-trailer, the manufactured home is wheeled to site on its own permanent chassis where it is mounted onto a permanent concrete slab foundation (16). Described as, "perhaps the most radical form of prefab housing", it is designated as a vehicle, rather than a building (Rybczynski, "Prefab Fad"). This house does not need to conform to building-codes, which enables it to be delivered at a lower cost. This has led to its success as an industry in North America - despite negative social connotations resulting from relegation to cheaper land areas at the outskirts of urban centres. Manufactured housing may have suffered from a lack of emphasis on aesthetic design, but its consumer-friendly marketing, distribution, and delivery systems are worth exploring in today's prefabricated housing (Ebong 17).

Terms of industrialisation and standardisation are often mistakenly used interchangeably with prefabrication. In 1972, Mary Mountier noted:

The essence of industrialised building, in contrast to simple prefabrication, is that it has an organisational structure similar to that of a manufacturing company (Mountier np). 


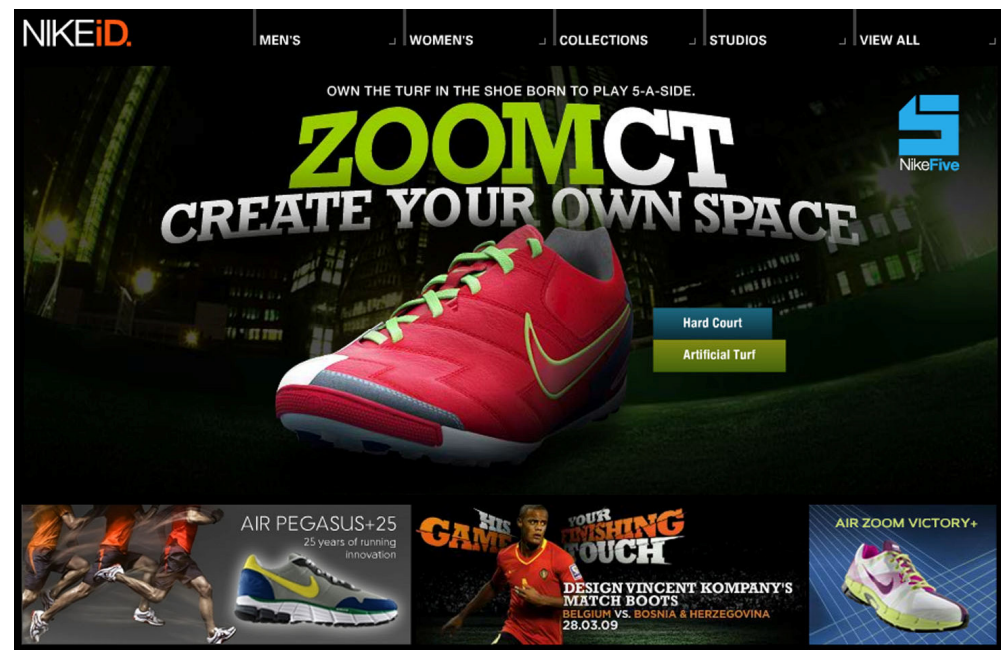

Figure 17: Mass-customised shoes on the NikelD website. Source: <http://nikeid.nike.com/nikeid/index.jsp>. 
As Mountier points out, the term industrialised refers to high-volume output and a large consumer market, while the term prefabricated can apply to small-scale production of any component or element of a building. In many instances, industrialised systems employ systems of prefabrication, but the terms are not necessarily interchangeable (Hay). Davies notes that:

Prefabrication does not necessarily imply either mass production or standardisation. In fact none of the three terms necessarily implies the other two. Standardisation is not essential and mindnumbing monotony is not inevitable (Davies 205).

Standardisation is the extensive use of components, methods or processes in which there is regularity, repetition and a background of successful practice. This may include standard building products, standard forms of contract, standard details, design or specifications, and standard processes, procedures or techniques (Gibb and Pendlebury 33). Standardisation of processes is inherent for efficiencies of prefabrication, but it does not always result in a standardised product or outcome.

Mass-customisation refers to the contemporary re-interpretation of mass production with the ability to incorporate change via new technology and web-based interfaces (17). Masscustomisation is a way to deliver this. It is, "a process using standard components to produce a variety of end products" (Cook 50). In their 2004 treatise, Kieran and Timberlake comment:

Mass production was the ideal of the early twentieth century. Mass customisation is the recently emerged reality of the twenty-first century (Kieran and Timberlake, Refabricating Architecture xii).

Post-World War Two economic, material and labour constraints developed the only real market for standardised housing products. Today the cultural context that consumers demand is more "choice, expression, individuality, and the ability to change [their] minds at the last minute", as well as a desire to have an active role in the design process (Kieran and Timberlake, Refabricating Architecture 133). 


\begin{tabular}{cc}
\hline MORE & LESS \\
\hline Quality & Time \\
\hline Reliability & Frustration \\
Efficiency & Material Waste / Energy Use \\
Design Variation & Cost \\
Testing & Defects
\end{tabular}

Figure 18: More for Less: potential advantages of prefabrication. Source: Author's Diagram.
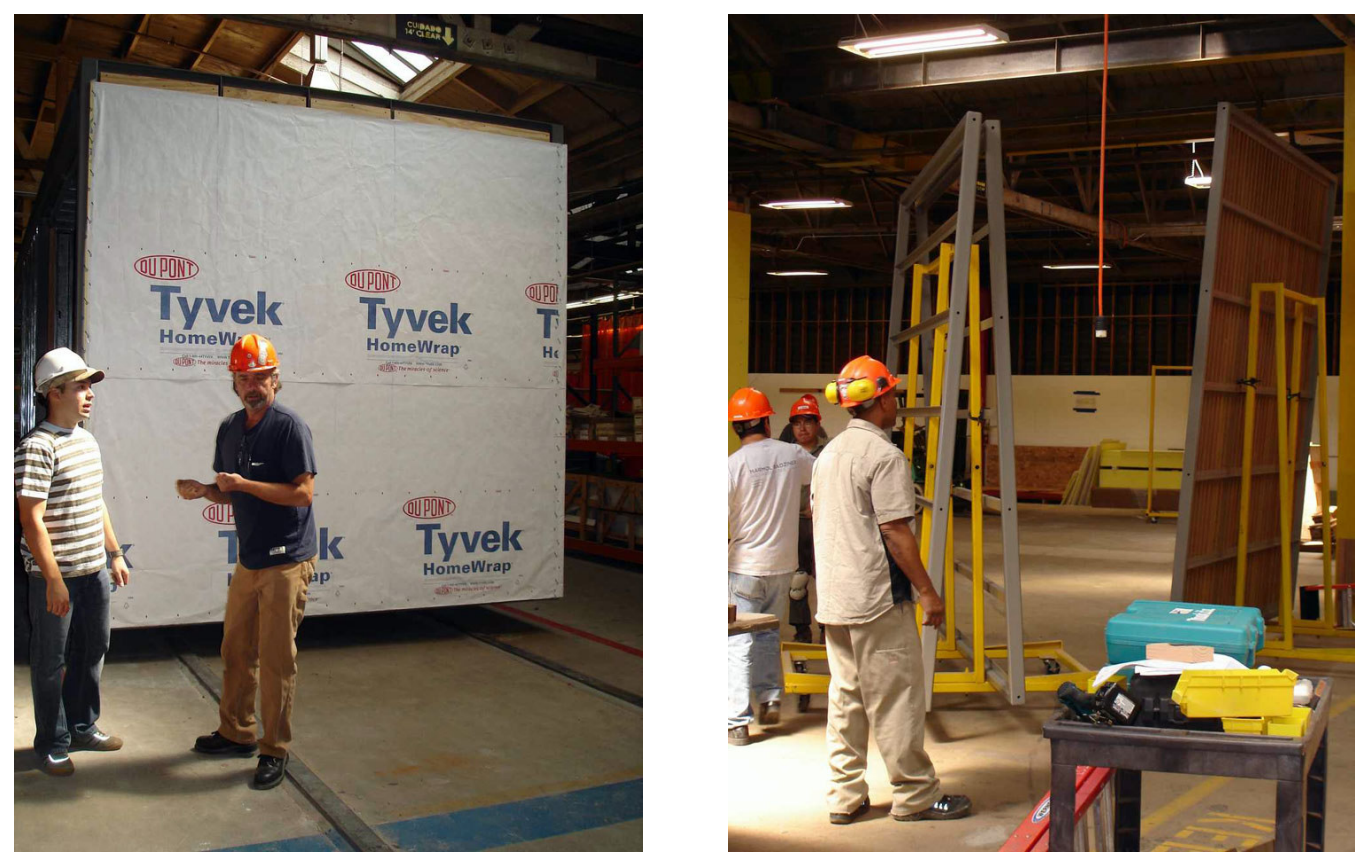

Figure 19 and 20: Indoor working conditions at Marmol Radziner Prefab's Venon factory, Los Angeles. Source: Author's photographs, 2008. 


\section{Merits of Prefabrication}

The advantages or merits of prefabrication are potentials, rather than givens, as each individual example of prefabricated housing possesses its own particular systems and processes. Prefabrication can potentially offer 'more for less': more quality for less time at site, more known outcomes and less unknowns, and potentially more energy efficiency for less resource use (18). The importance of tangible outcomes in cost, quality and timeframe are evident through the consumer process of visiting a show-home, choosing from material samples, observing the factory manufacture, and watching the housing product arrive on the building site.

There is still confusion - mostly amongst end-consumers - that prefabrication will primarily deliver a more cost-effective housing solution, when the industry acknowledges that the main advantage is a higher quality solution. In 2005, Brian Cook surveyed members of the United Kingdom prefabricated housing industry and noted:

Improvement in quality is regarded as the principal advantage of prefabricated housing (Cook 54).

This higher quality is achieved through closer coordination of labour, materials, machinery and sub-trades in factory conditions. Testing, evaluating and resulting remedial work can be carried out before the product leaves the factory floor. Further merits of prefabrication are grouped here into technical, social, economic and sustainability areas.

Technical merits include tight quality controls of workmanship and materials, increased speed of production through concurrent factory manufacture and site-based works, and the ability to test systems within the factory. This testing, together with minimising joints, can reduce the level of defects and subsequent defect liability period post-occupancy.

Social merits include being able to work under cover during inclement weather, having tools and amenities close at hand, and improvements in health and safety (19-20). Investment in machinery and training leads to longer-term employment stability. Prefabricated homes are potentially aesthetically dissimilar from each other, and often indistinguishable from conventionally constructed homes.

Economic merits include the cost savings to customers and developers from a shorter period of financial borrowing as a result of shorter timeframes, and reduced defect liability periods. Time savings are potentially between thirty and sixty percent of a traditional construction process according to some modular manufacturers (Modtech Holdings) (21). Timeframes and costs will also be decreased by eliminating dependence on weather for site-based construction, easier coordination of trades in-house, and price advantages from bulk ordering. Michael Buchanan notes: 


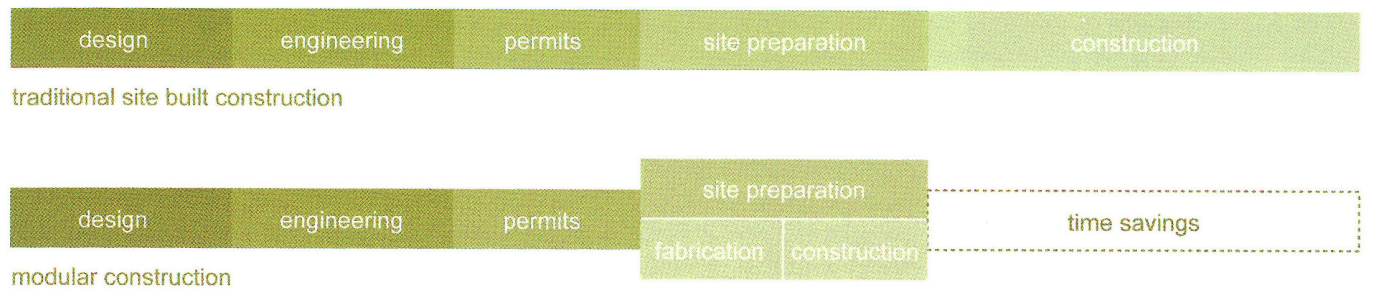

Figure 21: MKD's Glidehouse timeline comparing traditional and modular construction methods. Source: M. Kaufmann and M. McGrath, Prefab Green, San Francisco: MKD, 2006: 9.
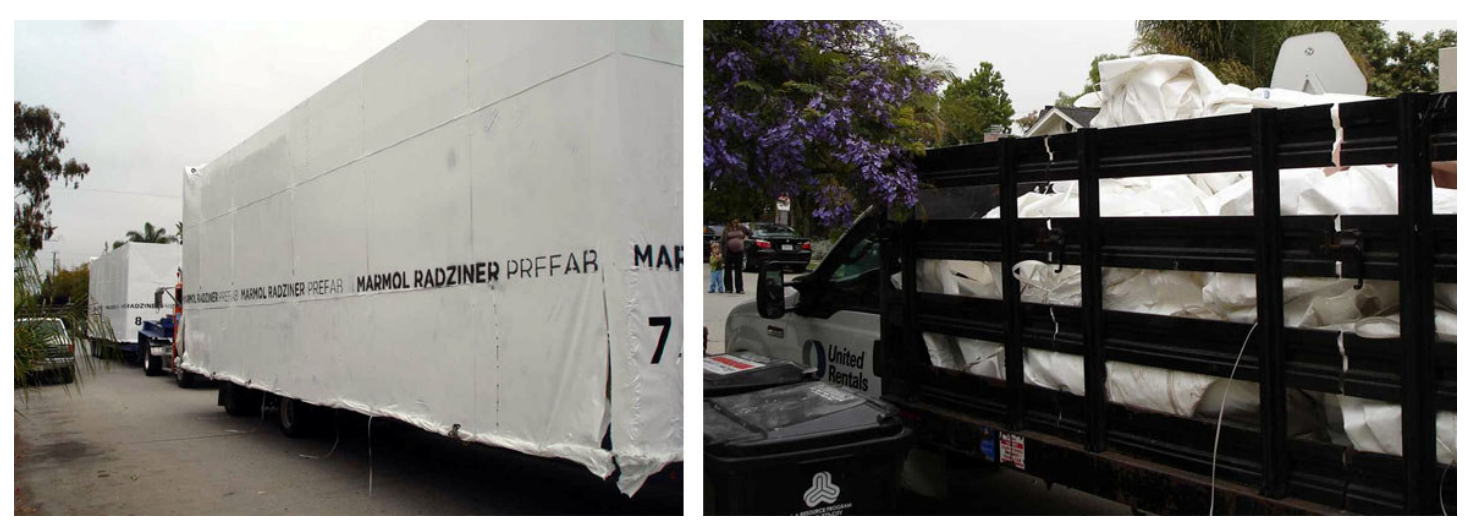

Figure 22 and 23: Modular construction waste at site is reduced to re-usable wrapping material. Source: Author's photographs, 2008. 
Given the cost savings inherent in the construction technique, a prefabricated shell will generally be less expensive than a site-built structure of exactly the same specifications, configuration, and quality (Buchanan viii).

Buchanan assures cost savings can be achieved. Time and money can also be saved by eliminating delays due to later material deliveries, non-appearance of sub-contractors, and worker travelling time. Transport costs can be reduced to the carrying of fewer finished components or the single trip of the final housing product from factory to site. Costs can be further minimised by reducing overall floor area; often a prefabricated home can be a scaleddown size for scaled-down living needs (Elliston and Nafzgar 10).

Sustainability merits include reduced material waste through efficient ordering, indoor protection, pre-planning and cutting, and re-use (22-23). Material usage is thought to be saved by up to seventy-five percent for modular construction (Smith). ${ }^{18}$ Currently forty percent of our country's waste is created by the New Zealand construction industry so there could be great improvements made in the area of waste minimisation (Wood "Govt" and Sustainable Government Building"). Potential site benefits of prefabrication include less disruption, noise, pollution, effluence, ground-works, traffic, and fewer deliveries. It has been estimated that a complete building delivered to site uses less than half the energy in running costs compared with an average house (Elliston and Nafzgar 10). ${ }^{19}$ Factory testing and quality controls enable a tighter building envelope and better energy efficiencies for reduced running costs.

Together, these merits of prefabrication are well poised to tackle current construction industry challenges such as a low-skilled construction workforce, increasing market demands for higher quality, and increasing industry regulation (Gorgolewski 121).

\footnotetext{
18 Savings have been documented by individual architects or manufacturers. Concise industry statistics have not been found. Michelle Kaufmann Designs states, "Modular factories can achieve 50\% to $75 \%$ less waste than the equivalent site-built home through precision cutting and storage capacity" (Smith).

19 This data refers to mobile homes in the United States prior to 1980 , most likely in the 1970s. It is possible that these mobile homes have a smaller floor area and use less energy as a result.
} 


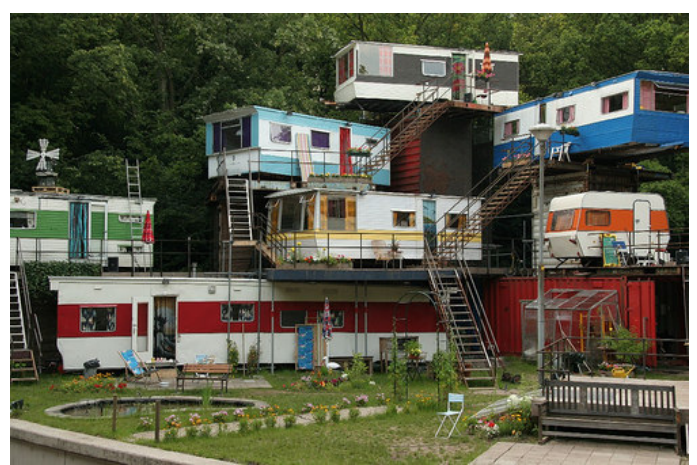

Figure 24: Prefabrication has associations with mobile home and caravan aesthetics. Source: Image courtesy of Georgie Bremner.

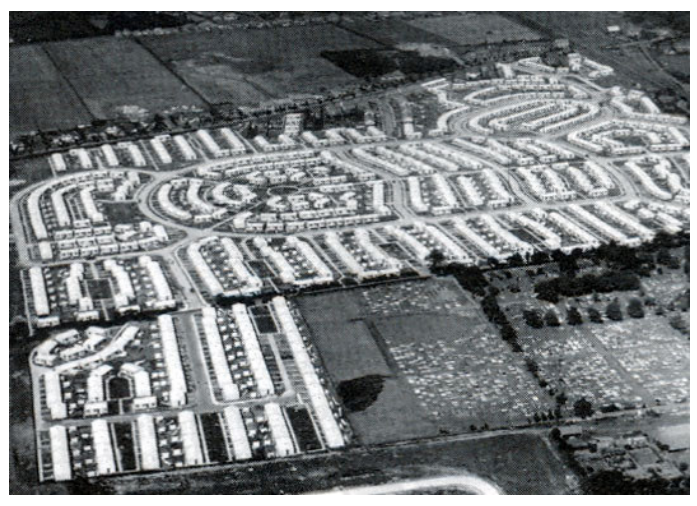

Figure 25: A prefabricated housing estate exhibiting repetition and monotony. Source: C. Davies, The Prefabricated Home, London: Reaktion, 2005: 63. 


\section{Challenges of Prefabrication}

The merits of prefabrication are established, yet traditional housing methods dominate the construction industry. Clearly, there are challenges that have proven to be insurmountable, which must be identified in order to be addressed in this investigation. The commercial success of prefabricated housing has been inhibited by reasons ranging from prohibitive start-up costs to limited market size, and from ongoing financing issues to wider economic conditions. This investigation focuses on the primary challenge being attributed to cultural issues, as identified by Pan, Gibb and Dainty (1). Burnham Kelly's mid-twentieth-century comment further recognises that, "there can be no mass production without mass marketing" (87). Understanding consumer behaviour and first-hand market research is still an issue today. A lack of consistent and effective marketing has led to a proliferation of misperceptions held by the industry and public alike. A wide range of these misperceptions can be grouped into historical, quality, aesthetic and socio-cultural issues.

Historical misperceptions of uninspiring standardised designs taint contemporary perceptions (Laing, Craig and Edge 81) (24). It would follow then, that New Zealander's perceptions are based on their historical experiences with prefab classrooms, kitset homes and relocatable baches. The United Kingdom is affected by historical perceptions of post-war prefabs and multistorey concrete structures from the 1950s and 1960s. ${ }^{20}$ Brenda Vale records perceptions of prefabrication from that era:

"People have got the idea that [prefabrication] means jerry-building, tumbledown shacks, caravans, shoddy work, ribbon development, draughts and leaks and everything that is bad in building" ("Picture Post" qtd. in Vale 21).

New Zealand architect Graham Dawson commented on the limits of prefabricated housing in 1952. He cited sub-standard plans, bad siting, poor proportions and different standards of finish (76). These historical perceptions continue to shape how some industry members view prefabrication today.

Similarly, the United States still judges prefabricated housing according to mobile or manufactured homes, with their connotations of being light, flimsy, temporary and cheap. ${ }^{21}$ Lowcost is confused with perceptions of low-quality. A widely-accepted myth about manufactured homes is that they are not well built, when in fact they are structurally reinforced to withstand lengthy road transportation (Elliston and Nafzgar 11). United Kingdom construction professionals perceive prefabricated houses as being less permanent and a poor investment (Cook 53). Contemporary high-quality exemplars are needed to combat these historical misperceptions.

${ }^{20} \mathrm{~A} 2000$ United Kingdom study into market resistance to prefabrication discovered that perceptions were based on aspects of poor quality and poor design from 1950s and 60s prefabrication (Laing, Craig and Edge 89). Their post-war prefab programme was successful in that the buildings were used beyond their intended use-by-date, yet wider perceptions suffered as a result of the visible deterioration (Vale 21).

${ }^{21}$ These homes are a more affordable housing solution due to their lower unit price and leasehold land. 


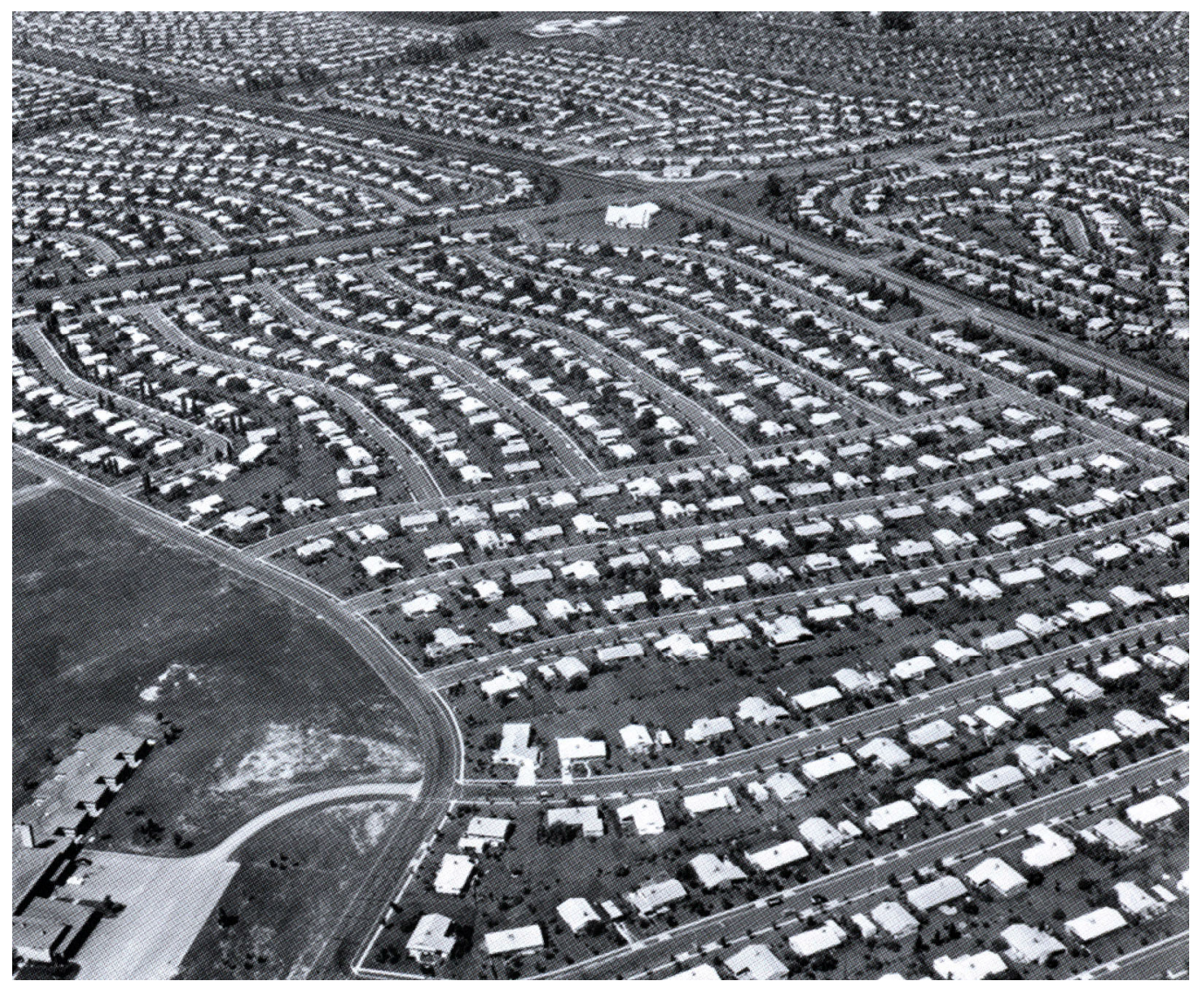

Figure 26: Monotony and repetition at Levittown, New York, developed in the late 1940s and early 1950s. Source: D. Goodman, A History of the Future, New York: Monacelli Press, 2008: 143. 
The common assumption that prefabrication results in repetitive outcomes and an overall confusion with mass-standardisation has caused aesthetic misperceptions (Elliston and Nafzgar 8) (25-26). Innovative prefabricated housing has been further thwarted by the public perception that equates unconventional materials or appearance with inadequacy in performance (Kelly 90). The wider public understands the traditional housing vernacular of the pitched roof, shuttered windows and horizontal linear cladding. Prefabricated housing that travels as a complete building on the back of a truck, by contrast, can have a low or flat roof which may be perceived as non-traditional. In these cases, architectural prefabrication may have failed because of the public rejecting a Modernist aesthetic. There is a discord between market demand and architect-designed supply, which goes to support Davies' plea for architects to learn to speak the same language as their clients in order to improve communication (203).

The main barrier to prefabrication in the United Kingdom has been identified as the sociocultural perception of the home as an economic investment, rather than a consumer good (Laing, Craig and Edge 92). The New Zealand concept of the family home as a primary investment and indicator of economic wealth is a dominant part of the national culture. In the late 1970s and early 1980s an influx of material and component options entered the New Zealand construction market resulting in a proliferation of consumer choice (Tuohy). This emphasis on choice and personal space creation has become intrinsic to the home-buying process today. It also poses a barrier to prefabrication because, "psychologically, mass production is considered an attack on individuality" (Mitchener 4).

Contemporary prefabricated housing businesses attempt to subvert problems caused by misperceptions by using pre-built, pre-configured or pre-planned terms instead. ${ }^{22}$ The range of misperceptions explained here affect prefabrication's uptake today. Further evidence is provided by the case studies in the following chapters.

22 Michelle Kaufmann Designs' website uses the term pre-configured and says their homes are "high-quality, high-performance homes that are built in the factory - not to be confused with 'manufactured' or 'mobile' homes!" New Zealand's Rod Gibson of Habode advocates the term manufactured rather than prefabricated, as we do not have the associated history of the mobile or trailer home. Firms in the United Kingdom and some in the United States use offsite, but this term is not used widely in New Zealand to date. 


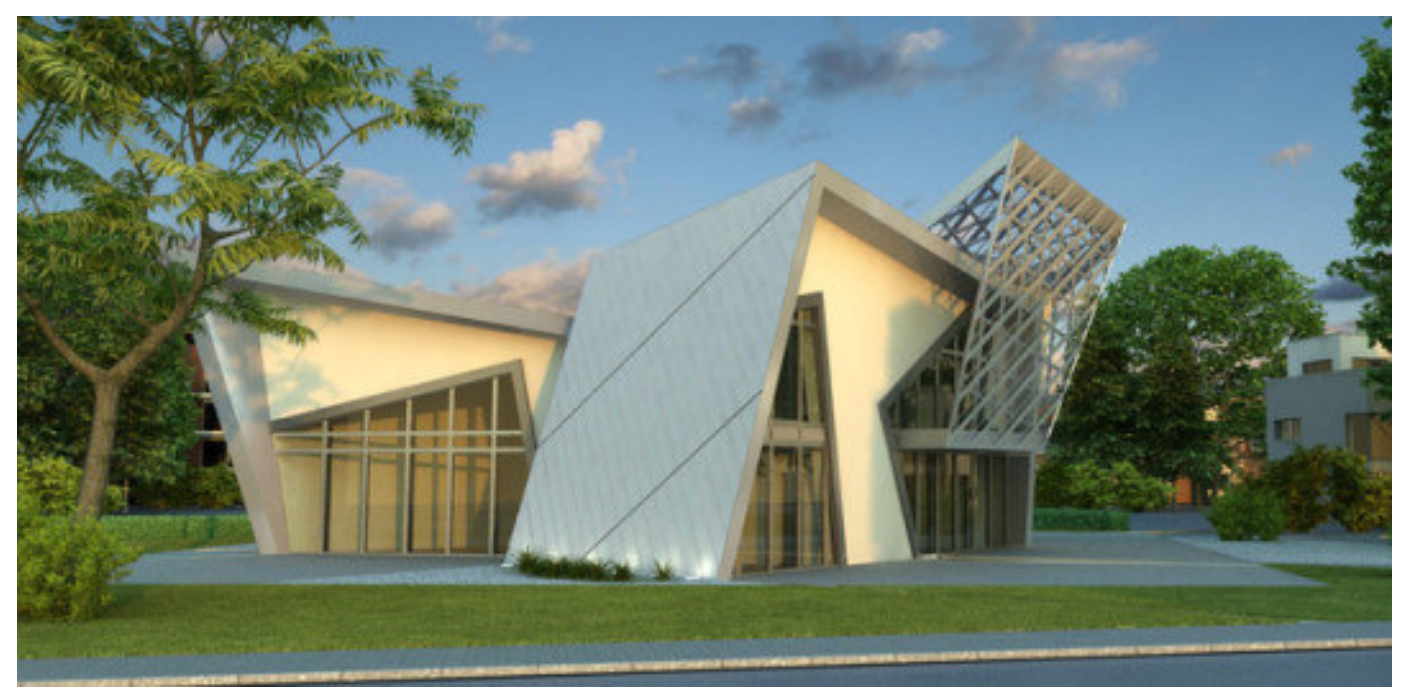

Figure 27: Architect Daniel Libeskind's proposed sustainable prefabricated Villa, 2009. Source: <http://www.inhabitat.com/2009/06/19/daniel-libeskinds-sustainable-prefab/>. 


\section{Prefabrication and Architecture}

Architects have been fascinated by prefabrication for a long time (Rybczynski, "Prefab Fad").

Architects were particularly fascinated by prefabrication during the mid-twentieth century when social motivators combined with booming post-war housing demands. Since then, many architects have thought about prefabrication, drawn up designs, or had to shelve prototype projects while they pursued more traditional custom work in order to stay in business. More recently, the combination of rising housing costs and lifestyle aspirations has led to niche resurgence in contemporary prefabricated housing, which the architecture profession has begun to address ahead of the residential construction industry (Ebong 12) (27).

Historically, there has been a distinction between prefabricated architecture and building. Architecture is associated with emotion, art and spirituality - whereas, "building is just construction" (Jones qtd. in Nilsen). Prefabricated buildings have been commercially successful whilst prefabricated architecture has not. In fact, "it sometimes seems that commercial and industrial success is itself sufficient to disqualify a prefabricated house from the status of architecture" (Davies 44). ${ }^{23}$ Successful prefabricated building exemplars include the balloonframe, mail-order house, mobile or manufactured home, modular hotel and kitset house. Davies believes the reasons for architecture's commercial failure are tightly entwined in the institution architecture, citing a disdain for the lightweight, an eager desire for authorship, a love affair with the site, miscommunication with its public, and an overall misperception of prefabrication. He suggests architects should embrace pattern-books, work collaboratively, and learn from precedents such as Japan's high-quality prefabricated housing (Davies 8).

In the past, architects who have experimented with prefabricated housing have been driven by design integrity as the bottom line, whereas commercially successful prefabs were driven by property developers and entrepreneurs. Examples include Bill Levitt's Levittown and Carl Strandlund's Lustron housing (Ebong 18). Experts suggest that architects could be better prepared with more emphasis on financial and marketing planning, and address affordability and construction technology issues earlier in the design process (Clark; Ebong 22). In 1951, John Ely Burchard suggested:

Successful factory manufacture of houses will depend upon a first-rate combination of managerial brains, financial acumen, engineering skill, aesthetic sensibility, social consciousness, and marketing wisdom. A study of the art stands therefore at the crossroads of the applied physical and social sciences (Burchard Foreword in Kelly ix).

Burchard's mid-twentieth-century observation reflects the historic difficulty of combining economic and architectural success. The current prefabricated housing revival is more concerned with this focus on both business sustainability and a contemporary aesthetic.

${ }^{23}$ In general, architectural prefabrication has not benefitted from continuing production of repeated housing units to produce a profit, resulting in commercial success. 


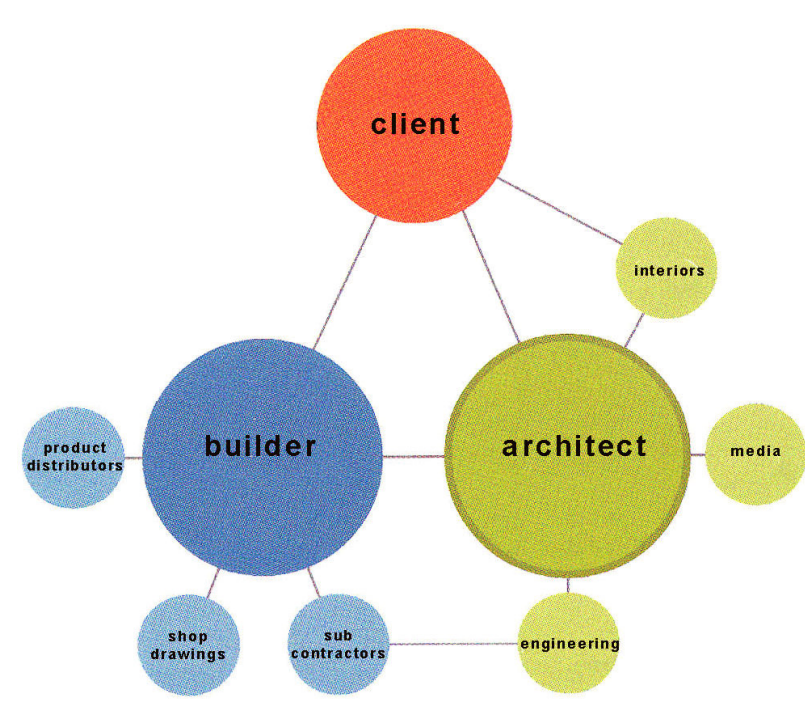

conventional architecture practice

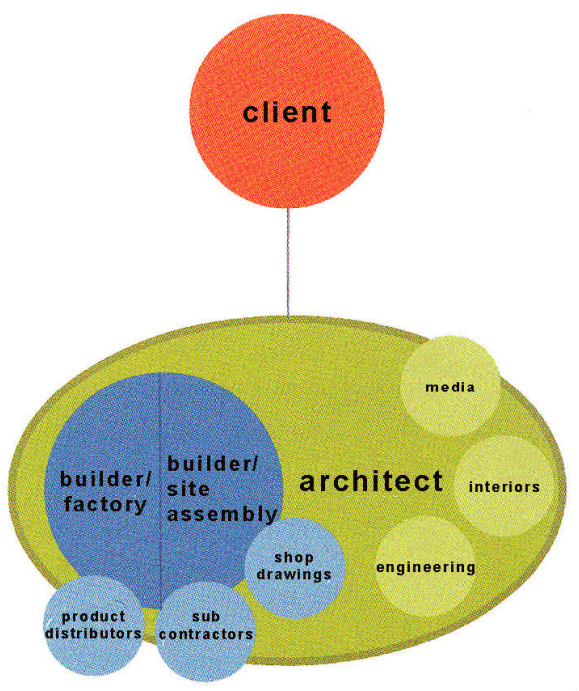

master builder practice

Figure 28: MKD prefabricated housing company structure with architect as master builder controlling construction. Source: M. Kaufmann and M. McGrath, Prefab Green, San Francisco: MKD, 2006:50. 
Davies notes, the "relationship between architecture and prefabrication has always been problematic" (9). Further historical misperceptions by the architecture profession have been about a potential for prefabrication to diminish the role of the architect. Yet contemporary architects would argue that the traditional construction process has done this anyway. Kieran and Timberlake suggest that the role of the architect has devolved through specialisation and fragmentation and propose a future that embraces commodity and art equally where architects take more responsibility for the construction process (Refabricating Architecture xii) (28).

Other architects have encountered direct resistance from the profession's governing body. Buckminster Fuller's mid-twentieth-century work was unfavourably viewed by the American Institute of Architects as a "peas-in-a-pod" design (Pawley 30). In the 1970s, Ivan Juriss of Industrialised Building Systems (IBS) encountered similar problems in New Zealand with opposition to its modular building ideas within the profession. ${ }^{24}$ Some of this resistance can be attributed to the observation that prefabrication "challenges architecture's most deep-seated prejudices" (Davies 10). Prefabricated housing is stereotypically non-site-specific, lightweight, requires knowledge of business and questions authorship. Furthermore, the problem of architect-design aesthetics not being appreciated by non-architects means that either everyone needs to be educated or architects need to listen to the market (Davies 9).

The historical context has been a discord between the realms of architecture and building. This has been manifested in a consumer market that misunderstands the roles of each and how prefabrication relates. There is an identified need to find a way to bridge this gap between the architecture profession and construction industry, and in turn between architect-designed prefabricated housing and end-consumers. This thesis examines prefabricated architectdesigned and non-architect-designed housing products, systems and businesses as one integrated whole.

${ }^{24}$ Even contemporary architects that produce prefabricated prototypes themselves, such as Douglas Gauthier, point to an architectural preoccupation with the one-off or bespoke as the only true architectural representation (Gauthier). 


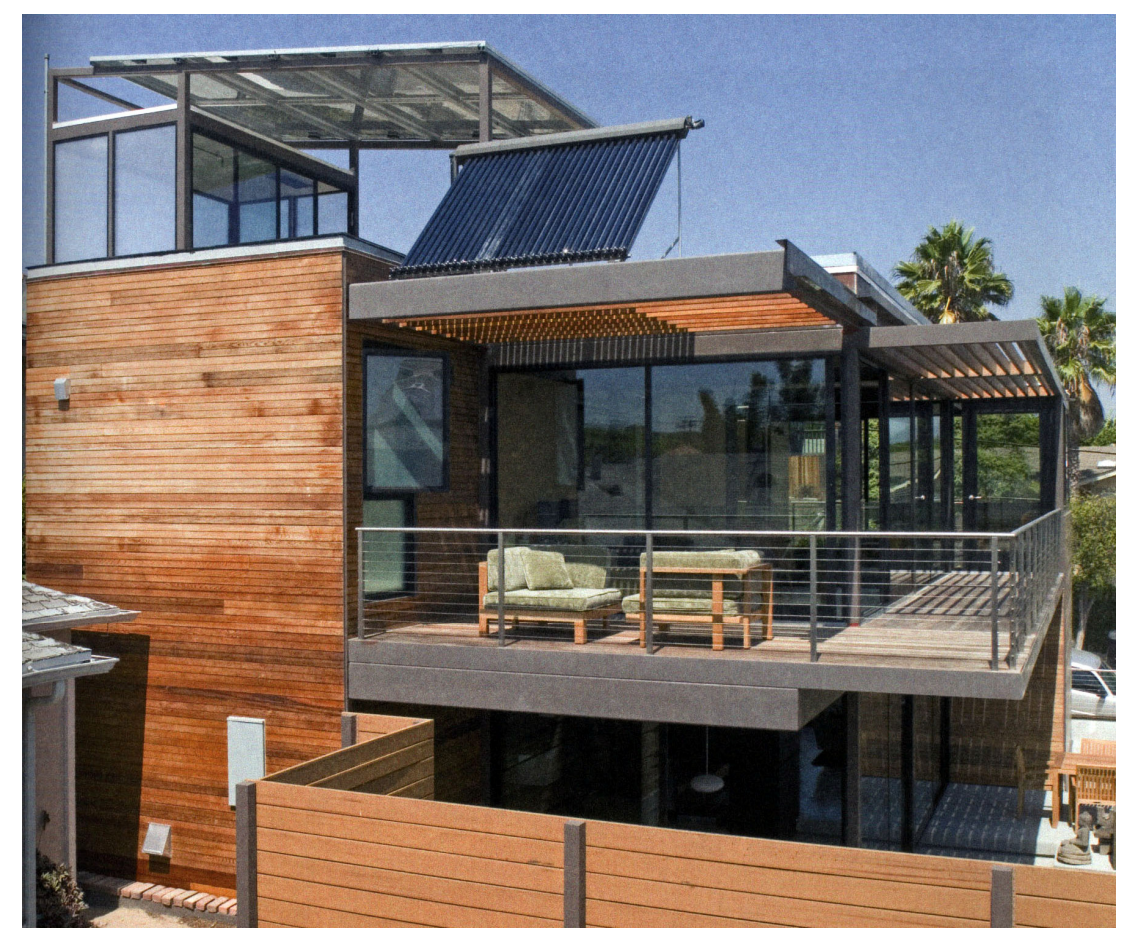

Figure 29: Sustainable features of LivingHomes' First House include: modular construction, material selection, photovoltaic panels, solar hot water heating and green roof. Source: S. Costa Duran, Green Homes, New York: Collins Design, 2007: 125. 


\section{Prefabrication and Sustainability}

Contemporary discussions about housing in the near future should include a reference to sustainability. ${ }^{25}$ It is hoped that environmentally sustainable design (ESD) principles will become an intrinsic component of design, business and lifestyle. The terms sustainable, green and ecoare used interchangeably when discussing architecture. Sustainability experts Paul Hawken, Alex Steffen, William McDonough and Michael Braungart have long held the belief that design is both a problem and a key approach to the ecological crisis. The objectives of both environmental sustainability and improved construction efficiency can be addressed by prefabrication (Gorgolewski 128) (29).

Prefabrication can potentially save material and energy resources. Chris Wood of the Ministry for the Environment describes construction as the "forty percent industry", in that New Zealand buildings are responsible for forty percent of energy consumption, forty percent of waste stream, thirty-five percent of carbon dioxide emissions, and forty percent of raw material-use ("Govt ${ }^{3}$ and Sustainable Government Building"). ${ }^{26}$ The long-term goal of the government's Govt ${ }^{3}$ sustainability programme to reduce construction environmental impacts by thirty to seventy percent. ${ }^{27}$ Sustainable prefabrication could go some way to achieve this. The United Kingdom's Waste and Resources Action Programme (WRAP) reported that up to ninety percent of waste could be reduced in the use of a variety of prefabricated manufacturing methods (Whiter). United States projections are similarly optimistic, with claims that construction industry energy consumption can be reduced by fifty percent by using prefabrication methods (Miller). Working indoors enables more reuse of materials, efficient computer-controlled cutting, and better capture of waste for recycling. The final product also benefits from the reduction of defects, and closer tolerances for tighter thermal and acoustic performance leading to better energy efficiency (Gorgolewski 127).

Another sustainability benefit is the prefabricated house's reduced carbon footprint through minimised transportation, smaller floor area and lower energy use over its lifecycle. Deliveries to site can be reduced by sixty percent in the case of modular volumetric construction (Gorgolewski 125). Other benefits are reduced noise, pollution and traffic at the final building site (30). Process benefits arise from a safe, healthy and controlled factory environment for workers, as well as savings in labour and material efficiencies. Work at a traditional site can fall up to fifty percent below potential, and it is estimated that thirteen to eighteen percent of materials delivered are wasted because they are not used properly (Gorgolewski 126). Some

\footnotetext{
${ }^{25}$ Sustainability is commonly referred to as the triple bottom line, taking environmental, economic and social factors into account (Marsh qtd. in Yang et al. ix). It has also been widely described as "development that meets the needs of the present without compromising the ability of future generations to meet their own needs" (Brudtland qtd. in Yang et al. ix).

${ }_{26}$ The greatest industry contributors to waste are packaging, timber and plasterboard (Whiter).

${ }_{27}$ This programme aims to change behaviour and practices within government agencies by increasing capability and knowledge, identifying best practice and promoting practical solutions and tools. The four key topic areas are recycling/waste management, buildings, transport, office consumables and equipment. On 9 March 2009, the National government disestablished the previous Labour government's Govt ${ }^{3}$ programme (Wood, "Govt ${ }^{3}$ Status").
} 


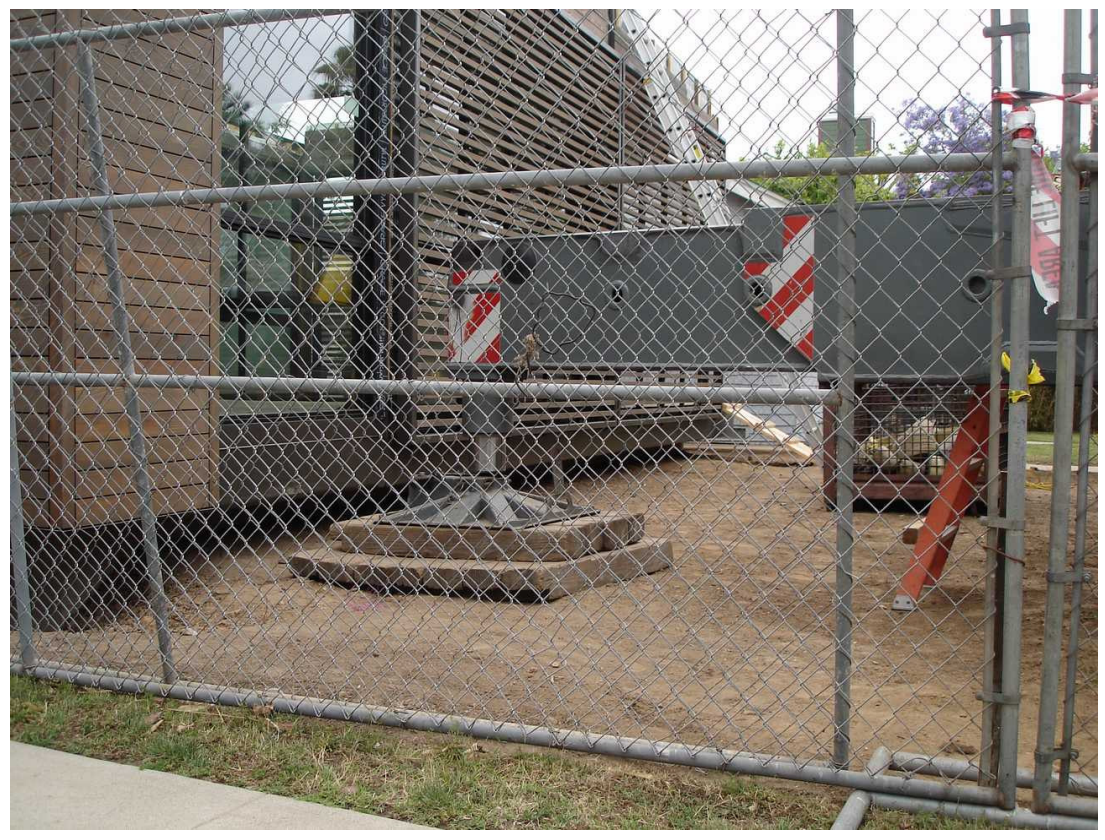

Figure 30: Lack of construction waste at site as a result of factory-based modular methods. Source: Author's photograph, 2008. 
prefabricated systems are also designed for disassembly which is seen as a leading direction for sustainability in architecture (Papanek 201). One drawback is in the over-engineering and subsequent additional material used in bracing modular units for transport. However, in some cases this over-building can make the house more durable once placed at the site (Wendt).

Prefabrication is subject to green-washing, where sustainable information is over-emphasised or presented out of context. ${ }^{28}$ Prefabrication has potential to be sustainable, "but few of these benefits have been measured directly, and most vary based on the conditions in the factory and the location of the building site" (Wendt). Sustainability is ultimately determined by the system and its implementation, including material choice, material sourcing, efficiency of production, reuse and recycling of scraps, and effective disposal of waste. Lloyd Alter comments on the context of prefabricated sustainability:

Prefab holds the promise of delivering a greener home in less time and perhaps even less money, but it is only as green as the designer and the builder (Alter "Prefab: Green or Greenwashing").

Relying on the designer and builder is not a measurable quality-focussed solution. The United Kingdom's Buildoffsite industry association has concluded that sustainability is about a lifecycle approach while prefabrication targets just design and construction phases. In order to become more sustainable, it purports that prefabrication will need to address measurable whole-life issues such as air-tightness and lowered energy costs for users.

This thesis takes Kieran and Timberlake's holistic view of sustainability as a context for economic survival of the construction industry, with prefabrication as a key strategy for futureproofing. It is recognised that sustainable features are imperative to architectural housing now and in the future, whether it is prefabricated or traditionally delivered.

${ }^{28}$ The term green-washing, or greenwashing, refers to the practice of companies deceptively using green public relations and marketing to mask a profit-making focus. One example is in presenting cost-cutting measures as resource-saving measures (Laufer). Refer to Glossary. 
Figure 31: Cover of Davies' Prefabricated Home.

Source: C. Davies, The Prefabricated Home, London: Reaktion, 2005. 


\section{A Theoretical Context for Prefabrication}

Conceptual and ideological motivations for prefabrication in the last century provide a theoretical grounding and a point of departure for later discussions. In 2009, architecture critic Witold Rybczynski reflected:

The motives for the search were sometimes economic - to apply the financial benefits of mass production to housing - and sometimes qualitative - to achieve the precision that accompanied factory production. But the impetus was also ideological... a chance to explore architectural concerns, especially an overarching interest in standardisation (Rybczynski, "Home Delivery" 254).

Historically, prefabrication has provided technologies to produce a more affordable, higher design quality, widely adopted housing solution. Architects and inventors alike have been inspired and spurred on by their social consciousness to produce innovative designs. At the turn of the twentieth century, it was fear of disease that led inventors like Thomas Edison to develop robust prefabrication systems (Bergdoll and Christensen 42).

Today, in the age of affordable, well-designed commodities provided by brand-leaders such as Ikea and Target, it is the pursuit of accessible well-priced high-design which creates market demand (Ebong 12). At the same time, architects are increasingly frustrated by the traditional design and construction process which is impeded by low-skilled workers and constant cost and time overruns. Prefabrication is seen as one way for designers to retain some control over the outcome, and particularly its quality. Prefabrication has also been a vehicle for experimentation, for innovative materials and system technologies. These conceptual and ideological motivators are illustrated through the following historical examples.

Author Sandy McLendon advocates prefabrication as a tool for lifestyle down-sizing, in response to contemporary socio-cultural conditions such as unaffordable houses, excessive dreams, long working hours and family disintegration (10). Le Corbusier was similarly motivated by the idea of affordable housing and explored more efficient construction systems. In 1923, Le Corbusier published his thoughts about mass-production, famously proposing that, "we shall arrive at the 'House Machine', the mass-production house" (210). He looked to aeroplane and automobile manufacture to produce a refined standard product through analysis and experiment, and advocated for the socio-cultural creation of a state of mind, or "spirit", of constructing, living and conceiving mass-production houses (4). He understood that the culture had to be in place before any technological change could be accepted, understood and takenup; something that the United Kingdom's Rethinking Construction report reiterated seventy-five years later (Construction Taskforce).

Social motivation to produce housing for lower-income groups led Burnham Kelly to outline current problems and future predictions alongside an analysis of one-hundred-and-thirty United States fabricators in his 1951 book The Prefabrication of Houses. He cited mid-twentieth- 


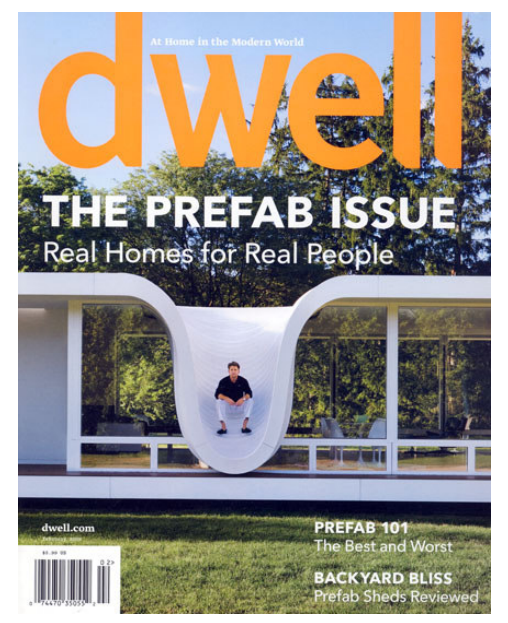

Figure 32: Cover of Dwell 'The Prefab Issue'. Source: Dwell magazine, February 2009.

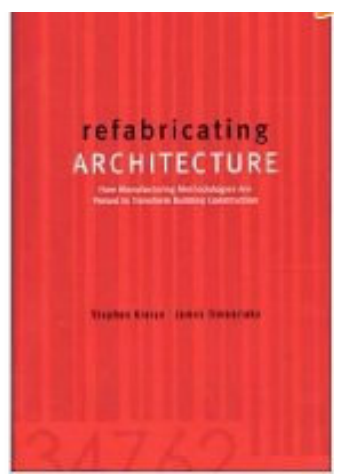

Figure 33: Cover of Kieran and Timberlake's Refabricating Architecture treatise. Source: S. Kieran and J. Timberlake, Refabricating Architecture, New York: McGraw-Hill, 2004. 
century problems in the United States of marketing, misperceptions by customers and industry, building code compliance, and financing issues, as well as future challenges such as sustainable material supply and mass-marketing. Kelly understood that business is integral to design for an enduring future of prefabricated housing, something that is shared by United Kingdom expert Colin Davies. Davies' 2005 book The Prefabricated Home is based on the proposal for more architect-designed prefabricated housing in the future (31). He draws on lessons from commercially successful prefabricated buildings to plead with architects to involve themselves with prefabricated housing.

The idea of high-design at affordable prices is a primary motivator today. Under editors Karrie Jacobs and Allison Arieff, Dwell magazine launched design competitions, feature articles and an annual prefab-specific issue which have all contributed to the contemporary resurgence of interest in 'green modern prefab' (32). ${ }^{29}$ Arieff's Prefab with Bryan Burkhart, set out in 2002 to, "inspire a change in the way people think of prefab and the way the architects, builders, developers, and financial institutions approach it - and ultimately, the way individuals live in it" (10). Its historical overview and case studies marked the start of the current revival of interest in contemporary prefabricated housing.

A group of practicing architects today have been questioning traditional construction processes and finding ways to produce a better quality outcome, becoming their own general contractors or moving construction indoors where they can maintain tight quality controls. Architects such as Marmol Radziner Prefab, Michelle Kaufmann Designs, Jennifer Siegal and LivingHomes have produced beautiful designs with exceptional construction quality through factory-based methods (refer to case studies in Chapter 4.)

Practicing architects, academics and authors Stephen Kieran and James Timberlake continue to pursue innovative construction systems as a way to improve the delivery process. Following in Le Corbusier's footsteps, they researched automobile, aeroplane and ship-building industries. Their 2004 treatise Refabricating Architecture lays out an argument that the design and fabrication of architecture has not evolved in the last century, while these other industries have (33). They propose a regulatory structure of information management tools to move forward, together with the chunking of components to minimise joints, assembly time and costs at the construction site.

Experimentation, innovation and improvement are recurring ideas throughout prefabricated housing's history. Academic and author Alistair Gibb documents ground-breaking United Kingdom case studies in his 1999 book Off-site Fabrication. Gibb makes the astute comment that there is not one correct application of prefabrication; that it is an approach developed for a unique client, brief, site and context, much like custom architecture. Curators of the

29 'Green modern prefab' is a term explained further in Chapter 4. It has come to mean an aesthetic style, and indicates smaller, more energyefficient homes, with open and flexible spaces. 


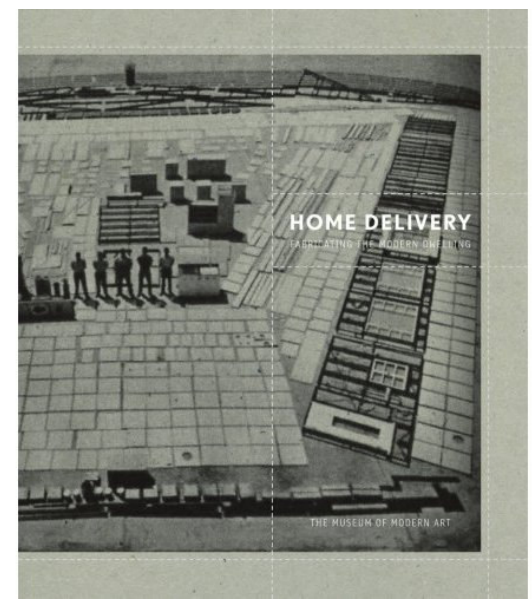

Figure 34: Cover of Home Delivery exhibition catalogue.

Source: B. Bergdoll and P. Christensen, Home Delivery, New York: MoMA, 2008: 40. 
prefabrication exhibition 'Home Delivery' at New York's Museum of Modern Art in 2008 and authors of its accompanying catalogue, Barry Bergdoll and Peter Christensen profiled over onehundred innovative exemplars from the last two-hundred years of architectural history (34). They compared architectural innovation against the successful commercial production of nonarchitectural housing products. Bergdoll's essay in the Home Delivery catalogue poses a question faced by architects throughout history: if factory production and modern transport systems could revolutionise the way consumable artefacts are produced and distributed then, "why is the culture of building so resistant to transformation?" (12). The cultural focus recurs throughout this thesis.

Today, the architectural interest in prefabrication is fuelled by both populist and academic activity. Karrie Jacobs envisages a socialist future where architects become more like brands and sell architecture from stock plans; resulting in affordable, well-designed housing for more people (97). Academics identify potential for digital design to couple with building fabrication technologies to open up prefabrication to mass-customisable solutions. Bergdoll predicts future opportunities in learning from historical lessons and combining these with digital technology and an increasingly globalised society (25).

This thesis will build on the intellectual foundations referred to by these prefabrication experts as a context for the discussion of New Zealand's unique history and opportunities. Bergdoll's emphasis on learning from historical challenges in order to make future predictions is a method that this thesis will adopt. Gibb's methodology of case study investigation and discussion is an approach that this thesis will also use towards discovering an unrealised potential for prefabricated housing in New Zealand.

Further background information about prefabrication will be laid out in the next chapter. An overview of prefabricated housing examples from history, both internationally and nationally, will provide a context for the contemporary case study chapters that follow on. 


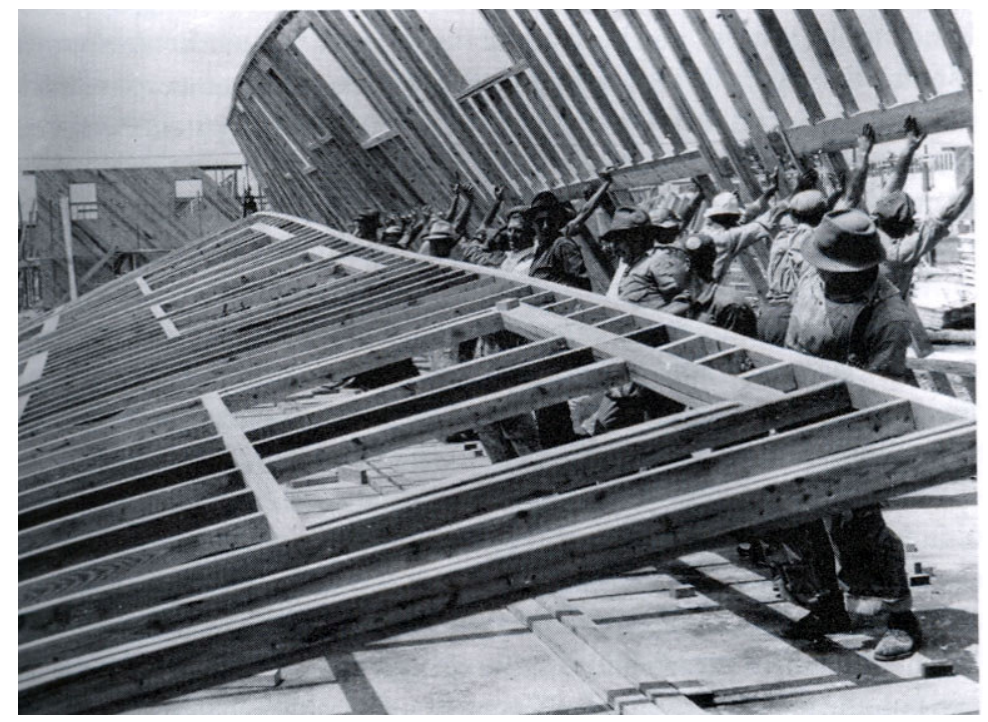

Figure 35: Balloon-frame structure being erected at a building site.

Source: C. Davies, The Prefabricated Home, London: Reaktion, 2005: 45. 


\section{Past Prefabs :}

\section{A Short History of Prefabricated Housing}

Beachside baches, portable classrooms, and state houses are all part of New Zealand's prefabricated history. Large tracts of rural land and vast stretches of coastline are sites for numerous prefabricated worker dwellings and holiday homes. These houses have become part of our architectural landscape and cultural heritage. The aim of this chapter is to investigate what can be learnt from this legacy. The issues that can be gleaned from past achievements and challenges are embedded in the experiences of our country's housing prefabricators. This short history will draw on the first-hand experiences of these innovators, in line with Barry Bergdoll's recommendations to learn from the past. The aim is to investigate past prefabricated housing characteristics towards discussing its future potential in New Zealand.

This chapter will provide a brief summary of the worldwide history of prefabricated housing, and in turn a context for the following overview of New Zealand's own history. Some key issues that arise from the history will be briefly discussed at the end of the chapter as a basis for the analysis and conclusions that will follow at the end of the thesis. ${ }^{30}$

This country's history of prefabrication is based on earlier histories from the United States and United Kingdom. In the seventeenth century, there is evidence that English panellised timber houses were imported to the United States (White 10). Architectural historians such as Colin Davies, Barry Bergdoll and Peter Christensen determine the Industrial Revolution and the age of the machine in the late eighteenth and early nineteenth centuries as the official start date of prefabrication $(11 ; 40)$. They cite pre-cut lumber, building components such as bricks, and the evolution of balloon-frame timber construction as marking out this beginning period (35). ${ }^{31}$

Since its early nineteenth century starting point, countless challenges have been overcome or succumbed to. A preoccupation with innovative designs over and above financial and marketing planning has been attributed as the main cause of business demise. Key issues, challenges and approaches for commercial success will be explored in this chapter.

${ }^{30}$ Further international history is provided in texts by authors such as Colin Davies, Barry Bergdoll and Peter Christensen, Burnham Kelly, Gilbert Herbert, and Allison Arieff and Bryan Burkhart.

31 These were particularly successful with up to eighty percent of housing utilising balloon frame construction by the end of the 1800 s (Giedion qtd. in Bergdoll 14). Balloon-framing is recognised as originating in Chicago around 1830 and attributed to Augustine Taylor (Bergdoll and Christensen 41). 


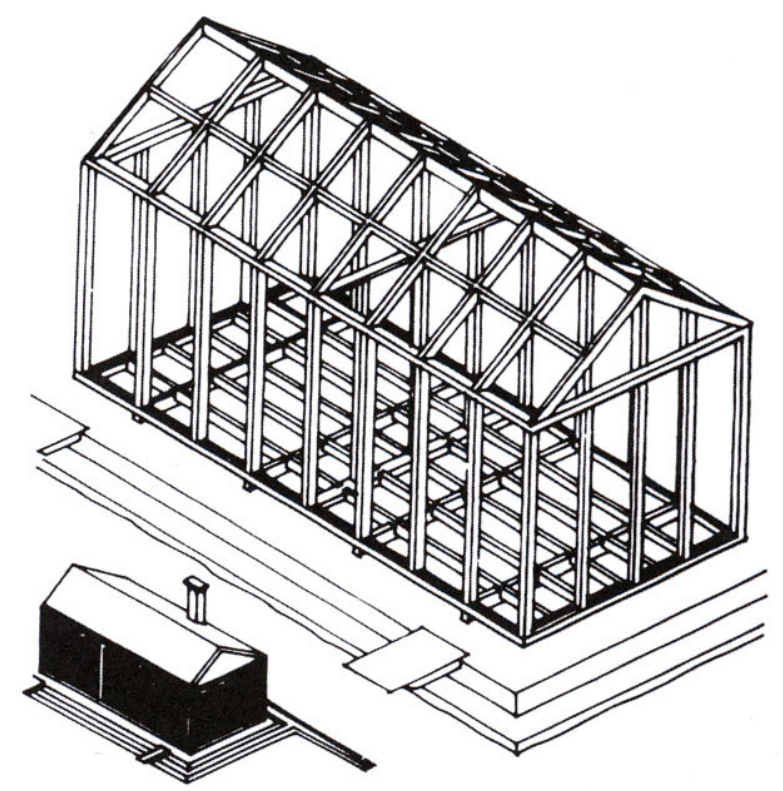

Figure 36: Manning's Portable Cottage: Drawing from an advertisement in the South Australian Record 1837. Source: B. Bergdoll and P. Christensen, Home Delivery, New York: MoMA, 2008: 40.

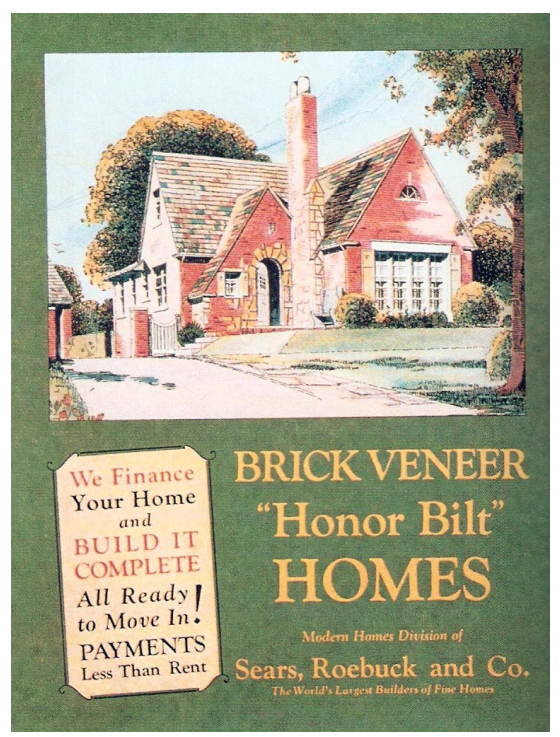

Figure 37: Sears, Roebuck and Company catalogue 1910.

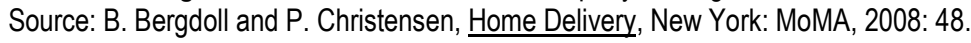




\section{International Historical Overview}

The Museum of Modern Art in New York paid homage to historical prefabricated housing in their popular 2008 exhibition 'Home Delivery: fabricating the modern dwelling'. The exhibition included full-scale structures alongside construction drawings and architectural models of over a hundred artefacts of prefabricated housing stretching from the 1800 s to today. This was a landmark retrospective for its depth, complexity and acknowledgement of the current resurgence of interest in prefabrication. The following summary draws on highlights of that exhibition and its accompanying catalogue in terms of recurring issues in prefabricated housing.

The history of prefabricated housing begins with pioneers and migrants who provided a market for innovative carpenters back in the United Kingdom. ${ }^{32}$ One such entrepreneur was H. Manning of London who exported pre-cut housing kitsets to Australia and New Zealand in 1833 to 1840 (36). His system consisted of pre-cut timber posts, roof trusses and panelised timber cladding bolted together at the site without any need for joints, cutting or nailing. The provision of various sized and priced models ensured a wide market base and commercial success (Bergdoll and Christensen 40).

By the early 1900s American Henry Ford was manufacturing cars on an assembly line and Sears, Roebuck and Company had begun their successful United States mail-order housing catalogue (37). They sold over one-hundred-thousand timber balloon-frame kitset homes between 1908 and 1940 (Bergdoll and Christensen 48). Their houses came complete with selfbuild instructions, and incorporated design flexibility with skilful marketing to make buying a home as simple as purchasing any other household product (Arieff and Burkhart 14). The system was exemplary in that it responded directly to market trends, incorporated client customisation, and offered three tiers of housing models in accordance with affordability and quality (Bergdoll and Christensen 48).

Within a few years of the Sears houses emerging, Frank Lloyd Wright became the first recognised architect to delve into prefabricated housing. He designed a series of American System-Built Houses, or the American Ready-Cut System, and in over nine-hundred drawings outlined a system of timber components to produce an endless array of housing designs. Despite a marketing campaign the houses failed to gain market attention, however Lloyd Wright leaves a legacy of design for mass customisation and the clustering of components (Bergdoll and Christensen 50).

Le Corbusier developed the patented Dom-ino structural building system in 1914. It consisted of piles or pilotis, perimeter load-bearing columns allowing an open-plan interior, horizontal ribbon

32 Manning's Portable Colonial Cottages are recognized as the first documented prefabricated housing by architectural historians Barry Bergdoll and Peter Christensen (40). 


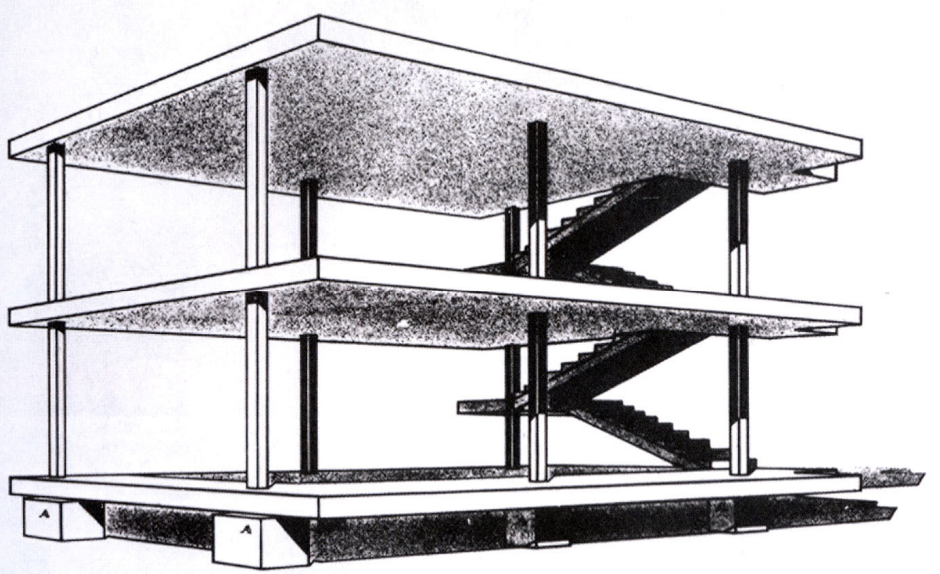

Figure 38: Le Corbusier's Maison Dom-ino: patent drawing 1914.

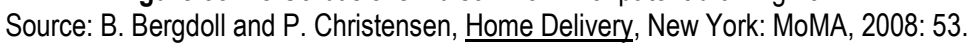
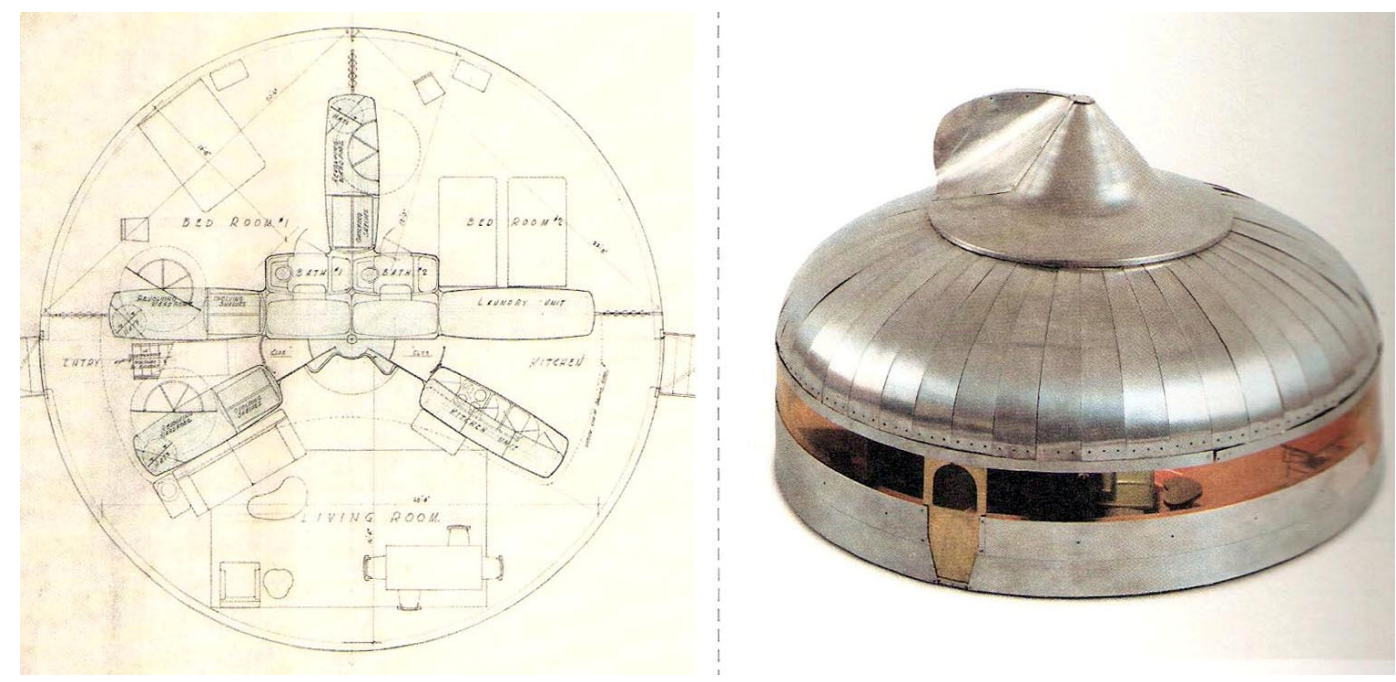

Figure 39 and 40: Wichita House plan and model by R. Buckminster Fuller 1944-46. Source: B. Bergdoll and P. Christensen, Home Delivery, New York: MoMA, 2008: 90. 
windows and a flat roof plane (38). This vision of the house as a machine or tool for living was expanded in his 1923 treatise Towards an Architecture (210). Le Corbusier was influenced by the design and manufacture of vehicles and aeroplanes, the idea of the consumer product, and he had an awareness of marketing. His views were extolled through publishing a magazine titled L'Esprit Nouveau. Le Corbusier patented a proto-architecture, a structural system that has since heavily influenced architectural thought (Bergdoll and Christensen 53).

Richard Buckminster Fuller was a prolific and future-forward designer with a head for both sustainability and marketing. He also understood communication tools and published his own magazine called Shelter in 1932 as a way to publicise his inventive creations. His 1927 Dymaxion House, "enclosed a maximum amount of space with a minimum amount of material and expense" (Mau and Institute without Boundaries 32). Both the Dymaxion series and his later Wichita House were built "using aircraft materials and techniques [where] performance per pound weight surpassed any conventional construction" (Pawley 107) (39-40). Buckminster Fuller was an advocate for lightweight components as a core concept to transportability and ease of erection. Pawley views the 1944 Wichita House as, "the most important prefabricated house design of the twentieth century" (13). Its circular roof was assembled top-down on a tensile frame supported by a central mast which could be erected on sloping as well as flat sites, and cost approximately half that of a conventional house. In less than a year 37,000 unsolicited orders were received but Buckminster Fuller's "fanatical determination to retain complete personal control of the project" led to financial disaster and his second business liquidation in twenty years (Pawley 109).

It is significant that Buckminster Fuller produced some of the earliest designs that encapsulate utility areas into stand-alone pods separated from living areas. He produced the innovative onepiece Dymaxion Bathroom originally in copper in 1936, and later in fibreglass in Germany in the 1950s (Pawley 90) (41). This idea was taken further with the design of the Mechanical Wing project in 1940 (42). Electric-heated water, reserve water tank, and cooking and sanitary facilities were combined into a caravan-like form which could plug-in next to a cabin or tent (Pawley 92). A further iteration was his black-boxed Autonomous Living Unit, a "road container that could be unpacked into a completely equipped dwelling interior" such as in one of his geodesic domes, which he became famous for (Pawley 119) (7).

Buckminster Fuller's ideas and designs were provocative, future-focussed and well ahead of mainstream consumer thought and acceptance. ${ }^{33} \mathrm{He}$ advocated for housing to be treated as a service, rather than a product, in order for it to be readily updatable with forthcoming design iterations, much like telephone rental. This idea proved to be too challenging as it was not aligned with widespread socio-cultural views of housing as an investment.

${ }^{33}$ Buckminster Fuller's Dymaxion House finally achieved critical acclaim as a design masterpiece in 2001 in a Michigan museum exhibition (Spunt). 

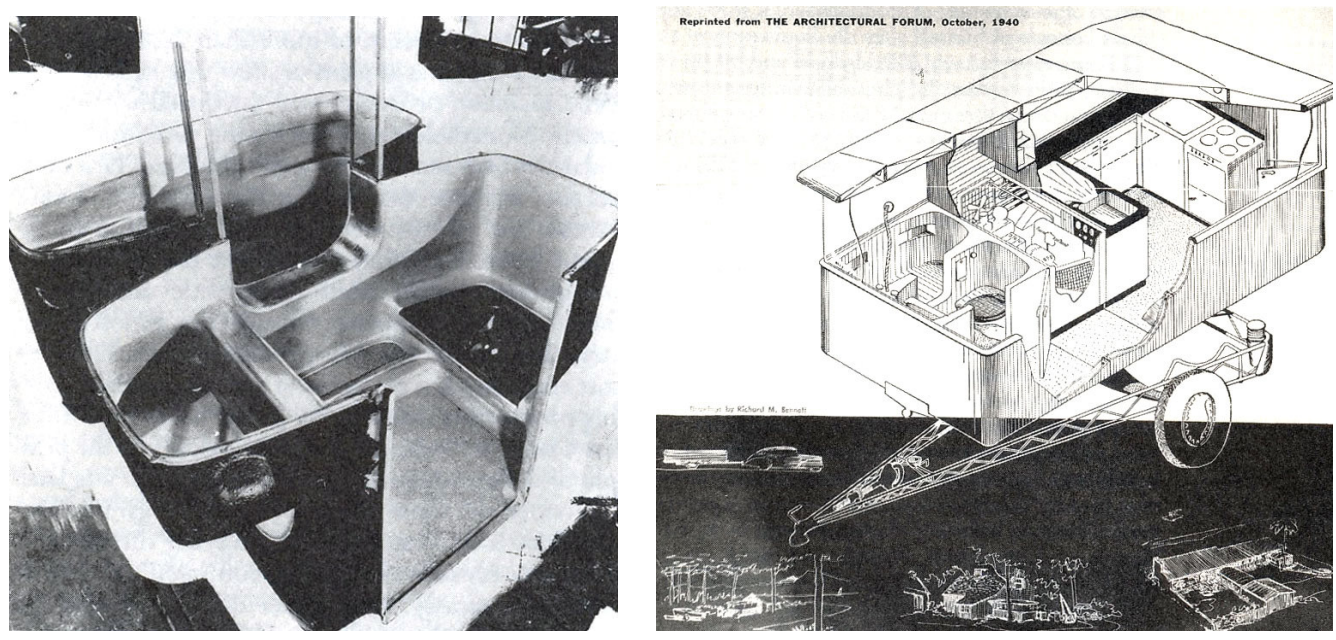

Figure 41 and 42: Copper Dymaxion Bathroom 1936 and Mechanical Wing 1940 by Buckminster Fuller. Source: M. Pawley, Design Heroes: Buckminster Fuller, London: HarperCollins, 1990: 90, 92.
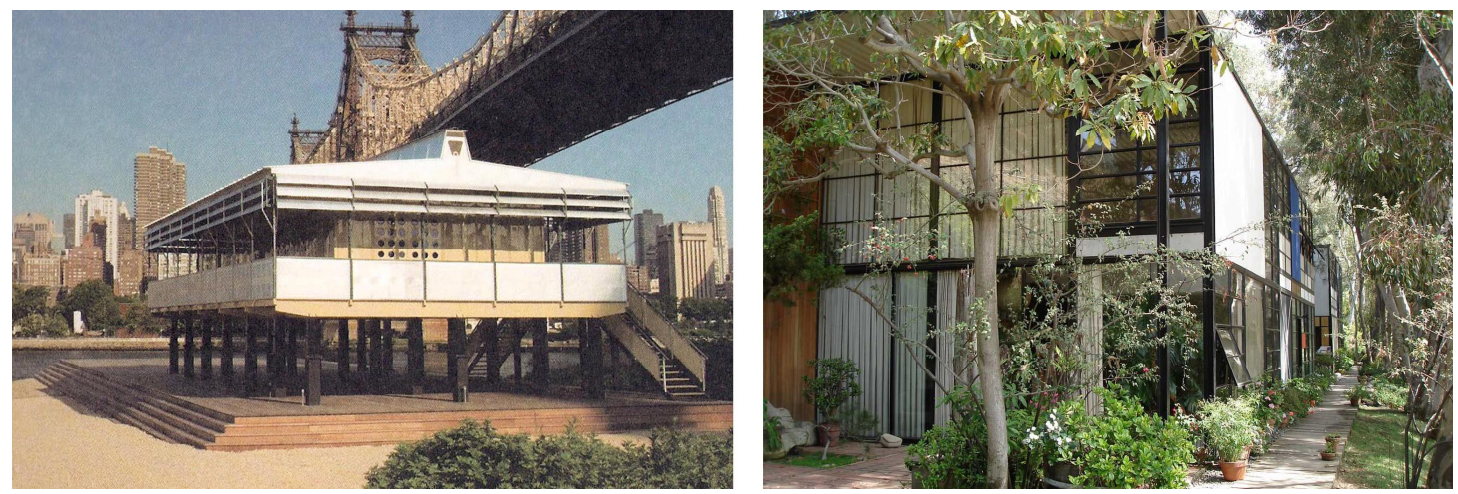

Figure 43 and 44: Maison Tropicale by Jean Prouvé 1949-51 (New York 2007) and Case Study House Eight by Ray and Charles Eames 1945-49 Los Angeles.

Source: B. Bergdoll and P. Christensen, Home Delivery, New York: MoMA, 2008: 115, and author's photograph, 2008. 
Post-World War Two prefabrication activity across the world was diverse: Jean Prouvé shipped his Maison Tropicale series to French colonies in the Congo; Marcel Breuer's 'House in the Museum Garden' was displayed at the Museum of Modern Art in New York; Ray and Charles Eames' Case Study House 8 was completed in Los Angeles; and the Lustron Westchester house model was in full production (43-44). ${ }^{34}$ In the United States, Walter Gropius and Konrad Wachsmann's Packaged House or General Panel System generated a detailed panel-plusconnector system, a factory and a single prototype before bankruptcy (1941-52). Colin Davies and Gilbert Herbert's books closely detail the development of this system which was conceptually interesting, but economically unsuccessful. The system's demise was attributed to the relentlessly tight design control at the expense of business acumen.

The Los Angeles-based Arts and Architecture magazine-led Case Study House programme ran between 1945 and 1966. It showcased new technology, Modern open-planning, and affordable housing (Koshalek 9). The emphasis on new technology such as steel framing was inspired by the shortage of skilled labour, factory surpluses and the need to keep the American economy afloat after World War Two. The Case Study House Eight is also known as the Eames House (1945-9) and is a prime exemplar from this design competition series (44). Marilyn and John Neuhart comment on its role as precedent and metaphor:

The Eames House stands as a metaphor for off-the-shelf, prefabricated industrial construction translated to residential building. A mention of the Eames House conjures up images of plugtogether components combined and built quickly and with dispatch (Neuhart and Neuhart 38).

The Neuharts recognise its importance as, "a flagship for a new approach to design" (54). The house is a symbol, a prototype, and an exemplar for a prefabricated component-based construction system which continues to influence architects today. ${ }^{35}$ Its legacy is to perpetuate the idea of the show-home or walk-through as being critical to consumer education. As Elizabeth Smith points out, "it is very hard for people to demand something they have never seen" (213). The show-home is a marketing tool used throughout history by successful companies to enable customers to experience a design and reduce the risk that such a large purchase inherently holds.

The post-World War Two demand for affordable houses led to a boom in catalogue homes and temporary success in the United States and Japan, but European attempts mainly failed (Willems 4). At this time, Swedish engineer and entrepreneur Carl Strandlund developed the Lustron Corporation range of homes in the United States with the assistance of a federal loan for forty-million United States dollars. He built almost two-thousand-five-hundred houses, before being made bankrupt due to increasing costs and lagging sales around 1948 to 1950 . Time magazine likened the experience of living in the enamelled steel homes to living in "a hot-dog

\footnotetext{
34 The Maison Tropicale house was auctioned by Christies for nearly five million United States dollars in 2007, which is ironic as Prouvé died in near-bankruptcy ("Prouvé Prototype").

35 The Case Study House Eight is a "metaphor" for prefabrication because it was finished largely at site (Neuhart and Neuhart 38). Ray and Charles Eames went on to design the Kwikset House system but chose not to continue pursuing prefabricated housing, instead choosing furniture, film and smaller items where they had complete design control without interference by related trades. The Eames House has become iconic and is still celebrated fifty years on, as a museum kept in trust by the Eames family.
} 


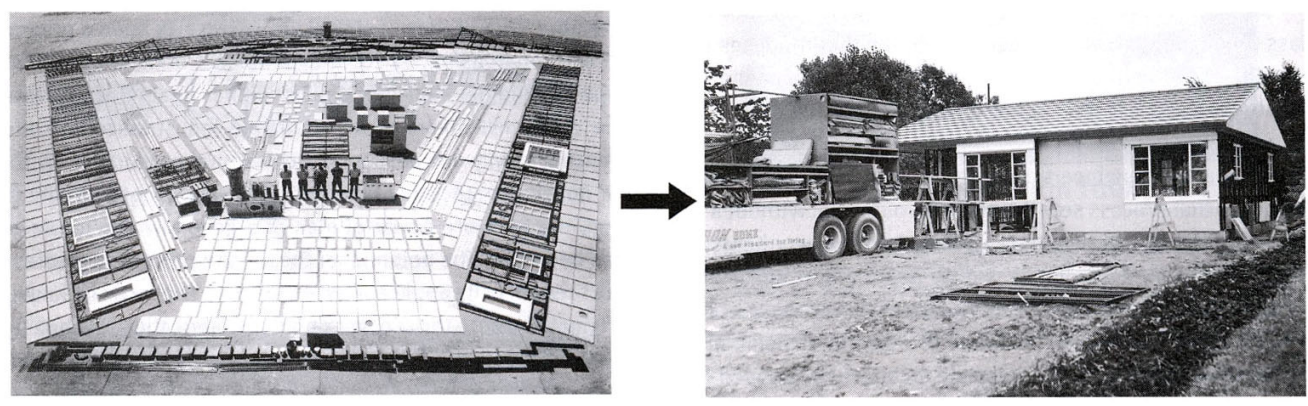

Figure 45 and 46: Lustron house kit of parts and assembly process at site.

Source: S. Kieran and J. Timberlake, Refabricating Architecture, New York: McGraw-Hill, 2004: 108.

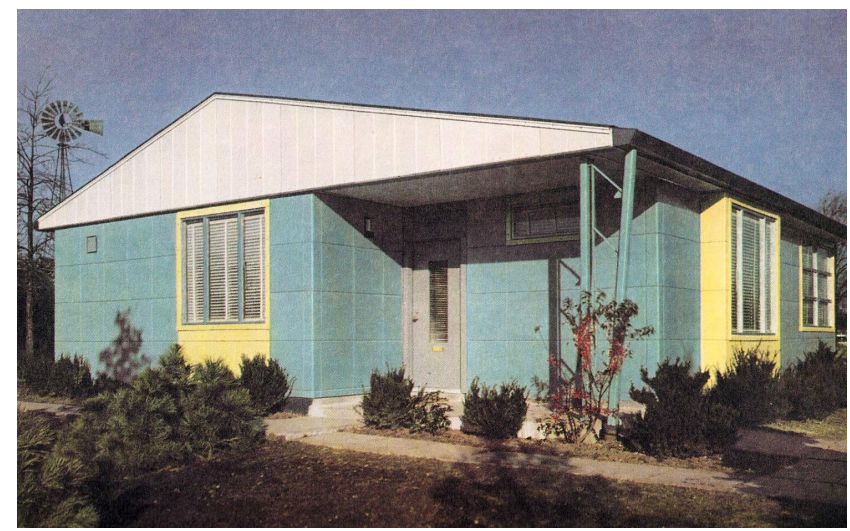

Figure 47: Westchester House show-home by Lustron Corporation 1948-50.

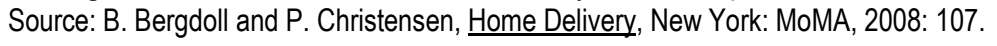
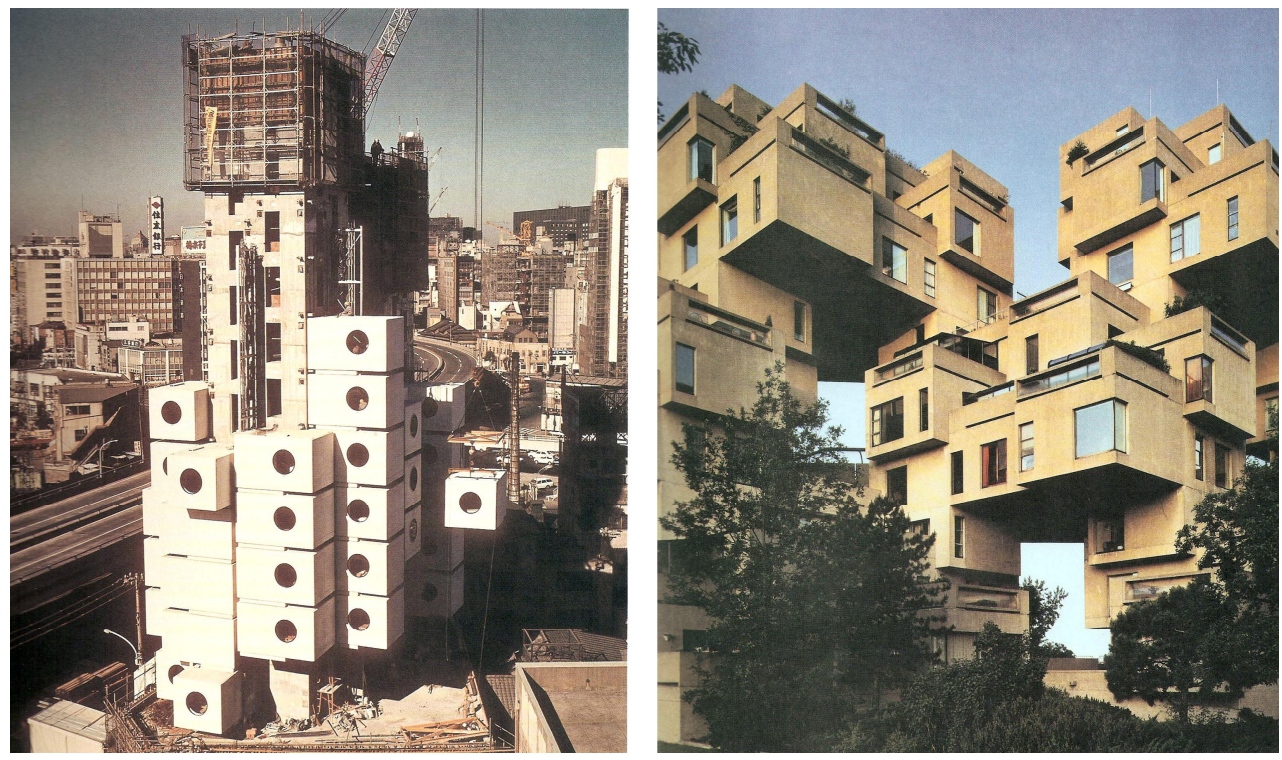

Figure 48 and 49: Nakagin Capsule Tower by Kisho Kurokawa and Habitat 67 by Moshe Safdie, late 1960s.

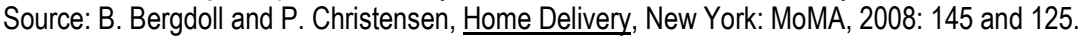


stand" (qtd. in Bergdoll and Christensen 104). The system was ideologically strong because its site-based assembly was aided only by a spanner, or wrench, but aesthetically weak in that it maintained a factory-like appearance both inside and out (45-47).

Large-scale standardised housing such as property developer Bill Levitt's Levittown in Long Island, Pennsylvania and New Jersey tainted the image of prefabrication for generations to come. Despite good intentions of widespread homeownership, the repetitive aesthetic earned them the nickname of looking like "cookie-cutters" and "little boxes of ticky-tacky" (Buchanan 31). Similar multiple iteration developments occurred in the United Kingdom, led by the government utilising spare capacity from the post-war aluminium industry. The United Kingdom's 'Temporary Housing Programme' is appraised by Brenda Vale as being a success due to the homes produced remaining inhabited, albeit modified, well past their intended useby-date (vii).

Prefabrication figures in the exuberant and experimental work of the 1960s Metabolist movement. Archigram and Richard Dietrich's work exemplifies this meta- or mega-structure movement of repeatable standardised structural elements together with plug-in living pod modules. Remarkably Kisho Kurokawa's Nakagin Capsule Tower and a handful of other projects, such as Moshe Safdie's Habitat 67, were actually built in the mid-to-late 1960s (4849). ${ }^{36}$ Habitat 67 was built of one-hundred-and-fifty-eight interlocking concrete modules as part of the World Exposition at Montreal in 1967.

Another provocative design at the time was the flying-saucer-like Futuro by Finland's Matti Suuronen (1968-78). It was originally designed as a ski cabin able to be transported by helicopter to remote mountain locations, yet it landed in locations around the world (50-51). It was made under licence in New Zealand and became home to various functions including a bank branch at the 1974 Commonwealth Games in Christchurch and a beachside bach at Raglan (Hansen 21; Grigor 28). ${ }^{37}$ However, many of these experimental projects failed to become commercially viable, most likely due to their futuristic aesthetic and lack of widespread consumer acceptance. ${ }^{38}$

By 1960 mobile homes made up fifteen percent of the United States' housing, but the post-war rush to build them resulted in poor design aesthetics, a perception for which they are still known today (Spunt). The early 1970s witnessed the rise of the manufactured home and modular housing in the United States, before experiencing a slump which also consolidated the wider prefabricated housing industry by the end of the decade (52). ${ }^{39}$ New Zealand's Industrialised

\footnotetext{
${ }^{36}$ Kurokawa's Nakagin is currently being pulled down. This is despite the Nakagin Capsule Tower being short-listed for World Heritage by the International Committee of Docomomo International since 1996.

${ }^{37} \mathrm{New}$ Zealand is home to 12 of the 60 surviving Futuros in the world (Hansen 21).

${ }^{38}$ Burnham Kelly attributes unconventional materials and appearance with a public perception of inadequacy of performance (90).

${ }^{39}$ A 1971 think-tank by six modular company executives identified several areas for improvement: singularity of building codes across the country; timing of finance to be at start of construction process; more research and development and service from suppliers; cheaper transportation
} 

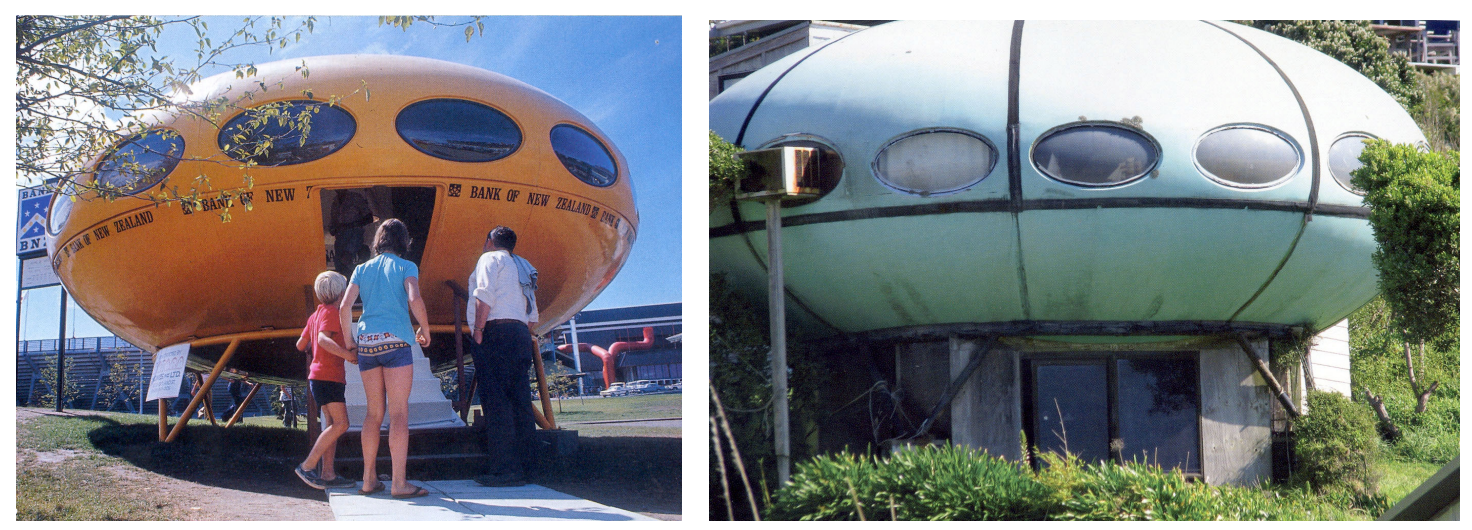

Figure 50 and 51: Futuro BNZ bank branch at Christchurch 1974, and bach at Raglan 2008.

Source: J. Hansen, "The Futuro's Bright" NZ Home and Entertaining, Apr/May (2006): 21, and J. Grigor, Baches and Cribs, London: Penguin, 2008: 28.

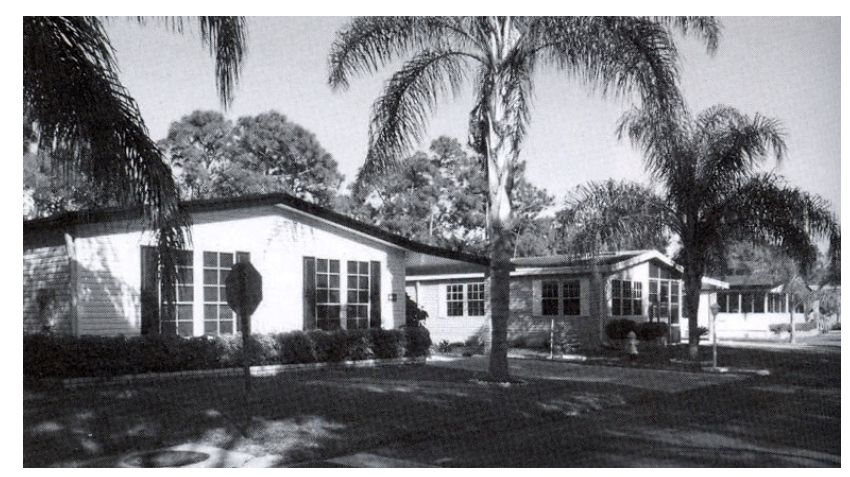

Figure 52: Manufactured housing in Florida.

Source: C. Davies, The Prefabricated Home, London: Reaktion, 2005: 70.

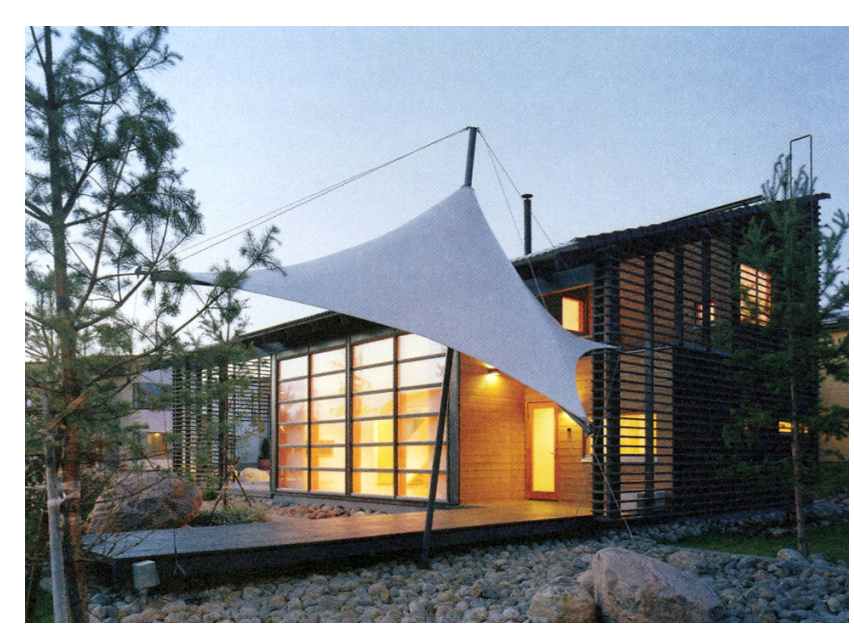

Figure 53: Touch House Heikkinen-Komonen, Finland 1998.

Source: B. Bergdoll and P. Christensen, Home Delivery, New York: MoMA, 2008: 115. 
Building Systems (IBS) conducted a research trip to the United States at this time and described the successful manufactured home model as having a number of aspects which they accredited to their success. These included the leasehold land structure, fully finished models sold from a sales yard, use of cheap seasonal labour, and an established network of highways (R. Hay). By 1980 manufactured home residents in the United States were estimated to number over eight million. Clearly manufactured housing was established as a major housing alternative (Elliston and Nafzgar 5).

The 1980s and 1990s were relatively bare in terms of prefabrication activity, with a few examples emerging from the mainly British high-tech school of architecture, such as Benthem Crouwel's Almere House (1982) and Richard Horden's Yacht House (1983). Waro Kishi's Kim House (1986) and Heikkinen-Komonen's Touch House (1998) are both examples of isolated stand-out architect-designed prefabricated homes amongst a wider established industry of prefabricated housing in Japan and Scandinavia respectively (53). ${ }^{40}$

Prefabrication today is being addressed by a number of architects such as Michelle Kaufmann, Adam Kalkin, Teddy Cruz and Greg Lynn. They are focussed on contemporary sustainable prefab, containerisation, disaster housing, and digital-customisation respectively. The 'green modern prefab' movement is spear-headed by United States architects Leo Marmol and Rod Radziner, Michelle Kaufmann, Jennifer Siegal, Charlie Lazor, and Rocio Romero, who began their businesses by designing and building prototypical homes for themselves (54). This prefab revival is publicised through the pages of Dwell magazine and popular websites. ${ }^{41}$

These architects advocate a more widespread acceptance of prefabrication and associated technologies. They acknowledge that the future possibilities of mass customisation is where prefabrication's greatest potential lies. Contemporary architects would be wise to also take into account issues emerging from the experience of prefabricators throughout the last century.

\footnotetext{
${ }^{40}$ Bergdoll and Christensen chose not to represent the Japanese and Scandinavian prefabricated housing industries, nor the United States manufactured and modular housing industries, in the 'Home Delivery' exhibition (Bergdoll).

41 These websites include Fabprefab, Inhabitat, Prefabs, Prefabcosm and Treehugger.
} 


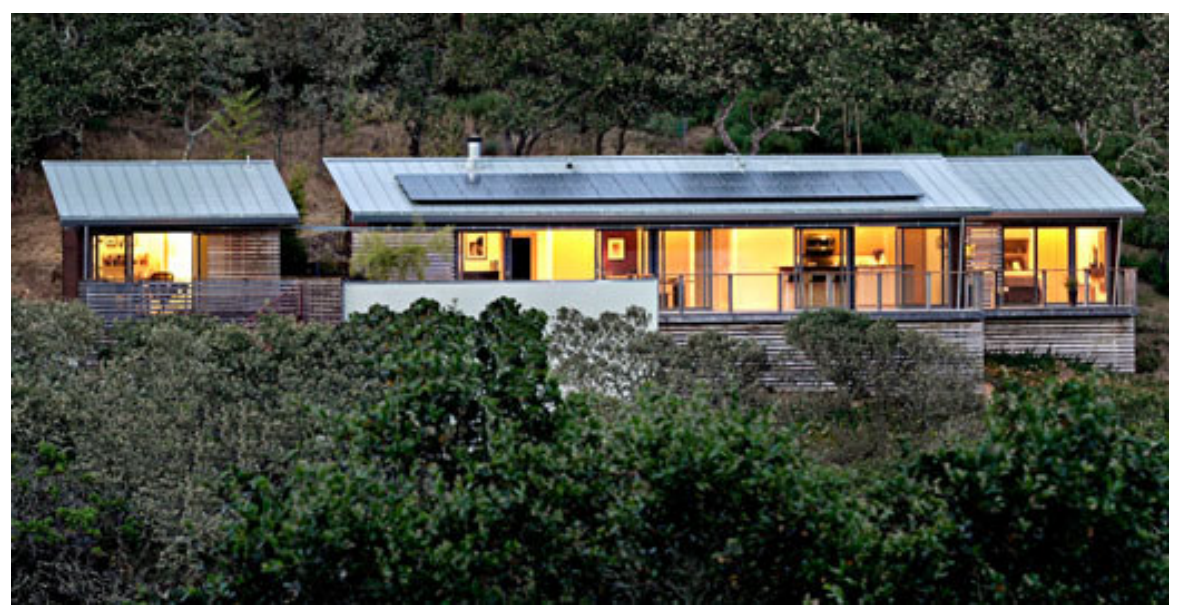

Figure 54: Glidehouse by Michelle Kaufmann Designs. Source: <http//www.mkd-arc.com/homes/glidehouse/>. 
Key historical messages to carry forward are as follows:

- Le Corbusier's Dom-ino structural system

- The Eames' use of off-the-shelf components

- Lloyd Wright, Gropius and Waschman's examples of flexible component-based systems

- Buckminster Fuller's utility pod

- The Eames' prototype as show-home

The use of a perimeter-based structural system has been shown to enable open-plan configurations and non-load-bearing internal partitions for future adaptability. Off-the-shelf components have been advocated in terms of affordability, flexibility, and continuity of supply. A flexible component-based system has enabled the variation in housing design that consumers demand, while a modular utility pod has encapsulated factory efficiencies. Prefabricated housing prototypes throughout history have acted as show-homes and marketing tools communicating their innovative systems, products and ideologies. Together, these building blocks have potential to be combined into contemporary iterations (refer to Chapter 4 for more information on contemporary international prefabricated housing). 

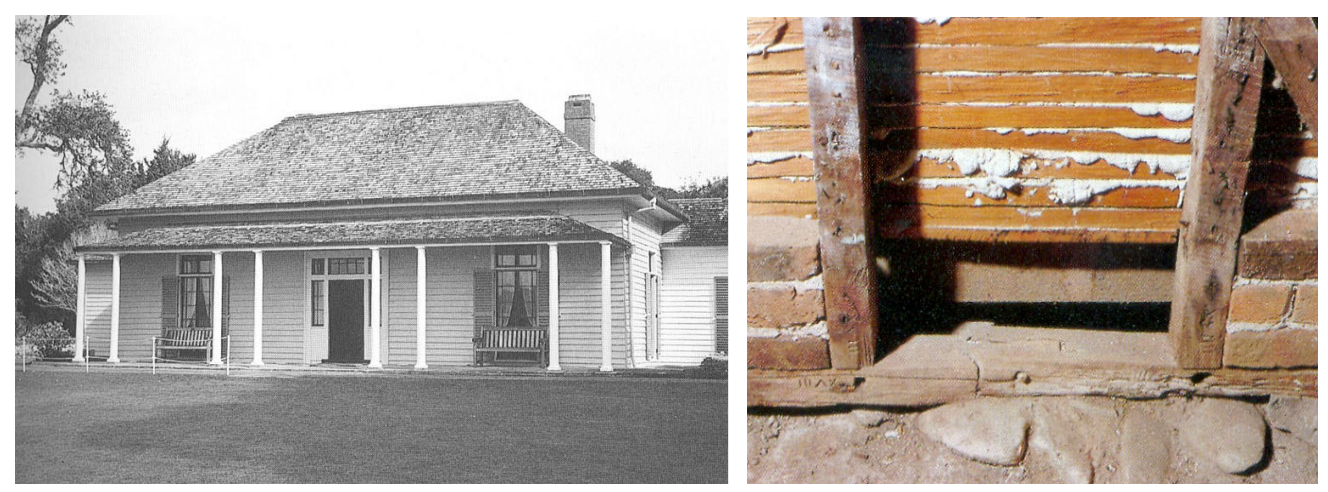

Figure 55 and 56: Treaty House by J. Verge 1833, and detail showing roman numerals in timber. Source: W. Toomath, Built in New Zealand, Auckland: Harper-Collins, 1996:15. Source: P. Shaw, Waitangi, Napier: Cosmos, 1996:37.

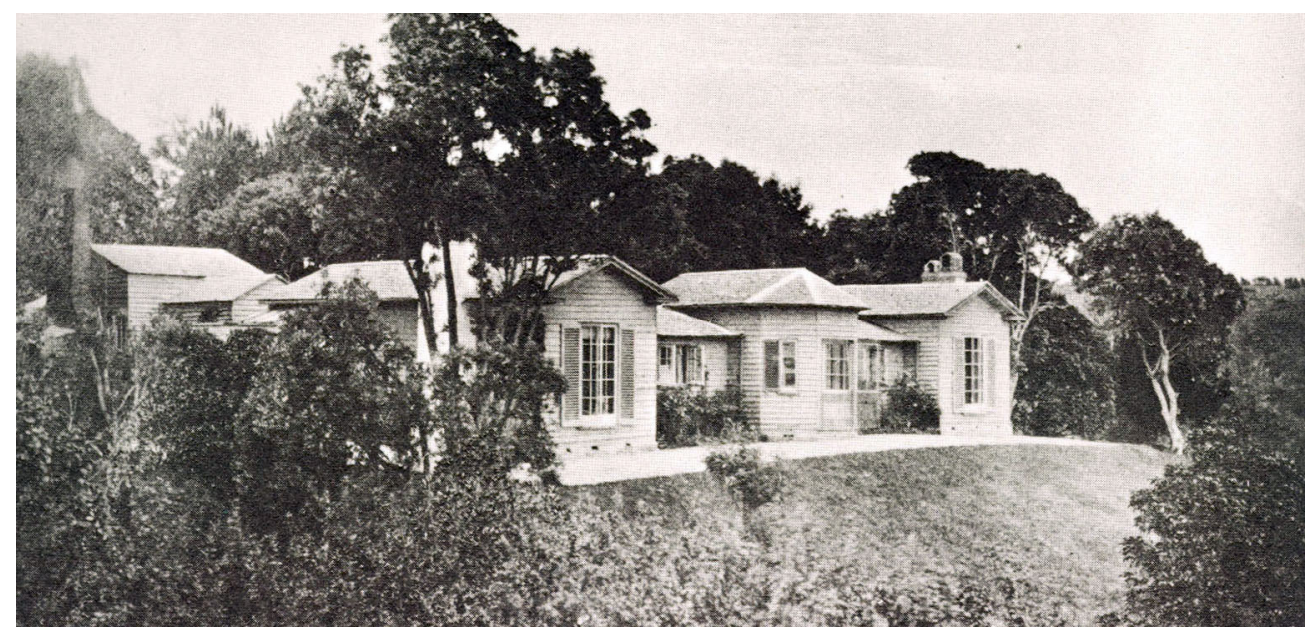

Figure 57: Justice Martin's house, Judges Bay.

Source: J. Stacpoole, Colonial Architecture in New Zealand, Wellington: Reed, 1976:15. 


\section{New Zealand's History of Prefabricated Housing}

As the rest of the world was busy innovating, experimenting and manufacturing, New Zealand looked on, adapted and applied accessible prefabrication methods. This overview of prefabricated housing begins with the Industrial Revolution and specifically with colonisation. ${ }^{42}$ This section begins the documentation of a history of prefabricated housing in New Zealand. It will chart historical exemplars, uncover successes and identify mistakes so that issues and opportunities can be further examined in later chapters.

\section{0s Colonial Settlement}

New Zealand shares its prefabricated housing origins with the rest of the world. This country's European settlers imported panelised housing kits from both the United Kingdom and the United States. London carpenter $\mathrm{H}$. Manning produced the first prefabricated house for his son who was migrating to Australia around 1833. His Portable Colonial Cottages were sold to British colonies in Australia and New Zealand through to the 1850 s and were commercially successful (Bergdoll and Christensen 40).

New Zealand's most familiar colonial house, the Treaty House, was brought by James Busby from Sydney to Waitangi in 1833 as a pre-cut frame with fittings and most materials (Toomath 15) (55-56). The Auckland Governor's house, an Early Victorian style bungalow with 16 rooms was prefabricated in England. Chief Justice Martin's house at Judges Bay was made before 1843 in England by Peter Thompson who supplied timber panel and concrete housing to Australia and New Zealand through to the 1860s (Lewis qtd. in Irving 277) (57). In Christchurch, Lyttelton and Akaroa, there were a great many ready-made houses shipped from England in sections and bolted together once at site.

In the mid-1800s, prefabricated Kauri cottages were made in the Bay of Islands and bound for Californian goldfields (Lewis 8). There is a record of seven houses shipped to Australia from New Zealand in 1850, and by 1870 pre-cut building components were prefabricated by local timber mills (Lewis qtd. in Irving 277; Thornton 22). Contractors in town centres such as Auckland assembled housing sections for transport to new settlements such as the gold rush sites in the Coromandel (Eldred-Grigg 170).

By the end of the 1800s United States pattern-books had spread populist designs to New Zealand. William Toomath refers to the Victorian style gable-and-bay component as a "consistent system of interchangeable, highly designed elements" (142). He comments that this

42 The precedent for prefabricated housing history beginning with the Industrial Revolution is the 'Home Delivery' exhibition by Barry Bergdoll and Peter Christensen. Pre-European techniques include traditional Maori raupo house construction which involved bundling or clumping of six to eight stems into three-hundred millimetre wide vertical panels with flax strips. These were bound prior to binding into the structure, which enabled "a very orderly and fast fixing technique" (Hoskins and Wilson 7). Although temporary binding was probably used to transport flax from wetlands, the final construction binding is likely to have occurred at the building site. To qualify as being prefabricated the components must be manufactured offsite. 


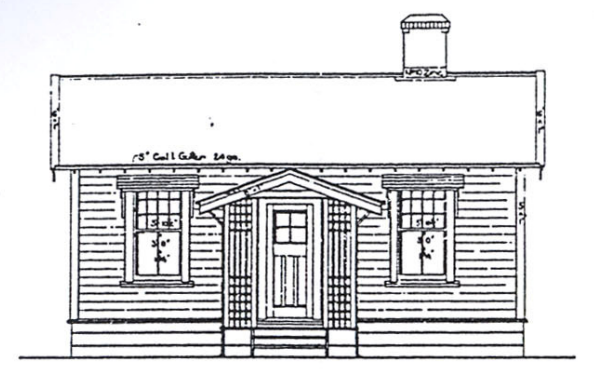

meNT IIEVATRON

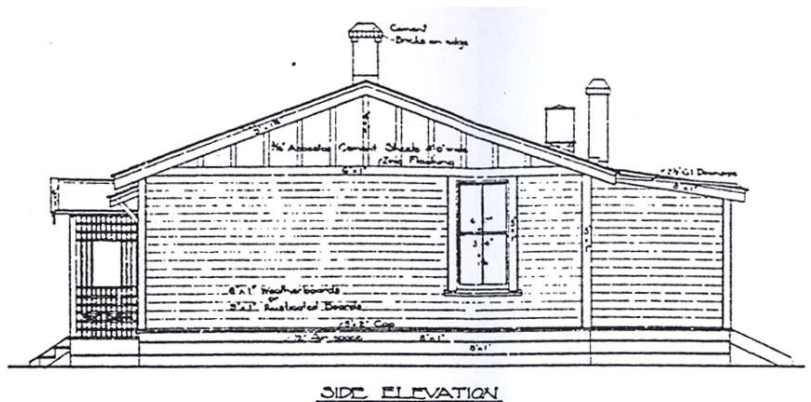

SIDE EIEVATION

Figure 58: An example of façade elevations from the Railway Housing scheme.

Source: L. Kellaway, "The Railway House in New Zealand", University of Auckland, 1993: figure 25.

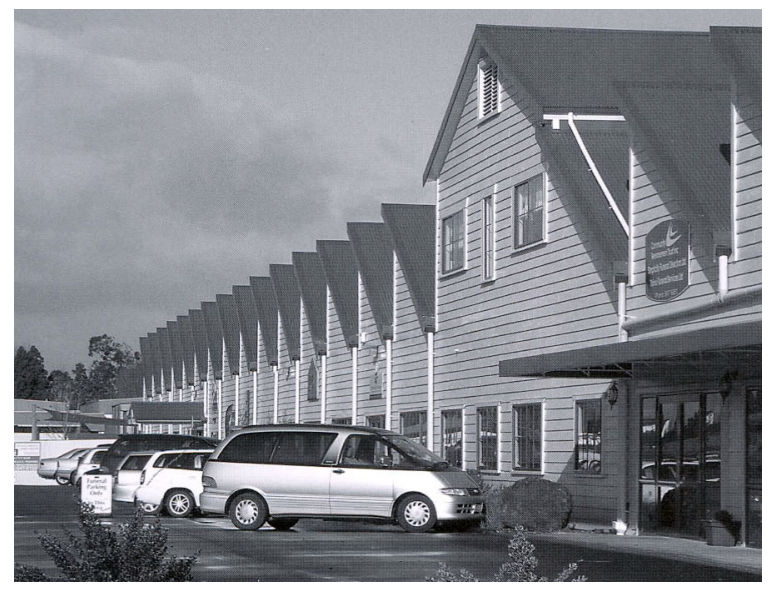

Figure 59: Frankton Railway Housing factory in 2008.

Source: J. Gatley, Long Live the Modern, Auckland: Auckland UP, 2008:15. 
approach incorporated site-based construction of the basic structural shell according to planbooks, complemented by factory-produced ornamental components from catalogues of standardised parts such as ornate cornices, eaves, veranda posts and gable ends.

\section{Early 1900s Government Housing}

The New Zealand Railways Department was the first and largest producer of prefabricated housing as early as the $1880 \mathrm{~s}$. In the early 1920 s a scarcity of timber, an acute housing shortage after the First World War, and the Depression all served to magnify housing problems. The resulting method used was standardised planning through pattern-books with a kitset of pre-cut and numbered timber components (Bowron and Mace 9) (58)..$^{43}$ The design was a modest bungalow cottage with variations to the principal façade treatment (McEwan 15). A factory was established in the early 1920 s at Frankton, the largest rail junction in the country (59). The factory could produce components for a house in a day and a half, which were transported by rail around the North Island for assembly at site by two people in two weeks (McEwan 15). ${ }^{44}$ Pre-cut components were previously confined to farm buildings and a small number of houses (Firth 41). In 1993, Laura Kellaway reflected:

A saving of thirty-three percent in labour resulted because of the process and the skill of the men on site, as expected. But by the efficient means of prefabricating, the men were also part of their own demise from 1925 onwards, until 1930 when the scheme was closed (L. Kellaway 20).

The efficiency of the system is a reference to supply exceeding demand. The Railways Department produced almost one-thousand-six-hundred houses over a six-year period, and yet the Railways scheme ended in 1930 (Ferguson 96; L. Kellaway 20).

The Railways scheme overlapped with the 1925 introduction of the Hutt Valley Lands Settlement Act to address the needs of returned servicemen. This new scheme involved houses from the Railways Department, land servicing by the Lands Department, and special loans scheme from the State Advances Corporation, to make a complete housing package (Bowron and Mace 9). This total state responsibility for every aspect of housing development is seen as a precursor to the Labour government's 'Public State Housing Scheme' which was developed in the 1930 s. $^{45}$ The scheme used standard house parts such as construction details, window and door sizes and internal fittings such as baths, wash-basins and cupboards. A single specification was used to cover over one hundred house plans (Firth 40). A schedule of colours was used for claddings, roof tiles and plasterwork to ensure each neighbourhood had an interesting and harmonious grouping (Ferguson 128).

\footnotetext{
${ }^{43}$ Architectural historians such as Jack Smith argue that the supply of a kitset package without pre-assembly precludes the term prefabrication, but this thesis argues that the prefabricated term applies to any construction material that is formed or manufactured away from the building site. This includes pre-cut and pre-nailed components. Refer to Chapter 1 for full definition.

44 The Department did not build houses in the South Island because of the difficulty of shipping the pre-cut dwellings at the time (Ferguson 96).

45 By July 1937, the first state houses were revealed in Miramar, Wellington (Schrader We Call it Home 95).
} 


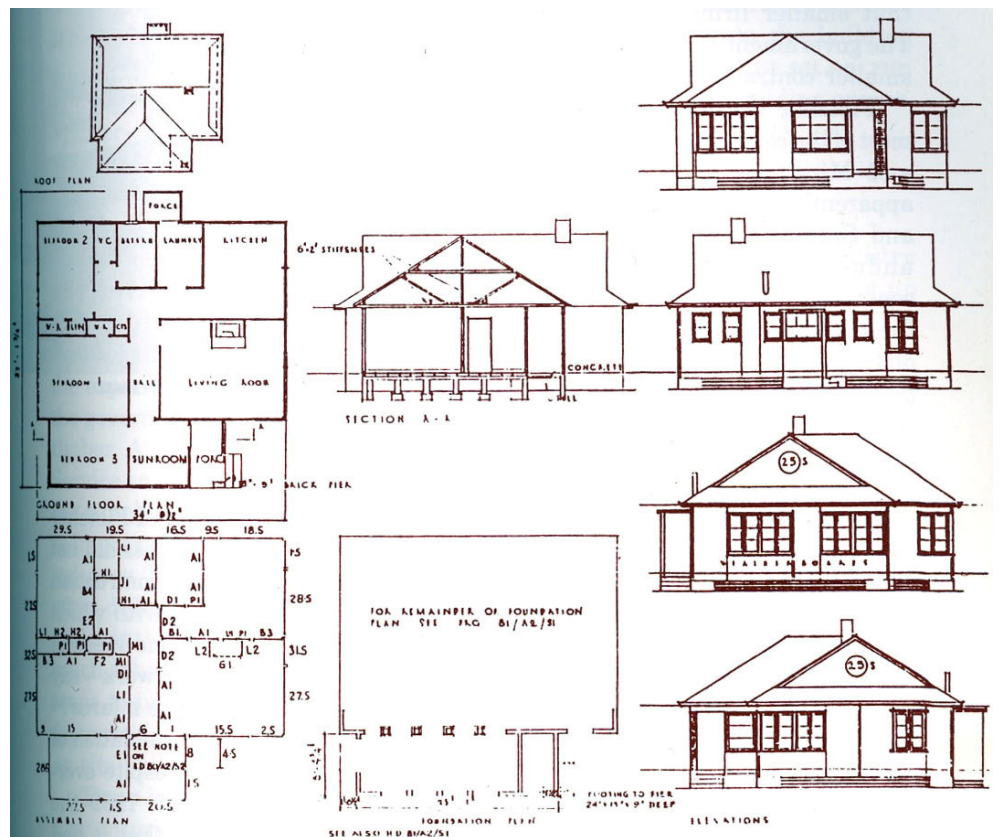

Figure 60: Plans for prefabricated panel state housing by the Department for Housing Construction, 1943. Source: G. Ferguson, Building the New Zealand Dream, Wellington: Dunmore Press, 1994:129. 
The State Housing programme utilised standard products with larger contractors such as Fletchers also supplying pre-cut framing and unlined wall panels (J. Smith). Over four-hundred housing designs were commissioned and although a standardised planning formula was followed, no two houses in the same area were exactly alike. Returned World War Two soldiers joined small construction gangs headed by a trained builder to assemble prefabricated wall panels, complete with external cladding that were made in joinery factories and trucked to site (Schrader We Call it Home 99) (60, 90-91). These panel techniques were "originally introduced with the hope of speeding up construction and saving costs [but] the panel house failed to achieve either of these aims" (J. Smith). In 1953, the timber panel-type house system was terminated as the houses needed level sites, had limited plan options and incorporated expensive additional joinery (J. Smith). However, the combination of pattern-book designs, use of unskilled labour and pre-cut prefabrication techniques enabled the State Housing Scheme of the 1930s and 1940s to become one of the most successful public housing schemes in the world (Schrader "Labour at Home" 133). Public housing continues today, with Housing New Zealand overseeing government-funded housing development using traditional construction techniques.

\section{Mid-1900s Government Research and Development}

By mid-twentieth-century prefabrication techniques were gaining popularity in Britain, the United States and Australia which led the New Zealand government to conduct experiments with prefabricated wall sections, multi-storey concrete construction, and imported technologies from Sweden, Austria and the United Kingdom (61). But high transportation costs and quality defects meant that importation was not pursued any further as a means of prefabrication. ${ }^{46}$

In 1942, Andrew Fletcher of Fletcher Construction presented information from a research trip to National Homes in the United States to G.W. Albertson, the Director of the Department of Housing Construction (J. Smith). ${ }^{47}$ Shortly afterwards in 1943, Chief Architect Gordon Wilson proposed a government competition to produce "practical modern data on prefabrication in home building". The Department invited local architects to compete in the design of prefabricated dwellings which resulted in the selection of eight house designs by R.S. Walker and Paul Pascoe, three of which were built in Christchurch (Bowron and Mace 43). In 1943, Gordon Wilson suggested:

It would seem that pre-cutting and partial prefabrication will be the immediate answer. Standard construction will be followed to the floor, with the exterior walls, interior partitions and roof trusses prefabricated (G. Wilson $n p$ ).

This method advocated by Gordon Wilson remains the predominant method used by the construction industry today. Roof trusses and open wall framing are pre-engineered and pre-

461943 Naenae, Wellington - five houses using prefabricated wall panels (Bowron and Mace 43)

1945-7 Petone, Wellington - five blocks of terrace flats using prefabricated concrete panels (Mace)

1947 Wadestown, Wellington - single house imported from Sweden using prefabricated wall panels complete with window and door joinery (Bowron and Mace 83)

1948 Wellington - two houses imported from England erected temporarily using aluminium components (Mace)

47 The Department of Housing Construction was created in 1936. In 1943, it was absorbed into the Public Works Department, which was divided into four divisions for engineering, architectural, housing and administrative functions (Kinsella "History" 23). 


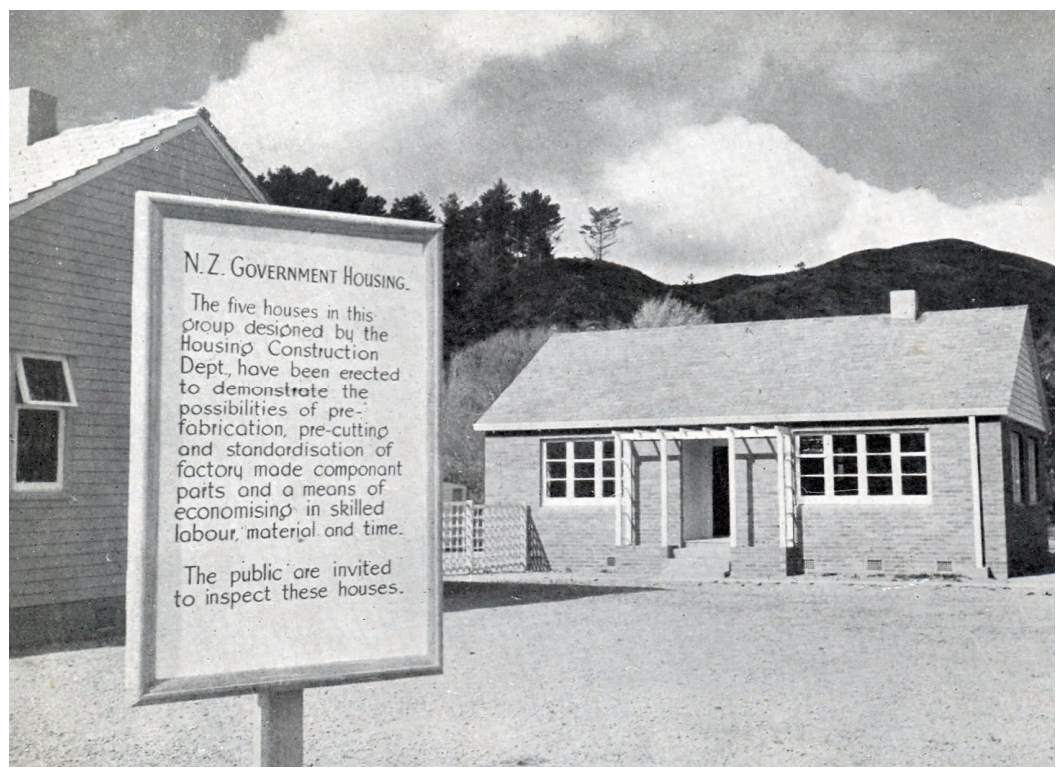

Figure 61: Government-backed prefabricated housing experimentation. Source: C. Firth, State Housing in NZ, Wellington: Ministry of Works, 1949:30.
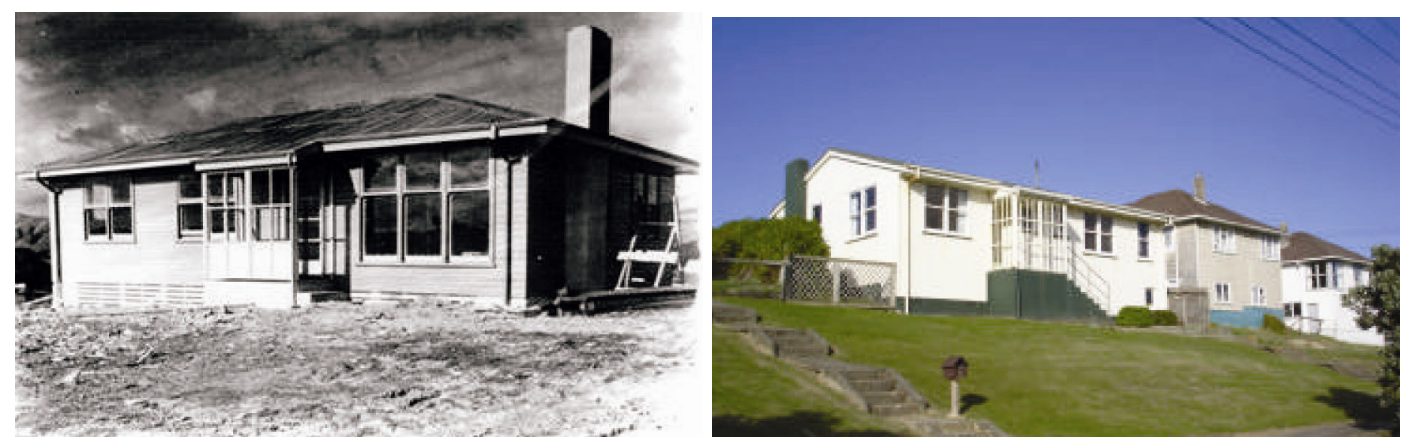

Figure 62 and 63: Imported prefabricated houses at Titahi Bay c.1953 and in recent years.

Source: Porirua Museum Collection F/1a/21 ref 134/25, CD10, Alexander Turnbull Library. Source: R. Murray and B. Fill Report 152: Austrian Houses, Porirua: Porirua City Council, 2007: 1. 
nailed away from site, with moisture barriers, insulation and exterior claddings applied at site. On this basis, Wilson's vision in the early 1940 s can be viewed as almost a reality sixty-five years later.

The Second World War years (1939-45) saw factories dominated by military construction activities. Over thirty-thousand prefabricated huts were fabricated offsite, along with tent floors for temporary buildings and transportable buildings for military camps. Most of these structures were destined for camps at Cornwall Park, Hobson Park, Victoria Park, Western Springs, Mangare Crossing and Avondale in Auckland. In Wellington, temporary settlements at Paekakariki, Pauatahanui and McKay's Crossing demanded over four-thousand buildings and huts (J. Smith). Some of the buildings for the Paekakariki camp were prefabricated in the South Island (Kinsella).

In the 1950s, the government embarked on several low-cost housing initiatives. They responded to a public outcry on the post-war housing shortage by ordering one thousand precut houses, five-hundred from England for Auckland, and five-hundred from Austria for Titahi Bay (T. Kellaway 3) (62-63). This initiative made the government unpopular with the building industry which was concerned about losing work to imported products. By the mid-1960s, the cost of regular repainting and replacement of rotting window sills, mullions and porches highlighted the pitfalls of imported timbers and products (Bowron and Mace 82). Forty years on, and despite the drawbacks of this additional maintenance, the houses have outlived a life expectancy of only twenty years to be still structurally sound. The construction industry gained skilled workers from Austria but the government decided not to import any more of these houses (Mace).

The government 'Part House Scheme' was set up in 1952 combining "notions of partiality, prefabrication, the temporary, and ex-servicemen labour" (McCarthy 39). The small basic plan houses were fabricated in a factory near Rotorua and transported to site complete with financing and plans for later additions. The reduced plan was indicative of a time when the government's War Cabinet placed restrictions on importing building materials, planning house areas and building of structures deemed to be luxurious, such as garages and baches (McCarthy 39$).{ }^{48}$

A national housing conference in 1953 spawned government initiatives for the National Housing Council (NHC) and the 'Group Housing Scheme'. ${ }^{49}$ The NHC was a forum for the government to promote prefabrication construction techniques, focus on housing targets, and encourage cooperation amongst the construction industry and related professions (Bowron and Mace

48 "A single storey, three-bedroom house could not exceed an area of 1,600 square feet [149 square metres]" (Mitchell and Chaplin 28). "A childless couple were restricted to a single-storey home not exceeding 1,150 square feet [107 square metres]" (Cheer 30$)$

49 Today the term Group Housing or Group Home refers to the design-and-build or speculative home industry which is made up of groups of builders or franchisees operating under one brand name. It is a reference to the 1953 Group Building Scheme that guaranteed the government would purchase any house a builder failed to sell within two months of its completion (Ferguson 184). Group builders frequently used state plans (Ferguson 185) 


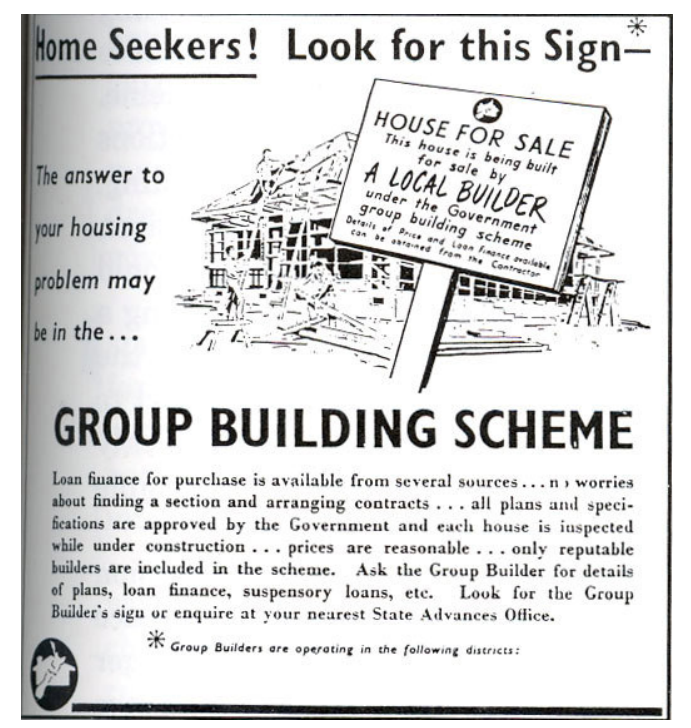

Figure 64: Group Building Scheme advertisement.

Source: G. Ferguson, Building the New Zealand Dream, Wellington: Dunmore Press, 1994:185.

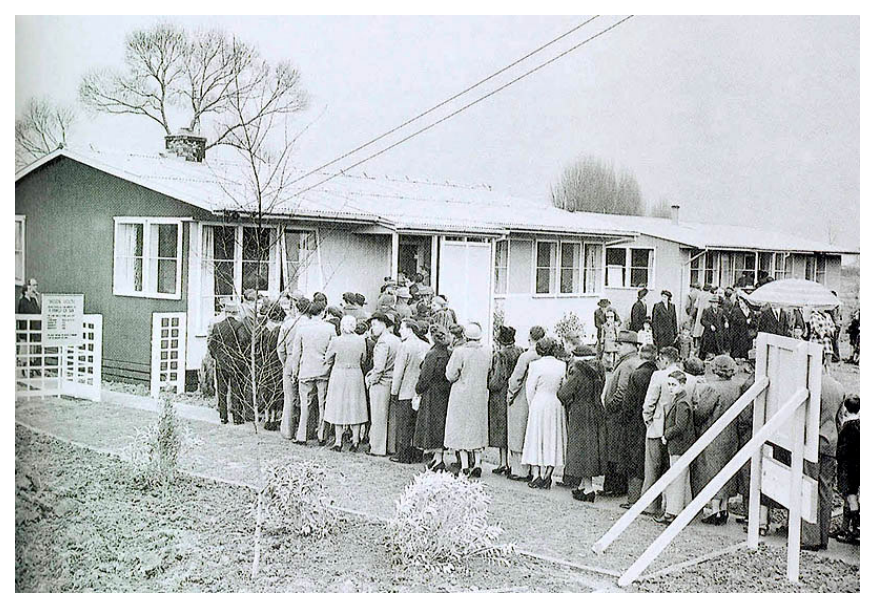

Figure 65: Government-backed show-homes open to the public.

Source: L. Shaw, "A Woman's Place?" At Home in New Zealand, Ed. B. Brookes, Wellington: Bridget Williams, 2000:169.
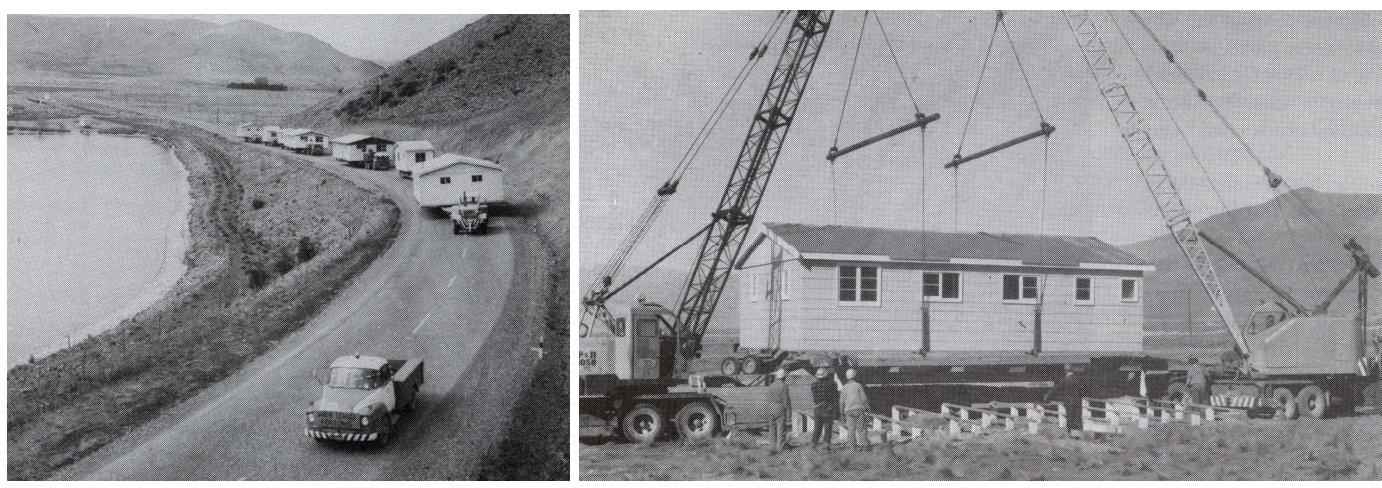

Figure 66 and 67: Prefabricated housing on its way from Otematata to Twizel, and set in place in Twizel 1970. Source: M. Sheridan, Dam Dwellers, Twizel: Sheridan Press, 1995:139 and 138. 
12). ${ }^{50}$ The 'Group Housing Scheme' encouraged speculative building by guaranteeing the purchase of houses built in groups of six or more that were unsold two months after their completion (64). The Scheme promoted the use of pre-cut elements in house construction, as used by Beazley Homes. Beazley, along with Neil Housing and others went on to become dominant housing suppliers in the 1960s (Ferguson 185). One of the NHC's marketing initiatives was the sponsorship of 'parades of homes' to showcase house designs and stimulate housing sales to the general public (65). They were well received, with their popularity being next "to racing and football amongst New Zealanders" according to one newspaper reporter (Bowron and Mace 13).

In 1956, the government set up a technical committee investigating new methods of construction. Two designs from the 'Experimental Component House Scheme' were built in Porirua once Cabinet approved a budget ten years later. These houses were test-beds for precast concrete load bearing wall panels and prefabricated timber roof trusses (Mace). Both of these elements are now commonly used in construction.

Nationwide hydro-electric schemes used prefabrication techniques so they could easily erect and shift worker housing from one scheme to another or for use in areas of housing shortages (66-67). Combinations of construction, transportation and relocation were used throughout the 1940s and 1950s for the North Island's Waikato Hydro scheme and in the 1960s and 1970s for South Island towns such as Otematata and Twizel (Linzey 60; Kinsella). The Ministry of Works set up a carpentry workshop at Otematata to build two-hundred-and-fifty houses on a production line. Other housing was provided by contractors such as Keith Hay Homes and Martin Homes of Timaru, and De Geest Brothers Construction of Oamaru. De Geest constructed five-hundred-and-forty-nine complete houses for Twizel and three-hundred-and-fifty componentised houses for Cromwell from their purpose-built factory (Kinsella). ${ }^{51}$

\section{0s - 1970s Commercial Innovation}

The 1950 s to 1970 s was a period of rapid population growth after World War Two. A number of prefabricated housing businesses were founded during this time. The government's investment in housing enabled businesses such as Keith Hay Homes, Beazley Homes and De Geest Construction to become established. Keith Hay and De Geest are enduring and offer examples of versatility, innovation and development (refer to Chapter 3 for De Geest contemporary case study.)

Barry Beazley established his house-building business in Tauranga in 1953 and it was bought by Fletchers in 1973 who eventually consolidated it under the Fletcher Homes umbrella in the early 1990s (Hunt). The pre-cut component kitset system included window and door joinery and

50 The NHC had lapsed by 1963 because the government's perceived housing shortage was over (Ferguson 184).

51 For more information on South Island hydro scheme housing refer to Fleur Kinsella's Master of Architecture thesis "Fifty Years of Construction

Camps in the South" due to be submitted in 2009. 


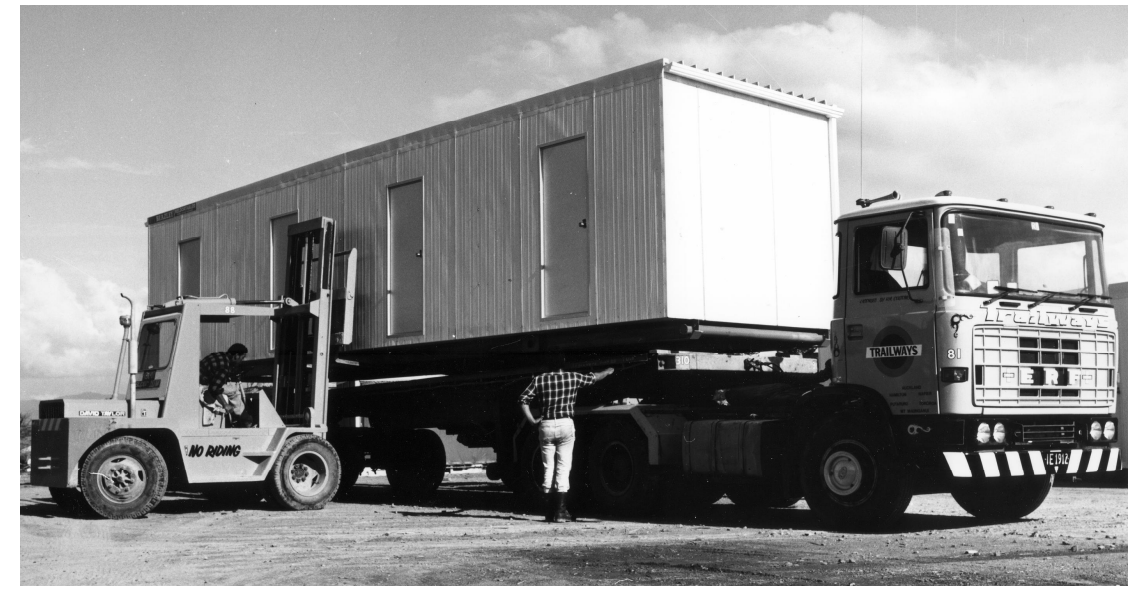

Figure 68: Beazley's relocatable, or complete building, housing model. Source: 9006P-6, Fletcher Archives, Auckland.
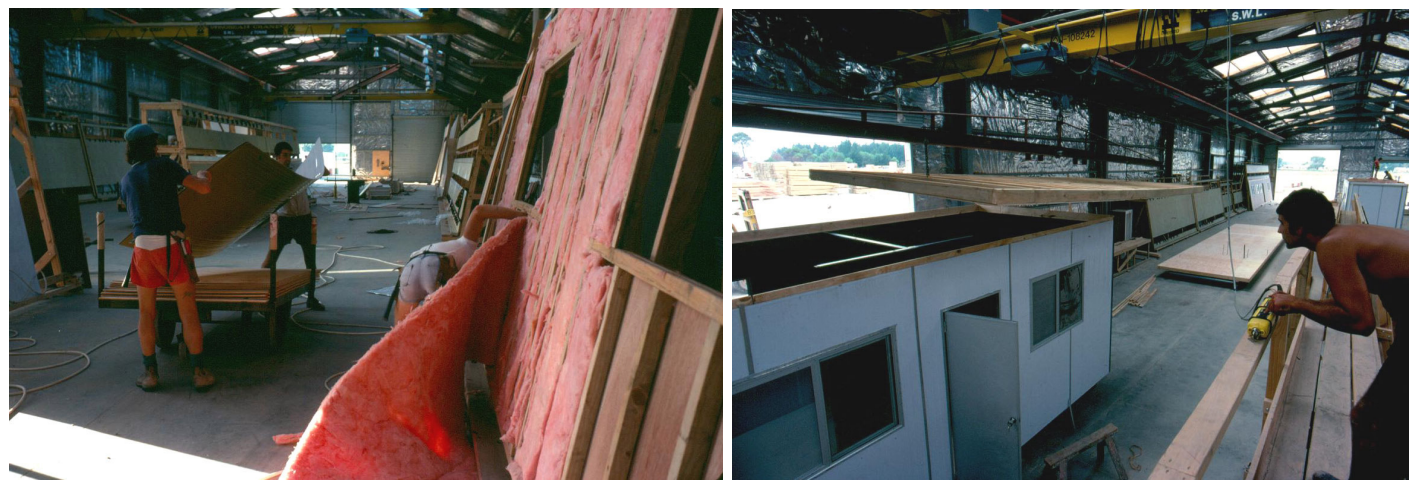

Figure 69 and 70: Beazley's prefabricated housing: wall panel and roof panel assembly at Mt Maunganui factory 1977. Source: 9041P-57 and 9041P-28, Fletcher Archives, Auckland.

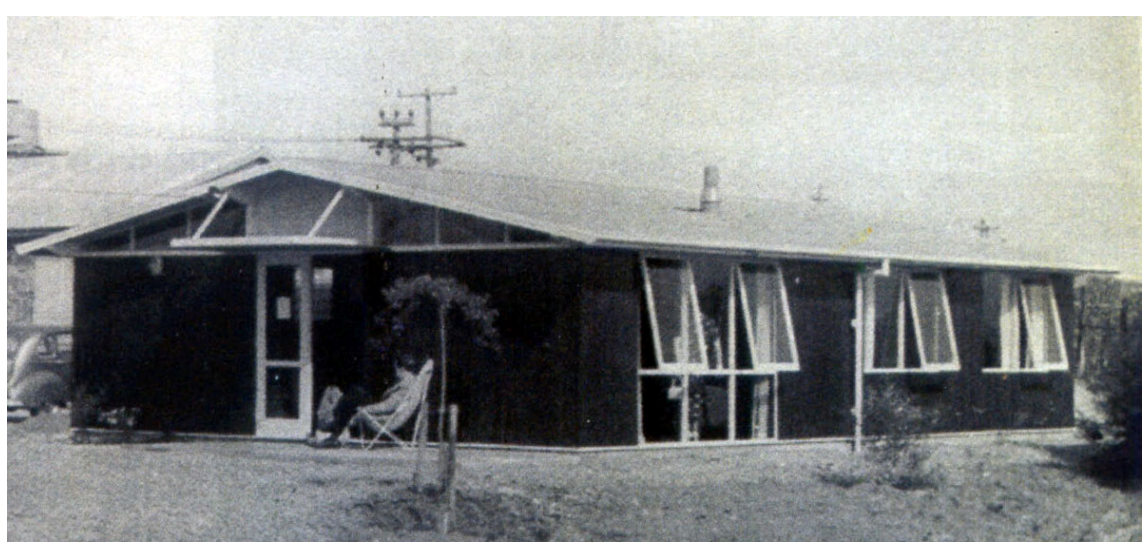

Figure 71: Solwood exhibition house.

Source: S. Cracknell. "Prefabricated Modernity: the Solwood house." Report, Victoria U. Wellington, 1999. 
plumbing fittings. One-thousand-two-hundred component-based and complete dwellings were produced a year by eighty accredited builders in the 1960s and early 1970s for markets in New Zealand and offshore (R. Wilson) (68). Gavin Hunt recalls that Beazley Homes "was a very significant and successful business in those days". They pioneered pre-cut housing in New Zealand, supplying all the pre-cuts for their builders throughout the country from their yard at Mt. Maunganui which had its own rail siding (69-70). Eventually, in the early to mid-eighties, the proliferation of small locally-based pre-cut manufacturers spelt the end of the business (Hunt). Despite this, during the late 1970s Beazley successfully exported housing construction services to Australia, Papua New Guinea and Noumea, as well as a relocatable site hut model to Saudi Arabia and Iraq. This transportable building was constructed in their factory on steel frames and shipped as a flat-pack with complex kitchen cabinetry as built modules. Export success was hindered by the dominance of Canadian and United States operations, as well as high ongoing running costs including marketing and sales staff offshore (Hunt).

A diverse range of prefabricated housing was produced commercially in the 1950 s to 1970 s. Several of these innovative, yet commercially unsuccessful, prefabricated systems are mentioned here. In the early 1950s, Napier architect Guy Natusch, of Natusch and Sons architects, founded the Solwood system of solid timber construction at a time when several other suppliers were also working with solid wood components. ${ }^{52}$ Six centimetre thick tongueand-groove boards were used to create wall and ceiling panels that functioned as both interior and exterior linings (Cracknell 35). The adoption of pine (Pinus Radiata) was innovative at a time when architects were specifying native timbers. In 1953, the Solwood house won the construction section in the National Housing Conference.

A Solwood exhibition house built in Napier was received enthusiastically by the public and it was widely thought to be a new opportunity for State House design (Cracknell 36) (71). Yet, a four-fold challenge led to the system's demise in the late 1950s: Napier City Council was reluctant to grant permits, the Carpenter's Union felt threatened and refused to participate, the State Advances Corporation would not approve loans for the homes, and New Zealand Forest Products were unwilling or unable to provide timber of a quality and quantity that met Solwood's specifications (Cracknell 38).

In the late 1960s Industrialised Building Systems (IBS) began under the leadership of entrepreneurial Palmerston North property developer Keith Clark. His company, Best Bilt Homes, used a combination of architectural pattern-book plans, cheap outer suburban land and efficient labour resources to produce some of the lowest cost houses in the country. The IBS team ambitiously planned for three separate consortia in New Zealand and six in Australia with each factory forecast to produce one-thousand-two-hundred homes per annum, or twenty-five

52 Modulock, Solwood, Putaruru Timber Yard, Conecta, Lockwood and Fraemohs were the solid wood component systems established in the 1950s-70s era. The latter two systems are enduring in that they are still in production today in the North and South Islands respectively. Refer to Chapter 3 for the Lockwood case study. 


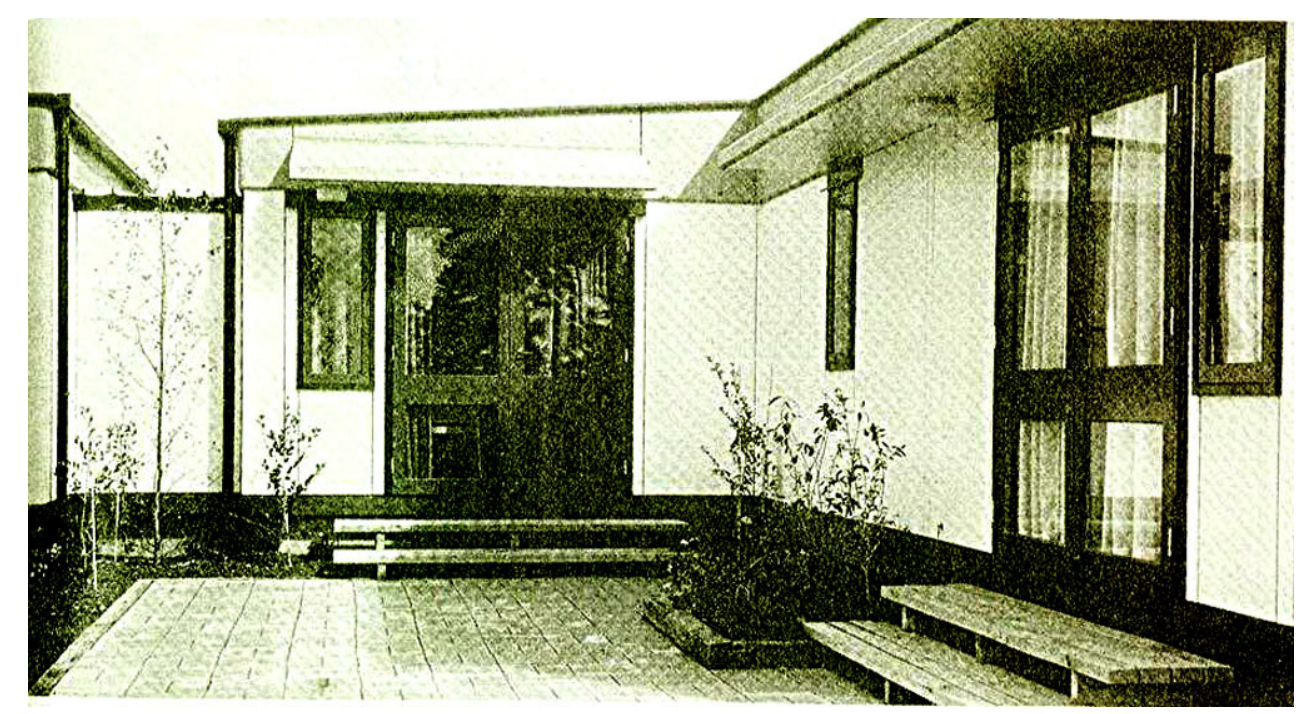

Figure 72: Industrialised Building Systems' show house at Avondale. Source: M. Mountier, "IBS" Designscape, 50 (1973): 7.
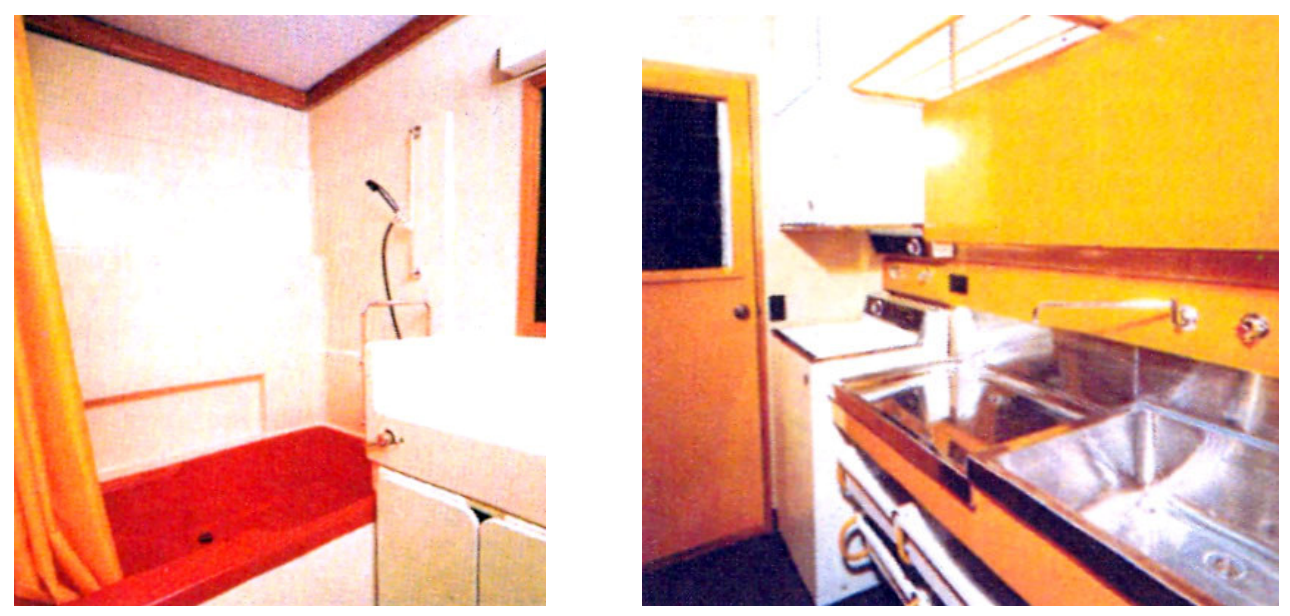

Figure 73 and 74: Industrialised Building System's Xybis bathroom and laundry. Source: Xybis catalogue, courtesy of Owen McShane. 
per week (Mountier, "IBS" 16). Architects Ivan Juriss and Roger Hay were part of the team that designed the IBS system of additive room modules. ${ }^{53}$ The team envisaged, "parts be re-sold back to the factory, additional ones bought, and worn out ones replaced" (Mountier, "IBS: an idea" np). The walls were made of a three-layer stressed-skin sandwich panel, together with a specialised jointing system. A rigid Ribsel floor panel was developed and patented to provide a strong and precise platform to withstand the stresses of loading, travel and installation.

By 1972 a one-thousand-four-hundred square foot family house, a motel unit and a weekend home were built in the IBS factory at Avondale (72). Stage Two of IBS was the creation of Xibis (pronounced Zy-biss), a house consisting of ground floor modules, with roof panels installed at site to create a second storey (73-74). ${ }^{54}$ Despite considerable interest from customers in New Zealand, Australia and the United States, IBS collapsed in 1978 as a result of the wider economic recession (Clark). It left a legacy of enduring innovations, one being the creation of the first examples of one-piece fibreglass showers, a product that remains in production today (refer to IBS Case Study in Appendix D).

The modular influence was clearly popular during this time as several other experimental businesses were launched based on this theme. Both Light Modular Construction and Modulock utilised modular semantics, despite neither actually using modular volumetric construction. Architect Roger Walker employed modular planning in his Vintage Homes foray, and the government experimented with modular design in a 1974 ten-unit project in Paraparaumu carried out by Kielich Modular Concepts. Despite decreased maintenance and reduced time at site this method was not pursued further by the Housing Corporation (Bowron and Mace 44).

Light Modular Construction (LMC) began operating in Wanganui in the late 1960s, became a subsidiary of Gemini Pepper Construction in the early 1970s, and was purchased by independent owners in 1977 (Knight; McGowan). The new owners went on to sell a further twenty houses until 1978 when it finally closed due to the tight recessionary market and difficulties achieving economies of scale (75-77). The LMC system consisted of load-bearing closed wall panels that were pre-wired, fully fitted with doors and windows, lined with particleboard and clad with vertical board and batten. Pre-nailed roof trusses completed the precision-built system. Mounting financial problems in the mid-1970s were attributed to low consumer demand, some of which was attributed to a perceived lack of product customisation (Knight). Low consumer demand equated to low sales and production which meant that overheads and margins could not be covered. According to co-owner and architect Denis McGowan, "the economies of scale were critical".

\footnotetext{
53 Ivan Juriss was a member of the 1950s Group Architects whose collaborative work was socially motivated and focused on efficient lower-cost housing solutions, modular planning and mass production techniques. Their built work was not technically prefabricated (Bell 22). The Group Architects' forays into prefabrication were at an academic level rather than production oriented, despite a pine panel house being built and reported in 1953 (Cracknell 37).

54 This combination of module plus panel is possibly the first example of a hybrid typology in New Zealand's history of prefabricated housing. But the prototype was made in the United States.
} 


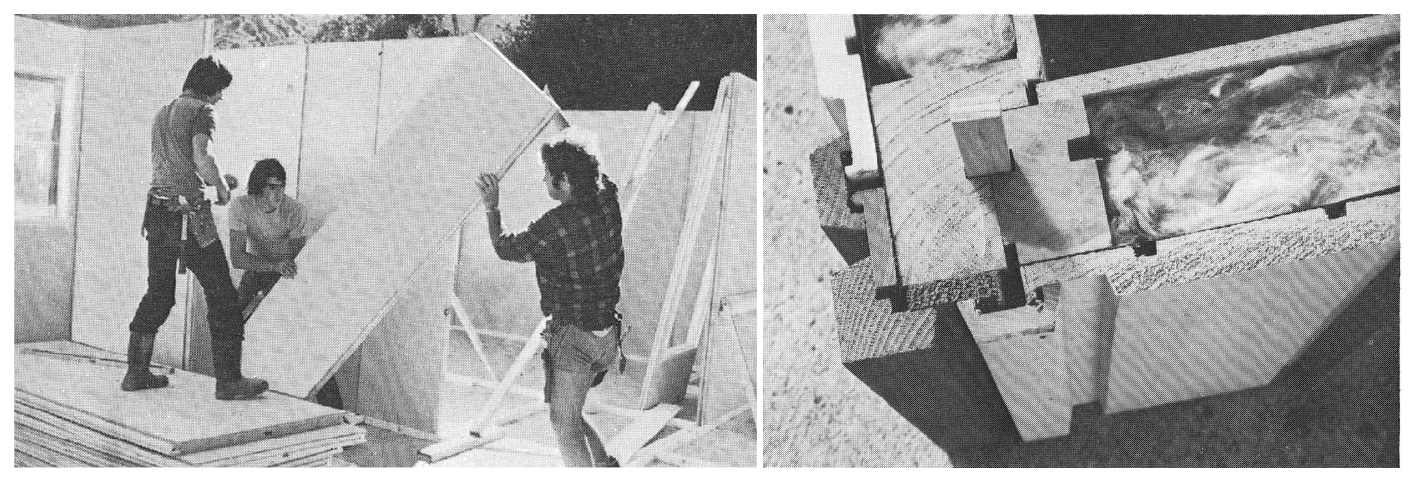

Figure 75 and 76: Light Modular Construction panel assembly and corner detail. Source: Light Modular Construction brochure, courtesy of Denis McGowan.
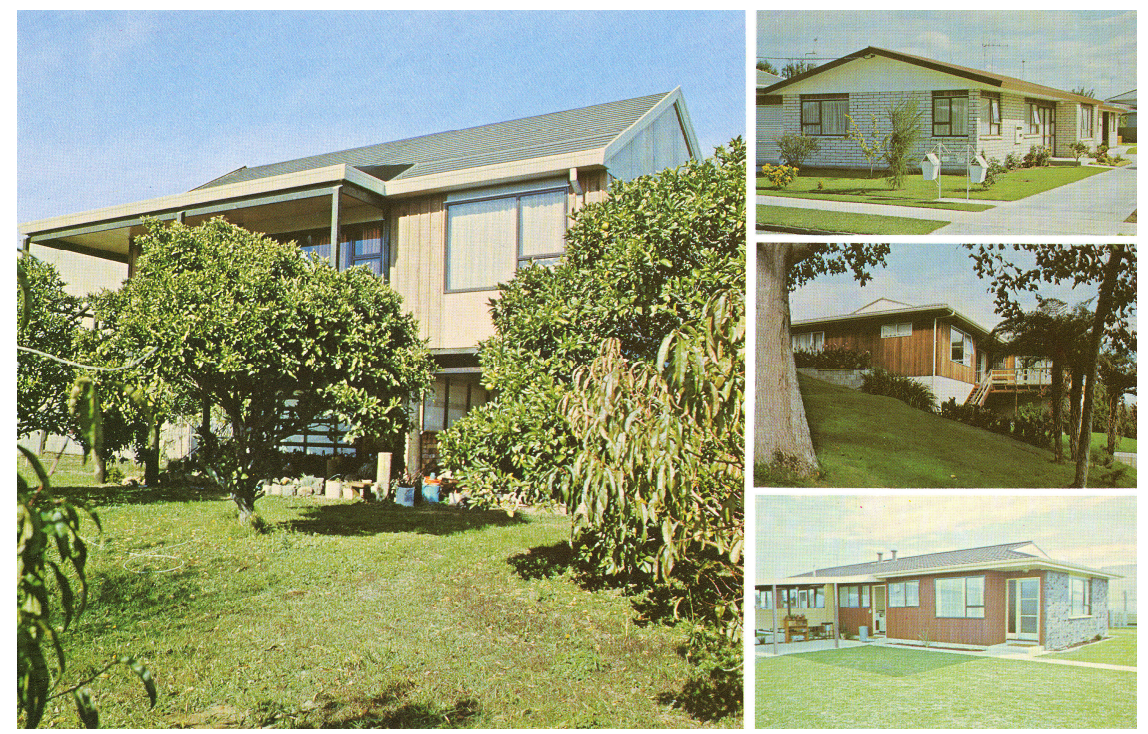

Figure 77: Light Modular Construction housing examples.

Source: Light Modular Construction brochure, courtesy of Denis McGowan.
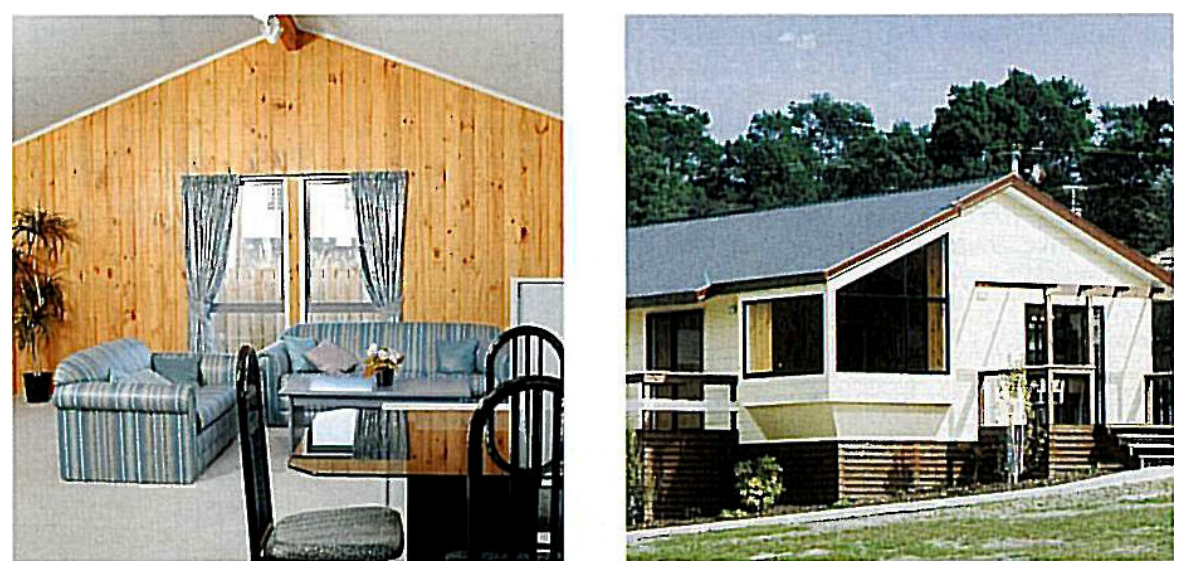

Figure 78 and 79: Modulock housing interior and exterior in the mid-1980s.

Source: Modulock brochure, courtesy of John Lockwood. 
The Modulock system began in Auckland in the early 1970s and was bought by Lanwood Industries from receivers in 1981 (78-79). It consisted of a panel-and-post grid-based system with solid timber vertical shiplap interior and imported plywood on the exterior, topped with a skilion roof made of a rebated beam and sheet system. At its peak, it achieved production capacity of five hundred houses per year, an export deal with Australia and houses supplied to the Pacific Islands (Mitchener 62). The business encountered difficulties with exterior cladding material failure in the late 1980s and never fully recovered from the adverse publicity and legal costs. ${ }^{55}$ In an effort to save the company, they re-branded as Pacesetter and Finemark Homes offering a variety of exterior cladding options. Despite supplying offshore markets and a large onehundred unit housing project, a mid-1990s housing market downturn dried up demand and Lanwood closed operations. ${ }^{56}$ Lanwood's John Lockwood reflects:

The success of any housing product is a function of marketing in the first instance rather than innovation and technical expertise (J. Lockwood).

Today Modulock Portable Buildings are rudimentary site units made by Lanwood in Palmerston North from steel insulated panels that bear only the brand name in common with the original housing product (J. Lockwood).

Architect Roger Walker began Vintage Homes in 1974 as a way to make architect-designed homes more affordable to a wider range of clients (80-83). They were inspired by colonial Gothic forms and underpinned by rational construction and a standardised modular planning system. Walker was successful in producing a number of iterations, but an inability to adequately cover overheads led to the system's downfall (Walker). Walker went on in 2004 to explore Triboard panel construction in a custom Queenstown home together with architect Del Lovie under their Pod business partnership. Today, he consults to the newly established Strawberry Homes which is backed by property developers Globe Holdings (Walker).

Relocatable classrooms were used by the Ministry of Education since the 1920s and gained popularity through the population boom period post-World War Two when they sometimes made up eighty-five percent of floor space built per year (Ayliffe and Jeffares 9). The Auckland and Canterbury regional boards produced innovative quality designs in the 1970s with their respective complete building A10 and A19 units and modular Leeston Design Module units (8485). The relocatable buildings, now commonly referred to as prefabs, were made of light-timber construction and clad with asbestos cement panels and corrugated iron roofing. They were estimated to cost fifty to seventy-five percent less than permanent buildings, with ongoing relocation costs at only ten to thirty percent which made their reuse particularly cost-effective (Ayliffe and Jeffares 13).

55 Fletcher's Structex product made of wood-chips and glue failed and was repaired at Fletcher's cost (Lockwood).

56 The large one-hundred unit housing project was for the 1990 Commonwealth Games in Auckland. They were later turned into state housing (J. Lockwood). 

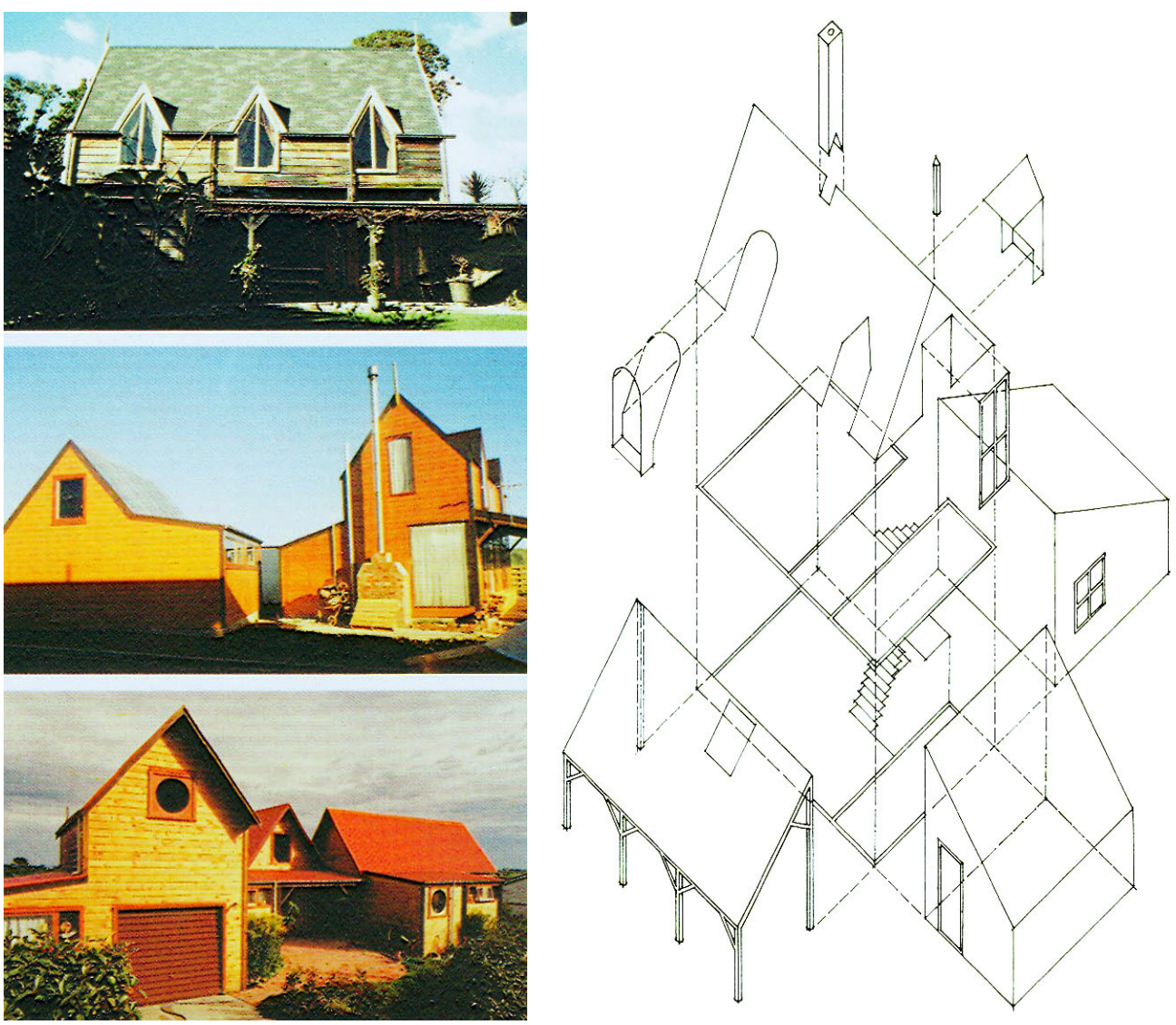

Figure 80 - 83: Vintage Homes housing configurations and system diagram. Source: Vintage Homes brochure, courtesy of Roger Walker.
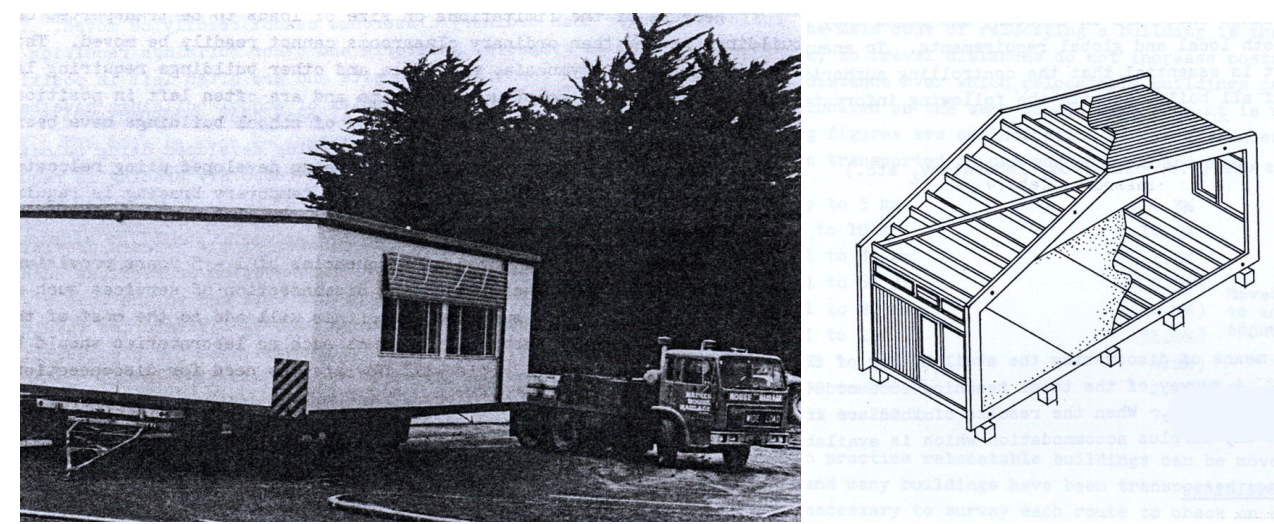

Figure 84 and 85: Auckland's A10 ready for transport and Canterbury's Leeston module diagram. Source: J. Ayliffe and M. Jeffares, Relocatable Schools in NZ, Paris: OECD, 1982: 11. 
Both complete and modular designs had load-bearing outer walls that enabled flexible internal layouts, as well as numerous potential combinations with other units on site. Auckland's complete building design could be made by semi-skilled labour but required special permits for over-sized transportation loads (Ayliffe and Jeffares 26). The Canterbury Leeston module consisted of timber portal frames with an under-floor tie beam, resulting in a smaller unit that could be made in a workshop and easily transported to site (Ayliffe and Jeffares 28) (86). Centralised class-room designs disappeared in 1989 when the Ministry of Education restructured regional boards into individual school boards, but numerous prefabs remain in schoolyards around the country (Sheerin).

\section{0s - 2000s Age of Consumerism}

Keith Hay Homes, Conecta and Lockwood were three companies that survived the late 1970s economic recession into the 1980s, an era of emerging consumer choice. Keith Hay pioneered Keith Hay Homes $(\mathrm{KHH})$ in 1949 when he began relocating second-hand buildings after a foray into caravan-building. Construction of complete houses began in the controlled environment of their Morningside yard where Hay used pine instead of native timber to speed up production processes, as well as cutting labour costs, and incorporating new plastics and other innovative materials. Through the 1960s and 1970s KHH became established through the supply of housing for the South Island hydro-electric schemes. Today, $\mathrm{KHH}$, managed by son David Hay, continues to offer a range of commercial and lifestyle transportable or traditional site-built buildings aimed at the affordable market (D. Hay).

Conecta was a panel-plus-connector component-based system designed by German-born Juergen Giess in Rotorua in 1971, after experience designing large pre-cutting plants in Europe. It was based on solid timber boards with a multitude of holes connected together by steel pins to form wall panels. In 1979, the Conecta system was bought by Fletchers and re-branded as Signature Homes, and by 1987 they had produced about seven-hundred-and-fifty homes. The Signature Homes brand was retained by Fletchers as a design-and-build contractor when Giess and Fletchers parted. Giess renamed the product Conecta and had it manufactured and marketed by the Hooper Group of Te Puke. According to Giess, "our motto was... if someone else can do it, let them". By 2000, he had refined the business to such an extent that all but the pre-cutting work was outsourced. But a lack of market demand, attributed by Giess to being unable to communicate their cost-effective yet high-quality product, meant Conecta closed their doors in 2006. He has since investigated offshore markets but has no immediate plans to reestablish the business (Giess).

Lockwood emerged in the 1950s as a solid timber component-based system and gained international exposure in the 1970s (Tuohy). With nationwide coverage through franchises and strong marketing through show-homes, together with architect-inspired ranges, they firmly 

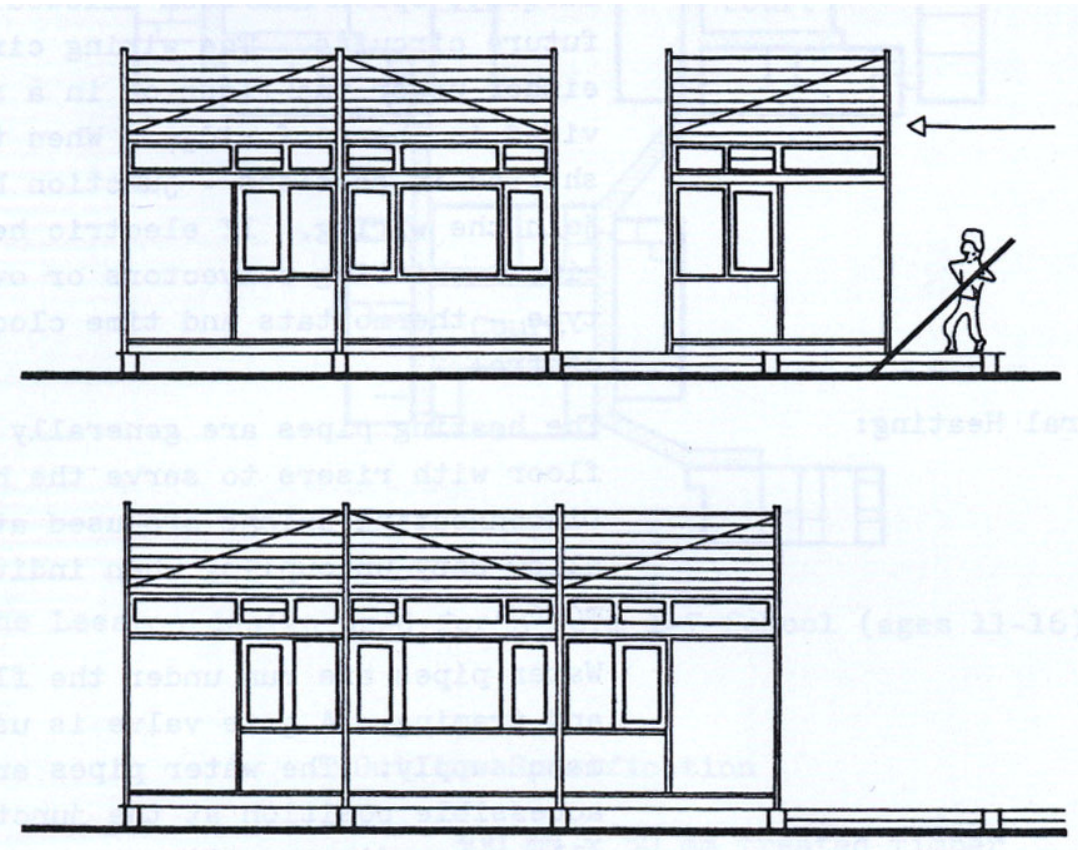

Figure 86: Canterbury's Leeston module assembly process on site.

Source: J. Ayliffe and M. Jeffares, Relocatable Schools in NZ, Paris: OECD, 1982: 32.

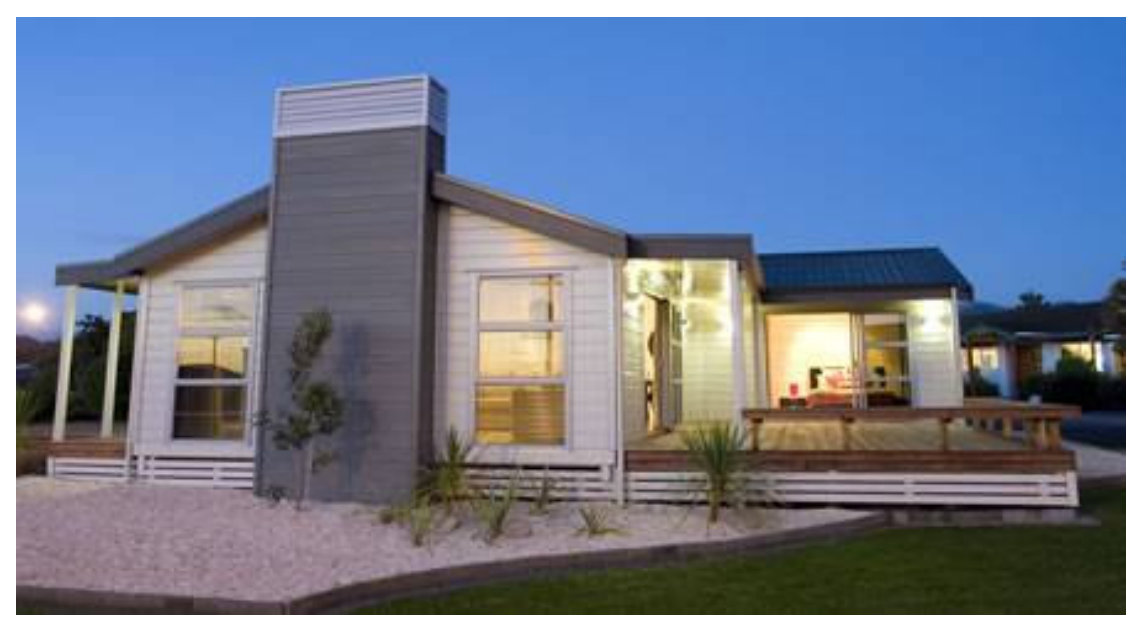

Figure 87: Opito show-home by Lockwood Group.

Source: <http://www.lockwood.co.nz/index.asp?pagelD=2145849356>. 
established themselves as providers of upmarket secondary and lifestyle housing (refer to Chapter 3 for case study) (87).

In the 1980s Allan Mitchener studied thirteen prefabricated building systems and identified several major issues relating to high production costs, low production rates and the difficulty posed when the housing product did not meet consumer demands (35). Rising production costs reflected material inputs, wages, consent compliance, and increasing consumer demand for highly-individualised luxury housing. Similarly, Peter Wong's 1980 thesis on three industrialized building systems described challenges of the small population, high transport costs and fluctuating economic conditions (79).

\section{0 - 2009 Contemporary Prefab}

The international 'fabprefab' movement has reverberated down-under with a wave of emerging prefab products boasting a neo-Modernist aesthetic and sustainable design features. ${ }^{57}$ Resurgence in interest in prefabrication is buoyed by offshore publications such as Dwell magazine and several magazine-style websites, including Fabprefab, Prefabcosm, and Inhabitat.

A New Zealand business which has not survived into this new era is Alpinehaus. From 2003 to 2005 Alpinehaus produced eight homes together with house transporters Clutha Homes of Balclutha (88-89). Their aim was to be affordable and simply designed based on the established bach, or crib, vernacular. The method used was standardised plans with traditional construction complete with joinery, plaster-board, and plaster and paint finish, which was then transported to site. They gathered a lot of market interest via their website and word-of-mouth, but went out of business when the consumer market demanded customised and larger homes which put them into direct competition with established design-and-build networks that had greater economies of scale (McCaul).

Architect Andrew Patterson's Relax series for Architects Homes resulted in fifteen custom housing solutions between 2002 and 2006. Patterson's own bach provided the prototype for these transportable homes. The demise was attributed to high transport costs, infrastructure issues and lack of a mass consumer market (Dawson).

Several other contemporary prefab projects never made it off the drawing-board. They include projects involving architects Stuart Gardyne, Max Herriot and John Melhuish. For reasons such as high start-up costs, low scales of economy, and client-driven rationale, these projects never made it to the prototype stage. In 2003, architect Stuart Gardyne, branding specialist Ray Labone, industrial designer Peter Haythornthwaite and furniture designer Humphrey Ikin collaborated on the design of a panelised housing system that could produce infinite design

57 'Fabprefab' is a term by Michael Sylvester: prefabrication expert, publisher of the Fabprefab website and content strategist for United States Dwell magazine. 


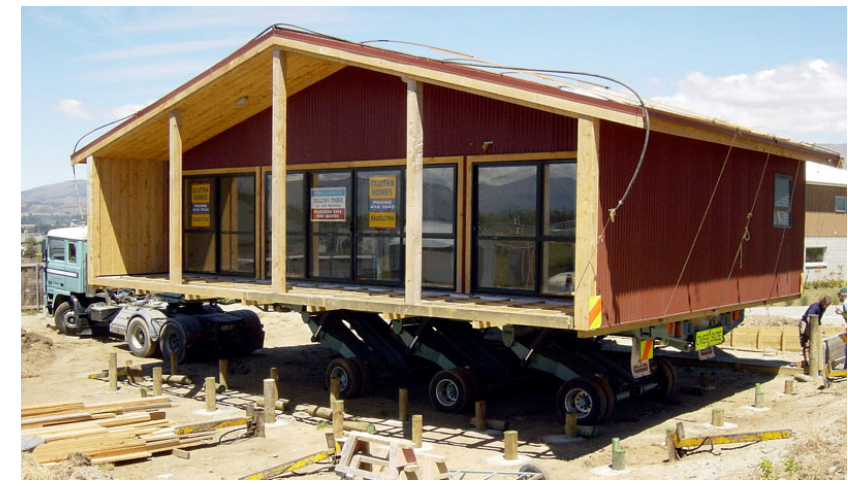

Figure 88: Alpinehaus dwelling being positioned for lowering at site. Source: Alpinehaus photograph, courtesy of Hamish McCaul.

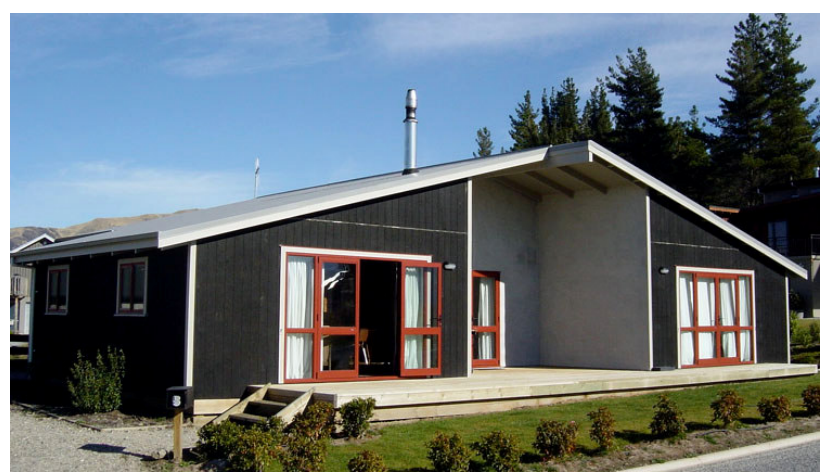

Figure 89: Alpinehaus dwelling after site works completed. Source: Alpinehaus photograph, courtesy of Hamish McCaul. 
variations with the addition of a series of components. The system lacked the investment backing to produce a prototype. The group's intention was to target the international market with a quality housing system, but they were faced with challenges from differing geographical conditions, cultures and construction compliance. The impetus is still apparent and the project would be resumed if research and investment issues were addressed (Gardyne).

In 2004, Wellington-based Herriot Melhuish Architecture (HMA) began working on a range of modular transportable dwellings for use as accommodation in Marehau, near Nelson.

Prefabrication was chosen due to the site's isolation, flood plain restrictions, and resulting cost advantages of factory production. Decking, linking volumes, and an ablution block were planned to be built at site to complete the development. The project did not proceed due to a lack of client financing, due to much higher infrastructure costs than originally anticipated (Melhuish).

Other potential prefabricated housing products may be carefully filed away in architecture offices around the country. ${ }^{58}$ This overview of New Zealand's history of prefabricated housing has identified issues which will now be summarised into topic groups. Following this, enduring contemporary prefabricated housing systems will be described as case studies (refer to Chapter 3).

${ }^{58}$ Further investigation would be interesting to document the obstacles encountered but was not possible within the constraints of this study. 

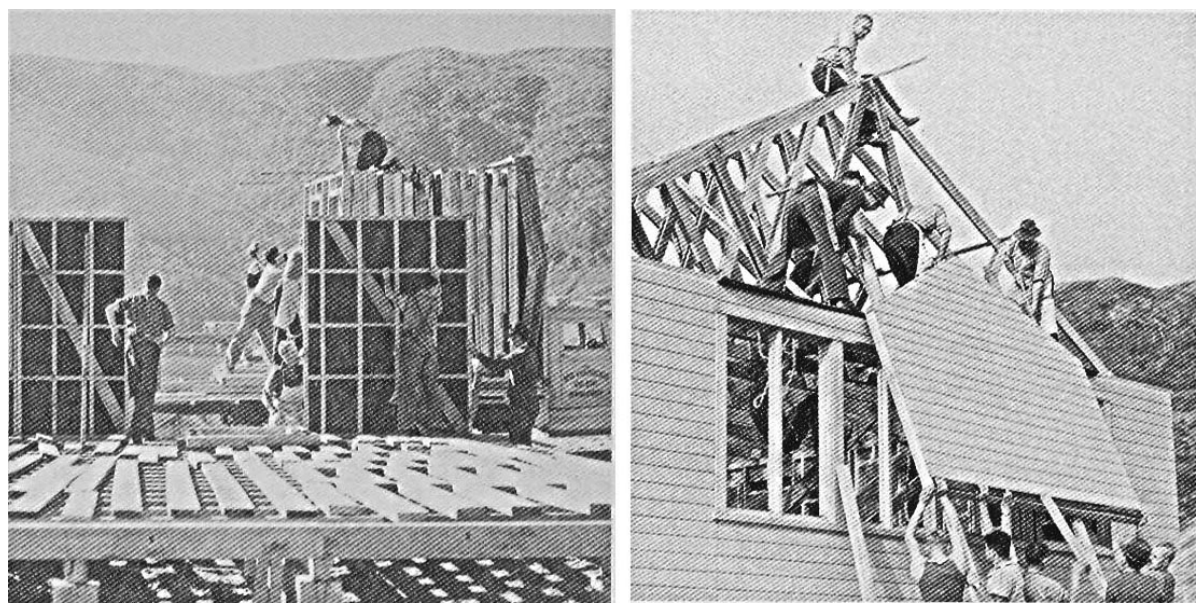

Figure 90 and 91: Returned soldiers headed by trained builders construct panelised state houses in the 1940s. Source: ABVF 7484 W4925/1 (1-16), Archives NZ, in B. Schrader, We Call it Home, Auckland: Reed, 2005:99. 


\section{Historical Issues}

There are few remaining kiwi prefabs. Despite several valiant attempts, very few examples of enduring prefabricated housing systems remain in business today. The problems encountered by businesses in this historical survey may offer helpful tactics for the future. Colin Davies argues that prefabrication has not achieved enduring economic success as an architectural product, however it is evident that there are other merits of prefabrication worth celebrating (9). Prefabrication's battle with commercialisation is based on three reasons; macro-economic factors, design and manufacture shortcomings, and socio-cultural issues such as communication and marketing. These three areas form the basis for discussing emerging issues from a short history of prefabricated housing in New Zealand. ${ }^{59}$

Macro-economic conditions of financial recession contributed to the downfall of several businesses including IBS when market demand waned and funding dried up. External economic factors are particularly frightening as they are out of the control of individual businesses. Companies that survived through tight economic times were those such as Lockwood Group and Keith Hay Homes that used their marketing skills and component-based systems to react flexibly and adapt to changing conditions.

Economic savings were one likely benefit of utilising groups of unskilled labour under the guidance of a trained professional. This tactic was used in the government's State House programme using returned soldiers after World War Two (90-91). It is in stark contrast to the contemporary and traditional practice of apprenticed worker training and skill specialisation. This example presents the opportunity for using un-skilled labour for assembly operations at the building site.

The disparate nature of the prefabrication industry in New Zealand has meant that government intervention and leadership has been powerful at affecting change through economic investment. A multitude of government-led research and development initiatives have led to long-term uptake of technologies, including precast concrete and the widespread use of prenailed trusses and wall frames. Government-funded housing projects have enabled businesses such as Keith Hay Homes and De Geest Construction to become established before being exposed to the wider and more volatile housing market. Investment in research and development has proven a key to innovation throughout the government's involvement in the home construction industry.

The government and industry-led NHC forum proved that tangible innovative results could be produced through collaboration. Their joint efforts produced a design competition, built

${ }^{59}$ This thesis identifies key points highlighted in bold. Chapter conclusions have a concise summary listed as bullet-points. 


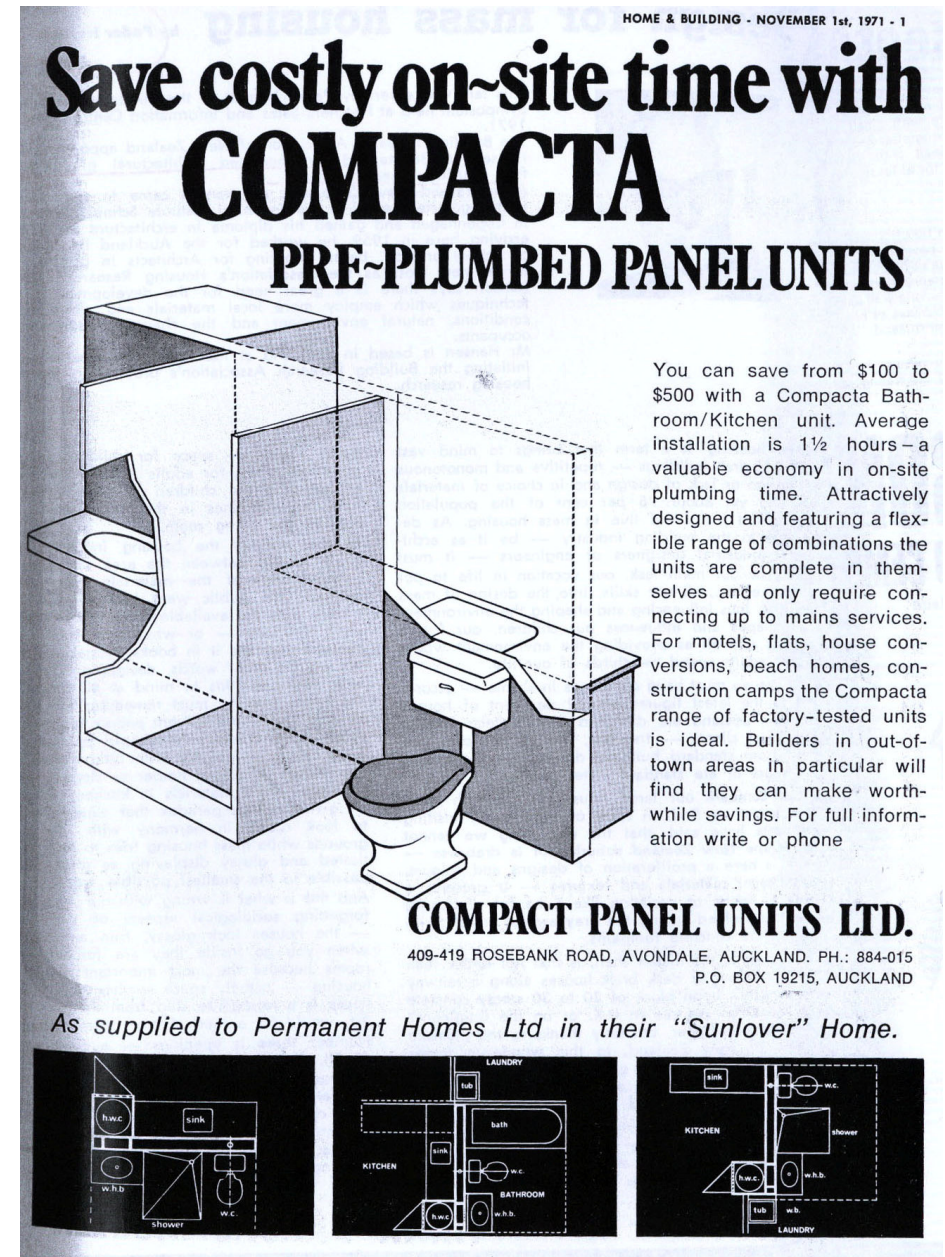

Figure 92: Compacta innovative prefabricated utility wall-mounted units, a hybrid product from 1971. Source: Home and Building, Nov. 1st 1971: 1. 
prototypical housing, and opened show-homes up to the wider public audience through the 'parade of homes' events. Each of these tactics acted as a way to communicate the benefits of prefabrication.

Material and technical innovations were evident in the systems used by Keith Hay, Lockwood and Solwood, particularly in pioneering the use of pine timber. IBS produced enduring innovations such as the Buckminster Fuller-inspired one-piece fibreglass bathroom and Ribsel patented panel system. A well researched and designed system, or product range, will likely create stronger and more consistent demand (92). Research and development also enables future-proofing for upcoming regulatory changes. ${ }^{60}$

IBS veterans advocate that financing and marketing both need to be in place before a product is launched, with an overall business plan and market research being integral to the enduring commercial success of the prefabricated system (Clark; R. Hay). Individual businesses must take responsibility for in-house research and development, as well as internal business planning focussing on financial and marketing areas in particular.

In the 1980s both Allan Mitchener and Peter Wong identified challenges to prefabricated housing businesses in New Zealand, including high production costs, low production output, restricted market size, and susceptibility to macro-economic conditions (35: 77). Both authors identified the issue of housing products and systems not meeting the demands of consumers. Learning about consumer demand and matching it to housing products can be achieved through market research. There is an identified need for market research and to learn from other competitors and manufacturing industries about increasing production efficiencies and lowering costs. Market demand must be met by consistent supply. Large-scale prefabrication needs continuous smooth factory working conditions, assured by continuity of supply of the necessary materials (Firth 41 ).

Gordon Wilson's 1943 comment highlights the public's misperceptions about the quality of prefabricated housing:

There appears to be a good deal of misconception about prefabrication, in as much as it has been considered by many people as being a cheap substitute for conventional building. It is, in fact, merely another way of building (G. Wilson $n p)$.

There has been a tendency to confuse the temporary nature of some prefabricated housing schemes with the overall realm of prefabrication. This is particularly apparent where these buildings have lasted longer than the original scope and have visibly deteriorated. As a result, several firms do not use the prefabricated term for fear of these negative connotations. Lockwood Group prefers the term system-building to avoid associations with a pre-determined outcome and other firms use words such as portable, transportable, kitset, pre-built and pre-

60 Predictions are that non-building regulations, such as those governing worker health and safety, will provide a strong push for house-building to move indoors to factory-controlled conditions (Walker). 


\section{A SHOW HOME A NEW CONCEPT IN MODERN LIVING}

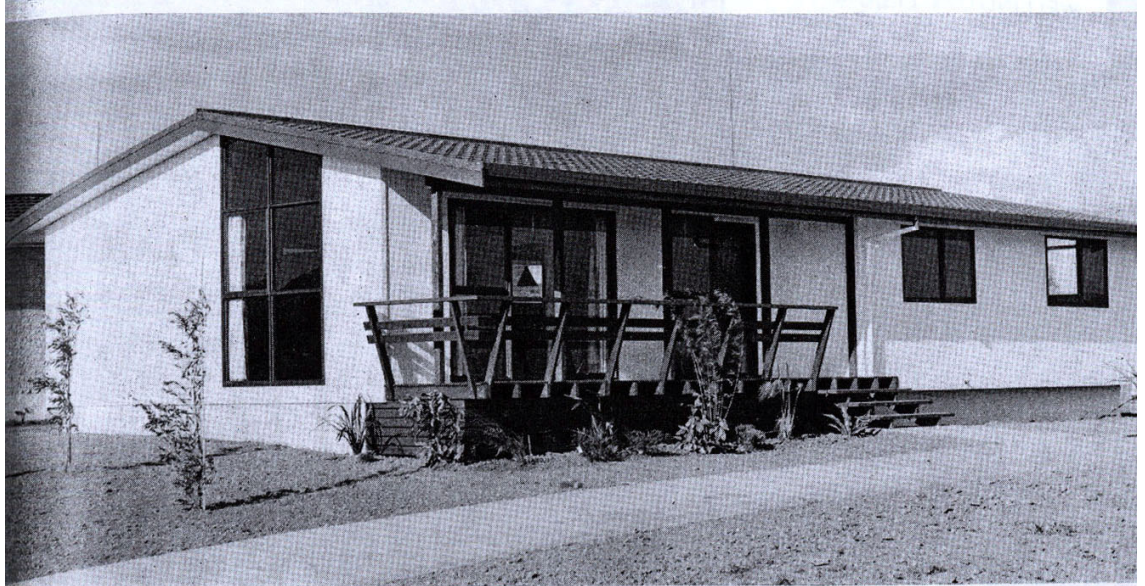

Open by Appointment (or weekends 2-5 p.m.) at 59 Gossamer Drive, Pakuranga (Open to 29th September, 1972)

\section{Modulock Is:}

Durability and low maintenance costs. Modulock homes have aluminium windows. The Modulock exterior panelling is protected with a factory applied long life

\section{Modulock Is:} Design. Modulock is a flexible system enabling us to
build to your design at no extra cost.

\section{Modulock Is:}

Economy. No other house offers such quality at such a low price.

MODULOCK (N.Z.) LTD. 109 May Rd,

Mt. Roskill.
Ph. 694-039, 694-038

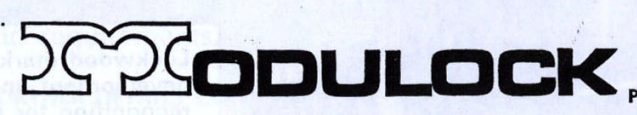

Units Contemporary Authorised Builders,
269A Mt. Smart Rd, Penrose
Ph. 596-555, 596-461

Figure 93: Modulock magazine advertisement, 1972. Source: Home and Building, May 1st 1972: 1. 
made. There is general consumer confusion between prefabrication's role as a system and the misperception that it describes a final product, which has contributed to low market demand.

General marketing is needed to target widespread misperceptions of cheap, low-quality and temporary attributes of prefabricated housing.

Various marketing tools have been used successfully by enduring businesses such as the Lockwood Group. Show-homes have enabled Lockwood's prospective customers to experience, examine and evaluate its housing in an intimate way. The use of pattern-books for Victorian villas, Railway Houses and State Houses allowed the customer to become more involved in the decision-making process. This empowered the customer, making it more likely that they would be satisfied with the resulting house product. Plan- or pattern-books are not widely used by architects in New Zealand but are becoming more popular overseas as midtwentieth-century techniques are revisited and revitalised. ${ }^{61}$ Consistent marketing through showhomes, plan-books and public relations material are all proven ways to communicate prefabrication's merits (93).

Historical challenges for prefabricated housing businesses were:

- wider economic recessionary conditions

- substantial start-up investment and large production runs have been required for economic sustainability

- consistent market demand has depended on a robust population with steady immigration met by an inadequate housing supply

- consumers have demanded prefabricated systems that allow design variability

- quality issues have been encountered with material supply

- difficulty with financial management and marketing planning

- misunderstandings of prefabrication processes and products have been held by the public, construction industry and government

An overall lack of financing, marketing and market awareness has caused the demise of many prefabricated housing businesses and consequently the loss of innovative systems to the construction industry and wider market.

In the next chapter, these historical issues will be reinforced with contemporary concerns from national precedents. Commercially successful and enduring systems will be exemplified by case studies of De Geest Construction, Lockwood Group and McRaeway Homes. The following chapters will look closely at international exemplars, and New Zealand's emerging prefabricated housing (refer to Chapter 4 and 5). A discussion of the combined lessons learned will follow these case study chapters (refer to Chapter 6).

${ }^{61}$ United States plan-book websites include those by Houseplans, Eplans and Garella Associates (Cannell). 


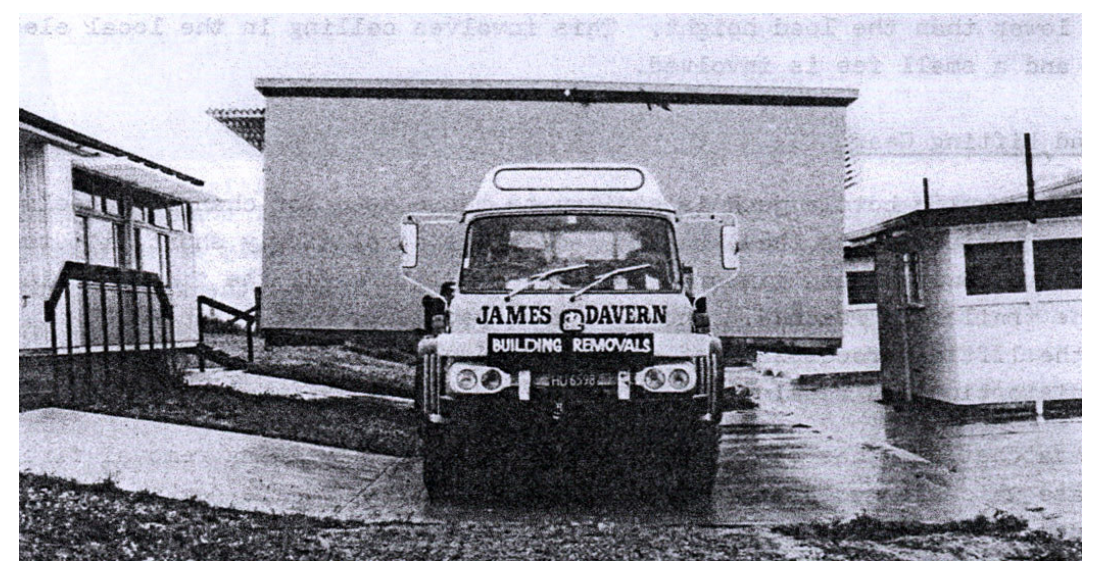

Figure 94: The uninspiring window-less façade of a prefab classroom ready for relocation. Source: J. Ayliffe and M. Jeffares, Relocatable Schools in NZ, Paris: OECD, 1982: 35. 


\section{Kiwi Prefabs Today :}

\section{Contemporary New Zealand Case Studies}

Many New Zealanders have memories of prefabricated classrooms from 1970s and 1980s childhoods; those seemingly lost and lonely cubicles, outcast to the outskirts of school fields and playgrounds, lightweight and flimsy, temporary dwellings which outlived their use-by-date, showing rapid deterioration (94). This formative experience was not the best introduction to prefabrication, but one which nevertheless has enduring influence over wider perceptions. Despite this introduction, many architects and designers have contemplated prefabrication in the hope of discovering a replicable, bankable, 'widget'. Many of these systems have not made it to market, which begs the question about what determines commercial success or failure; one of the initial motivations for this thesis.

The previous chapter identified key historical issues such as an overall lack of financing, marketing and market awareness. To see if these challenges are still applicable today, this chapter will investigate New Zealand's established contemporary prefabricated housing industry in 2009. The issues identified here will build on past challenges in order to design opportunities for a way forward.

It is a challenging task to investigate the current state of the prefabrication industry as it is widespread and fragmented, lacks overall coordination and organisation, and suffers from very little collaboration. ${ }^{62}$ There are no focussed publications or singular sources of contact information. This section of the research has compiled information from primary resources. It is intended to represent a snapshot or cross-section of the New Zealand prefabricated housing industry today, not a comprehensive survey. The following case studies were derived from conversational interviews and site visits. Where face-to-face was not possible, a phone or email interview was conducted. These conversations focussed on questioning start-up motivation, prefabrication strategies, merits, challenges, and future predictions. ${ }^{63}$ This exchange of ideas utilises Bruce Nussbaum's 'Design by Conversation' approach in that it provides fertile breeding ground for the creation of new ideas (Nussbaum qtd. in Baldwin). ${ }^{64}$

${ }^{62}$ Any coalitions are driven by the narrowness of industry supply, such as Mitek pre-nail systems, and Triboard wall panels by Juken New Zealand. ${ }^{63}$ Refer to appendix A, B, C and D for interview questions, list of participants, sample interview transcript and sample case study respectively. ${ }^{64} \mathrm{~A}$ number of companies chose not to reply to research questions. Reasons cited were confidentiality (market competitiveness is apparently high), health and safety (when denied access to the factory floor), and business instability (several companies said they were closing down due to financial difficulties). 


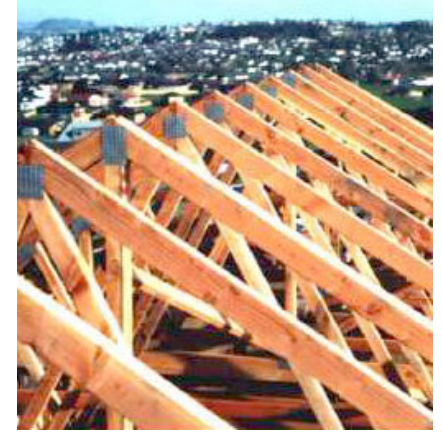

Figure 95: Mitek nail plate system used in pre-nailed roof truss component-based construction. Source: <http://www.mii.com/newzealand/>. 


\section{Contemporary Case Studies}

Prefabricated housing in New Zealand can be classified as previously defined typologies: component, panel, modular, hybrid and complete building. The following case-study investigation of contemporary kiwi prefabs is grouped according to housing system or product type.

\section{Component-based Prefab}

According to New Zealand architect Gerald Melling and American architectural historian Barry Bergdoll, the mostly widely used prefabricated component is the four-by-two inch (one-hundredby-fifty millimetre) timber stud (Melling qtd. in Walker). On this basis, any element brought to site in a pre-finished condition, such as a tree cut into framing timber or clay formed into bricks, could be considered by some as prefabrication. The definition of prefabrication in this thesis begins with components such as pre-cut stick elements (refer to Chapter 1).

Component and stick housing packages are commonly referred to as kitsets. New Zealand has an established kitset home industry made up of design-and-build businesses. ${ }^{65}$ This system can be assembled by either the house owner or a contracted builder which can lead to cost advantages for home owners with some do-it-yourself (DIY) ability. However, this market is changing due to the Licensed Building Practitioner (LBP) scheme introduced in 2007. ${ }^{66}$ Many companies providing kitsets are now moving into full construction in their own factories or outdoor yards in order to supply transportable housing. These businesses also usually offer traditional site-built housing. ${ }^{67}$ The kitset industry also includes garages and accessory buildings made of roll-formed pre-cut steel structural members ${ }^{68}$ Steel is gaining popularity as a residential structural system, with several established building companies experimenting with introducing steel framing to the New Zealand housing market.

Pre-engineered, pre-cut and pre-nailed roof trusses and wall frames are components that contribute to an estimated ninety-eight percent of new residential construction (Hunt) (95). They are supplied by large national networks of timber suppliers such as Carters Manufacturing, Placemakers, ITM and Mitre Ten, as well as independent local manufacturing facilities such as

\footnotetext{
65 Design-and-build businesses are nationwide networks of builders under license or franchise-holders. They include Jennian Homes, Keith Hay Homes, Sunshine Homes, David Reid Homes, G.J. Gardner, Golden Homes, Haven, The Housing Specialist, Signature Homes, The House Company, Location Homes, and Woodridge Developments. These companies build less than a quarter of new home starts, which shows that the industry is dominated by small-scale builders (Page 46).

66 The intention of the LBP was to protect the consumer, in the wake of the 'leaky buildings' experience. However, the effect has been to prevent non-qualified people from building their own homes.

${ }^{67}$ Kitset suppliers include The Housing Specialist, Latitude Homes, Letts Buildings, Location Homes, McRaeway, NZ Building Supplies, Pinecone Timber Buildings: Cabins and Sunshine Homes. Also A1 Homes, Clutha Homes, Country Lifestyle Homes, Customkit Buildings, Designer Kitset Company, GaraPlan, Highmark Homes, Homemaker Homes, Horizon Homes, James Kitset Homes, Kitset.co.nz, Kit SetHome.com, Letts Buildings, Lifestyle Log Homes, Neil Timber, Ryan Austin Steel Frame Kit Homes, Shack N Shed and Steel Frame Concepts.

68 Garage and accessory building suppliers include Totalspan, Kiwispan, Galaxy Steel Buildings, Ideal Homes and Garages, Fair Dinkum,

Versatile Buildings and Garages and Contour Roofing.
} 

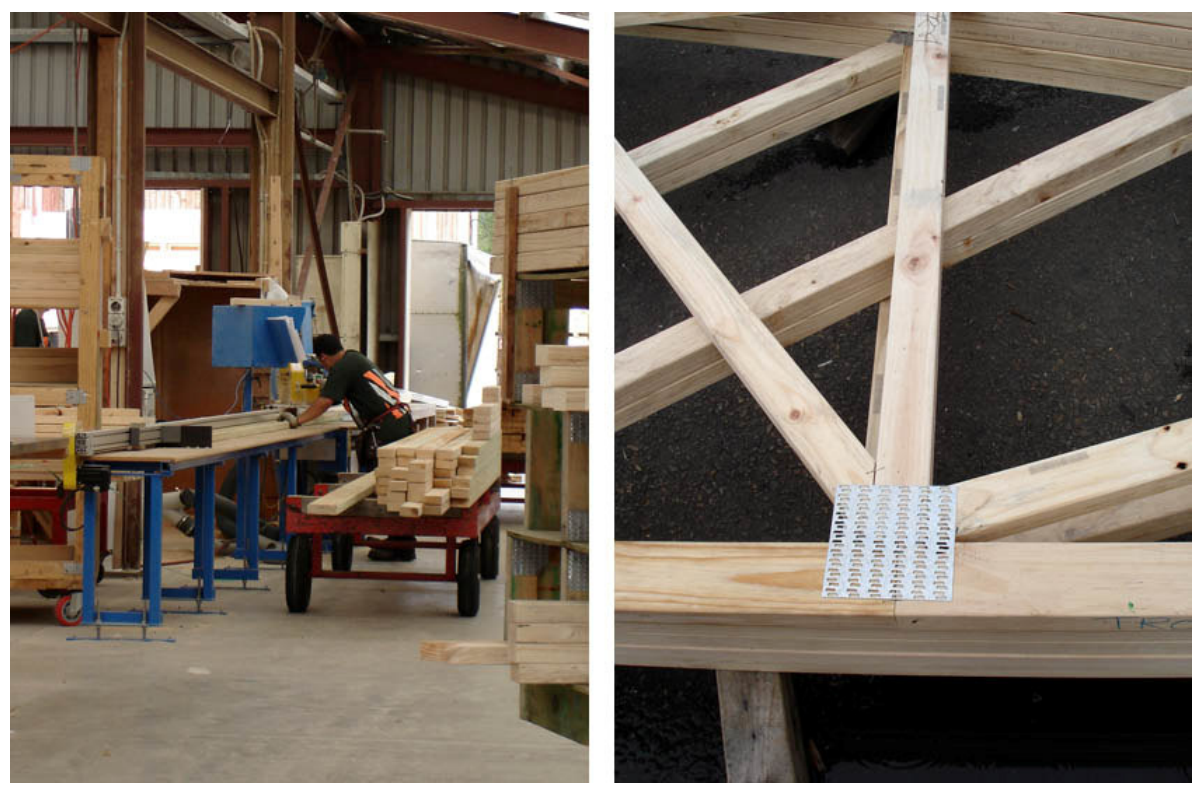

Figure 96 and 97: CNC machinery and completed pre-nailed truss at Carters Manufacturing, Rotorua. Source: Author's photograph, 2008. 
Awanui's Durapanel Systems and Timber Construction Solutions (TCS), as described in the following case studies. ${ }^{69}$ New Zealand's pre-nail industry is dominated by two nail-plate manufacturers, Mitek (with ninety-one fabricators) and Pryda (with forty fabricators). Both manufacturers supply engineering software to design components and direct machinery, as well as supplying computer hardware, plant and machinery, advice on factory layout, plant audits, best practice guidelines, ongoing education, certification and association support (Hunt).

Current forecasts are for consolidation in the pre-nail industry due to the economic recession. It is predicted that the one-hundred-and-forty-five fabricators that were in operation in 2007 will be reduced to ninety-six by 2017. Improved efficiency is predicted to produce an average of almost five houses per week, up from the 2007 average of three houses per week (Gaiardo "Challenges"). The extensive use of pre-nailed frames and trusses in traditional house-building is not commonly acknowledged as prefabrication, due to the widespread misperception that prefabrication is confined to modular or complete building typologies.

Custom architect-designed homes account for about five percent of new houses in New Zealand by volume and almost all utilise architectural components such as laminated timber joists and beams, cabinetry built away from the site, window and door joinery systems or precast concrete technology (Albert). ${ }^{70}$ Two current systems utilising prefabricated component technologies are Replica Architects' bachkit and Lockwood, and their case studies follow.

\section{Carters Manufacturing - Rotorua}

Carter Holt Harvey $(\mathrm{CHH})$ is New Zealand's largest privately-owned company and one of two major timber retailers, the other being Placemakers owned by Fletcher Construction Company. ${ }^{71}$ The $\mathrm{CHH}$ Wood Products group manufactures structural timber, plywood, laminated veneer lumber (LVL), medium density fibreboard (MDF) and particleboard. These products are marketed through a building industry scheme called Future-Proof Building (FPB). As a subsidiary of Wood Products, Carters Manufacturing fabricates pre-nailed timber roof trusses and wall framing using engineering by Mitek to coordinate with their Gang-nail brand of folded-steel jointing components. This information system coordinates the measurement and cutting of timber lengths using computer numerically controlled (CNC) machinery (96-97). Final assembly into trusses and frames is by hand-held nail-guns on table-top jigs, before stacking and wrapping to await delivery. ${ }^{72}$ Work flow is coordinated by Carters' Batch-cut program to produce on a just-in-time basis. Before it closed down in late 2008 , the six-hundred square

${ }^{69}$ About half the pre-nail truss and frame manufacturers are affiliated to the two largest timber suppliers Carters and Fletchers (Hunt; Gaiardo Email).

70 The New Zealand Institute of Architects refers to research by NFO CM Research, now called TNS Research. The figures are from around 2004 and reflect that homes designed by Registered Architects account for approximately five percent by volume and eleven percent by value of all new homes built. The sample size was about two-thousand (Albert).

${ }^{71} \mathrm{CHH}$ employs nine-thousand people across one-hundred-and-thirty locations in New Zealand, Australia and Asia, and is the biggest earner of New Zealand's wood product exports which are worth over three billion dollars (Fox).

72 There are problems with the costs of disposal of wrapping material as it cannot be reused. Carters Manufacturing Rotorua had an awareness of waste management issues, sending nine square metres of waste to landfill each week and sending useable off-cuts home with employees for firewood (Hossack). 

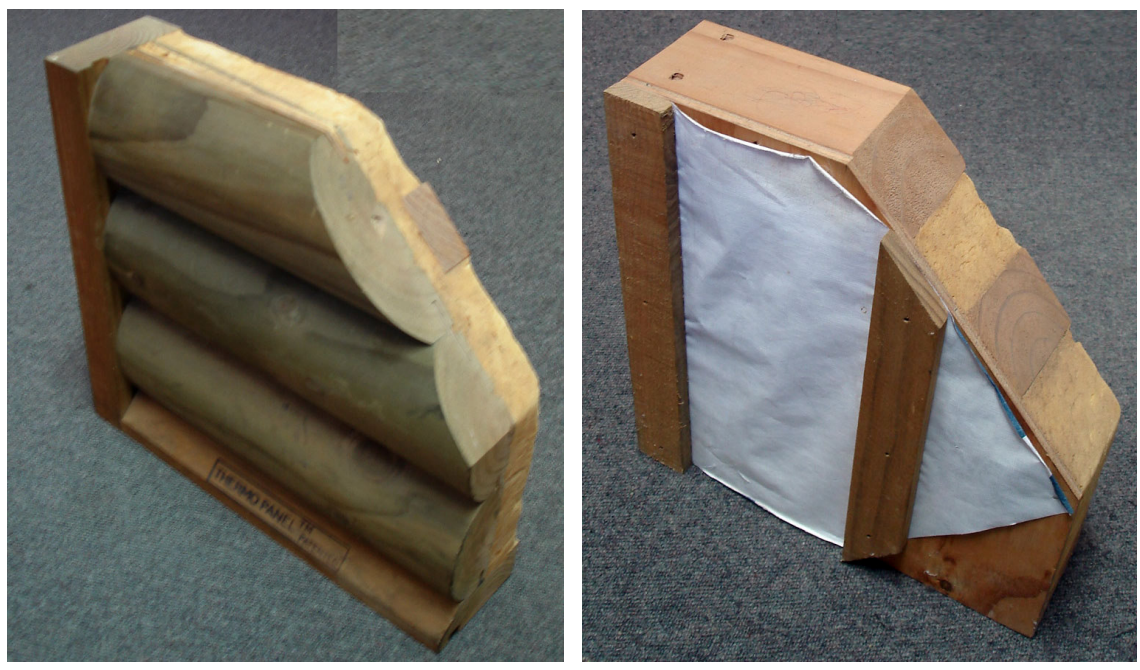

Figure 98 and 99: Exterior surfaces of Thermopanel and InsulFrame panel products by TCS. Source: Author's photographs, 2008. 
metre area Rotorua factory employed up to eighteen people and was capable of producing framing for a two-hundred-and-twenty square metre house in a single day. The factory also produced laminated veneer lumber (LVL) window lintels, beams, floor joists and fruit-bins in an effort to even out cyclical construction demand (Hossack).

The large numbers of frame and truss makers nationwide are differentiated only by location. The Frame and Truss Manufacturers Association (FTMA) has about sixty percent of these fabricators under its umbrella and gives quality assurance branding to those products that comply. At the time of the interview, in early 2008, Carters Manufacturing Rotorua was supplying almost half of its production to design-and-build businesses, and the remaining half to local residential and commercial contractors. When the factory was closed down, plant and machinery were moved to the Carters Cambridge operation, and staff were laid off. Reasons given for the closure were the general economic slow-down which has resulted in decreased demand, together with over-supply from Carters' Cambridge and Tauranga within the same region. Carters forecast further consolidation within their manufacturing operations until the expected industry recovery in 2010 (Rozbicki).

Carters Manufacturing faced challenges of consent compliance costs, inclement weather affecting yard work and the cyclical nature of the building industry (Hossack). Despite their demise, it is worth noting the merits of support of national bodies such as Mitek and FTMA for quality assurance and branding, the Future-Proof Building scheme for cohesive marketing directly to the end-consumer, and the acknowledgment that weather difficulties will ultimately force future production indoors.

\section{Timber Construction Solutions (TCS) - Awanui}

Tristyle Industries began in the 1990s selling Thermopanel Log Homes to offshore markets. By 2007 the operation had grown to employ nearly thirty people and produce twenty high-end homes each year. ${ }^{73}$ Difficulties in managing cash-flow through lengthening job procurement timeframes led to a mid-2008 company restructure into two separate businesses; Timber Construction Solutions (TCS) structural design services and Frame-It frame and truss manufacture. ${ }^{74}$ TCS's current focus remains on offshore markets and kitset production of frame and truss components, wall panel systems and some finishing materials. Their two wall panel products are Thermopanel, a solid timber half-log cladding with foam-in polyurethane insulation, and InsulFrame, a plywood clad timber frame with foam-in insulation (98-99). Internal linings, electrical and plumbing work are all fitted by local contractors at site with coordination from TCS. Both panel products are currently sold to the Japanese market, with plans to supply the local market in the future (Turner and Heere).

${ }^{73}$ Tristyle employed almost thirty people between the Awanui timber manufacturing site and the Auckland component assembly site, including an architectural designer with solid timber system experience from Holland's Finnhouse (Turner and Heere).

${ }^{74}$ Frames and trusses are supplied to local builders in Northland. These components are computer kiln-dried and cut by hand to CAD designs (Turner and Heere). 


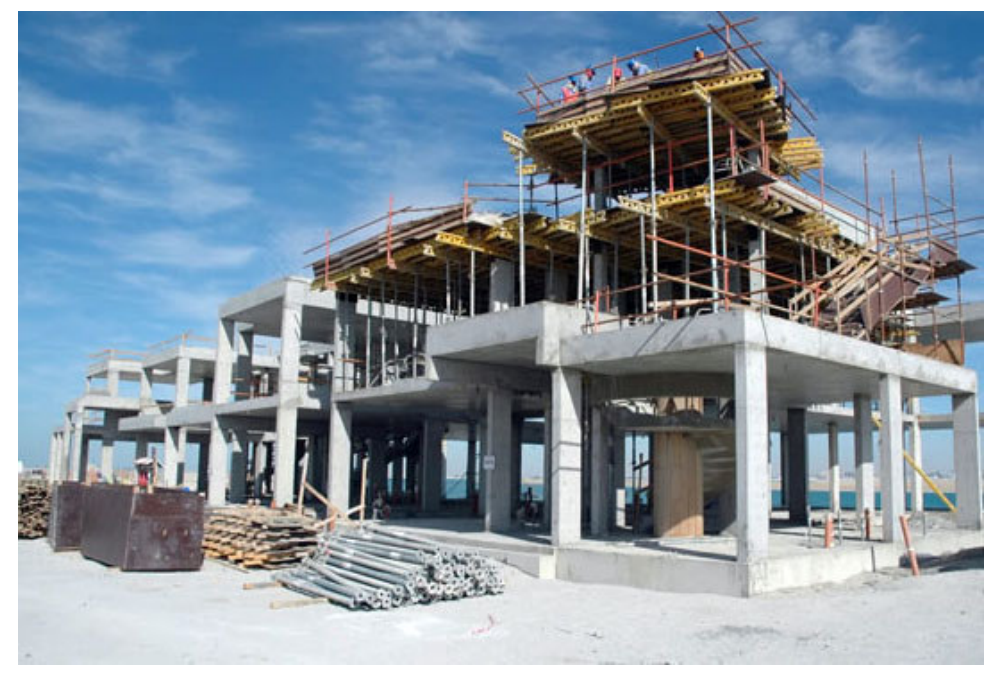

Figure 100: 'Palm Jebel Ali Water Homes' Dubai. Source: <http://www.palmjebelali.ae/construction-updates.php>.

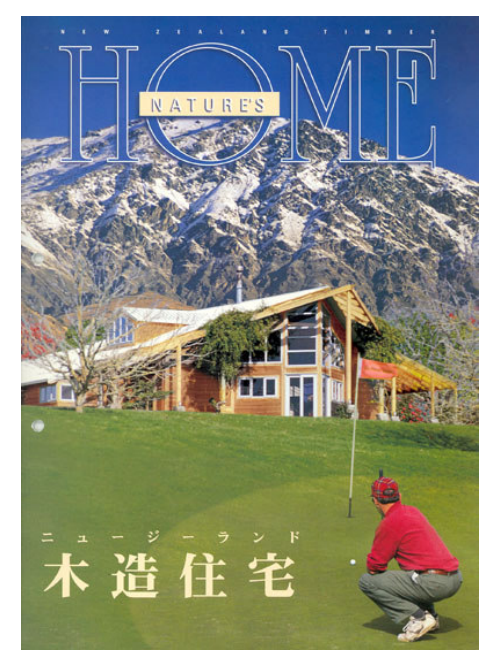

Figure 101: 'Homes NZ' brochure cover. Source: Brochure courtesy of TCS. 
The next five years are focussed on two major projects in Dubai which are the result of employing a locally-based marketing professional over the past five years. 'Palm Jebel Ali Water Homes' is an over-water housing development of more than five-hundred homes with timber framing planned to be produced in TCS's recently established India factory (100). Prefabricated bathroom pods are to be supplied by an Italian manufacturer. The second project is for timber structure supply to a United Kingdom-designed restaurant through Global Timber Homes (GTH), a joint venture business between TCS and Auckland laminated veneer lumber (LVL) timber supplier McIntosh (Turner and Heere).

TCS's focus on manufacturing offshore is a direct result of New Zealand's high labour rates and standard of living. ${ }^{75}$ This has exposed them to wider economic and political influences, as evidenced by a history of failed projects in China, Japan, Argentina and Fiji. These disappointments were despite marketing subsidies from the government through Trade and Enterprise. From 1995 to 2000, TCS coordinated a national strategic alliance to supply housing to Japan, but the 'Homes NZ' (House Exporters Association of New Zealand) initiative was not economically successful (101).

TCS has maintained a positive attitude in the face of adversity. It is notable for its focus on offshore markets for both demand and fabrication, through the use of locally-based marketing personnel and New Zealand-based joint ventures. Their involvement in Dubai indicates that international construction projects are tending towards country specialisation of supply, where Italy is a source of bathroom pods, the United Kingdom is a source of architectural design, and New Zealand is a source of timber structure.

\section{Bachkit by Replica Architects - Christchurch}

The bachkit has been described as, "an adroitly worked example of architecture as commercial product" (2005 New Zealand Institute of Architects Jury qtd. in "Expert and Stylish"). This architectural product was designed by Auckland's Andre Hodgskin Architects with input from Holmes Consulting engineers, communication and marketing firm Mandela, graphic design company Seven, and construction company Maddren Homes in $2000 .{ }^{76}$ Replica Architects, then Replica Homes, bought the bachkit housing system in 2001 to add contemporary low-pitched design to their selection of traditional pattern-book homes $(102,103,207)$. An architectural design and project management company, Replica has sold a number of bachkit iterations to clients in New Zealand, Australia and Tahiti. ${ }^{77}$ National sales are predominantly North Island-based due to the design's large expanses of glazing, decks and its flat-roof (McKenzie) $(102,104)$.

\footnotetext{
75 Turner referred to the cost of plasterboard as being sixteen times more expensive in New Zealand than in India (Turner and Heere)

${ }^{76}$ Maddren Homes went on to produce 'e-homes' in 2008. Refer to Chapter 5 for emerging case studies.

${ }^{77}$ Replica prefers not to give actual numbers of bachkit and derivatives sold (McKenzie).
} 

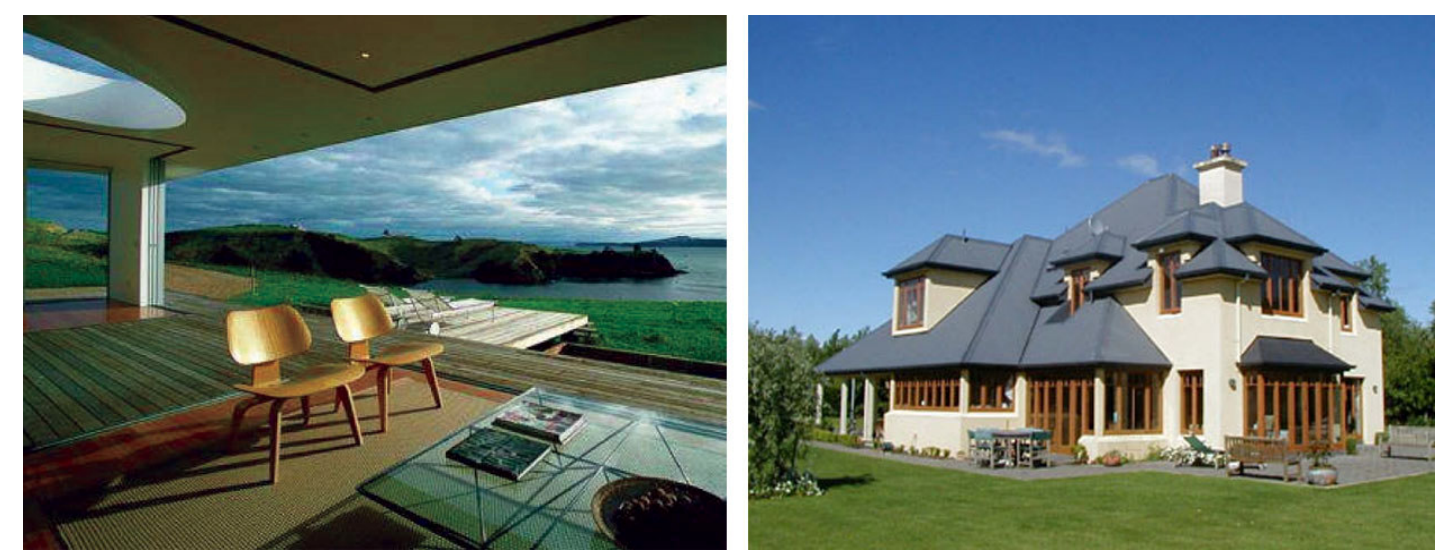

Figure 102 and 103: Bachkit alongside traditional housing by Replica.

Source: 'Replications' brochure courtesy of Replica and <http://www.replica.co.nz/gallery.htm>.

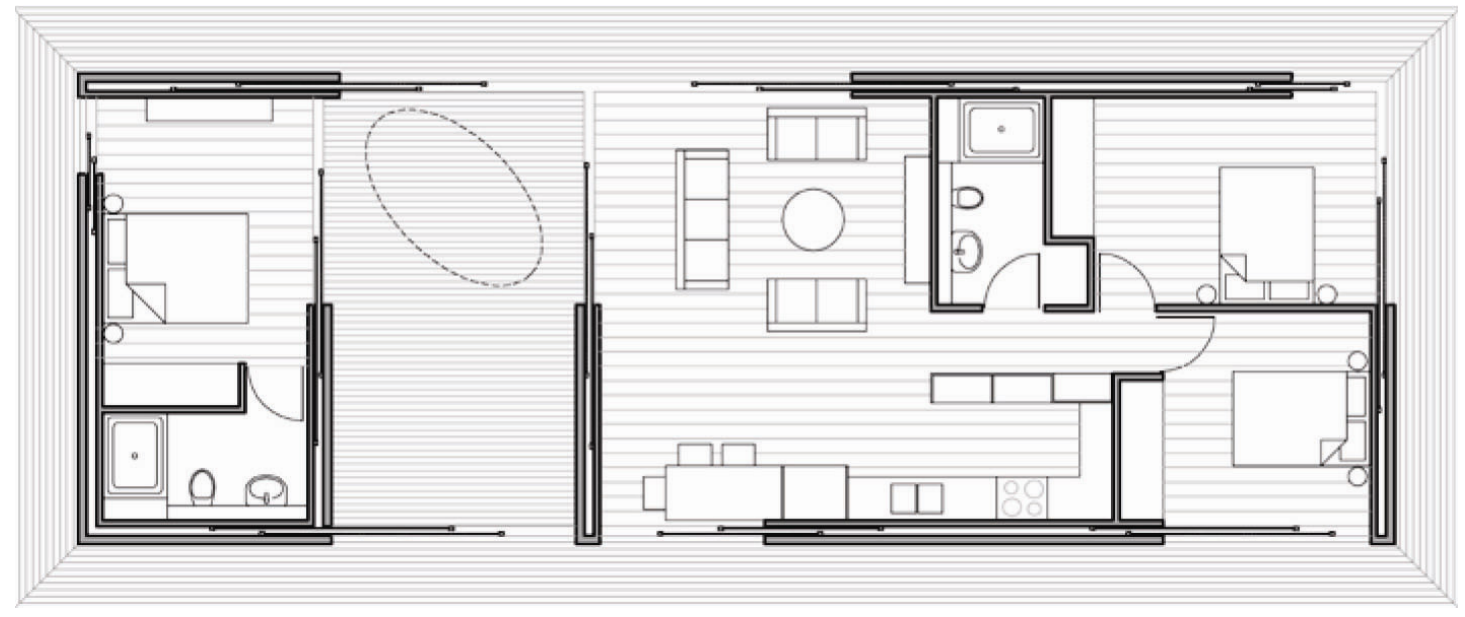

Figure 104: Bachkit 'Total Bachkit' floor plan option.

Source: <http://www.bachkit.com.au/images/stories/bachkit_floorplans.pdf>. 
The bachkit design is based on standardised planning with five additive models starting from the basic pavilion and extending to a full version complete with deck and studio pavilion (104). The system consists of pre-cut, pre-formed and pre-made components delivered to site as a kitset. These include steelwork, sub-floor timber, wall framing, doors and shutters, track system, roof ellipse and flat-pack internal cabinetry (McKenzie). Replica has tried to extend this current level of prefabrication but encountered difficulties with loyalty in research and development partnerships. ${ }^{78}$ Based on their experience they do not see a future for complete buildings to be prefabricated in New Zealand, but will investigate containerisation of kitset elements to inaccessible sites as well as a modular approach for two volumes (McKenzie).

Bachkit's simple pavilion is reminiscent of mid-twentieth-century Modernist architecture, complete with a roof woggle, an aesthetic that has established it as New Zealand's most recognisable contemporary architect-designed prefab (Levy; Sylvester). Its slick marketing image has generated a lot of media interest, even if this has not been backed up by actual sales.

The prefabrication process has been fraught with difficulties, failed business alliances, weak market demand, public misperceptions, costly regulatory processes, and a lack of material development and supply. ${ }^{79}$ This has caused them to look offshore to export markets in the Pacific and Australia (McKenzie) ${ }^{80}$ Points of note from the evolution of bachkit include the separation of initial design and product creation from the ongoing fabrication and market supply, partnering with industry for research and design opportunities, and an offshore focus to increase market size.

\section{Lockwood Group - Rotorua}

Lockwood Homes began in 1954, a few years after Johannes La Grouw and John Van Loghem emigrated from Holland. La Grouw brought experience in construction, design and Dutch prefabrication methods, which complimented the sales and marketing background of Van Loghem. Together they established a factory in Rotorua near the pine forest industry and began by producing five holiday homes a week. In the 1960s they developed a national franchise network which now enables the Lockwood Group to build up to five-hundred houses per year, a total of over forty-thousand houses to 2008 (Lockwood Group, History). Many of these are in overseas markets, as a result of international exposure and sales initially gained when Lockwood built New Zealand's Pavilion at the 1970 World Exposition at Osaka, Japan

${ }^{78}$ At one stage they partnered with Auckland-based campervan producer Freestyle to develop an aluminium-frame plus timber-board jointing system with glue-fixed plywood and plasterboard internal walls and ceiling. This relationship did not endure (McKenzie).

${ }^{79}$ McKenzie says the industry needs to come up with new materials and systems, such as larger sheet sizing and peel-off protective coatings.

80 In early 2009 a 'heads of agreement' contract was in place with an Australian distributor and an Australian website for the Perth-based operation advertised bachkit with four kitchen options (Bachkit). The Perth show-home was due to be completed in mid-2009 (McKenzie). 


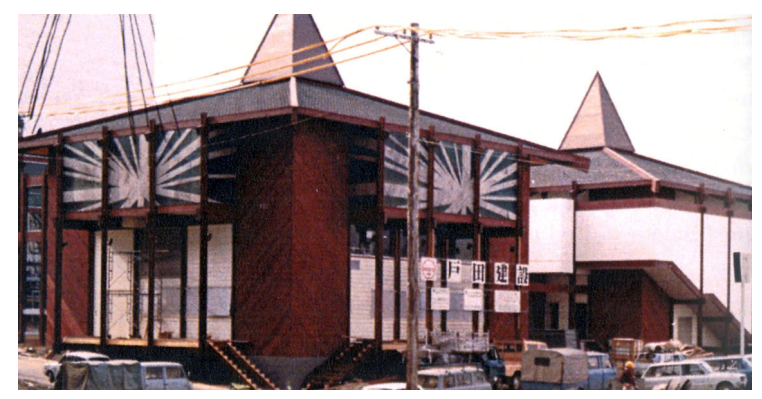

Figure 105: New Zealand Pavilion restaurant under construction at World Expo, Osaka Japan, 1970. Source: M. Payne, A Charmed Life, Whanganui: Michael Payne, 2008: 71.
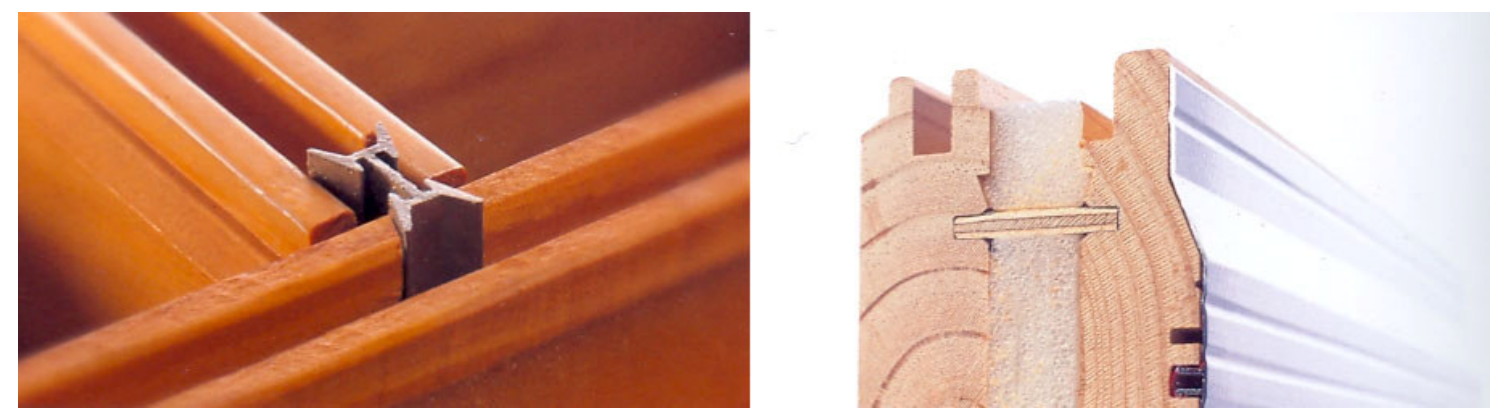

Figure 106 and 107: Lockwood system: joint and section of insulated board. Source: "Lockwood Lifestyles" plan-book 2008, courtesy of Lockwood Group: 46 and 52. 
(Gainsford 22) (105). ${ }^{81}$ Today, the Lockwood Group is headed by Jo La Grouw (Junior) and remains New Zealand's foremost prefabricated housing company, with twenty-eight franchisees nationwide, and a line of affordable transportable housing under the Initial Homes brand.

The patented component-based building system consists of polyester resin coated aluminium sheeting pressed into solid pine wall boards that interlock with each other and with aluminium jointing profiles (106-107). The resulting wall system is attached to foundations below and roof above with vertical steel tie-rods, in an assembly process that takes about half the time of a traditional stick-built house (Gainsford 16). The Lockwood Group responded to changing legislation by updating its pre-manufactured board with insulation; closed-cell polyethylene foam sandwiched between interior and exterior timber surfaces. ${ }^{82}$

The success of the Lockwood brand is the result of over fifty years of consistent marketing through show-homes, plan-books and advertising. The brand has been supported by the franchise system in which the Rotorua factory supplies materials, components and marketing with franchisees being responsible for their own show-homes, processing design plans, and site-based construction. Show-homes are updated every few years, so are built to be transportable in the future. They enable prospective customers to experience a home before purchase. The Lockwood plan-books act as "conversation starters" between clients and salesagents, rather than as standard design templates (Tuohy). ${ }^{83}$

Extensive national advertising is through magazines, newspapers, television and websites. In recent years, the Lockwood Group has recognised the marketing benefits of architect-design and aligned its products with high-profile architects through the 2003 Pete Bossley and Associates range and the 2008 EcoSmart Home series by architect Dave Strachan (108). The sales of these homes are a low percentage of total sales, yet they are "a drawcard to get people to come and investigate", and to learn about potential for architect-design (Parker). Within a few months, ten-thousand people had visited the EcoSmart show-home at the Rotorua site and numerous negotiations with potential home-owners had begun (Bryce Heard qtd. in Kenworthy 159).

The longevity of the Lockwood business has been challenged by competitors, cultural shift, and consent compliance. At least six other solid-timber housing systems have emerged over the years, including Signature Homes, Conecta, Modulock, Intalok, Fraemohs and Touchwood. The latter three are still in production, Fraemohs in the South Island and Touchwood and Intalok in the North (refer to Touchwood in Panel section following). The Lockwood Group experienced a cultural shift in the 1980s when the market reacted against prefabrication, possibly in confusing

81 Lockwood Group has an international trading arm called Lockwood International which has supplied housing to Australia and Pacific Islands, Russia, Middle East, Peru, and Japan (Lockwood Group, Lockwood International).

${ }^{82}$ Consent compliance for structure and insulation has been a challenge for the firm in the past and they now employ a person dedicated to these specific issues (Parker).

${ }^{83}$ The Wanaka has been the most popular house design since the mid-1980s. Other popular designs are the Caribbean and the Jamaican (Tuohy). 


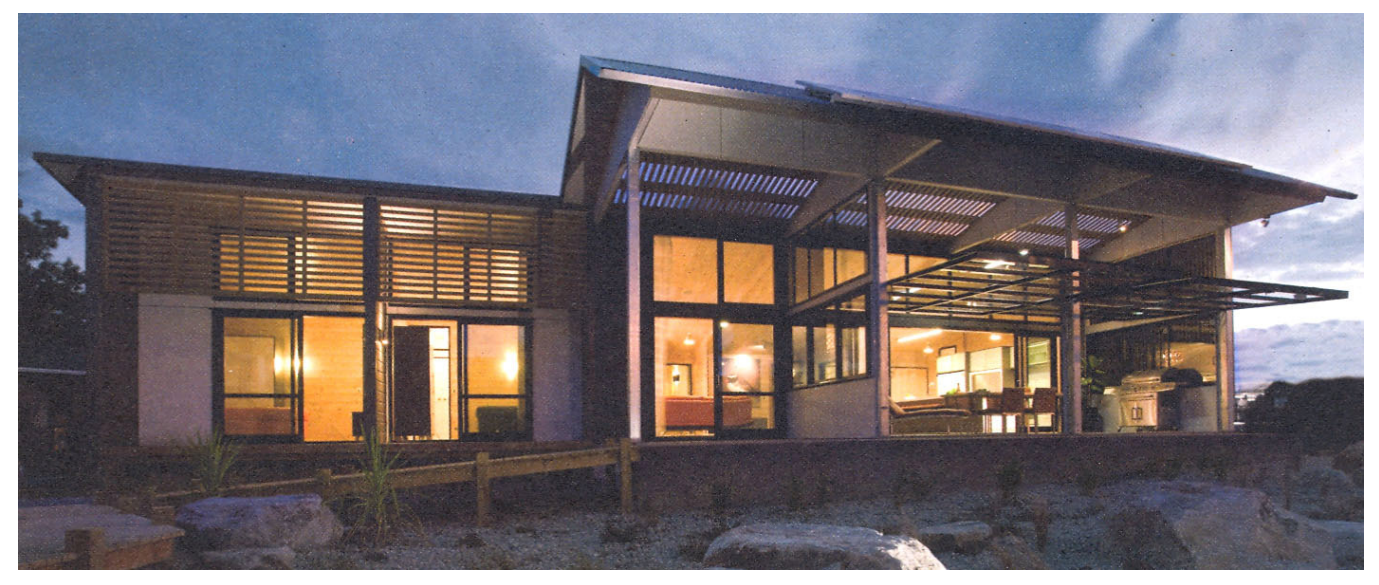

Figure 108: EcoSmart Gullwing house model by architect Dave Strachan for Lockwood. Source: "Lockwood EcoSmart" plan-book, courtesy of Lockwood Group. 
it with standardisation. ${ }^{84}$ This was at a time when the construction market swelled with an increasing range of options; together with economic prosperity and an increased desire for individualisation in housing. The Lockwood Group's business response was to target a higherpriced growing market of large second homes in lifestyle areas such as Coromandel, Taupo and Queenstown (Tuohy). ${ }^{85}$

Lockwood Group is one of four solid timber product companies that have formed the 'Solid Wood Building Initiative' to access research funding from the government's 'Forest Industry Agreement Fund' ${ }^{86}$ The future focus at the Lockwood Group is on keeping up with local and national compliance issues, such as those for structure, insulation and reduced reflectivity of exterior claddings, as well as more research and development on refining the prefabrication process. This will likely mean an effort to move past pre-cut components and panels towards modular construction, as well as incorporating more CNC technology, updating processes and systems, and introducing new manufacturing machinery (Parker). In mid-2009, Lockwood Group announced over six-million dollars of investment to upgrade its Rotorua headquarters. A key part of this investment was the design and purchase of a two-million dollar timber processing machine which is forecast to increase productivity from three-hundred houses a week to three-thousand. Lockwood plans to send machines to offshore markets and set up franchises on the ground, rather than continuing with housing kit export (Hall).

The Lockwood story offers many useful strategies, and this is from only knowing part of it, as intellectual property is guarded closely. ${ }^{87}$ Enduring marketing tools include the national franchise network, international exposure, show-homes, alliances with architects and accessible plan-books. They combine both plan-books and high-end architecture in their business, something which is not widely embraced in the architecture profession. The Lockwood Group's component-based housing system is notable for its flexibility in that no two homes have been designed exactly the same, despite the popularity of their plan-books. The business is interesting as an example of mid-twentieth-century Dutch influence in New Zealand's prefabricated housing industry, and for its enduring privately-owned family business structure which has enabled continued investment in research and development.

${ }^{84}$ Peter Wong identified the association with standardization as an inhibitor to the uptake of prefabrication in the 1980s (77).

85 The Lockwood brand is targeted at a "niche market" for holiday home clients in the middle-to-upper price range. Houses sold in 2008 by the Plimmerton-based Lockwood franchise were in the $\$ 650-700,000$ price bracket (Tuohy).

86 The other three companies are Fraemohs (Christchurch), Interlock (Tauranga) and Organic Building New Zealand (Blenheim). The research is investigating thermal mass and interior moisture levels of solid timber products (Solid Wood).

${ }^{87}$ Access to the Lockwood Group's factory floor was denied for this research with health and safety reasons cited although intellectual property concerns are more likely to be the reason for this decision. A complete overview of their operations and how the Lockwood Group fits into the New Zealand prefabrication industry overall can not be obtained as a result. In the past, they have guarded their intellectual property closely as evidenced when they tried unsuccessfully to sue Juergen Giess for copyright infringement of its solid timber component system. Giess was an exemployee who developed the Conecta solid timber system (Giess). Refer to Chapter 2 for Conecta. 


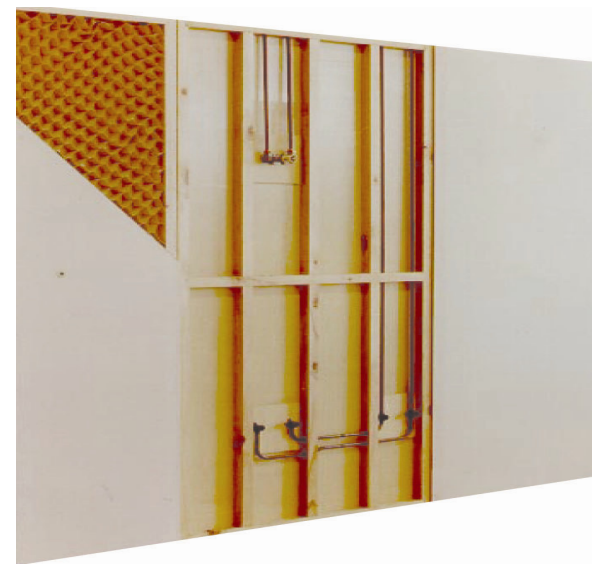

Figure 109: Trower Panel internal wall system, with honey-comb structure and plumbing revealed. Source: 'Branz Appraisal Certificate 328', September 1996.
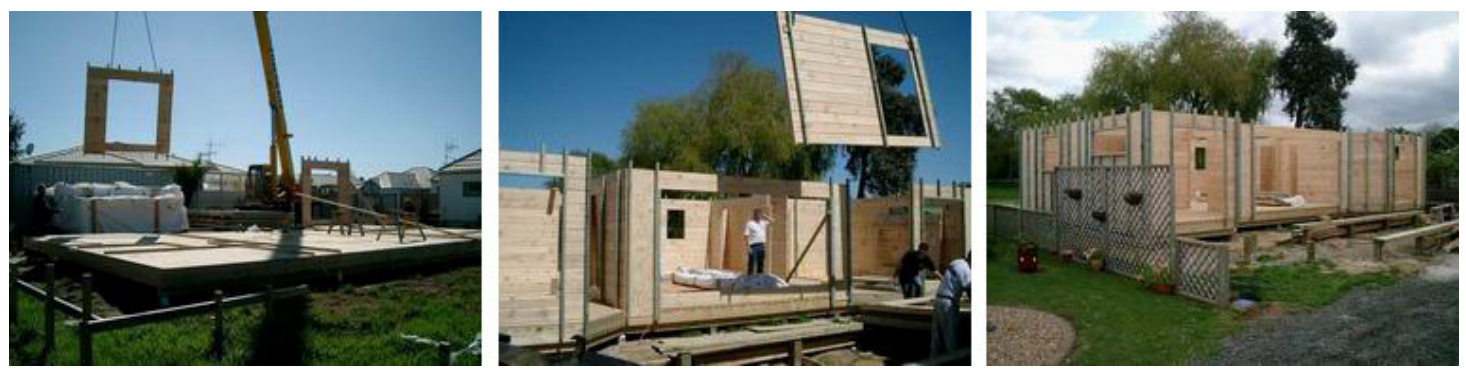

Figure 110 - 112: Touchwood wall panel assembly process at site. Source: <http://www.touch-wood.co.nz/default.asp-|D=17.htm>. 


\section{Panelised Prefab}

Prefabricated panels in New Zealand are created in a number of ways; by compressing layers of timber particles in resin, by lining and cladding a structural frame with off-the-shelf board products, by creating an insulated panel sandwich, or by casting concrete in panel forms. Juken New Zealand's Triboard and Fletcher's Maxim panel are two examples of a three-layer compressed timber panel system. Both systems have a network of re-manufacturers and installers who are licensed to construct buildings. A re-manufacturer takes the raw board from the factory, coats it with primer and cuts the walls according to design plans using CNC machinery. Site visits were made to Juken New Zealand's Triboard mill in Kaitaia, Triboard remanufacturer Durapanel Systems in Awanui, and Maxim licensed builder Laing Homes in Christchurch. Their case studies follow.

Grove Lifestyle Homes and Trower Panel are examples of businesses that manufacture frameplus-board panel systems. Grove Lifestyle Homes are supplied from a Porirua factory manufacturing pre-nailed and pre-clad wall panels together with traditional truss and framebased construction. Trower Panel specialises in interior wall panels made of reduced timber framing with a glue-pressed honeycomb cardboard core (109). The interior walling of a twohundred square metre house can be installed at the building site in a single day. Trower Panel's main factory was established in Matamata in 1967 by Tony Trower and is now run by his son John. During the construction boom of the late 1970 s and early 1980 s they supplied up to six house lots a day, but after thirty years in operation the additional Manukau facility was closed in 2006 due to increasing competition from within the larger pre-nailed framing industry (Trower).

Touchwood is a solid timber panel system screw-fixed to conventional floor and roof construction with a variety of exterior cladding options (110-112). It was started by Corgi La Grouw, the son of Lockwood's founder, after working for thirty-five years at the Lockwood Group and selling his shareholding to brother Jo La Grouw in 1998. The family operation includes Corgi's son Brooke and is aimed at a lower socio-economic market than Lockwood with house prices starting at one-hundred-and-fifty-thousand dollars ex-yard (Touchwood). The Aucklandbased firm, like the Lockwood Group, has a nationwide network of assemblers and a Rotorua manufacturing facility (“Touchwood: new options").

Structurally Insulated Panels (SIPs) are a sandwich of either exterior metal sheeting or timber composite board with a rigid polystyrene or polyurethane filling (113-116). ${ }^{88}$ Thermawise Homes supply housing within New Zealand and the Pacific Islands using paint-finished or texturecoated metal exterior SIPs and Maxim interior walls (Senior). Timber SIPs have been available for half a century to European and North American manufacturers but the technology is not yet

${ }^{88}$ Metal-based SIPs are more common in New Zealand and are used for cool-store applications by portable building companies such as 'Bondor' and 'Porta-cabin'. They have been used in a few architectural applications, such as the Cardrona Alpine Resort base building in Wanaka where they function as cladding rather than structure. 


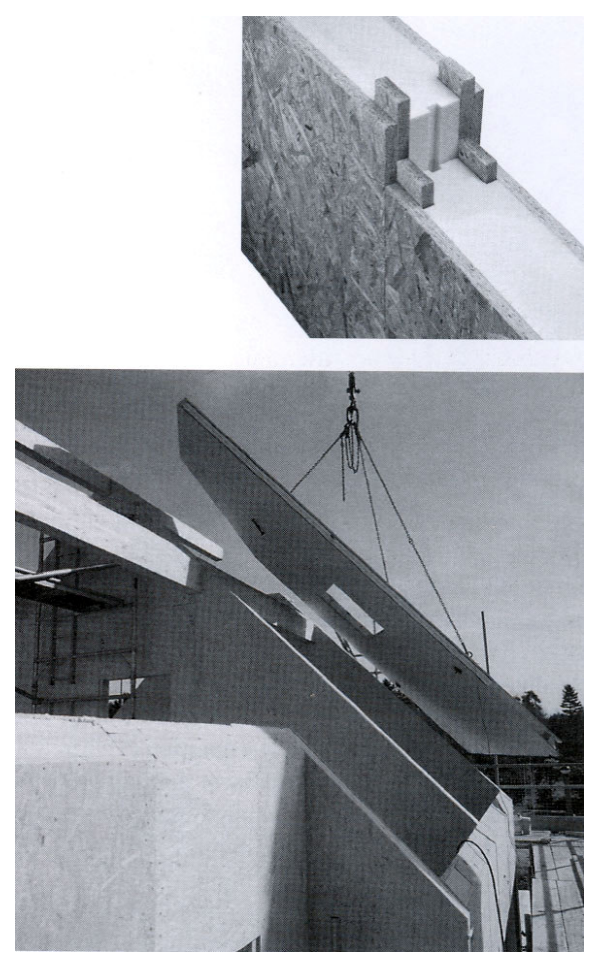

Figure 113 and 114: SIPs panel joint section and roof assembly into house under construction. Source: C. Davies, The Prefabricated Home, London: Reaktion, 2005: 149.
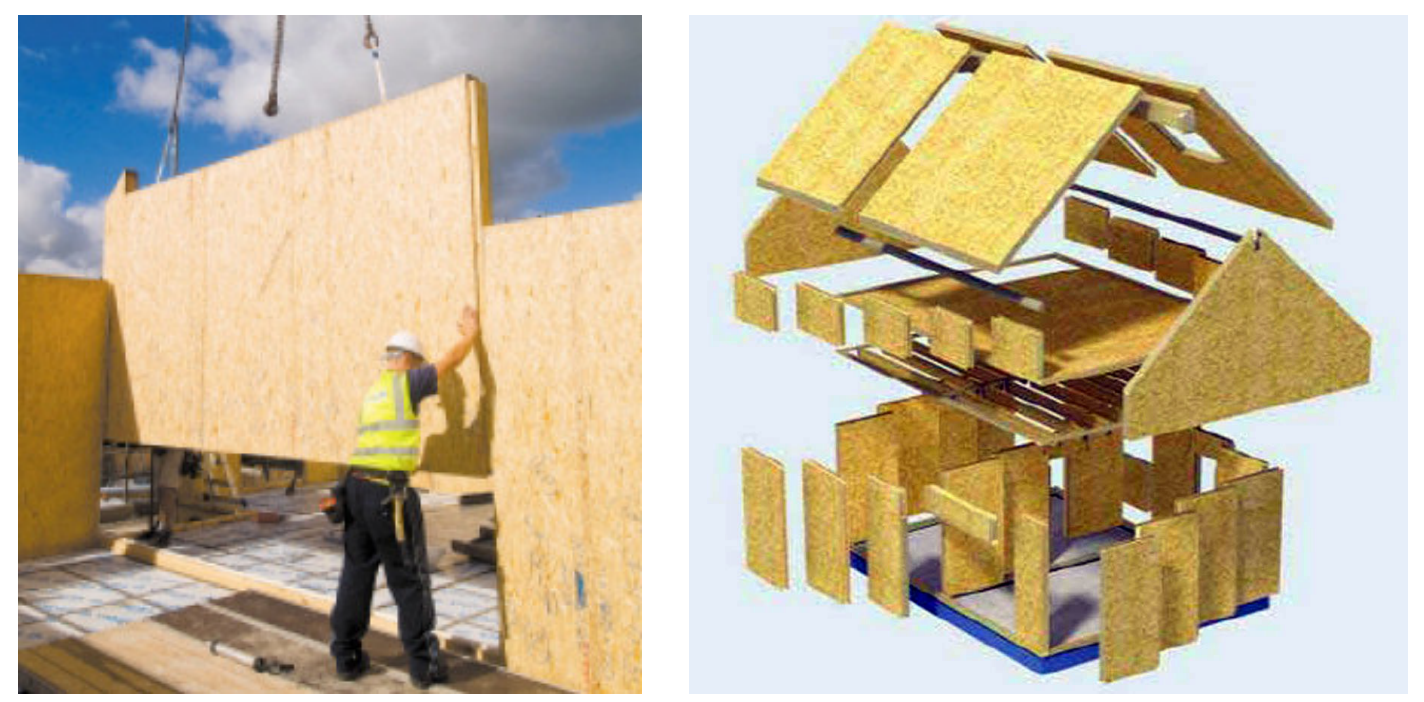

Figure 115 and 116: SIPs panel installation and complete house assembly diagram. Source: <http://www.tek.kingspan.com/uk/building_process.htm>. 
widely available in New Zealand, despite Juken New Zealand having recently started developing and manufacturing oriented strand-board (OSB) as used overseas.

Research into timber-based SIPs was carried out in the early 2000s with the aid of a Foundation for Research, Science and Technology (FoRST) grant by Carter Holt Harvey's Fibre-gen thinktank on a product dubbed Tuffbuild, but its lifetime was short and information is scarce which points to a lack of successful development outcomes. ${ }^{89}$ Architectural SIPs applications are currently being researched by a team led by architecture lecturer Jacqueline McIntosh of Victoria University of Wellington's School of Architecture and Design, as well as individuals in the construction industry. ${ }^{90}$ Researcher Mark Harrington identifies challenges such as sourcing the insulation product, building standards compliance and a construction industry culture that favours low capital expenditure and higher operating costs. Individual researcher and contractor Bruce James claims the viability of timber SIPs hinges on determining the strength of adhesives used between the timber and insulation. These must comply with government legislation for fifty-year building durability, but testing is thwarted by a lack of international-standard laboratories in New Zealand. There is a need for an independent product certification system similar to that used in Australia (James).

Precast concrete panels are manufactured in factory conditions, as opposed to tilt-up panels which are made at the building site. There is considerable competition between tilt-up and precast manufacturers with precast claiming that the additional cost of factory fabrication is offset by the quality and time-savings gained. Precast also offers inherent finishing options and interesting shape and texture possibilities as a result of factory-controlled casting (Gjerde 57) (117-119). The precast industry is well-established and represented by Precast New Zealand, an incorporated society with twenty associated precast concrete companies that function together to exchange information and foster research and development.

Precast panels are used in Europe and the United States, but are not used much in New Zealand housing due to our historical affinity with timber construction, dominance of the housing industry by Carters and Fletchers, and the socio-cultural need of consumers to have individual house differentiation (Kirby and Leach). Current uptake is only about one-to-two percent of individual manufacturers' output, the rest being used by commercial construction (Beavis). The houses that are being built using precast are high-quality top-of-the-range architect-designed homes (Beavis; Freeman). Relegation to this market segment is because of the additional costs due to custom design, architect and engineering consultant fees, and crane hire, despite cost savings from quick site-based assembly. For costs to come down and wider market accessibility to open up, more standardisation and repetition would need to occur (Freeman).

89 Tuffbuild possibly came to market for a short time, a housing group Lifestyle Homes may have been set up, and some homes were built in conjunction with Waikato University (Banks; Porou). $\mathrm{CHH}$ is considering investigating SIPs again, but a research programme would not be underway until after the current recession (Wakefield).

90 Jacqueline Mclntosh and Mark Harrington have identified potential in New Zealand-developed Biofoam (Biopolymer Network) and Agriboard (Agriboard Industries) to make BioSIPs using oil-based soy foam or carbon dioxide foamed polymer. 

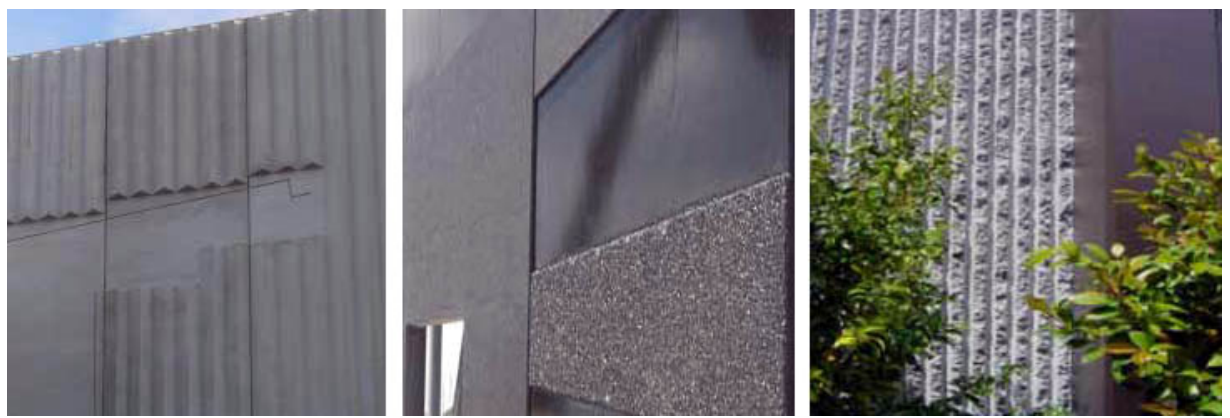

Figure 117 - 119: Examples of precast concrete texture options from factory-controlled casting. Source: <http://www.wilcoprecast.co.nz/>

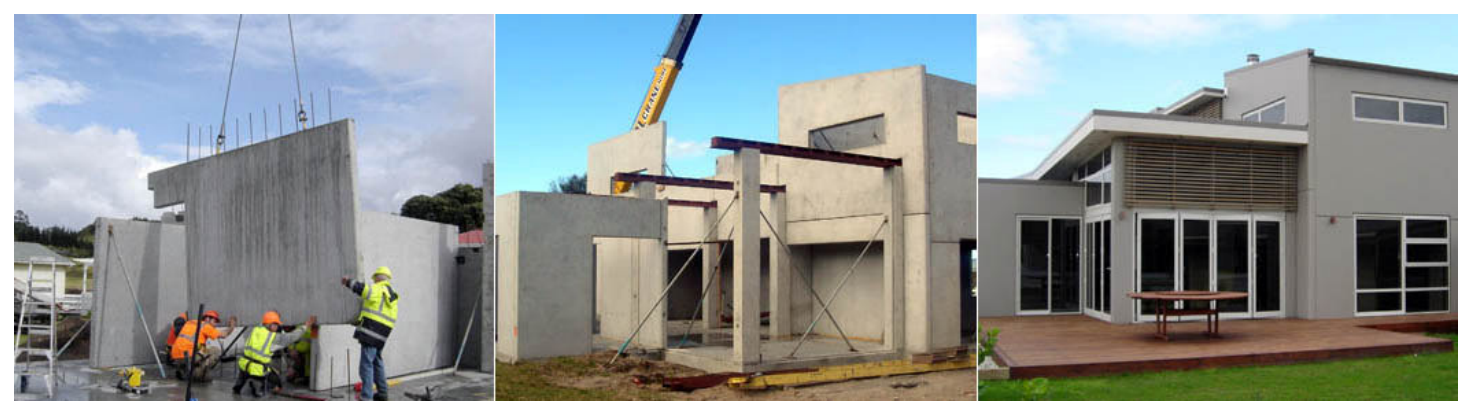

Figure 120 - 122: Wilco's Litecrete precast concrete panels assembled in residential construction. Source: <http://www. wilcoprecast.co.nz/>.

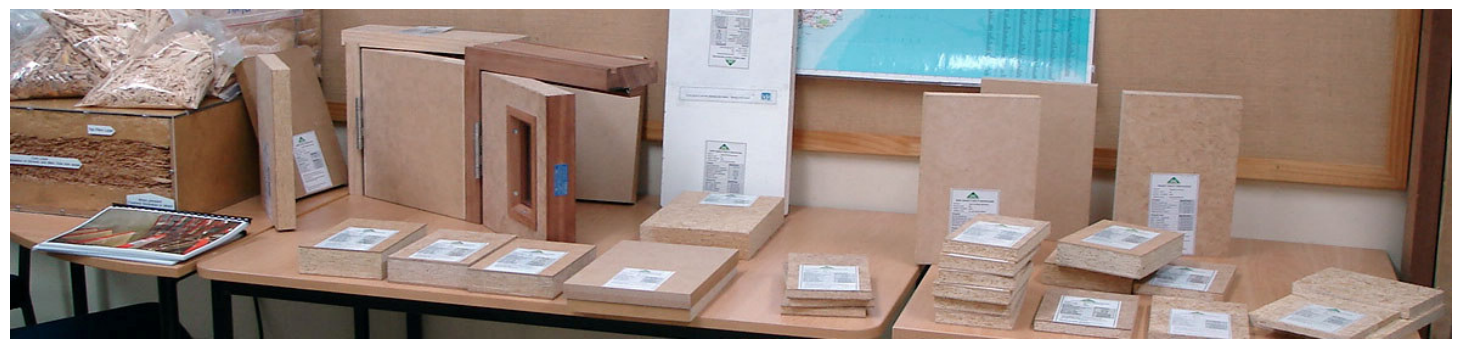

Figure 123: Juken New Zealand timber board products displayed at Kaitaia mill. Source: Author's photograph, 2008. 
There is potential in new material advances of insulated sandwich systems, such as Thermomass, and light-weight precast panels that use pumice as aggregate, such as Wilco's Litecrete (120-122). Precast insulated sandwich panel systems use a thick structural internal concrete wall tied to a thin exterior concrete façade with high-strength non-conducting glassreinforced-plastic anchors that span the polystyrene insulation filling. Thermal isolation ensures thermal stability, reduced condensation, and reduced lifecycle costs (Freeman).

\section{Triboard by Juken New Zealand (JNL) - Kaitaia}

The Northern Pulp timber mill was established in Kaitaia in 1987 and bought by Japan's Juken Nissho in 1991. JNL went on to purchase forestry licenses, double production with a second line, and establish mills in Gisborne and Masterton. Historically, the Kaitaia mill has supplied eighty percent of its output to the Japanese market, and is only recently looking to local and Pacific markets since Japan's demand has reduced. The parent organisation has supported an extensive research and development programme enabling over two-hundred different product code types to be created. Compressed timber sheet products include strand-board, oriented strand-board (OSB) and Triboard (123). ${ }^{91}$ The non-restrictive research budget reflects the parent company's strong culture of innovation and the long-term outlook of private ownership which means they do not need to answer to short-term shareholder demands (Richardson).

Triboard is a structural panel system consisting of a three-layer composite board of strand core and fibre surfaces made by soaking wood chips in resin and compressing them into four metre long moulds resulting in finished panel thicknesses between ten and one-hundred millimetres (Juken NZ). ${ }^{92}$ It is re-manufactured by associated companies outside of JNL, such as Durapanel Systems where it is primed, cut and routed according to design (see following case study). It is used for floors, walls and ceilings with dual functions of structure and surface, in place of traditional timber framing and plasterboard. ${ }^{93}$ For this reason, it saves time at the site and decreases footprint by six percent due to its reduced wall thickness (Semenoff).

The construction process is significantly different to traditional methods, in that the house is built from the inside-out. The thirty-six millimetre thick wall panels are lifted into place by crane, Hiab or manually and then butted against each other for stability prior to an eighteen millimetre thick ceiling panel completing the structural diaphragm bracing. Traditional roof trusses, insulation and external cladding complete the house. Alternatively, with the insertion of a ridge beam, Triboard ceilings can be raking to achieve a variety of spatial experiences.

$91 \mathrm{JNL}$ is one of only two suppliers of OSB in the southern hemisphere, the other being in Chile (Semenoff).

92 The fibre surfaces can be low, standard or high density and are typically two-to-three millimetres thick with the inner strand core making up the remaining thickness (Semenoff).

93 Triboard panel can be used as the sole structure in the construction of one or two-storey houses. Multi-storey buildings must use traditional methods for the lower levels, such as timber framing, concrete or Hebel block (Semenoff). 


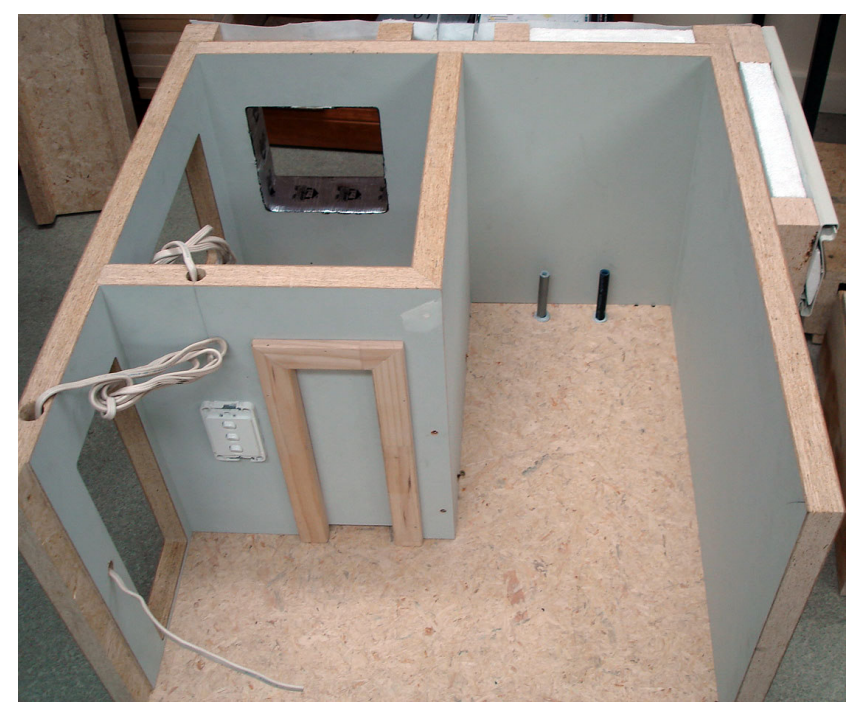

Figure 124: Triboard model showing cladding, plumbing and wiring details. Source: Author's photograph, 2008.
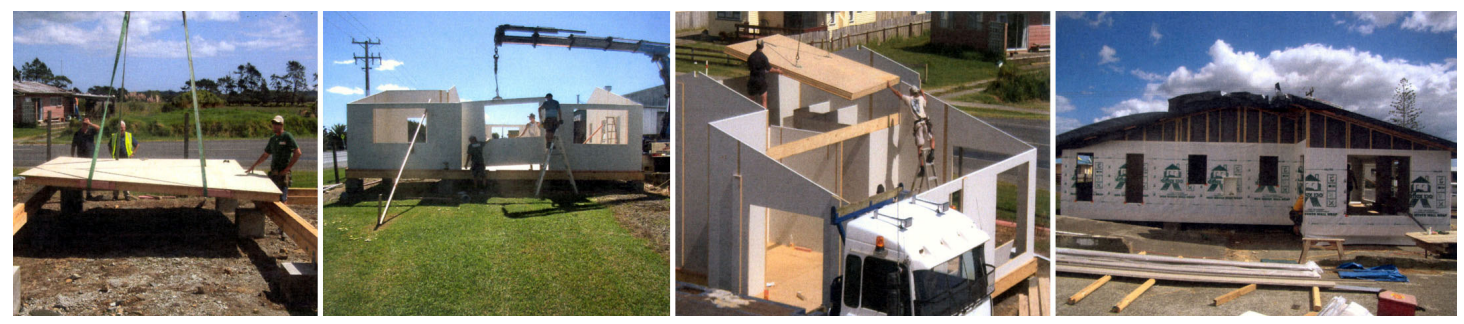

Figure 125 - 128: Triboard House assembly: stressed-skin floor panels, Triboard exterior and interior wall panels, stressed-skin ceiling and roof panels, and exterior battens, insulation and waterproof membrane prior to cladding. Source: Images courtesy of Juken New Zealand

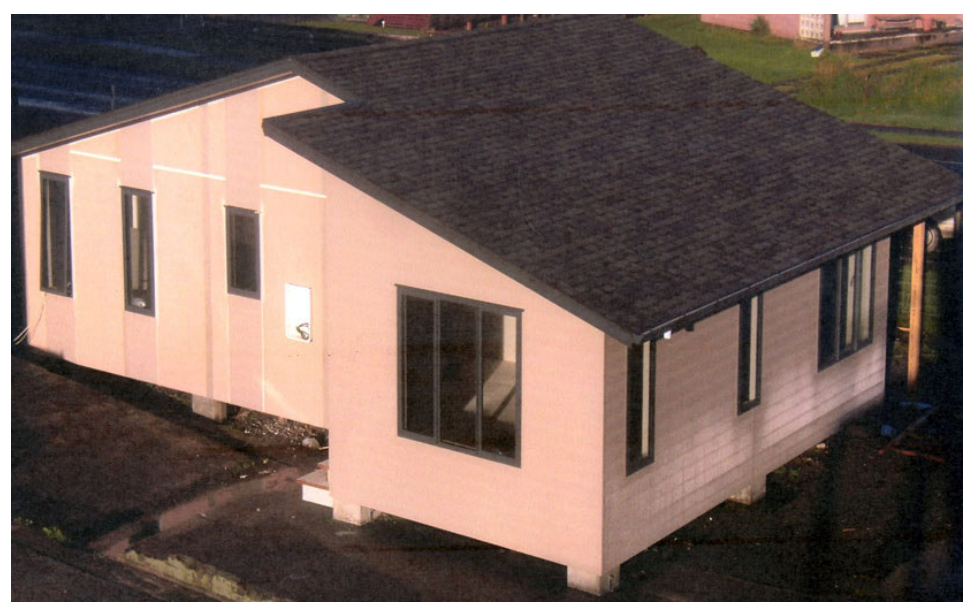

Figure 129: Completed Triboard House at Awanui, 2009. Source: Image courtesy of Juken New Zealand. 
Triboard walls are more durable than traditional plasterboard walls, but they lack acoustic insulation and space for ducting. Plumbing fixtures must be backed onto external walls or cabinetry, plumbing pipes are run through sub-floor cavities, and electrical conduits are routed into wall panels (124). There is very little wastage, with door leafs reused when cut from their wall panels, and window opening off-cuts being reused as cabinetry shelving (Semenoff).

JNL's ongoing emphasis on research and development has led to the design of a threebedroom Triboard House for the starter home market priced at less than one-hundred-thousand dollars. ${ }^{94}$ It has been designed using as many of their in-house materials as possible in order to control costs and supply. Strand-board stressed-skin panels have been designed for floor and ceiling, laminated veneer lumber (LVL) studs and battens, and Triboard exterior wall panels with insulation pre-installed (125-128). The planning is based on a four metre module to coincide with the Triboard panel sizing and to reduce plastering costs. A show-home was completed at the Durapanel site in mid-2009, and took only seven days to close-in and become weather-tight (Semenoff) (129).

Challenges for JNL's Triboard in New Zealand have included competitor imitations and traditional construction industry resistance. The competing three-layer pressed composite Maxim board was developed by Fletchers in 1996 at The Laminex Group plant in Taupo, and the rights for re-manufacture have changed hands several times, now being held by Maximpanel in Huntly (refer to Laing Homes in Complete Buildings section). The dominance of New Zealand's construction industry by Fletchers and Carters makes it extremely difficult for non-traditional materials and processes to become accepted (Semenoff). Despite these stumbling blocks, nearly four hundred homes are built each year by Triboard and Maxim installers (Semenoff; Savage). ${ }^{95}$

These challenges highlight the need for tight intellectual property control and marketing that is both consistent and effective. JNL's future focus is on developing reduced-emission products for new local and Pacific markets. Already there has been interest from an Australian consortium for cost-effective Triboard housing supply to Papua New Guinea. A weakening Japanese market and New Zealand industry resistance has made JNL aware of a need to market their products more effectively. It has been identified that they need to complement their participation at industry exhibitions by starting a direct dialogue with the design profession, government and educational institutions, but there are no plans for this as yet (Parrant; Semenoff). ${ }^{96}$ The key lesson to be learnt from JNL is their emphasis on research and development.

94 The development of the Triboard House is together with Opus International architects and engineers and JNL's Australian distributor and architect Lloyd Parrant. Opus Architects entered the Triboard House in the Department of Building and Housing 'Starter Home Design' competition but it didn't place (Semenoff).

${ }_{95}$ Over two-hundred-and-fifty Maxim homes are built each year through their network of thirty builder-installers (Savage). Triboard homes built in 2008 numbered up to one-hundred-and-twenty-five (Semenoff).

96 JNL has exhibited at BuildNZ / Designex (Auckland 2007) and Southern Build (Christchurch 2008) (Semenoff). Parrant is already speaking to building science and construction students at Australian universities but despite being an architect himself, he has not identified architecture students as recipients for these sessions. 


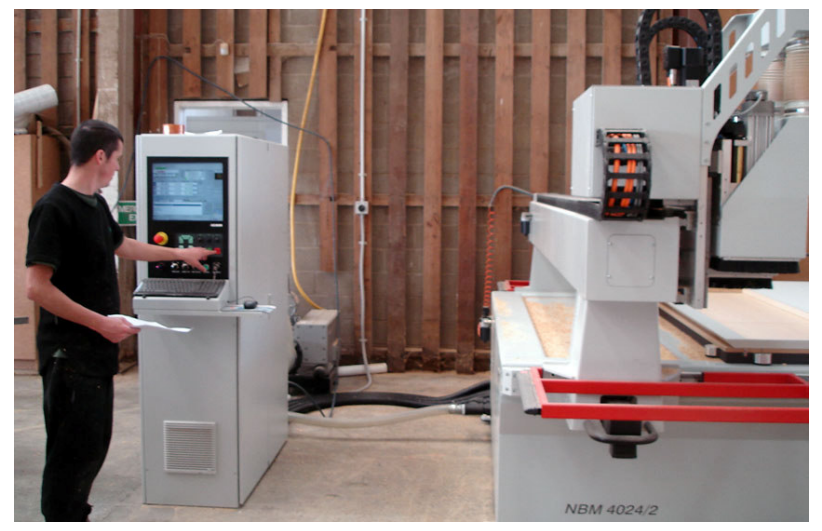

Figure 130: Computer numerically controlled (CNC) machinery at Durapanel, Awanui. Source: Author's photograph, 2008.
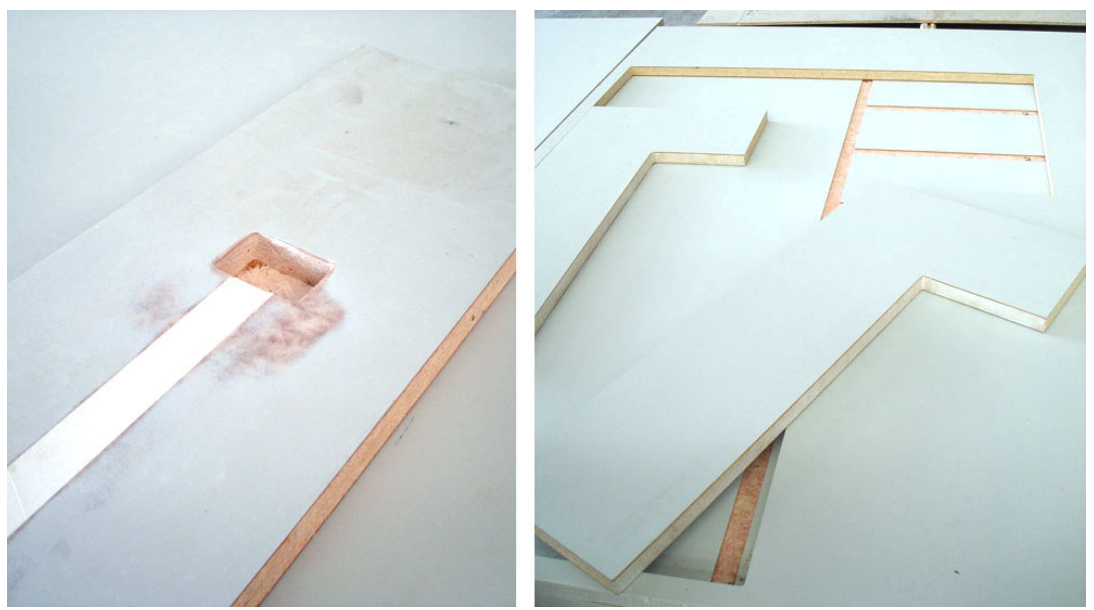

Figure 131 and 132: Detail of wiring duct with plastered filler and, and pre-cut shelving from Triboard wall panels. Source: Author's photographs, 2008. 


\section{Durapanel Systems - Awanui}

Ian Stewart established Durapanel Systems in 1994 after experience as a Triboard remanufacturer with Woodstock Homes. Durapanel has been steadily growing ever since, with acquisitions of surrounding factory buildings, a new spray booth, and CNC machinery (130). More factory expansion is planned, partly due to the increased shareholding by a Southland dairy businessman and Triboard re-manufacturer. Durapanel takes JNL's raw product, applies primer in its spray booth, uses a vacuum lifter to transfer it to the CNC laser-cutter, then numbers, stacks, straps and packs the panels as a kitset for transport (Stewart) (131-132). ${ }^{97}$

Durapanel has a close working relationship with JNL; it is one of the members of its accredited re-manufacturers group, the Association of Triboard Remanufacturers of New Zealand (ACTRANZ), and benefits from initiatives such as the Triboard House development and potential offshore relationships. Current high demand from New Zealand's dairy industry has buoyed Durapanel's fortunes, enabling repeat business and satisfied customers. Challenges ahead will be from changing building code compliance, as well as shifting economic conditions that affect housing demand. The support of JNL through sourcing housing contracts and performing marketing functions will become critical during these times.

\section{Modular Prefab}

New Zealand does not have an established modular housing industry like that in the United States. Most businesses using the modular term are merely inspired by modular planning rather than modular construction methods. However, there are multi-unit modular developments constructed by Stanley Modular (a division of the Stanley Group) from their Matamata factory. Modular bathroom pods for multi-unit housing and hotels are made by De Geest Construction from Oamaru in the South Island and by Phillip Leather Builders (PLB) Construction Group from Huntly in the North Island. De Geest Construction was established in the 1950s and supplied prefabricated components and transportable housing before embarking on modular bathroom units. They are New Zealand's primary example of utility pod manufacture, and their case study follows.

Stanley Group established its Modular division from plant and factory that was originally Carters Modular in 2004. They completed a major multi-unit refurbishment project at the Chateau Tongariro in mid-2005 using a similar method to that used in the United States modular industry, where factory-produced units are wrapped and trucked to site, then craned and fixed into place. The modular approach was chosen to adhere to strict Department of Conservation constraints and to avoid extreme alpine weather conditions. Other projects include architectdesigned multi-unit accommodation projects in Napier and Whitianga, as well as schools in Ruatoria and Albany (133-135). Stanley Group's international focus will see them join the United

${ }_{97}$ Durapanel also supply pre-nailed trusses and framing for local contractors using the Mitek Gangnail system, as well as a small amount of at site construction work (Stewart). 

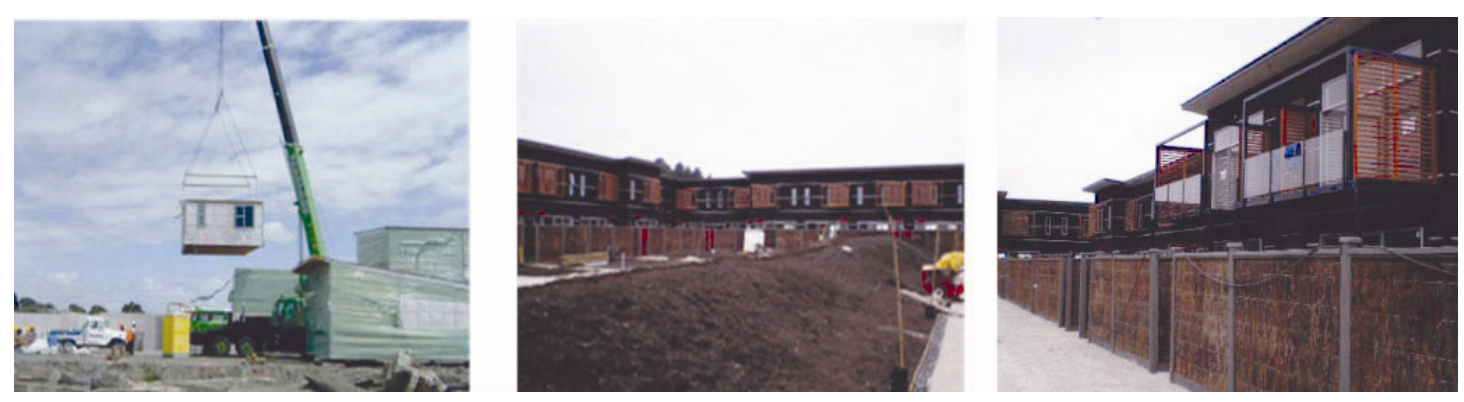

Figure 133 - 135: Stanley Group's 'Ahuriri Quadrant' multi-unit residential project, Napier 2006.

Source: <http://www.stanleygroup.co.nz/page/60-Case-Studies+Ahuriri-Quadrant/>.

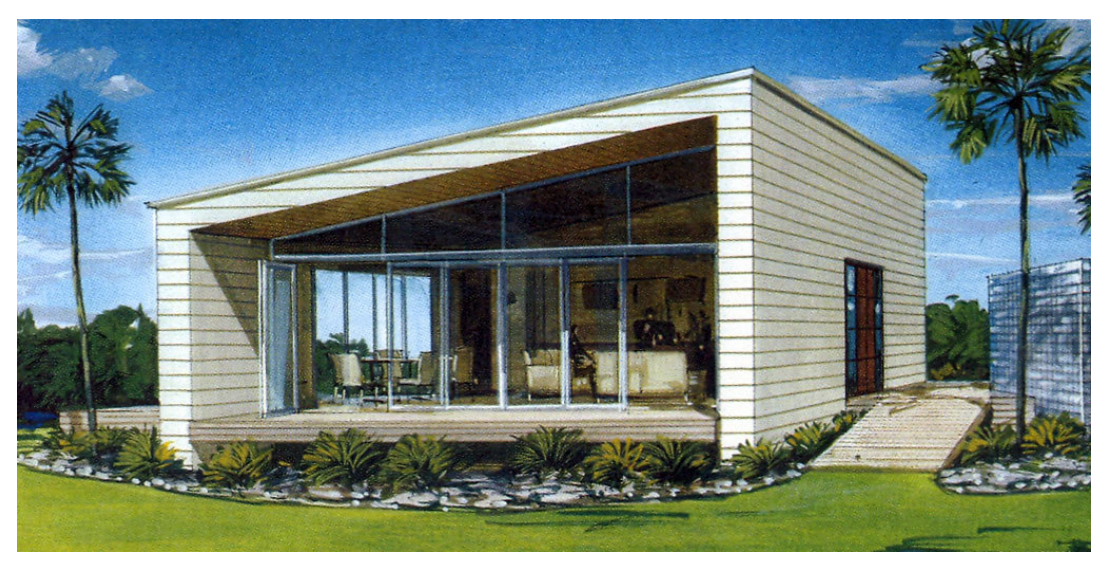

Figure 136: Mod-pod by Haven.

Source: Mod-pod postcard courtesy of Haven.
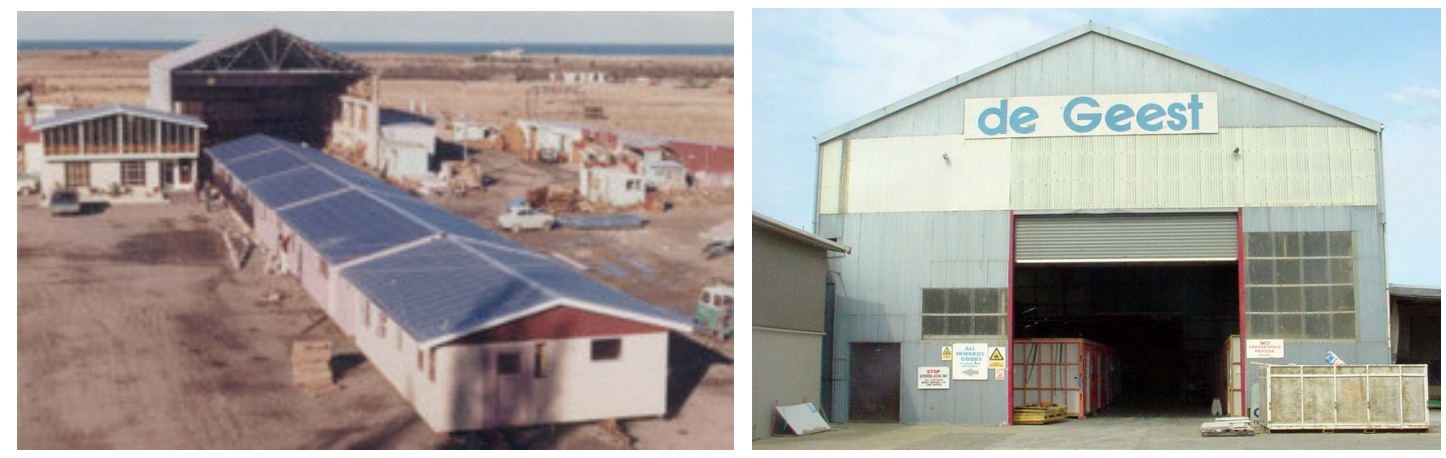

Figure 137 and 138: The De Geest Construction factory in Oamaru, 1974 and 2008.

Source: <http://www.degeest.com/09/history.html> and author's photograph. 
States Modular Building Institute (MBI) and potentially collaborate with London-based Verbus Systems on a hotel in Auckland. Verbus Systems currently manufactures modules in China for accommodation markets around the world (Caulfield). Stanley Group is currently participating in panel development as part of the 'Composite Structural Assemblies' research programme managed by Rosemary Scofield at the Heavy Engineering Research Association (HERA). Tertiary organisations Unitec and Auckland University are also involved, and the overall programme has funding from the manufacturing arm of the Foundation for Research, Science and Technology (FoRST) (Scofield). ${ }^{98}$

Haven's Modular Pod series was launched at Auckland's Home Show in 2002 as a result of collaboration between contractors Haven, and designers Red Turtle and CTM Architectural (Haven) (136). The use of the word modular is misleading, as the original design intention was for modular planning where additional volumes could be added according to client demand. While this has not come to fruition, they have successfully built about ten homes to date, each as variations of the original design. Prefabrication is not their current standard mechanism but it is seen as the way of the future due to affordability issues (Millington).

\section{De Geest Construction - Oamaru}

Albert de Geest was a Dutch émigré who established his South Island construction business in 1955. In 1969, despite public derision, he built a concrete-framed factory in Oamaru in which it was large enough to build complete houses $(137-138) .{ }^{99}$ This enabled the business to move from prefabricated bridge-beam components to the supply of nine-hundred houses for 1970s power schemes in the central South Island (De Geest Construction). A trip to Europe provided the inspiration to supply houses as flat-pack components together with bathroom and cabinetry volumes to Cromwell for the Upper Clutha Power Scheme (de Geest). This is an early example of hybrid prefabrication in New Zealand.

In 1983 De Geest built their first bathroom modules for a motor inn at Te Anau. Since that time they have supplied over seven-thousand-five-hundred utility pods to office and accommodation projects around the country and offshore to Australia and Vanuatu. The mid-1980s boom years saw De Geest factories set up in Otaki and Huntly, and ended when the 1987 sharemarket crash forced a retreat back to Oamaru. During this time they experimented with exporting houses to Japan and Venezuela as panelised components stacked flat into a shipping container, as well as a panelised indoor-ensuite for use in renovations (139). Albert's son Brian also came on board and introduced direct marketing to architects and contractors through office visits and presentations. Today under Brian's leadership, De Geest Construction is primarily a

98 The research programme findings were not publicly available at the time of writing this thesis.

${ }_{99}$ The initials of Albert de Geest and his brother John de Geest along with the year 1969 are marked in the factory's concrete structure. There is no mention of John's involvement in the business on the website's history and Brian de Geest did not mention his input so his contribution is unclear. 

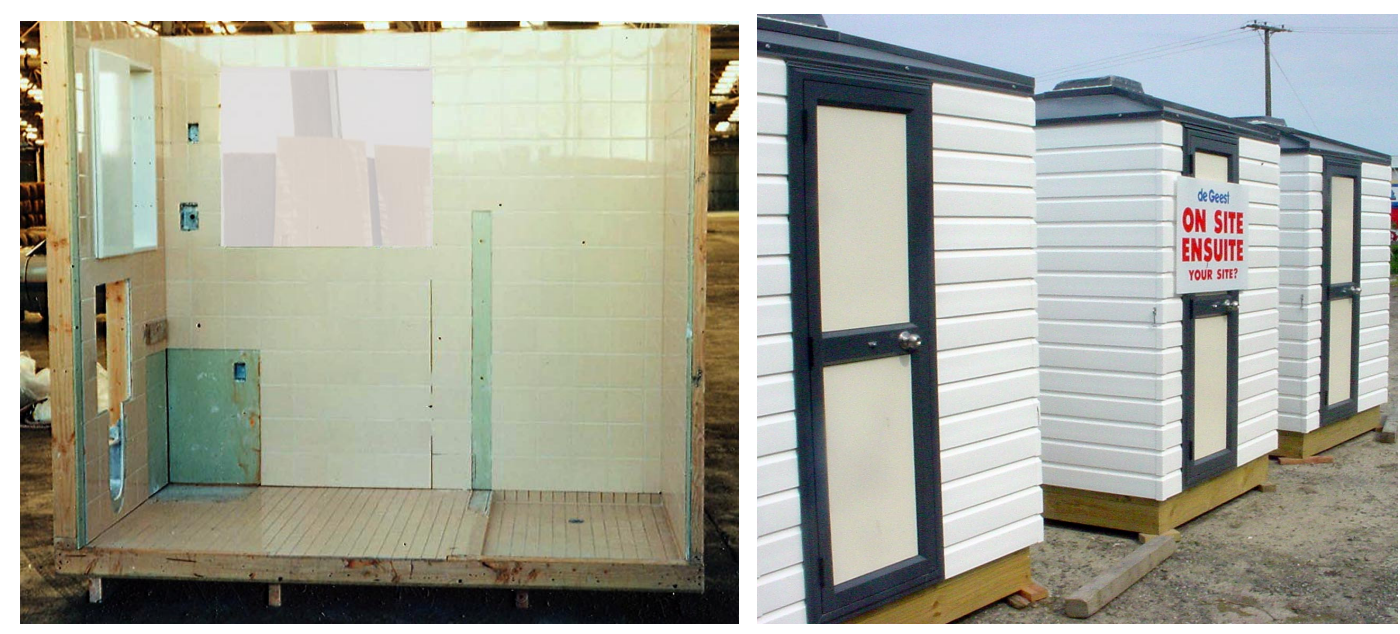

Figure 139 and 140: Indoor Ensuite under construction in 1980s, and Onsite Ensuite models in yard today. Source: Photograph courtesy of Brian de Geest, and author's photograph, 2008.

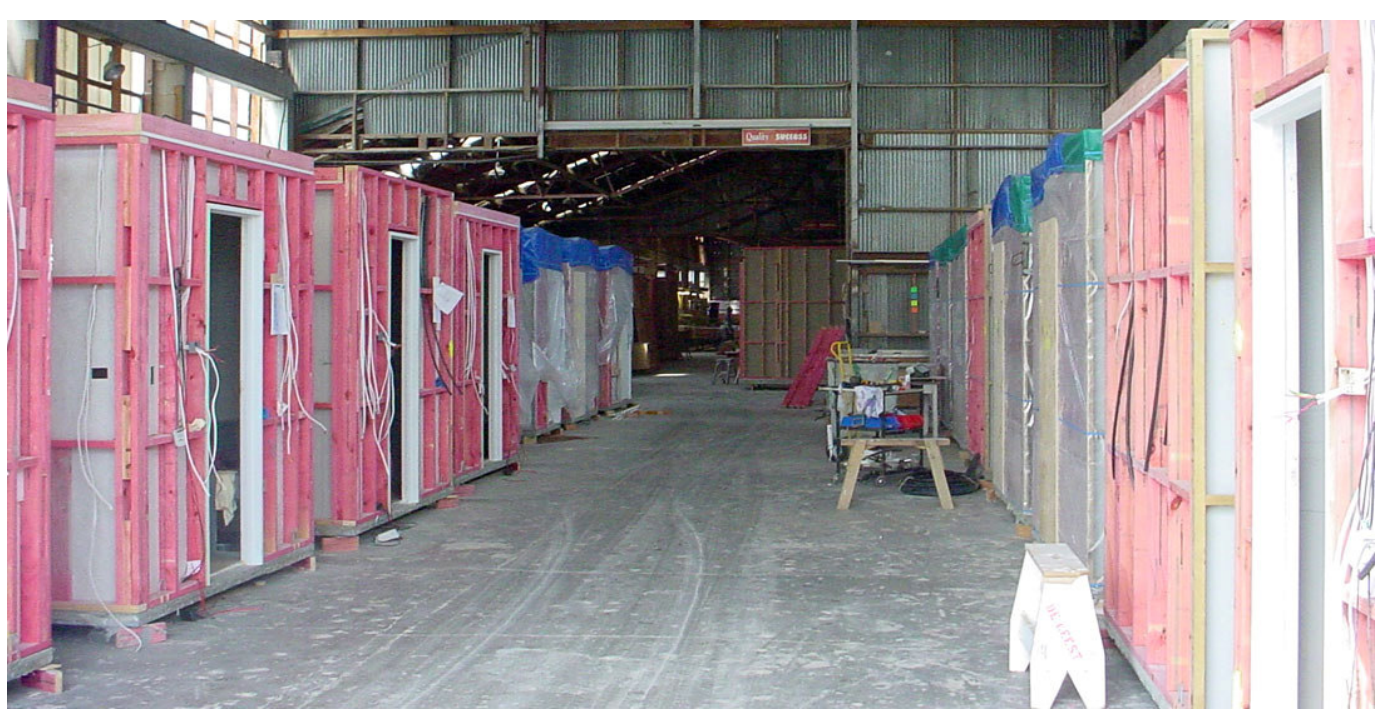

Figure 141: Bathroom modules during construction at De Geest Oamaru. Source: Author's photograph, 2008. 
commercial construction company with bathroom module production making up to half the workload depending on demand (de Geest). ${ }^{100}$

The bathroom module construction process begins with prototypes which are tested and inspected by clients before further production commences. Once approved, the units are built from the floor-up on the factory floor using traditional construction methods (141). Concrete slabs are contracted near-by, modules are moved by forklift from station to station where up to twelve different trades work on them, panels are cut by hand-controlled machinery, components are painted in the factory spray booth, and the completed unit is security-sealed, plastic-wrapped and plywood-braced prior to travel. Once at site, the first module is supervised by De Geest staff as it is lifted into place, secured, and connected to each of the major services, before handover to the project management. Minimal remedial work is required due to the high-quality and minimal tolerances achieved in being built away from the site (de Geest).

De Geest Construction has been enduringly successful with over fifty years in business. This wealth of experience has assured them market dominance in the supply of bathroom modules, despite their traditional construction methods. Challenges that they currently face include customer misperceptions, the traditional tender process and safeguarding intellectual property. Adverse consumer misperceptions are of low-quality materials and workmanship and reduced choice due to standardized designs. For these reasons Brian de Geest prefers the term pre-built despite the website also using the phrase 'prefabricated solutions'. The traditional construction tendering process does not quantify savings in time, which makes it difficult to accurately compare site-based to pre-built work. Most quantity surveyors are not familiar with this complexity so it can be difficult to educate the industry as a result (de Geest). Intellectual property is vital to the success of De Geest, with forty-two years of knowledge held by the key factory manager. There are potential risks in this arrangement until the knowledge is documented and protected, as this information is of economic value. One option is for potential competitors to purchase that information, and Brian de Geest envisages a future where a larger construction firm will purchase De Geest's modular business as a clip-on operation. ${ }^{101}$

De Geest is currently protected by the large start-up costs that potential market entrants face. Their market dominance means that they now receive requests from around the world for multiunit projects requiring bathroom modules. Brian de Geest is planning on re-visiting his 1980s direct marketing approach; this time it will be to project managers and developers which indicates a power shift away from architects and contractors. The appeal to developers is the ability to save money by reducing a project's timeframe, as well as off-loading risk to an offsite supplier providing a workmanship warranty (de Geest). De Geest regularly receive queries

100 The De Geest Construction business is further diversified beyond bathroom modules and construction. They also have a range of site-based ensuites for lease or purchase for camping grounds and motels, and are involved in crane hire, land development and restaurant ownership (de Geest) (141).

101 This almost happened in the mid-1990s when Hardies Australia enquired about purchasing the technology, but the process didn't go any further than that (de Geest). 

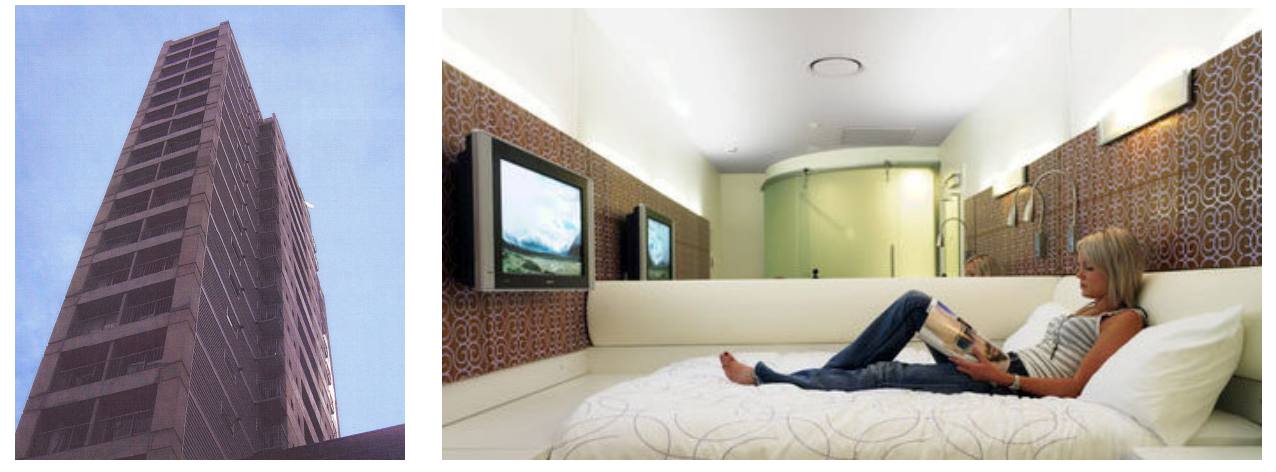

Figure 142 and 143: Formule 1 Hotel, Auckland, and Hotel SO, Christchurch.

Source: Image courtesy of Maxim Panel and <http://www.hotelso.co.nz/Rooms>.

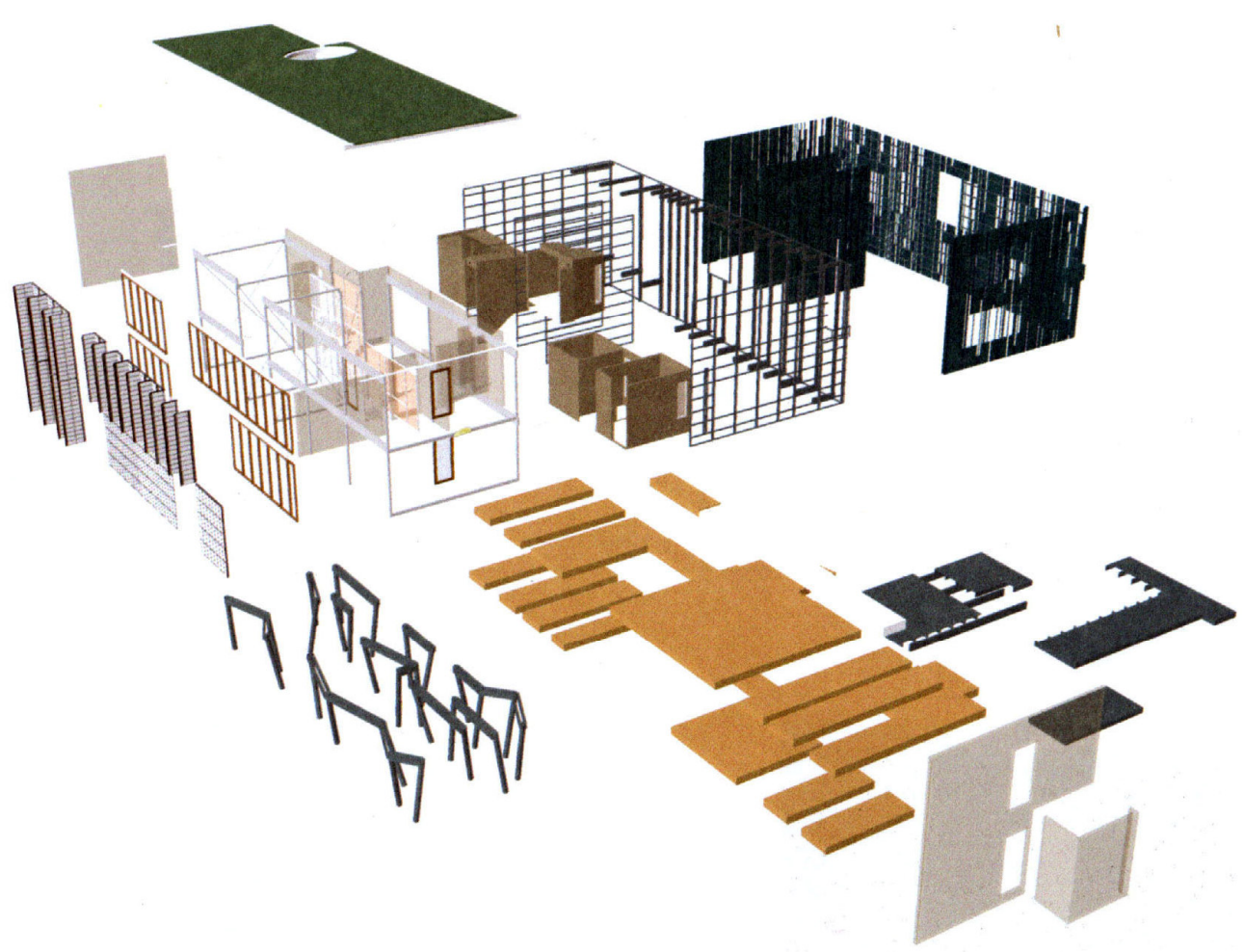

Figure 144: Loblolly House by KieranTimberlake: hybrid prefabricated element assembly diagram. Source: S. Costa Duran, Green Homes, New York: Collins Design, 2007: 110. 
regarding kitchen production, but will not branch out into this area as there is a lower labour content and subsequent margin. Kitchens are already largely prefabricated as either flat-pack or modular cabinetry, but De Geest will install services in a bathroom module if it backs onto a kitchen area. The business is not looking to employ CNC technology or improve current traditional operating systems because of the comfortable niche it inhabits and the limited market demand in New Zealand, despite numerous enquiries from offshore.

De Geest is one of New Zealand's most successful prefabricators, whether measured by units produced or by commercial and historical longevity. A company that began from Dutch heritage and the foresight of an entrepreneurial individual, De Geest gained a foothold through government-funded hydro schemes, and has since adapted into a versatile niche prefabrication provider through clever marketing and product specialisation. As Brian de Geest sees it, "success is when people understand the quality of pre-built solutions".

The business has a role in re-educating the industry about the quality benefits of prefabrication and their triumph is evident in the testimonials by client-developers on the De Geest website. Their achievements are due to diversification which enables fluctuating prefab demand to be easily managed, retaining intellectual property through holding onto key employees and a willingness to directly communicate with the industry.

\section{Hybrid Prefab}

There are currently no examples of hybrid module-plus-panel housing being produced in New Zealand, although there are several designs proposed. There are two multi-unit accommodation examples: Christchurch's Hotel SO inserted Japanese modular bathrooms into their conventional building refurbishment and Auckland's Formule 1 hotel contains modular bathrooms by PLB Construction Group within Maxim panel internal and external walls set into a concrete structural frame (McCaw; Savage) $(142-143) .{ }^{102}$

International exemplars are only just emerging into reality from the imagination of architects. They include the well-documented Loblolly House by United States architects KieranTimberlake and System 3 by Austrian architects Oskar Leo Kaufmann and Albert Ruf. Loblolly contains three system-intensive modules within a pre-cut aluminium framing system enclosed by floor, ceiling and wall panels. The modules contain bathrooms, mechanical rooms and closets in various configurations, with the kitchen being installed at site $(3,8,12,13$ and 144).

System 3 is based on a central container-sized utility core containing kitchen, staircase and bathroom, together with panelised floor, wall and roof sections that make up the living area (145). The combined use of modular and panelised existing technologies increases potential economic

${ }^{102} \mathrm{Hotel} \mathrm{SO}$ is currently investigating prefabrication of entire hotel rooms for their next construction project (McCaw). 


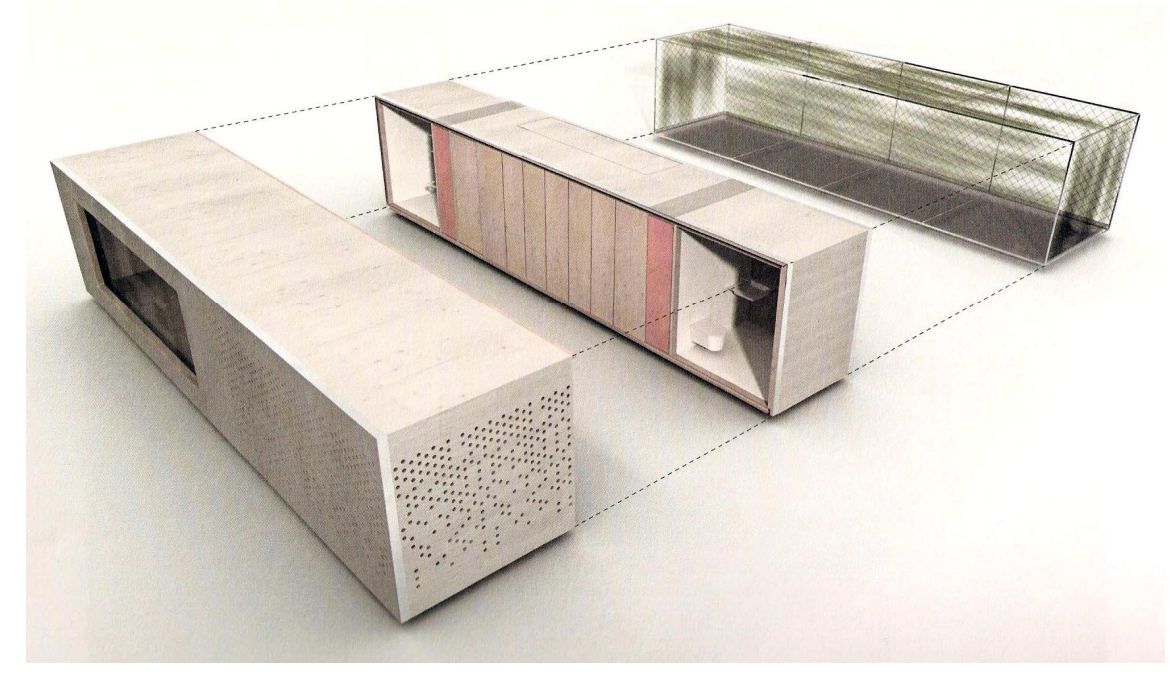

Figure 145: Oskar Leo Kaufmann and Albert Ruf's System 3: panelised living, central utility module and site-built courtyard.

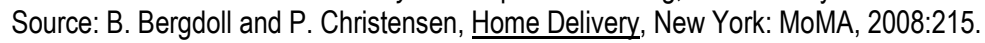

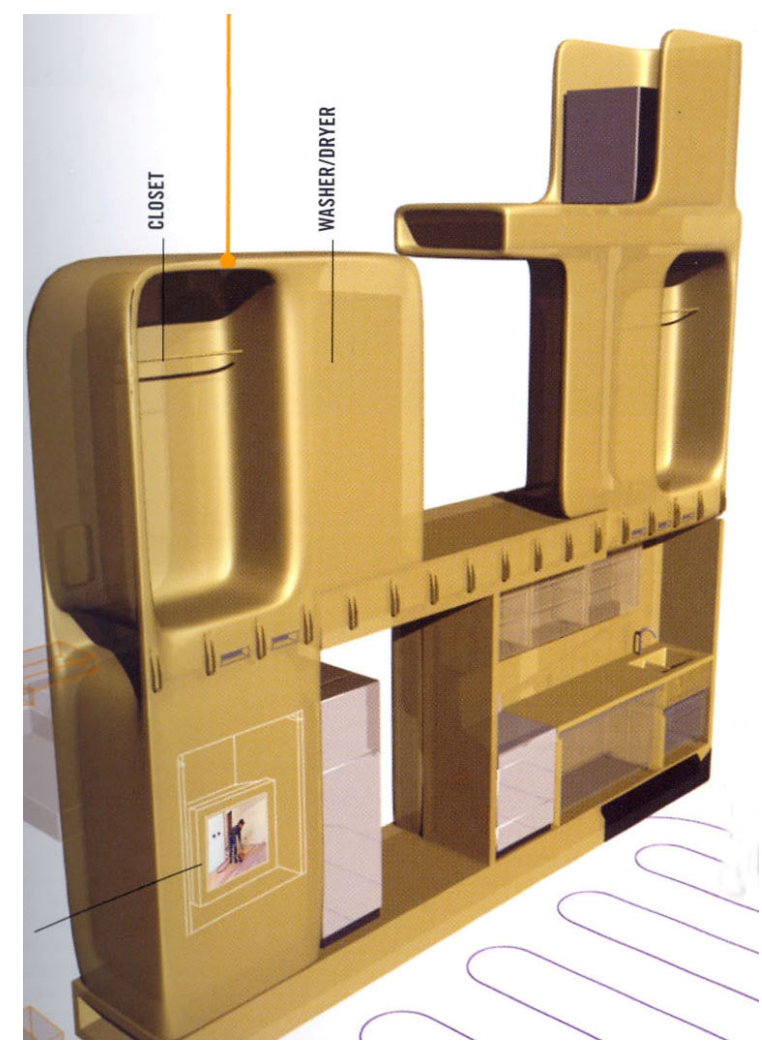

Figure 146: Gradient House's two-storey prefabricated volumetric utility wall. Source: D. Brown, The Home House Project, Cambridge: MIT UP, 2004:25. 
feasibility as well as collapsing the division between module and panel manufacturers in international prefabrication industries (Bergdoll).

United States architect Beth Blostein entered her Gradient House design in the 2004 'Home House Project' (146). It consisted of a green-house frame, translucent polycarbonate panels with shade-cloth and a recycled-plastic moulded system wall containing plumbing, ventilation, electrical, closets, cabinetry and appliances. It did not make the finalists in the competition but it does provide another example of a hybrid module-plus-panel system (Brown 34).

Closer to home, Wellington's Herriot and Melhuish Architecture designed their Module 1.2 entry into the Department of Building and Housing's 2008 'Starter Home Design' competition as a hybrid module-plus-panel system. The utility module contains kitchen, bathroom and laundry, with proposed bio-SIPs panels made of plywood and soy-oil foam. Although making the final short-list of twenty entrants, the bathroom was deemed to be too small by the judges, prohibiting the project from making it into the top finalists (Melhuish).

The lack of established New Zealand residential examples raises a question for the future. Could there be the creation of a new hybridised prefab housing product, or is its lack of existence due to a lack of viability. Some prefabrication enthusiasts argue that the benefits of full or complete building prefabrication are lost when partial prefabrication is used (Novak). Yet, New Zealand's small market and customer demand for differentiation indicates that an adaptable design product is the logical choice if a potential for prefabricated housing is to be realised. Further discussion on hybrid design will be later in this thesis (refer to Chapter 7).

\section{Complete Building Prefab}

Historically, the New Zealand prefabrication industry is split broadly into component-based kitsets and complete or transportable buildings with barely any typologies in between (refer to Chapter 2 for history). The widespread appeal of complete buildings delivered to site is the apparent instant delivery of a housing solution. Consumers also benefit from being able to view a show-home so they can accurately visualise their end-product. These complete buildings are known as portable, transportable, mobile or relocated buildings (147-149). ${ }^{103}$ These three terms are used in an interchangeable way, yet there are subtle and distinct differences: portable refers to a small temporary building that is light and easily moved repeatedly such as a toilet or site office; transportable means a larger building that is moved once from place of construction to its final site; mobile indicates a tow-able caravan-like structure on a permanent chassis which can potentially be moved repeatedly; and relocated can be applied to any type of building of any age that is moved once either in parts or its entirety to a new location.

${ }^{103}$ Colloquially, the terms relocatable and reloc have been used for relocated buildings. 

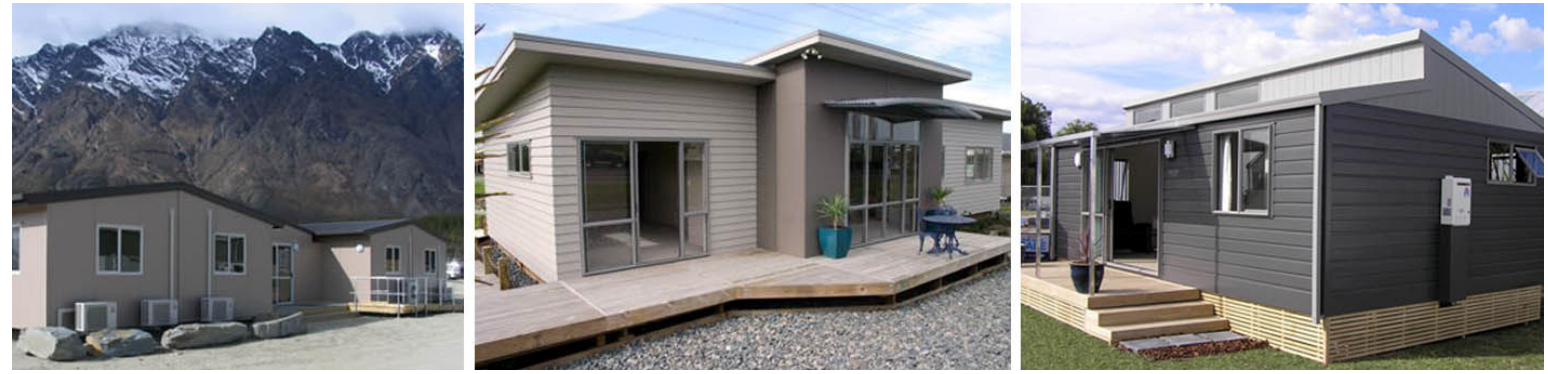

Figure 147 - 149: Portable Portacom office, transportable Keith Hay Home, and mobile Leisurebuilt bach.

Source: <http://www.portacom.co.nz/imgGallery/default.aspx>, <http://www.keithhayhomes.co.nz/index.php?page=raglan>, $<$ http://www.leisurebuilt.co.nz/Products.asp $>$.

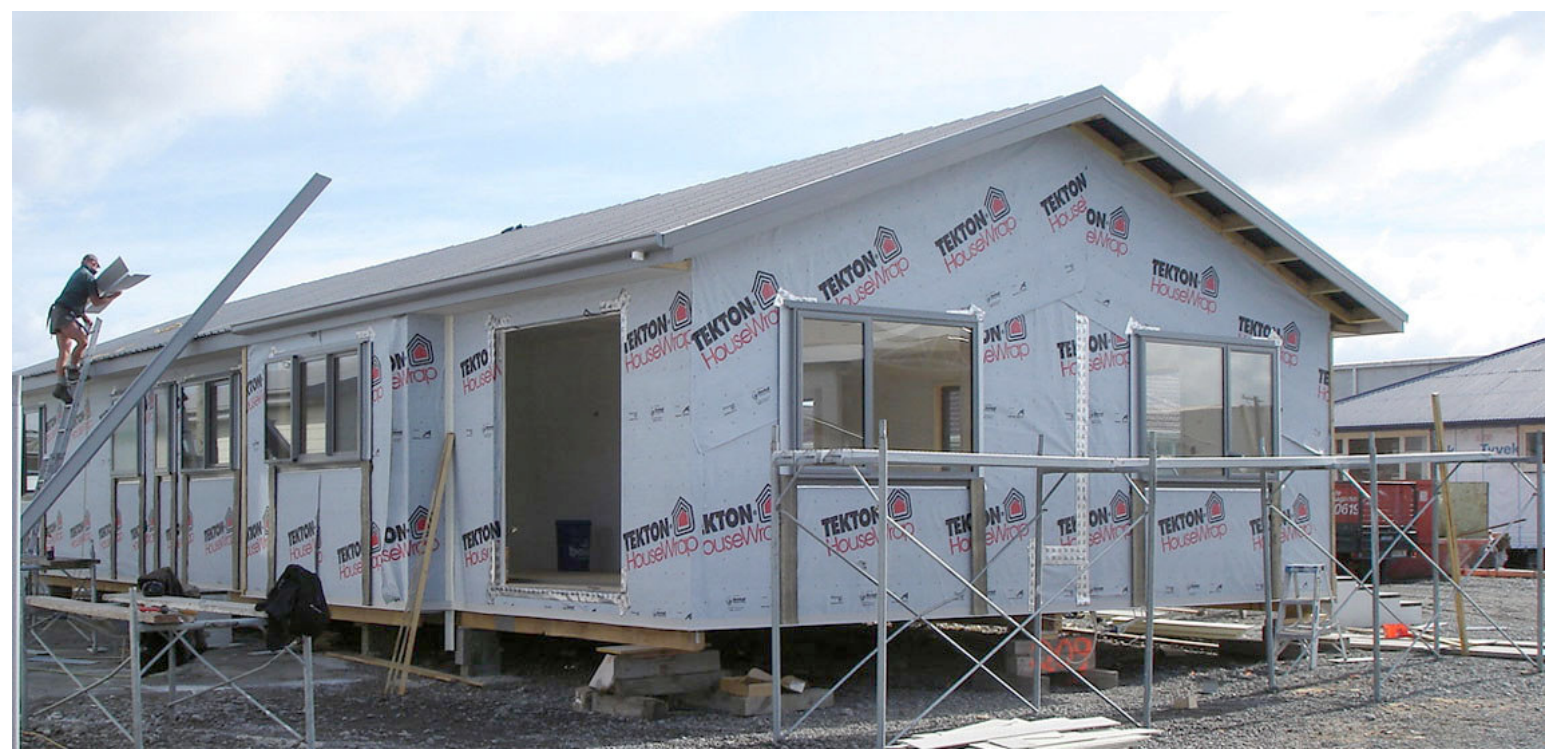

Figure 150: Laing Homes' exterior yard with house construction in progress.

Source: Author's photograph, 2008. 
Portable buildings such as those made by industry leader Portacom are used for construction site offices and other short-term needs such as toilets and showers for events. They are made of metal SIPs, steel or aluminium on either side of polystyrene insulation. ${ }^{104}$ Transportable housing is now replacing kitset housing as New Zealander's prefabricated housing of choice, due to the introduction of the Licensed Building Practitioner (LBP) scheme. Housing built using traditional construction methods in an outdoor yard prior to transportation is supplied by a number of businesses including Laing Homes and McRaeway Homes which are investigated in the following case studies. ${ }^{105}$ Mobile homes are akin to the United States-based manufactured home industry, formerly known as trailer-homes. These caravan-like structures do not need building permits; instead they are approved by the Land Transport Authority to be considered as trailers with registrations and warrants of fitness. Towable caravans, camp-ground cabins and motel units are made by a number of firms, several of which are based in the Waikato region. ${ }^{106}$

\section{Laing Homes - Christchurch}

Grant Laing began relocating houses in 1992 and split his business in 2000 into contract shifting and dealing in relocated housing which prompted the need for a large investment in transport. At this point, he created a third business stream, the design-and-build Laing Homes brand. Houses are supplied within a $500 \mathrm{~km}$ radius to schools, lifestyle areas and the booming dairy industry. Standard dairy worker accommodation consisted seventy-five percent of total production in 2007, with one farmer ordering fourteen houses. Laing's construction yard has from six to twelve individually designed and built houses in progress at any one time for a period of eight to ten weeks before being completed for delivery to site (150). ${ }^{107}$ The houses are constructed on a floor-plate using timber engineered I-beams as floor joists to eliminate squeaky floors. On this, the Maxim panel interior and exterior walls are fixed before being clad in conventional light-weight materials. Internal finishes, fittings and fixtures are applied in the yard, so that single water and electrical connections are all that need to be made at the site (Laing).

Laing credits a strong relationship with supplier Placemakers as being integral to the success of his house manufacturing business. He has also enlisted the skills of architectural designer Grant Miles of Hill and Miles Architecture to create the five-home Ultimate Range. Launched at the Christchurch Star Home Show in mid-2008, the prototype Sanctuary 94 show-home was visited by fourteen-thousand people before being advertised for sale through TradeMe and

\footnotetext{
${ }^{104}$ Because of their robust nature and ability to be stacked alongside or on top of each other, they are sometimes referred to as "modular transportable buildings". Portacom's website describes itself as being in "the New Zealand modular building industry" which is misleading. The portable term also covers a range of secondary buildings for use as sleep-outs, cabins, sheds, studios, offices, cottages, granny flats, baches, and farm worker accommodation. These buildings are brought to site on a flat-bed truck, hoisted into place with a crane, and then attached to permanent foundations. Suppliers include Cabins to Go, Cabins to Rent, Cosy Cabin Rentals, Cozie Homes, e-Homes, Highlander Accommodation, Karicom Kabins, Karicom Portable Building Solutions, Kiwi Cottages and Tourist Buildings, KiwiSpan, Laing Homes, LeisureCom, Modcom Portable Buildings, Pinecone Timber Cabins, Porta-Build and Hire, and Sunshine Cabins.

105 Other transportable housing businesses include A1 Homes, Rig River Homes, Clutha Homes, Exceed Homes, Haven Transportables, Initial Homes, Keith Hay Homes, Laing Homes, Latitude Homes, LeisureCom, McRaeway Homes, PlumTree Studios, and Sunshine Homes.

106 Mobile home businesses include Kiwi Cottages, Leisurebuilt, Caravans International Munro, GoHomes, 1880 Cottage Co and Barrons.

107 The Laing Homes website describes this exterior construction yard as a "controlled environment" (Laing Homes).
} 


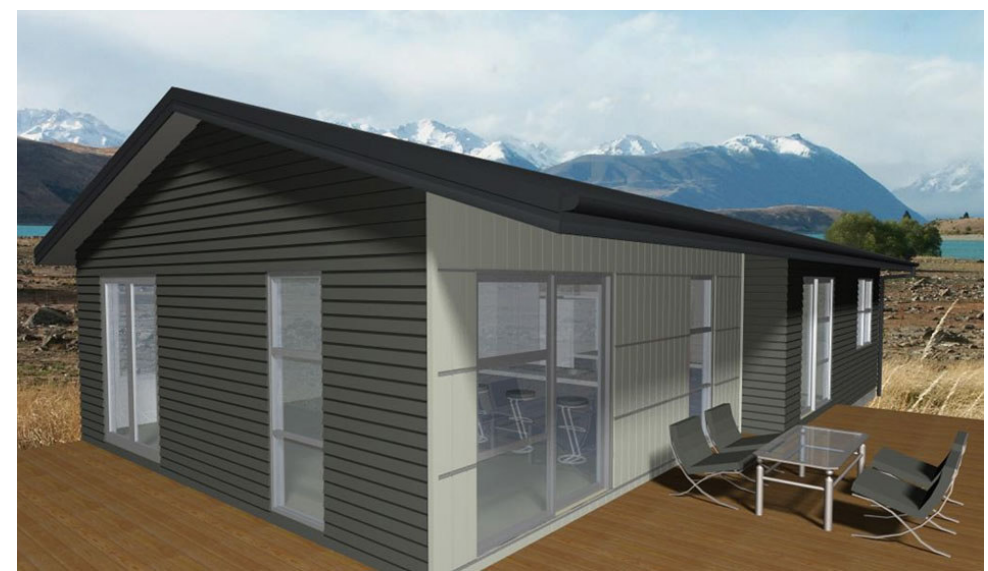

Figure 151: Sanctuary 94 by Hill and Miles Architecture for Laing Homes. Source: Image courtesy of Laing Homes.

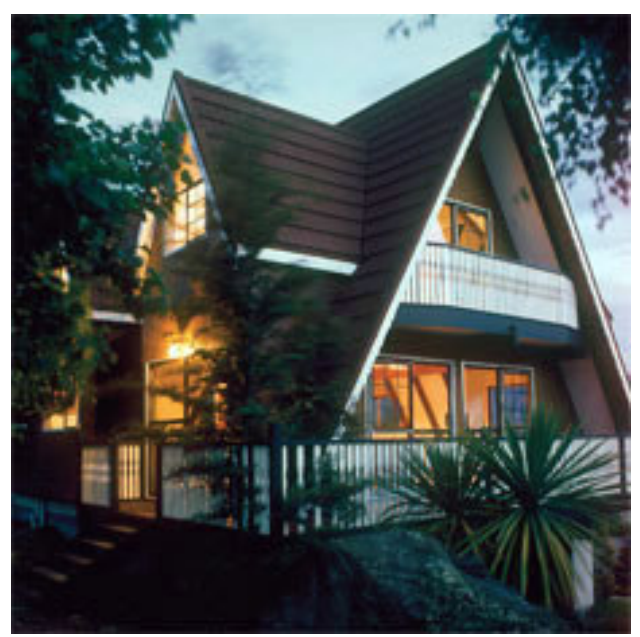

Figure 152: A-frame housing by McRaeway Homes. Source: Image courtesy of McRaeway Homes. 
Laing Homes websites (151). Further collaboration is with architect Paul Wilkins on the monopitch Escape range of baches destined for alpine, coastal and rural environments.

Challenges facing Laing Homes include the limited South Island market and the impending end of the dairy boom. Regulatory issues such as the separate building consents needed for construction yard and final site are restrictive, and Laing sees a place for an industry-wide organisation to lobby government on these and other prefabrication issues. Consumer misperceptions based on the temporary aspect of some transportable dwellings has meant Laing addresses exposed sub-floor spaces with extended base-boards and sensitive landscaping in an effort to achieve a more permanent appearance. Laing's suggestions for the future of the prefabrication industry in New Zealand are for an industry-wide umbrella organisation, a portal website, more deregulation from councils, government subsidies for affordable housing, more debate about starter-house size, consistent material supply and improving industry education on prefabrication.

Laing Homes is exemplary in their approach to utilising architectural input, marketing via the show-home at an exhibition and using established sales channels through the internet. Laing is convinced that affordable housing can emerge from the starter-house concept, based on a standard seventy-five square metre dairy industry dwelling of one-bedroom and living room, with potential for the future addition of a bedroom wing.

\section{McRaeway Homes - Timaru}

lan McRae started McRaeway Homes in 1965 and gained a strong foot-hold in the market when he supplied the Upper Waitaki hydro scheme with two-hundred-and-fifty pre-cut and pre-nailed kitset garages from Timaru. In the late 1960s he bought an A-frame housing business and turned it into a successful prefabricated kitset with over two-thousand homes built by the early 1970s (152). The Pioneer Series carried through to the mid-1990s selling over three-thousandfive-hundred houses around the country, firmly establishing their reputation as kitset housing suppliers. The mid-1990s saw a customer demand for changing design packages so new models were introduced until the contemporary situation where a wide range of design templates for home-packages are currently available (Tipa and Keys) (153). ${ }^{108}$ McRaeway Homes have produced over six-thousand homes in over forty years, currently offer fifty standard house designs, and produce up to twenty houses per month from their Timaru production plant (McRaeway Homes).

In 1992 McRae passed away, his daughter Raewyn followed in his footsteps as a director and sales manager, and general management passed to Matt Tipa who proceeded to learn more about prefabrication from a Swedish entrepreneur. McRaeway entered a joint-venture with Universal Homes and Modular Rapid Build for a Warren and Mahoney-designed modular

108 Approximately ninety-five percent of standard designs are changed by clients, usually because of site issues, such as orientation (Tipa and Keys). 


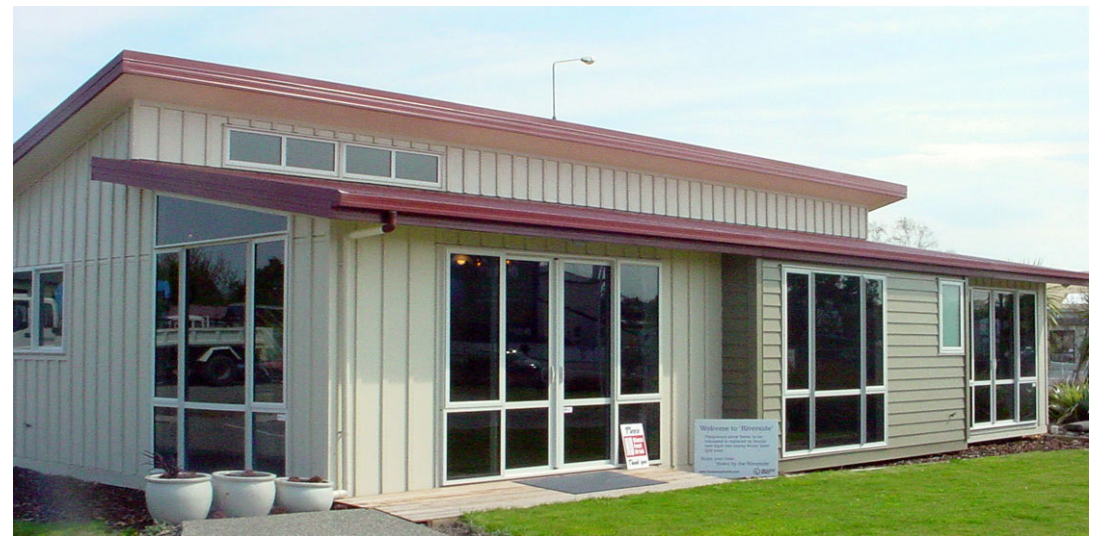

Figure 153: Riverside show-home on display at McRaeway Homes Timaru. Source: Author's photograph, 2008. 
housing subdivision in West Auckland. Four French-provincial style houses were delivered to site as modules complete with internal finishes, plaster and paint and external plywood cladding. Exterior cladding of Hebel block was applied at the site. Although McRaeway Homes lost money because of time and effort spent educating contractors, it was successful in starting the conversation on modular building for residential applications (Tipa and Keys).

Believing that, "there is still a place for modular in New Zealand", Tipa visited the United States to research twelve modular building companies that had converted from kitset, and soon realized that they were twenty-five years ahead of New Zealand's industry in terms of technology and processes. Tipa returned with software, including ArchiCAD and MiTek, and made the decision to move towards modular technologies. The result is their intended development of a First Base range: a modular two-bedroom ninety square metre two-storey house with additive elements designed by architect John Rushton. ${ }^{109}$ The proposed show-home aims to combat common misperceptions about prefabrication and to, "dispel this relocatable building thing" of associations with cheapness and poor quality. They plan to use their visible main-road site in Timaru to showcase the new housing model, and hope to repeat a past success in changing perceptions when they built a two-storey Hebel block Leon home model to show that kitset housing can imply solidity and does not have to mean lightweight and flimsy (Tipa and Keys).

McRaeway Homes envisage that "modular with style", or architect-designed prefabricated housing, will be their core business within the next ten years. Matt Tipa's United States research trip showed that it took between five and ten years for the market to catch up before reaching a tipping-point (Tipa and Keys). ${ }^{110}$ McRaeway Homes exhibit a willingness to learn about new concepts, an emphasis on thorough first-hand research and focussed attention on correcting common misperceptions through the combined use of architectural design, show-homes and a high-visibility site.

\footnotetext{
109 In 2009 the First Base project was modified due to difficulty with making preliminary costs applicable for the targeted first-time home buyer market. McRaeway Homes intend to launch the new model in the second-half of 2009 (Tipa).

110 The term tipping-point was coined by Malcolm Gladwell in his 2000 book by the same name. It refers to the point at which a product or concept becomes popular to the extent that it has its own momentum and does not need any further marketing support.
} 


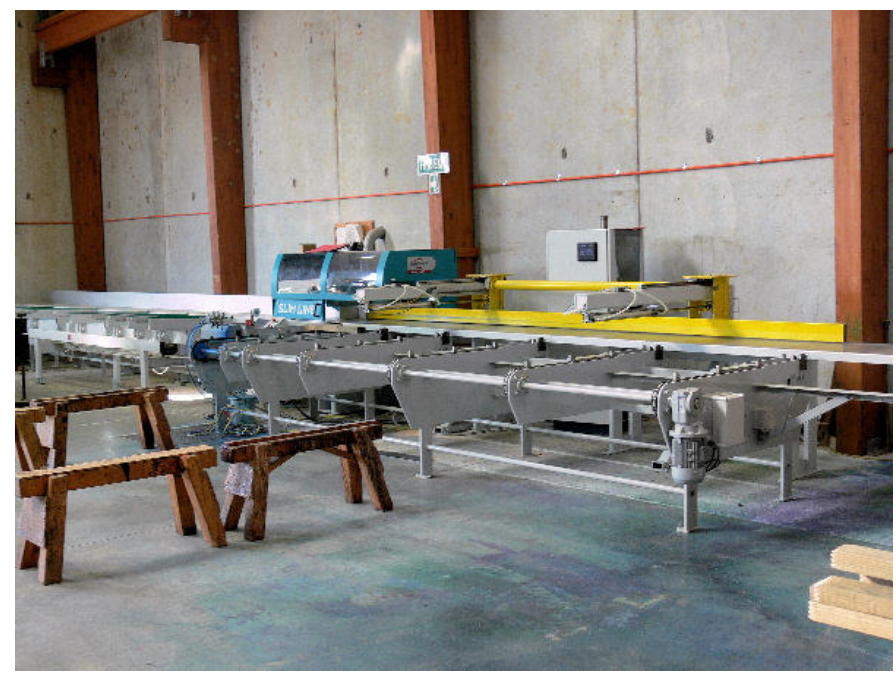

Figure 154: Investment in research and development: McIntosh's A-Grader timber technology. Source: <http://www.mcintosh.co.nz/newsandlinks/>. 


\section{Contemporary Issues}

Most industry participants believe prefabrication is an important way to address issues of housing affordability, and accessibility of architectural design to a wider audience. Their common attitudes, approaches and tactics are considered here. The three main areas of issues from the previous chapter - economic, design and manufacture, and socio-cultural - provide a context for this discussion.

The economic reality of business in New Zealand is constrained by our small population. For this reason the approach of increasing market demand by looking offshore was taken by several firms. Timber Construction Solutions (TCS) found that having a marketing agent on the ground was successful in procuring projects, and then chose to establish a factory offshore to supply components at a more competitive price. By comparison, Replica chose to establish an agreement with an offshore company, so that its bachkit product could be made there according to original intellectual property guidelines. A third strategy is that adopted by Lockwood Group in the past, of supplying offshore markets with products manufactured in New Zealand. In the future, Lockwood plans to supply offshore franchisees with manufacturing machinery that can cut to digital plan designs. The key drawback to interacting with foreign markets is the exposure to wider macro-economic influences which is a potentially high-risk situation as TCS can attest to.

Several businesses chose the strategy of prefabrication specialisation to secure niche market demand, such as TCS with timber structure and De Geest with bathroom pods. In this way prefab products become part of an overall diversification strategy which sees businesses such as Lockwood's franchisees, Replica, De Geest and TCS all carry out other more traditional construction work which enables them to smooth out fluctuations in demand for their prefab products. It is interesting to note the international trend towards specialisation, as seen in TCS's current projects where bathrooms are sourced from Italy, design from the United Kingdom, and structural timber from New Zealand.

The local construction industry's overall lack of research and development, vision and funding is a key reason to move offshore in search of markets and support (Giess). Historically, government investment and leadership enabled several businesses to become established, such as De Geest and McRaeway Homes. TCS also benefited from government marketing funding and the Lockwood Group gained international exposure from the 1970 World Expo. Lockwood's 2008 EcoSmart home series was the result of a million dollar research and development investment, and was attracting great customer interest (Kenworthy 159). An emphasis on research and development provides the chance to lead the market, and not merely respond to it (154). 

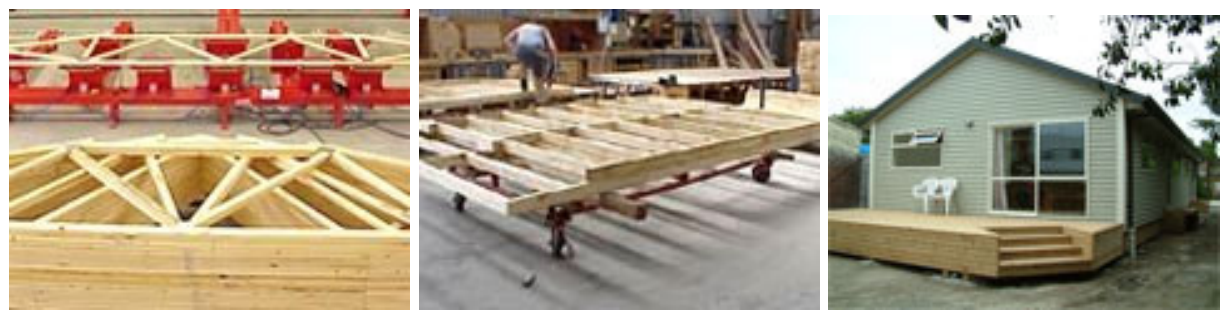

Figure 155 - 157: Common typologies: Pryda pre-nailed roof truss and wall frame components, and Laing complete house. Source: <http://www.pryda.co.nz/index.php?sectionid=115/> and <http://www.laing.co.nz/Homes/popular-range.html>. 
Collaborations and joint ventures with industry members are potential ways to pool resources for research and development. However, there is a level of pessimism and exhaustion from past failed partnerships, such as that felt by both Replica and TCS. Innovation has flourished in the case of JNL where there is internal funding from private ownership and an open attitude to creating new knowledge. The recent evidence of a FoRST-funded collaboration between industry associations, businesses and tertiary institutions is a positive step towards future information sharing.

Contemporary prefabricated housing systems are dominated by component and complete building typologies (155-157). Componentised prefabrication is used widely in pre-nailed roof trusses and wall framing for traditional construction, while complete buildings target the secondary dwelling market. There are few panelised and modular examples; the most notable being modular utility pods for multi-unit accommodation. There is an identifiable gap in the hybrid module-plus-panel typology.

Battling misperceptions through marketing and communication tools is an ongoing challenge for all industry participants. The Lockwood Group is exemplary for its approach through a nationwide franchise network, visible show-homes, promotional plan-books, and inclusion of high-profile architect-designs. Lockwood Group, McRaeway Homes, and Laing Homes have all successfully used highly-visible show-homes to influence perceptions in the past. The showhome provides an intimate housing experience and enables the brand to come to life. Industry and public shows are celebrated housing events to showcase new design and manufacture developments, as evidenced by Laing Homes when fourteen-thousand people visited their prototype at the Christchurch Star Home Show. Lockwood, McRaeway and Laing are all proponents of architect-design, and envisage new housing models helping change perceptions about the quality of prefabricated housing. ${ }^{111}$

An emphasis on future marketing methods has been identified by industry participants Brian De Geest, Chippie Semenoff (JNL) and Brian Laing. De Geest plans to revisit 1980s direct marketing techniques with targeted approaches to developers and project managers rather than traditional specifiers such as architects and engineers. This shift of power is notable. Others see the value in educating new industry entrants by direct communication to design and construction industry students. Future strategies suggested by Brian Laing include the formation of an industry-wide umbrella organisation, a portal website, and lobbying of government on prefab regulatory issues. New Zealand's prefabrication industry suffers from being disconnected, small and highly competitive, resulting in a general unwillingness to share issues, discuss challenges, and combine forces. There are currently several small associations looking after specific material suppliers but no overall body to link the industry.

111 Aesthetically, prefabricated housing is currently dominated by traditional residential vernacular with pitched, hipped and gabled roof forms. Several companies now offer a more contemporary mono-pitched option but overall there is a lack of architect-designed models and therefore great scope for aesthetic improvement on the back of proven production and delivery systems. 


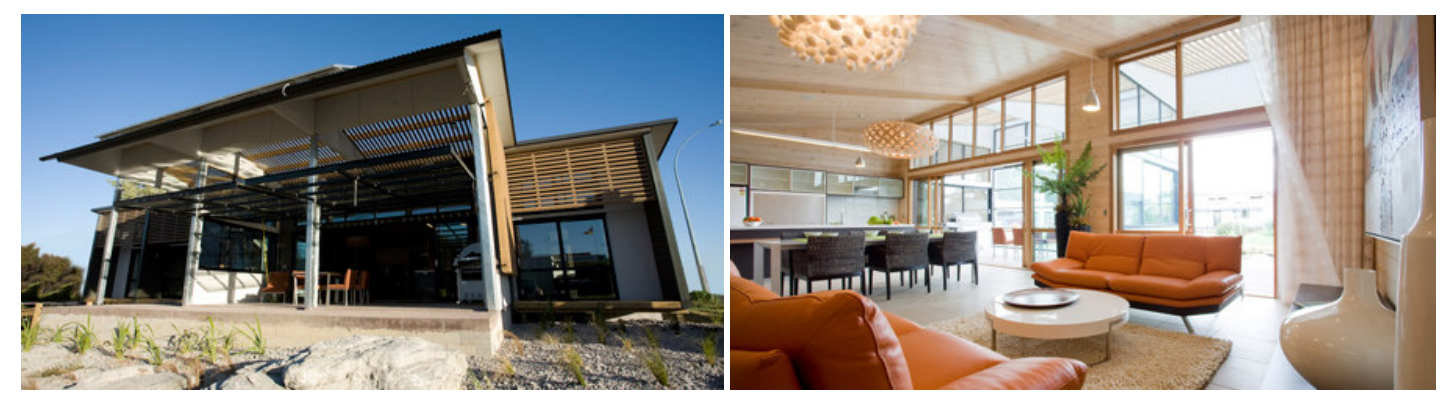

Figure 158 and 159: Lockwood's EcoSmart architect-designed prefabricated housing: exterior and interior. Source: <http://www.lockwood.co.nz/index.asp?pagelD=/>. 
An umbrella organisation could use its influence and coordination to address misperceptions about quality. Individual business strategies that focus on quality include prototyping, providing a workmanship warranty and holding only experienced employees, as used by De Geest. The Lockwood Group's approach to promoting quality is to target the upper-end of the lifestyle housing market. Direct architect involvement is another way to promote quality, and is used by several prefabricated housing businesses (158-159). All industry participants agree that the market's misperception about quality is holding prefabricated housing back.

Despite ongoing challenges, the New Zealand prefabricated housing industry exhibits great passion, perseverance and determination. ${ }^{112}$ Contemporary challenges include:

- the small, disparate and competitive-nature of the overall industry

- over-emphasis on component and complete building typologies, to the detriment of alternative methods

- a lack of future-proofing in terms of intellectual property protection and uptake of recent manufacturing technologies

New Zealand's established prefabricated housing businesses exhibit a range of approaches to shared challenges in this disparate industry. Enduring established prefabricated housing businesses such as De Geest, Lockwood and McRaeway have all shown flexibility and adaptability over time, in product, system, research and development, joint ventures, innovation and marketing approaches.

Contemporary approaches for a commercially successful kiwi prefab are:

- targeting offshore markets to increase consumer market size

- advancing innovative systems through research and development

- collaborations between industry and tertiary institutions

- architect-designed housing models to target a specialised niche market

- utilising marketing tools such as show-homes, plan-books and housing events

Despite several businesses being unwilling to collaborate, there are positive indications to develop relationships with design professionals, to actively pursue offshore markets and to further develop prefabrication systems. The widespread acceptance of pre-sized timber and pre-nailed components into traditional building practice is evidence that New Zealand's house building process is capable of change over time, providing inspiration for future potential incremental changes.

An international context for the discussion of New Zealand's prefabricated housing industry will be provided in the following chapter. This will be followed by chapters on recent local innovations (Chapter 5), a discussion of identified issues (Chapter 6 ) and recommended strategies (Chapter 7).

112 It is notable that innovative Dutch entrepreneur migrants were at the helm of family-owned businesses De Geest Construction and Lockwood Group. Their offspring manage these businesses today and continue their legacy of an equal emphasis on marketing and innovation.Other multigenerational family firms include Trower Panel, Touchwood and McRaeway Homes. 


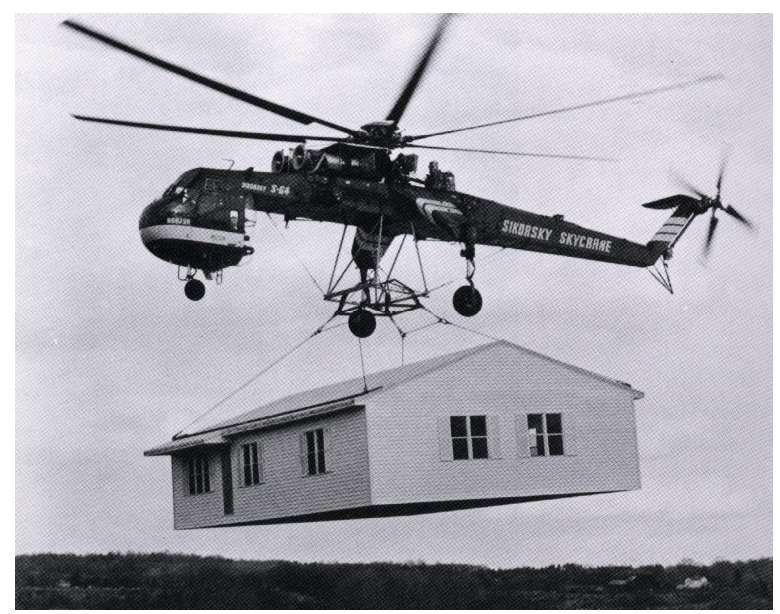

Figure 160: Helicopter transportation of prefabricated complete building in the United States, 1970. Source: D. Goodman, A History of the Future, New York: Monacelli Press, 2008: 144. 


\section{Prefab Precedents :}

\section{Contemporary International Overview and Case Studies}

New Zealand's industry is individualistic, raw and rugged; much like its inhabitants. In the previous chapter, it was found that refined marketing, integrated research and development, and industry collaborative networks are currently missing. Natural curiosity and colonial selfdoubt spur on a wider investigation into international prefabricated housing (160). Responding to this enquiry will provide a context for the critical consideration of prefabricated housing in New Zealand.

The following chapter will introduce the prefab revival, provide a brief overview of prefab housing worldwide, and document first-hand investigations in California, home of the 'green modern prefab' movement. ${ }^{113}$ As in the previous historical and established New Zealand case studies, interviews and site visits focus on start-up motivations, prefab systems, advantages, challenges and future predictions.

113 'Green modern prefab' refers to prefabricated housing that is architect-designed, has neo-Modernist design aesthetics and exhibits sustainable technologies or features (refer to Glossary). 


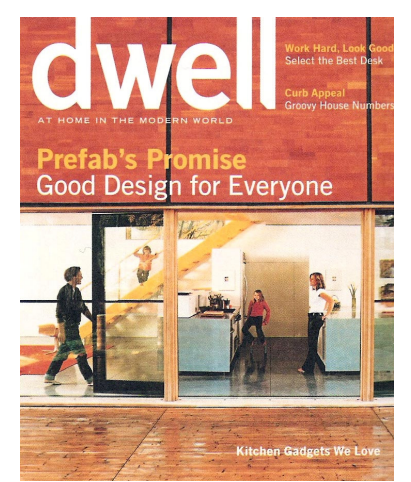

Figure 161: Dwell magazine April / May 2005

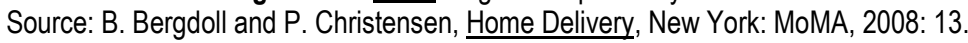




\section{The Prefab Revival}

'Green modern prefab' has come to mean an aesthetic style, and indicates smaller, more energy-efficient prefabricated homes, with open and flexible spaces. ${ }^{114}$ The renewed interest and optimism for architect-designed prefabrication has been dubbed both a "movement" and a "mini-phenomenon" (Hart 123; McGuigan and Kuchment). After a 2001 Dwell article on prefabricated housing, editor Allison Arieff described the subsequent reaction as "a prefab frenzy". Mainstream media websites and magazines have since contributed to the hype, creating publicity that is out of proportion to prefab's economic success. ${ }^{115}$ From the pan-Pacific distance of New Zealand, seen only through a computer screen, the glossy websites seemed too good to be true. A key motivator for the first-hand investigation was to delve past the apparent marketing hype of "prefab's promise" (Dwell Apr/May 2005: cover) (161).

Rising customer expectations and contemporary technology are now enabling the delivery of high-quality individualised housing solutions that were not possible in the past. The United States holds great potential for architect-designed prefabs based on the successful established modular and manufactured housing industries. In 2007, Witold Rbyczynski commented that, "it has been estimated that as many as a third of all new single-family houses built are either modular or manufactured homes" ("Houses"). Architect-designed prefabs are growing their market share, making up "ten percent of the United States six-and-a-half billion dollar modular home market [in 2004], five times the share a decade ago" (Jeffrey and Keates). However, the unstable start-up market together with the current worldwide economic recession is proving to be challenging.

The following contemporary case studies identify approaches and tactics being used to address current challenges. A brief look at contemporary international prefab housing precedes this investigation.

114 The Fabprefab website's online community members have submitted these explanations of modern values: minimal, clean lines, lack of ornamentation, revealed structure, undisguised materials, open floor plan, use of glass, living with nature, pure living, honest (Fabprefab "Glossary").

115 The number of 'green modern prefab' homes built in the United States since the rebirth in 2001 is approximately 150 (Spunt). 

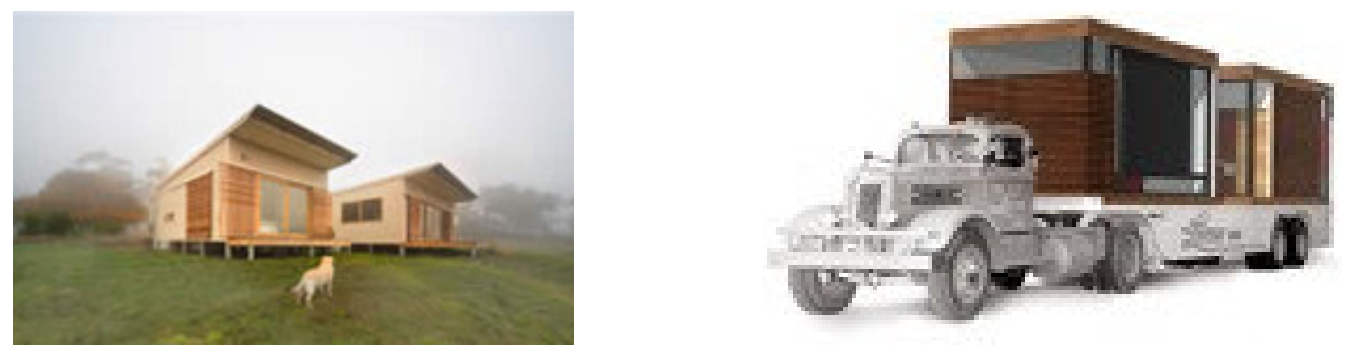

Figure 162 and 163: Pod by Prebuilt Housing Solutions and architect Andrew Maynard's Quon Modular system. Source: <http://www.prebuilt.com.au/> and <http://www.prefabhouse.com.au/Quon.html> 


\section{Introduction to Contemporary International Prefab}

\section{Australia}

Australia is our closest geographical country with a similar housing culture. ${ }^{116}$ It has a number of architect-designed prefabricated housing products, as well as a modular industry servicing the mass-housing needs of the wealthy mining industry. ${ }^{117}$ The nation's timber products industry has identified prefabrication as a future-proofing strategy. ${ }^{118}$ Regulatory changes have seen multi-unit builder-developers and planned-community builders enter the market alongside the design-and-build companies that focus on detached dwellings. ${ }^{119}$ Widespread, low-level prefabrication is evident through the use of pre-nailed frames and roof trusses by these large housing contractors.

"Most of Australia's architect-designed prefabs end up as weekenders at the beach or in the bush", which is much like New Zealand's prefabrication market for secondary dwellings or baches (Apelgren 39). Architect-designed prefabs are often brought to market through joint ventures with contractors. ${ }^{120}$ Architect Andrew Maynard's Prefab House Quon Modular is a proposed semi-custom prefab system made of self-contained modules placed side-by-side, stacked, or each by itself (163). Alternatively, established housing contractors are enlisting the design services of architects in a traditional manner for specific projects. Prebuilt Housing Solutions is a Melbourne-based prefabricated housing company that collaborates with architects Susi Leeton, Pleysier Perkins and Collins Turner (162). Together they offer a range of models for residential and commercial clients, and have completed eighty prefabs from 2003 to mid-2007.

Design competitions educate the wider public and provide fertile breeding grounds for new industry collaborations. In 2004, great interest in prefabrication was generated when Sydney hosted the Year of the Built Environment 'Houses of the Future' exhibition of six architectdesigned sustainable, affordable and futuristic house designs based on six different materials. The Steel e-bode house by United Kingdom Architects Paul Lucas and Sarah Bickford of

\footnotetext{
116 Australia has a legacy of transportable and kitset homes similar to New Zealand. Contemporary kit homes and cabins include RAL Homes, Valley Kit Homes, Ecohut, SALA homes and PAAL (Ryan). Australia also has unique environmental conditions that some prefabricators have addressed with specific designs, such as RAL Homes' bush-fire-proof construction and Force Ten's hurricane-resistant designs.

117 Modular transportable units for accommodating coal miners, construction workers and tourists in Queensland, South and Western Australia are manufactured by The Marley Accommodation Centres Services Group, known as The MAC (Biddle). Western Australia's Fleetwood Durabuilt also supplies transportable homes for the retirement, recreational, rural and resource markets. ATCO Structures in Queensland is another supplier of workforce housing, and a member of the United States Modular Builders Institute (MBI).

${ }^{118}$ Approximately ninety percent of Australian homes are timber-framed, so the industry's report is a protectionist measure in direct acknowledgement of needing to be prepared for new and emerging technologies. It is based on the Building Construction Technology Roadmap (Copper Development Centre, 2004) which identified that "home construction will increasingly rely on prefabrication and offsite construction, allowing infrastructure and technology to be embedded" (Paevere and MacKenzie 3). Forest and Wood Products Australia (FWPA) is jointly funded by industry and government and in November 2006 it published an extensive two-part report Emerging technologies and timber products in construction that comprises both literature review and an exhaustive compendium of innovative prefabrication technologies and products.

${ }_{119}$ Builder-developers such as Delfin, Mirvac and Central Equity are utilising prefabrication techniques along with speculation to provide dwelling units quickly to the market (Burke and Hayward 28).

120 Joint ventures include Kim Crestani's Pod System with Eden Brae Homes, Smartshax by architect Ken Latona with Upton Building, and architects Gabriel and Elizabeth Poole's Takeaways with Gateway Manufacture. Other architects with proposed or prototyped products include Sean Godsell's FutureShack, Jean-mic Perrine's Perrine Pod and Rita Qasabian's Studio Internationale Platform 1234.
} 

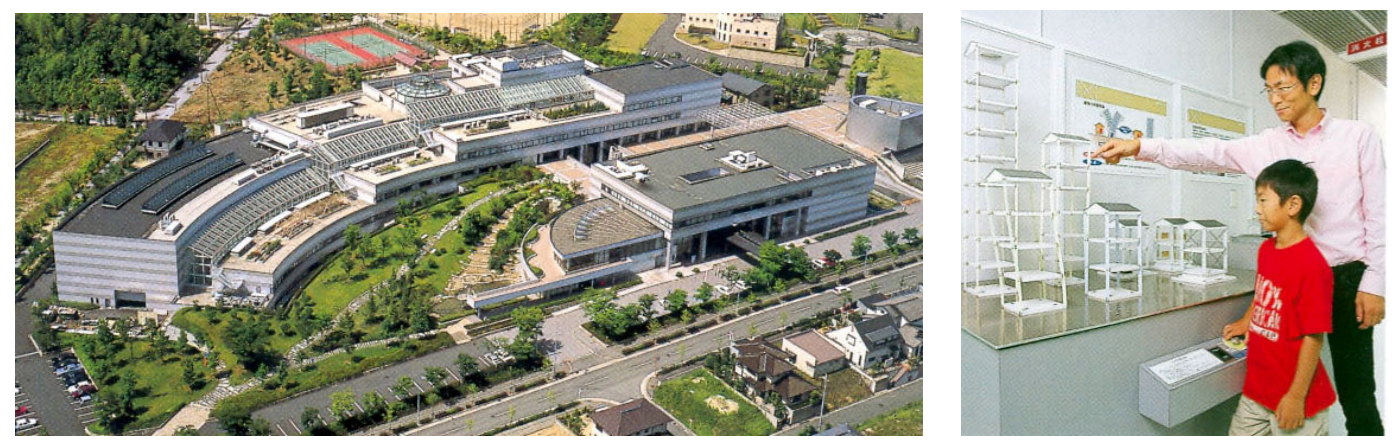

Figure 164 and 165: Sekisui House: Comprehensive Research and Development Institute, and earthquake demonstration model. Source: Sekisui House brochure: 30 and 8. 
Modabode is now in production with Albury manufacturer Mod-Eco. Other designs were influential but have not become commercial products. ${ }^{121}$

Australian prefabricated housing offers exemplars in architect and contractor joint ventures and architecture design competitions that generate publicity about prefabrication's merits.

\section{Japan}

Japan has a high population density, a low birth-rate and a culture of new housing lasting between twenty to forty years before being replaced. In 2004, Shuichi Matsumura commented that Japan led the world in the production of panelised and modular prefabricated houses, which constituted as much as twenty percent of the domestic housing market (3). It is further estimated that seventy percent of traditional timber houses are built with pre-cut components (Matsumara 9). Japan has heavily invested in research in the building industry since 1946 resulting in a mature prefabricated housing industry today. This was achieved through the establishment of national sales networks, and government financial and legal assistance for technical development. Five major businesses evolved from other manufacturing industries in chemical, steel and home appliances which together make up eighty percent of the established prefabricated housing market. ${ }^{122}$ Mostly steel-frame and panel or module systems were developed, although some timber-frame and precast concrete panel systems are also used (Matsumara 5).

The industry is enhanced by Japan's strong culture of cooperation, collaboration and close links through joint ventures and vertical transfer of technologies (Gann 437). Direct knowledge transfer is made with the car manufacturing industry by Toyota who produces both cars and homes from its fully-automated factories. ${ }^{123}$ Manufacture uses principles of lean production combining, "some advantages of craft work with those of mass production, but avoiding high costs of craft and rigidities of factory systems" (Gann 441). This includes the supply of parts on a just-in-time (JIT) basis rather than being held in stock, together with tight defect and quality control, computer-aided-design (CAD) and computer-aided-manufacture (CAM) technologies, and team-working techniques (Gann 441).

Japan's prefabricated housing consumer market is maintained by high levels of customer service and brand protection. ${ }^{124}$ Prefabricated homes are targeted towards middle to high income prospective home owners through exemplary technology centres or housing institutes

\footnotetext{
${ }^{121}$ Tone Wheeler and Jan O'Connor of Environa Studio exhibited their Clay House based on six shipping containers and acknowledged that future use of brick would be best applied in panelised construction. The other exhibits were the Concrete House by Peter Poulet and Michael Harvey of the New South Wales Government Architect's Office, the Cardboard House by Stutchbury and Pape (in association with the lan Buchan Fell Housing Research Unit at University of Sydney), the Timber House by Stephanie Smith and Ken McBryde of Innovarchi, and the Glass House by the University of Technology Sydney Institute for Nanotechnology (Houses of the Future).

122 The five businesses are Sekisui Home, Sekisui House, Misawa, Panasonic's PanaHome and Daiwa House.

${ }^{123}$ Toyota has been in the business of making homes for over twenty years. They are strong and guaranteed for about sixty years, which is about twice the average lifespan of a home in Japan (Koerner).

124 Sales, marketing and management overheads account for twenty-five percent of the value of manufacturer Sekisui's houses (Gann 446).
} 


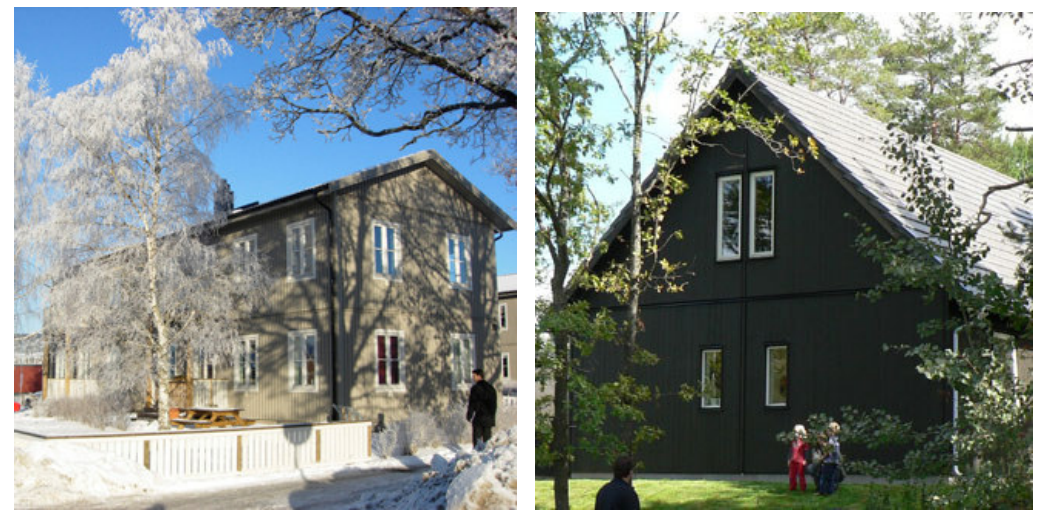

Figure 166 and 167: Bo Klok Housing by lkea with Skanska, Sweden. Source: <http//www.boklok.com/>. 
where research and development processes are on display (164-165). The institutes conduct elaborate tours to explain various aspects of house selection, construction methods and structural testing, to the primarily female customer-base. This enables user involvement in design and understanding of the prefab process. It is this emphasis on high-quality, superior performance and the reliability of large firms that persuades clients to choose prefabricated solutions (Matsumura 11). According to architect Roy Fleetwood, despite Japan's large population and industry domination by a handful of prefabricated housing companies, there is strong individuation and no two housing designs are fabricated exactly alike (R. Fleetwood).

Japan's prefabricated housing industry is exemplary for its dedicated government investment, industry research and development, joint ventures, cross-fertilisation between industries, showhome centres, customer service, client communication and market education.

\section{Western Europe}

Eastern Europe's prefabrication industry has been affected by a post-World War One history of low-quality and poorly planned multi-storey concrete panel buildings known as Plattenbau. In Western Europe, such as Spain and France, prefabricated housing makes up less than five percent of the market, but further north in Scandinavia the colder weather causes the housing industry to head indoors for production. Scandinavia has a rich history of prefabrication based mainly on pre-cut timber elements for individual houses and precast elements for multi-unit affordable housing.

In Sweden, prefabrication technologies make up ninety percent of housing, and in Finland more than half the population lives in prefab houses (Egan; Stungo 46). The Scandinavian countries of Sweden, Denmark, Norway and Finland have a legacy of socially-inspired prefabrication through architect-designs from mid-twentieth-century such as Alvar Aalto's AA-System Houses which were based on the concept of flexible or "humane standardisation" of living-cell parts of housing plans (Aalto qtd. in Pallasmaa and Sato 254). ${ }^{125}$ Other well-known proponents of historical prefabrication include Ralph Erskine in the 1950s; and Matti Suuronen, Jorn Utzon and Arne Jacobsen in the 1960s. Contemporary examples include Pinc House, Swedish Passive Houses by Kjellgren Kaminsky Architecture and the joint venture between construction company Skanska and furniture-behemoth Ikea. ${ }^{126}$ The various Scandinavian governments support projects through joint ventures, housing district planning, and tertiary institute research. A "third age of prefabrication" has now been reached with internationalisation of timber-mill production and housing concepts such as Bo Klok (Waern 31) (166-167).

\footnotetext{
125 In Scandinavia "prefabrication methods of some sort [were] used in eight-five percent of private homes by the 1980s" (Waern 30). 126 Ikea began in the late 1940s when Ingvar Kamprad began producing "home furnishing products of good function and design at prices much lower than competitors". Ikea began as a mail-order company marketing through news brochures and free catalogues to farmers, and grew through the 1950s to include showrooms, its own designs, self-assembly products, stores and restaurants. A motel and office were added in the 1960 s, along with expanded product lines for children, office, storage, workshop, kitchen and garden. Manufacturing is now sourced from western and eastern Europe, as well as Asia. This extremely successful franchise operation has grown to include two-hundred-and-sixty stores in thirtythree different countries turning over more than twenty-thousand million Euros per annum (Ikea).
} 


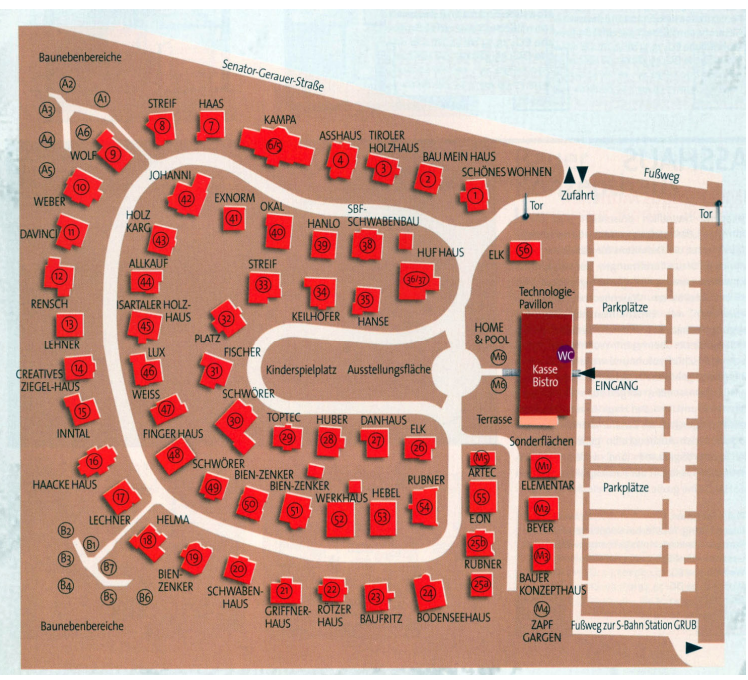

Figure 168: A large prefabricated housing show-home village: Poing housing village in Germany. Source: Hausbau Sep/Oct (2007): supplement.

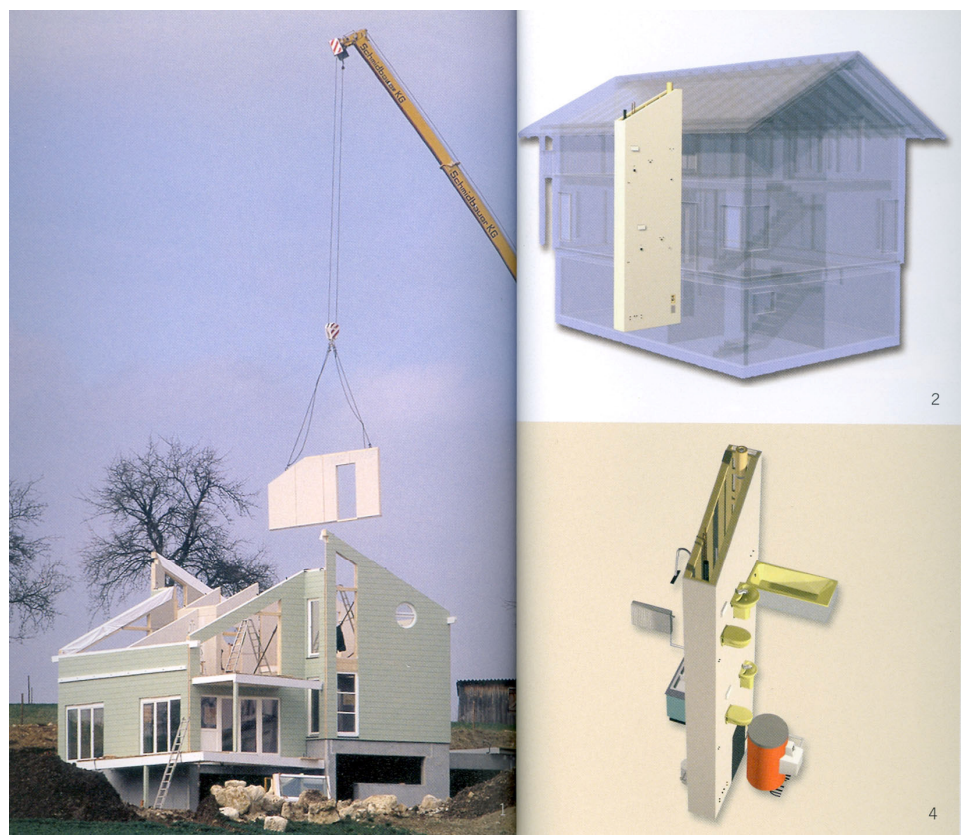

Figure 169: Baufritz housing's multi-storey prefabricated utility module and panel-based system, Germany. Source: Baufritz 'Klassikund Moderne' brochure. 
Ikea and Skanska partnered in Sweden in 1996 to build Bo Klok (pronounced Book-Look and translated as Live Smart) affordable homes for small households. The partnership used researchers to track trends in household size, in order to identify a model homeowner and their housing priorities (Rose). By 2007, Ikea had established forty-five multi-unit timber-framed modular Bo Klok communities in Sweden, Denmark, Norway and Finland, and over threethousand-five-hundred prefabricated homes across Europe (Egan; Jeffrey and Keates). The homes are targeted towards lower-income families, single-parents and micro-families, and focus the community around shared gardens (Egan). They are now sold into the United Kingdom under the Smart Homes brand and large developments of over one-hundred units are planned.

A 2004 mission to Germany by the United Kingdom's Department of Trade and Industry's 'Global Watch' focussed on two show home parks containing over fifty prefab houses (168). They discovered that almost ten percent of new homes in Germany were constructed from prefabricated systems with the market continuing to grow. Prefabricated housing is widely associated with high-quality, as a result of industry initiatives to develop rigorous quality standards, establish certification schemes and promote prefabrication's merits through consistent marketing. There are over one-hundred suppliers of timber systems using a high degree of customisation and environmental technologies that enable energy and water conservation (Venables and Courtenay 3).

Both Austria and Germany's established timber industries are characterised by a number of small and medium-sized family businesses. The German industry is supported by a Timber Institute which freely gives away educational information, and mainstream magazines dedicated to prefabricated housing with information on construction, pricing, planning and websites. Upmarket German houses by Baufritz are architect-designed with an emphasis on superinsulation and some models utilise a consolidated multi-storey service wall (Baufritz 'Klassikund Moderne') (169).

Architect-designed prefabs include those by Austrians Oskar Leo Kaufmann and Albert Ruf. Operating as KFN Systems, Oskar Leo Kaufmann and his brother Johannes produced the expandable Fred and Su-si complete buildings in 1996 (170-172). In 2008, Kaufmann and Ruf's System 3 hybrid housing was chosen to be exhibited at the New York Museum of Modern Art's 'Home Delivery' exhibition (145).

The Netherlands is of interest to New Zealand as several 1950s migrants became the forefathers of prefabricated housing in this country. Architectural roots are evident in avant-garde movements of Expressionism from 1910 to 1924. The Dutch De Stijl movement evolved under influence from Frank Lloyd Wright and the machine aesthetic, leading to a functionalist style exemplified by architects such as Gerrit Rietveld. Since World War Two there have been numerous attempts to investigate steel-based housing systems, but an operational building 


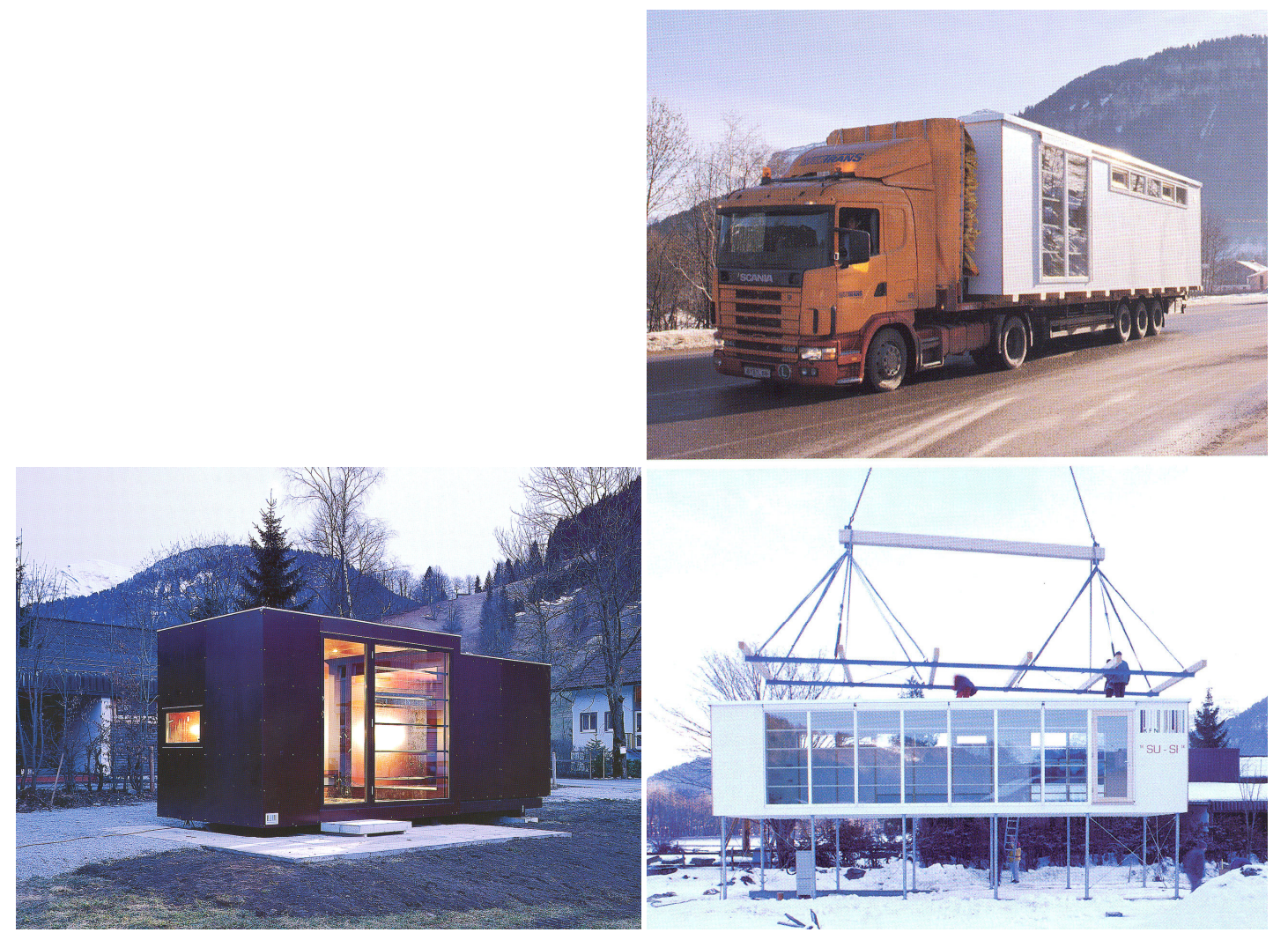

Figure 170 - 172: KFN's Fred extended at site, and Su-si in transport and site-assembled. Source: A. Arieff and B. Burkhart, Prefab, Layton: Gibbs Smith, 2002: 96 and 101.

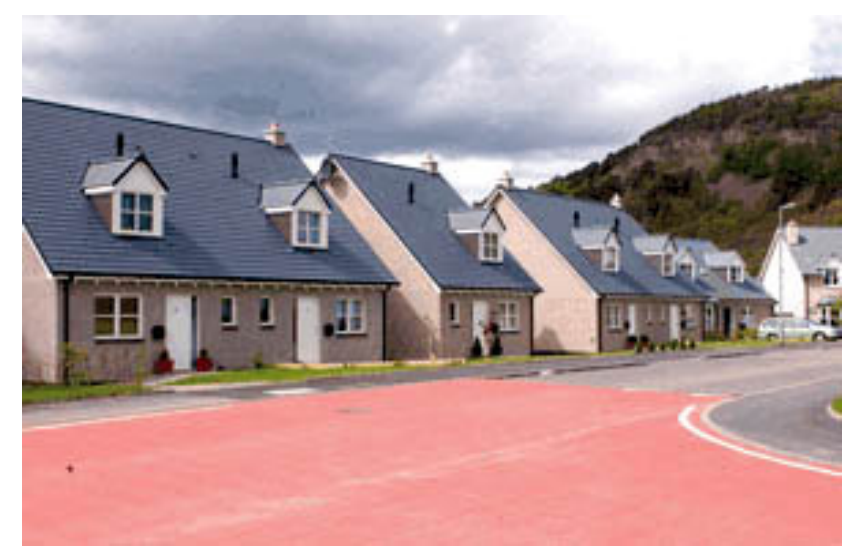

Figure 173: Tenants First's housing built from Dutch prefabricated panels, Scotland.. Source: <http://www.communitiesscotland.gov.uk/>. 
system has not yet made it to full maturity (Willems). In the last thirty years, prefabricated construction systems have become well-established with export markets to surrounding European countries. Factory-finished roof and wall panels have become commonplace with typical housing schemes utilising a hybrid method of site-based concrete shell construction together with prefabricated panels and elements such as staircases and doors (Gibb 17). Community housing in Scotland is one example and has been built using Dutch prefabricated panels consisting of bricks, insulation and concrete with in-built plumbing, electrical conduits, windows and door-frames ("Housing Co-op") (173).

New Zealand's prefabricated housing industry can learn from Germany's customer focus, marketing investment, show-home parks with customer centres, and dedicated magazines (Venables and Courtenay 3). There are also strategies to be learnt from established familyowned firms that invest heavily in research, technologies and marketing, have a reputation for quality and customer service and place emphasis on partnerships with suppliers (Venables and Courtenay 61). Western and Northern European countries have mature prefabricated housing industries that offer innovative timber technologies, established marketing and collaborative joint venture precedents.

\section{United Kingdom}

Despite a geographic proximity to Western and Northern Europe, the United Kingdom housebuilding industry is still dominated by traditional crafts practices, namely solid construction or brick veneer that has the appearance of permanence (Stungo). ${ }^{127}$ Due to land constraint issues, the current industry emphasis is on multi-unit residential and commercial applications, rather than single-family stand-alone residential. The building industry is being assisted by government research, recommendations and focus towards affordable prefabricated social housing. This industry has adopted the term offsite as a way to avoid negative connotations from failed 1960s prefabrication initiatives (Stungo). The new term comes complete with an industry-wide marketing organisation called Buildoffsite (174).

Buildoffsite is an industry-wide campaigning organisation that promotes greater uptake of offsite techniques by United Kingdom construction (Buildoffsite).

It is an alliance of clients, architects, developers, contractors, manufacturers, suppliers, government, advisors and researchers that has been set up specifically to address the dilemma of growing demand, poor quality and a reducing skills base leading to low productivity (Gibb and Pendlebury). ${ }^{128}$

\footnotetext{
127 Prefabricated housing was less than four percent of new buildings in 2005 (Pan, Gibb and Dainty 1). The United Kingdom market is different in each country, with Scotland having a higher uptake of timber framing than England. Overall the United Kingdom has a low rate of timber frame, or light-weight, construction at about eight percent in 2003 compared with ninety percent for Australia and New Zealand, Canada and the United States, Norway and Sweden (Cook 53).

128 Buildoffsite has performed market surveys, produced publications (newsletters, glossary, and e-zine to one-thousand-five-hundred contacts), developed the IMMPREST tool, conducted case studies, promoted visits to manufacturers under its Discovering Offsite programme, participated in industry conferences and events, created a Registration Scheme, developed an Architects Award programme, met with government Ministers and departments, and lobbied for research and development tax credits (Ogden). The Buildoffsite Registration Scheme operated by the Lloyd's Register Group is the first accreditation scheme of its kind for the British offsite industry. IMMPREST is an Interactive Method for Measuring PREassembly and STandardisation benefit in construction. It is a cost and value comparison toolkit developed by collaborative government funding and university research.
} 


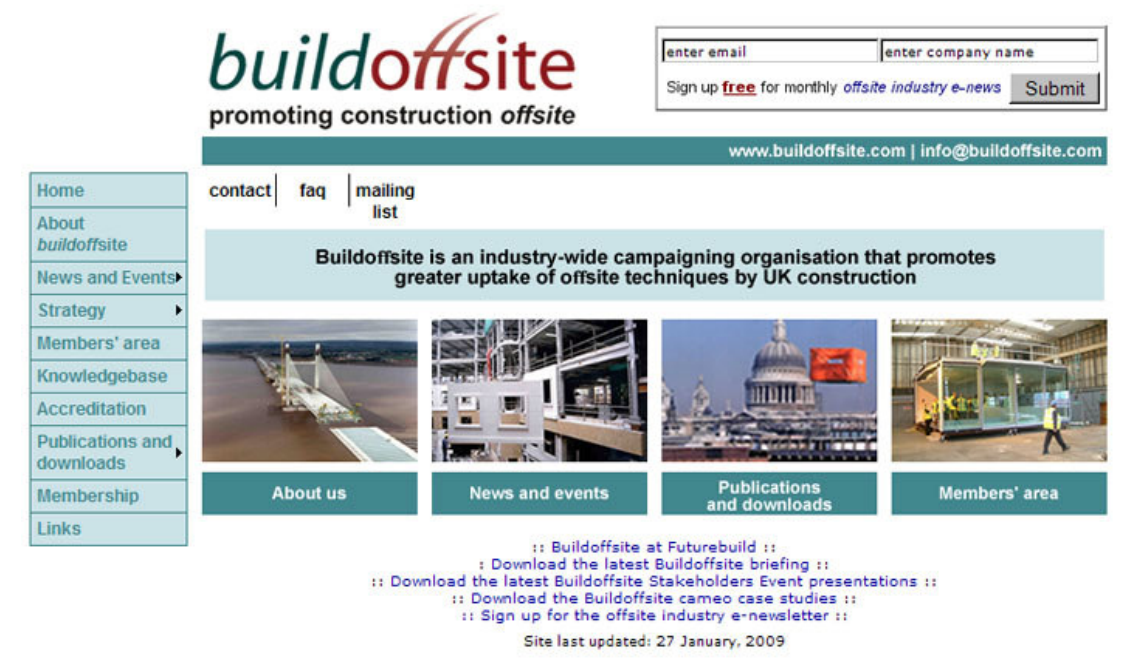

Figure 174: Buildoffsite website front page. Source: <http//www.buildoffsite.co.uk>.
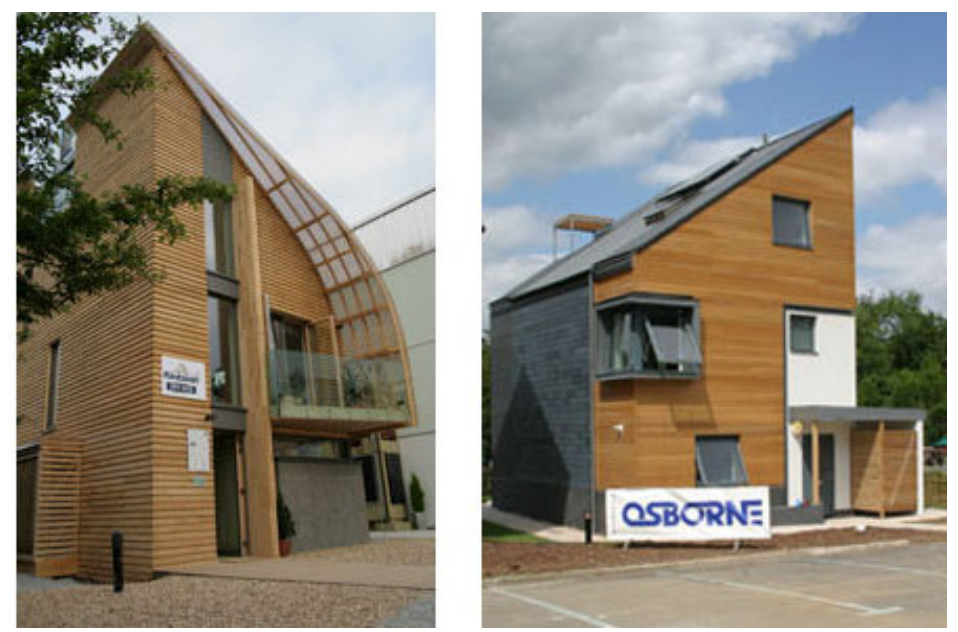

Figure 175 and 176: BRE 'Innovation Park' show-homes: Kingspan Lighthouse and Osborne House. Source: <http://www.bre.co.uk/page.jsp?id=634>.

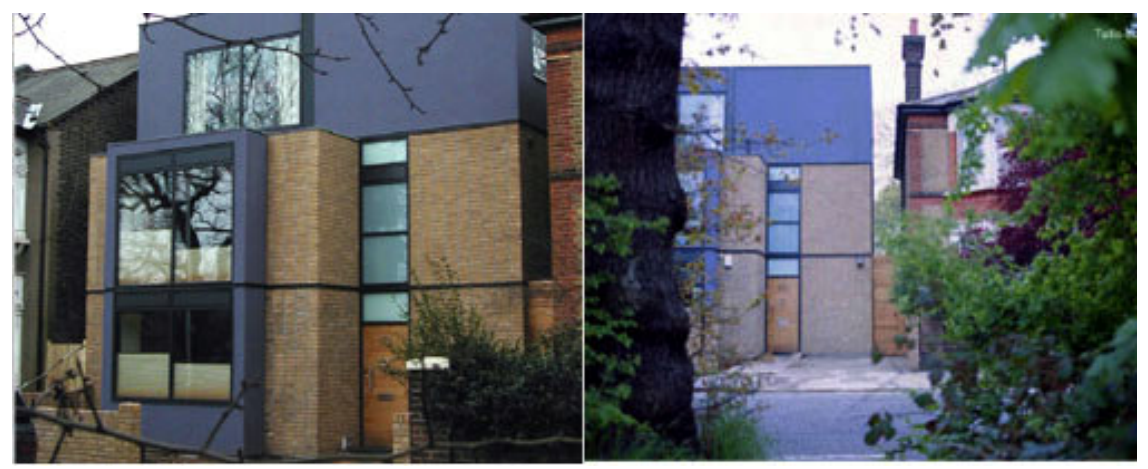

Figure 177 and 178: Bryden Wood Associates' modular Tallis Lock House, London 2004. Source: <http://www.brydenwood.co.uk/>. 
The British government has been instrumental in leading the construction industry towards process improvement, innovation, environmental initiatives and prefabrication methods. ${ }^{129}$ As a result of findings in reports headed by Michael Latham and Sir John Egan with the Construction Taskforce, the Deputy Prime Minister's office has allocated two-hundred-and-fifty million pounds for social housing to be built using offsite techniques. In 2004, the British government pledged to build two-hundred-thousand new homes over the next twenty years utilising these fast-track technologies (Stungo). In 2007, reports revealed the Housing Corporation had set a target for prefabrication and Modern Methods of Construction (MMC) to be used in twenty-five percent of new social housing applications (refer to Glossary). ${ }^{130}$ Cost is still seen as the greatest barrier to uptake, and industry-wide collaboration is seen as the answer (Gaze et al 6).

Prefabrication research is carried out through the Construction Industry Research and Information Association (CIRIA), the Timber Research and Development Association (TRADA), Loughborough University and the Buildoffsite initiative. Collaborative built environment research is overseen by the Building Research Establishment (BRE) Trust. ${ }^{131}$ BRE established an 'Innovation Park' in Watford in 2005 to showcase experimental methods of construction through demonstration projects to over twenty-thousand visitors, and plans to open a park in Scotland in 2009 (175-176).

Architects are mostly concerned with multi-unit social and urban infill housing projects rather than detached residential dwellings. Bryden Wood Associates are architects and designers for manufacture that are involved with complex commercial, social and residential construction. In 2004, the firm completed the Tallis Lock House in London comprising six modular steel-framed and brick-clad units assembled over five days (Bryden Wood) (177-178).

The United Kingdom's prefabricated housing industry provides a model for government and industry leadership, and collaboration through research, recommendations, and marketing. New Zealand's prefabricated housing industry can learn directly from the Buildoffsite industry umbrella organisation and the BRE 'Innovation Park' as exemplars for communicating the benefits of prefabrication technologies to a wider audience of industry, government and public alike.

\footnotetext{
${ }^{129}$ Reports such as Michael Latham's Constructing the Team in 1994 and Sir John Egan with the Construction Taskforce's Rethinking Construction in 1998 highlight deficiencies in the construction industry (Cook 51).

130 The United Kingdom Housing Corporation closed in late 2008 and was replaced by Tenant Services Authority (TSA) and Homes and Communities Agency (HCA) (Housing Corporation).

131 The BRE Trust is a charitable company made up of firms, professional bodies, and universities with the objective to advance knowledge, innovation and communication through research and education. BRE provides building industry research and advice through consultancy services, certification, commissioned research, event management, publications, training and education (BRE).
} 


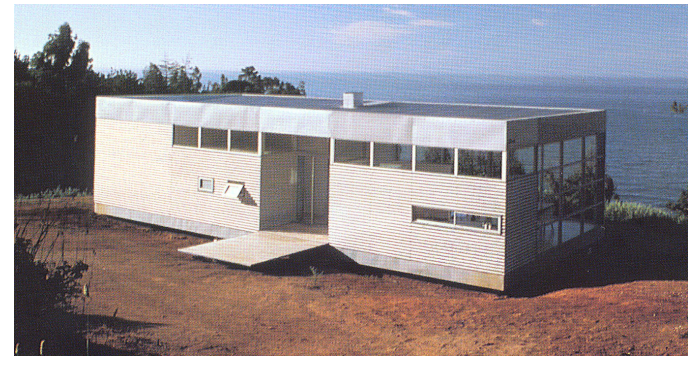

Figure 179: Architect Rocio Romero's LV Home.

Source: A. Arieff and B. Burkhart, Prefab, Layton: Gibbs Smith, 2002: 56.

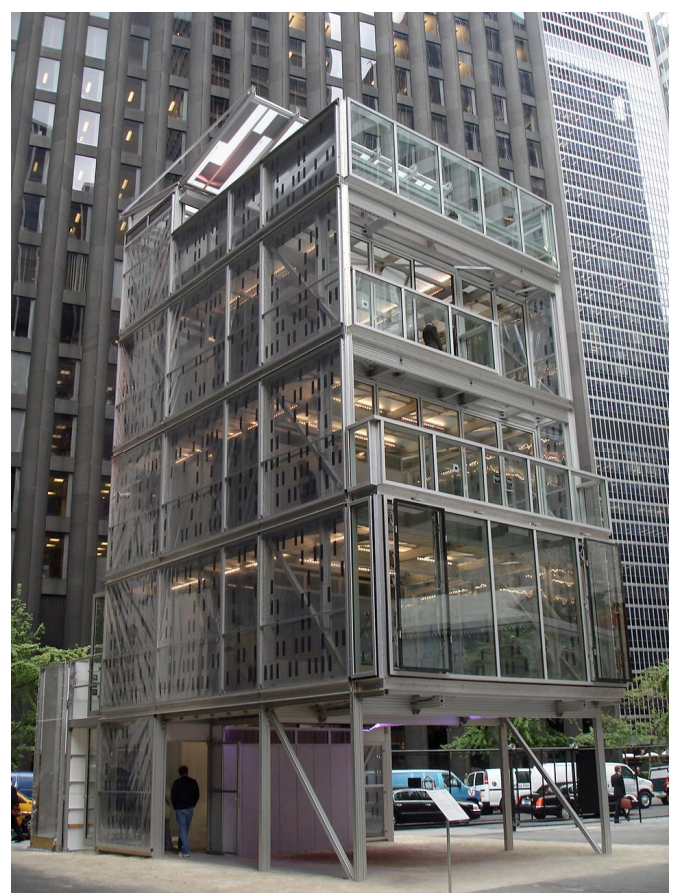

Figure 180: KieranTimberlake's Cellophane House at the 'Home Delivery' exhibition, New York. Source: Author's photograph, 2008. 


\section{United States of America}

The United States has a strong history in both modular and manufactured housing industries. ${ }^{132}$ Manufactured home-parks are strewn with standard-sized boxes, some stacked double-wide, in homage to road capacity dimensions. These established modular and manufactured industries have enabled contemporary architects to bring their prefabs to market. There are currently a range of businesses supplying a variety of sized and priced dwellings from thirty-three-thousand United States dollars for a kitset $L V$-Home by Missouri-based Rocio Romero, up to multi-million dollar homes by Marmol Radziner Prefab (Egan) (179). Several of these firms are profiled in the following Californian case studies.

A focus on disaster-relief housing has been highlighted after Hurricane Katrina devastated New Orleans in 2005. High-profile international competitions such as 'Make it Right' have garnered numerous prefabricated responses from architects such as KieranTimberlake. Other national and international competitions featuring prefabricated designs include the 'Lifecycle Building Challenge' and 'Solar Decathlon'. ${ }^{133}$ Some of these competitions are the focus of university-led programmes where prefab studios are taught and designs are built. Numerous state-wide exhibitions and housing events have enabled prefabrication to gain national exposure, with a stand-out being the 2008 'Home Delivery' exhibition at New York's Museum of Modern Art which showcased five innovative built designs, including KieranTimberlake's Cellophane House (180).

The key messages that New Zealand's prefabricated housing industry can learn from United States exemplars are of architect collaborations with established housing manufacturers, and widespread education about prefabrication through design competitions, university-led courses and museum exhibitions.

132 In the 1970s two percent of all housing units were produced by the two-hundred modular manufacturers using traditional construction methods within a factory-controlled environment ("What's holding back modular?").

${ }^{133}$ Mississippi State University's Michael Berk won the 2007 Lifecycle Building Challenge with his GreenMobile project constructed from green SIPs. He received a grant for almost six million United States dollars from the Federal Emergency Management Agency to construct prefab units for disaster areas (Staedter). 


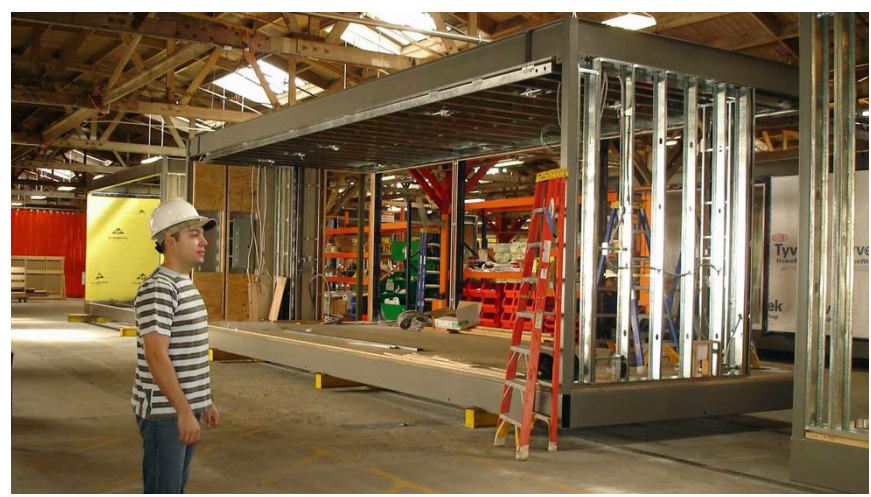

Figure 181: Project engineer and modules on factory floor, Los Angeles. Source: Author's photograph, 2008. 


\section{Californian Case Studies}

California is chosen for first-hand investigation as it is a locus for contemporary prefab. It is home to Dwell magazine, the 'Dwell on Design' event and several high-profile prefabricated housing businesses. It also shares similarities with New Zealand in several areas: a geographical proximity to the Pacific Ocean; consumers demanding individuality in their housing; clients wanting to have input in the design process and personal relationships with professionals involved; a niche design-educated audience revering a mid-twentieth-century Modern aesthetic; and a temperate climate conducive to living outdoors at times.

A visit to Los Angeles firms and factories to speak directly with prefabrication business leaders helped to develop a three-dimensional view of the industry, rather than the edited and imagebased view from behind a two-dimensional computer screen (181). Many products and systems were impressive in their uptake of technology and polished marketing presentation. The research visit enabled a first-hand experience of the assembly, or setting, of Marmol Radziner Prefab's Palms House, shortly after the 'Dwell on Design' conference.

Allison Arieff is quoted as saying the most successful contemporary United States prefabricated house designs are those by architects Michelle Kaufmann (MKD), Jennifer Siegal (Office of Mobile Design, OMD), Marmol Radziner Prefab (MRP), Rocio Romero (LV Home), Resolution: 4 Architecture (Res4), and Charlie Lazor (FlatPak) (Arieff qtd. in Keeps). ${ }^{134}$ Jennifer Siegal adds developer Steve Glenn's LivingHomes by architect Ray Kappe to this list. Of these seven firms, four are located in California and are examined in the following case studies. ${ }^{135}$ They all offer examples of prefabricated housing that is architect-designed, neo-Modern in aesthetic, currently in production and accessible for first-hand investigation in Los Angeles during a research trip in mid-2008. ${ }^{136}$ These case studies provide an opportunity to identify relevant issues and learn lessons that can be applied in New Zealand.

\footnotetext{
${ }^{134}$ Allison Arieff's architectural criteria for design success are "forms, the materials, the siting, the floor plans are all well thought out and make the most of natural light, ventilation and landscaping" (Arieff qtd. in Keeps).

${ }^{135}$ As well as the four dominant architectural prefabrication businesses profiled here, there are other smaller architecture firms in California that are incorporating prefab into their range or launching it as a separate sub-brand. These include Roger Kurath (Design 21) and Davis Studio A+D (Piece Homes). Architectural shed businesses which have the capacity to grow into a full-scale home include Modern Cabana and kitHaus. Container-based Logical Homes is an emerging Los Angeles firm headed by architect Peter de Maria and Fabprefab's publisher Michael Sylvester. Established architectural practices with emerging products include KAA Design Group's HOM Escape in Style brand and Warren Wagner of W3 Architects with Smartbox.

${ }^{136}$ A research trip to Los Angeles was taken in June 2008 to coincide with Dwell magazine's 'Dwell on Design' event which had a section of lectures and exhibition space dedicated to prefabricated housing.
} 


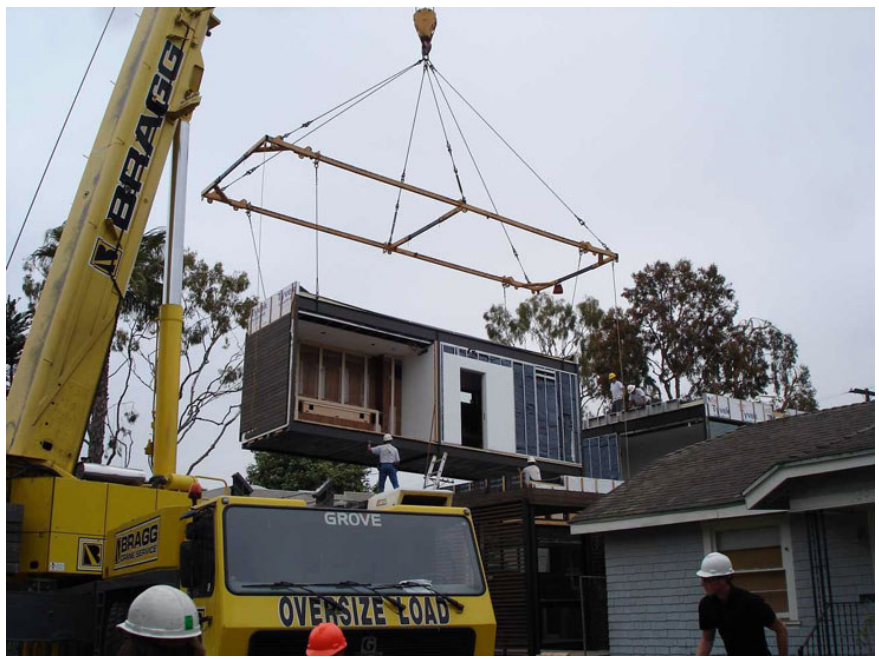

Figure 182: Palms House by MRP being assembled at site, Los Angeles. Source: Author's photograph, 2008.

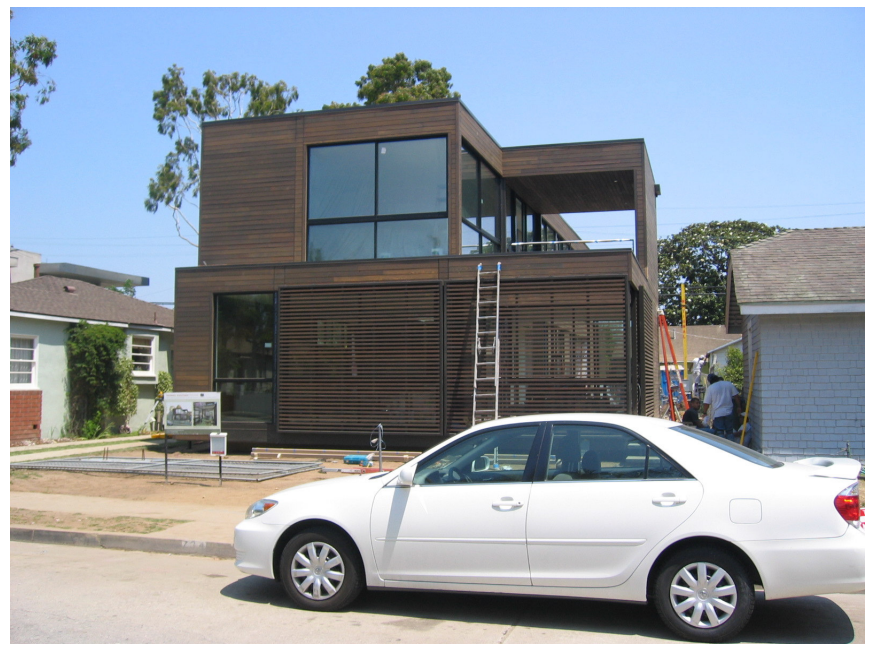

Figure 183: Palms House by MRP nearing completion, Los Angeles. Source: Courtesy of MRP. 


\section{Marmol Radziner Prefab (MRP) - Los Angeles}

Investigations began with producers of top-of-the range elegant prefab housing; their latest show-home is nearly three million United States dollars (Dakota Smith "MRP Venice Home"). Architects Leo Marmol and Ron Radziner formed Marmol Radziner and Associates (MRA) in 1989 and started their own metal shop, then cabinetry and structural steel shops, before extending this lineage to form Marmol Radziner Prefab (MRP) in response to Dwell's 2003 prefab competition. The establishment of their own factory enables "the ultimate of total control"; with all trades under one roof and architects taking on the role of general contractor (Marmol) $(19,20,181,202,289,290,305)$. MRP was established independently from MRA in 2006 with a third partner bringing manufacturing and business experience to the company and a fourth equity partner brought on board in 2007 for further investment, such as acquisition of a CNC machine.

Eight custom-designed modular prefab houses had been completed to mid-2009, all to exacting quality standards due to the architect-controlled fabrication process. ${ }^{137}$ The system is based on a rigid modular steel frame with SIPs inset as roof and floor panels and light-gauge steel wall framing with plaster-board interior finish and various external claddings. The modules are bolted together at site before the utility hook-ups and module lines, or mod-lines, are completed. This modular approach, together with tools such as Revit design software, gives MRP the freedom to design as, "architecture in the most timeless way possible" (Radziner). Further efficiencies are gained by having state-wide building code pre-approval which makes their system more efficient at interfacing with regulatory authorities across the country (Sylvester).

The Palms House show-home was set in place on its Venice site over two mornings in mid2008; the fourteen highly-crafted modules were assembled as the ground and first floor, and the resulting site-based work was planned to take only a few weeks $(11,182-183)$. This house is a prime example of MRP's top-of-the-line housing product aimed at the lucrative early-adopter or cultural-creative market. ${ }^{138}$ Their major point-of-difference is the design and construction quality of being a luxury brand, or in their words, "the Hermes of the prefab housing market" (Marmol). This perception of quality is reinforced by brand recognition and close alignment with MRA's nineteen years of architect-design and contracting experience, as well as streamlined factory processes, efficiencies and attention to detail (Radziner).

But the emphasis on quality comes at a price. The cost of the MRP product is higher than the architects would like, yet is still cheaper than an equivalent architect-designed site-built home. The cost could be reduced by further increasing factory-floor efficiencies, but it is a major challenge to improve factory processes without sacrificing quality of finish, something which MRP are hesitant to do. Their aim is to enable a faster process in order to produce more

${ }^{137}$ Architecture-trained employees oversee all aspects of the manufacture at the Marmol Radziner Prefab owned and operated factory in Vernon, Los Angeles.

138 Cultural-creatives are those operating on the leading edge of cultural change, and coming up with the most new ideas in United States culture. They tend to be middle to upper-middle class, with a few more on the West Coast than elsewhere. The overall male-female ratio is forty-to-sixty, or fifty percent more women than men. Cultural-creatives are a very large pool of people, forty-four million bigger than any comparable socioeconomic group (Ray 4). 

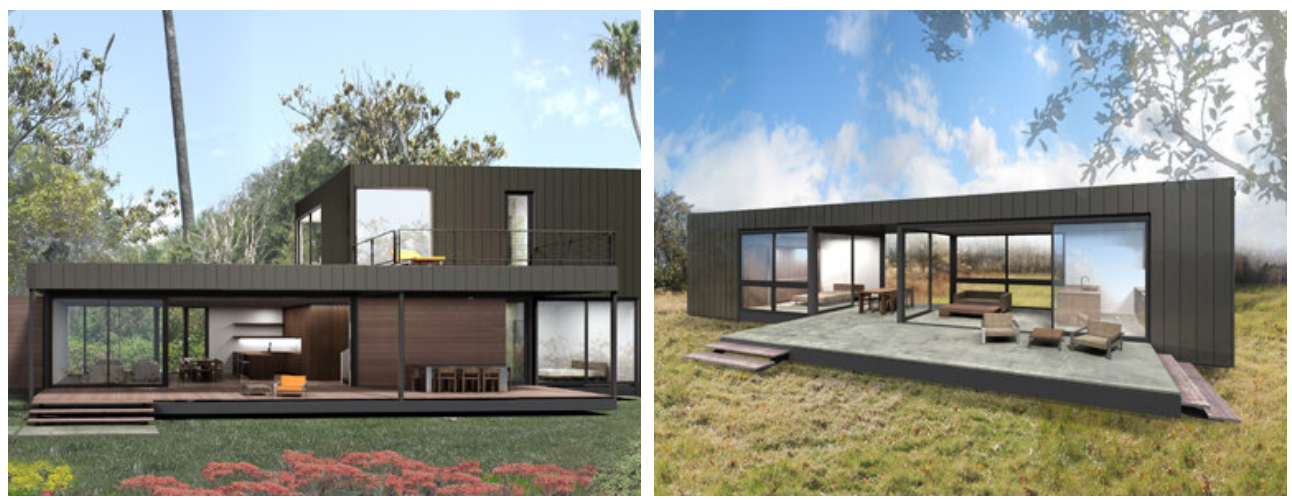

Figure 184 and 185: Skyline and Rincon housing models by MRP.

Source: <http://www.marmolradzinerprefab.com/model_prefab_homes.html>. 
products and increase turnover. As Leo Marmol points out, there is a huge complexity of process; it is "more than a house, [but] less than an aeroplane".

In an effort to reduce housing prices, MRP launched Skyline and Rincon pre-configured models in mid-2008 at the 'Dwell on Design' event (184-185). The Skyline series has options that conform to restrictive urban sites, while the Rincon is a minimal accessory building. Marmol hopes these pre-designed model costs will be driven down as costs increase for custom-designed prefabs so that customers will accurately perceive the difference between the two ranges of product offerings. In mid-2009, MRP announced the Skyline series would form part of the Dwell Homes Collection by Dwell magazine, to be launched at the 2009 'Dwell on Design' event (MRP, Email).

The newness of the industry is a mixture of both excitement and struggle and the current economic downturn is frightening, yet it has positive spin-offs (Marmol). The business is learning about more efficiency that will make them leaner in the long-term, and the industry will be consolidated as less financially secure companies will not be able to survive. In mid-2009, MRP made the decision to invite other contract works into their Vernon factory, in an effort to maintain consistent supply on the factory-floor (Archinect). Their future focus is on lowering the cost to the consumer through repeatability and standardisation while improving the rhythm of manufacturing and assembly, yet still maintaining their high-quality finish. They expect the dialogue with developers to grow in the next five years, particularly around multi-unit housing. MRP's ultimate goal is to push technological boundaries so that the prefab product is ninety-five percent complete when it leaves the factory (Levy; Marmol).

There is much to learn from their precedent. MRP leads the way in high-quality production through in-house factory control and exceptional architectural design standards. They show exemplary marketing methods, professional show-home presentation, and prefab product diversification between custom and pre-configured models. 


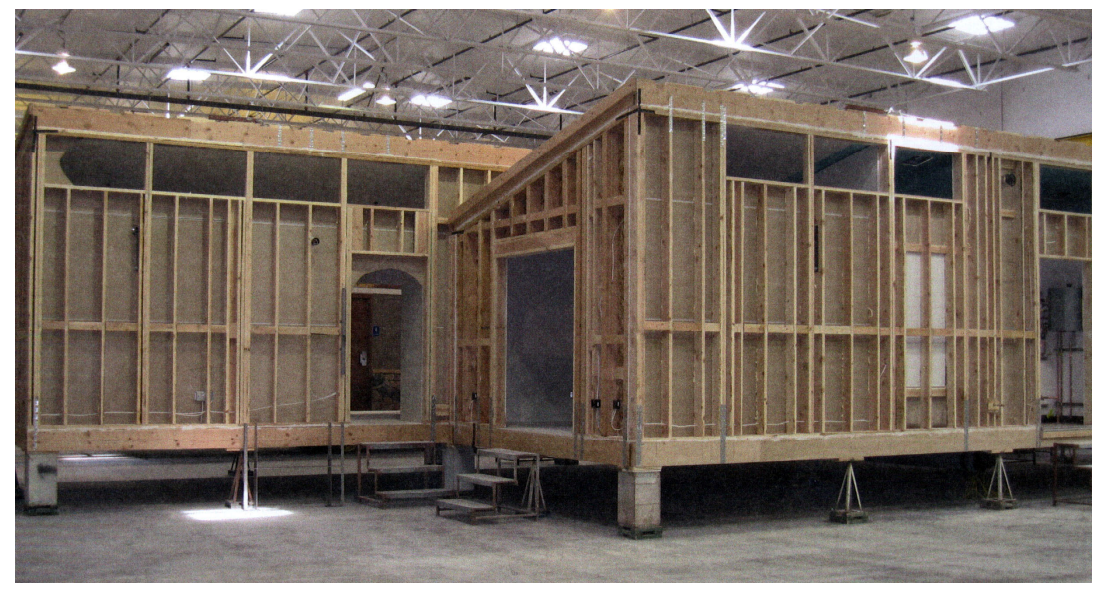

Figure 186: MKD Glidehouse modules in factory production. Source: S. Costa Duran, Green Homes, New York: Collins Design, 2007: 69.

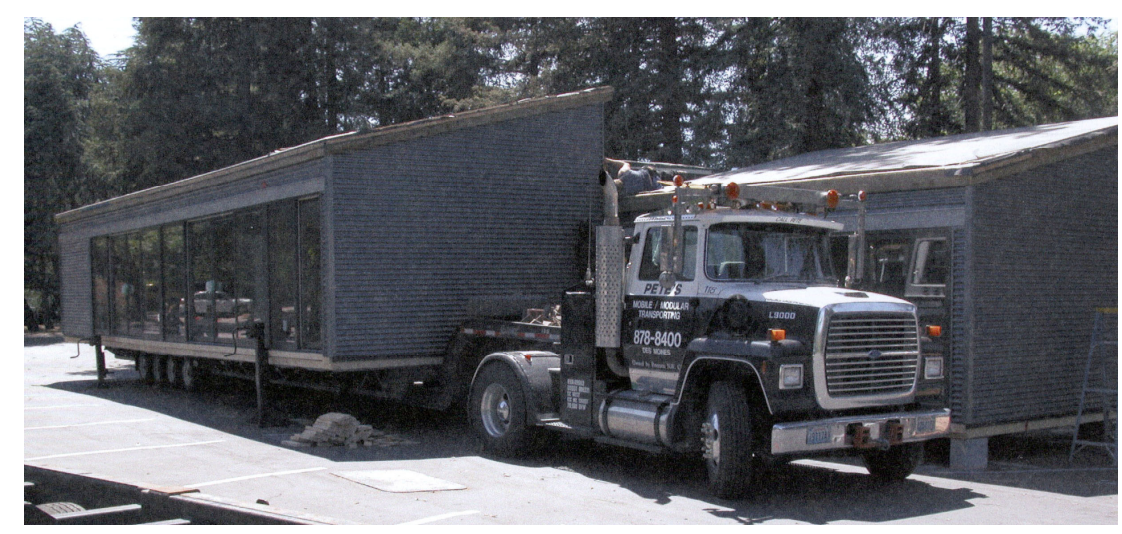

Figure 187: MKD Glidehouse modules ready for transportation to site. Source: S. Costa Duran, Green Homes, New York: Collins Design, 2007: 69. 


\section{Michelle Kaufmann Designs (MKD) - San Francisco}

Michelle Kaufmann is a leading figure in the promotion of 'green modern prefab'. In 2002, she created MKD, a full-service design-and-build architecture firm focussed on the prefabricated house industry, driven by her own frustrating house-hunting process (28). Her own Glidehouse was built using traditional construction techniques, at the same time as producing a modular trademarked Glidehouse product for a client. Kaufmann and McGrath's self-published 2006 book Prefab Green documents this process showing the modular house was cheaper and took just four months to build, compared with fourteen months for the site-built house (21). ${ }^{139}$

MKD began outsourcing to Canadian Britco Factory Built Buildings which had experience with modular building since 1977. The first Glidehouse was built at the factory in twenty-four days, wrapped and transported to California for a Sunset magazine publicity event, then transported to its final site in Washington (Egan) (186-187). In 2006, MKD started Seattle MkConstructs factory to service the Western States and Hawaii. Ownership and control enabled them to conduct more design-based research and development by accepting full legal liability (Kaufmann). More recently, they had to work with other factory partners such as Blazer Industries and Modtech in order to handle increasing volume and expanding territories. ${ }^{140}$

Kaufmann is a proponent for sustainable prefabrication citing green, modern and modular as the three criteria employed in order to make "thoughtful sustainable design accessible". MKD maintain that its system "reduces waste by up to fifty percent to seventy-five percent through the use of precision cutting, storage capacity and material reuse" (Dana Smith). Other sustainable design aspects include healthy materials, efficient planning, and energy-saving systems. ${ }^{141}$

MKD produces a range of pre-configured models, custom solutions and multi-unit communities built from timber-framed modules with SIPs panel infill. ${ }^{142}$ The Breezehouse model uses two volumetric modules to frame an open-plan living area which is covered by a roofing volume (188, 291). ${ }^{143}$ Commercial success is evident in twenty-eight homes having been completed to mid2008, and plans in place to complete one-hundred homes in 2009 and a further two-hundred in 2010. Of the one-hundred projects completed or currently in progress, eighty percent are preconfigured and twenty percent are custom designs (Dana Smith). In an effort to reduce housing cost, Kaufmann considers it necessary to collaborate more with developers on multi-unit projects.

139 The Prefab Green book was updated and commercially published under the same name in February 2009 by Gibbs Smith by authors Michelle Kaufmann and Cathy Remick. This research refers to the 2006 self-published book.

140 Mid-2009 indications are that Modtech is in receivership, a victim of the economic recession (Dakota Smith "Prefab Sad").

141 The five MKD eco-principles include smart design (for flexibility and to use less resources), eco materials (including renewable and recycled), energy efficient (systems and monitoring), water conservation (reduce, reuse and conserve), healthy living (low emission materials and paints) (Michelle Kaufmann Designs).

142 Pre-configured homes allow clients to customize by choosing finishes from pre-selected options. MKD currently offers six pre-configured designs to choose from: Glidehouse, mkLoft, mkLotus, mkSolaire, Sidebreeze, and Sunset Breezehouse. Custom homes enable clients to create one-of-a-kind designs, add additional space, or incorporate higher-end materials, while still enjoying the benefits of prefabrication. Community projects allow MKD to focus on a fast-growing market segment that includes multi-family dwellings, hotels, resorts, and educational facilities (Michelle Kaufmann Designs).

143 Lloyd Alter argues that this is a hybrid typology, but this does not conform to the definition of hybrid module-plus-panel set out in this thesis (Alter). 


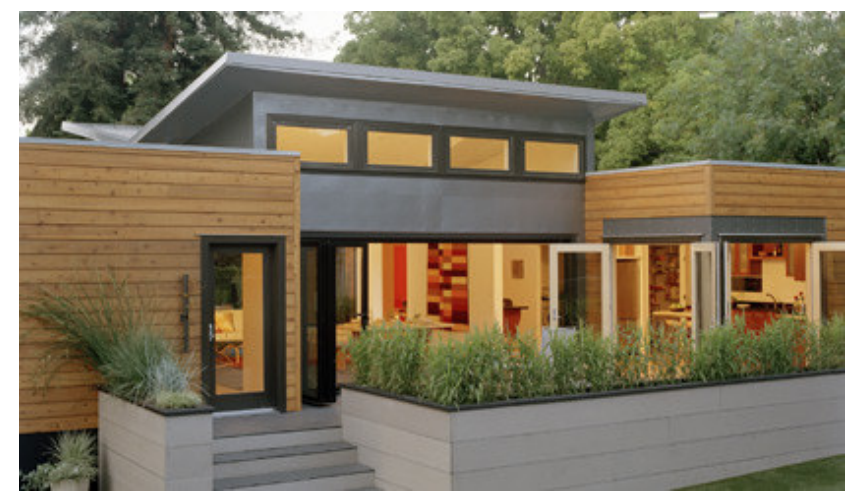

Figure 188: Sunset Breezehouse volumetric modules and roofing module spanning between. Source: <http://www.mkd-arc.com/homes/>.

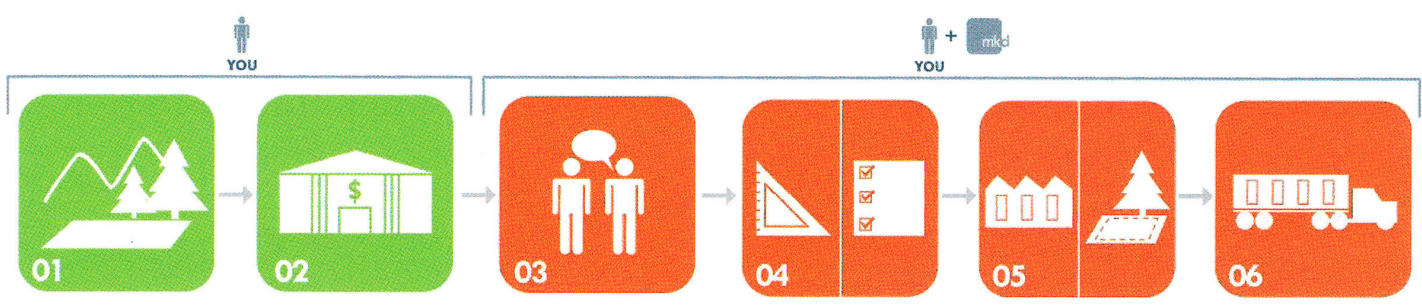

Figure 189: Simple website icons represent stages of the prefabricated housing process. Source: M. Kaufmann and M. McGrath, Prefab Green, San Francisco: MKD, 2006:55. 
Michelle Kaufmann exhibits an extremely professional marketing approach. Her work is widely published and MKD homes have been showcased at a number of exhibitions and museums, including the National Building Museum, the Vancouver Art Centre and the Museum of Contemporary Art (MOCA) in Los Angeles. ${ }^{144}$ Most recently, the first $m k$ Solaire housing model debuted at Chicago's Museum of Science and Industry as the central focus of the 'Smart Home: green and wired' exhibition (205). ${ }^{145}$ Show-home model exhibits and personal appearances at events such as 'West Coast Green', 'CABoom' and 'Dwell on Design' are complemented by extensive marketing material. Marketing tools include a polished informative website selling homes and lifestyle products, a personal blog, monthly e-mail newsletters, home-show representation and conference presentations. Part of her marketing strategy is to lead thought on 'green modern prefab' design through publishing research papers on subjects such as proposing sustainable-labelling for homes and outlining water conservation strategies. ${ }^{146} \mathrm{Her}$ website goes a long way to simplify the prefabrication procurement process and sustainable benefits by using strong graphics, colourful icons and informative fact sheets (189).

MKD faces similar challenges to the other California-based prefab firms; tight economic conditions in the housing industry, tough building regulatory codes, and housing product prices that are higher than the market would prefer. In her address to the 'Dwell on Design' conference, Kaufmann acknowledged the personal toll and difficulty of establishing a 'green modern' architectural prefabrication business in the current start-up industry, citing that she had lost track of the six "dog-years" of work where design is such a small part of the overall process (Kaufmann). In May 2009, the challenges became overwhelming and the difficult decision to close the business was taken. Michelle Kaufmann cited commercial difficulties in prosperous economic times as factories were too busy fulfilling orders and did not want to experiment, and also difficulties in a recessionary economy as two modular housing factories had closed and customer finance conditions were tight. In the near future, she intends to contract to established businesses and focus on multi-unit developments which are more sustainable housing methods (Hawthorne) (304).

Considering these recent events, Michelle Kaufmann shows an exemplary attitude of tenacity and leadership. Her MKD 'green modern prefab' homes remain precedents for their build-ability, sustainability and marketing. New Zealand prefabricated housing businesses can learn from Kaufmann's experience of prototyping her own home, emphasis on business fundamentals, diversification between custom, pre-configured and multi-unit housing, and recognition of the importance of professional public relations.

144 The Glidehouse has been featured in several books including Koones' Modular Mansions and Stang and Hawthorne's The Green House. Kaufmann's own book Prefab Green is another example of her pervasive marketing strategy.

145 The original MkSolaire exhibit was so successful that it was kept on for a further term, from 19 March 2008 to 3 January 2010.

146 In 2008 Kaufmann released white papers on 'Nutrition labels for the home' and 'Re-defining Cost', and in 2009 'Prioritizing water conservation', available through her website (Michelle Kaufmann Designs). 


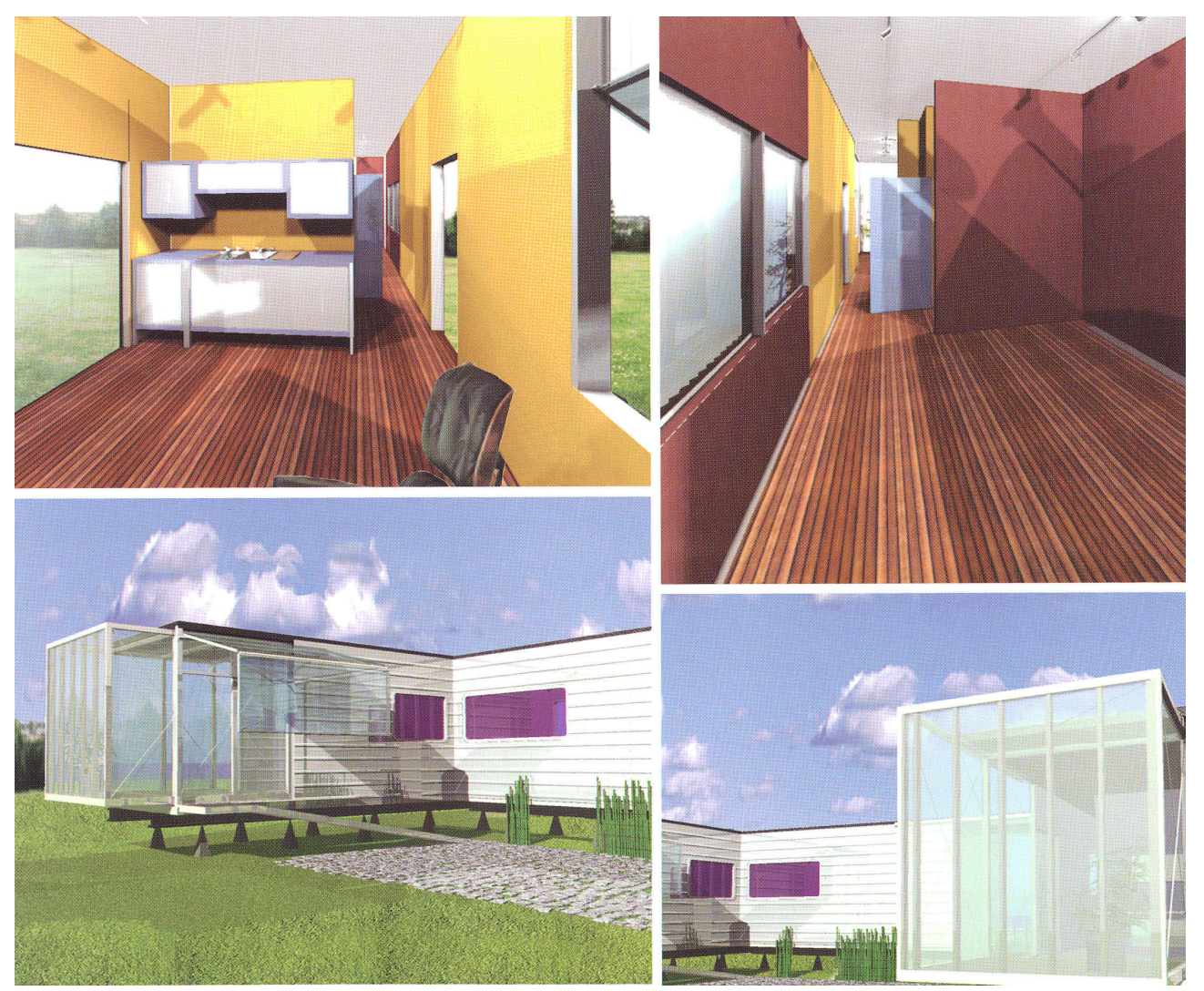

Figure 190 - 193: Renderings of Jennifer Siegal's Portable House. Source: A. Arieff and B. Burkhart, Prefab, Layton: Gibbs Smith, 2002: 142. 


\section{Office of Mobile Design (OMD) - Los Angeles}

Jennifer Siegal is the founder and principal of Office of Mobile Design (OMD) and has academic experience in North Carolina and California. Her university masters and fellowship positions enabled her to focus on the "use of intelligent, kinetic, and lightweight materials", as well as enlist the assistance of students towards projects such as the Mobile EcoLab. ${ }^{147}$ She was inspired by nomadic lifestyles, new technologies and a desire to respond to the "underdesigned" examples of manufactured housing (McGuigan and Kuchment). Re-thinking the manufactured home and associated stereotypes led to a design solution she envisaged would plug into existing parks to create better environments and influence architectural change (Arieff and Burkhart 143). Six years later, her designs have not been taken up by current manufactured home park residents, but instead by the early-adopter market. These OMD customers are primarily first-time home buyers who are educated, appreciate contemporary design, and are in the middle-to-high income bracket (Siegal, Interview).

Siegal's completed projects are testament to her personal persistence and relentless selfpromotion. She was the one-time 'It' girl of prefabricated residential architecture having generated a wealth of publicity surrounding her small amount of work. ${ }^{148}$ As editor of Mobile: the Art of Portable Architecture in 2002, she established her reputation as a primary proponent of contemporary prefab. ${ }^{149}$ Siegal's hands-on attitude is evident in her boutique architectural practice of three staff, her refusal to grow through external funding and her successful personal management of marketing and publicity.

OMD uses a range of prefabricated structural solutions. The Portable House is based on the manufactured home in that it arrives as a complete building to site (190-193). The Swell House structure is made of exposed steel S-shaped frames bolted back-to-back once at the site, together with SIPs wall panels containing electrical, plumbing and cabling. The steel-framed Show House is a complete building that functions as a show-home and was for sale at a site near the OMD office in Venice (194). Its offshoot, the Take Home pre-configured range, is an inhouse development as part of an exclusive factory relationship with the Brandall Modular factory (Siegal, Interview).

OMD prides itself on its sustainable architecture, utilising a range of materials which are not yet readily available in New Zealand. ${ }^{150}$ Siegal estimates her prefab houses offer a saving of fifteen percent on conventional building and are the least expensive of the contemporary architectural prefabs on the market. She admits her greatest challenge is to find a way to increase customdesigned production to make prefab houses more affordable without resorting to

\footnotetext{
147 This interest in materials led to her role as founder and Series Editor of "Materials Monthly" in 2005 to 2006, and use of lightweight and sustainable materials in her ongoing designs (Siegal, Interview).

148 She has been the subject of her own 2005 monograph, and her work appears in over thirty other titles (Amazon).

149 Siegal's latest edited book is More Mobile: Portable Architecture for Today published in 2008.

150 Materials include Durapalm (coconut-based flooring), Plyboo (plywood-based flooring), Wheatsheet (internal wallboard), Kirei Board (sorghum plant wallboard), Biocomposites (such as sunflower seed board for cabinetry), and non-VOC (volatile organic compound) paints (Siegal, Interview).
} 


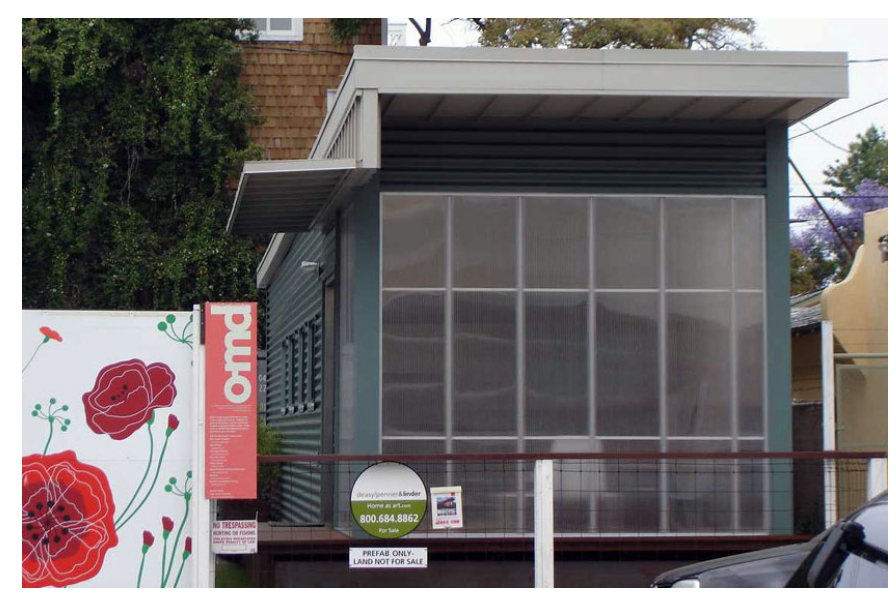

Figure 194: OMD's Show House street frontage, Los Angeles. Source: Author's photograph, 2008.

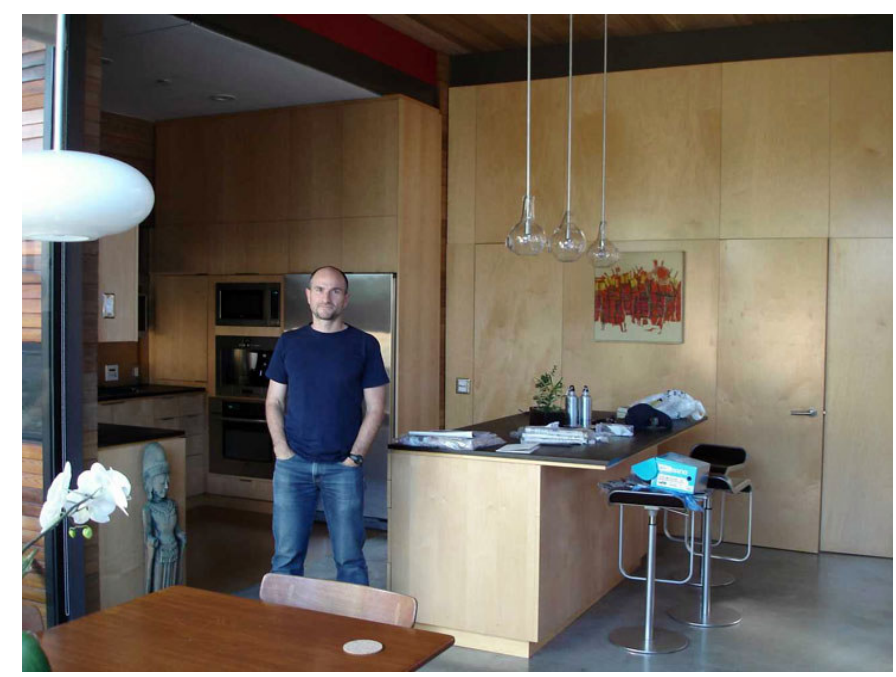

Figure 195: Steve Glenn in the First LivingHome, Los Angeles. Source: Author's photograph, 2008.

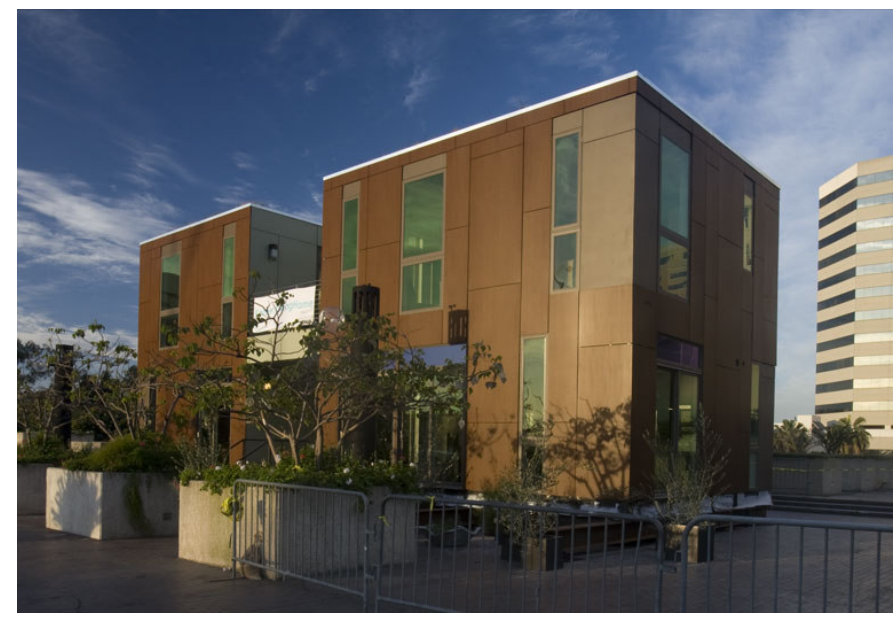

Figure 196: KieranTimberlake-designed KT1.5 LivingHome, Long Beach. Source: <http://www.livinghomes.net/gallery/>. 
standardisation that would "dumb the work down to hit that market". She identifies market opportunities in supplying more school and multi-unit developments. Siegal hopes that there will soon be a greater supply of composite and recycled materials, and more sustainable technologies from renewable sources, as well as promotion of prefabrication by local and national government through tax incentives. ${ }^{151}$ Overall, Siegal is optimistic about prefab's future and predicts that fifty percent of homes will be built in a factory within five years time (Siegal, Interview).

Prefabricated housing suppliers in New Zealand can learn from Jennifer Siegal's prefab prototypes that result from combining academia and practice, from her pervasive marketing emphasis, and from her focus on schools in addition to multi-unit and custom residential prefabrication to widen OMD's potential target market.

\section{LivingHomes - Los Angeles}

Founder and CEO Steve Glenn insists he had "neither the talent nor the temperament" to finish the architecture degree that he started in his youth.

I realized that developers, not architects, control what gets created in the built environment, and I concluded that I should become a developer... who could wed profit and purpose in my work (LivingHomes).

After a career in the lucrative field of information technology development where he learnt about the object-oriented design approach, Glenn applied this principle in starting his LivingHomes business with the construction of a prototype home in 2003. His childhood fascination for Lego building blocks, combined with his passion for mid-twentieth-century Modern architecture led to this first collaboration with architect Ray Kappe. After building two prototypical homes to Kappe's designs, LivingHomes had sixteen houses in various stages of the design-build process in mid-2008. Seven of these were for multi-family homes designed by New York architects KieranTimberlake, while others were custom designs (Glenn).

The First LivingHome where Glenn resides was constructed seventy percent offsite by Profile Structures in their Sante Fe Springs factory $(29,195,197,320)$. Concrete slabs were poured on the site due to the changing floor level design and prefabricated steel portal frames were set in place. The Second or Wired Magazine LivingHome at Rochedale was eighty percent completed offsite as the concrete floor slabs were poured in to steel-framed modules in the factory. The new LivingHomes designs by KieranTimberlake feature a hybrid system consisting of a utility core, timber frame, and pre-wired, pre-ducted cold-rolled steel panels (196, 297-298). These are future-proofed by add-on flat-pack rooms and are planned for sites in San Francisco after having showcased at the 'International Builders Show' (IBS) in Las Vegas in January 2009 and the 'Technology Entertainment Design' (TED) conference in Long Beach in February. In both cases, the housing system was assembled at the site in less than four days.

151 OMD has a current dialogue with Los Angeles' Community Redevelopment Agency (CRA) about land ownership and a possible recommendation for incorporating prefabricated technologies (Siegal, Interview). 

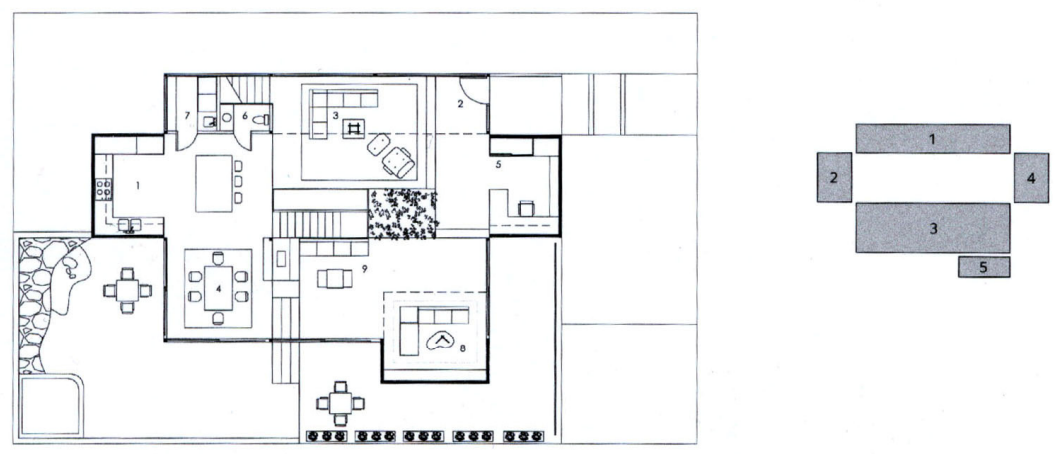

Ground floor

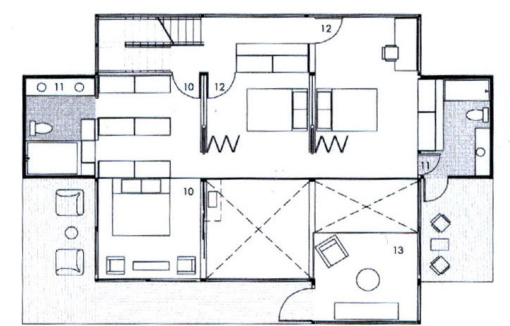

First floor
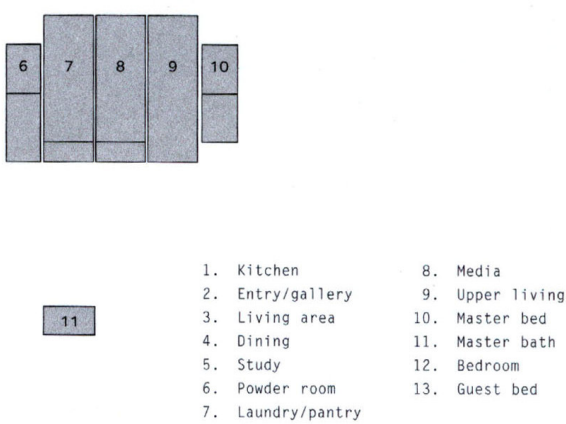

Figure 197: LivingHomes' First House floor plans and module assembly layouts. Source: S. Costa Duran, Green Homes, New York: Collins Design, 2007: 124. 
LivingHomes products are aimed at the upper-end of the market, yet Glenn maintains the homes are still cheaper than similar site-built custom architect-designs. They are made by Modtech in an exclusive relationship with LivingHomes. ${ }^{152}$ The emphasis on marketable sustainable design is evident in LivingHomes being the first United States business to offer prefabricated homes with LEED platinum certification. ${ }^{153}$ It is the highest residential accreditation available under the United States Green Building Council and features include a greywater-ready system, photovoltaic panels, solar hot water panels, a living roof, and an environmental monitoring system to measure water and electricity usage. ${ }^{154}$

The start-up process for LivingHomes has been fraught with challenges. Glenn identifies the battle to correct consumer misperceptions as one of the key challenges in this emerging industry. The stereotype of prefab is that people think they can get a fantastic contemporary design for an unrealistic price (Glenn). ${ }^{155}$ Other issues include transportation size restrictions which are relevant to modular design more than panelised, and difficulties accessing sites, which necessitates a feasibility study early in the process. Glenn also cites the overall start-up period of the contemporary prefab industry and associated higher costs in production and overheads. Therefore, he foresees a consolidation of the industry, along with improving efficiencies, particularly during current tight economic conditions.

Glenn is an adept marketer who attends and speaks at industry events such as the National Association of Home Builders conference (NAHB) and 'Dwell on Design'. LivingHomes has a polished website and is an industry member of the National Modular Housing Council (NMHC). The show-home at the recent IBS event is integral to their marketing strategy, enabling them to reach thousands of people first-hand (Glenn). LivingHomes offers New Zealand prefabricators an insight into architect collaboration, and exemplary marketing through show-homes, website, publicity, exhibitions and seminars.

\section{Dwell Homes by Empyrean - Massachusetts}

The Dwell Homes by Empyrean are included here because of their exemplary branding relationship with Dwell magazine and presence at the 'Dwell on Design' exhibition. Despite being a large company manufacturing prefabricated homes for more than sixty years, Empyrean became one of the first casualties of the 2008 and 2009 worldwide economic recession. Their story follows, in the hope that some value can be gained from it.

\footnotetext{
152 Both Marmol Radziner Prefab and MKD have also worked with Modtech. Mid-2009 information suggests that the company is in receivership (Dakota Smith "Prefab Sad").

153 LEED is an internationally recognized certification construction sustainability rating system that measures how a building or community performs across metrics such as: energy savings, water efficiency, $\mathrm{CO}_{2}$ emissions reduction, improved indoor environmental quality, and stewardship of resources and sensitivity to their impacts. LEED was developed by the United States Green Building Council (USGBC). 154 The LivingHomes website features a claim to six zero-based environmental factors (Z6); zero energy, water efficiency, lower emissions, reduced carbon, waste reduction, and zero consumer ignorance through the monitoring system which focuses on life-cycle running costs. On one project seventy to eighty percent of initial demolition waste was diverted to Habitat for Humanity (LivingHomes)

155 This opinion was also expressed by Jared Levy at Marmol Radziner Prefab (Levy).
} 


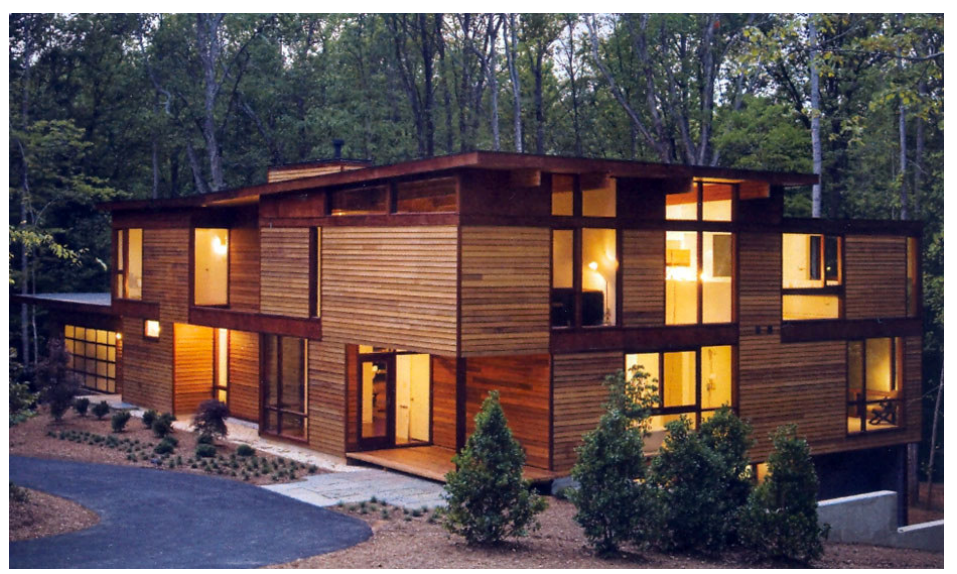

Figure 198: NextHouse by Resolution: 4 Architecture for Empyrean. Source: Empyrean Dwell Homes brochure, courtesy of Empyrean.
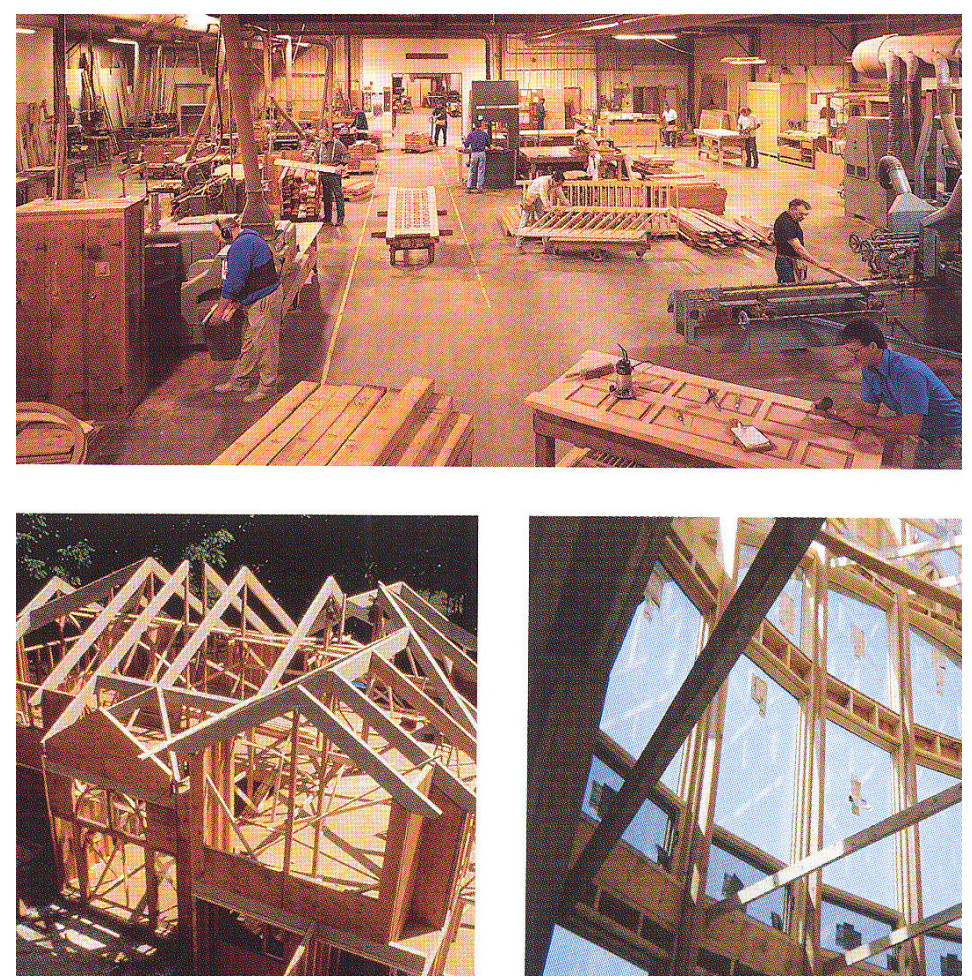

Figure 199 - 201: Empyrean factory and timber components for Acorn and Deck houses. Source: Empyrean 'Architecture Planning Fabrication' brochure, courtesy of Empyrean. 
In its sixty-one year history, Empyrean manufactured prefabricated houses for over twentythousand homeowners. These were mainly from their traditional prairie-style Deck House line and craftsman-style Acorn House line, originally separate companies that merged in 1995 (Empyrean brochure). Dwell Homes by Empyrean began in 2005 in a meeting with the magazine's editor-in-chief Allison Arieff who connected them with Minneapolis architect Charlie Lazor. Empyrean proceeded to extend their prefab housing line with the NextHouse by New York's Resolution: 4 Architecture and they received more than seven-thousand-five-hundred customer inquiries as a result (Schonfeld) (198). In 2008, shortly before their demise, Empyrean launched new designs for the HingeHouse model by architect Maryann Thompson (Eli and Giliane).

A branding partnership with Dwell meant Empyrean received a free full-page colour advertisement in each monthly issue, worth about a quarter of a million United States dollars annually, and in return the magazine received a licensing fee on every home sold (Schonfeld). Empyrean used standard details, rather than standard plans, to allow customisation and flexibility to deliver predictability with design, costs and construction time (Eli and Giliane). They utilised a pre-cut and pre-drilled timber post and beam structure with prefabricated panels and proprietary components installed once at site. By mid-2008, they had shipped thirty-two Dwell Homes around the country and had twenty-five in the design process, as well as a fifty-unit project destined for the United Kingdom to be shipped in flat-pack form from their two-hundredthousand square foot Acton, Massachusetts factory (Eli and Giliane) (199-201).

In 2006, Empyrean predicted the level of consumer interest to make up as much as half their existing business of two-hundred traditional prefab homes per year within two years (Schonfeld). This was an ambitious goal which they almost reached, with around seventy-five dwellings in the design-build process by mid-2008. Unfortunately the gravity of the United States-focussed economic recession forced the company into receivership in December 2008, with remaining hopes pinned on finding a buyer for the faltering business. One of their key challenges was in market education as homebuyers and builders were yet to understand the benefits of prefabrication, despite architects seeming to have a wider awareness (Eli and Giliane). To combat some of these misperceptions, the Empyrean brochure carefully uses terms such as pre-engineered, pre-cut, proprietary components, panelised construction and systembuilt instead of prefabrication, and "climate controlled indoor environment" instead of factory.

The New Zealand prefabricated housing industry can learn from Empyrean's strategy of using a flexible construction system to provide an infinite range of housing configurations, collaborations with well-known architects, offering a range of styles to broaden their marketing base and forming a marketing relationship with an established magazine brand to develop housing products for identified target consumer niches. 


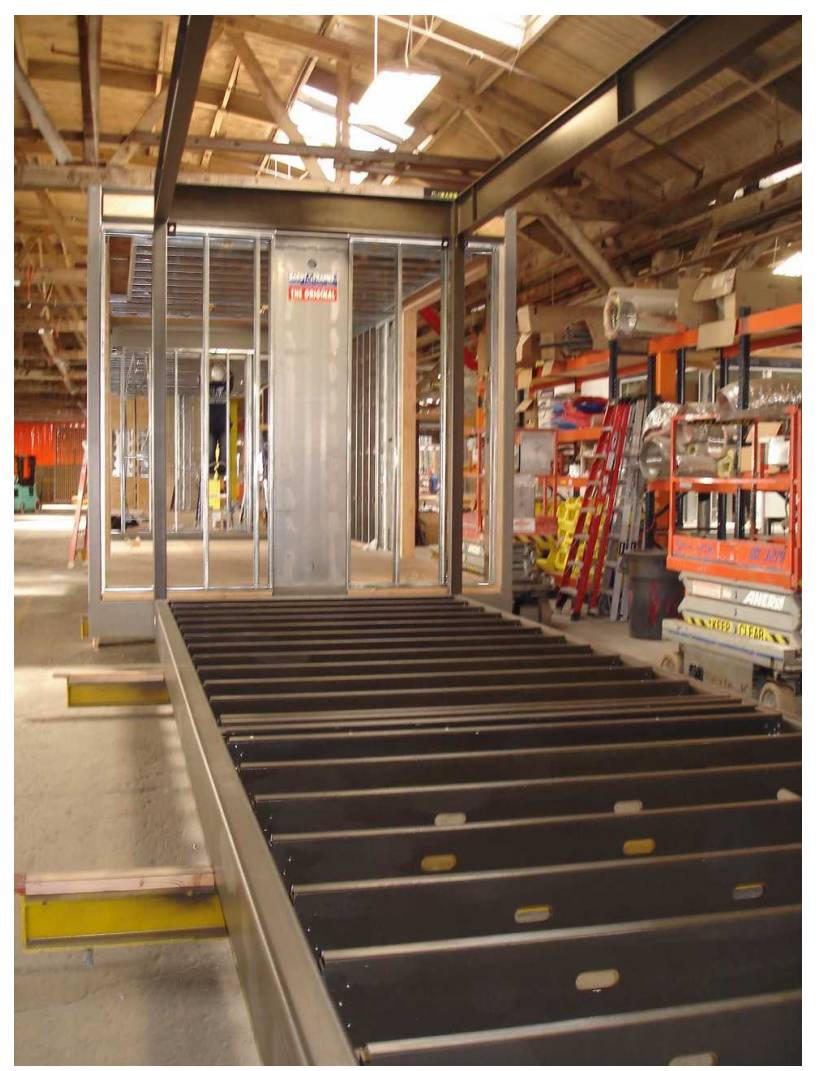

Figure 202: Marmol Radziner Prefab factory module fabrication. Source: Author's photograph, 2008. 


\section{International Issues}

Architects have been motivated to join the 'green modern prefab' movement in reaction to low construction standards, an overall lack of quality control and the intention to supply betterdesigned housing at a more affordable price to a wider range of people. Common issues identified in the California case studies and international overview are summarised here, grouped according to the three main areas of economic, design and manufacture, and sociocultural themes.

In terms of the international economy, there are indications that China will likely become a primary source of steel-based housing manufacture, based on Chinese manufacturers' current production of a wide-range of household products. In the United Kingdom, government mandates have been successful at setting minimum levels of prefabrication in multi-unit social housing.

The contemporary architect-designed 'green modern prefab' housing movement has been in a start-up period since the turn of the millennium. This period has recently coincided with worldwide recession and as a result, developer interest in new projects is at an all-time low. ${ }^{156}$ This start-up industry is being judged by what it has delivered, rather than the potential for innovation that it represents. Allison Arieff notes:

\section{"...nationally there are only one-hundred houses of this type that have actually been built. A lot was over-promised and under-delivered, so now we are going through this period of realism where the consumer wants to see what is available and possible. For a lot of people it is still conceptual - architecture on paper" (Arieff qtd. in Keeps).}

The financial viability of the contemporary prefab industry is still uncertain. Adaptable businesses may use this period of economic uncertainty as an opportunity to increase efficiency through developing more standardised components, and by close control of demand flow through the factory (Marmol).

Industry bodies were not commented on by the Californian participants, although MKD joined the Modular Building Institute and LivingHomes used industry association membership as a way to attend exhibitions and reach a larger target market audience. Several of the case study precedents are doing an exemplary job at marketing and sourcing investment funding on their own. New Zealand's small and disparate prefabricated housing industry can learn from the protection provided by a marketing umbrella association like the United Kingdom's Buildoffsite initiative, as well as from research outcomes as a result of programmes by BRE. 

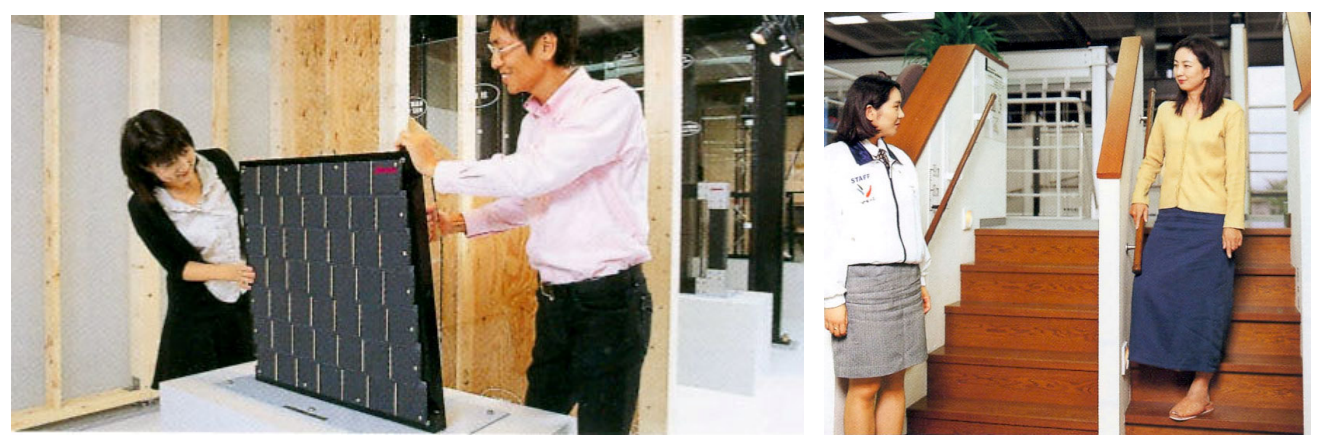

Figure 203 and 204: Female customers at Sekisui House's R+D Institute, Japan. Source: Sekisui House brochure: 8 and 20. 
Several industry participants identified a need to achieve architectural and quality control through the construction process. ${ }^{157}$ Architects acting as general contractors further benefited from owning and running factories which allowed experimentation of innovative products and technologies without risking litigation, as well as a strong focus on quality, consistency and care which was previously lacking in the building industry (Kaufmann; Marmol) (202). An identified drawback was in taking control for continuous supply through their factories. Other businesses, such as Jennifer Siegal's OMD and Steve Glenn's LivingHomes, formed exclusive relationships with established manufacturing facilities which meant they did not have to control the supplyflow.

Technology developments used internationally, that are yet to be widely utilised by the New Zealand industry, include rapid prototyping and manufacturing (RP and RM), building information management software (BIM) and electronic bills of materials (eBOM) (Kieran and Timberlake 61). These are backed up by more widespread CAD-CAM interfaces between computing and manufacturing equipment. Other increasingly used information technologies such as e-mail, websites and digital-based communication enable a close traditional architectclient service-based relationship despite long distances. Together they facilitate masscustomisation of architectural prefabricated housing through interactive web-based programs such as Google Sketch-up and Google Earth, as used by MKD on its website. Further technical and manufacturing examples applicable to New Zealand's timber-based industry can be learnt from advanced wood-techniques used in Germany and Austria. ${ }^{158}$

Sustainability factors are paramount in the 'green modern prefab' marketplace. The United States modular home industry generates about two percent waste compared with traditional site-based home construction which sheds thirty to forty percent in wasted materials (Redmond). ${ }^{159}$ MKD quoted construction waste savings of fifty to seventy-five percent from less packaging, efficient cutting, and re-use of off-cuts, as well as water use decreased to one-third of the average person's usage (Pattison). Site benefits such as less noise, dust, pollution, disruption, storage, and deliveries to site, all contribute to make a more pleasant environment in built-up urban areas. Many of the materials used internationally are not currently available in New Zealand. Materials our industry could import or replicate include recycled denim insulation, SIPs, Kirei board, and other recycled components and boards. Michelle Kaufmann identifies that sustainable housing developments in the near future will likely be configured as multi-unit complexes rather than detached dwellings. The future of multi-unit housing relies on developers being able to access investment financing.

\footnotetext{
${ }^{157}$ A 2004 survey on United States builders identified increased quality as the main benefit to their firms for adopting new building and construction products, materials and practices over the last five years (Koebel et al qtd. in Paevere and MacKenzie 22).

158 United Kingdom government-supported research trips have further identified that the Austrian timber prefabrication industry is successful for its multi-generational family businesses (Venables and Courtenay 60).

159 The only waste that leaves the modular prefabricated housing site is the wrapping from transportation. The single trip that a module makes to the site is more efficient than the multiple trips of contractors and sub-contractors and material deliveries (Redmond).
} 


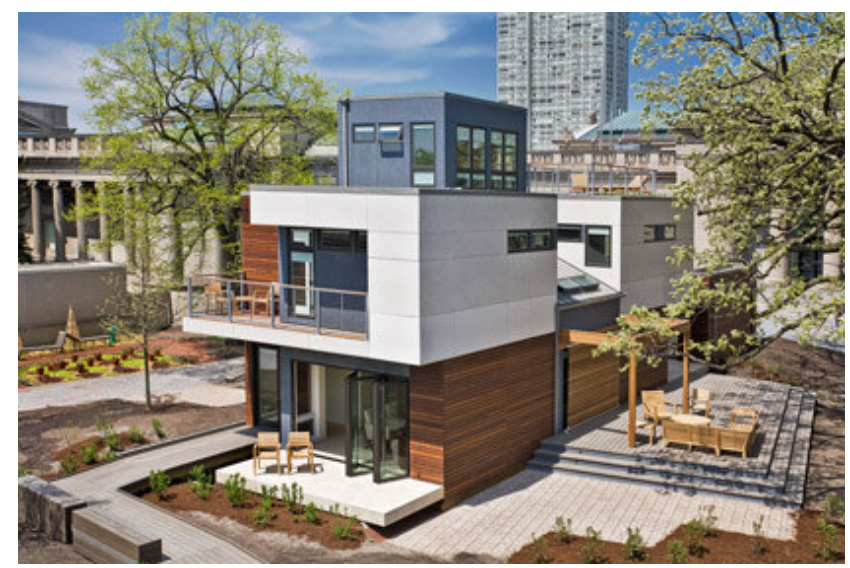

Figure 205: MkSolaire ${ }^{\mathrm{TM}}$ by MKD exhibited at the Museum of Science and Industry, Chicago. Source: < http://www.mkd-arc.com/homes/>. 
The importance of establishing strong socio-cultural communication messages can be learnt from Japanese prefabricated housing businesses. Despite a large population, no two houses produced in Japan are identical (R.Fleetwood). This lesson effectively dispels the myth that customers from a culture that accepts repetition and homogeneity more readily than our own will accept a more homogenous housing product. The Japanese industry can teach us about high levels of customer service through educating their potential customers. They have identified female customers as their primary market group, and appropriately designed a communication approach using home-shows and research and development factory tours (203204). In the United Kingdom, the BRE show-home parks contain housing experiences from a range of prefabrication businesses, as well as educational information centres.

The California case studies are exemplars in professional marketing. ${ }^{160}$ They use combinations of show-homes, exhibitions and events as the most visible ways to enable firsthand experience and to influence customer perceptions of prefabrication (205). Numerous magazines and books track the evolution of prefabrication and its contemporary incarnation

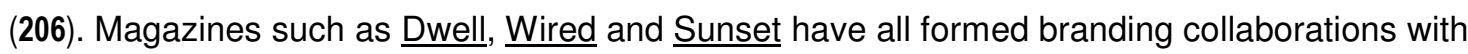
prefab architects in an effort to promote their joint housing products to established market niches (188).

Design competitions are another way to bring prefabrication into the public arena. Australia's 'Houses of the Future' exhibition spawned business opportunities for participants, as did the international 'Lifecycle Building Challenge', 'Solar Decathlon', and 'Make it Right' campaigns. In the United States, universities are embracing their role as educators, influencers and advisors by offering courses on prefabrication through design-and-build studios. Collaborations between practicing architects, academics, tertiary institutions and industry offer opportunities for cross-fertilisation of skills.

Clearing up misperceptions amongst the industry and public is a key challenge identified by most of the case study participants. In the United States, there is a clear disagreement of terms between panelised and modular prefabricators. ${ }^{161}$ There is also some concern within the construction industry about housing valuation standards that take physical area into account but do not take time or environmental savings into account. According to several industry

\footnotetext{
160 Historically, prefab businesses have failed because they didn't make the leap from architectural prototype to successful business. The contemporary situation is that polished marketing with computer renderings is in place before a successful product has even been adequately detailed. This makes it confusing to the end-consumer, and the researcher, both who are often completely reliant on internet-based information. The high-quality control that prefabrication is known for does not extend to its related marketing material. The interviewees Jennifer Siegal, Michelle Kaufmann, Steve Glenn, Leo Marmol and Ron Radziner, have all commanded a substantial amount of television, newspaper, magazine, and website publicity. Glenn's LivingHomes has produced just two homes, both prototypes for his company, yet the body of marketing and publicity material is far greater than this would seem. This is because prefab news is covered from various angles by independent journalists and bloggers, and the same article can appear word-for-word in numerous publications online and in print.

161 Ron Radziner says the prefab "term is thrown around wildly" and believes it should be restricted to modular and volumetric designs. MRP's Jared Levy agrees, saying that flat-pack, kitset, or panelised homes, such as those by Rocio Romero, Charlie Lazor, and LivingHomes with KieranTimberlake, are not 'true' prefab. Levy's reasoning is the large amount of at site assembly work precluding it from realising the full benefits of volumetric prefabrication (Levy).
} 

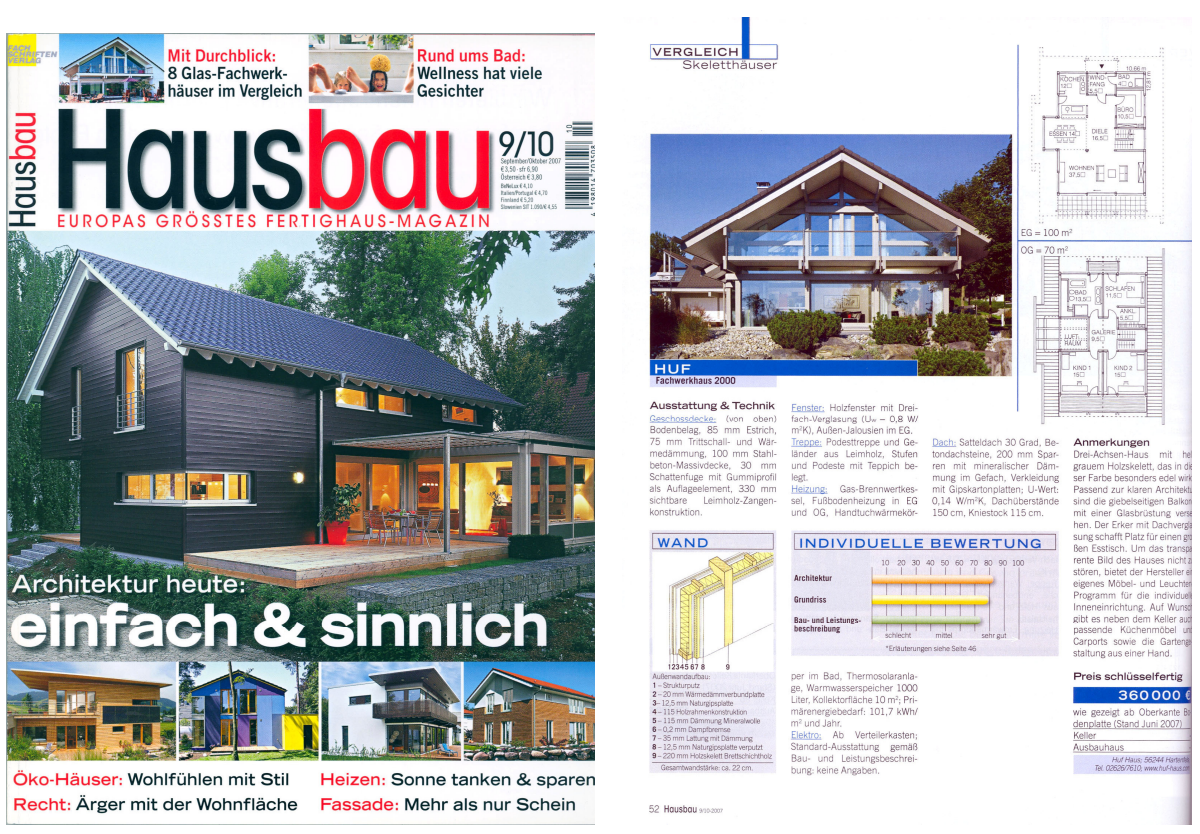

Figure 206: Hausbau magazine cover and typical product case study page of Hufhaus, Germany. Source: Hausbau Sep/Oct (2007): cover and 52. 
participants, the current system is the "most inconsistent and least transparent way to cost" as it doesn't take time-savings or sustainable factors into account (Marmol). Prefab businesses face ongoing battles with consumer misperceptions that prefab will offer great cost savings.

Businesses are faced with the decision to either educate customers about the virtues of architectural quality, or to reduce standards to make a more affordable product. This is a difficult ethical decision for high-architecture businesses such as MRP, who are intent on maintaining the quality standards they have worked so hard to achieve.

International contemporary approaches to common issues are summarised as:

- government leadership, investment and intervention (United Kingdom)

- research and development emphasis on local products (such as timber in Austria and Germany)

- sustainable materials (United States)

- quality-controlled factory environments

- professional marketing approach by individual companies (California) and a holistic marketing body (United Kingdom)

- marketing mechanisms including combined show-home parks, professional events and public exhibitions

- public relations promotional materials such as websites, direct e-mail newsletters, illustrated books and specialised magazines

- an emphasis on high-levels of customer service with a strong focus on education, testing and display facilities (Japan)

The importance and potential of marketing is the greatest lesson for New Zealand prefabricated housing businesses to take from the Californian case studies. Further first-hand research of United Kingdom and Western European prefabricated housing markets would be advantageous to investigate industry associations and timber technologies respectively.

New Zealand's prefabricated housing industry stands to benefit from adapting these international approaches. The next chapter will examine recent New Zealand prefabricated housing products and systems to investigate emerging issues. Based on this developing context, a future potential of prefabricated housing in New Zealand will start to materialise in the chapters that follow. 

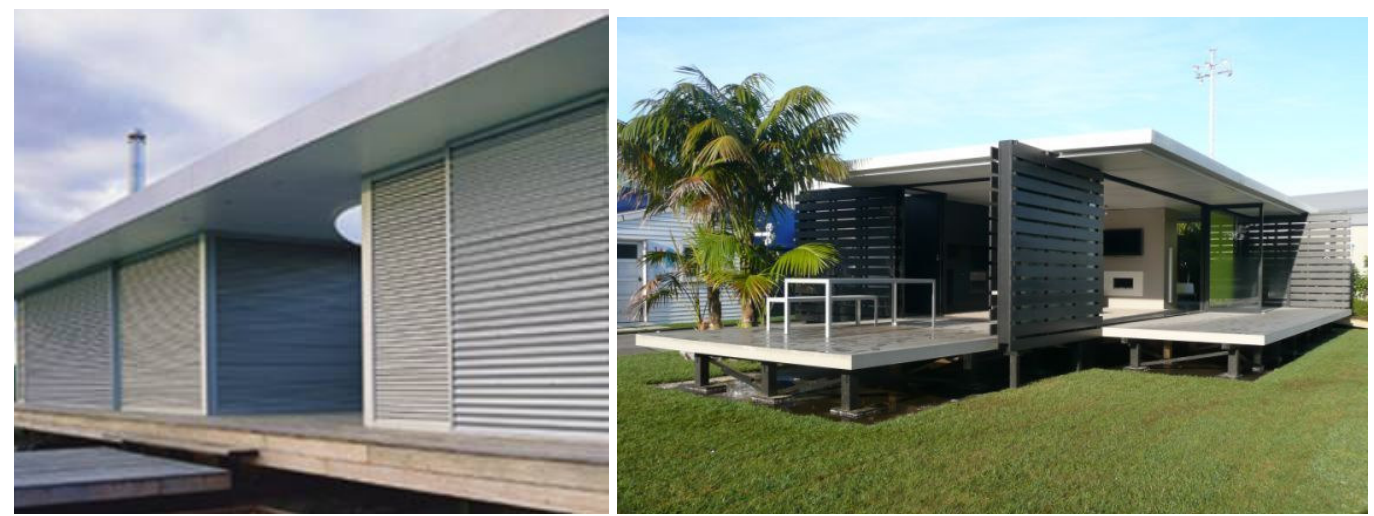

Figure 207 and 208: From bachkit to ipad: prefabricated housing iterations by Andre Hodgskin. Source: <http://www.bachkit.com/> and image courtesy of Architex. 


\section{New Kiwi Prefabs :}

\section{Recent New Zealand Case Studies}

A prefab revival is upon us. Sustainable materials and mid-twentieth-century aesthetics are combining with architect-designed, factory-controlled environments and polished marketing, as seen in the Californian exemplars. In New Zealand, bachkit led the way in 2000 and defined a new standard for high-architecture housing products (refer to Chapter 3) (207). A niche market exists for this housing, but the depth of the market is still unclear. Established firms are developing further product iterations, looking closely at extending prefabrication methods, and collaborating with architects in efforts to lead the way (208). A number of recent innovative systems by architects, builders and industrial designers will be explored as case studies in this chapter.

New systems and products have emerged from collaborations between designers and businesses, from architects taking control of manufacture, and from manufacturers contracting architectural services. Several have made it to market; others have been prototyped and await business input, and a few may never make it off the drawing-board. There may be more housing products in the design stages that this research has not uncovered, or which are too sensitive to allow investigation at this time. It is particularly challenging to launch a new housing product during an economic recession when financial risk-taking is at an all-time-low, despite opportunities to develop from an efficient stand-point and prepare for the forecast pent-up housing demand when a healthier economy emerges.

This chapter will investigate the innovative and exciting prefabricated housing products that are emerging in New Zealand's marketplace in 2009. Issues for discussion will be identified as a means to develop recommended strategies to strengthen New Zealand prefabricated housing in the future. 

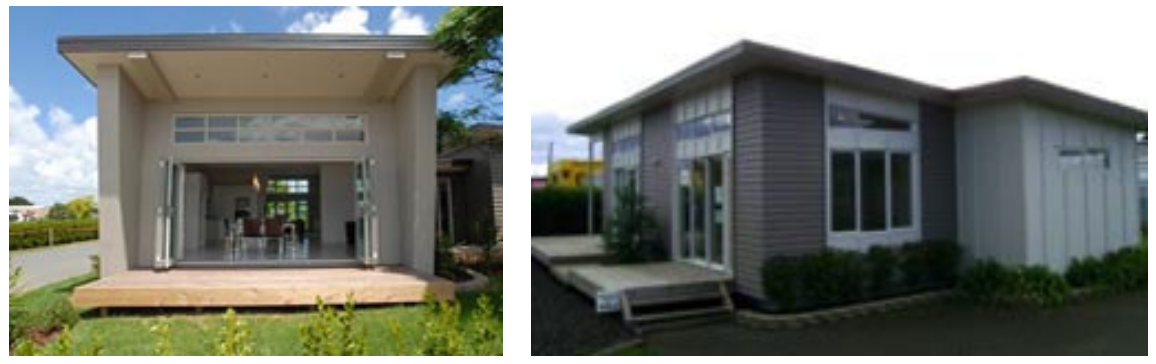

Figure 209 and 210: E-homes by Maddrens: kitset option and transportable options. Source: <http://www.e-homes.co.nz/>.

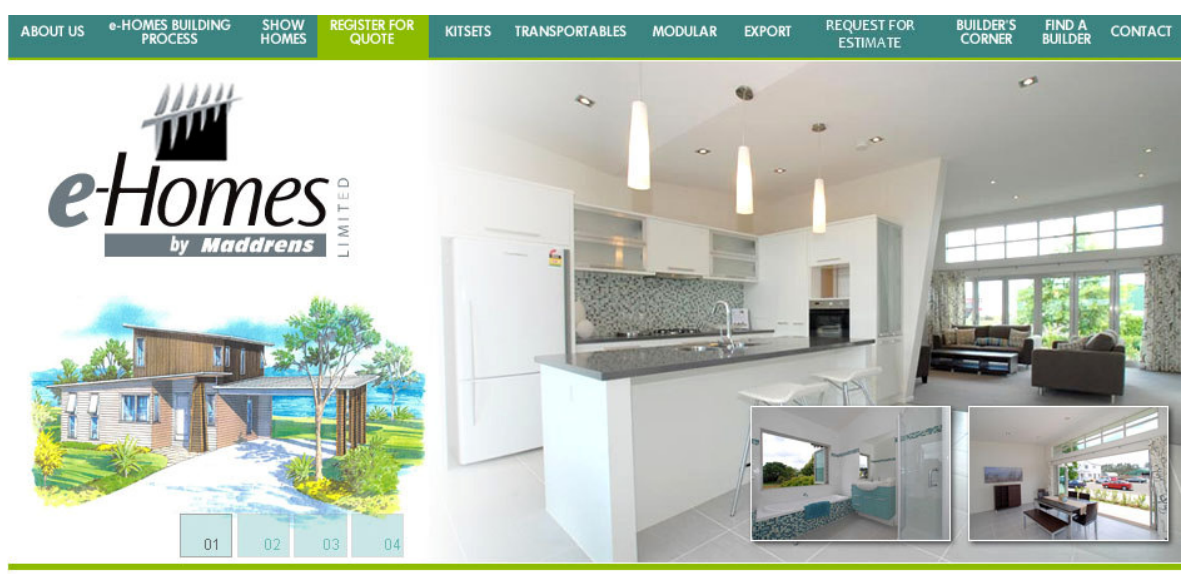

Design package Step4 - Design Your Home Plan help (2)

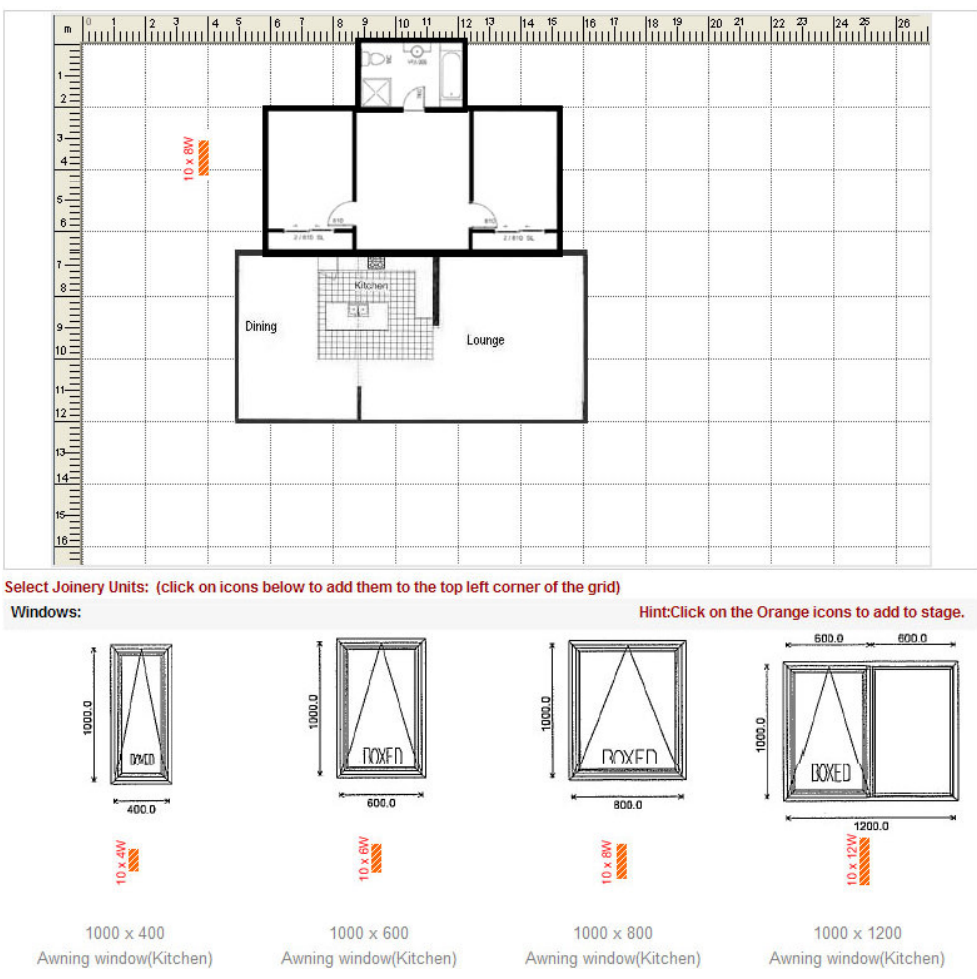

Figure 211: $E$-homes by Maddrens: drafting pad online interface. Source: <http://www.e-homes.co.nz/>. 


\section{Recent Case Studies}

The following case studies span a range of typologies in the New Zealand prefabricated housing industry in 2009. Due to the immediacy of the material, these case studies were largely assembled from first-hand research interviews and site visits, with reference to publicity brochures, websites, electronic articles, and magazines. For reasons of confidentiality and commercial sensitivity at the time of bringing a prefabricated housing product to market, some information has had to be omitted.

\section{Component-based Prefab}

The long-standing kitset industry is a stalwart of New Zealand's DIY tradition. Newcomer ehomes by Maddrens have found this to be a lucrative market, selling over three-million dollars of kitset homes in its first eighteen months (208-209). These homes are sold to a largely Aucklandbased holiday home market for sites in Taupo, Coromandel and north of Auckland (Taylor). Maddrens was one of the partners in setting up bachkit in 2000 and has used this experience together with creating new internet-based tools. The e-homes website offers an in-house Drafting Pad service where the registered user can select standard modules which can be rotated or windows and doors added before being submitted for their three-day quotation service (211). This system is currently clumsy and forces potential clients to think in twodimensions; it would benefit from a three-dimensional modular approach.

\section{Pinespan by Pinecone Timber Buildings - Wellington}

Builder industry veterans Clem Thorn and Bernie Gibbs began working on construction research and development when they met in 2006. They started with small rental cabins and now produce these alongside a larger structural, "kitset module solution" called Pinespan (Thorn and Gibbs) (212-218). The cabins for rent or purchase are constructed in standard modular dimensions, with plywood and timber batten exterior cladding, skilion ceiling options, and a variety of window and door sizes and positioning. They are made in the workshop on table-top jigs using traditional methods, transported flat to site, and then assembled in just a few days by affiliated builders. ${ }^{162}$

Their Pinespan structural system is based on $70 \mathrm{~mm}$-thick plywood timber components and steel knee-joints to create a half-round barrel-shaped structure. The standardised modular configuration enables an amount of design flexibility. Their new Pinespan Lite structural system is made of thinner forty-five millimetre plywood and custom folded steel purlin-hangers with carefully-placed cut-outs in the plywood components to reduce the weight of the system without

${ }^{162}$ Cabin work to-date has been mainly for residential customers who are using cabins as secondary dwellings and sleep-outs on their property, as well as a made-to-order zookeeper flat for the Wellington Zoo, complete with bathroom and kitchenette (Thorn and Gibbs). 


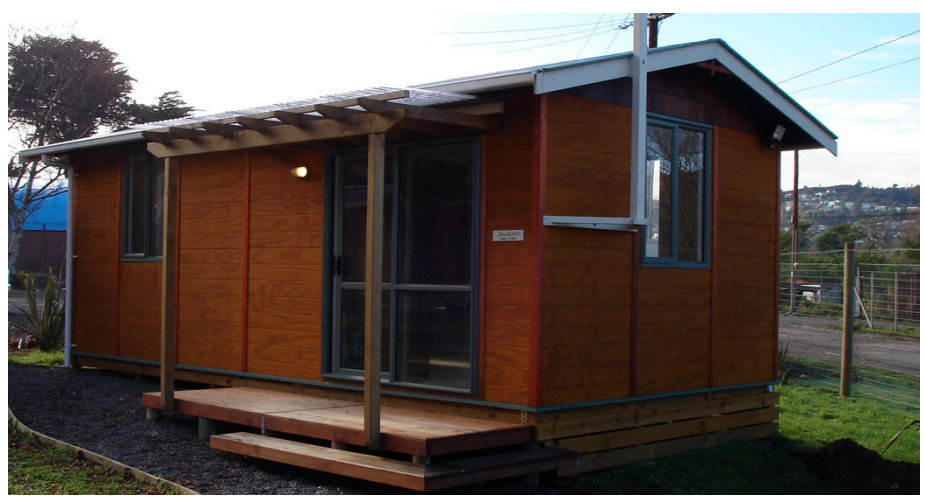

Figure 212: Pinecone Timber Cabin at Manor Park, Wellington. Source: Author's photograph, 2008.
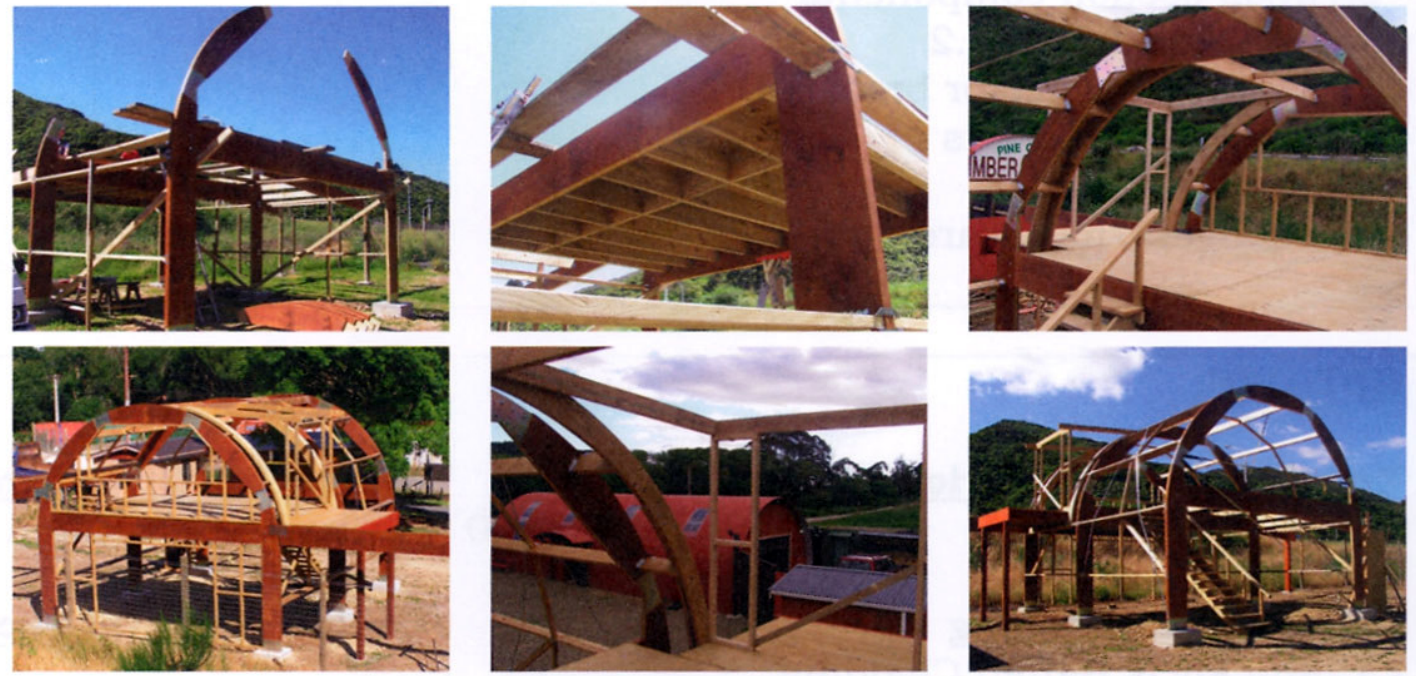

Figure 213 - 218: Pinecone Pinespan system under construction at Manor Park site, Wellington. Source: Pinecone 'Pinespan' brochure, courtesy of Pinecone.

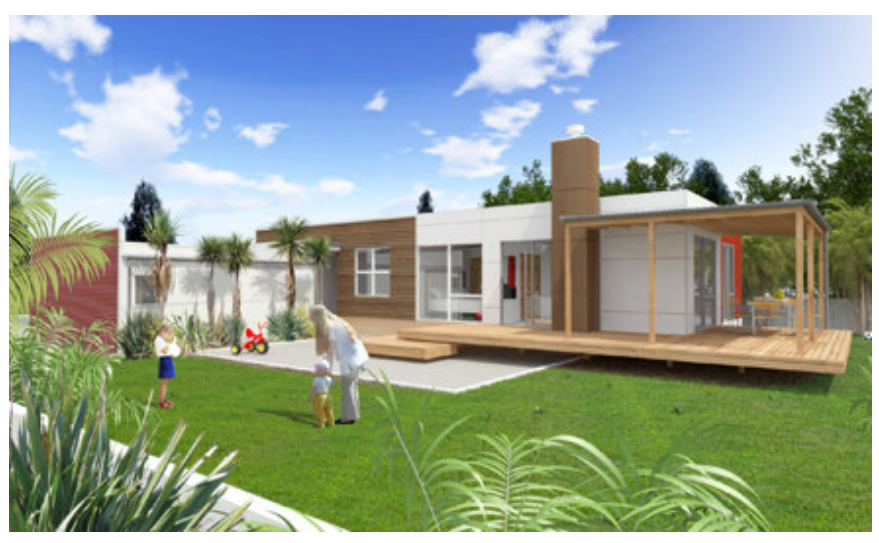

Figure 219: Strawberry Homes Robinson housing model.

Source: <http://www.strawberryhomes.co.nz/index.php?page=robinson>. 
jeopardising its structural integrity. They envisage the new Pinespan systems will enable timber to be used in larger commercial and residential buildings in place of steel. ${ }^{163}$

Thorn and Gibbs are attempting to bring their Pinespan structural system to market on their own which is challenging and exciting as they have received interest from offshore clients for postdisaster housing. This interest is a result of the business' visible location next to the Upper Hutt motorway. Pinecone plans to use CNC fabrication for the Pinespan Lite components and to develop their system nationally through a network of regional accredited builders to complement their existing timber cabin contractors in the Wellington area.

Pinecone's experience shows the advantages of a high-visibility site close to a major road-way, their responsiveness to customer enquiry, first-hand application of research and development, and their future-proofing strategy to use CNC technology.

\section{Panelised Prefab}

Structurally Insulated Panels (SIPs) are a promising emerging technology which is currently used offshore but not available yet in New Zealand (refer to Chapter 3). Products on the market include Triboard and Maxim compressed timber panel systems. Maxim panels are used for internal and external walls by Strawberry Homes in their Hawkes Bay factory. Strawberry Homes was launched in 2008 after two years of research, and is a business venture of established developers Globe Holdings with contracted architecture services from well-known architect Roger Walker (Hartley) (219).

\section{Drop-Loc Building System by Bay Property Care- Opotiki}

In 2005, in remote Opotiki, Graeme and Christine Gerrard used their twenty years of construction industry experience to conceive the Drop-Loc Building System. They were motivated by rising consent, compliance, and construction costs due to site-based delays, weather issues, shortage of skilled labour, and interruptions to the supply of materials. They both thought "there must be a better way" and imagined a takeaway or drive-through type of housing that could provide more options to the market (Gerrard and Gerrard). According to Graeme Gerrard, Drop-Loc is also a response to a perceived need for relocatable state houses under the government's rural house programme for Maori land. The Drop-Loc panel system was designed with locally-based architect Peder Hansen from Denmark. ${ }^{164}$ As of 2008 , the system

163 The Pinespan system is competitive with the steel-framed Totalspan system for garages and sheds, although just for smaller sized buildings (Thorn and Gibbs).

164 Peder Hansen was influenced by a 1967 trip to Greenland where he saw houses that could tumble and be re-erected (Gerrard and Gerrard). Hansen was the first Housing Research officer to the Building Research Association of New Zealand in 1971. He presented a talk at the 1971 Building Products Design Symposium on "Design for Mass Housing" which was published in Home and Building magazine (P. Hansen 9 and 53). 

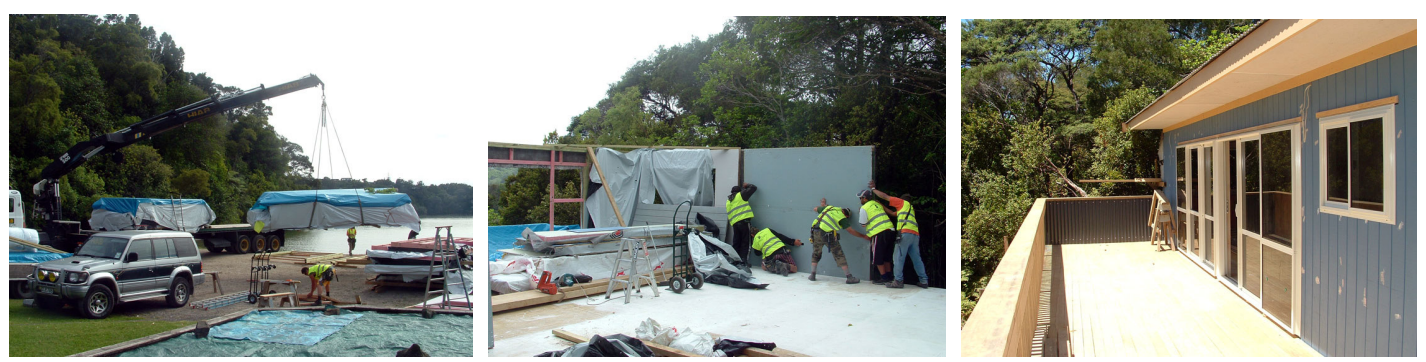

Figure 220 - 222: Waitakere Drop-Loc house: drop-off, panels being installed, and exterior closed-in. Source: Photographs courtesy of Mark Grimes.

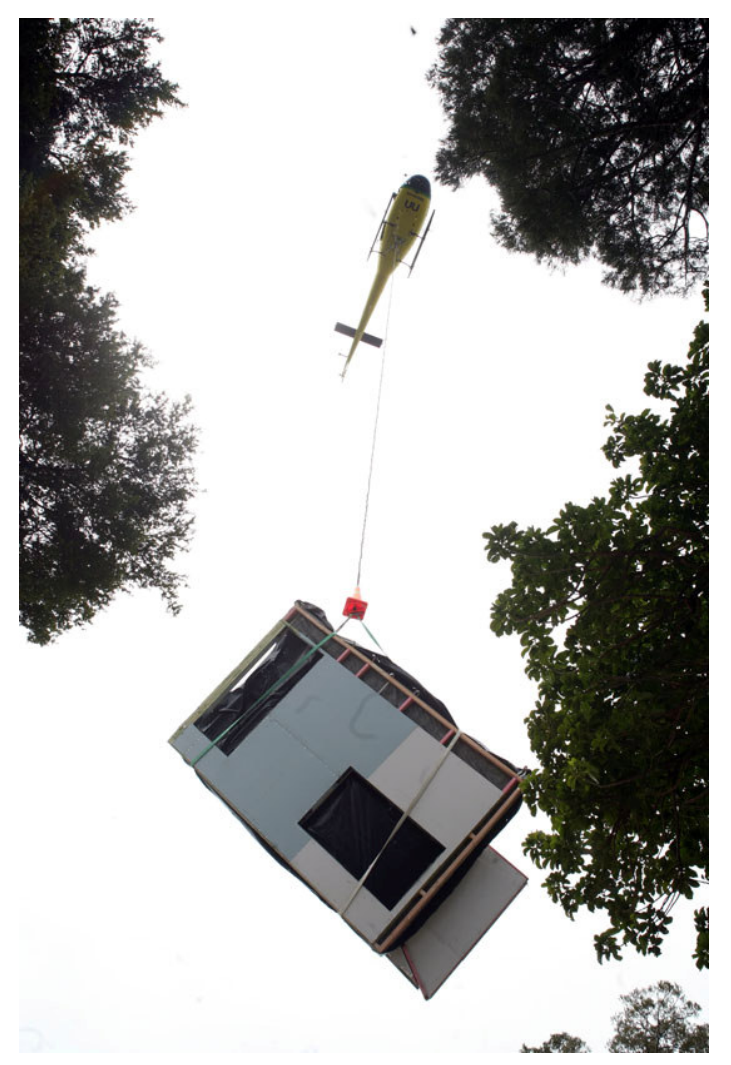

Figure 223: Waitakere Drop-Loc house: helicopter lifting prefabricated panels to site. Source: Photograph by Niels Schipper, courtesy of Mark Grimes. 
was being engineering appraised and registered with Branz, prior to efforts towards commercialisation with funding partners (Gerrard and Gerrard). ${ }^{165}$

Drop-Loc was officially launched at Opotiki's 2005 'Christmas in the Park' celebrations in a house assembly demonstration by a team of six people. The components for the seventy-six square metre house were prefabricated in their factory over a three-week period before being assembled at the exhibition site in a single day. Site-based assembly began at the floor plate and progressed from the inside-out with the roof component in one piece including trusses and cladding. ${ }^{166}$ A second Drop-Loc house was completed in 2008 on a remote site in the Waitakere Ranges, one-hundred-and-eighty metres from the nearest road, which meant that components had to be transported by helicopter. The entire house, excluding floor-plate and piles, was constructed in the Drop-Loc factory prior to dismantling and transport by truck (220-223, 261).

The Drop-Loc Building System consists of closed wall panels complete with exterior cladding, building wrap, timber framing, insulation, and wiring conduits. These are transported as flatpacks to site and tied at the corners with an aluminium jointing system which is not dissimilar to the Lockwood system concept. A locking steel tie joins the roof through the wall panel to the floor plane and tightens as you twist it in place. Kat Walsh describes the Drop-Loc system:

... a conventional system of building with the house constructed in the same way it would be if it was built on site, and to the same quality. But the house is built under cover - including cladding and painting the exterior - before being broken into sections to be re-assembled at the building site ready for wiring and internal finishing (Walsh).

The flexible system can be built to any design, and they envisage having a range of house plans on hand to inspire potential clients. ${ }^{167}$

The Gerrards have forecast some impressive statistics. They estimate that an average threebedroom house should take four people just six days to build in the factory and two to three days to assemble at site. ${ }^{168}$ They forecast the system to save a third off the price of a traditionally built house, due in part to site-based assembly time being cut down by half to twothirds (Walsh). Housing New Zealand is their ideal primary customer as the plywood wall-based system would potentially reduce maintenance costs in tenanted housing. The prototyping process has highlighted a need to educate council inspectors on the system's installation process in order to avoid future delays once work starts at the building site. They expressed an interest to partner with a prefabricated flooring-and-piling supplier, as this is outside their current production capabilities. Despite being focussed on the grass-roots supply of housing, they have

\footnotetext{
165 Branz is an independent and impartial government-funded research, testing, consulting and information company providing resources for the New Zealand building industry (Branz).

${ }^{166}$ As this was a test house, the corners were nailed in place rather than locked, as is intended in the Drop-Loc system design. Many materials were donated or subsidised by local businesses such as ITM in return for marketing (Gerrard and Gerrard).

167 Print-quality images of the Drop-Loc system could not be obtained prior to thesis completion. Bay Property Care's phone numbers and e-mail addresses had changed and repeated messages left on Graeme Gerrard's mobile phone were not returned. It was evident that the Gerrards had struck personal and business relationship difficulties which will likely influence the development of Drop-Loc any further (Grimes).

168 If the factory ran twenty-four hours per day, it should be able to produce one house every three days (Gerrard and Gerrard).
} 


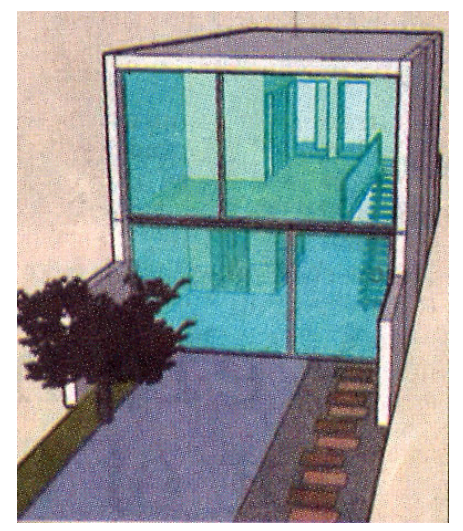

Figure 224: Model $T$ by Fletcher Architects for The Wellington Company.

Source: R. Palmer, "Affordable 'Model T' House for the Masses" Dominion Post, 29 Mar 2008: A2.

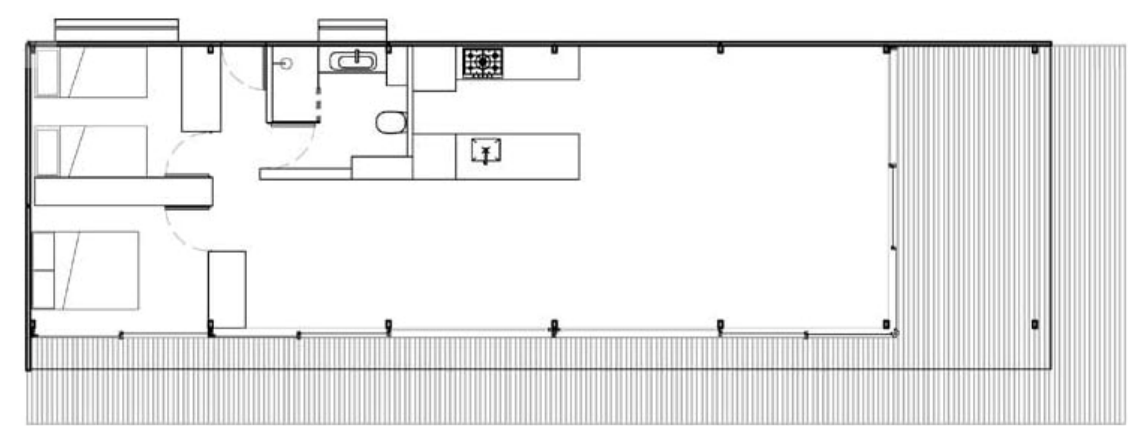

Figure 225 and 226: Module 130 by Quick Living: exterior rendering and plan. Source: <http://www.quickliving.co.nz/plans/module-130.php>. 
their eyes on the international future of construction, predicting that if the local industry does not move towards prefabrication, it will face a great risk of competition from China entering the domestic housing market.

The Drop-Loc story has potential to produce substantially cheaper housing in a reduced timeframe. Their experience teaches about educating councils, using in-house research and development, and a willingness to establish industry relationships. It is interesting to note the Scandinavian design influence in their system as these countries have a richer history of prefabrication than New Zealand.

\section{Modular Prefab}

The threat of distant manufacturing economies becoming closer through increased transport links is a real one. It is particularly applicable for components, panels and modules that fit within shipping container dimensions. As seen previously, Christchurch's Hotel SO chose to import Japanese flat-pack bathrooms and assemble them within the existing structure, and KieranTimberlake used United Kingdom bathroom modules in their New York Cellophane House (McCaw; Timberlake). De Geest Construction continues to supply modular bathrooms to multi-unit projects around the country, and has fielded enquiries from offshore.

Contrastingly, the modular residential market remains largely untouched. Stanley Modular has experience with multi-unit construction and potential to enter the stand-alone residential market, but no current inclination to do so. They are part of the 'Composite Structural Assemblies' industry and government-funded research programme. Stanley Modular is developing a concrete hybrid panel and intends to build a low-cost housing model to demonstrate its potential use (Caulfield). New Zealand is currently far removed from the precedent set by the United States modular housing industry. McRaeway Homes are developing a new series of architectdesigned modular housing and display show-home (refer to Chapter 3 McRaeway Homes case study). Both of these panel and modular developments will be of interest to the wider prefabricated housing industry.

\section{Hybrid Prefab}

Similarly, there are currently no New Zealand hybrid module-plus-panel prefab houses available, and only a few promising projects on the proverbial drawing-board. For this reason, hybrid prefabrication offers the most unexplored potential.

The Wellington Company property developer lan Cassels has put forward the proposal for a multi-unit hybrid housing solution dubbed Model $T$ (Palmer) (224). Model $T$ is named in reference to Henry Ford's motor car assembly line at the turn of the twentieth century. Cassels 

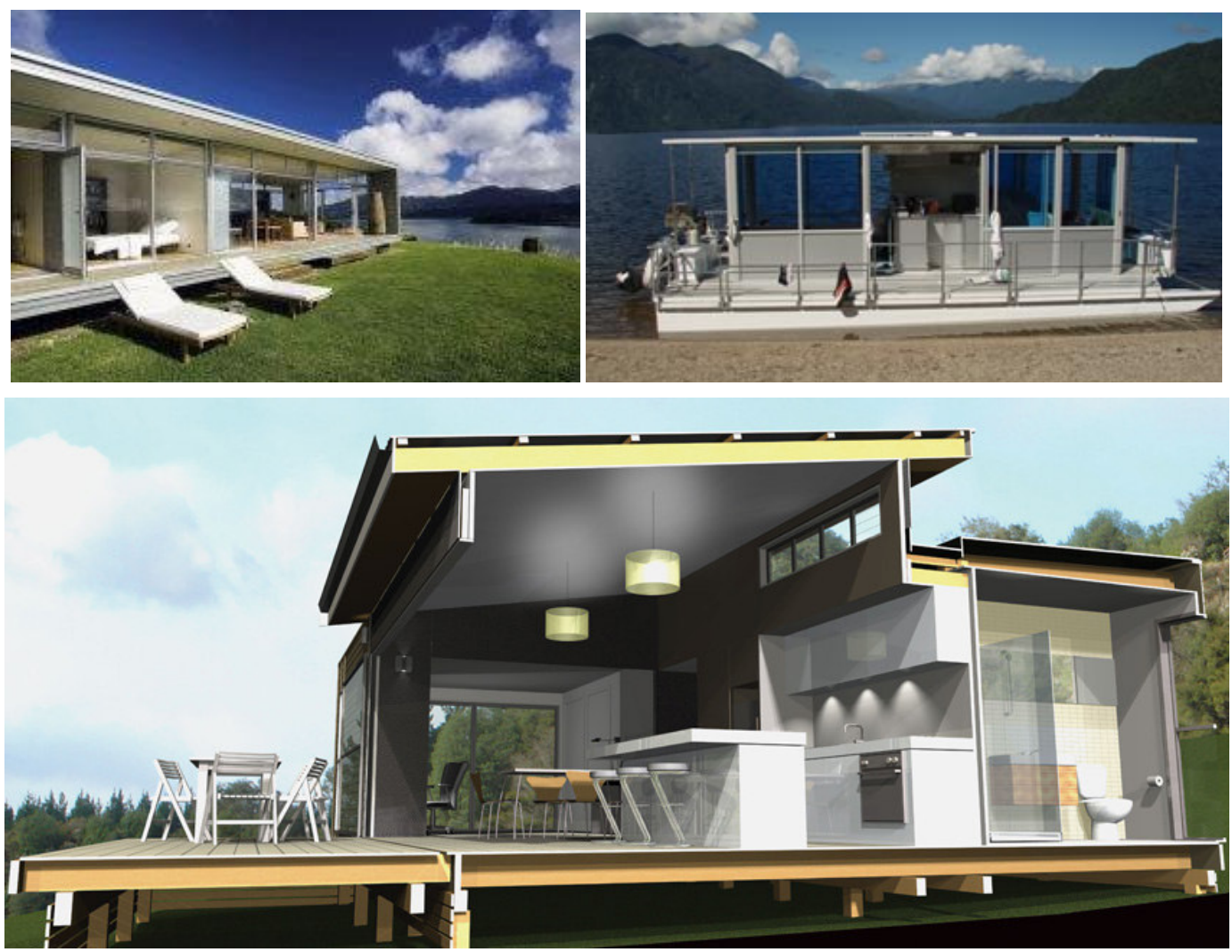

Figure 227 - 229: Bachbox and Aquabach prototypes, and Axis Designer Home sectional rendering. Source: <http://www.cantilever.co.nz/>, <http://www.aquabach.co.nz/gallery.html>, $<$ http://www.axisdesignerhomes.co.nz/contact.html>. 
was motivated to provide a housing solution for under two-hundred-thousand dollars (Palmer). Leasehold land is being looked at as a way to reduce the additional land costs and potential clients include the Wellington City Council who has already expressed interest (Cassels). The design by architect Geoff Fletcher of Fletcher Architects is of a hybrid two-storey service module plus panelised construction; tilt-slab concrete for the party walls, Triboard interior walls, and Kingspan aluminium SIPs roof and end-wall. Houses are planned to be grouped up to ten at a time to offset any negative effects from over-repetition and to enable some shared amenities and management.

A hybrid-type system already on the market is Quick Living Modular Housing, designed by Christchurch's Module Creative (225-226). Contractor Nick Hill and retail designer Jeremy Pankhurst launched their range of sleek neo-Modernist box-like designs in late 2008 after a few months of internet-based research. Their approach is to package prefabricated components from a range of manufacturers and assemble them at the site within a month. Modular kitchen and bathroom cabinetry come to site in a volumetric form, while the steel frame, walls and windows are flat-packed for transport. Customers are limited to their selection of modular plans but can choose from a palette of colour schemes, materials and surface options (Hill). While not strictly hybrid module-plus-panel, this concept does attempt to marry advantages of different component-based systems, but the standardised plans do not offer the design flexibility that a hybrid module-plus-panel system would enable.

\section{Complete Building Prefab}

New Zealand has an established history of transportable or complete buildings. However, the industry is yard-based and there are few examples of architect-designed factory-assembled prefabs. There is great potential to learn from modular Californian case studies to service our existing market demand for complete houses for rural and coastal sites. This second home or bach market is where most emerging housing products lie. Both ipad and $K$-bach will be made in factories and offered to the North Island initially while port-a-bach, Habode and $i$-houz will be made in Chinese factories to be delivered anywhere in the world. Their case studies follow. Other recent prototypes include Cantilever Design's Bachbox the fully towable Aquabach house-boat from Christchurch, and the Axis Designer Homes by PLB Construction Group with Mark Frazerhurst Architects in Huntly (227-229). Maddren's e-homes offer a transportable option, but in the first eighteen months it was the kit-homes which proved to be most popular.

\section{ipad by Architex - Auckland}

Architect Andre Hodgskin's bachkit is the predecessor to the ipad humble studio or bach (refer to Chapter 3 bachkit case study). The prototype was first launched in 2007 at the Auckland Home Show where thousands of people visited the house, a thousand business cards were picked up, and the website received hundreds of hits as a result (230-232). In 2009 iterations 


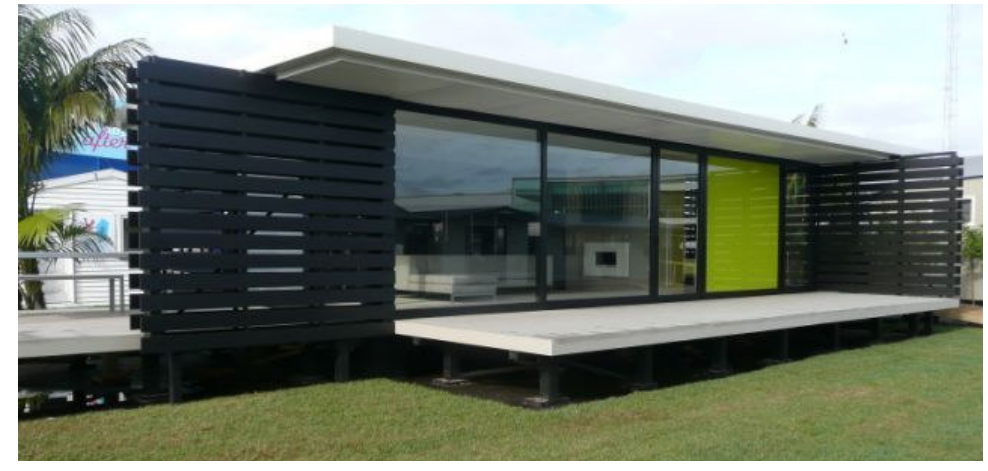

Figure 230: Ipad at Auckland Home Show, 2007.

Source: Image courtesy of Architex.

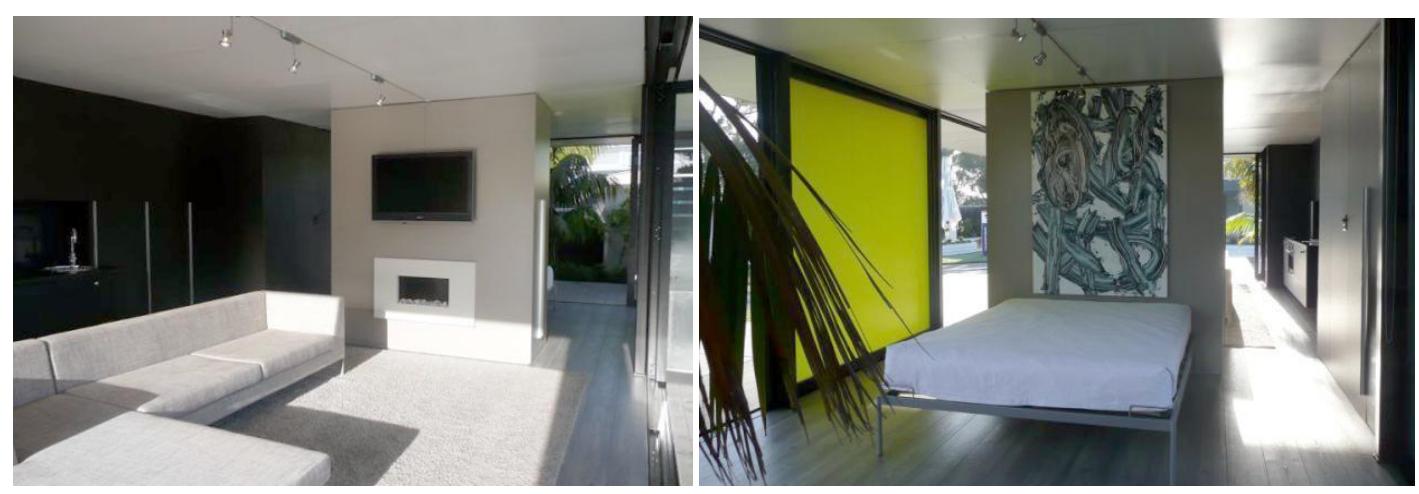

Figure 231 and 232: Black utility wall housing kitchen and bathroom, and central fireplace-bedhead. Source: Images courtesy of Architex.

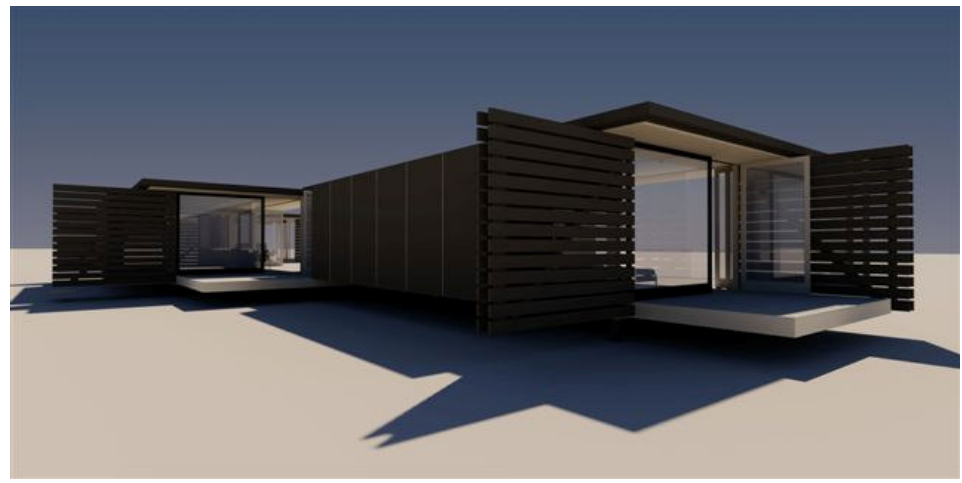

Figure 233: Multiple ipad configuration rendering. Source: Image courtesy of Architex. 
were planned for the Marlborough Sounds, Taranaki, Auckland and Fiji, and negotiations had begun with a potential Australian distributor (Hodgskin).

The ipad is available in kitset or complete building, and has been cleverly designed to extend past the transport-restricted dimensions of its box-form. Once it arrives at site, it breaks out of the box, with "wing-like walls [that] extend to brace the house and conceal the opened sliding doors" (Coughlan, "Pad Fab" 72). The kitset component-based assembly process takes three people three weeks (Hodgskin qtd. in J. Hansen 150). Clip-on decking doubles the fifty square metre living area, and closely links the interior to the exterior landscaping reflecting traditional bach uses, as well as influences of Californian mid-twentieth-century architecture. ${ }^{169}$ Like the bachkit, there are numerous possibilities for design iterations based on multiple module combinations to fit various site dimensions (233).

There are several interesting and well thought-out architect-designed details with electrical services and lighting attachments hidden away in a central conduit beam or within cabinetry. All services are contained on one side of the plan with an externally accessed utility cupboard containing gas heating, plumbing and electrical ready for singular site-based connections. Other well-considered details include the insertion of recessed roller blinds into purposely-designed gaps in the ceiling plane, and the front-door-swing exactly matching the depth of the roof soffit.

Hodgskin's Architex practice worked closely with building contractor Vistalite, who also supplied the steel structural sections and aluminium joinery. Traditional construction methods were used with steel post-and-beam structure and infill timber framing. Interior walls have been minimised to a singular wall of cabinetry and a central fireplace-cum-bedhead, eliminating the need for plasterboard and wet trades (232-232). This paring-back is in line with Hodgskin's goal to produce a more affordable alternative to his original bachkit design, which he has achieved with an estimated price of one-hundred-and-twenty-five-thousand dollars (plus consent fees and site costs). Further cost-savings were achieved through reducing waste by using modular planning, standard detailing and off-the-shelf components (Hodgskin). ${ }^{170}$

Hodgskin is well-versed in the virtues of marketing and publicity from his experience with bachkit. The ipad has received media interest from its appearance at the Auckland Home Show through articles in Urbis and Life n'Leisure magazines, so he has not seen a need for advertising to date. ${ }^{171}$ Challenges have been with a lack of material supply and industry unwillingness to collaborate during the prototyping process. Hodgskin initially wanted to create a

169 Both the bachkit and ipad are aesthetically reminiscent of the Southern Californian mid-twentieth-century work of Peter Blake, Pierre Koenig and Albert Frey (Bell).

170 There are also a number of modular planning tools which help to reduce construction waste. The interior utility pod containing kitchen, laundry, and bathroom is built to three standard width modules, according to sheet sizes. The rest of the cabinetry is in half standard width modules. The aluminium section window and sliding door joinery is designed for these standard modules, and future-proofed to take double-glazing as needed (Hodgskin).

171 In mid-2009 the 'ipad' show-home was destined for a high-visibility rural site on State Highway 16 between Drury and Pukekohe in Auckland (Hodgskin). 


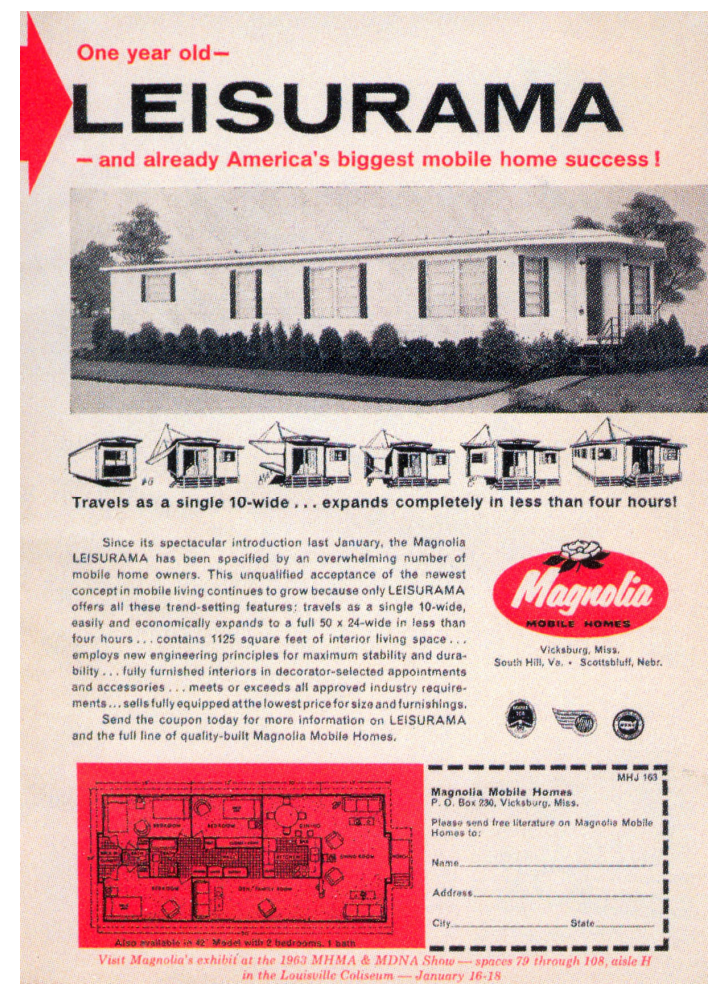

Figure 234: Richardson's Bi-Level Trailer, 1956. Source: S. Topham, Move House, Munich: Prestel, 2004:14. 
single roof-and-ceiling sandwich panel to span the building's full width, but a lack of industry cooperation meant off-the-shelf panels were used to create roof and ceiling linings separately.

The iterative design and prototyping process from bachkit to ipad and beyond enables learning to be translated into modifications. ${ }^{172}$ The ipad is exemplary in three areas: innovatively dealing with the box-form; cost savings achieved through standard details, components, modular planning and reduced trades to site; and the evolutionary prototyping process from previous products to future incarnations.

\section{Habode and i-houz - Wellington}

Dynamic Wellington-based designer Rod Gibson is behind the Habode and i-houz housing products. ${ }^{173}$ His Habode story began over ten years ago when he searched for a solution to the lack of timeliness in trades-people which disrupts the traditional building process. His design process began with international freight restrictions and resulted in an ingenious unfolding design where side panels fold down to complete the eighty square metre floor while other hinged panels underneath fold up to form the butterfly-roof $(235,238,239) .{ }^{174}$ All the external wall panels, cabinetry, and appliances are stacked inside this single container before being fitted into place once at site (Gibson). ${ }^{175}$ The unfolding concept is not new, and can be seen in historical references to architect Carl Koch's Acorn House from 1947 and Richardson's Bi-Level Trailer from 1956 (Alter "Acorn House") (234).

The ten-year multi-million-dollar research and development period produced a partial prototype in New Zealand which quickly became prohibitively expensive. Manufacture was then moved offshore to China where sixty to seventy percent cost-savings could be made (Frost and Lamb). Gibson chose an industrial design approach to focus on pragmatic process-driven workings. $\mathrm{He}$ solved the main weatherproofing challenge with a unique patented wall-system of a singular floor-to-ceiling window frame with special transoms into which glazed or steel sandwich panels fit. A staggering two thousand individual parts have been designed, which has implications for safe-guarding intellectual property and prohibiting customer modification. This is pertinent as the business has encountered a number of intellectual property hurdles and now employs a fulltime patent attorney. ${ }^{176}$ A previous failed business relationship led them to set up their own

\footnotetext{
172 Future 'ipad' modifications include hinging the four external screens so they can fold back for transportation and security, removing the small roof light over the utility pod area, and inserting a single shower tray as the entire bathroom floor to reduce Building Consent compliance issues (Hodgskin).

173 Gibson has business interests in a number of entrepreneurial activities, including graphic design, brand asset management, and ideas generation, and has now stepped back into a Research and Development position at Habode IP Ltd. His business interests include: Gibson Rusden Design Group (graphic design and branding), Habode IP Limited, ecoloji (ideas company), and e-see.com (internet-based brand asset management) (Gibson).

174 Container dimensions are 12.2 metre length $\times 2.4$ metre width $\times 2.9$ metre height (Gibson).

175 The at site process is: unfold floor (with bamboo flooring in place); unfold roof; install window, door and panel joinery; attach external guttering down-spouts, accessories; and connect gas, electricity, phone, sewerage and waste (Frost and Lamb).

176 They have patent protected the Habode as a manufactured appliance, rather than as architecture which can not be protected. This is in line with Gibson's view of his products being manufactured, rather than prefabricated. Intellectual property is particularly difficult to deal with in China where Habode IP continues to defend copyright challenges from previous business collaborators through court cases. The first Chinese Habode prototype was lost in intellectual property legal wrangles with ex-colleagues (Gibson).
} 


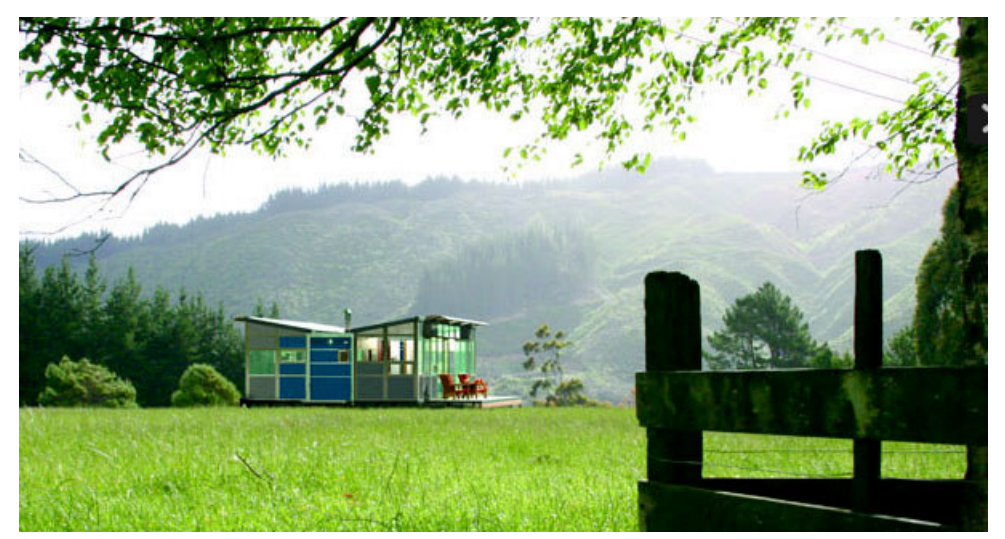

Figure 235: Habode model near Wellington. Source: <http://www.habode.com/gallery.html>.

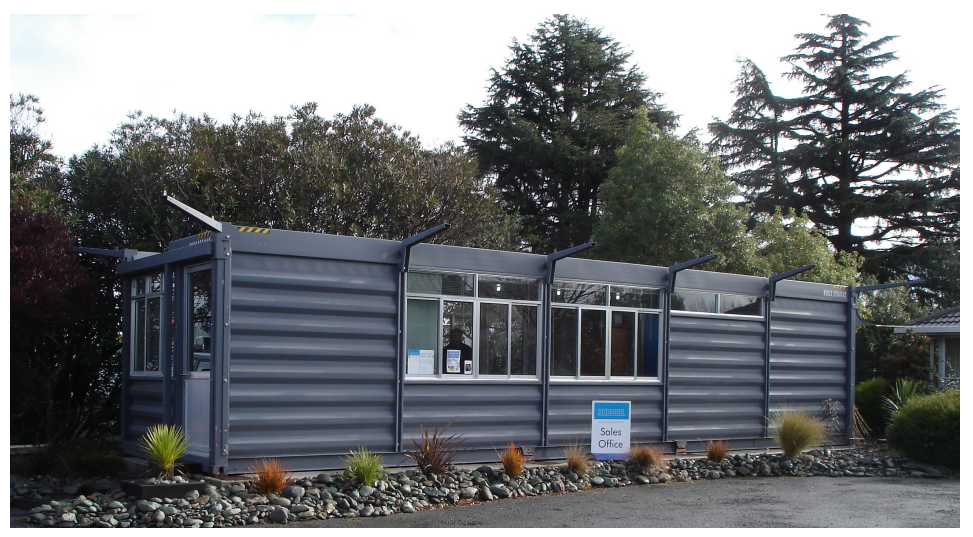

Figure 236: I-houz prototype at Habode Homes, Nelson. Source: Author's photograph, 2008.

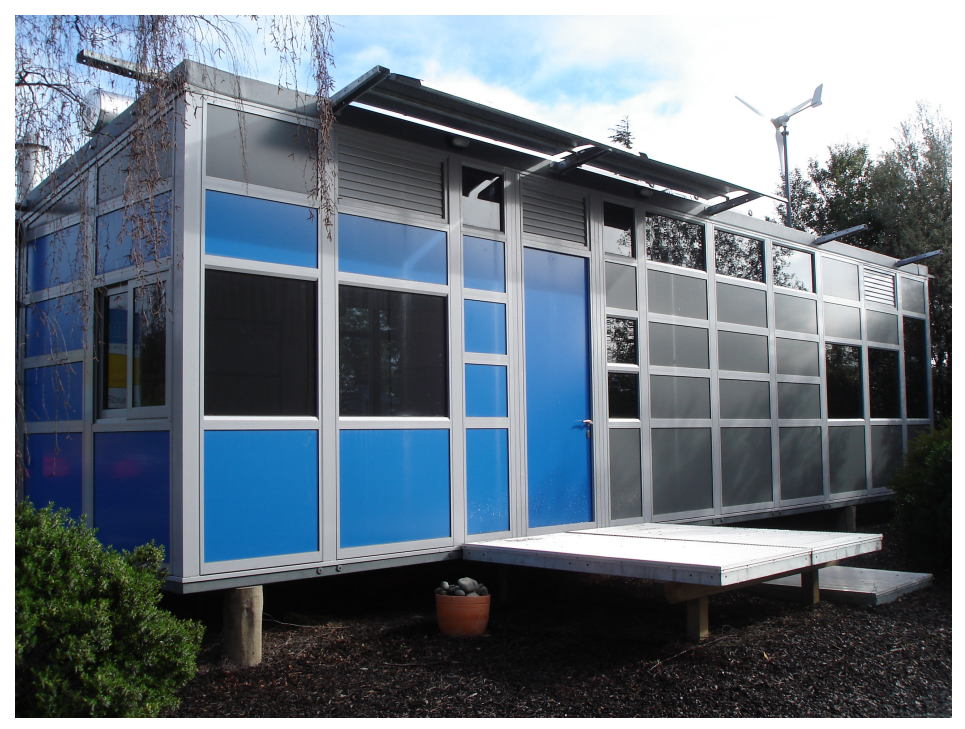

Figure 237: Habode show-home at Habode Homes, Nelson. Source: Author's photograph, 2008. 
premises in a factory that had manufactured shipping containers. By 2006, an extensive company hierarchy was set up covering regional distribution, national distribution, international manufacturing, and international IP. ${ }^{177}$

Four Habode prototypes are displayed by distributors in Auckland, Masterton, Southland and Nelson leading to sales to mid-2008 in Christchurch and the South Island's west coast (237). ${ }^{178}$ At that stage there were thirteen Habodes on the production line for New Zealand and thirteen for Australia. Monthly production capacity was predicted to double to eight Habode units and sixteen i-houz units from 2009 onwards when a second factory was in operation (Frost and Lamb).

In Australia, the distributor Habode Australia (HAPL) distributes Habode and targets $i$-houz to the mining industry through Western Australian-based developers Pindan. The i-houz was developed for temporary housing of workers in inhospitable climates with the steel weatherboard-profiled container-form arriving to site and sliding open along its length to create additional space $(236,251)$. It can potentially be stacked into multi-storey iterations and costs approximately one-hundred-thousand dollars (Gibson).

Habode shares an industrialised aesthetic with $i$-houz, although one that is softened for the residential market through the use of a pitched butterfly-roof and coloured wall panels. The interior planning is influenced by Gibson's own childhood camping experiences, living on boats, and in hotels and motels. A process of design reduction questions the necessity for more than one bathroom, or even for a separate toilet, and in the kitchen a simplicity-grid based on kitchen-bench and door datum is used. The central container floor-plate carries the powerpoints, while other electric conduits and plumbing run in the corresponding ceiling-plate. The Habode sells for approximately one-hundred-and-seventy-thousand dollars excluding site work and utility hook-ups (Gibson).

Both Habode and $i$-houz are over-engineered compared with conventional buildings because of the demands of shipping houses from China. ${ }^{179}$ As a result they are able to withstand typhoons and tropical storms which mean they could be marketed to exposed locations in coastal regions. A key concept to Habode and $i$-houz is that they arrive fully-contained to site, without the need for a single nail or screw. According to Frost, no other house can be built in just two days. Its transportability means it can be folded-up and moved repeatedly and can be used with off-the-

177 The business structure comprises Habode Homes (regional), Habode Homes (NZ), International Housing Solutions Ltd (manufacturing), and Habode IP Ltd (intellectual property) (Frost and Lamb).

178 The Nelson distributor, experienced builder Tony Frost, became involved as a shareholder in the larger national and international parent company structures. As overseer of production in China he visits monthly and has a close working relationship with the factory floor there. Design input is from industrial designer Adrian Lamb, and contract architect Kim Grinlinton (Frost and Lamb).

179 Shipping demands led to the design of removable corner castings, each capable of eighty-four tonnes direct bearing weight during the twentyone day voyage from China to New Zealand. This bearing weight is equivalent to more than four Habodes stacked on top of each other.

Individually, the Habode is over eighteen tonnes due to its steel frame structure and metal sandwich panel cladding construction (Frost and Lamb). 


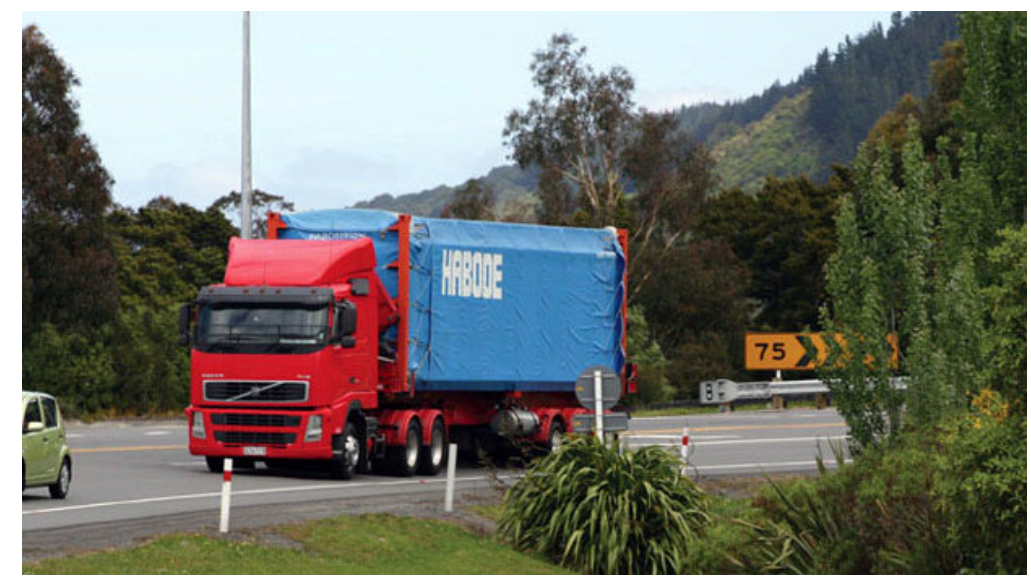

Figure 238: Habode in container form for transportation before unfolding at the final site. Source: <http://www.habode.com/gallery.html>.

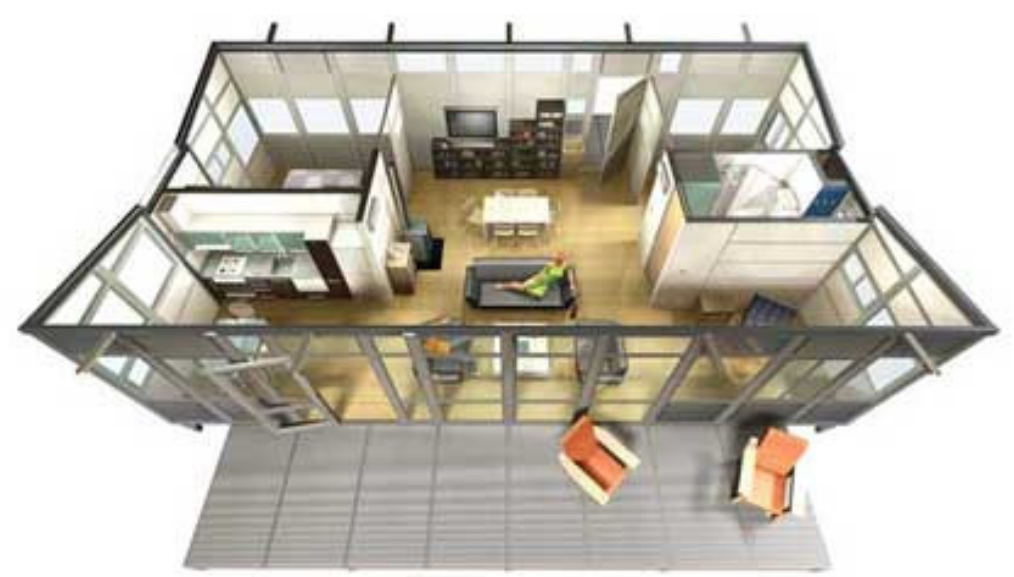

Figure 239: Habode floor plan.

Source: <http://www.habode.com/overview.html>. 
grid power which makes them particularly suitable for leasehold land and hopefully attractive to developers (Gibson).

Habode has received good publicity in newspapers, magazines, the internet and home-shows, as well as generating media attention in 2006 prior to the official launch. ${ }^{180}$ Serious marketing has not been a priority due to the overwhelming demand they have received, but they do produce their own colourful glossy brochures, maintain a website, and have plans for television advertisements. ${ }^{181}$ They intend to take their products on the road and attend eco-festivals using a custom-built trailer with hydraulic arms that unfold the floors and roof (238). So far consumer response to the show-homes has been generally positive, particularly amongst those nearing retirement, due to the low maintenance aspect and opportunity to down-size. Other enquiries are from people looking for granny flats, baches, starter homes and leasehold land dwellings. Negative responses have been due to limited plan choices, reduced storage, and some movement in floor-boards over the central hinge-joints (Frost and Lamb) (239).

The Habode team has faced numerous challenges during its lengthy research and development process, with the personal toll being particularly hard on creator Rod Gibson. Most of these issues stem from custom-designing thousands of parts, manufacturing off-shore, and the lengthy battle to protect intellectual property. The language barrier in China is an ongoing challenge, as is procurement of Chinese products, with many of them having to be bought from New Zealand distributors in order to receive the appropriate warranties. ${ }^{182}$ As word of Habode and $i$-houz spreads, consumer and industry perceptions of the Chinese origin will become a growing issue. ${ }^{183}$

Other challenges are future-focussed opportunities such as keeping up with changing consent issues, and with customer demand (Frost and Lamb). Frost estimates this future demand to be up to six-hundred Habode units per year in Australia and two-hundred units in New Zealand. Future design iterations are planned such as variations on a half-size Habode for use as extension, motel-unit or granny-flat, and several plan options within the standard Habode including a number of kitchen designs in various colour-ways (Frost and Lamb). They are also investigating using an Australian-patented 'mega-anchor' prefabricated piling system that would enable quick assembly on a variety of site conditions (Gibson). Off-the-grid features such as a gas califont, gas cooker, energy saver light-bulbs, composting toilet, and solar hot water, as well as closer supplier relationships are also being developed (Gibson). Future Habode and $i$-houz

\footnotetext{
180 The Dominion Post coverage in the summer of 2005-06 for a Wellington harbour temporary office building generated a lot of attention before Habode was ready for it, and meant the product was known to consumers before being fine-tuned (Gibson).

181 The Habode brochure suffers from not showing the unfolding process which would clearly explain their concept. One reason for this could be Gibson's reluctance to mention any allusion to the container for fear that is would be negatively received by consumers.

182 Frost and Lamb estimate that only sixty percent of intended communication to Chinese factory workers is successful.

183 The Chinese origin is already perceived to be a threat by the local construction industry, with some subcontractors having refused to work on the China-based products (Frost and Lamb).
} 

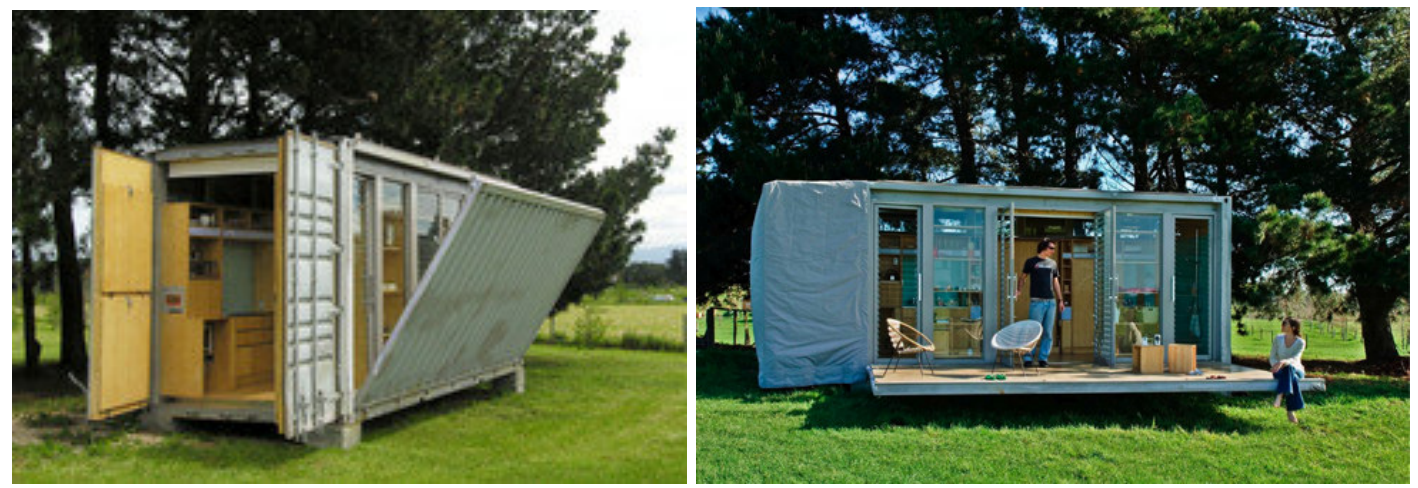

Figure 240 and 241: Port-a-bach prototype during installation and once opened with canvas-covered bunk-beds, 2007. Source: Images courtesy of Atelier Workshop.
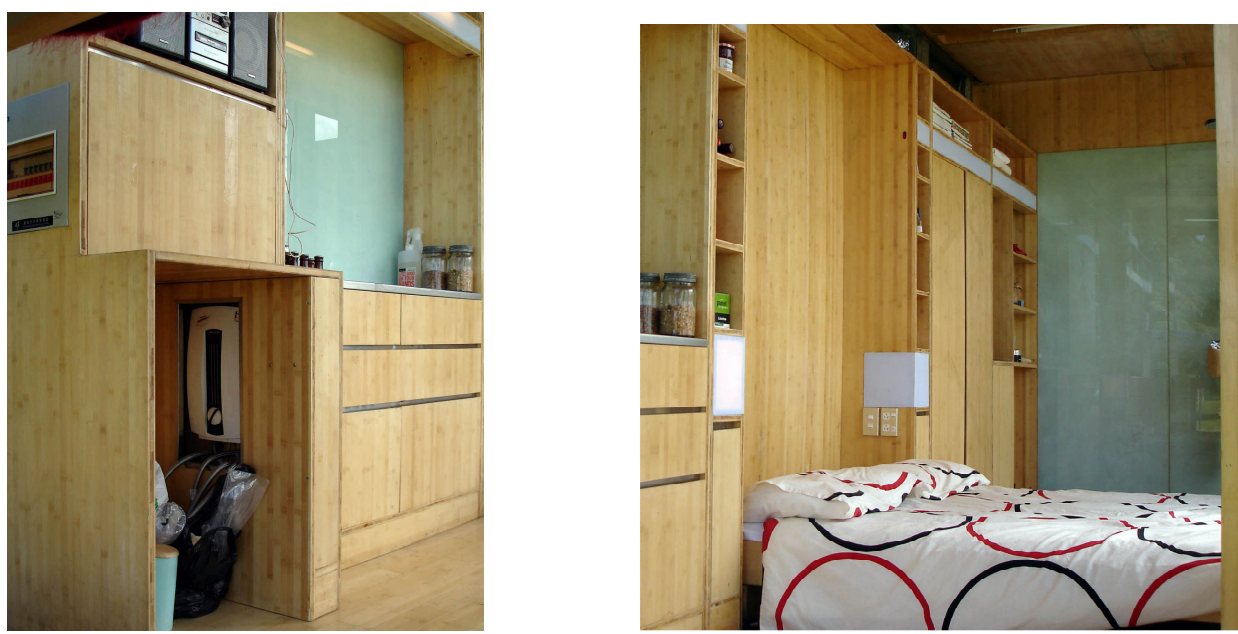

Figure 242 and 243: Storage wall containing kitchen, shelving, fold-down bed, and bathing area. Source: Author's photographs, 2007. 
products may come with a user-manual or guide-to-install much like any other appliance (Frost and Lamb).

There is much to be learnt from the development of Habode and i-houz, most notably their design approaches to extending out of the transportation box-form by unfolding and sliding. Manufacture in China may present shipping and language barriers, but it also provides opportunities to market to international locations as well as reduced manufacturing costs. Their huge start-up investment is a lesson for potential market entrants to learn from, and the customdesign of components goes against historical thought which advocates using elements off-theshelf, but it may be an appropriate approach to safeguarding intellectual property in today's litigious environment. Time and sales will tell if these durable transportable housing products will offer consumers benefits that outweigh their less-attractive aspects such as the metal interior surfaces, limited storage, and chunky industrial aesthetic.

\section{Port-a-bach by Atelier Workshop - Wellington}

Architects William Giesen and Cecile Bonnifait of Wellington's Atelier Workshop designed the port-a-bach when a transportable holiday-house was required for leasehold land. They were motivated by a lack of accessible and affordable architecture and "the need to reclaim the concept of the original affordable bach" (Churchouse). Their aim was to keep port-a-bach under one-hundred-thousand dollars resulting in a clever and efficient design that evokes the raw and pioneering sprit of this country's forebears.

It is made from a recycled shipping container which qualifies it as 'container architecture', a recognised architectural approach (Kotnik 10). With the help of a China-based business partner and investor funding, the first prototype was produced in late 2007. Once at site, one long side of the container is hinged open to form a deck and reveal a glazed façade of hinged doors and adjustable louvres (244). Doors at a far end open and two single bunk-bed platforms insert to extend the space. Canvas covers can enclose this bunk-bed protrusion and the deck to form the thirty-six square metres of extended living space. These canvas elements emphasise the inhabitation experience somewhere between a tent and a house (240-241).

The interior comes complete with a long wall of cabinetry containing a shower with partition, fold-out double-bed, and kitchen with gas-cooking, sink and under-bench fridge (242-243). Sustainable features include the use of bamboo flooring, potential for off-the-grid power, and the re-use of a shipping container carcase. ${ }^{184}$ They intend to offer standard models to the market at a set price, with additional fees charged for customer design changes (Giesen).

184 Shipping containers re-use is most sustainable in ports where there are stock-piles of containers, such as in the United States. This is less the case in China where most containers are used for export with only a very few imported back into the country (Kotnik). This would make the sourcing of containers in China more difficult. 


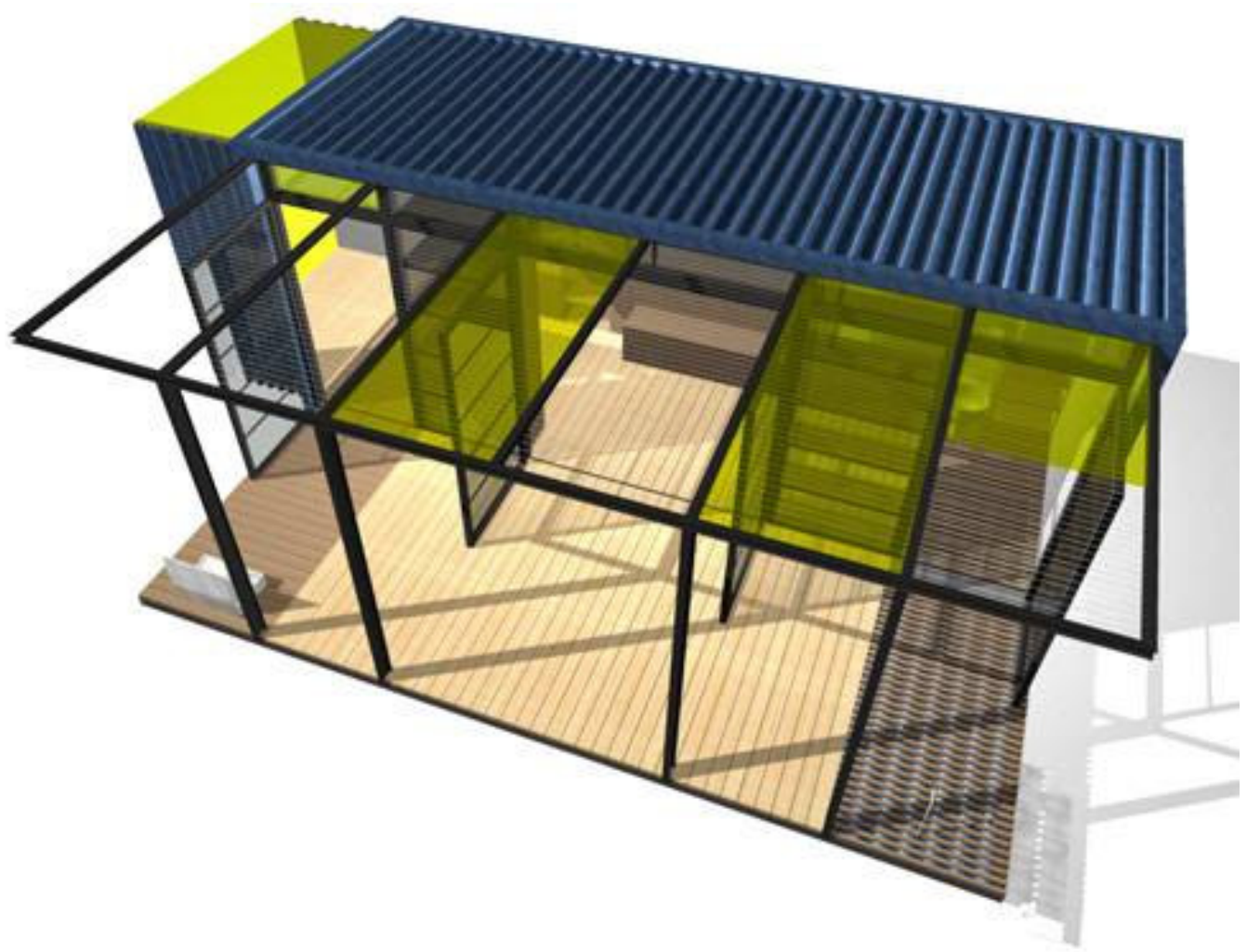

Figure 244: Port-a-bach rendering from website. Source: <http://www.port-a-bach.com/>. 
The port-a-bach prototype received a lot of media interest increasing their website hits from twenty per day to several hundred. ${ }^{185}$ One reason for the bach's wide-ranging media appeal is its link with camping holidays and New Zealanders' love affair with remote locations. As Polly Greeks points out, "its portability means it could be air-lifted into remote regions or transported between summer and winter sites" (89). Giesen has taken a proactive approach to media generation, utilising friends and contacts, his Facebook web-page, and directly e-mailing architecture magazines. As a result media interest has grown from local newspaper to national magazine, television, international websites and an international monograph. ${ }^{186}$

Atelier Workshop is currently in discussions with potential business partners to oversee distribution, marketing, and sales. Like Andre Hodgskin's experience with bachkit, Giesen and Bonnifait have the skills to design an architectural product, but not to bring that product to the market. If a business relationship is not founded, the worst case scenario is still a positive one in that the port-a-bach currently acts as a flagship to attract new clients for custom projects. This is an example of innovation as a branding message.

They have identified future opportunities in multi-unit accommodation for local tourism markets, offshore export markets in the Pacific and United States, and possible relief housing. Planned design iterations will explore using a longer container base, refinement of joinery details, doors and windows, and the canvas structure (Giesen). A second generation prototype is in the planning stages, and a Master of Design research project is focussed on incorporating off-thegrid solutions (Bowie). ${ }^{187}$

Atelier Workshop's experience with port-a-bach demonstrates their proactive approach to media, use of the prototype as a branding tool, and iterative design process of multigenerational prototyping.

\section{Koastline Beachouses by Kodesign Builders - New Plymouth}

Cheryl Brown and Rocky Hawke of Kodesign Builders began their foray into prefabrication through the design process for a small bach on a leasehold site at Urenui Beach, New Plymouth. Auckland architect Grant Boniface gave them a pocket-sized model to explain their project to friends which inspired Brown to think it would be a good construction technique to prebuild a house and then place it on a site. The bach was built at site in 2005 , using pre-finished products to reduce delays from sub-trade involvement and with clever design features such as versatile built-in cabinetry (245). It received television media attention and was the recipient of a New Zealand Institute of Architects (NZIA) Local Award and Resene Colour Award in 2005 (Boniface).

185 They estimate that the Dominion Post newspaper article alone created one-thousand-two-hundred hits on the day after publication. Of the onehundred-and-fifty serious e-mail enquiries, a third are from offshore, many are for customisation requests, and one is for commercial applications (Giesen).

186 The international monograph is Jure Kotnik's Container Architecture published by Links Books in Barcelona, 2008.

${ }^{187}$ Charlotte Bowie is a Master of Design candidate at Massey University, Wellington, in 2009. 


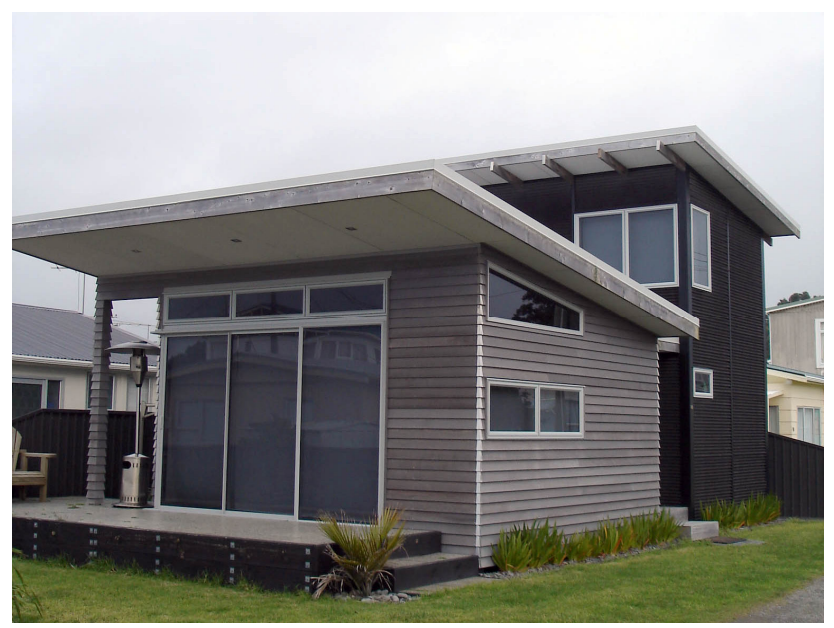

Figure 245: Urenui Bach by architect Grant Boniface near New Plymouth. Source: Author's photograph, 2008.

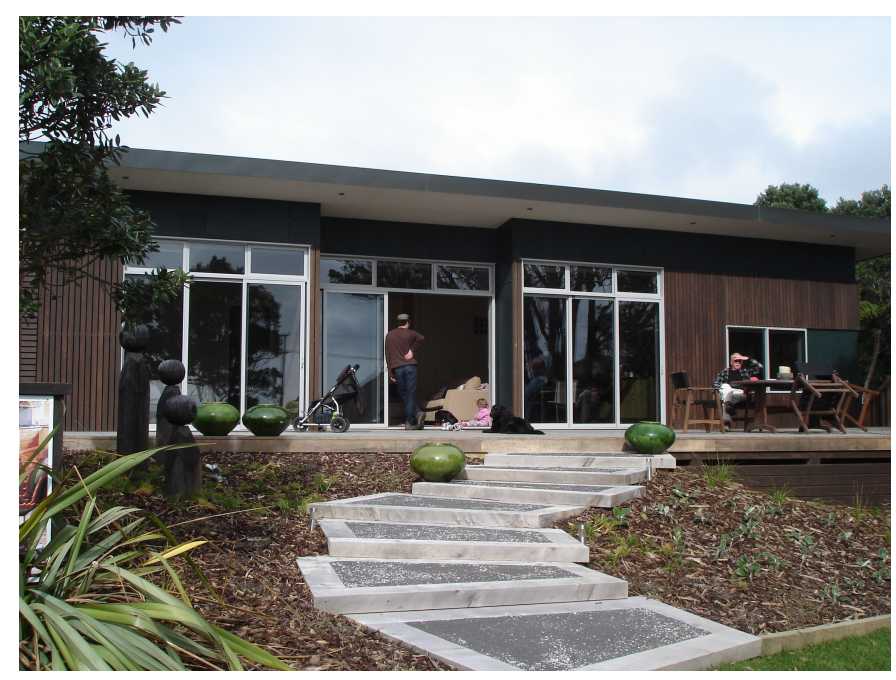

Figure 246: K-bach show-home at Oakura Beach near New Plymouth. Source: Author's photograph, 2008.
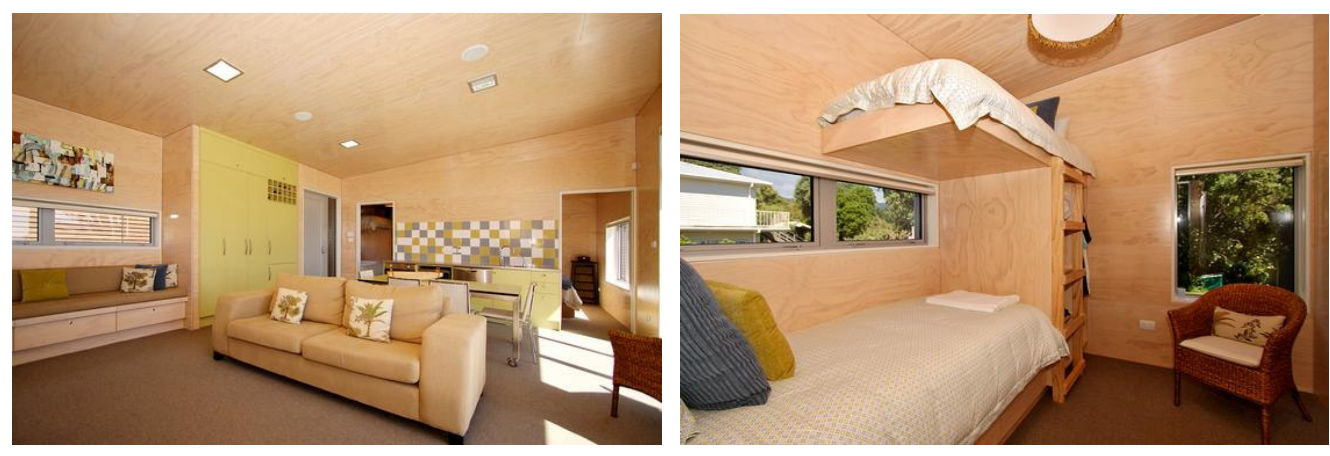

Figure 247 and 248: $K$-bach open-plan kitchen and living area, and third bedroom with offset bunks. Source: <http://www.bookabach.co.nz/holiday_homes/dsp_listing.cfm?bachld=8444>. 
In mid-2006 they joined GJ Gardner Homes with the idea that they would develop and distribute modular Koastline Beachouses within the wider network of twenty-three other franchisees. ${ }^{188}$ But this was not possible when the architect did not want to relinquish design copyright and the GJ Gardner network material supply proved to be too limited. This led to the design of the $K$ bach by Wellington-based Studio Pacific Architecture (246-249). The resulting "beautiful architecturally-designed beach house" prototype was built in their New Plymouth factory and transported to a stunning site nearby at Oakura Beach (Brown and Hawke).

They plan to offer a selection of models, rather than a flexible design, including the Kabin containing a bedroom with ensuite and small living area. The $K$-bach is supported by a laminated veneer lumber (LVL) structure with non-load-bearing internal walls. Durable lowmaintenance materials were employed such as plywood interior wall linings, stained cedar rainscreen, stainless-steel screw fixings, and stainless-steel pile legs (Brown and Hawke).

The Oakura K-bach is both Brown and Hawke's own home and the planned show-home for the yet-to-be-released Koastline Beachouses range. Most comments are that the seventy-eight square metre space is surprisingly liveable, which is testament to its clever design. ${ }^{189}$ The $K$ bach is a leading contemporary example of architect-designed high-quality housing built in a factory. Their marketing campaign is planned to emphasise the ease of delivery, succinct tenweek production time, and completeness of finish, to the recession-proof baby-boomer market.

It is priced around two-hundred-and-eighty-thousand dollars, about twice the price of other lesser-quality prefab houses on the market which presents the challenge of communicating the architectural and construction quality, with its associated costs, to their intended consumer audience. It is also challenging when the housing market still operates on the cost accounting system of price per square metre. ${ }^{190}$

Other challenges are presented by competitors beating them to market. Brown believes in getting the marketing right before launching their Koastline Beachouses. During this time-lag, competitor Bach2go has turned up in the K-bach's Oakura neighbourhood (250). It is designed by New Plymouth architect Jeff Salisbury of Oulsman and Spiers and consists of two-bedrooms and eighty-two square metres at a cost under two-hundred-thousand dollars with further options for bathrooms, material finishes, and colour and lighting schemes. The most interesting part of this product is that consumers can literally try before they buy. The website advises that any

\footnotetext{
188 Greg Gardner started building in 1983 on the Gold Coast and built over one-thousand homes there using system building techniques that employed efficient use of material and labour resources. Kodesign Builders used to build four architect-designed homes a year, and since taking on the GJ Gardner franchise now build thirty-five to forty homes per year (Brown).

189 Brown and Hawke's own smooth transition from their former three-hundred square metre home surprised them, as they continued to design and build another new three-hundred square metre home intended for themselves. Once completed, they put the larger house on the market; proof that good design is more important than floor area. The benefits of a smaller house include minimal housework and reduced running costs estimated at a sixth of their previous house (Brown and Hawke).

190 Costing per square metre as an invalid system was commented on by IBS's Keith Clark (refer to Chapter 2) and MRP's Leo Marmol (refer to Chapter 4).
} 


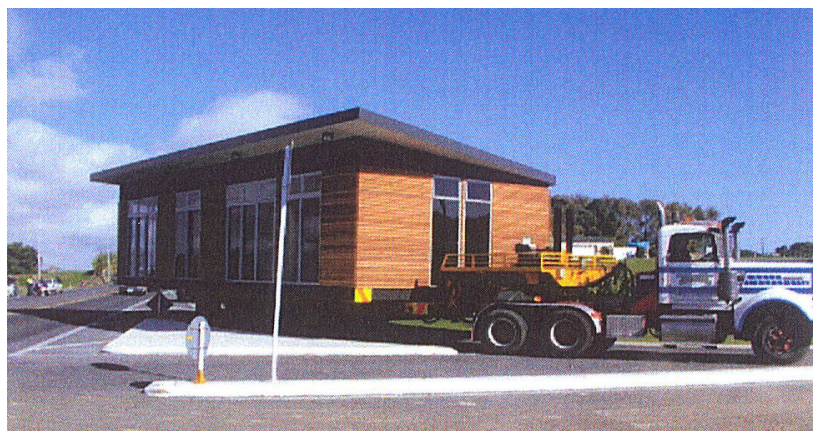

Figure 249: Koastline Beachouses office destined for The Links development, Taranaki. Source: Image courtesy of Studio Pacific Architecture.

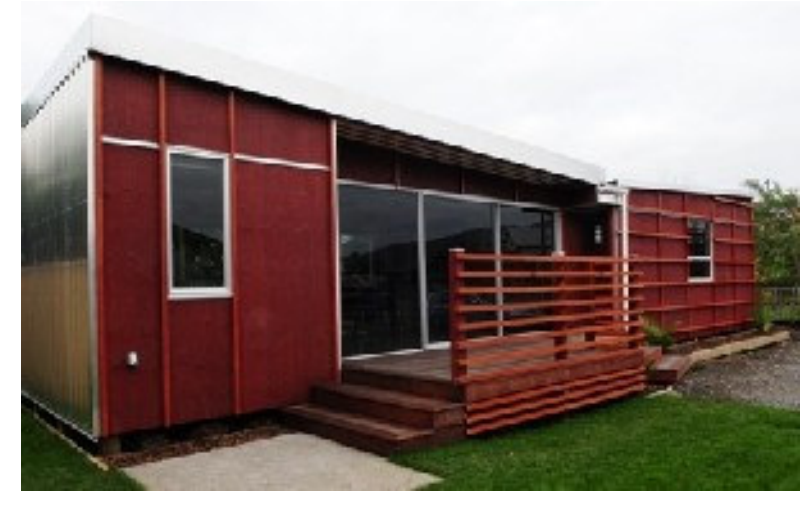

Figure 250: Oakura show-home by Bach2go. Source: <http://www.bach2go.co.nz/>. 
adults can stay for a night or two, with accommodation cost being refunded if a Bach2go is purchased within six months. ${ }^{191}$

Due to the current recession, Brown and Hawke's focus on their GJ Gardner franchise, and the difficulties of selling a high-end product in the Taranaki region, the launch of Koastline Beachouses was put on hold in mid-2009, and the show-home put on the market (Brown, Kbach update).

Despite these developments, there are strategies to be learnt from Kodesign's concentration on research and development, high-architect-design, indoor factory construction, and careful material selection to achieve a high-quality product. The remaining issue is how to educate consumers to pay for this architectural quality.

191 Bach2go refused to participate in this research (Salisbury). All information gathered was from their website. 


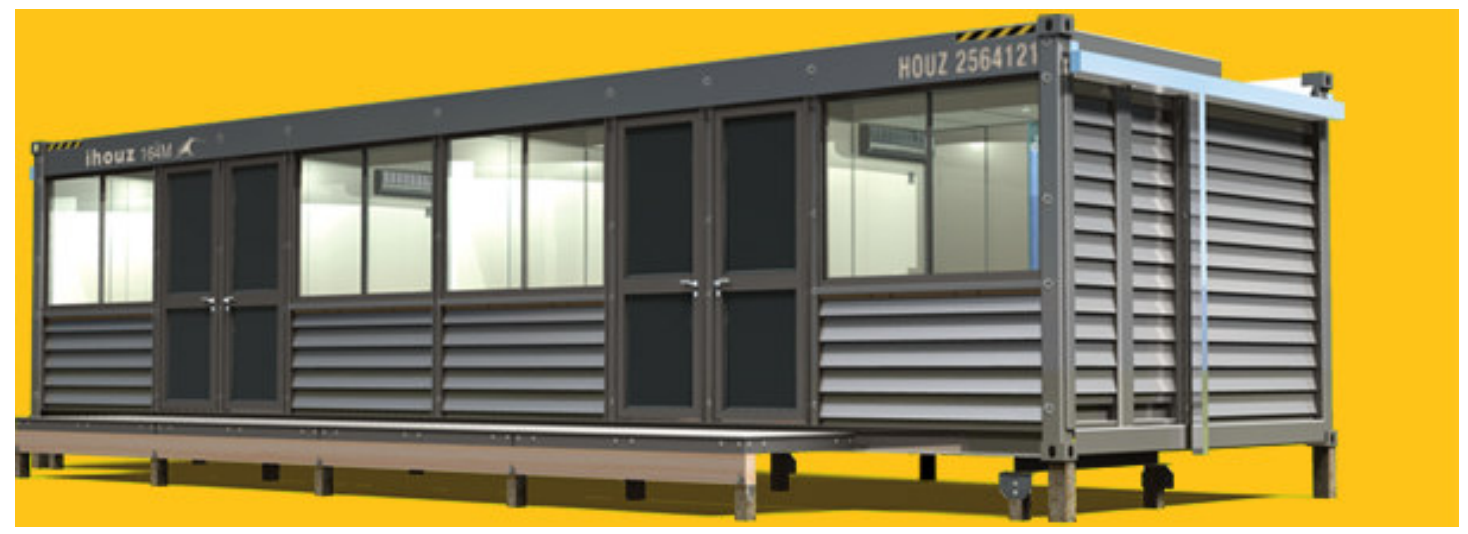

Figure 251: Ihouz's industrial aesthetic for container-based transportation from China. Source: <http://www.ihouz.com/>. 


\section{Recent Issues}

There is an increase in architect involvement, yet a number of innovative housing opportunities are being oppressed by the current economic recession. Issues for a strong New Zealand prefabricated housing industry are prohibitively large start-up costs, resistance in the traditional construction industry, a culture based on valuing houses according to floor area, and widespread misperceptions about prefabrication and architectural quality. Issues gleaned from recent and emerging prefabricated housing examples are summarised below.

The economic downturn that began in 2008 is causing the established construction industry to retract and making it difficult for new market entrants to gain market share. There is the risk of seeing a repeat of the late 1970s recession when businesses such as IBS and LMC were forced to close. Prefabrication critic Lloyd Alter predicts that, "in a recession labour is cheap and available and prefab's overhead and transport and crane costs kill it" ("Will Prefab Ever Catch On"). One approach to tight economic times is adopting a position of flexibility and responsiveness which comes from being small and agile. Pinecone has adapted to consumer response and integrated this feedback into its in-house research and development process.

In an effort to reduce costs, several firms are looking to manufacture in China. Products such as Habode, i-houz and port-a-bach all share an industrial container-based aesthetic that may be cheaper but is challenging for many prospective home-owners (251). China-based manufacture is perceived as threatening to some New Zealand construction industry sub-contractors. There is a need to communicate that these housing products are complimentary to the industry, and not intended to replace all traditional construction. Industrial design aesthetics that deviate too far from traditional residential construction may jeopardise the market acceptance and commercial futures of those prefabricated housing products. Once market-entry barriers are down or manufacture occurs in another country protection of intellectual property through patents becomes important, as used for Pinespan, Habode and $i$-houz systems. Cost-savings from offshore manufacture weigh up against intellectual property risks and quality control issues that need to be adequately resolved prior to market entry.

Industry relationships for research and development need further assistance in nurturing, as well as cultivating a stronger culture of innovation. The Drop-Loc business has shown a willingness to collaborate, while the creators of both Habode and ipad have been disheartened by past difficulties with general construction industry inertia. The complete, or transportable, building typology looks set to dominate New Zealand's prefabricated house market with emerging products such as the ipad, Habode, i-houz, port-a-bach and k-bach. However, there is the clear and present danger of repeating historical mistakes by adhering to traditional typologies without researching the full range of options. Research and development of alternative typologies such as hybrid module-plus-panel offer flexible housing solutions that 


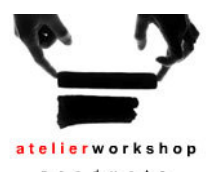

products
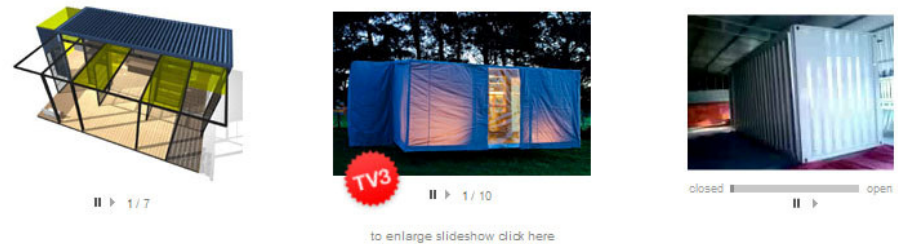

Figure 252: Atelier Workshop's port-a-bach website home page. Source: <http://www.port-a-bach.com/>. 
need to be investigated. Similarly, there is scope to improve on current traditional pre-nail component-based construction systems into a more complete panel system. There is currently a gap in the market between component-based and complete building typologies which can only be filled by investment in research and development.

Further attitude shifts need to take place amongst the prefab industry regarding future-proofing through investing in CNC technology as recognised by Pinecone. There is potential to learn from associated industries such as steel manufacturing in their semi-automated use of plasmacutters and laser-cutters. Almost all industry participants successfully use an iterative prototyping process as part of their research and development strategy.

Designing out-of-the-box is an innovative response to transportation limitations exhibited by ipad, port-a-bach, Habode and $i$-houz through folding, sliding and extending wall, roof and floor elements. These compact living solutions are currently acceptable as second homes and baches, but will hopefully become more desirable for primary homes when there is a wider awareness of sustainability issues such as decreased footprints. The small prefabricated house is challenged by traditional house valuation perceptions of price per square area, an attitude that can only be combated through market re-education. The importance of marketing is highlighted in the case of Atelier Workshop which has found a use for its prototype as a brand to attract clients for its traditional bespoke work (252). Other businesses can learn from this use of the prototype as a marketing tool for related products and services.

Prototypes as show-homes are a valuable form of marketing enabling consumers to try out the dwelling. Bach2go provides the opportunity for overnight experience combining accommodation services with inhabitable marketing. Pinecone's high-profile site beside a busy motorway has been a successful location for generating first-hand interest from passers-by. Others have found home-show events successful at generating a large level of interest, although it does not always equate to sales, as ipad found (253). Several businesses have generated media interest through traditional channels of newspaper, magazine and television publicity, as well as more recent website mechanisms.

Drop-Loc advocated for educating councils, territorial authorities and building inspectors to enable a smoother and faster consent process. Educating the public about paying for architectural quality is imperative for the commercial success of architectural prefabs such as $k$ bach. The current cost-per-floor-area system is not relevant for drawing direct comparison between smaller prefabricated products and larger design-and-build housing. A direct comparison between housing design, construction quality and energy performance is needed. The perception of design quality is a problem that the entire architectural profession faces. Education of the construction industry, the architecture profession and the wider public is needed to clarify definitions, terminology and merits of prefabrication. There is a further need for 


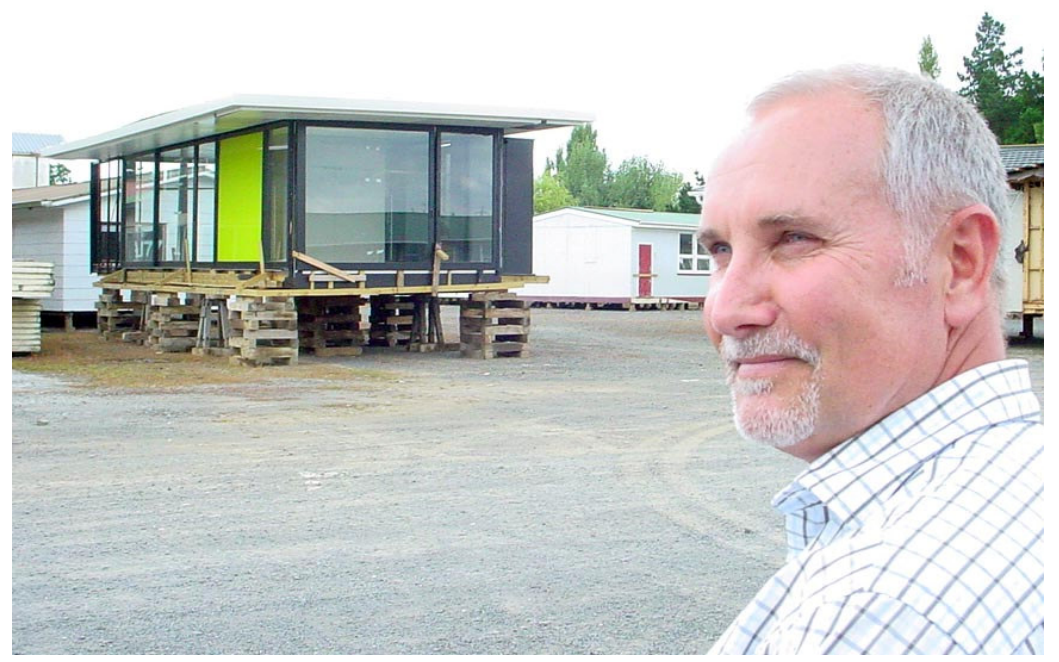

Figure 253: Andre Hodgskin and the 2007 Auckland Home Show ipad in transit to a new location. Source: Author's photograph. 
education to overcome a general lack of innovation in the construction industry. There are identified opportunities for cross-communication between related industries, such as manufacturing or boat-building, which may potentially lead to collaborative joint ventures and inter-industry groups. For maximum effect, businesses will need to join together with industry bodies and associations, or form new ones to face specific prefabrication challenges and opportunities.

Established and emerging New Zealand prefabricated housing industry participants were almost all male. There is a notable absence of women in the industry. This is in stark contrast to the United States industry which has female architects and experts at the forefront. ${ }^{192}$ It is widely acknowledged in the construction industry that women make or strongly influence homepurchasing decisions (Tuohy; Giess). This is a particularly important consideration for marketing and communication, as the prefabricated housing industry in Japan has found (Bottom et al 139). It is also an architectural design consideration for efficient space use, inclusion of storage, and options for utility areas. There is opportunity for increased participation by women in New Zealand's prefabricated housing industry.

Several of these innovative housing products may never achieve commercial success due to overwhelming challenges including:

- wider economic recession

- lack of prefabricated housing industry cooperation

- construction industry resistance to innovation

- few sustainable materials and systems incorporated in housing products

- over-emphasis on historical typologies, with alternative typologies not well investigated or represented

- restriction of housing market to secondary dwellings (due to smaller footprint of complete building typology)

The potential for sustainable technologies, alternative typologies and industry collaboration are worth further investigation. Recent kiwi prefab approaches to emerging issues are:

- sourcing fabrication and manufacturing offshore

- increasing emphasis on intellectual property protection

- innovative out-of-the-box designs for complete buildings

- design flexibility of component-based systems

- visible site-based show-homes and representation at major housing events

- prefab prototype used as a branding tool for other business products or services

The future potential of prefabricated housing in New Zealand will need to address these recurring challenges and approaches to opportunities, together with those gathered from historical, established and international exemplars. The next chapter will summarise these case study issues and identify key challenges and opportunities to inform future strategies.

192 Allison Arieff, Michelle Kaufmann, Jennifer Siegal, and Rocio Romero are some examples of 'modern green prefab' industry leaders in the United States. 


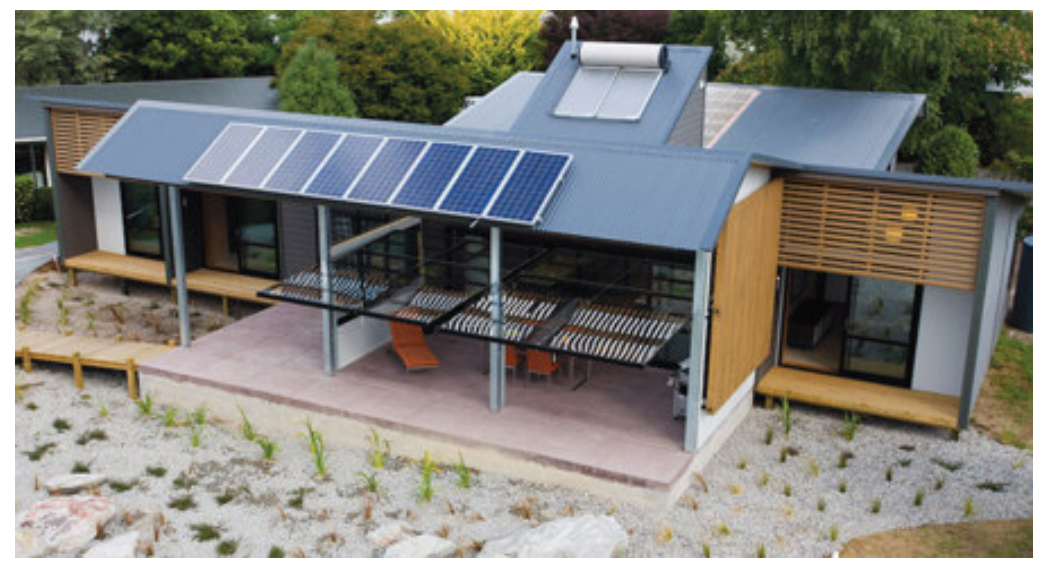

Figure 254: Lockwood's EcoSmart range: sustainability features, architect-design and marketing. Source: <http://www.lockwood.co.nz/index.asp?pagelD=/>. 


\section{Challenges and Opportunities :}

\section{Summary of Lessons Learnt}

The background and case study chapters presented prefabricated housing issues to be addressed in the near future. They offered a wealth of lessons to learn from: history highlighted the need for business planning; case studies have shown the challenges of New Zealand's disparate and competitive industry; international exemplars proved the importance of customer focus, marketing, and research and development; and emerging products exhibited opportunities for sustainable materials and new typologies. There is a repetitive pattern of issues that identifies potential for research and development, joint initiatives, specialisation niches, industry quality standards, robust finance and marketing planning, alternative typologies, marketing and education, and market research (254).

This chapter marks the start of the synthesis section of this thesis. The issues gleaned from industry case studies will be considered, lessons learnt will be summarised and key focus areas will be identified. ${ }^{193}$ The following chapter will then investigate these key areas and propose strategies. The final two chapters will postulate a future context and discuss conclusions towards discovering potential for prefabricated housing in New Zealand.

${ }^{193} \mathrm{~A}$ summary of case study outcomes can be seen as the table of findings in appendix $\mathrm{E}$. The businesses are also charted in a chronological index in appendix $\mathrm{F}$. 


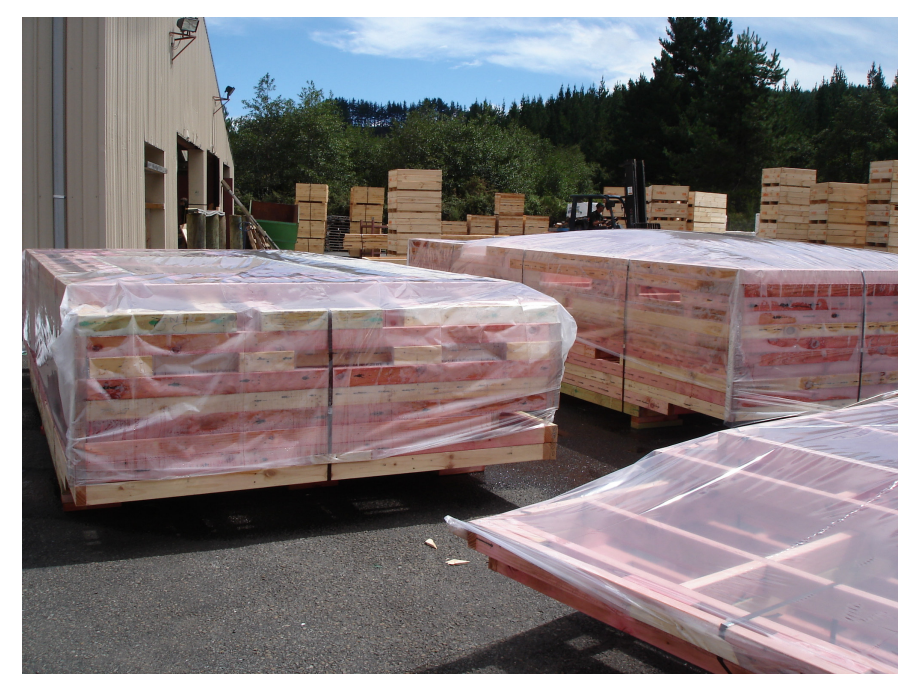

Figure 255: Pre-nailed timber frame components stacked and wrapped for transport. Source: Author's photograph, 2008. 


\section{Lessons Learnt}

Lessons for potential kiwi prefab systems are founded in the grouping of concerns from previous background and case study chapters. Key lessons on economical, technological and socio-cultural issues and opportunities are summarised. Increasingly the globalised economy offers opportunities in offshore markets for both supply and demand of prefabricated housing. China is now the source for manufacture of several New Zealand prefabricated dwellings, and is likely to be the location of more in the future. As international construction industries become established in the production of different building components, it will become increasingly important for New Zealand's prefabrication industry to identify its own specialised niche. This may be in the supply of prefabricated timber structural components like Timber Construction Solutions does currently (refer to Chapter 3) (255).

In any industry context, research and development is imperative at the start-up stage and to stay ahead of the market. This lesson resurfaced time and time again, yet emerging housing products varied in research and development investment from mere months of unsubstantiated, internet-based research to almost a decade and tens of millions of dollars of investment. Prefab research and development was challenged by wider construction industry resistance to innovation, with several businesses encountering difficulties within the construction industry. Historically, the New Zealand government recognised the importance of nurturing innovation through experimental housing projects and large-scale public works. This support led to the establishment of several enduring prefabricated housing businesses. This research and development leadership could support the growth of prefabricated housing in the future.

The 1950s national housing industry forum provided the opportunity for government and business to tackle housing issues side-by-side. Cross-fertilisation of skills and technologies encourage innovation, as seen by the current use of computer-controlled techniques from manufacturing sectors being applied to construction. Stronger ties between prefabrication businesses and developers will demystify the process and enable exemplary projects to be undertaken. The design and construction industry needs strong contemporary models and case studies to prove potential prefab merits, break down misperceptions, and move the industry forward. Joint initiatives within the construction industry, with other industries, with government tertiary institutions have resulted in innovations and are to be encouraged.

Several prefabrication businesses failed because of a lack of robust financing and marketing planning in place from business inception. There continues to be a large emphasis on the technical design and prototyping process prior to other business strategy. These priorities should be reassessed. Greater use of off-the-shelf components is a means recommended in order to reduce supply risks and lower costs. Historical examples of mechanical utility pods are a precursor to a hybrid prefabrication typology that combines volumetric modules with other 

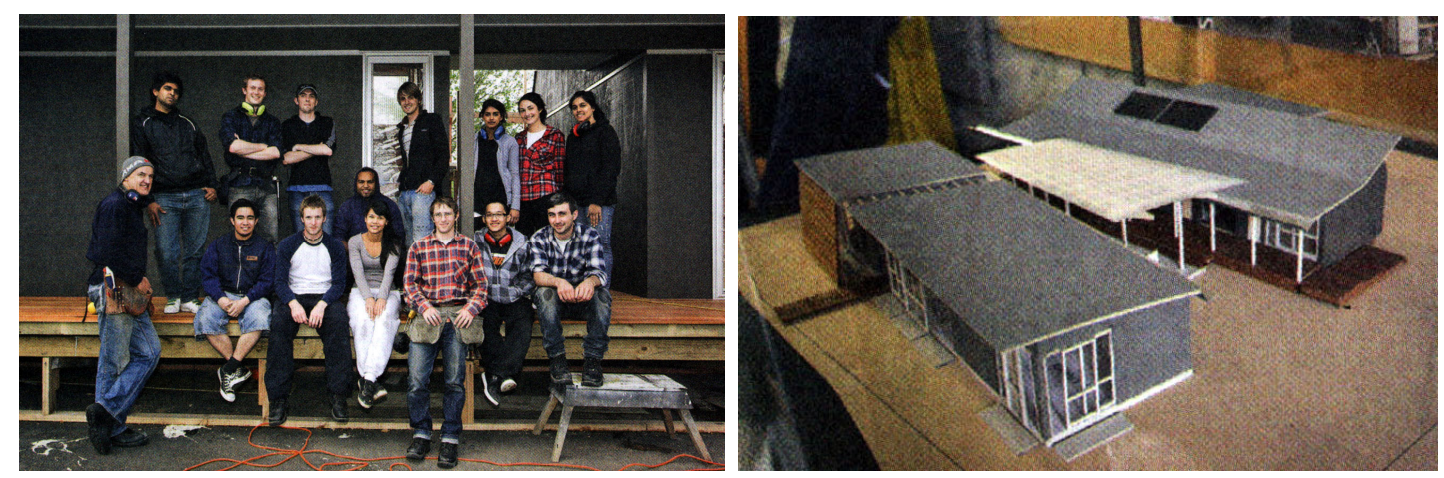

Figure 256 and 257: Unitec Auckland design-and-build students with architect Dave Strachan, and modular design. Source: A. Kenworthy, "A Fine Bach (of Students)." Home New Zealand, Dec / Jan 2008/09: 135. 
prefabricated and site-based construction methods. Examples of this hybrid module-plus-panel typology are coming to market offshore, but have not been explored locally. Flexible outcomes from combining custom design with off-the-shelf parts make the hybrid typology worthy of more focussed research and development.

There is much that New Zealand's prefabrication industry can learn in terms of marketing. Historically pattern-books, show-homes and 'parades of homes' have been successful methods employed to promote and communicate prefabricated products to a wider consumer market. International and local exemplars expand this range of marketing tools with dedicated conferences, exhibitions, magazines, books and tertiary-led design-and-build courses (256-258). A widespread emphasis on marketing to the public should include targeted education of the construction industry, government and councils. Confusing terminology about prefabrication typologies needs to be clarified and understood by the wider industry for all communications with the public. Industry quality standards need to be agreed and enforced in order to protect businesses from publicised mistakes, time delays and quality issues suffered by other firms in the small industry. Prospective home-owners should be educated about the cost benefits of architectural quality. There are unaddressed opportunities to use market research to target female prospective home-owners and industry members, as well as the starter-home market.

Historical and contemporary prefabricated housing exemplars suffer from widespread misperceptions and architectural commentators have criticised the lack of commercial success in architect-designed products and systems. The case studies have revealed three ways to view success; in commerce, innovation and branding. Commercially successful prefabricated housing exemplars from history have been identified by Bergdoll and Christensen as Sears and Roebuck, Lustron Homes, and tilt-panel East-European construction. Enduring New Zealand examples identified in this research include Lockwood, McRaeway and De Geest. Innovative architectural success was honoured by New York's Museum of Modern Art 'Home Delivery' exhibition in showcasing failed prefab attempts. Prefabrication was shown to be a catalyst for innovation and change in the entire architecture profession. Prefabrication has successfully influenced industry-wide integration of new systems and processes. Pre-nailed components that are now commonly used in traditional house construction are one example of this innovation. Branding success was introduced by the role of the prototype and its "capacity to provoke a discussion", as "good architecture is always a provocation" (Colomina 27). In this case, prefabricated housing exemplars seek attention, inspire conversation, stimulate debate, and stand for something greater than their material whole. Clearly prefabrication, defined from componentised to complete building, has been successful in numerous applications in New Zealand's housing industry in the past. The lessons learnt continue to inform the industry today and have potential to change the industry future. 


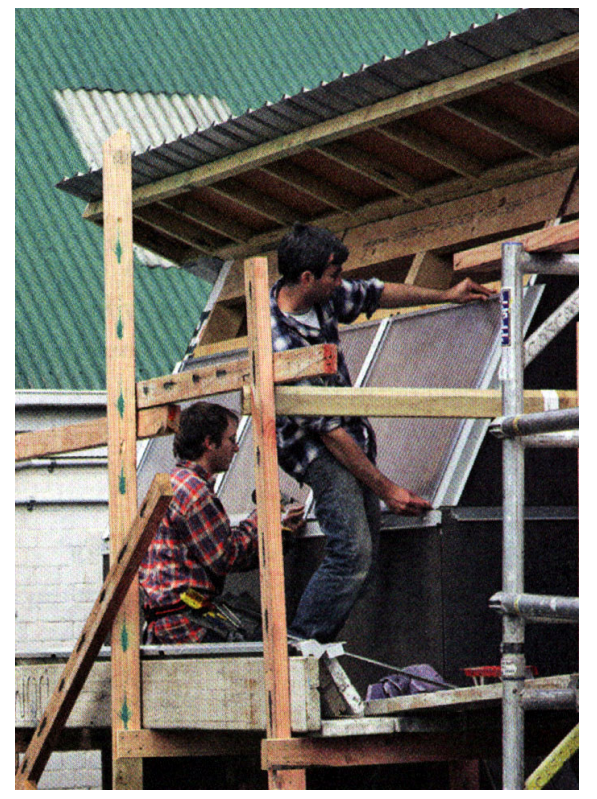

Figure 258: Unitec design-and-build students at work constructing a prefabricated module. Source: A. Kenworthy, "A Fine Bach (of Students)." Home New Zealand, Dec/Jan 2008/09: 135. 


\section{Key Challenges and Opportunities}

Communication opportunities such as the internet, and digital-based design, production and marketing, allow for individualised design in respect to both physical site context and cultural needs. New design interfaces open up a dialogue between the traditional roles of the architect and the general public (Naumann 94). Internet sites with embedded programs that allow clients to self-arrange homes through customisation and visualisation also serve to educate and facilitate communication (Naumann 95). These new technologies should come with a warning, however:

There have been celebrated examples of new technology being used to reinforce outdated and wasteful processes - and it does not work. The advice offered to construction by leading manufacturing industries is to approach change by first sorting out the culture, then defining and improving processes and finally applying technology as a tool to support these cultural and process improvements (Construction Taskforce 28).

An identified issue is the need for a clear definition and understanding of cultural expectations which is explored further here.

The socio-cultural aspects of communication and marketing affect every relationship in the house design, procurement and construction process. Cultural perceptions affect the customer's receptiveness to prefabricated products. A change in cultural perceptions would potentially increase the market for prefabricated housing. This change in cultural perceptions needs to be facilitated and applied first, in order for process and technological improvements to be more readily accepted by the wider New Zealand housing market. The issue of poor communication is the major impediment to the adoption of new technologies and products (Paevere and MacKenzie 15). Specific communication challenges include lack of industry integration, inadequate product education and training, poor communication between universities and industry, and inadequate information flow within the industry and with manufacturers.

The context or underlying problem is that misperceptions in prefabrication are abundant and create barriers to the uptake of prefabrication (Pan, Gibb and Dainty 1). This socio-cultural reaction to prefabrication is a deeply-embedded, learned psychological response. In 1984, Allan Mitchener noted:

The customer [is] becoming less amenable, if not hostile, to mass production in general, and to housing that even hints 'mass produced' in particular. Psychologically, mass production is considered an attack on individuality (Mitchener 4).

Widespread misperceptions of repetition, flimsy, cheap, temporary, poor quality and prefab as an end-product rather than a means of construction show that there is a clear need for a reeducation process. ${ }^{194}$ The question is how to change perceptions at a number of levels; from the government, construction industry and architecture profession through to the end-consumer.

194 Comments such as "too many of them look weird", "there is almost never a discussion of siting", "a prefab house is a cookie cutter product" and "there is no one-size-fits-all design" reflect a misunderstanding of a potential for prefabrication as a system and as an approach to improving quality through factory-built standards and computerised customisation to create a variety of architectural solutions for individual clients and sites (Mengisen). 

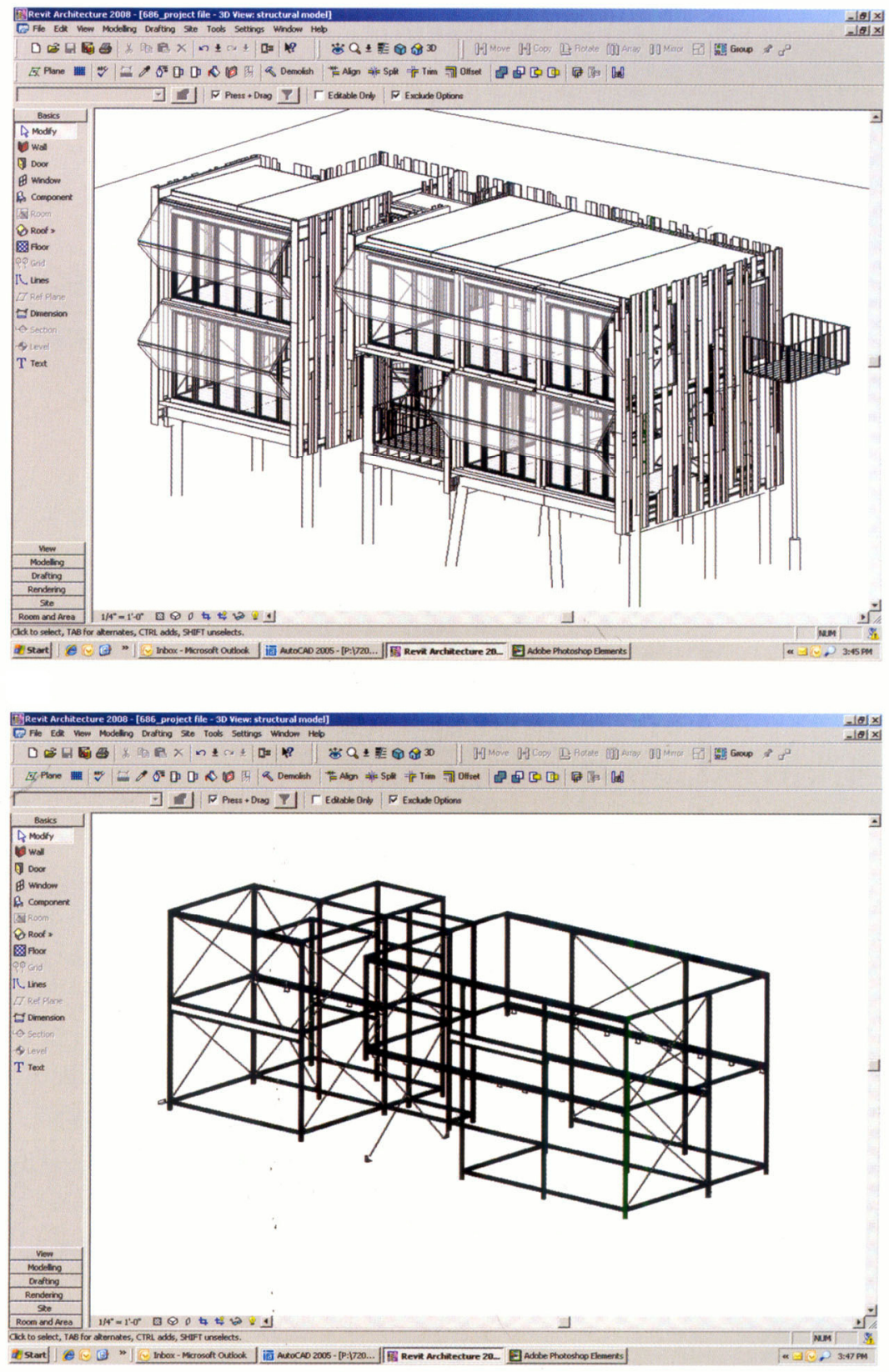

Figure 259 and 260: Computer-based models of Loblolly House by KieranTimberlake, 2006. Source: S. Kieran and J. Timberlake, Loblolly House, New York: Princeton AP, 2008: 49. 
Identified channels and social networks for both communicating and adopting new ideas include informal and indirect links, word-of-mouth, opinion leaders, mass media, professional and trade associations (Koebel et al. qtd. in Paevere and MacKenzie 21).

Marketing and communication inform socio-cultural perceptions. Once these marketing tools are established and effectively operating, improvements to prefabricated housing through research and development can be more effective and widespread. This approach is consistent with the United Kingdom Construction Taskforce's recommendation to improve the underlying culture before improving processes or applying technology (28). New Zealand industry participants have identified areas for process-based improvement and innovation.

Historically, prefabricated housing has been associated with site constraints which necessitated flat sites with easy drive-on access. Today, smaller components and panels are more manoeuvrable, computer technologies enable more customisation, and combinations of work at site concurrent with work in a factory lead to time and potential cost savings (259-260). Custom foundation systems together with prefabricated housing products create a new precedent and a solution to site-based misperceptions of prefabrication.

Existing prefabrication business research practices are not rigorous or deep enough. A few months of internet-based research before launching a prefabricated housing product is not adequate. Thorough research and development provides foundational market and technology knowledge to improve prefabrication processes and implement technologies.

The New Zealand housing industry has wide-spread, low-scale uptake of prefabricated technologies through the use of pre-nailed components and the cultural acceptance of this technology is as a result of small changes and improvements: "like nature, incremental steps will always lead to a more realistic and 'of this world' feeling" (Hect 34). Industry experts reiterate that, "the vast majority of successful innovations result from a stream of small incremental changes" that work together to influence consumer behaviour (Foxall qtd. in Barlow 24). Recognising that the housing marketplace is driven by cultural perceptions, David Oxley also recommends this evolutionary approach rather than a revolutionary one, to enable acceptance by the wider community (134). Small changes will ensure enduring change (de Geest).

A potential for prefab in New Zealand's future is in several small approaches that are executed with high quality and great attention to detail. One approach is to pre-nailed components; the next step is to add in services such as wiring and plumbing ducts, then to enclose these panels with insulation, lining and cladding, leaving just the joint to deal with at site (261). Considering the success of low-level prefab components, extending the extent of prefabrication into panels or modules is both practicable and attractive within current trade practices (Oxley 134). 


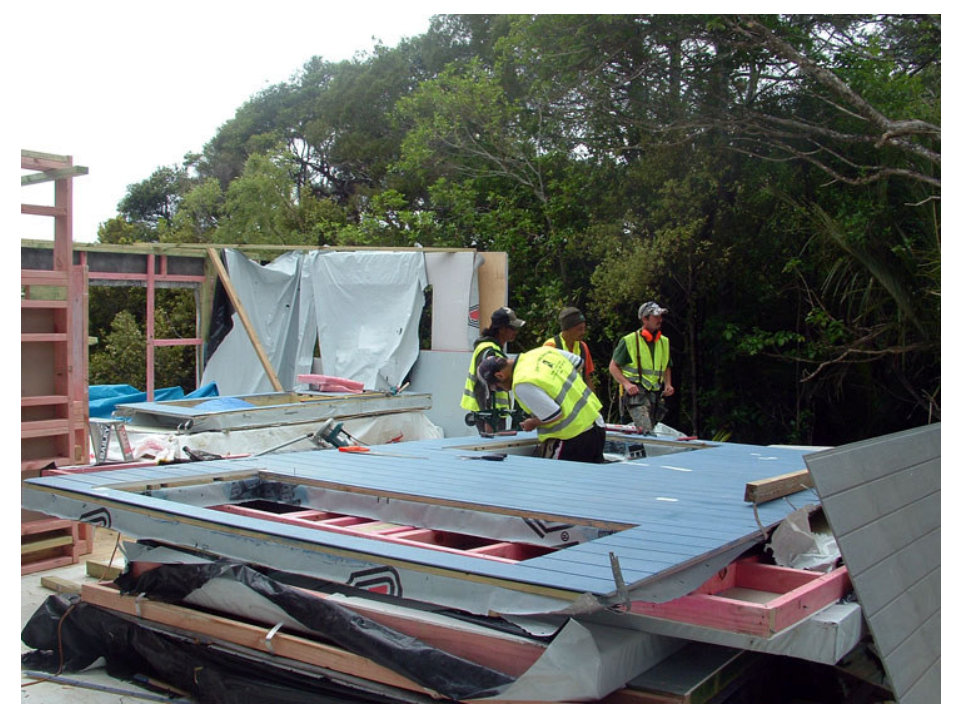

Figure 261: Drop-Loc panels at site: potential for the pre-nailed component industry to learn from. Source: Photograph courtesy of Mark Grimes. 
Colin Davies reinforces the concept of building on existing knowledge and industry in that, "it is usually safer and cheaper to adapt an old technology" (203). He suggests that architects should work with established manufacturers, indicating the United States manufactured and modular housing industries. Paul Weideman suggests that existing manufactured housing factories should offer one or two contemporary design options to target these niche markets. This should be a more easily achievable approach than creating new prefabrication systems and business processes from scratch. Allison Arieff and Bryan Burkhart point out that architectural prefabricated housing has suffered enough from its history of "noble failures" and the curse of the prototype (9). New Zealand's established prefabricated industry is transportable housing so future focus should be on architectural iterations, research and development, and business ventures with these companies.

This research has found a need for more emphasis on professional marketing and communication tools to combat misperceptions and create new precedents. The need for increased research and development initiatives, collaboration and investment has also been identified. These are the two key areas of challenge and opportunity for prefabricated housing in New Zealand. A detailed investigation and proposed solutions will be elaborated in the following chapter. 


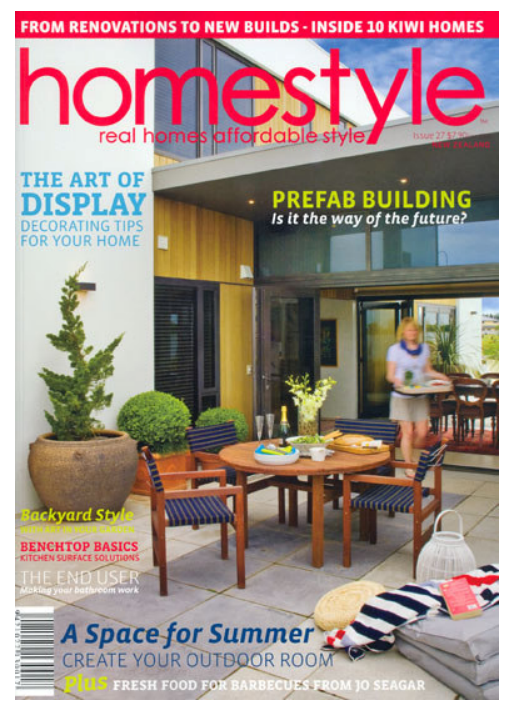

Figure 262: Marketing and Communication: prefabricated housing case featured in a lifestyle magazine.

Source: Homestyle, Issue 27 (2008): cover.

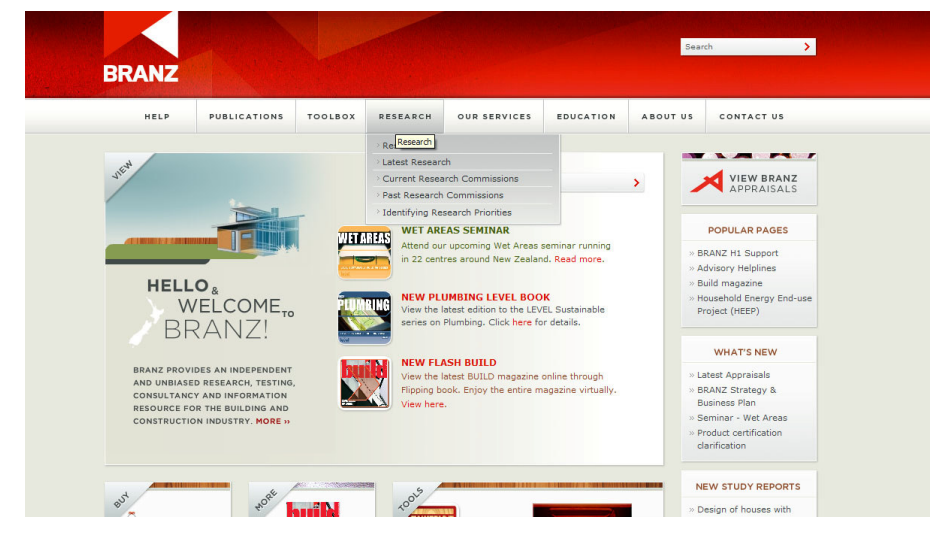

Figure 263: Research and Development: Branz website front page with research category highlighted. Source: <http://www.branz.co.nz/cms_display.php>. 


\title{
Strategies :
}

\section{Key Opportunities, Solutions and Recommendations}

\begin{abstract}
A two-pronged strategy framework of marketing and communication, and research and development is proposed. This represents the merging of business and architecture towards successful prefabrication. Numerous obstacles have been identified between the New Zealand prefabricated housing industry today and a potential future Kiwi prefab.
\end{abstract}

One key finding is the need for marketing and communication, particularly to address the issue of widespread misperceptions and lack of coordination by a holistic industry organisation. Internal marketing strategies are within the control of individual prefab housing businesses while industry cooperation is needed for large-scale marketing and communication initiatives (262). Le Corbusier advocated for cultural change in order for prefabrication to be accepted when he wrote, "it is essential to create the right state of mind for living in mass-production houses" (245).

A second key finding is the need for research and development, particularly to address a lack of established industry relationships and potential for investigations into alternate typologies. Both industry and government support for research and development will enable technical design to be tested and evaluated thoroughly before being brought to market (263). This future focus on communication, cooperation and research and development is consistent with recommendations from the top one-hundred United Kingdom house-builders (Pan, Gibb and Dainty 11).

These two key findings will be further discussed and developed in this chapter, drawing on national and international examples. Specific strategies will then be recommended to advance the prefabricated housing industry in New Zealand. 

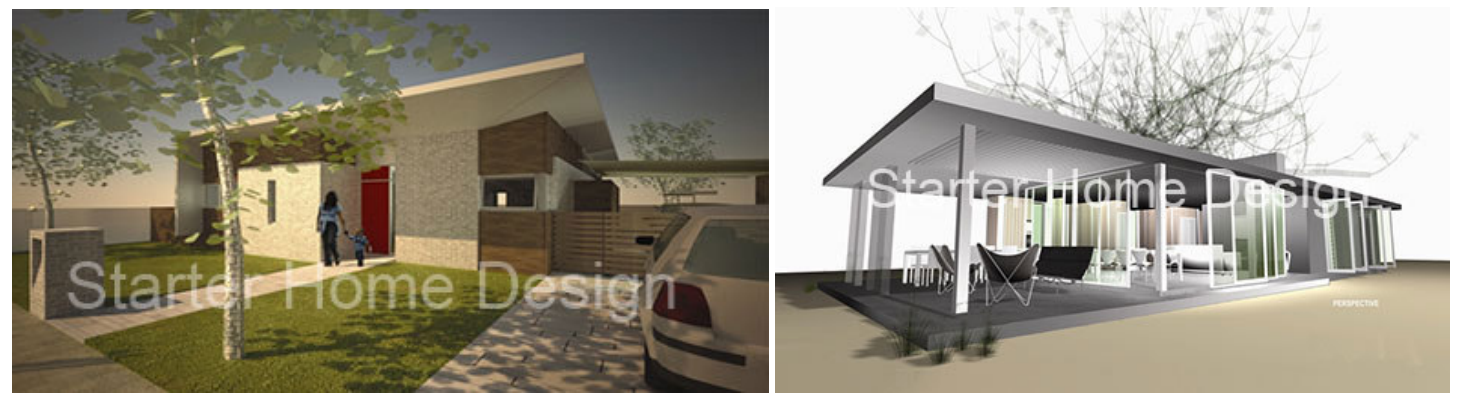

Figure 264 and 265: 'Starter Home Design' competition winners S3 Architects and Koia Architects. Source: <http://www.dbh.govt.nz/starter-home-design>. 


\section{Marketing and Communication}

Marketing and communication approaches used nationally and internationally that New Zealand's prefabricated housing industry could learn from are now explored. The discussion focuses on marketing and communication tools to combat misperceptions about prefabrication shared by government leaders, industry specifiers and suppliers, and the consuming public.

A direct approach to educating the industry is needed, through seminars, design-and-build tertiary courses, events and publications. Market research is required to connect the prefabricated housing industry with the wider public. Prototype exemplars should be demonstrated through show-home parks with information centres, home-show events, exhibitions and museums. Mainstream media channels of television, magazines and illustrated books can be used to bring prefabrication messages into consumers' homes. A holistic industry association should coordinate the instigation of these methods to connect the industry together.

The building and construction sector is a key part of the New Zealand economy and has a critical role to play in economic recovery and growth as it contributes more than five percent of gross domestic product (GDP) and employs about eight percent of the workforce. It is likely that prefabrication could play a part in increasing construction efficiencies and productivity through government recommendations. The New Zealand government can learn from initiatives in the United Kingdom where prefabricated applications are supported by recommendations from the British government. The central government has an integral leadership role in regulating the construction industry through building codes, legislation, patronage, and research and development.

The government played a historical role in promoting innovative housing through research and development and state-funded projects. Former Building and Construction Minister Shane Jones released a blueprint for simple housing with a reduced building code focussing on, "the three Ss: standardisation, simplification and size" ("Red Tape"). This initiative was reinforced by the Department of Building and Housing's 2008 to 2009 'Starter Home Design' competition, with the winning design planned to be built by Housing New Zealand (264-265). The blueprint and competition specifically recognise prefabrication as a way to increase efficiency and productivity through government and industry collaboration. Local councils play an important role in the administration of building code compliance through building consent documentation and inspections. Building inspectors need to be well-versed on prefabrication definitions and typologies, and specific products and systems in order to efficiently mitigate the construction consent process. In future, the government should support research and development to ensure high-performance technologies make their way to market quickly (Larsson). 


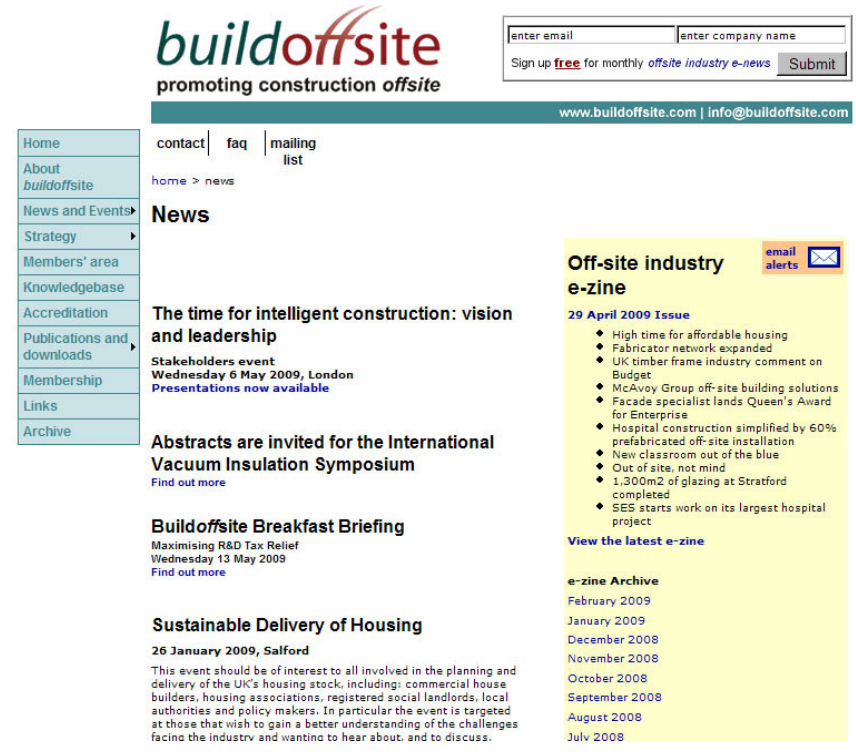

Figure 266: Buildoffsite website news page with information on events and industry collaborations. Source: <http://www.buildoffsite.co.uk/news.htm>. 
A lack of construction industry cohesion is a key barrier to the uptake of innovative technologies (Paevere and MacKenzie 20). New Zealand's prefabricated housing industry is similar to the United Kingdom's in that it is fragmented, has modest barriers to entry, is made up of small companies, has few exemplars, and suffers from limited experience amongst industry professionals and little exposure at universities (Ogden). The currently disparate and competitive nature of the industry means that few members are working together to advance the future of prefabrication in our country. This attitude will need to change if prefabricated housing businesses wish to improve the uptake of these technologies.

In moving towards commercially enduring prefabricated architecture, the profession will need to embrace building, work collaboratively with the building industry and communicate more clearly with its consumers. Colin Davies notes that the architecture profession does not currently speak, "the common language of domestic architecture that everybody understands. Architects should respect that language and learn to use it gracefully" (203). There are clear benefits for market research to increase communication between the design profession and endconsumers.

There is a clear need for a marketing-based umbrella association like the United Kingdom's Buildoffsite to act as a single point-of-contact, and be responsible for industry-wide marketing, event organisation, media publicity, portal website, and industry education (266). Buildoffsite acknowledges that awareness building, informing, enthusing and setting standards are all important for the benefits of prefabricated construction to be widely understood and applied. This is based on the Construction Taskforce's comment that, "training and quality are inextricably interlinked" (26). Increasing industry education on products and materials, installation techniques, and methods of operation and maintenance will lead to increased adoption of prefabrication technologies (Paevere and MacKenzie 20).

Other national marketing bodies include the United States' Modular Building Institute (MBI), a non-profit trade association representing non-residential modular construction and the National Modular Housing Council (NMHC) representing the residential industry. ${ }^{195}$ Within New Zealand, 'Future-Proof Building' is a scheme initiated by Construction Marketing Services Group to publicise their clients' products through direct contact with construction material specifiers (refer to Chapter 3 Carters Manufacturing case study). Professional associations such as Solid Wood and the Frame and Truss Manufactures Association of New Zealand (FTMA) provide support to prefabricated component suppliers. Primary material suppliers each have their own industry bodies such as the Cement and Concrete Association (CCA) and New Zealand Wood. ${ }^{196}$

\footnotetext{
195 New Zealand business Stanley Modular has joined MBI as it has a multi-unit and commercial focus. United States MKD is a member of MBI despite a focus on residential buildings. The NMHC offers networking, technical and legal support, marketing solutions, recognition of excellence through awards programmes, research and trends statistics, and a voice to shape national policy. LivingHomes is a member of NMHC.

$196 \mathrm{NZ}$ Wood aims to provide tools and information to both specifiers and the general public. They have identified that there are misperceptions about building with wood in low-rise non-residential buildings so have commissioned market research to investigate this further. As a result, NZ Wood discovered that a majority of specifiers and manufacturers were interested to learn more about the benefits of using wood from a dedicated website which was then set up.
} 


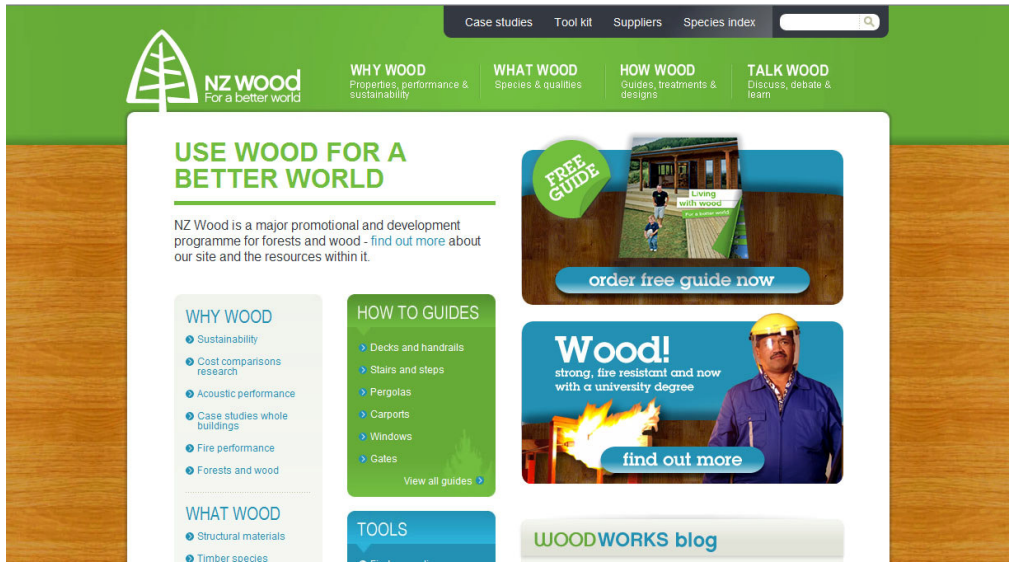

Figure 267: NZ Wood website front page. Source: <http://www.nzwood.co.nz/>.

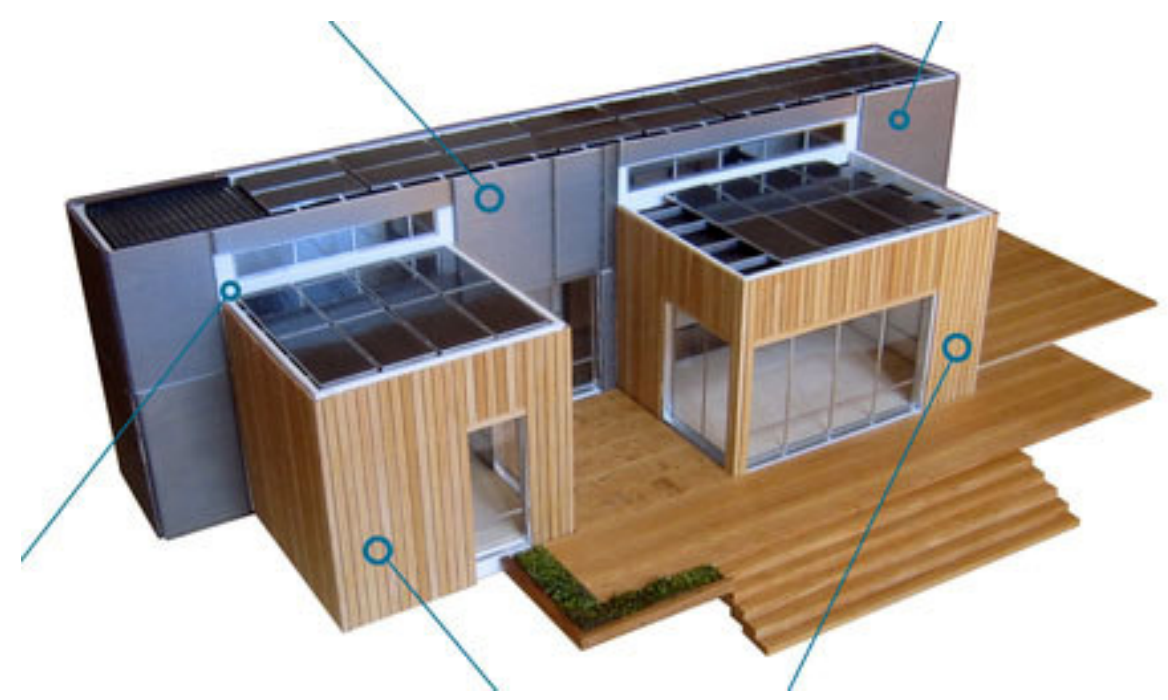

Figure 268: Tripod core and pods by Carnegie Mellon University, winner of 2008 LBC student category. Source: <http://judging.lifecyclebuilding.org/entries/view/63>. 
A great precedent for the prefabricated housing industry is Precast New Zealand, because it has brought together a range of small competing firms to create a sense of unity and shared purpose in the industry. The brand Stratalam offers New Zealand glue-laminated timber component manufacturers an umbrella brand and a quality mark to differentiate their products. The prefabrication industry could also learn from New Zealand Wood's experience with market research, investigating misperceptions, and setting up a communicative website to address them (267).

An initial step towards industry group formation could be a one-off workshop with published findings, such as the one conducted by House and Home for the United States modular industry in 1971. The magazine invited top executives of six leading modular manufacturers to a session where they discussed modular's most serious issues over a two-day period, resulting in recommended areas of focus published in a nationwide magazine article ("What's Holding Back".

Historically, housing design competitions were prompted by the New Zealand government, which is re-visiting the concept with the current 'Starter Home Design' competition. British government housing associations ran a 'Design for Manufacture Competition' beginning in 2005, with housing models completed in 2007 and lessons learnt published in 2008 (Design for Manufacture). The mid-twentieth-century Case Study House programme was instigated by media with the support of industry. Current international competitions such as the Solar Decathlon and Lifecycle Building Challenge (LBC) enable students, academics and practitioners to submit solutions side-by-side (268). ${ }^{197}$ The contemporary 'green modern prefab' movement has partly resulted from Dwell magazine's 2003 Dwell Home Design Invitational. The winning design by Resolution: 4 Architecture was built in 2004 and opened to a stream of two-thousandfive-hundred visitors. Editor-in-chief Allison Arieff subsequently received nearly ten-thousand emails asking advice on purchasing a prefab home (Jana). This interest led to the 2005 Dwell Homes by Empyrean branding partnership where prefabricated homes were available for site visits, lectures and in-depth coverage through magazine articles (refer to Chapter 4 Empyrean case study). Housing competitions have a role to initiate debate and expose design innovations to the wider construction industry and public alike.

Poor communication links between universities and industry inhibit the uptake of innovation (Paevere and MacKenzie 20). Direct contact between universities and industry through presentations and lectures, and student participation in design-and-build studios are two means to improve communication links. Prefabrication terms and merits need to be clearly communicated to the next generation of specifiers, including architecture, design, building science, engineering, quantity surveying and construction students. There are many research projects, design studios and design-and-build programmes at universities overseas, yet only

${ }^{197}$ KieranTimberlake's Loblolly House won the Residential Built section of LBC in 2008. The Student category winner was Tripod, a plug-and-play concept incorporating a mechanical core and living pods (Lifecycle Building Challenge). 


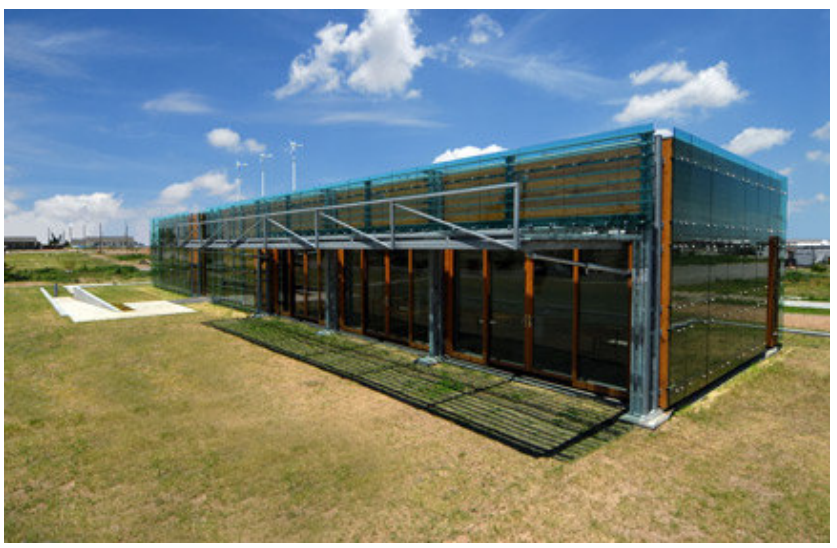

Figure 269: Sustainable Prototype by Studio 804, 2008. Source: <http://www.studio804.com/>.

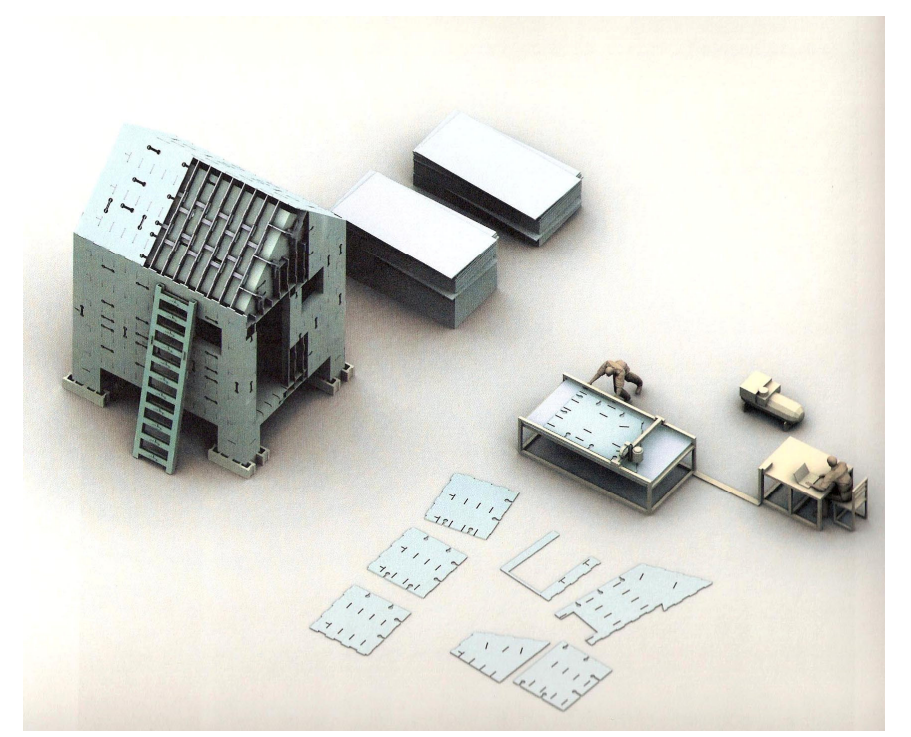

Figure 270: 'Digitally Fabricated Housing for New Orleans' by Larry Sass and MIT. Source: B. Bergdoll and P. Christensen, Home Delivery, New York: MoMA, 2008: 202. 
one established in New Zealand - at Auckland's Unitec (256-258). Unitec ran a design-and-build studio in 2008 and 2009 with architect Dave Strachan in conjunction with industry and media (Strachan). The modular housing design was built in the university's car-park before being shifted to a Coromandel site and auctioned for a televised charity telethon (Kenworthy 135). ${ }^{198}$ New Zealand polytechnics currently use design-and-build studios to teach carpentry students first-hand techniques and the homes are then auctioned off to the public.

Leading United States architecture schools such as Harvard, Yale, Massachusetts Institute of Technology (MIT) and Columbia all offer design studios on manufactured housing. ${ }^{199}$ Many of these studios are headed by architects who combine practice with teaching to develop innovative prefab prototypes. One of the more well-known is Studio 804, a self-funded, notfor-profit corporation affiliated with the University of Kansas School of Architecture and Urban Design since 1995 (269). Each year since 2004, the studio has created a new modular housing iteration for a wait-list of social housing developers and documents progress on its website. Studio 804's 2006 Modular 3 was one of the winners of Architect magazine's 'Home of the Year' award, an acclaim that is recognised by the wider architecture profession.

MIT architecture professor Larry Sass created the yourHouse digital design system with a team of students, and exhibited a prototype at MoMA's 'Home Delivery' exhibition in 2008 (270). The system comprises laser-cut, puzzle-type plywood pieces assembled in just a few days by untrained workers using only rubber mallets. This system potentially enables architecturallydesigned housing to be accessible to developing countries through e-mail and a table-top lasercutter (Sass).

Other university-led prefabrication programmes in the United States are the University of Virginia School of Architecture's 2006 ecoMod project series, the Prefabrication Laboratory at the University of Texas, the Catholic University of America's School of Architecture and Planning's Nomadic Transit Module, the University of Colorado's 2007 TrailerWrap, Tulane University's Greenbuild, and Canada's McGill University School of Architecture's Grow Home and Next Home projects. Designing and constructing prototypes not only educates students in design-and-build methods but also educates the wider public through exhibitions and events. ${ }^{200}$ In Europe, the Royal Danish Academy of Fine Arts School of Architecture's Centre for Industrial Architecture (CINARK) is dedicated to research and education of the architectural potential in prefabrication. Copenhagen is also home to the Foundation Realdania's Building Lab DK, which

\footnotetext{
198 The charity event was the 'Big Night In' telethon on June 20 2009, in conjunction with KidsCan and TV3 (Kenworthy 135). 199 In 2008, MIT and modular housing company Bensonwood joined with other construction industry members to develop the 'Open Prototype Initiative' to combine efficient factory construction with energy conservation and mass customization (Open Prototype Initiative). 200 The original Grow Home demonstration house was built to test the theory that people experiencing the advantages of high-quality, smaller, more flexible, and more adaptable houses might choose smaller houses when making house purchasing decisions. About ten-thousand people visited the Grow Home and several hundred filled in questionnaires. The results were that three quarters of people said they would live in a house smaller than one-hundred square metres, and almost all respondents approved of an unfinished second floor that could be completed according to their needs (Rybczynski).
} 

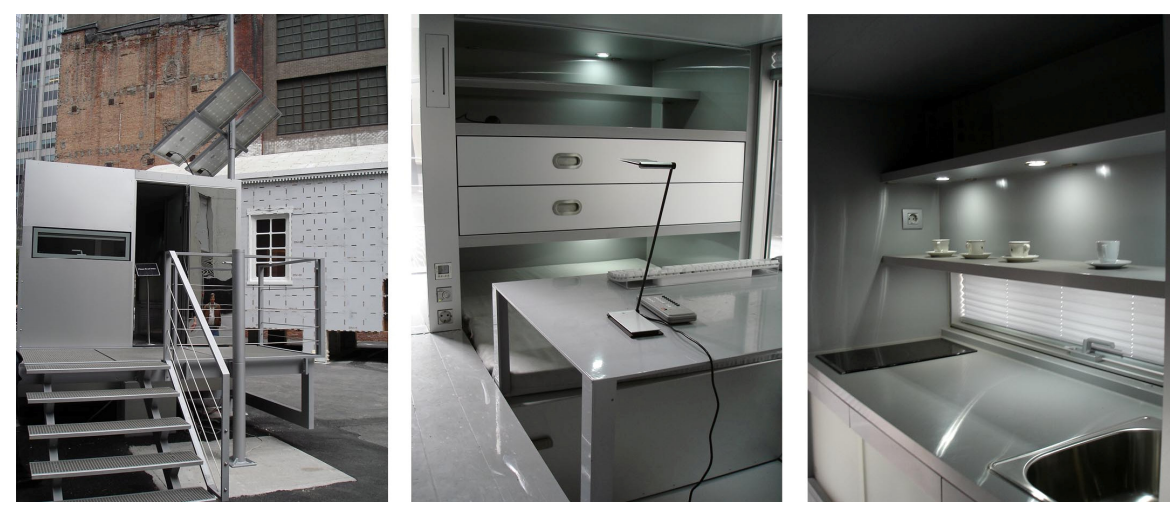

Figure 271 - 273: Exterior and interiors of Micro Compact Home at 'Home Delivery' New York. Source: Author's photographs, 2008. 
was active between 2005 and 2008 as an innovation unit to improve coherence between construction firm initiatives in mass-customisation. In Germany, a university and professional relationship has spawned a commercial prefab product. Richard Horden collaborated with architecture students at TU Munich and architects Haack and Hopfner to produce the Micro Compact House (m-ch) (271-273).

Prefabrication technologies are incorporated into university design courses in the United States, Europe and United Kingdom. Buildoffsite reported a substantial increase of architecture student and academic visitors to its exhibition stand at 'Futurebuild 2008' (Buildoffsite). The University of Salford launched a new master's course in advanced manufacturing, to address this increasing demand for prefabricated solutions - the first course of its kind in the United Kingdom (Buildoffsite). The 'CommercialiSE' initiative creates opportunities for collaboration between businesses and leading universities. This British scheme is made up of eleven industrial sectors, including the Built Environment Sector, and provides funding assistance, collaborations, mentoring and training to improve the relationship between industry and tertiary institutions. Loughborough University has produced a wealth of prefab research, is home to expert Alistair Gibb, and has a dedicated 'Innovative Manufacturing and Construction Research Centre'. These are just some of the international precedents that link industry with university-led design-and-build programmes. There are opportunities for New Zealand universities to learn from and emulate these programmes.

Marketing has a wide meaning for the prefabrication industry. According to Burnham Kelly, "this includes the determination of markets, prices, channels of distribution, and methods of sale; and the procedures used in financing, site selection, transportation, erection, and servicing" (359). These are all considerations for which businesses must plan. Marketing material used widely in the prefabrication industry includes plan-books, websites, brochures, e-mail newsletters and personalised invitations to show-home openings. Many of the methods described below are used in an exemplary way by Californian prefabricated housing businesses, but only in a very limited way by New Zealand firms.

Direct contact through workshops, lectures and informative seminars run in conjunction with industry partners are other popular publicity techniques learnt from Californian precedents.

Digital Video Discs (DVDs) are a back-up source of manufacturer information designed to help architects and specifiers understand the benefits of using prefabricated solutions. ${ }^{201}$ Opportunities for an industry association, educational presentations and accompanying DVDs exist in the New Zealand prefab industry.

201 One example is the DVD produced by Prater and Ruukki available online in the United Kingdom. It shows project footage, design and manufacture through to delivery at site and installation and interviews with key personnel (Ruukki UK). 


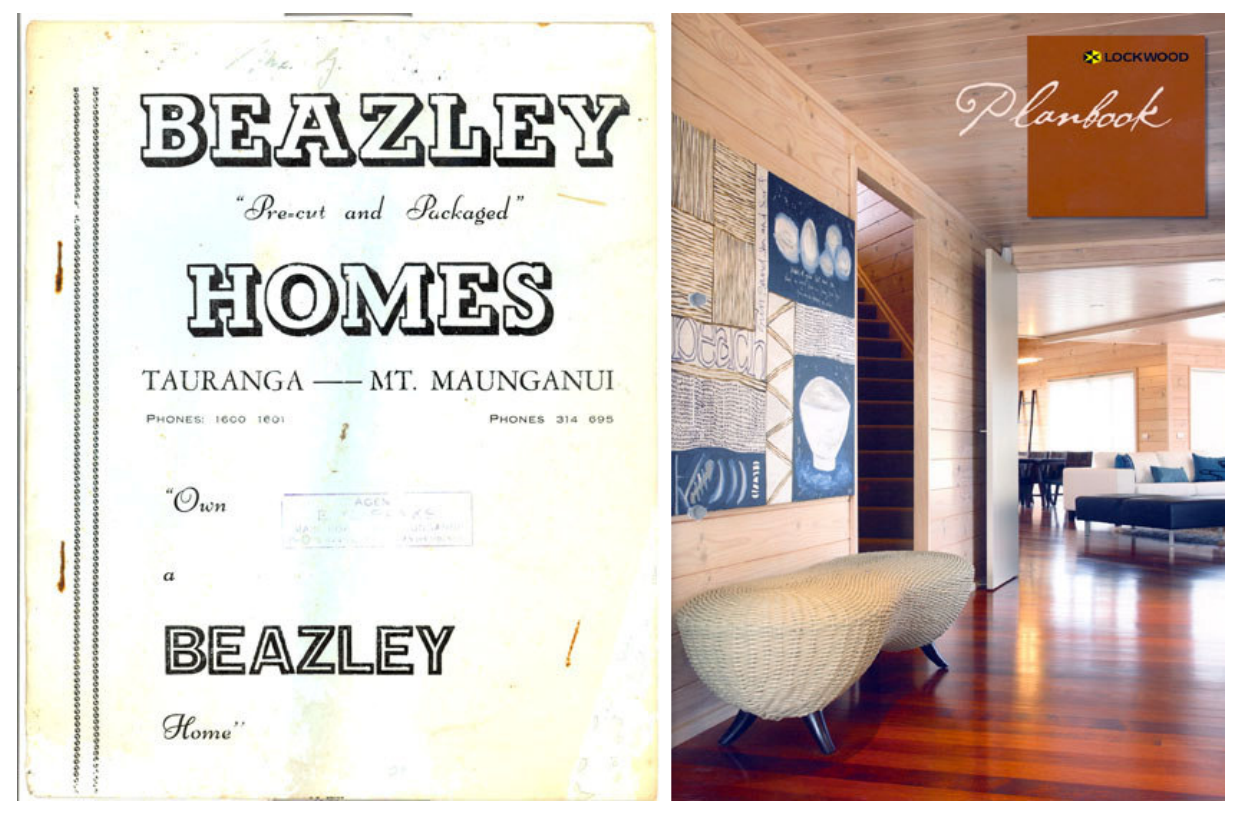

Figure 274 and 275: Plan-books from mid-twentieth-century Beazley Homes and 2008 Lockwood Group. Source: Beazley plan-book courtesy of Lindsay Park, and Lockwood plan-book courtesy of Lockwood Group. 
New Zealand has a historical legacy of plan-books, from mid-twentieth-century 'Beazley Homes' to contemporary 'Lockwood' iterations (274-275). These have a role to initiate the design consultation process, rather than act as exact blueprints (Tuohy). The increasing use of architect-designed plans is opening up this conversation to more design-savvy clients. In the United States, websites sell house-plans at a fraction of the cost usually paid to architects, revitalising an earlier twentieth century ideal and adapting it to the current market (Cannell).

All participating California prefab firms use the internet as an introduction to their business. This includes websites, video, news articles, web-based procurement, blogs, newspaper websites, and direct e-mail newsletters. Several New Zealand companies use websites, but many would benefit from improvement, including bachkit, habode and i-houz. Popular United States prefab websites Fabprefab, TreeHugger, Inhabitat and JetsonGreen submit daily or weekly blog postings that encourage debate and discussion (276). The internet is also used for product prereleases, enabling further refinement before widespread release. Web-based interactive design tools are becoming more popular such as MKD's use of Google Earth and Sketch-up and New Zealand's own e-homes by Maddrens Drafting Pad service. There is significant scope for future refinement and improvement of these currently rudimentary internet-based services.

Television and web-based video bring prefabrication to life. The site-based assembly of MRP's Palms House in Los Angeles was documented by a television crew with footage shown on several newspaper and blogging websites. Other videos are available on You-tube where 'Dwell on Design' has its own channel and New Zealand's bachkit has a promotional clip. United States prefabricators are televised regularly and the United Kingdom has the ten-year series of Grand Designs hosted by architect Kevin McCloud. A 2004 episode on German prefabricated housing firm Huf-Haus, "received an outstanding response and...still [does] today, after repeats of the programme are shown" (Fuller). The success of Grand Designs indicates that there is potential for a New Zealand programme to promote local businesses, systems and products.

History lays out numerous prototype and show-home marketing successes. Buckminster Fuller's 'Wichita House' had thirty-seven-thousand advance orders placed, although just two prototypes were ever made (Kronenburg). As Smith points out, "it is very hard for people to demand something they've never seen", so it is a very convincing sales tool to offer prospective purchasers (213). The 1945-62 'Case Study House' programme was designed as a format for the general public to learn about architectural concepts of pragmatism, service, standardisation and modularity (277). 'Case Study House Eight' by Ray and Charles Eames has been described as, "displacement of architecture from a stable enclosing form to a lightweight, demountable, infinitely re-arrangeable storage system....an even more radical displacement into product design and the consumable image" (Colomina 31). It has become one of the most influential pieces of architecture produced during this era for signifying the potential use of off-the-shelf components. 


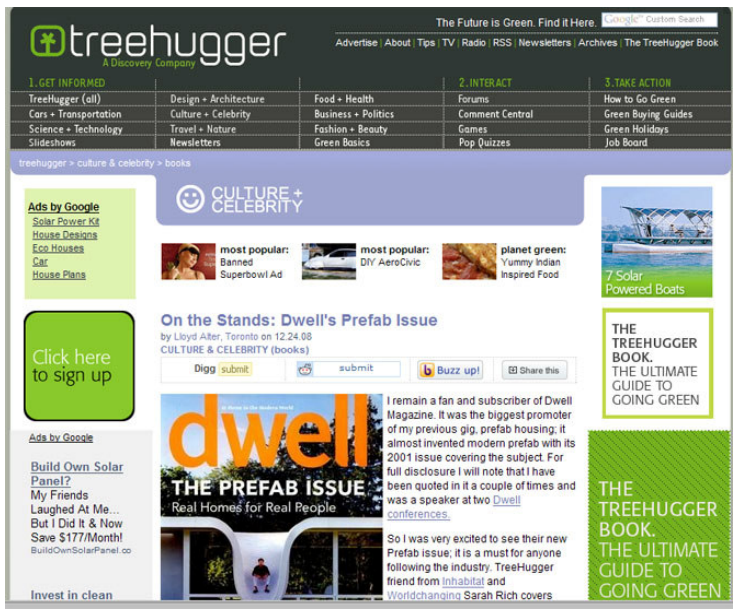

Figure 276: Prefab article on Treehugger website. Source: <http://www.treehugger.com/files/2008/12/dwell-magazine-prefab.php>.

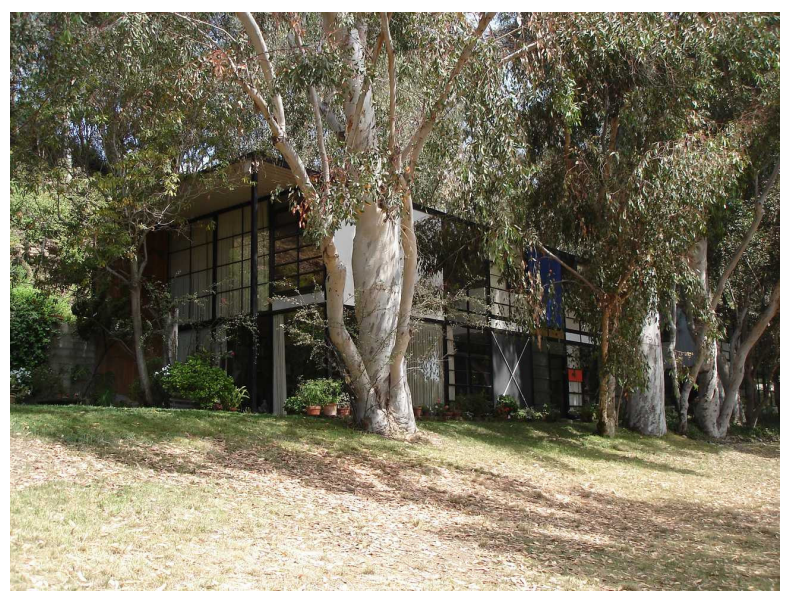

Figure 277: The Eames' Case Study House Eight Los Angeles. Source: Author's photograph, 2008. 
Experimental house programmes today are often interactive exhibits which are later sold to a private party or endowed to a research programme. They are typically the outcome of a combined effort between industry consortiums, not-for-profit organisations and think-tanks, rather than a single client. In the United States, prefab show-homes are displayed at homeshows, exhibitions, and museums. Over just a few days, thousands of people get the chance to experience these innovative homes and hear the architects speak. Several thousand people visited the MRP 'Palms House' before it was put up for sale, and MRP intends to continue this sales strategy of building more prefab model homes for public relations purposes (Smith).

In Europe, the United Kingdom and Japan, prefabricated housing businesses showcase prototypes at permanent show-home parks, sometimes alongside other manufacturers. The United Kingdom's BRE 'Innovation Park' at Watford was established in 2007 to showcase houses built by a number of different architects and contractors. ${ }^{202}$ Individual businesses also build show-homes at their factory sites, such as Wolseley's Sustainable Building Centre, complete with lecture theatre and café (Buildoffsite). This is a similar approach to the Japanese research and development centres at their factories, such as Sekisui's four-level dedicated facility to showcase its interactive testing and enable consumers to experience prefab housing (278-279). Although many New Zealand businesses feature show-homes at their sales office site or franchise, there is much that can be learnt from offshore exemplars. Grouping several manufacturers at a single location puts a united front on the prefabricated housing industry as well as facilitating consumer choice and education. Displaying scientific testing facilities increases consumer education and trust in a quality housing product. Providing high levels of customer service makes each individual consumer feel valued and encourages establishing a business relationship. These are three of the reasons to advocate for a combined show-home park.

Historically, international exhibitions such as the World Expositions showcase innovative housing products to an even wider audience. ${ }^{203}$ The Lockwood Group's contribution to the New Zealand pavilion at Osaka in 1970 put the system on the world stage and directly led to international orders. In the 1950s, the National Housing Council sponsored 'home weeks' which soon became known as 'parades of homes'. These featured demonstration houses, competitions, talks, newspaper features and tours showcasing new designs in order to test public reactions. ${ }^{204}$ Other historical exemplars are from the United Kingdom and United States. London's 'Ideal Home Exhibition' was extremely popular through the mid-twentieth century, and

202 A new innovation park has been proposed to be built in Scotland with up to six show-buildings and a Technology Pavilion for visitors to gather and receive information. Buildings will be chosen to align with government strategies on energy performance and sustainability, and offsite construction methods (BRE).

203 The World Exposition, World Fair, or Universal Exposition is one of the largest economic and cultural events. Joseph Paxton's prefabricated steel and glass Crystal Palace was shown at the first Expo in 1851. Buckminster Fuller's Dymaxion was meant to be built for the 1933 Expo, and Moshe Safdie's Habitat 67 was successfully built for the 1967 Expo in Montreal. New Zealand's pavilion in 1992 at Seville used Mclntosh prefabricated timber components. The next Expo is in 2010 at Shanghai.

204 The 1956 Auckland 'parade of homes' consisted of 56 houses visited by two-hundred-thousand people over a fortnight, up to thirty-thousand per day. Twenty-four cities and towns around New Zealand hosted the parade which made the innovations accessible around the country (Shaw 169). 

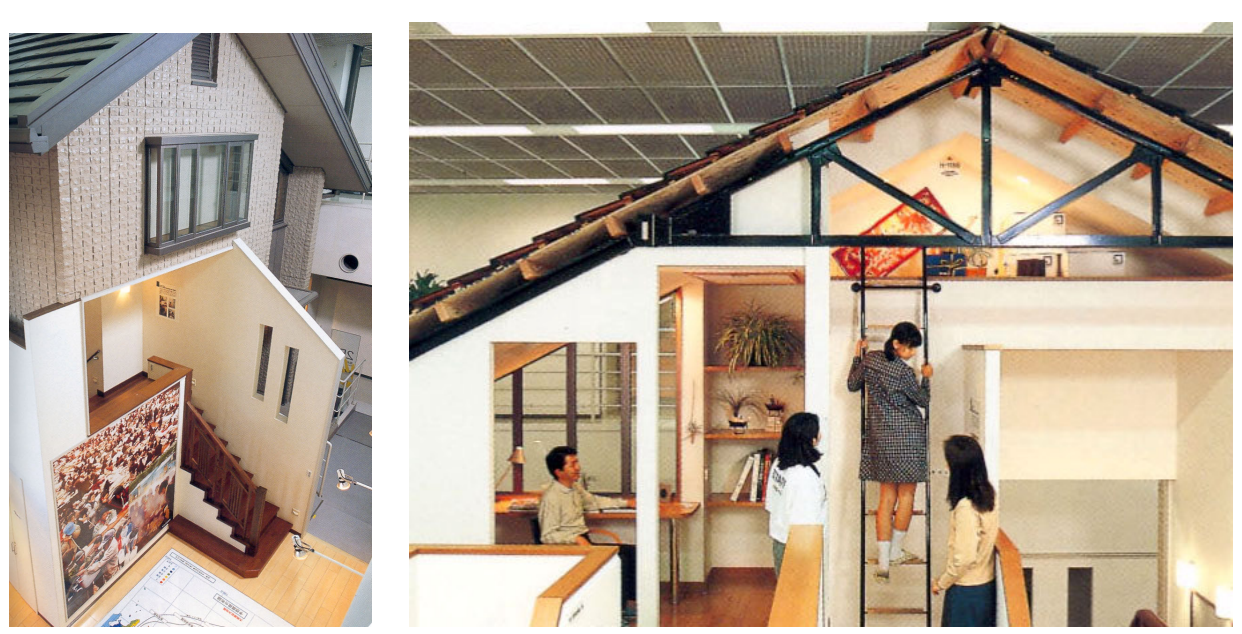

Figure 278 and 279: Sekisui House: Home Amenities Experience Studio and consumer experience. Source: Sekisui House brochure: 20. 
in 1950 a prefabricated state house from New Zealand was shown. ${ }^{205}$ During the month-long exhibition over one-hundred-and-forty-thousand people passed through the house and over a million gazed at its exterior (Skinner). In New York, MoMA exhibited mid-twentieth-century architecture through its 'House in the Museum Garden' series by architect and curator Philip Johnson. ${ }^{206}$

New Zealand has an existing series of disconnected home-shows in major city centres, and several rural agriculture-based lifestyle events. The annual Auckland Show has a street-ofhouses which is used by a few New Zealand prefab businesses to launch new housing products. A larger permanent housing village would be beneficial for consumers to directly compare prefab housing products on the market. It is a logical extension to want to experience a house for a length of time, even overnight. An historical example is Buckminster Fuller's Dymaxion Deployment Unit (DDU) that was test-dwelt by the head of the University of Michigan's Department of Architecture and his wife in 1941 (280). Closer to home, the Bach2go in New Plymouth can be rented as accommodation before deciding whether to purchase it. This concept has not been explored fully in New Zealand, and is not widespread offshore either, but its benefits warrant that it should be looked at more carefully as a means to demonstrate and educate about prefabrication.

Conferences are instrumental in educating niche audiences. Dwell magazine produced the 2005 'Prefab Now' conference with guest speakers from contemporary and historical prefab pioneers and a tour of contemporary prefab homes. Annual 'Dwell on Design' conferences continue this legacy, as do annual industry events such as the 'International Builders Show' (IBS), 'Nextbuild' run by the National Association of Home Builders (NAHB), 'CABoom' and 'West Coast Green'. In the United Kingdom, the annual co-joint 'Futurebuild' and 'Ecobuild' industry exhibitions attracted twenty-five-thousand visitors in 2008, twice as many as 2007. Some thirty-thousand are expected in 2009. Prefabrication industry body Buildoffsite exhibited at the 'Innovate Offsite' zone to promote its work and offer advice. Offsite consultancy M-tech organises an events calendar for Buildoffsite with over seventy events including conferences, expositions, briefings, house tours, factory tours, talks, shows, summits, forums, breakfast clubs and awards.

Museum-based exhibitions enable members of the public to participate directly with prefabrication and be educated about its characteristics. In 2006 and 2007 a travelling exhibition titled 'Some Assembly Required: Contemporary Prefabricated Houses' originated from the Walker Centre for Art in Minneapolis. It was a precursor to the most encompassing prefabrication exhibition to date; the New York Museum of Modern Art's 'Home Delivery:

205 The House of the Future exhibit in 1955-56 by architects Alison and Peter Smithson was a prototype for prefabrication. The Smithson's predicted dramatic lifestyle and home-building changes which have not eventuated and result in the design maintaining its futuristic qualities (Colomina 296).

${ }^{206}$ In 1949, MoMA (New York) featured a Marcel Breuer house as an example of high architecture. The Breuer house "was not a unique art object. It was a prototype" (Colomina 40). Breuer was fascinated by prefabrication and this house led to a handful of sales after being visited by seventythousand people over a six-month period (Bergdoll). 


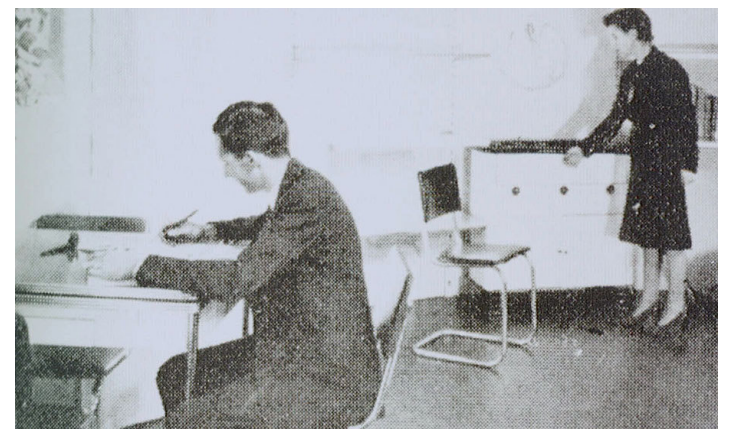

Figure 280: Test-dwelling Buckminster Fuller's DDU in 1941. Source: B. Colomina, Domesticity at War, Cambridge: MIT, 2007: 113.

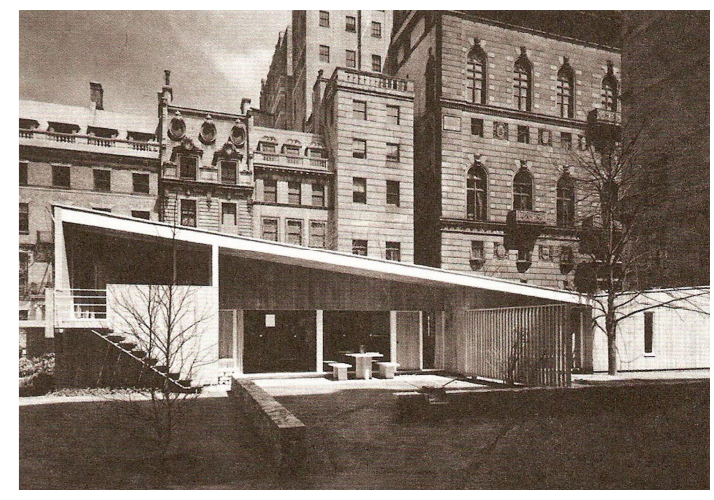

Figure 281: 'House in the Museum Garden' by Marcel Breuer at MoMA New York, 1949. Source: B. Bergdoll and P. Christensen, Home Delivery, New York: MoMA, 2008: 9.

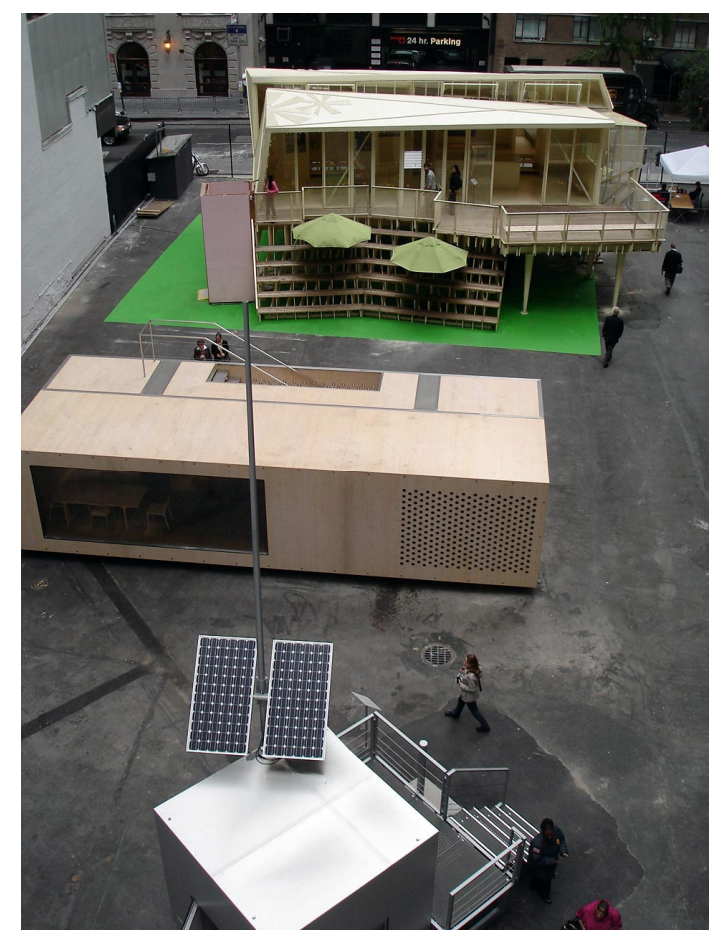

Figure 282: Burst 008 (top), System 3 and $m c-h$ at 'Home Delivery' exhibition, New York. Source: Author's photograph, 2008. 
Fabricating the Modern Dwelling' in 2008. ${ }^{207}$ This exhibition was a landmark in prefab history, bringing architecturally innovative, non-commercial historical projects to life through full-scale models reminiscent of the mid-twentieth-century 'House in the Museum Garden' series (281-282). 'Home Delivery' received a large amount of media attention; over fifty internet-based articles were generated within the first month of its opening and a website was created to document the fabrication and delivery of the exterior housing exhibits, with the delivery to site and assembly functioning as a real-time urban event in downtown New York City.

A profusion of international illustrated magazines and books has facilitated communication about contemporary prefabricated housing in recent years. Dwell magazine has been instrumental in professing 'green modern prefab' merits since its founding in 2000 and first prefab-specific issue in 2001. The February 2009 prefab issue was criticised by Lloyd Alter for not acknowledging contributions by Allison Arieff, and other industry women such as Michelle Kaufmann, Rocio Romero and Jennifer Siegal (Alter "On the Stands"). Collaborations between prefabricated housing companies and magazines are evident in the relationships between LivingHomes and Wired, MKD and Sunset, Lindal Homes and Dwell, and recently MRP and Dwell. ${ }^{208}$ LivingHomes produced a show-home for the 2009 International Builders' Show (IBS) in Washington together with Builder magazine. ${ }^{209}$ Germany goes one step further, with dedicated prefabricated housing magazines such as Hausbau featuring case studies, product and cost information. In New Zealand, the local media features home and lifestyle magazine titles such

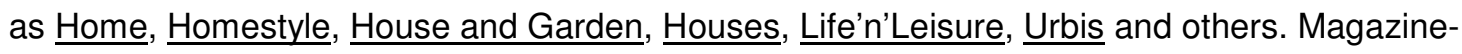
based promotion can be further utilised by New Zealand prefabricated housing businesses, as shown by both ipad and port-a-bach (refer to Chapter 5).

These approaches to marketing and communication challenges and opportunities are distilled into specific recommended strategies in the next section.

\footnotetext{
207 The three month exhibition included an interior gallery with over two-hundred historical projects and an exterior site featuring five full-scale prefabricated housing exemplars. Curator Barry Bergdoll said the popularity exceeded all expectations. It was aimed at a wide audience of architects and non-architects, young and old alike with the curators focussed on showing the process of making prefabricated architecture through a series of film clips, models, drawings, renderings, partial full-scale installations, audio, lectures and architect-guided house tours. The extensive exhibition catalogue documents the historical aspect and includes essays on Scandinavian and Japanese prefabrication, two aspects which didn't make it to the exhibition floor (Bergdoll).

208 Sunset's 2004 'Celebration Weekend' showcased MKD's GlideHouse and then in 2005 the new Sunset BreezeHouse model. The Sunset Modern Cottage by Modern Cabana was shown in 2009. Prefab proponent Allison Arieff is an editor-at-large at Sunset. MRP announced in June 2009 that it was launching a series of Skyline homes as part of the Dwell Homes Collection (MRP).

209 This is the eleventh in a series of innovative idea homes produced by Builder magazine for this annual show (Builder Living Home).
} 
Gross Expenditure on Research and Development (GERD) \% of GDP, 2003

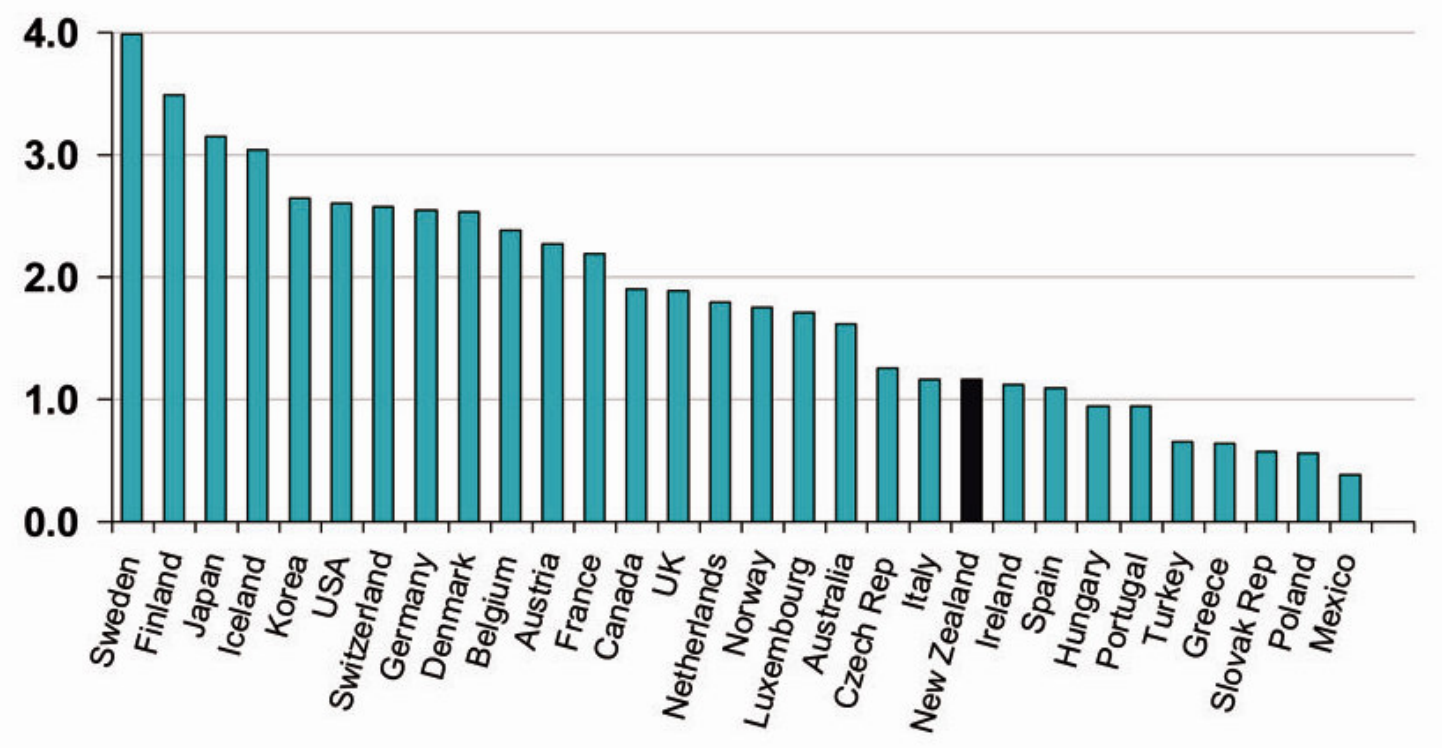

Figure 283: OECD research and development statistics: country comparative expenditure on R\&D, 2003. Source: D. Skilling, Preparing for the Future, Auckland: New Zealand Institute, 2007: 10. 


\section{Research and Development}

Research and development approaches used nationally and internationally that New Zealand's prefabricated housing industry could learn from are now explored. The context or underlying problem is that New Zealand currently makes comparatively little investment in knowledge. This country's investment in research and development, software and higher education is about one percent of gross domestic product (GDP), and well below similar cultures in Australia, the United Kingdom and the United States (283). Our research and development spend is half of the Organisation for Economic Cooperation and Development (OECD) average. Sweden, Finland and Japan lead the OECD in research and development (Skilling 10). It is notable that these countries lead the world in prefabricated technologies and construction output (284). If $\mathrm{New}$ Zealand's prefabricated housing industry is to grow to reach its potential the emphasis on research and development must increase.

Specific approaches to the research and development issues identified earlier are discussed here based on evidence from exemplars around the world. The discussion focuses on the need for government support, industry collaborations, market research, and exploration of aesthetics, technology, materials and the hybrid module-plus-panel typology. There is a lack of coordinated research and development in New Zealand's design and construction industry.

In an effort to encourage industry research and development, the Labour government introduced a tax credit as part of the Taxation Act 2007 which came into force for the 2008 to 2009 financial year. The fifteen percent tax credit was for self-assessed research and development programmes with a minimum expenditure of twenty-thousand dollars per annum. The scheme benefitted international companies conducting research through local companies, as well as a wide range of medium-sized local businesses (Wallis and Gravatt). The scheme was disestablished by the current National government so will not endure past its inception period. The removal of this tax credit is disheartening during the current recession when industries in other countries such as the United Kingdom have research and development tax relief available (Whiting).

There were opportunities for in-house research and development collaborations with university researchers and government through initiatives such as the Tertiary Education Commission's 'Bright Futures' scheme, but these were lost when the current National government disestablished ninety-eight million dollars of research scholarships in May 2009 (Hay). The 2009 'Global Innovation in Construction Conference' at Loughborough, United Kingdom, recognises the contribution that academia and industry jointly achieve through research and collaboration. Governments now demand that research funding is transferred and adapted through industry (GIC). Current opportunities for business research and development funding are through the Tech NZ arm and specific programmes of the Foundation for Research, 


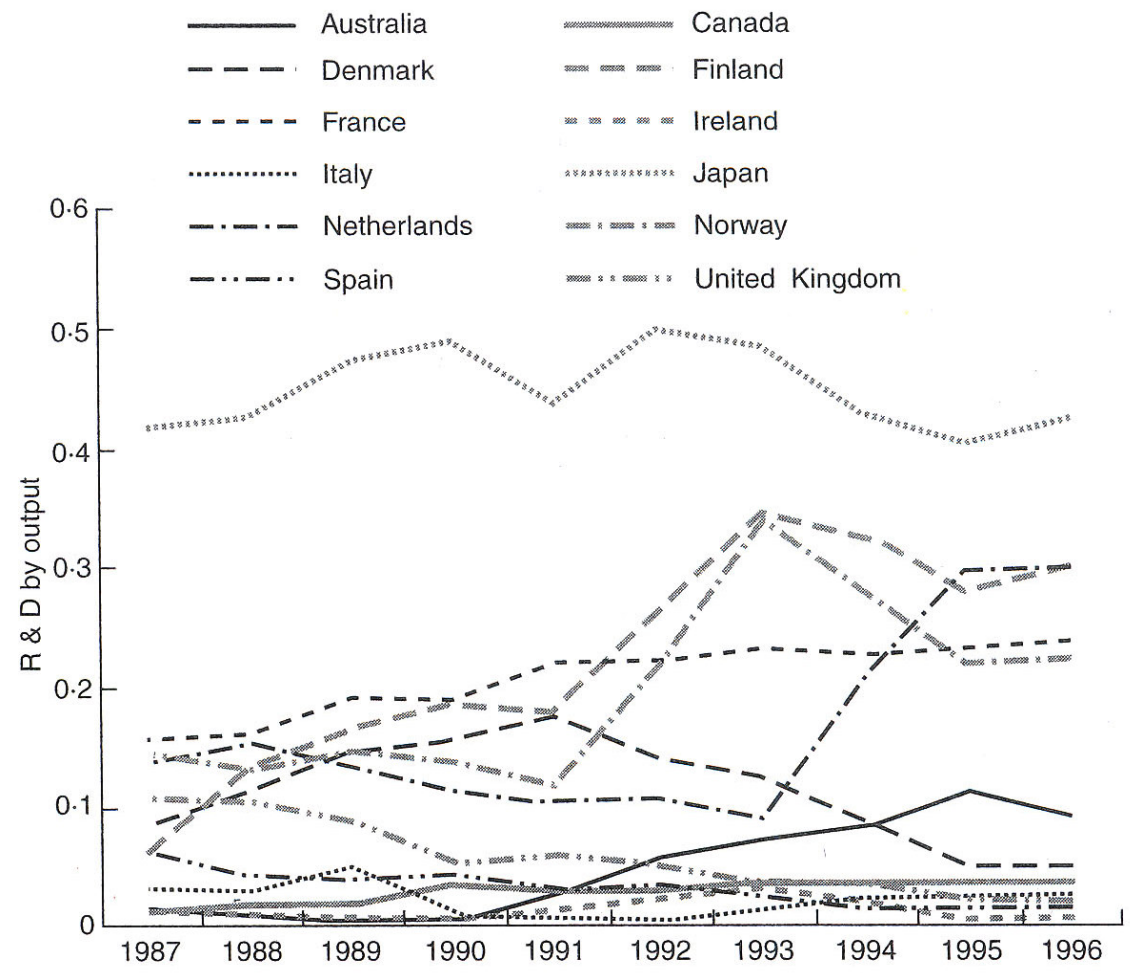

Figure 284: OECD construction R\&D expenditure as a proportion of construction output. Source: D. Gann, Building Innovation, London: Thomas Telford, 2000: 197. 
Science and Technology (FoRST, Current Funding Available). Existing manufacturing exporters can also access the 'Better By Design' government-based initiative for design mentoring assistance (Revington 34).

There is an opportunity to establish an independent research-based prefabrication industry body similar in structure to the United Kingdom's 'Building Research Establishment' (BRE) to reach out to government and the investment community and develop innovation programmes in collaboration with industry. New Zealand's current building research bodies such as Branz, material associations such as NZ Wood, and industry collaborations such as Beacon, should all be lobbied by prefabrication industry groups to help identify future research priorities. ${ }^{210}$ There is an urgency for first-hand market research into home-buyers' needs and perceptions of prefabrication. Research into perceptions of design quality would be advantageous for the New Zealand prefabrication industry, in order to learn how best to communicate this quality in the future. New Zealand's prefabrication industry can learn from United Kingdom suggestions for a platform for discussion and experience exchange. ${ }^{211}$ Industry and government could work together to provide a subsidised site for a national housing exposition of innovation, as well as sourcing funding specifically for these projects. United Kingdom experience has identified the importance of the funding mechanism recognising the early costs of the increased professional expertise required in setting these actions in motion.

Industry clusters can be viewed as a form of bundling analogous to prefabrication. The act of clustering makes the participating businesses more accessible, recognisable and understandable to a wider range of user groups. New Zealand's Beacon consortium is made up of industry members focussed on upgrading housing stock through academic and industry research together with prototype show-homes and practical applications. In the United Kingdom, knowledge transfer and collaboration is overseen by the Modern Built Environment Knowledge Transfer Network (MBE KTN).

Joint ventures and an open-source approach offer further opportunities for collaboration amongst industry. ${ }^{212}$ An open-source approach of many minds applied to a common problem is inspired by software development. Joint venture opportunities abound, but businesses need guidance about how to manage them, as several local prefabrication businesses have suffered negative experiences which made them reluctant to try this approach again. New Zealand's

210 Rosemary Scofield and Suzanne Wilkinson highlight the work of three additional organizations in the area of prefabrication research and industry knowledge networks: Constructing Excellence (UK and NZ), ManuBuild (UK) and PATH or Partnership for Advancing Technologies in Housing (USA).

211 The Commission for Architecture and the Built Environment reported on the use of prefabrication in social housing schemes, finding no direct correlation between its use and a quality design outcome. Other findings highlighted the lack of cost data about complex prefabrication systems (CABE).

${ }^{212}$ An example of an emerging joint venture in the United States is the one between Free Green, a provider of free sustainable house-plans, and R-Control, the largest SIP manufacturer and distributor. Together they released ten free SIP-based house plans free online in October 2008.

Design customisation and consultation is available for a fee (Free Green). 


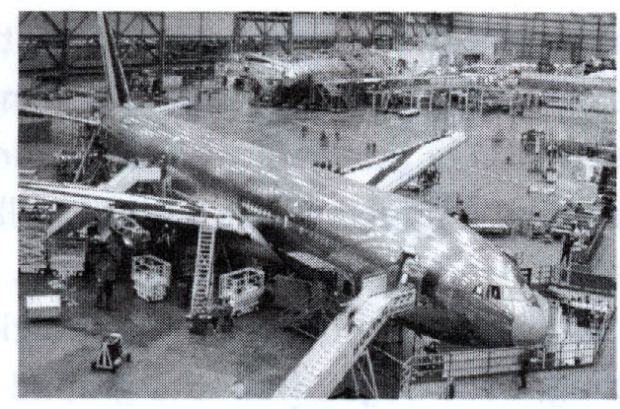

Airplanes

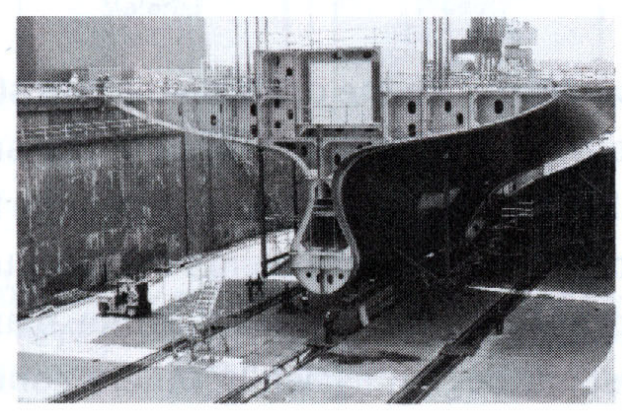

Ships

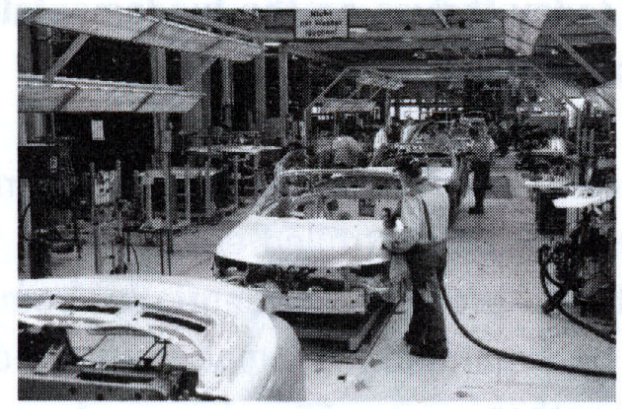

\section{Cars}

Figure 285: Aeroplane, ship and car industries are potential sources of learning.

Source: S. Kieran and J. Timberlake, Refabricating Architecture, New York: McGraw-Hill, 2004: 16. 
prefabricated housing businesses could benefit from establishing similar networks and approaches, and from learning from the experiences of other start-up industries. ${ }^{213}$

Stephan Kieran and James Timberlake recognise the need for industry collaboration due to the limited communication between construction disciplines that is not hierarchical, and suggest collaborative software to facilitate this (51). Martin Pawley advocates for government-led industry cooperation and "a willingness to depart from the traditional demarcations between industries" such as aircraft, motor and steel (360). He suggests industry cross-fertilisation between manufacturers of caravans, boats, conservatories and tents (Pawley 360). Kieran and Timberlake also recommend looking closely at airplane, car and boat-building industries to learn about modular clustering of components (69) (285).

Manufacturing industries offer lessons of flexible or agile production methods, and increasing customer choice while retaining production efficiencies towards a customer-focussed housebuilding strategy. New technologies towards mass-customisation and agile production may benefit the industry (Laing, Craig and Edge 4). Architecture can learn from manufacturing industries that utilise flexible production methods such as New Zealand's Fisher and Paykel, which manufactures a number of differing appliance products simultaneously on a single factory line (Miller). These technologies are expensive and require significant investment but the advantage is in future-proofing and safe-guarding from competitors. There may be opportunities for joint ventures or shared learning with other manufacturing sectors such as cabinetry, lightsteel engineering or even boat-building.

In New Zealand factory technology is virtually non-existent. The term factory-like setting is often used in marketing when homes are constructed in an outdoor yard. Improvements to coordination and efficiency arise from a central fabrication facility (Oxley 135). Few New Zealand businesses are benefitting from indoor working environments with protection from weather conditions, increased worker safety and material security.

Architects can already access recent information technologies such as rapid prototyping or three-dimensional printing, computer aided drafting (CAD), computer numerically controlled machining ( $\mathrm{CNC}$ ), building information modelling (BIM), and digital bill of materials databases (eBOM) (286). ${ }^{214}$ These software programs can be used in conjunction with digitally controlled machinery and decision support software specifically designed for the offsite sector, such as Modex for modular engineering projects (Gibb). These technologies enable individual flexible designs without the need for large production runs, for mass-customisation instead of

${ }^{213}$ The sustainable building industry is in a start-up phase and faces similar issues with historical misperceptions and industry disparity. Key recommendations to that industry are for an overall industry strategic plan, consumer research and education, communication to housing consumers, and supporting regulatory tools and services (Stonyer).

${ }^{214}$ BIM encompasses all of the information for a building, including geometry, spatial relationships, geographic information, quantities and properties of building components (Kieran and Timberlake 63). 


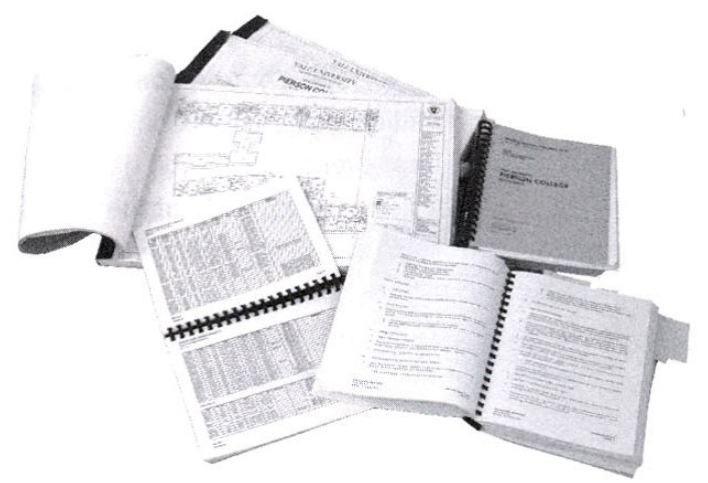

TRADITIONAL PAPER CHASE

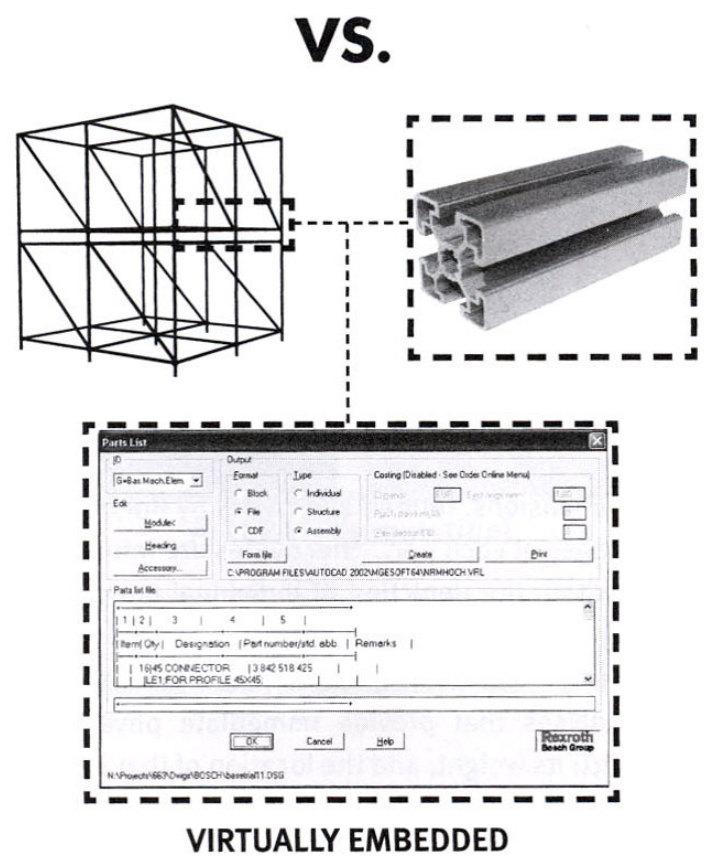

Figure 286: Information technology enables all data to be available at the click of a button. Source: S. Kieran and J. Timberlake, Refabricating Architecture, New York: McGraw-Hill, 2004: 62. 
standardisation. The integration of mass-customisation offers potential to improve efficiencies and integrate personal preferences in future prefabricated housing.

Web-based interfaces open up a dialogue between architect and general public (Naumann 3).The brand Nike ID is a well-known example of a web-based interface that enables customers to personalise their products (287). ${ }^{215}$ The resulting individual design is likely assembled by traditional manual processes in factories located in China and Indonesia (Gibson). According to the Nike ID website, the consumer pays a twenty to thirty percent premium for this service and receives their creation within four weeks. The New Zealand business Ponoko provides a lesson from the manufacturing industry (288). This web-based interface enables individuals to design objects that are produced on demand (POD) and sold through the internet to capture infinitely small markets. Prefabrication businesses can learn from Ponoko's concept of masscustomisation and its use of a blog to facilitate two-way communication.

The question for mass-customisation is whether prefabricated housing can also offer this personalised design experience at the click of a mouse. Potential is there according to architectural historians such as Barry Bergdoll and Peter Christensen:

The power of the computer to accommodate the expression of the architect and the individual needs of a client promises to offer an unpredictable panorama of choices to the consumer rather than the limited palette of types that characterise the prefabricated systems of the Modern movement (Bergdoll and Christensen 'Home Delivery' exhibition text).

This combination of customer input and computer technology is the vision for prefabricated housing in the near future. Bergdoll describes this shift in thinking as, "a paradigm shift from Modernist mass-production to neo-Modernist mass-customisation". Kieran and Timberlake describe this new phase as one of, "cultural production as opposed to...industrial output" (111).

Specific areas for potential research and design focus are in sustainable materials, consumer markets, design aesthetics and alternative typologies. Future-proofed prefabs will need to take into account sustainable materiality, appliances, life-cycle energy use, embodied energy and minimal waste. 'Buildoffsite' recommends robust, easy to understand and universally applied regulation as the fairest way to improve energy performance of products and services. New Zealand's prefabricated housing market stands to benefit from the importation or local production of new sustainable materials such as structurally insulated panels (SIPS), recycled denim insulation, and other recycled board products (289-290).

Several industry participants commented on the need for innovative and flexible complementary systems such as prefabricated foundations as a way to dispel site-based misperceptions of prefabrication's limitations. David Oxley points out the need to investigate new materials and processes that minimise interaction between trades, improve thermal insulation, and testing for environmental performance before leaving the factory (136). There is potential in fourth-

215 Other examples are Puma's Mongolian BBQ and Adidas' Miaddidas brands that both have websites with interactive design (Gibson). 


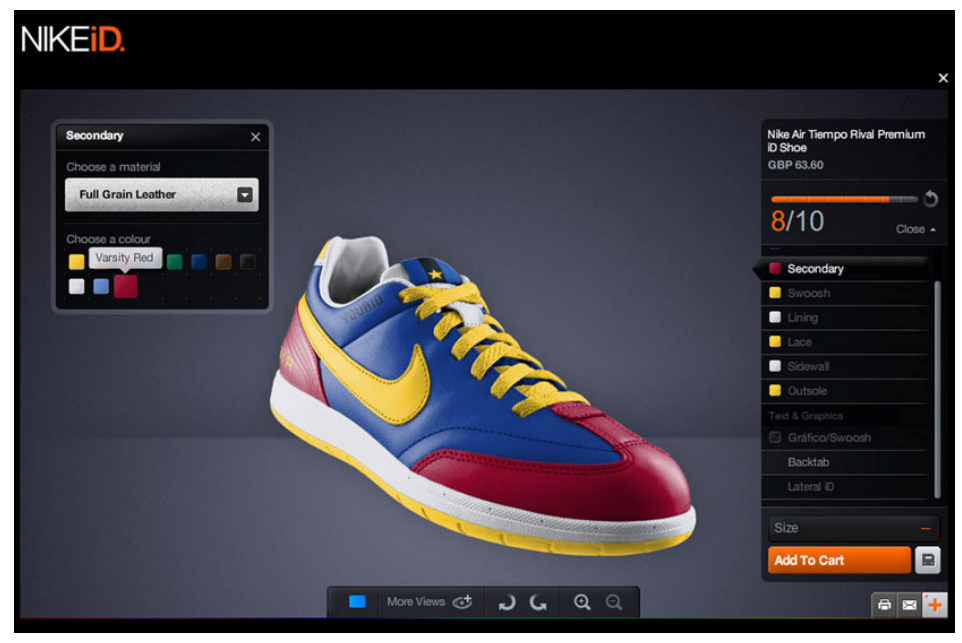

Figure 287: Nike ID shoe customisation website. Source: <http://nikeid.nike.com/>.

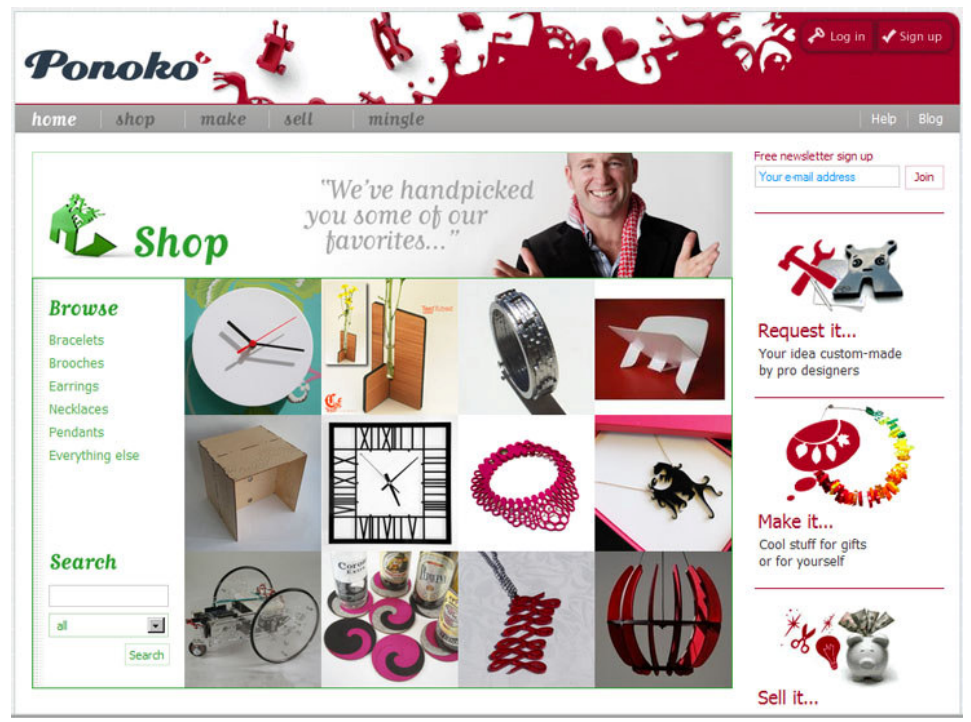

Figure 288: Ponoko website front page. Source: <http://www.ponoko.com/>. 
generation materials such as fibreglass, structural plastics, foams and advanced lightweight aerated concrete products (Oxley 137). Architect Moshe Safdie believes prefab today is being held back by a lack of suitable materials. He predicts that affordable lightweight fireproof carbon and plastic derivatives will lead a new renaissance in multi-unit complexes (Spunt). British modular expert John Prower identifies potential for internal wall lining and external wall cladding material development (Birkbeck and Scoones 19).New Zealand prefabricators would like to see larger sheet sizing to minimise joints and more protective coatings for transporting products (McKenzie). New Zealand prefabricators have experienced industry resistance with material experimentation. This attitude is holding the prefabricated housing industry back.

Market research is needed to find out which consumer markets are suitable to particular typologies and what their preconceptions of prefabrication are, in order to identify specific barriers to the uptake of prefabrication. A Branz survey of households on housing preferences and lifestyle aspirations found double-garaging rated as the highest sought-after feature for new house owners, just above total house size and quality of kitchen and bathroom fittings (Page 35). ${ }^{216}$ In the United Kingdom, there have been consumer surveys focussed on prefabricated housing concerns which provide a framework and potential expectations for New Zealandbased research. Laing, Craig and Edge found that prospective home-owners have traditional material preferences, but will pay more for increased security through a buy-back guarantee or an extended guarantee for parts and labour (12). International market surveys provide precedents for local research.

Post-occupation research is another invaluable tool to determine whether the prefabricated housing process lived up to the consumers' dreams. Heather Boerner surveyed a handful of United States homeowners, who are some of the early-adopters of contemporary prefabricated homes. ${ }^{217}$ The clients are cultural creatives; largely adventurers, innovators and architecture buffs that chose prefab houses for their neo-Modern aesthetic, high quality finish, sustainable features and low running costs. Their experiences vary but overwhelmingly the prefabs met expectations in terms of being finished on time and within budget, despite delays caused by the permit process and local contractors.

Historically, the aesthetic design critique of prefabricated housing has focussed on the confines of the rigid transport-box form and a lack of integration into individual site contexts. Today, there are individual approaches and custom solutions that can be delivered using prefabricated systems so that no two housing solutions appear alike. A truly sustainable approach to housing can only be achieved where views and needs of the target group are

\footnotetext{
216 The major complaint by new house owners was poor house layout, including orientation of house, configuration of rooms, lack of storage space and a desire for less open-planning. Architectural design was not a priority, yet housing complaints are as a result of sub-standard design (Page 35). There is a public misunderstanding of the benefits that architectural design can deliver.

${ }^{217}$ Architect-designed contemporary prefab homes sold in the United States to December 2008 totaled one-hundred-and-thirty-two for four suppliers: Alchemy Architects, ideabox, Michelle Kaufmann Designs and Rocio Romero (Raymond).
} 


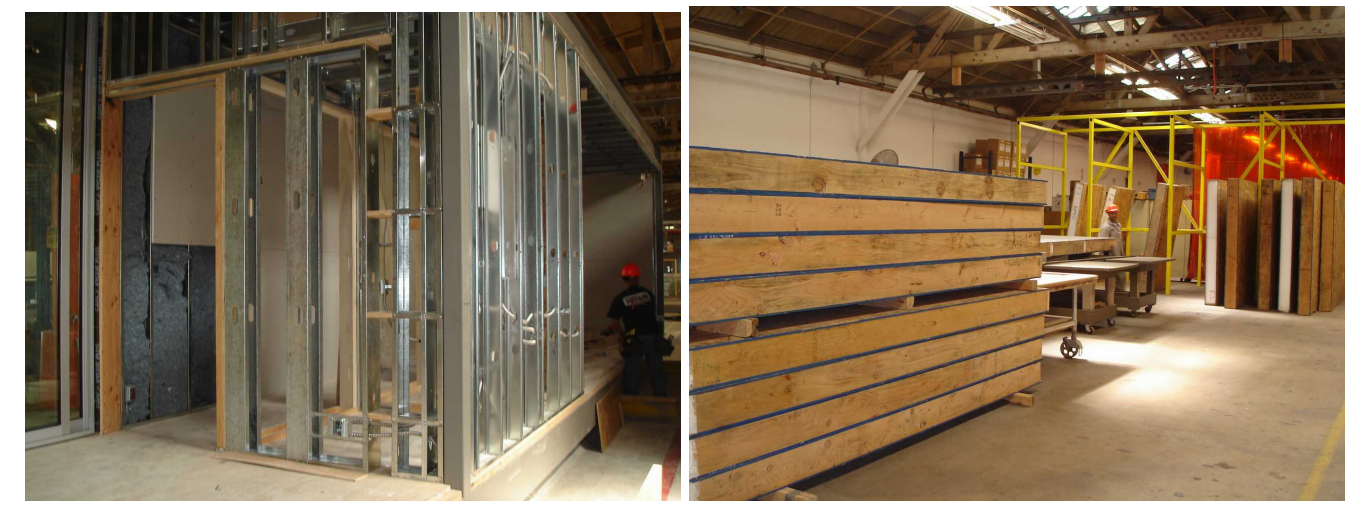

Figure 298 and 299: Recycled denim insulation and stacked SIPs at MRP factory, Los Angeles. Source: Author's photographs, 2008 
recognised and incorporated into the design process (Craig, Laing and Edge 7). Architects and consumers are becoming increasingly comfortable with contemporary prefab designs, as a result of mainstream media focus on mid-twentieth-century Modernism and a growing interest in high-design. Design boundaries are currently being pushed by architect-designed prefabricated housing that extends beyond its restrictive transport-box dimensions. Strategies include unfolding wall planes to become floor or roof elements, accordion-like structural components, and mixtures of modules and panels within the transport-box. ${ }^{218}$ Dimensional limitations could be more efficiently used for smaller elements such as service modules.

Mixing prefabricated modular and panel typologies in a hybrid approach is currently not exemplified in New Zealand prefab housing. Historical lessons learnt from Industrialised Building Systems recommend a hybrid approach of a structural service module with traditional construction that can be finished by either home-owners or builders. ${ }^{219}$

This offers the opportunity of removing the highly serviced areas from the critical path of the project, and potentially brings together the benefits of different construction systems. It can also address the issues of providing flexibility and consumer choice... A kit of parts can be used to provide flexibility yet maintains the benefits of standardisation (Gorgolewski 124).

Other experts agree that the hybrid module-plus-panel typology enables increased customisation of design through a range of service modules together with flexible panelised construction. The importance of adaptability is highlighted in this current age where people value individuality more than conformance.

Some international semi-hybrid systems have been prototyped and commercialised. MKD's Sunset BreezeHouse, Oskar Leo Kaufmann and Albert Ruf's System 3 and the Habode, "are all a mix of traditional modular and folding or sliding or flat sections, and avoid the cost of shipping empty space" according to Lloyd Alter ("Acorn House") (291-295, 235). However the resulting complete building is still determined by modules restricted by the transport-box, such as Kaufmann's roof module that spans between two ground modules. In this way, the semi-hybrid typology does not have the full advantages of flexibility of planning configurations that a hybrid module-plus-panel system could potentially have.

The Austrian System 3 is a hybrid module-plus-panel system that has evolved after its architects Oskar Leo Kaufmann and Albert Ruf spent several years experimenting with complete building typologies. The System 3 arrives to site in a transport container from which the service module emerges followed by wall panels that form an expanded liveable space within a matter of hours. The resulting traditional rectilinear form does not exploit a potential for hybrid as a flexible form-maker. In this case, the box-form was designed to be stackable as a multi-unit development.

${ }^{218}$ Refer to ipad, Habode, i-houz and port-a-bach designs in Chapter 5.

${ }^{219}$ IBS's Xybis is an early example of modules used in conjunction with traditional roof construction (refer to Chapter 2). IBS founder Keith Clark's strategy for delivering affordable housing is based on the concept of providing the service core module containing bathroom and kitchen facilities. This would enable the remaining walls to be built by the house-owner or a contractor, potentially using other prefabricated components or panels. Learning from automobile manufacture, the service pods could be pre-wired with electrical circuits, or wiring looms (Clark; McShane). 


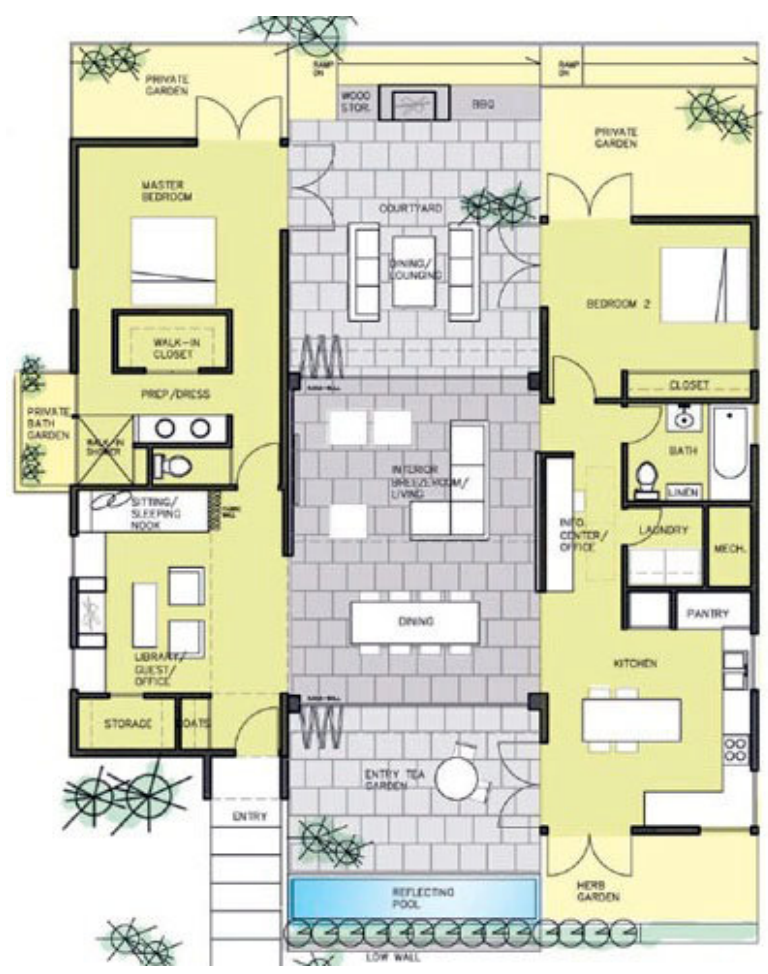

Figure 291: MKD BreezeHouse semi-hybrid plan: modules flanking open living area with roof module. Source: <http://www.mkd-arc.com/homes/breezehouse/floorplans.php>.
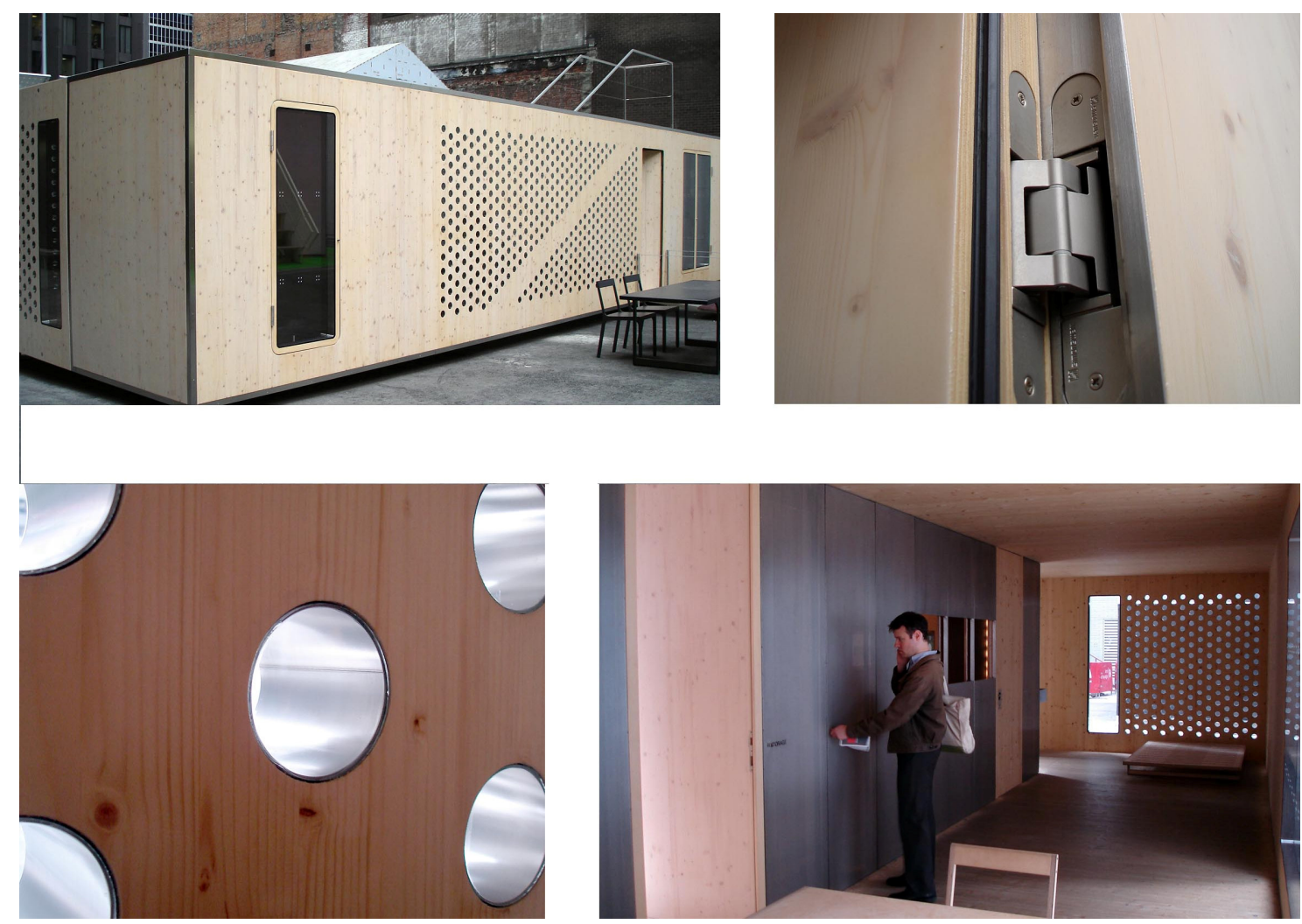

Figure 292 - 295: Oskar Leo Kaufmann and Albert Ruf's hybrid System 3: exterior, hinge, window detail and interior utility unit. Source: Author's photographs, 2008. 
Other contemporary hybrid module-plus-panel examples are KieranTimberlake's Loblolly House and the recent KT1.5 with LivingHomes. In Loblolly House structural components, wall and floor panels, and service modules combine with a new approach to design and construction. In the $K T 1.5$ four steel-framed modules with composite timber sub-framing make up the living areas, with two of them containing utilities, mechanical, plumbing and electrical systems. The roof, floor and wall panels that contain the third bedroom and carport are closed panels that are pre-wired and insulated in the factory. Some hybrid propositions have not yet made it off the drawingboard. Architect Beth Blostein's Gradient House features a two-storey recycled plastic system wall containing plumbing, electrical, appliance and storage (Brown 34). New Zealand's Herriot and Melhuish Architecture's submission for the 'Starter Home Design' competition featured a utility module plus SIPs panel system.

A wider hybrid approach worthy of further research and development is one that combines some prefabricated and some site-built aspects. Chad Ludeman's method advocates for quality stock architectural plans, educated clients, prefabricated panel building envelope, internal prefabricated modular kitchen and bathroom pods, pre-wired framing panels, and better scheduling with local subcontractor cooperation. Small utility pods are advocated because they would not be subject to the strict structural requirements of larger modules.

These approaches to research and development challenges or opportunities are distilled into specific recommended strategies in the following section. 

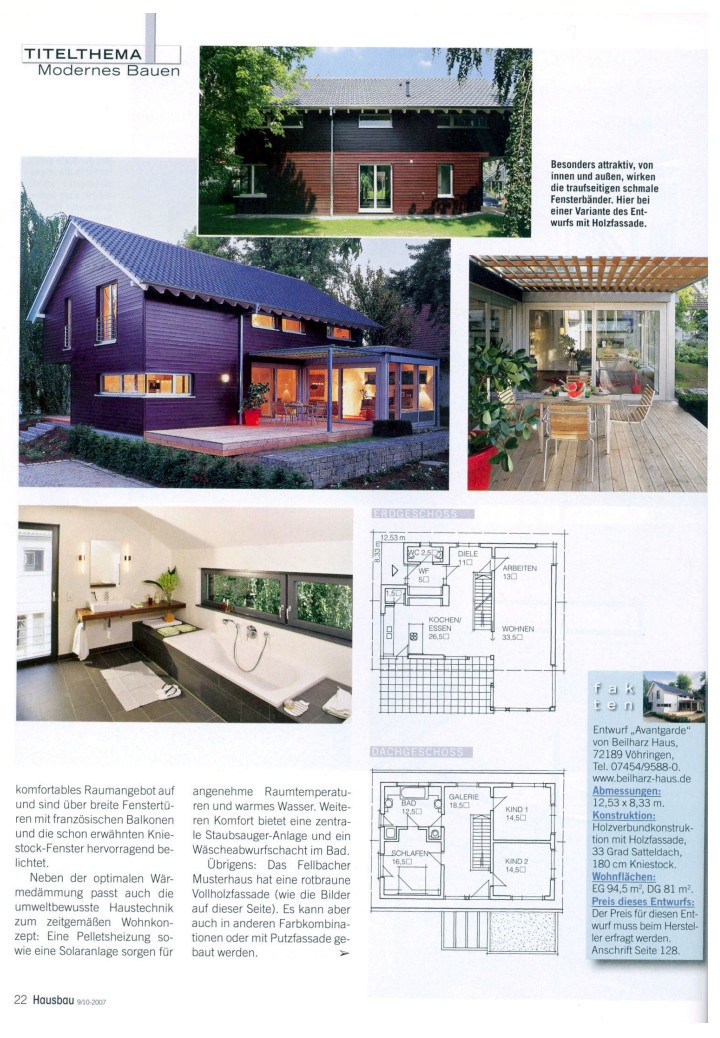

Figure 296: Prefabricated housing case study, plans, photographs and information in $\underline{\text { Hausbau magazine. }}$ Source: Hausbau, Sep/Oct (2007): 22. 


\section{Recommendations}

\section{Proposed Marketing and Communication Strategies}

Marketing and communication issues faced by the prefabricated housing industry can be approached as opportunities through the use of tools such as customer service, show-homes, mainstream media, direct contact, and industry education through university courses, events and publications. The following strategies for change are recommended as a means to address the marketing and communication issues identified in the previous case study chapters and investigated earlier in this chapter.

1. Government policy initiatives are required to increase prefabrication uptake in statefunded housing and the wider housing construction industry.

2. The establishment of a prefabrication industry association to establish common terminology, perform market surveys, administer industry registration and quality control, oversee marketing, conduct training, and offer consultancy services.

3. Initiation of industry conferences, exhibitions and events to educate industry associations, architects, designers, engineers, contractors, manufacturers, developers, quantity surveyors, real estate agents, lending institutions and tertiary institutions about prefabricated housing.

4. Architecture schools encouraged to incorporate prefabricated design-and-build studios in collaboration with industry.

5. A prefabricated housing industry portal website should be established, with links to member websites and supported by e-mail newsletters, video clips, news of events, case studies and product profiles.

6. A government- and industry-supported 'Innovation Park' should be established showcasing a range of prefabricated housing solutions, supported by educational tours, demonstrations and opportunities for test-dwelling.

7. Existing home-shows should be coordinated as a national network with specialist prefabricated divisions, show-homes, real-time house assembly demonstrations, and linked with educational seminars about prefabrication.

8. Television coverage of prefabrication should be increased through news articles and segments on a home and lifestyle-focussed programme to educate a wider public audience.

9. A highly-illustrated book, magazine and newspaper articles on New Zealand prefabricated housing, terminology, systems, merits and case studies should be published (296).

The holistic overview of a governing body is needed as the single most important step to connect the industry and coordinate these campaigns. 


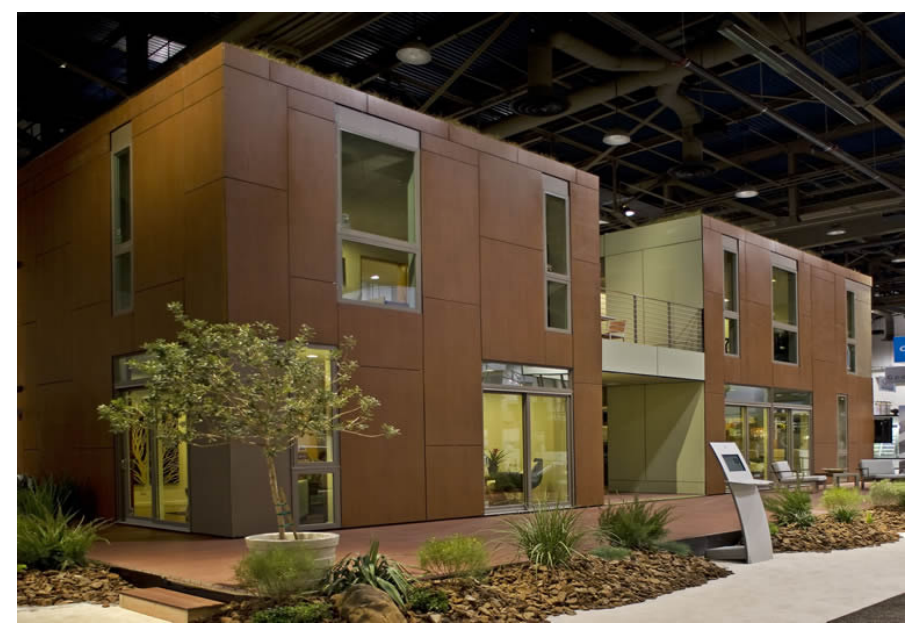

Figure 297: LivingHomes' KT1.5 hybrid housing by KieranTimberlake at the 'International Builders Show' 2008. Source: <http://www.builderlivinghome.com/>. 


\section{Proposed Research and Development Strategies}

There is evidence that consumers and contractors would both benefit from increased clustering and pre-packaging of existing building elements through prefabrication techniques. Identified areas for future research and design focus are in sustainable materials, consumer markets, design aesthetics and alternative typologies. The following strategies for change are recommended as a means to address the research and development issues identified in the previous case study chapters and investigated earlier in this chapter.

1. Increased government and industry investment in research and development.

2. Industry should be encouraged to collaborate in integrated research and development programmes with tertiary institutions.

3. Research and development of applied technology solutions for factory-based manufacture in areas such as flexible and agile production, mass-customisation, integration of information technology and web-based interfaces.

4. Research and development of locally-produced components and materials such as super-insulated timber panels, SIPs, recycled insulation, prefabricated foundations, fourth generation materials, larger sheet-sizes and protective coatings for transport.

5. Market research should define contemporary consumer housing needs, wants and aesthetic preferences.

6. Research and development of hybrid typologies combining modular, panelised and site-based work with off-the-shelf components should occur (297-298).

There is particular potential to research and develop a new hybrid module-plus-panel housing solution that utilises existing off-the-shelf components, cuts down sub-contractor work at the site and eliminates unwanted materials. This could be advanced by university-led design-based research, collaborative industry consortiums, and prototype demonstration and testing. 


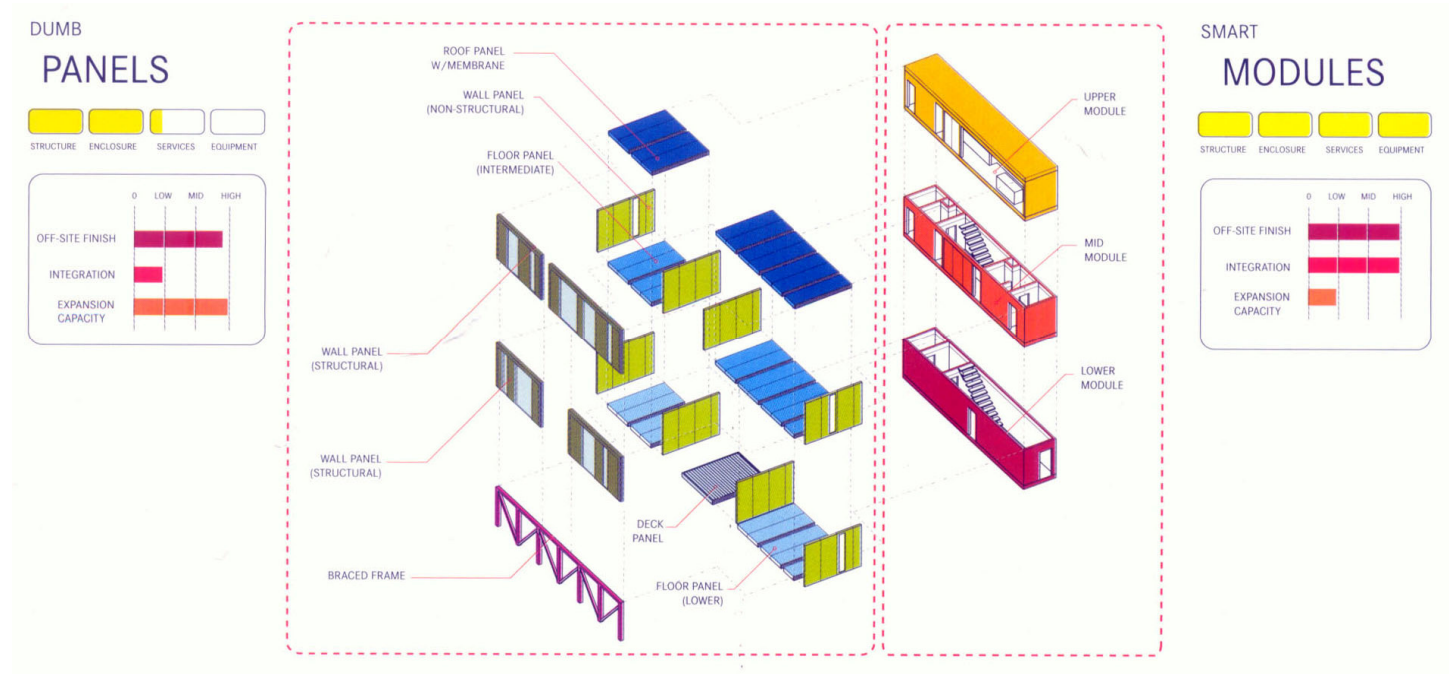

Figure 298: LivingHomes KT1.5 hybrid elements: dumb panels and smart modules. Source: S. Kieran and J. Timberlake, Loblolly House, New York: Princeton AP, 2008: 145. 


\section{Strategy Summary}

The recommended strategies outlined in this chapter reflect the outcomes of first-hand case studies into the local and international prefabricated housing industry. Common issues have directly informed the development of these strategies as practical, achievable and relevant goals to be carried forward.

Marketing and communication, and research and design issues are also faced by the entire architecture profession and construction industry. Architect Stephen McDougall comments:

"As a profession, we're not very good at promoting ourselves. We're thought of as expensive, poor listeners and elitist. That perception has to change and it's our jobs to change it" (McDougall qtd. in Rewi 49).

The prefabricated housing industry and design and construction industries share a challenge in educating consumers about economic, environmental and lifestyle benefits of architectural quality. First-hand market research with consumers is needed to determine the detail of their housing requirements, and overall understandings of prefabrication, architecture and construction industries. This information is a necessary foundation for prefabricated housing businesses in the design, distribution and marketing of their systems, if they are to meet market expectations and demand.

The recommended strategy areas are inter-linked and in many cases will be most effective if administered by a singular body in close communication with government, industry and consumers. A means to achieve this would be to begin the strategy implementation process with a meeting of key prefabricated housing industry participants; a workshop to discuss the proposed strategies and an order of priority.

The following chapter will look at the future context. It will outline predictions for New Zealand housing and the prefabricated housing industry, the implications of recommended strategies in that context, future action steps and suggested areas for further research. 

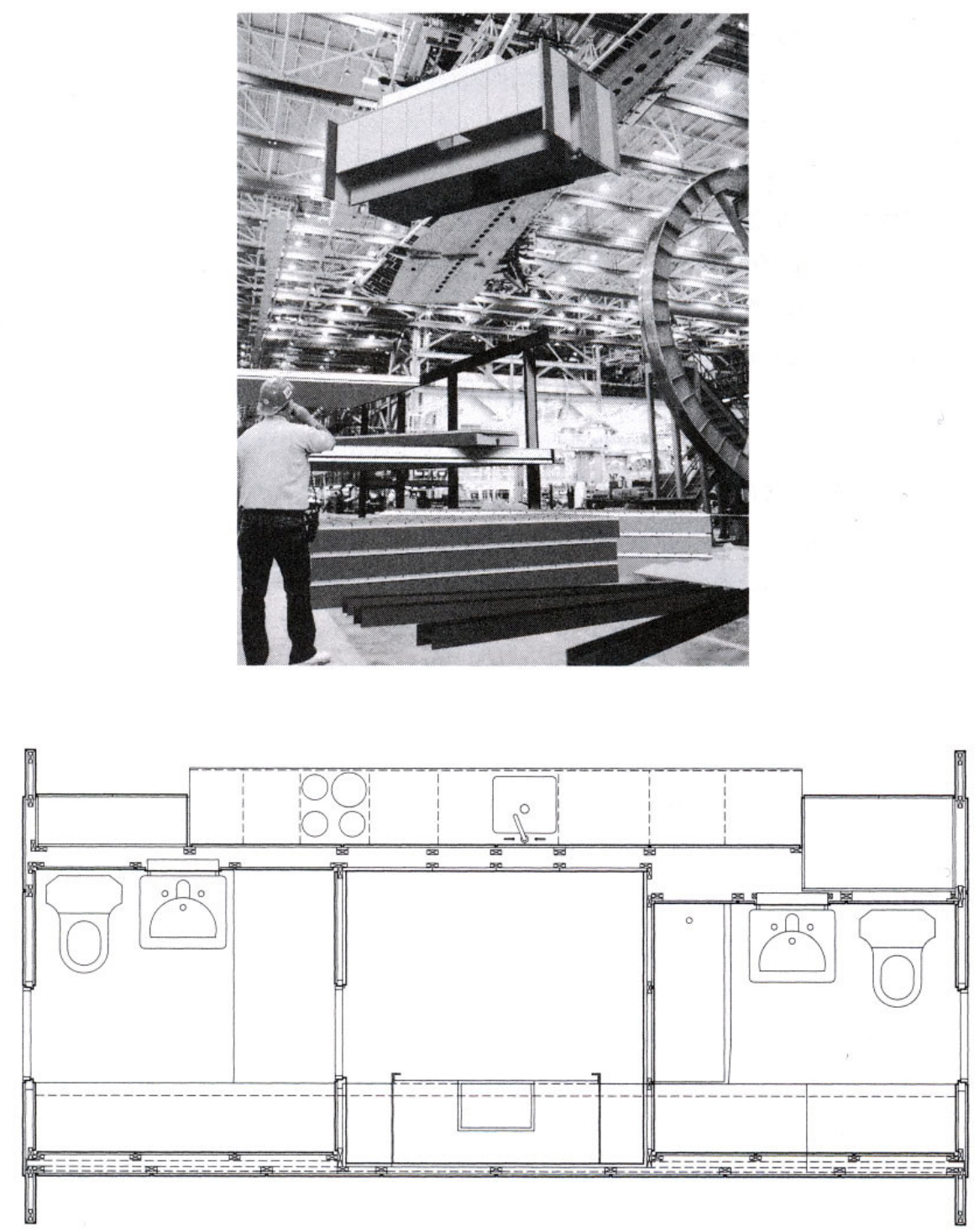

Figure 299: The kitchen core module: a potential combination of kitchen and bathroom unit assembly. Source: S. Kieran and J. Timberlake, Refabricating Architecture, New York: McGraw-Hill, 2004: 164. 


\section{What Now?}

\section{The Future of Prefabricated Housing in New Zealand}

Imagine a future of choosing a new house at the click of a mouse by using the internet to customise, purchase and watch its fabrication and assembly process unfold. All this after spending a weekend at a dedicated 'Innovation Park' touching, examining and experiencing different housing models first-hand, followed by a night spent in your final home of choice. The industry needs more successful prefabricated housing case studies to hold up and celebrate, in order to address fears and dispel misperceptions, to quieten industry critics and arouse wider public interest.

The previous chapter identified fifteen recommended strategies to move the prefabricated housing industry forward. To realise New Zealand prefab's potential, the housing industry will need to work together and research and development collaborations with government and tertiary bodies will need to occur. A key area identified for future investigation is alternative typologies such as the combination of modular with panelised technologies (299). A holistic industry-wide body to coordinate marketing tools and communication initiatives will also need to be formed. The design and construction industry would benefit from focusing on researching a hybrid typology, communicating with consumers, and expanding its vision to look beyond the traditional housing model.

The current period of economic consolidation is an opportune time to plan and prepare for the forecast critical housing shortage. First-hand market analysis, high-quality prototypes and a coordinated approach will each play their part in changing culture towards a broader uptake of prefabrication. In the near future, some emerging prefabricated systems will falter and others will fail. Forecasts from prefabricated housing critics, predictions for local systems and products, recommendations for future research areas, and suggested action steps will follow. This overview will provide a context for the discussions and conclusions that follow in the final chapter. 


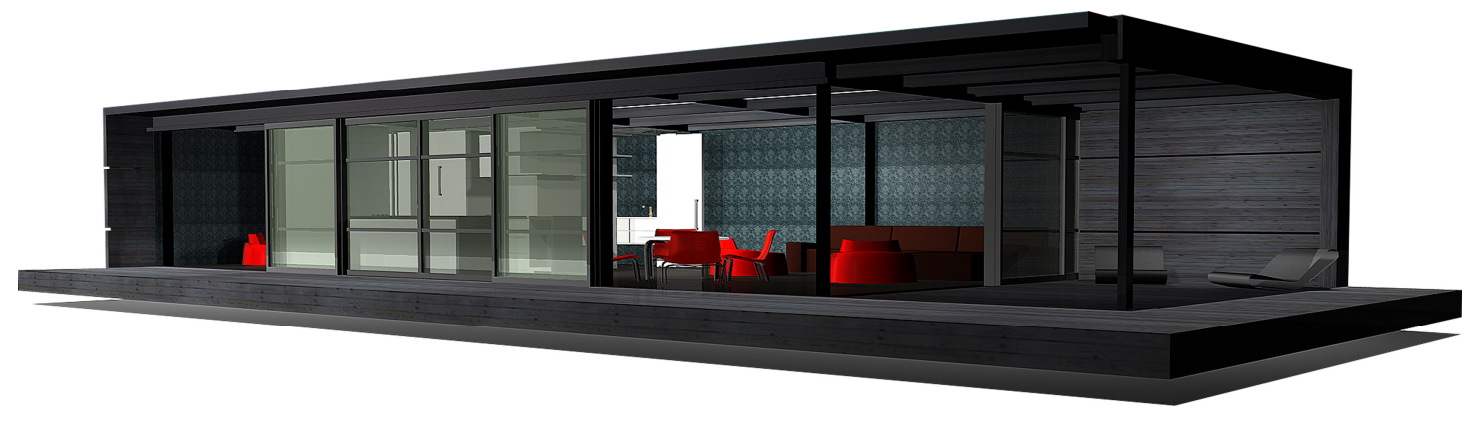

Figure 300: Internet-based house shopping at Quick Living's website: exterior rendering of Module 110. Source: Courtesy of Module Creative. 


\section{New Zealand Housing in the Near Future}

Prefabrication has potential to thrive, if lessons are learnt from the past and the recommended strategies suggested are followed. These strategies have been summarised as research and development, and marketing and communication. The next step to assess their potential effectiveness is to evaluate the strategies against the context of the wider New Zealand housing industry.

Currently the recessionary market means that the residential construction industry is suffering from reduced demand. ${ }^{220}$ Some businesses risk going into receivership. The New Zealand Institute comments on emerging priorities for our economy and identifies the goal of increasing labour productivity growth which is hindered by low levels of investment in businesses, knowledge, and research and development. Macro-economic issues of aging and ethnicallymixed demographics, environmental constraints, the rise of China as a manufacturing superpower, globalisation of goods, and new communications environments all have direct implications for housing (Skilling 14) (300). ${ }^{221}$

Craig, Laing and Edge predict continued worldwide consumer demand for increased flexibility and choice in housing based on the changing age and ethnicity demographic and the increased numbers of people working from home (6). Future housing opportunities exist in a growing retirement housing market, rising sustainability awareness, international specialist niches of production, and internet-based technologies. ${ }^{222}$

Stand-alone houses and second-homes are less sustainable options in terms of resource use. Dominique Gauzin-Muller asks us to consider, "whether making one's family home far larger than what is actually required, or owning a holiday home, are environmentally acceptable practices" (11). Multi-unit prefabricated accommodation is a more sustainable mode of construction and dwelling.

Research into Changing Housing Need in New Zealand found the average number of people per house will continue to fall as the population ages (Page 14). Smaller households of more educated occupants will lead to increased high-quality housing demand. This demand together with new technologies and a shortage of construction skills will be likely to lead to a rise in

\footnotetext{
220 In October 2008 the number of new dwelling units authorised was the lowest monthly total since January 1992. Residential building consent values were down thirty-two percent compared with October 2007 (Welch). The overall building industry is predicted to be in decline by nineteen percent in 2008 to 2009 (Mellor).

221 Frame, Taylor and Delaney's Four Futures of New Zealand outlines challenging scenarios that envisage a future where the economy is largely re-structured in response to climate changes. According to their predictions it is unlikely that current economic growth can be retained alongside improved sustainability measures (Page 31). Bengtsson, Hargreaves and Page's assessment for of climate change for Building Research looks more closely at the physical and social impacts on housing. Increased insulation, rainwater storage tanks, fire-resistant claddings, and allowance for extreme weather events will necessitate house design changes (Page 32).

222 The retirement market has been identified by New Zealand prefabricators such as Habode as a target market for their houses. Page identifies that approximately half of all over-fifty-year-olds will move to a smaller house on retirement (41).
} 


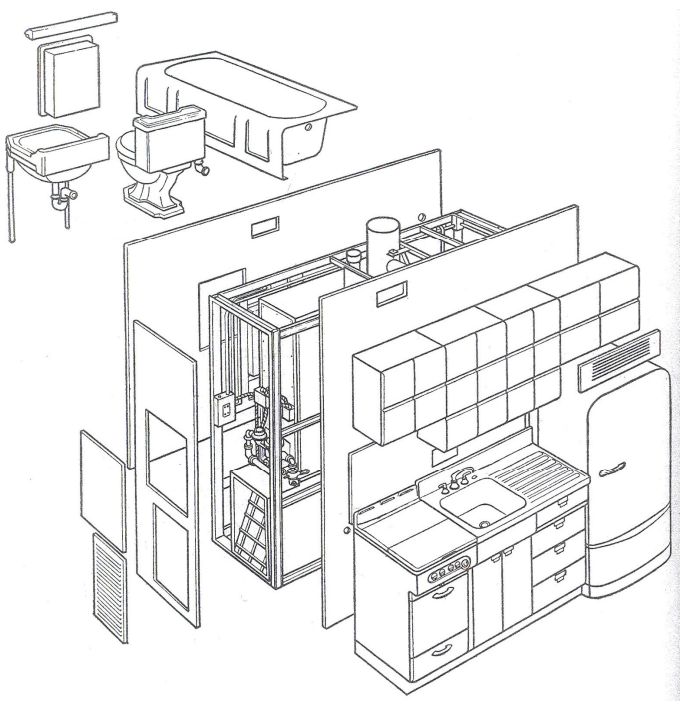

Figure 301: Historical hybrid precedent: Ingersoll Utility Unit for insertion between kitchen and bath areas, 1949. Source: B. Kelly, The Prefabrication of Houses, New York: MIT and John Wiley, 1951: 266. 
factory-built houses utilising standardised components (Bates and Kane qtd. in Page 28). lan Page predicts that this increased demand for prefabricated housing will lead the industry to shift towards larger firms rather than the current small site-based firms. There is a place for all housing providers in the market, with the small-scale builder predicted to remain important to the industry for site-based addition and alteration work (Page 46).

There are almost twenty-seven-thousand new dwellings forecast to be built in New Zealand each year between 2007 and 2016. A third of these housing units will be located in the Auckland region, and include multi-unit developments. Almost half of all households will be of Asian ethnicities, although the majority of new housing is expected to be for European couples and singles. Universal design and climate change adaptation features are suggested to be included in all new housing (Page 46). Consistent market demand has historically depended on a robust population with steady immigration and inadequate housing supply (Wong 79). Such conditions were in place post-World War Two and might be replicated at the end of the current economic recession. Current housing supply looks to be inadequate with new housing starts at the end of 2008 being about half the amount in 2004. Bank of New Zealand chief economist Tony Alexander predicts a critical housing shortage in the second half of 2009 due to dropping consent numbers and steady immigration outweighing migration (Gibson 2). With government leadership and industry support an increasing amount of these predicted new housing starts will be able to benefit from prefabrication technologies. 

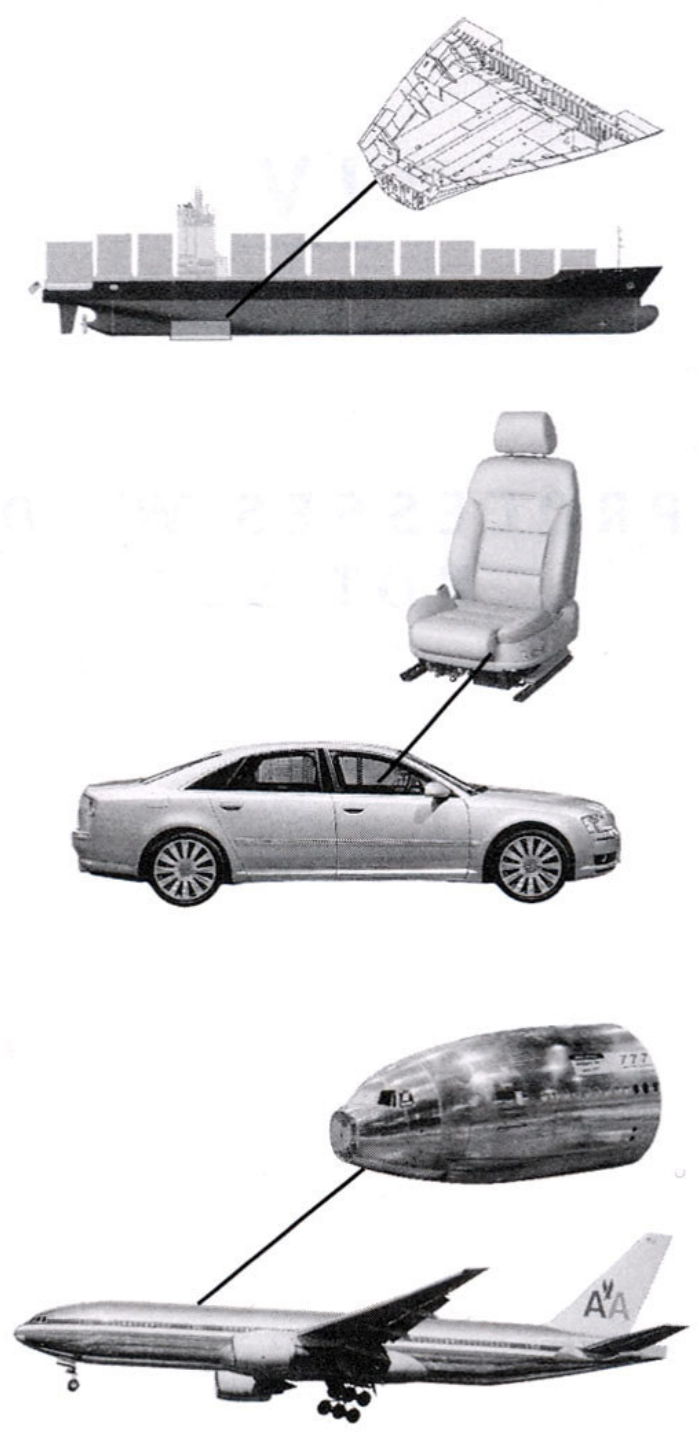

Figure 302: Blocks, chunks, modules: independent assemblies in ship, car and aeroplane manufacture. Source: S. Kieran and J.Timberlake, Refabricating Architecture, New York: McGraw-Hill, 2004: 68. 


\section{Future Potential of Prefabricated Housing}

In the United States, a third of all single-family residences are manufactured houses, and the other two-thirds are built at site from mainly industrial components made in factories.

Prefabrication, whether total or partial, "is central to the modern housing industry" (Rybczynski 254). The construction industry could further benefit from a more prefabricated future; however issues, strategies and action points that have been raised in this research will need to advance if any real change is to take effect. Consideration of future drivers for New Zealand's housing industry identified five areas for the emergence of kiwi prefabrication; retirement housing, more sustainable housing, multi-unit housing, smaller housing and overall pent-up housing demand. Potential future recommendations of international prefabricated housing experts will now be discussed.

In 2004, Stephen Kieran and James Timberlake forecast their ideal future:

Now, when the world thinks of building, it thinks of low-maintenance, long-life structures assembled from component packages that are delivered on schedule and on budget. The world thinks of the reification of the dream they sought to produce architecture at the highest quality ever achieved (Kieran and Timberlake 169).

Kieran and Timberlake present a compelling image of a future where, "construction is simpler, faster, more precise, and less expensive. What Le Corbusier did not realise... was that to create a machine to live in you need to build it as you would a machine" (Kieran and Timberlake 172). Just as Kieran and Timberlake focus on the module, chunk or 'grand block' as a building technique to reduce jointing interfaces, so too the New Zealand prefabricated housing industry could productively apply this approach to clustering services, materials and components (97). An implication of this approach will be a future focus on minimising joints and maximising interconnectedness through greater utilisation of component and modular prefabricated typologies (302-303).

The development of smaller and retirement housing will be likely to incorporate more individualisation of design. ${ }^{223}$ New hybrid typologies will use standardised assemblies such as mechanical cores and off-the-shelf components. This utility module, pod, unit or core is an approach advocated by several experts in the last century, extending back to the 1920s and Buckminster Fuller's Dymaxion bathroom and autonomous living unit (Kelly 101; Bahamon 6; Clark; McShane; Buchanan 150; Pawley 119) (301). In 1951, Burnham Kelly suggested:

If the mass market cannot be fully developed for a highly standardised product, the line of models made up from standardised assemblies should prove to be the most economical. Undoubtedly, there will also develop a substantial market for simpler components such as panels, manufactured for general distribution as a sort of superior building material (Kelly 120).

${ }^{223}$ The future prefabricated housing purchasing experience is likened to buying a car such as a Mini Cooper which is mass-produced but customisable (Arieff qtd. in Jana). 


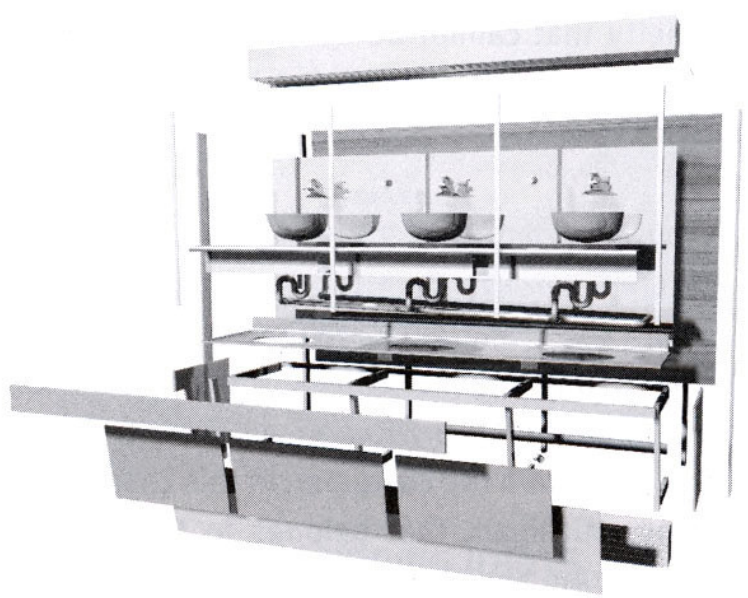

200 JOINTS ON SITE

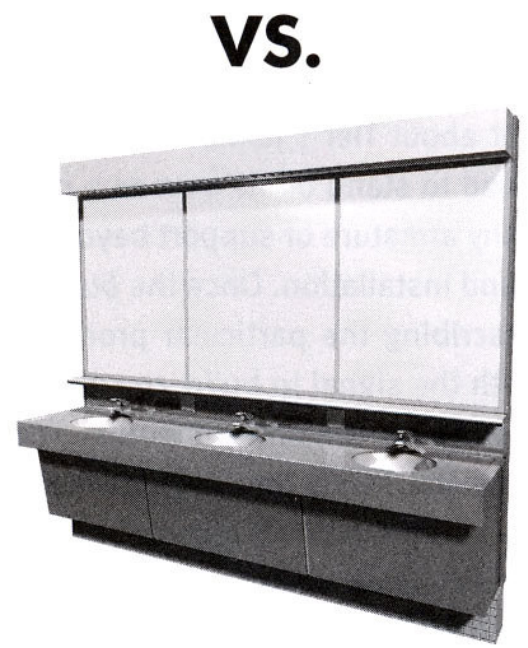

1 JOINT ON SITE

Figure 303: Reduction to a singular joint at site: factory assembly of components for increased efficiency. Source: S. Kieran and J. Timberlake, Refabricating Architecture, New York: McGraw-Hill, 2004: 100. 
Kelly advocated for standardised assemblies which could be used by the wider construction industry, not just for specific housing products. David Gann also envisages an increasingly wider choice of pre-assembled, tested and guaranteed components (140).

An industry move towards more sustainable housing will likely focus on reducing material waste and increasing energy-efficiency through higher-quality construction and reduced joint tolerances. This indicates more refined factory finishing (Kelly 101). British Member of Parliament Nick Raynsford introduced Jacqueline Glass' 2000 report on the future of precast concrete in the United Kingdom, advocating for factory-based manufacture:

Only manufacture in controlled factory conditions can achieve the defect free, waste free quality production on budget, on time that clients and consumers deserve. And only factory conditions are likely to provide the sort of safe, healthy, pleasant working environment that will be acceptable to the young, talented, skilled workforce that the industry needs (Raynsford, qtd. in Glass 6).

Factory-controlled conditions and efficient manufacturing techniques will increasingly produce the high-quality housing which is regarded as the way of the future (Wong 74; Giess) (305).

More multi-unit projects, rather than detached houses are likely to result from the design and construction industry increasing its emphasis on sustainable housing. Increasing house density will "include semi-detached or terraced housing, individual houses grouped side by side or vertically" (Gauzin-Muller 10). This matches a shift in the larger sustainable design movement towards macro issues and green urbanism, rather than the isolated performance of a standalone dwelling. Architect Michelle Kaufmann has a future focus on co-housing and compounds for groups of families and retirees (Hawthorne, "Green Prefab"). Kaufmann believes that prefab infill apartment complexes and cooperative housing can benefit more from high-design than a suburban mass-production model (Hawthorne, "Prefab Movement") (304).

Quality developer-driven multiple home and multi-unit projects have the potential to establish prefabrication as a visible and viable approach to construction. This has been recognised as one of the only ways in which to drive costs down for the end-user (Arieff). Developers can reap economic benefits from shorter timeframes at site, predictable costs, and lowered risks and liability. Allison Arieff believes that developer-driven projects are needed to be seen as profitable and upheld as case studies of successful architect-designed prefabricated housing. Michelle Kaufmann agrees with Arieff that developer collaboration is essential to the commercial sustainability of contemporary prefabricated housing (Hawthorne, "Green Prefab"). Developer investment in prefabricated housing supply will need to reflect a consumer demand. There are also opportunities for established housing suppliers to enter the architect-designed prefabricated housing market, using their existing production experience to endure the difficult start-up period. ${ }^{224}$

${ }^{224}$ An example of established suppliers bringing a contemporary housing product to the market is provided by United States manufactured housing supplier Clayton Homes. In late 2008, Clayton released designs of its I-house, professing sustainable features and design aesthetics similar in concept to the contemporary prefab movement (Alter "Thoughts on Clayton"). 


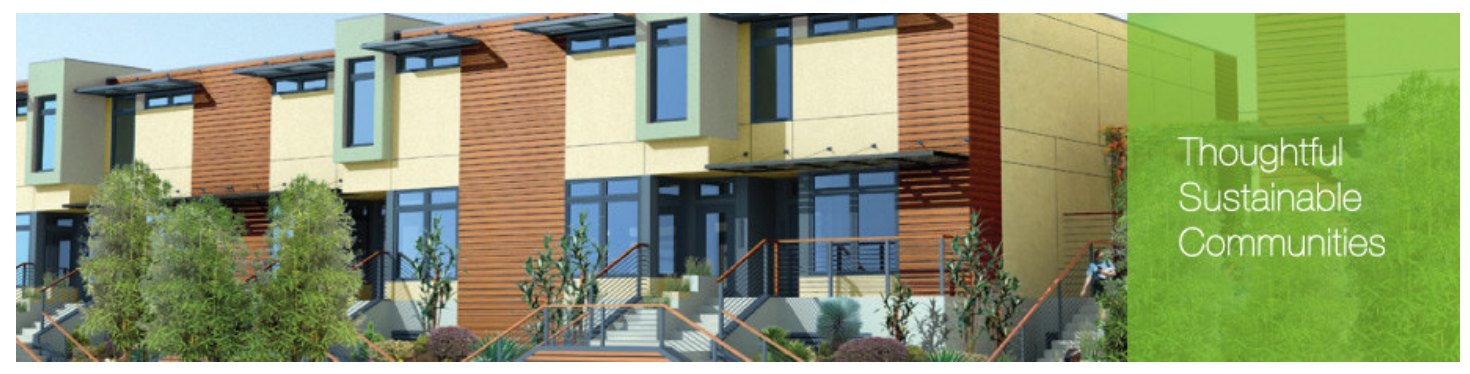

Figure 304: Michelle Kaufmann Designs' rendering of prefabricated community projects. Source: <http://www.mkd-arc.com/community/>. 
The recent demise of Michelle Kaufmann Designs highlights the constrictive effects of the current worldwide economic recession. These effects are felt particularly harshly by the construction industry which is susceptible to traditional boom and bust cycles. The last few years have seen a large drop in home lending, especially in the United States, which has made continuous factory manufacture of high-end architect-designed prefabricated housing difficult. This has caused several modular housing factories to close and others, such as Marmol Radziner Prefab, to advertise in-house factory facilities. Some critics see this period of prefab industry consolidation as a repeat of historical fates. Christopher Hawthorne comments:

For nearly a century, hopes of building crisply Minimalist houses in factories - and in the process democratising home design - have always raced ahead of market realities (Hawthorne, "Prefab Movement").

The market reality is currently constrained by restrictive lending and tight economic conditions. But this period is an opportune time for conducting research and development, and refining marketing and communication strategies (Hall).

The forecast post-recession pent-up housing demand will provide the opportunity to benefit from a surge in market demand if consumer and industry acceptance are already in place.

Consumer and industry acceptance are imperative considering that, "the biggest barrier to modern prefab is resistance to change" (Arieff). The emphasis on consumer acceptance was commented on by Le Corbusier in 1927. He noted that, "it is essential to create the right state of mind for living in mass-production houses" (263). Targeted education campaigns and exemplary projects will be needed to increase consumer and industry acceptance in the future.

Future emphasis will be needed on management, marketing and materials such as metals and plastic composites, large panels for floors, ceilings, roofs and partitions (Kelly 101) (306). Keith Clark advocates for secure financing, marketing and business planning. Juergen Giess adds an emphasis on uninterrupted material supply, flexible production and knowledge of international markets. A future is predicted where over half of workers will be women due to modernisation of the construction culture. In this future, "scope and quality are finally exceeding time and costs for the first time in the history of construction" (Kieran and Timberlake 165). Kieran and Timberlake envisage that everything is accounted for through computercontrolled systems such as bills of materials (BIM) where "no parts are lost or wasted. Everything is traced and properly placed [and] parts are never damaged" (167). A close and careful emphasis on information technology-led management practices could lead to this potential future. 


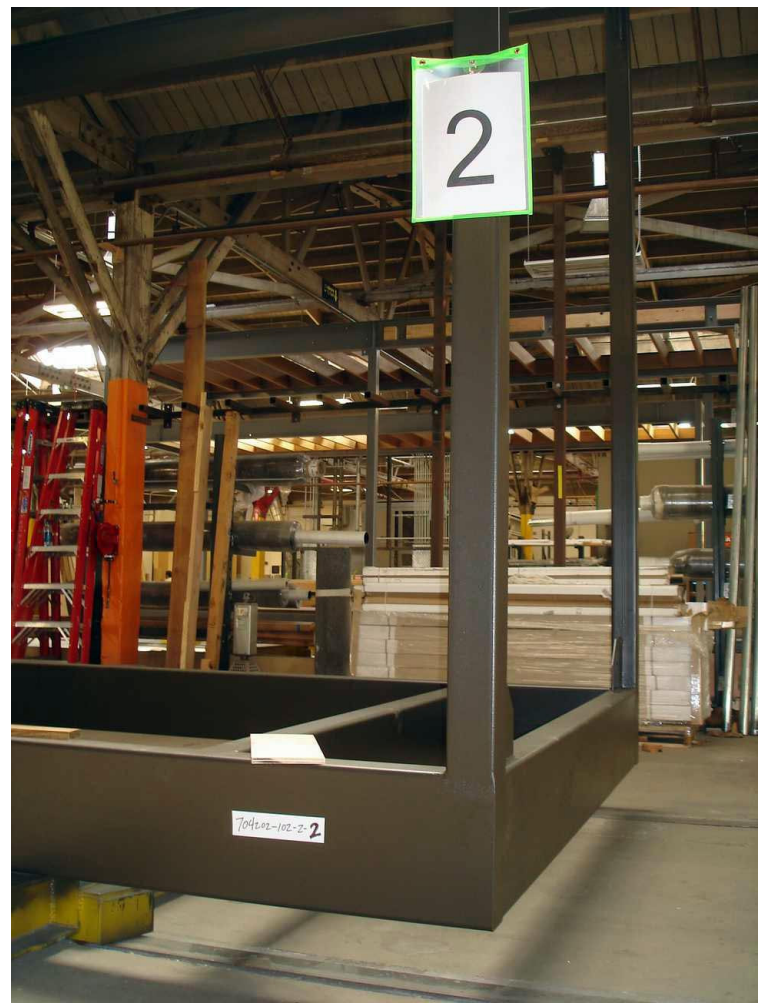

Figure 305: More factory-based manufacture is a future-focussed direction for prefabricated housing. Source: Author's photograph, 2008. 
Internationally, prefabricated housing industry predictions are for future growth. ${ }^{225}$ Innovation, research and development look set to become more important to the construction industry as more processes take place away from the construction site, reducing skills needed at site and increasing demand for value-added components.

In order to achieve this, the industries involved need to develop a commitment to learning from previous experience, gaining feedback from users. They need new techniques for measuring improvements enabling assessments of performance over time to be made (Gann 14).

Ongoing market analysis is recommended for continued consumer housing demand (Kelly 110; Clark; Wong 79; Giess). David Gann offers a concluding piece of advice that, "a culture of life-long learning is needed in this industry" (239).

${ }^{225}$ Buildoffsite, predicts a two-fold future increase in prefabrication's market share in the United Kingdom from five percent in 2007 to ten percent by 2010 and a ten-fold increase to fifty percent by 2020 (Cook). This is possible given that offsite grew from two percent in 2004 and current predictions are that the industry is growing at twenty-five percent per year. 


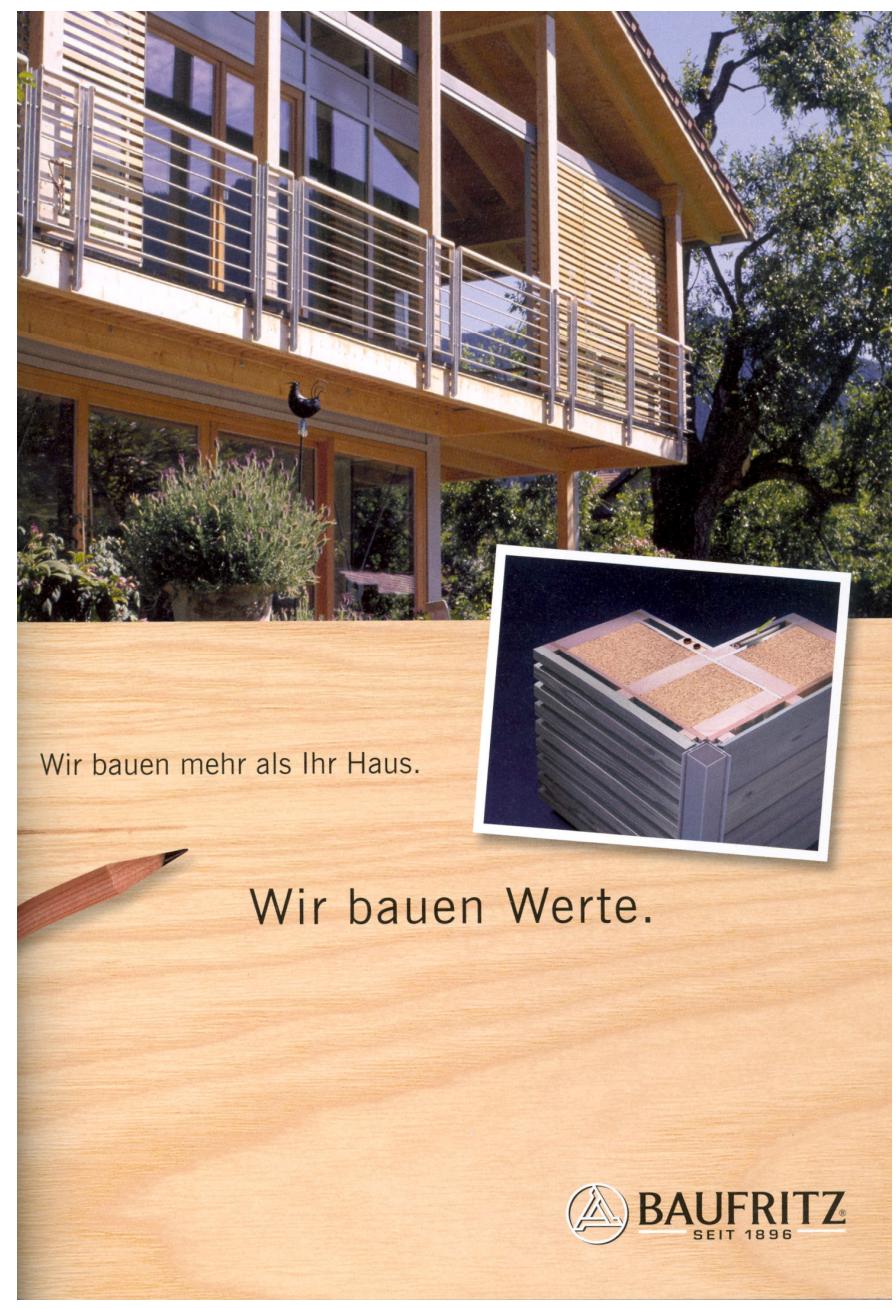

Figure 306: Baufritz super-insulated prefabricated wall panels, Germany. Source: Hausbau, Sep/Oct (2007). 


\section{Future Predictions, Suggested Research, and Action Plan}

"You succeed only when you stop failing" (Buckminster Fuller qtd. in Pawley 119).

Helping to promote change in an industry that is locked into traditional practices and constrained by limited material supply is a challenge. The process of change could be spurred on by government incentives and recommendations to foster innovation and research and development. This may require lobbying and coordination from an industry collaboration to educate the government, industry and public. Buckminster Fuller's attitude for success inspires these future predictions, potential research areas and action steps towards increased prefabricated housing in New Zealand.

Future predictions based on outcomes of this research indicate that successful emerging housing products will favour flexible design solutions to meet diverse potential home-buyers' needs. Inflexible designs will likely struggle, as will higher-priced housing if the recessionary market continues. Housing that deviates too far from traditional socio-cultural acceptance will not create enough market demand to stay in business, particularly prefabs with inhospitable interior surfaces or that are too small to be comfortable. Established firms that are contracting professional architects and designers in order to focus on design quality will have more chance of enduring. Architect input is more likely to focus on quality, open up a niche customer market, and instil a high-value perception of the prefabricated housing industry. The frequently repetitive nature of prefabrication systems means that it is essential to achieve the required design quality at the outset. Mistakes or successes are compounded with subsequent iterations.

Suggested research areas to advance were outlined in the previous chapter. Additional areas identified from the course of this investigation are:

- specialised timber technology precedents in Germany and Austria (306)

- cost-benefit analysis of prefabricated typologies

- construction industry resistance to innovation and ways to approach a potential change in culture

- multi-unit prefabricated housing developments

This research has been focussed on the detached house as a starting-point to discuss prefabrication in New Zealand, but future research should include multi-unit housing due to its potential for repetition and standardisation through economies of scale.

A suggested action plan to work towards implementing the recommended strategies would begin with an industry workshop and education paper. Agreement and consolidation amongst the current participants of the New Zealand prefabricated housing industry is needed to develop a steering group, confirm overall strategy direction and form a cohesive voice. A new attitude towards industry cooperation is needed, "a change of style, culture and process, not just a 

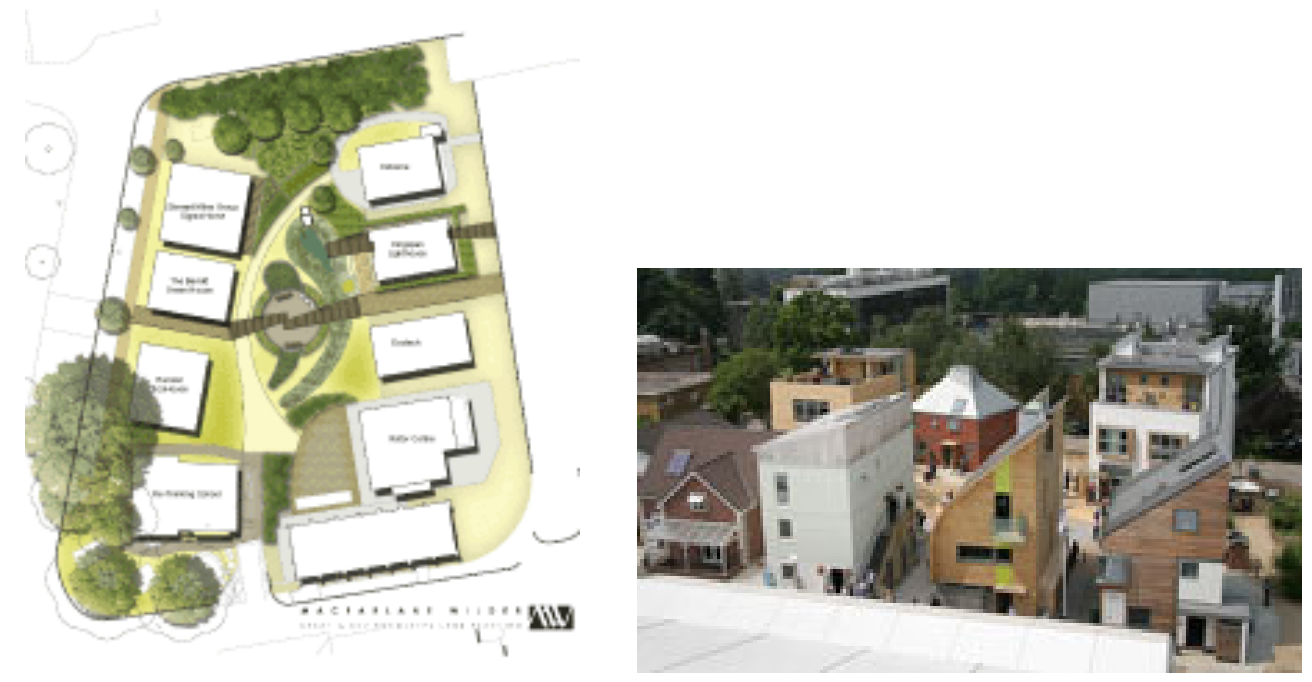

Figure 307 and 308: BRE 'Innovation Park' plan and view of show-homes. Source: <http://www.bre.co.uk/page.jsp?id=634>. 
series of mechanistic activities" (Construction Task Force 37). Without cooperation there will be no action.

A first priority would be to convince industry members that they will benefit from participating in a forum. An industry education paper would be an initial means to convince and re-educate about prefabrication terminology, challenges, opportunities and strategies based on the findings in this thesis. In the next two years, this could extend to wider education of the industry and public on primary definitions, merits and case studies through events, magazines and an illustrated book. During this time an industry association with portal website could be set up, as well as a university design-and-build course.

Within five years - and with industry cooperation - research and development of a hybrid prototype could be undertaken, implemented and published. Within ten years, the government could develop policies for the recommended uptake of prefabrication techniques and establish an 'Innovation Park' of show-homes to publicise sustainable, prefabricated and innovative construction techniques, following first-hand research from precedents in the United Kingdom, Germany and Japan (306-308). Ideally, a new culture of innovation and understanding of prefabrication's quality merits would be emerging by this time.

Prefabrication technologies have existed for some time yet a critical mass of awareness and expertise has not yet been reached (309-310). Alex Steffen's suggestions for actions towards sustainability could also be viewed as steps towards prefabrication:

Small steps are great, but look for small steps that influence the big systems to which we are all connected...

Individual actions are great, but look for individual actions that will influence others...

Good intentions are great, but remember that only passion changes the world...

The equation we should all follow is this: do the easy things, then do a few more challenging things that we really believe in and enjoy (23).

A change in culture is based on many people playing their part: "every little bit helps, and once you get a lot of people making small changes, it really does make a difference" (McVeagh quoted in Hansford 51).

The overview of future forecasts and suggested actions proposed in this chapter provide further context for the discussions and conclusions that will follow in the final chapter. These research outcomes clarify what will need to be done to realise a latent potential for prefabricated housing in New Zealand. 

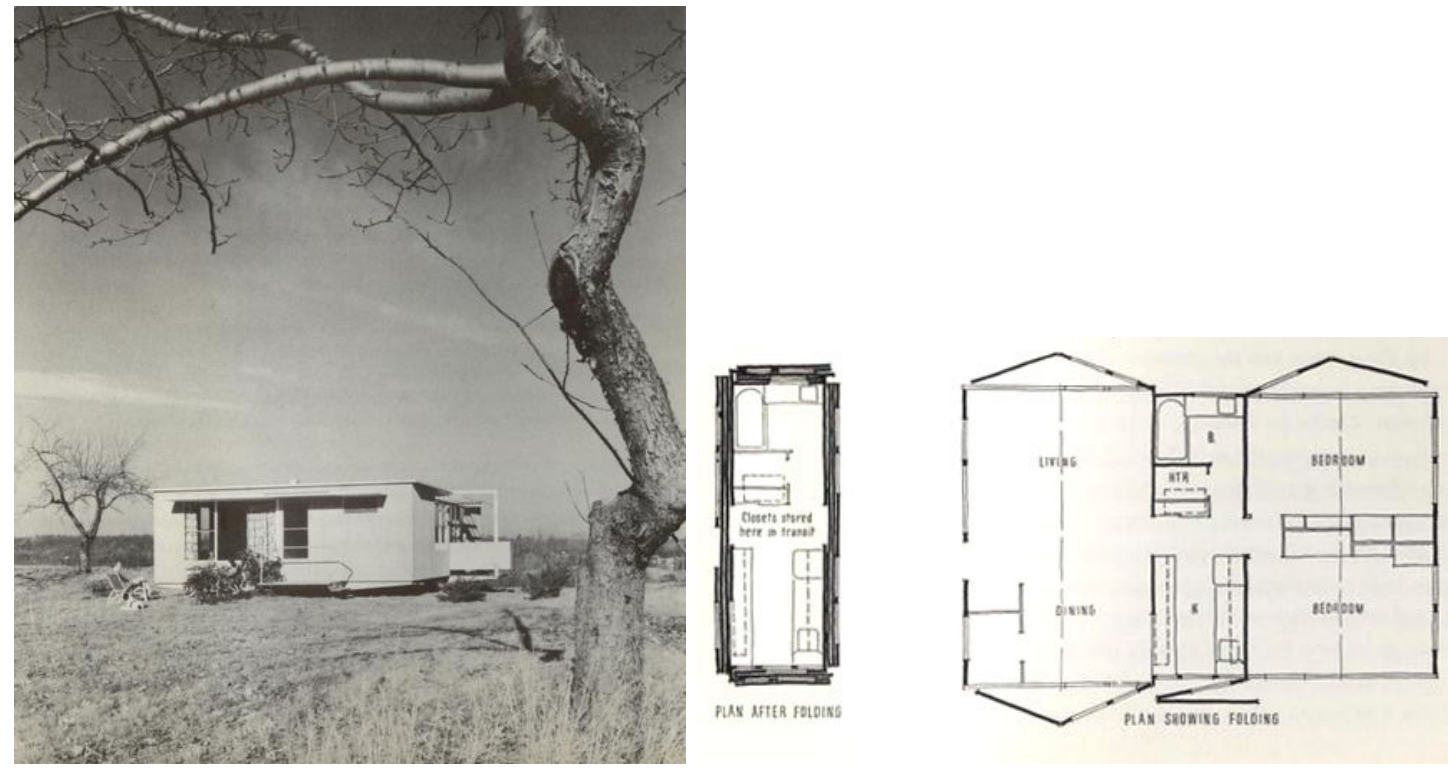

Figure 318 and 319: Hybrid technologies have existed since mid-twentieth-century in response to transport restrictions. Acorn House exterior and floor-plans show process of unfolding panels at site, 1947.

Source: <http://www.treehugger.com/files/2009/01/the-acorn-house-unfolds.php>. 


\section{Conclusions :}

\section{Evaluation, Reflection and Implications}

The previous chapter determined that New Zealand's future housing context is likely to focus on smaller, more sustainable and multi-unit housing in response to an increased housing demand, forecast to be in place when the economy stabilises. Future predictions, research and actions will need to concentrate on areas of technology development and culture change.

This chapter will critically reflect on this investigation into New Zealand's prefabricated housing industry (311-312). It will look at how the original aim set out in the introduction has been addressed. It will reflect on the particular scope of the study and implications of this context for the research findings. It will outline the particular significance and implications of key findings. Finally, it will finish with the potential for prefabricated housing in New Zealand informed by the research and its findings. 


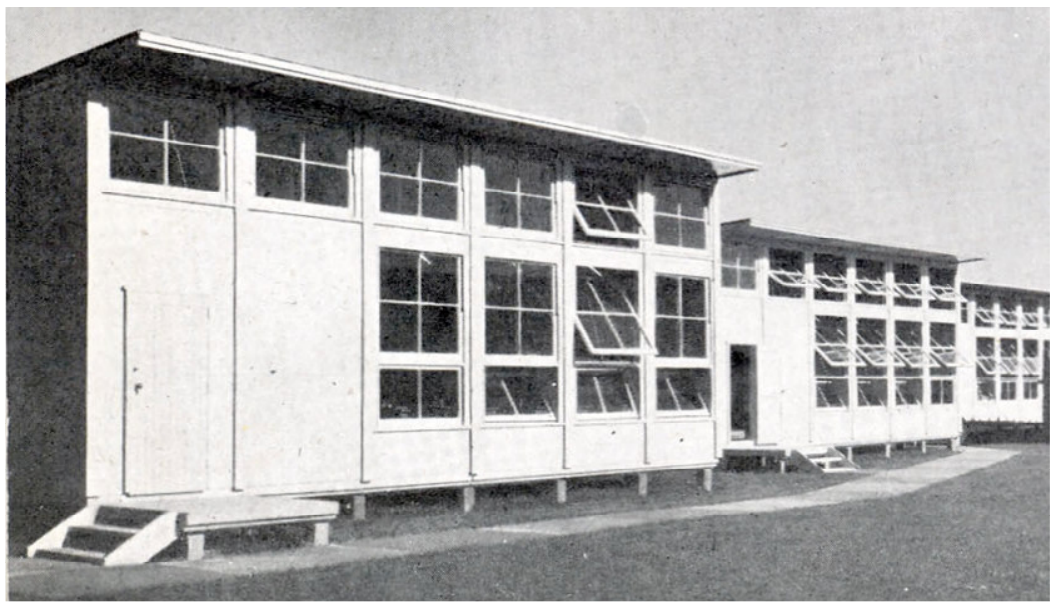

Figure 311: From temporary prefab classrooms....

Source: C. Firth, State Housing in New Zealand, Wellington: NZ Ministry of Works, 1949: 92.

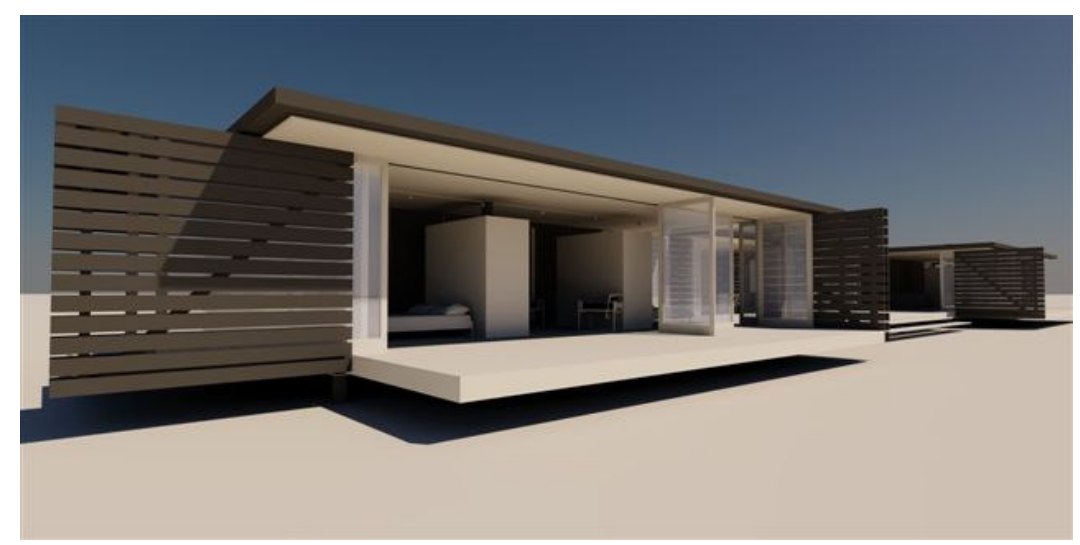

Figure 312: ...to innovative unfolding box-forms - evolving responses to transport restrictions. Source: Image courtesy of Architex. 


\section{Addressing the Aim}

The basis for this investigation was the belief that there is an unrealised potential for prefabricated housing in New Zealand. The key findings presented in this chapter have proved this to be the case.

The aim of this research was to determine strategies that would address persistent issues which prefabricated housing systems, products and businesses have encountered up to 2009. These strategies are designed to promote action which will increase the uptake of prefabricated housing in New Zealand in 2010 and beyond. Proposed strategies and a recommended action plan have both been laid out. These are likely to be of practical use and of interest for further discussion and evaluation by members of the prefabricated housing industry.

There were two initial outcomes proposed for this thesis: to document prefabricated housing in New Zealand and to facilitate a greater uptake. Documentation was carried out by a process of first-hand data collection and case study presentation which brought together historical and contemporary information for the first time (311-312). Challenges and opportunities were identified through analysing issues arising from case studies, investigating key areas, designing recommended strategies and suggesting action steps.

The research process has provided reference material and bench-marks towards reaching the specific strategies. A new clarity of understanding about prefabrication definitions, typologies and merits has been established. The early setting of a wide definition of prefabrication, from component to complete building, enabled an inclusive and comprehensive survey to follow. It reflected on misperceptions in current practice which refer to only modular or volumetric typologies as forms of prefabrication. The inclusion of pre-nailed components established a wide basis of prefabrication technologies currently used in traditional house construction. The identification and reinforcement of the hybrid module-plus-panel typology as a fifth and important type of prefabrication is an addition to current theory and practice. These clarifications will offer theorists and practitioners the opportunity for increased understanding of the merits of prefabricated housing in New Zealand.

The little-known stories of prefabrication pioneers in the last century of New Zealand's history were documented for the first time through primary research interviews and site visits. Case studies of contemporary and emerging housing products were similarly documented. Key prefabricated housing industry participants' attitudes and approaches to issues were summarised for the first time. The results of these achievements reflect both new information and a need for theorists to revise their previous understanding of success in prefabricated housing. It was shown that prefabricated systems and products can offer commercial, innovative and marketing benefits. 


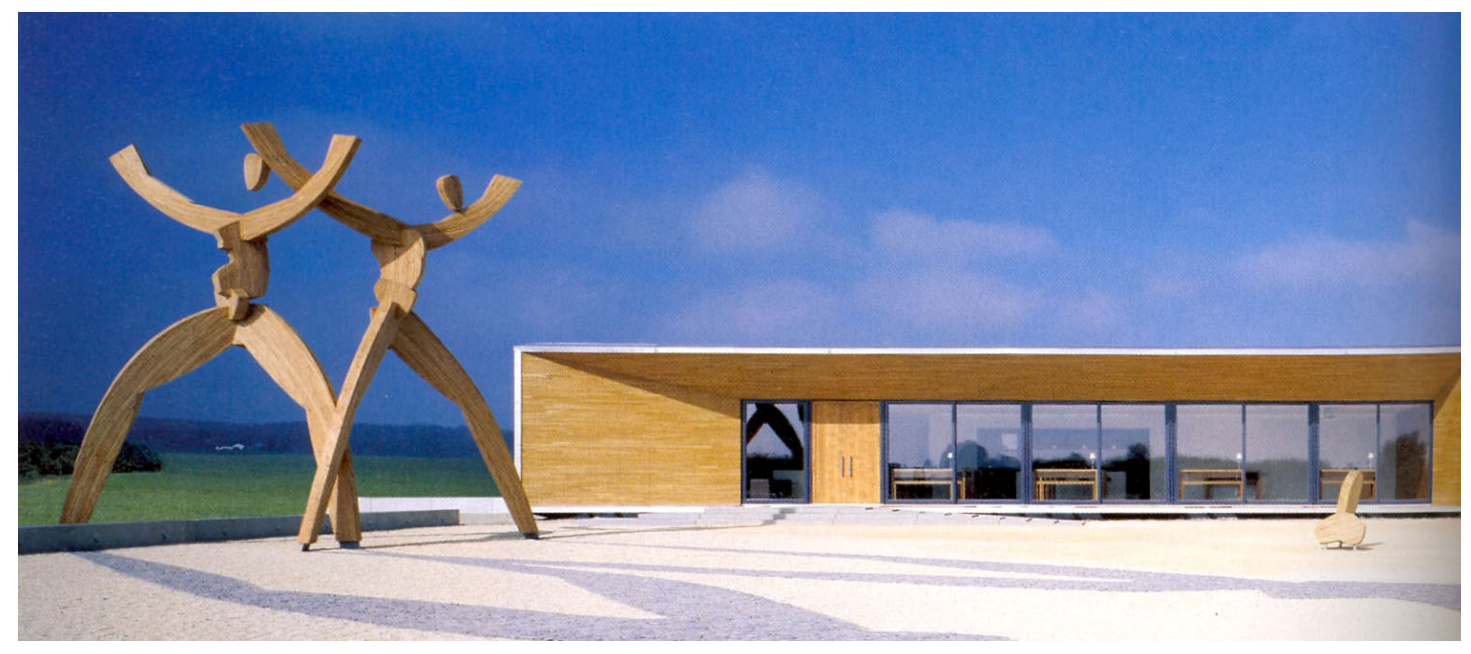

Figure 313: Baufritz show-house, Germany. Source: Source: Baufritz 'Klassikund Moderne' brochure. 


\section{Scope of the Investigation}

The chosen interview method allowed participants to tell their stories, select their facts and edit the information revealed. The author's transcription method was indirect, capturing each interview in a holistic way, rather than word-for-word. The interpretation of both participant and author is reflected in the final case studies. The methodology provided a clear snapshot of the industry. The final research outcomes of issue identification and strategy formation were largely unaffected by individual interpretation because they were cross-referenced against a context of international publications.

There is a relative lack of published information on prefabricated housing in New Zealand and industry participants were reluctant to reveal evidence of numbers of products sold or particular construction methods used. This is due to the small and competitive nature of the industry and close safeguarding of intellectual property. Some businesses refused to participate in interviews, while others provided information but refused access to their factory floor. This attitude is particularly prevalent amongst industry participants who are currently successfully operating in business or are considering bringing a new product to market.

The author acknowledges the generosity of industry participants who have shared their knowledge and enthusiasm for prefabricated housing in New Zealand. This is a positive sign for a potential future collaborative industry. Few participants were immediately receptive to the idea of an industry workshop. The sharing of information could begin with the publication of these thesis findings as edited papers. This strategy may stimulate interest in the attendance at a possible future industry forum.

This investigation has taken place in isolation to other simultaneous research that may be occurring and is not publicly available. It has recently become known that a FoRST-funded three-year research programme into 'Composite Structural Assemblies' is nearing completion and the results of this are not yet publicly available. Programme business manager Rosemary Scofield indicated there is a proposal to develop a New Zealand industry association equivalent to the United Kingdom's Buildoffsite, as is also recommended in this investigation. Potential clearly exists for the industry to move forward in line with the proposed strategies in this thesis. This is a sign of opportunity and a positive future direction for the industry, and indicates that a basis exists in industry and government collaboration toward a coordinated future for prefabricated housing in New Zealand.

Suggested research improvements are outlined in the identified areas for investigation in the previous chapter. Further investigation would benefit from a directed and concise timeframe, more researchers and participants, and first-hand visits to Buildoffsite and BRE in the United Kingdom, and German and Austrian prefabricated timber housing businesses (313). 

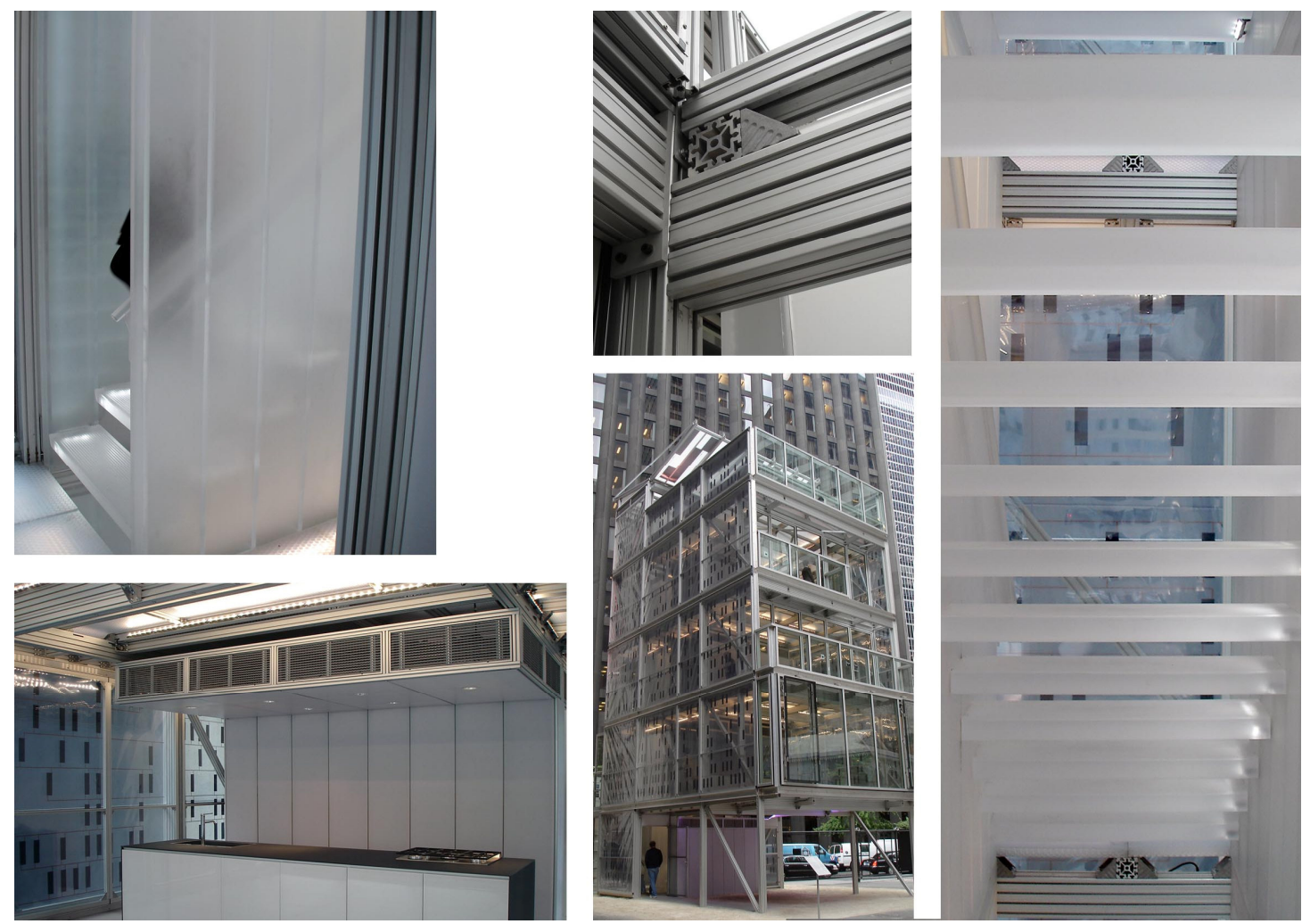

Figure 314 - 318: Innovative materials, assembly and systems in KieranTimberlake's Cellophane House at 'Home Delivery'. Source: Author's photographs. 


\section{Reflection on Key Findings}

The particular significance and implications of key findings are considered in this section. The investigation began by looking at prefabricated housing's record of relative success, comments about current construction systems being broken, and the statement that prefabrication represented a 'holy grail' for architects. It was found that prefabrication offers an approach to housing construction that is worthy of more focussed attention than it currently receives. It is not proposed that prefabrication is the only method of house-building, but one that is complementary to the traditional process that already incorporates prefabricated components.

The existing industry is based on traditional construction practices and does not yet fully incorporate twenty-first-century potential. Several ways were found to increase the uptake of prefabricated technologies in New Zealand: integrating more prefabricated components in traditional house-building; investigating under-represented typologies such as panel, modular and hybrid; and encouraging collaborations between architects and established housing providers to create a wider range of housing products to reach market niches that are not currently catered for. Traditional construction practices stand to benefit from learning about potential merits of prefabricated housing in New Zealand

Prefabrication definitions, theoretical context and background history demonstrate that prefabrication represents much more than just the modular and transportable homes historically associated as such (refer to Chapter 1 and 2). A wider definition from component to complete building is the reality. The proposition for five prefabrication types questions the conventionally accepted four types. The investigation has revealed an opportunity for a fifth hybrid moduleplus-panel typology. This is a significant finding as an area that has not been extensively documented and which holds considerable potential for a customisable, flexible, housing solution with substantial financial, quality and timeframe benefits.

The investigation questions prefabrication's commonly-accepted merits. Critics do not widely identify the importance of prefabrication's role as a testing ground for innovation. This role was central to the 'Home Delivery' exhibition and referred to in the ongoing literary critique of commercial failure of architect-designed systems (314-318). The lack of research and development was found to be a key issue across historical, contemporary and emerging precedents (refer to Chapters 2, 3, 4 and 5). Prefabrication was found to have a significant role as an exemplar of innovation, which has both theoretical and practical implications.

Prefabrication was found to have a practical role as leader, experimenter and brand for the wider architecture profession and construction industry. The broad area of marketing and communication was found to be a key issue emerging from historical, contemporary and recent case studies (refer to Chapters 2, 3, 4 and 5). An emphasis on education, publicity and market 


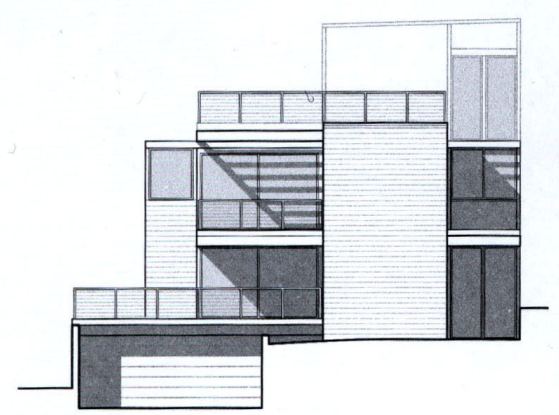

East elevation

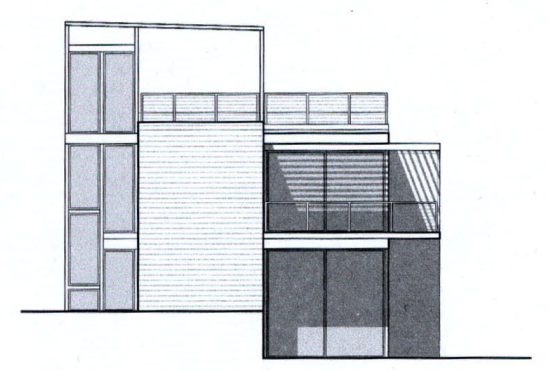

West elevation

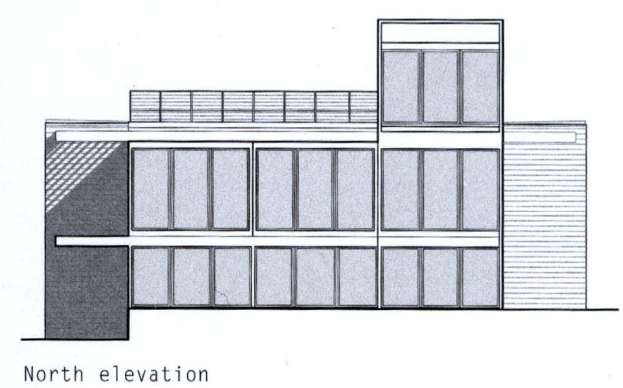

North elevation

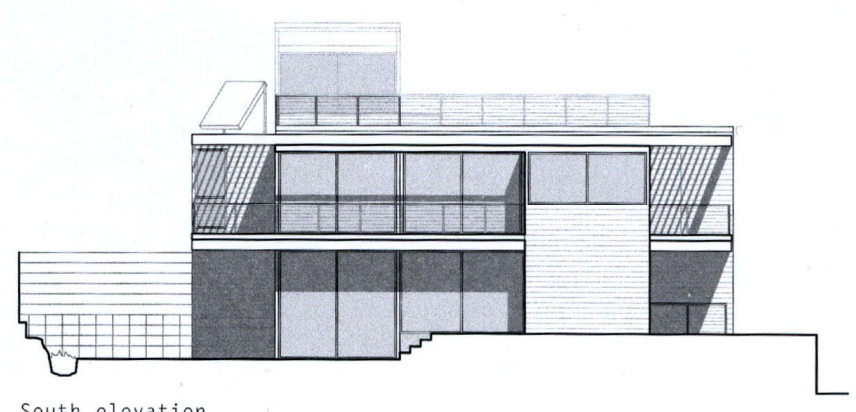

South elevation

Figure 319: LivingHomes' First House elevations: modular form is adaptable to changing site levels. Source: S. Costa Duran, Green Homes, New York: Collins Design, 2007: 124. 
research to communicate directly with potential home-owners and industry participants was also identified. An implication of this finding is that professional and positive achievements of innovative prefabricated housing have potential for wider dissemination to the design and construction industry and general New Zealand public.

Key findings questioned prefabrication history and common issues. Challenges for New Zealand prefabricated housing were identified through background research and case studies (refer to Chapters 2, 3, 4 and 5). Specific approaches and opportunities arising in response to these issues included (refer to Chapters 6 and 7):

\section{- Economic vulnerability}

Wider economic conditions are out of the direct control of individual businesses. As a result, prefabricated housing businesses must be responsive and futurefocussed to remain competitive. Looking for areas of potential change and taking a proactive approach is necessary to remain in business. Several businesses surveyed are not yet future-focussed and may suffer from the current changes in the economic climate as a result. The extent of technology investment and uptake, and appropriate protection of intellectual property are key issues for prefabrication businesses to resolve if they are to plan for the future.

\section{- Large start-up costs}

Establishment costs pose a significant barrier to entry to the industry which is reflected in a low number of current industry participants. Barriers have been overcome in the past with assistance through government investment and experimentation. In the future there will need to be collaboration between industry and government, or between businesses within the industry, to share resources and costs. Established businesses could also be contracted to produce product components and services. Failing to act may result in a national market that is not competitive at an international level.

\section{- Constrained market size}

The current consumer market is determined by population growth and migration. Some businesses identify larger offshore markets and others identify specialised product markets with deeper penetration. The key is to identify and research the target consumer market and then supply according to their particular demands. Hence, there is a need for ongoing market research by individual businesses and the prefabricated housing industry as a whole. 


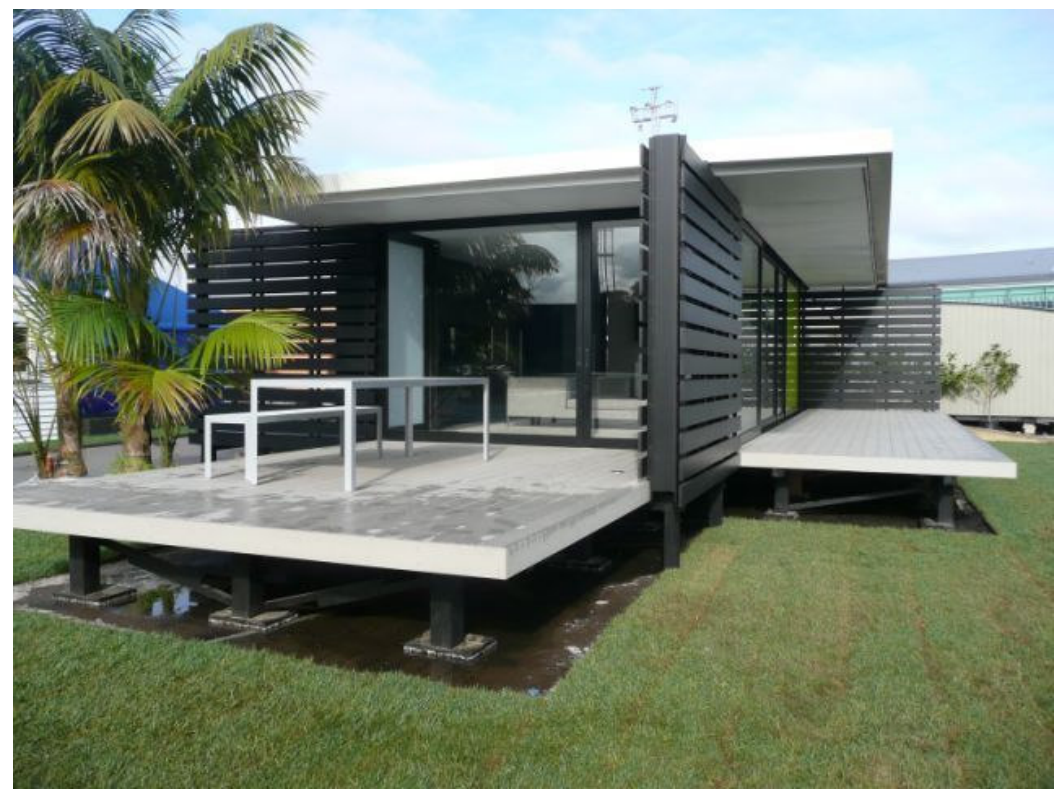

Figure 320: Ipad's wing-wall screens and add-on decks adapt the transport box-form at site. Source: Image courtesy of Architex. 


\section{- Lack of innovation in construction industry}

The construction industry is mostly using traditional methods which remain largely unchanged since the turn of last century, with the exception of pre-nailed components. Members of the construction industry need to be convinced and educated about potential merits of prefabrication if a change of culture is to occur. There are opportunities for innovation in component development, sustainable materials and technologies, site-adaptable elements such as prefabricated piles, hybrid typologies, industry collaboration, and between related industries such as manufacturing (321). More emphasis is needed on factory conditions, rather than outdoor yards, to achieve potential benefits from prefabricated processes in terms of safety, efficiency and productivity. The implication of a continuing resistance to innovation is for increased housing costs for consumers and a decrease in international competitiveness.

\section{- Site-based restrictions}

There are persistent historical site-based misperceptions about the limited design options for prefabricated housing in varying site contexts. Current prefabricated technology and information systems allow for custom design solutions for specific site constraints (319). Time and cost-saving benefits can be gained from simultaneous site-based and factory-based construction. Wide publication of exemplary case studies could clearly communicate the potential use of prefabricated housing on a variety of sites.

\section{- Transport restrictions}

Relatively cheap international shipping and national road transport has implications that restrict volume dimensions. Flexible design considerations are needed to adhere to these restrictions. Recent emphasis on out-of-the-box designs has shown various approaches to meet this challenge (320). There is a potential opportunity for future transport-sized boxes to contain utility modules and other prefabricated systems such as flat-pack panels and components. An investigation into hybrid module-plus-panel systems is warranted. This is significant in that transport cost savings can be potentially passed on to housing consumers without sacrificing design quality or variation.

\section{- Demanding consumer market}

New Zealand consumers demand custom housing solutions. This presents opportunities for flexible systems, adaptable designs, and a strong customer service focus. Consumers have not had sufficient knowledge of the range of housing types that are available in order to demand variety. There is an identified need to educate consumers through real-life exhibits, combined show- 

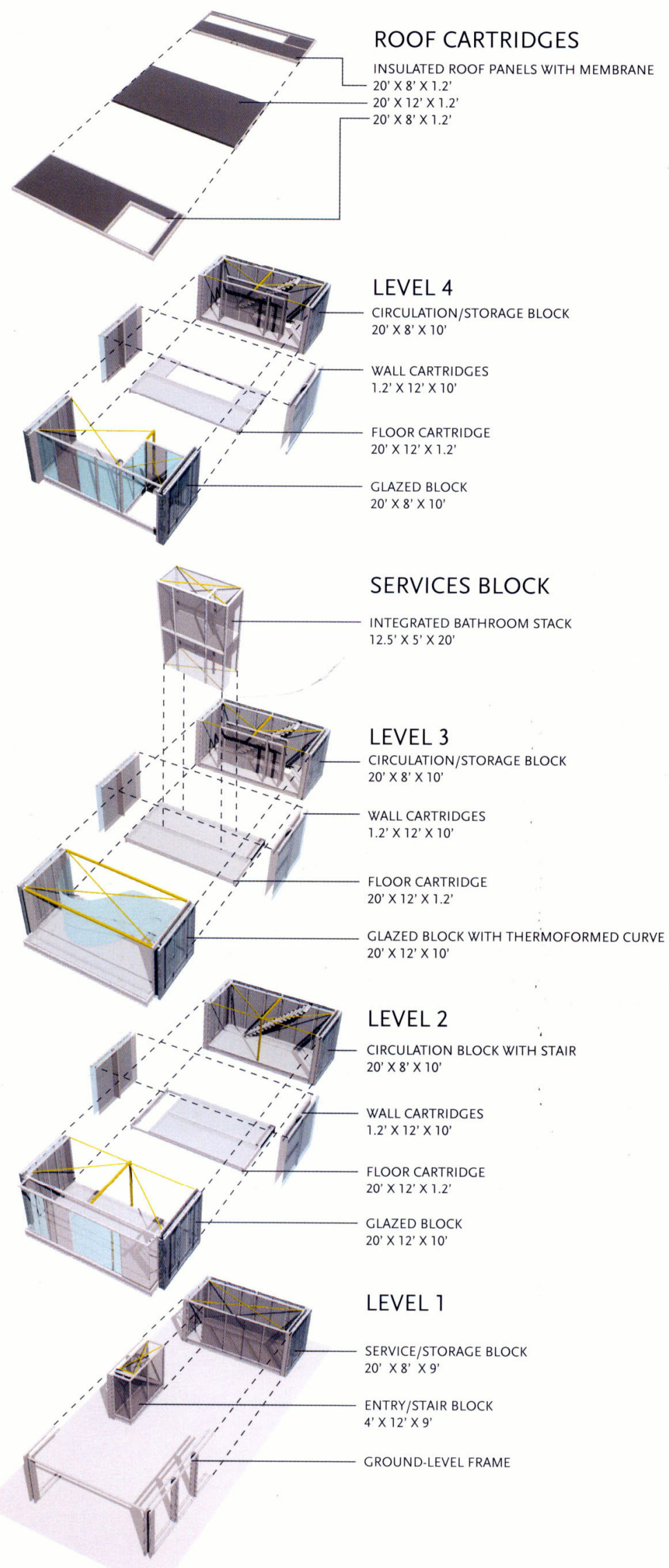

Figure 321: Hybrid prefabrication of panels and modules in Cellophane House by KieranTimberlake. Source: S. Kieran and J. Timberlake, Loblolly House, New York: Princeton AP, 2008: 154. 
homes, coordinated displays at home-show events and general publicity through books, magazines, newspapers, television and websites. There are significant prefabricated housing options which are not currently being presented to potential home-owners in an accessible, understandable and attractive manner.

\section{- General misperceptions}

These are held by design and construction industry members, government and the general public alike. All three groups need specific targeting concurrently to reach all parts of the housing supply-chain spectrum. A cultural change of acceptance is needed for the industry to benefit from potential opportunities posed by prefabricated housing.

The investigation identified and focussed on two key areas which were discussed and a number of specific approaches were suggested in the form of proposed strategies (refer to Chapter 7 ). They are significant in that they comment on prefabrication's role as an innovator in research and development, and as exemplar for marketing and communication, for the wider profession and industry. Prefabricated housing deserves greater recognition as an industry for its potential to show leadership to the wider related design and construction industries.

Further investigation in prefabricated housing will likely uncover increased potential and guidance for the industry as a whole. The existence of prefabricated housing as a discrete design and construction industry sub-section and subsequent role in leadership are outcomes of identified needs for improved marketing and communication. Innovation and investigation are characteristics of the research and development process. The identification of the importance of these two key areas to the future development of kiwi prefab is an important outcome of this thesis.

Applying the proposed strategies for these two key areas was considered in the context of New Zealand housing in the near future (refer to Chapter 8). The fifteen recommended strategies involve collaborative action from industry, government support, and wider public re-education. A holistic approach is needed in order to equally target demand, design, manufacture and supply areas of the housing production process. 


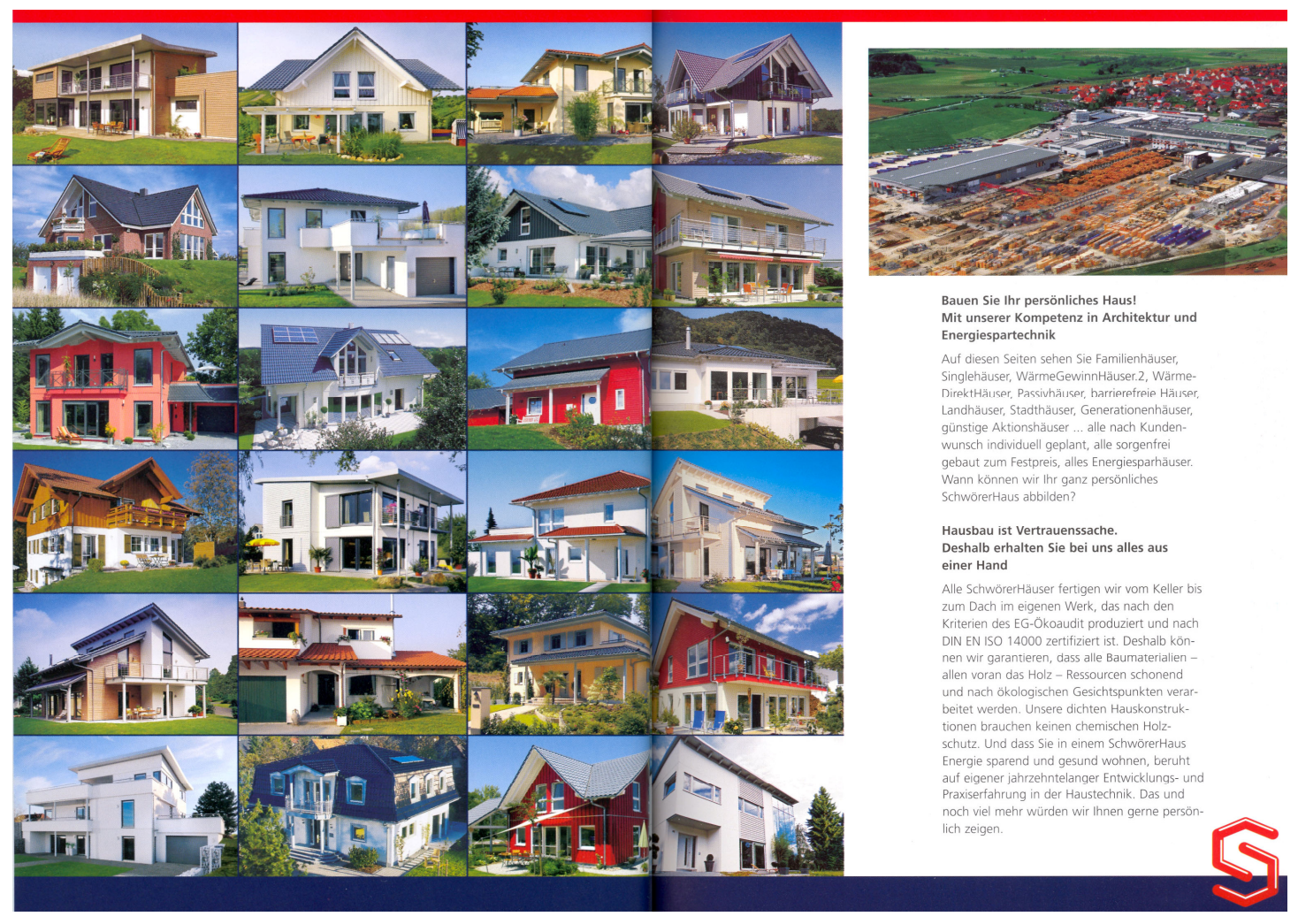

Figure 322: An extensive range of prefabricated housing: a potential future for kiwi prefab. Schworer Haus advertisement in German prefabricated housing magazine. Source: Hausbau, Sep/Oct (2007): np. 


\section{A Potential for Kiwi Prefab}

The aim of this research was to discover a potential for prefabricated housing in New Zealand. A case study methodology was used to offer a new appreciation of existing knowledge particularly in consolidating approaches to challenging issues which were developed into focussed strategies. The significant outcome is the recommendations in two key areas; research and development, and marketing and communication. It is clear there is potential for prefabricated housing to update traditional construction practices, to enable architects to have more control of the final outcome and to better serve prospective home-owners (322).

Prefabrication can potentially save money, save time, save resources, increase quality and ensure known outcomes. These benefits occur when construction activities are taken indoors, prefabrication systems are integrated early in the collaborative design process, and high levels of customer service ensure a streamlined housing delivery. The recommended strategies put forward in this thesis should move New Zealand's prefabricated housing businesses towards a more cohesive, collaborative and educated industry. This would benefit both industry participants and housing consumers.

Ways to view prefabrication that have emerged from this research include: prefabrication as a continuum of processes or systems rather than a singular product; prefabrication as an approach to housing industry problems of low-productivity, decreasing affordability and high waste creation; and prefabrication as an exemplary sub-section of the design and construction industry as a whole, particularly in innovation. Prefabrication has a key role in research and development for the larger design and construction industry. It operates as prototype, exemplar and branding tool. Important issues affecting the prefabricated housing industry are noted to be a microcosm of those that affect the wider architecture profession and construction industry.

The thesis findings indicate that government and industry collaboration is required in research and development. An industry-wide education campaign is necessary and new prefabricated housing exemplars are needed to help change public opinion. The creation of prototypes as show-homes or housing developments also has potential to create new perceptions. Quality is regarded as a principal advantage of prefabricated housing, so careful attention should be given to clearly bench-marking, monitoring and communicating this. Research and development prototype production together with marketing and communication initiatives need to focus on the perception of quality in construction, architect-design and material components.

The change in culture needed to solidify New Zealand's prefabricated housing industry will depend equally on commitment, cooperation and communication. Clearly there is potential for a positive long-term sustainable future for kiwi prefab that will have an important role in shaping the wider New Zealand design and construction industry. 
KIWI PREFAB 


\section{References}

These references are for the works cited according to in-text citations in the thesis body. They are presented according to Modern Language Association (MLA) conventions. No page number is cited for electronic articles and personal communications.

\section{Introduction}

Arieff, Allison, and Bryan Burkhart. Prefab. Layton: Gibbs Smith, 2002.

Bergdoll, Barry, and Peter Christensen. Home Delivery: fabricating the modern dwelling. New York: The Museum of Modern Art, 2008.

Davies, Colin. The Prefabricated Home. London: Reaktion Books, 2005.

Department of Immigration. Summary of Terms. 2 June 2009. <http://glossary.immigration.govt.nz/Kiwis.htm>.

Ebong, Ima. Kit Homes Modern. New York: Collins Design, 2005.

Gann, David. Building Innovation: complex constructs in a changing world. London: Thomas Telford, 2000.

Gardyne, Stuart. Personal Interview. 29 Apr. 2009.

Gibson, Anne. "New Zealand Workers Catching the Wall Street Blues." NZ Herald, 17 Oct 2009. 17 Oct. 2009.

<http://www.nzherald.co.nz/unemployment/news/article.cfm?c_id=353\&objectid=10537900>.

Herbers, Jill. Prefab Modern. New York: HarperCollins, 2004.

Home Delivery: fabricating the modern dwelling. Curators Barry Bergdoll and Peter Christensen. New York: Museum of Modern Art, July 20-Oct.20, 2008.

Jacobs, Karrie. "The Prefab Decade.” Dwell Feb. 2009: 96-7.

Kelly, Burnham. The Prefabrication of Houses: a study by the Albert Farwell Bemis Foundation of the prefabrication industry in the United States. New York: MIT and John Wiley and Sons, 1951.

Kieran, Stephen, and James Timberlake. Loblolly House: elements of a new architecture. New York: Princeton Architectural Press, 2008.

---. Refabricating Architecture: how manufacturing methodologies are poised to transform building construction. New York: McGraw-Hill, 2004.

Laing Richard, Anthony Craig, and Martin Edge. Prefabricated Housing: an assessment of cost value and quality. Proc. of International Conf. on Construction (Construction for tomorrow, Hong Kong, 19-21 June 2001. 80-92. Vol. 1.

Mitchener, Allan, "Towards Industrialised Housing." Thesis. U. of Auckland, 1984.

Wong, Peter. "Industrialised Building Systems: with specific reference to the domestic sector of the New Zealand building industry." Report. Victoria U. of Wellington, 1980. 


\section{Chapter $1:$ What is Prefab?}

Alter, Lloyd. "1947: The Acorn House Unfolds." Treehugger, 9 Jan. 2009. 23 Jan. 2009. <http://www.treehugger.com/files/2009/01/the-acorn-house-unfolds.php>.

---. "Prefab: Green or Greenwashing?" Treehugger, 17 Apr. 2007. 1 Nov. 2008. <http://www.treehugger.com/files/2007/04/prefab_green_or.php>.

Arieff, Allison, and Bryan Burkhart. Prefab. Layton: Gibbs Smith, 2002.

Bergdoll, Barry, and Peter Christensen. Home Delivery: fabricating the modern dwelling. New York: The Museum of Modern Art, 2008.

Bergdoll, Barry. "Home Delivery: viscidities of a Modernist dream from Taylorised serial production to digital customisation." Home Delivery: fabricating the modern dwelling. Ed.s Barry Bergdoll and Peter Christensen. New York: The Museum of Modern Art, 2008.

Brown, Lesley, ed. The New Shorter Oxford English Dictionary. Vol. 2. $4^{\text {th }}$ ed. Oxford: Clarendon Press, 1993.

Buchanan, Michael. Prefab Home. Salt Lake City: Gibbs Smith, 2004.

Buildoffsite. Home Page. 2 Feb. 2008. <http://www.buildoffsite.com/>.

Clark, Keith. Personal Interview. 4. Feb. 2008.

Colomina, Beatriz. Domesticity at War. Cambridge (Mass.): MIT Press, 2007.

Construction Task Force. Rethinking Construction. London: UK Dept. Trade and Industry, 1998.

Cook, Brian. "An Assessment of the Potential Contribution of Prefabrication to Improve the Quality of Housing." Construction Information Quarterly 7.2 (2005): 50-55.

Davies, Colin. The Prefabricated Home. London: Reaktion Books, 2005.

Dawson, Graham. "Prefabricated Houses." Journal of the New Zealand Institute of Architects 19.5 (1952): 75-76.

Ebong, Ima. Kit Homes Modern. New York: Collins Design, 2005.

Elliston, Callie, and Cheryl Nafzgar, eds. Practical Guide to Mobile Homes: an affordable home...still a reality. New York: Bantam-Hudson Idea Books, 1980.

Gann, David. Building Innovation: complex constructs in a changing world. London: Thomas Telford, 2000.

Gauthier, Douglas. Personal Interview. 22 Sep. 2008.

Gaze, C., et al. "Modern Methods of Construction (MMC) in Housing: drivers and barriers to their use." BRE Information Paper 3.1 (2007): 1-6.

Gibb, Alistair, and Martyn Pendlebury. "Glossary of Terms V1.3." Buildoffsite. July 2006. 11 Jan. 2008. <http://www.buildoffsite.co.uk/downloads_publications.htm\#glossary>.

Gibb, Alistair. Off-Site Fabrication: prefabrication, pre-assembly and modularisation. New York: John Wiley and Sons, 1999.

Gorgolewski, M.T. "The Potential for Prefabrication in United Kingdom Housing to Improve Sustainability." Smart and Sustainable Built Environments. Ed.s J. Yang, P.S. Brandon, and A.C. Sidwell. Oxford: Blackwell, 2005. 121-128. 
Hart, Sara. "Prefabrication, the Speculative Builder's Tool, has been Discovered by Modernist Designers." Architectural Record 191.12 (2003): 123-126.

Hawken, Paul. The Ecology of Commerce: a declaration of sustainability. New York: Harper Collins, 1993.

Hay, Roger. E-mail to the author. 29 Jan. 2008.

Home Delivery: fabricating the modern dwelling. Curators Barry Bergdoll and Peter Christensen. New York: Museum of Modern Art, July 20-Oct.20, 2008.

Jacobs, Karrie. "The Prefab Decade.” Dwell Feb. 2009: 96-7.

Juriss, Ivan. Personal Interview. 30 November 2007.

Kelly, Burnham. The Prefabrication of Houses: a study by the Albert Farwell Bemis Foundation of the prefabrication industry in the United States. New York: MIT and John Wiley and Sons, 1951.

Kieran, Stephen, and James Timberlake. Loblolly House: elements of a new architecture. New York: Princeton Architectural Press, 2008.

---. Refabricating Architecture: how manufacturing methodologies are poised to transform building construction. New York: McGraw-Hill, 2004.

Laing Richard, Anthony Craig, and Martin Edge. Prefabricated Housing: an assessment of cost value and quality. Proc. of International Conf. on Construction (Construction for tomorrow, Hong Kong, 19-21 June 2001. 80-92. Vol. 1.

Laufer, William. "Social Accountability and Corporate Greenwashing." Journal of Business Ethics 43.3 (2003): 253-261.

Le Corbusier. Towards a New Architecture. Trans. Frederick Etchells. London: Architectural Press, 1946. London: J.Rodker 1927.

Mau, Bruce, and the Institute without Boundaries. Massive Change. London: Phaidon, 2004.

McDonough, William, and Michael Braungart. Cradle to Cradle. New York: North Point Press, 2002.

McLendon, Sandy. Prefab Elements: adding custom features to your home. New York: Harper Design-HarperCollins, 2005.

Miller, Mark. "Architect Leads by Example: sustainability issues to drive acceptance of highperformance, factory-built structures." Modular Building Institute. 30 June 2008. 16 July 2008. <www.mbinet.org/htmIPage.aspx?HtmIPageld=454>.

Mitchener, Allan, "Towards Industrialised Housing." Thesis. U. of Auckland, 1984.

Modtech. About. 24 June 2008. <http://www.modtech.com/about/off-site-construction.php>.

Mountier, Mary. "IBS: an idea whose time has come." Designscape 35 April 1972: np.

Nike ID. Home Page. 24 Aug. 2008. <http://www.nikeid.nike.com/nikeid/index.jsp>.

Nilsen, Richard. "Form, Function and Feeling." The Arizona Republic. 28 May 2006. 20 Oct. 2007. <http://www.azcentral.com/>. 
Pan, Wei, Alistair Gibb, and Andrew Dainty. Offsite Modern Methods of Construction in Housebuilding. Loughborough: Loughborough UP, 2005.

Papanek, Victor. The Green Imperative: ecology and ethics in design and architecture. London: Thames and Hudson, 1995.

Pawley, Martin. Design Heroes: Buckminster Fuller. London: HarperCollins, 1990.

"The Prefab Issue." Dwell Feb. 2009.

Reidelbach Jr., John A. Modular Housing 1971: facts and concepts. Boston: Cahners, 1971.

Rybczynski, Witold. "Home Delivery: fabricating the modern dwelling." Journal of Society of Architectural Historians 68.2 (2009): 254-6.

---. "The Prefab Fad". Slate. 8 Aug. 2007. 10 Aug. 2007. $<$ http://www.slate.com/id/2171842/fr/flyout>.

Smith, Dana. "FAQ." Michelle Kaufmann Designs. Apr. 2008. 17 July 2008. $<$ www.mkd-arc.com/pressroom/>.

Steffen, Alex, ed. Worldchanging: a user's guide for the $21^{\text {st }}$ century. New York: Abrams, 2006.

Tuohy, Phil. Personal Interview. 13 May 2008.

Vale, Brenda. Prefabs: a history of the UK temporary housing programme. London: SponChapman and Hall, 1995.

Wendt, Allyson. "Prefabrication's Green Promise." McGraw Hill Construction (Continuing Education). Jan. 2009. 6 Feb 2009. <http://continuingeducation.construction.com/article.php? L=5\&C=482>.

White, R.B. Prefabrication: a history of its development in Great Britain. UK Ministry of Technology Building Research Station: SP 36. London: Her Majesty's Stationery Office, 1965.

Whiter, Rebecca. "New Report Shows Offsite Manufacture Can Reduce Construction Waste." WRAP, 21 Mar. 2007. 1 July 2008. <http://www.wrap.org.uk/wrap_corporate/news/new_report_shows.html>.

Wood, Chris. "Govt ${ }^{3}$ and Sustainable Government Building(s)." Property Institute, Wellington. 2008.

---. "Govt ${ }^{3}$ Status." E-mail to the author. 20 May 2009.

Yang, J., P.S. Brandon, and A.C. Sidwell, eds. Smart and Sustainable Built Environments. Oxford: Blackwell Publishing, 2005. 


\section{Chapter 2 : Past Prefabs}

Arieff, Allison, and Bryan Burkhart. Prefab. Layton: Gibbs Smith, 2002.

Ayliffe, J., and M. Jeffares. PEB 12: Relocatable Schools in New Zealand. Paris: OECD, 1982.

Bell, Pamela. "Marketecture*: marketing an architecture via branding, fashion and media." Report. Victoria U. of Wellington, 2002.

Bergdoll, Barry, and Peter Christensen. Home Delivery: fabricating the modern dwelling. New York: The Museum of Modern Art, 2008.

Bergdoll, Barry. "Home Delivery: viscidities of a Modernist dream from Taylorised serial production to digital customisation." Home Delivery: fabricating the modern dwelling. Ed.s Barry Bergdoll and Peter Christensen. New York: The Museum of Modern Art, 2008.

Bowron, Greg, and Tania Mace. "State Housing: a thematic survey." Wellington: Housing New Zealand Corporation, 2007.

Brookes, Barbara ed. At Home in New Zealand: houses, history, people. Wellington: Bridget Williams Books, 2000.

Buchanan, Michael. Prefab Home. Salt Lake City: Gibbs Smith, 2004.

Cannell, Michael. "Do We Really Need Architects?" FastCompany. 31 Mar. 2009. 2 Apr. 2009. $<$ http://www.fastcompany.com/blog/michael-cannell/>.

Cheer, Karen. "Economic Reality or Philosophical Change?" From Over-Sweet Cake to Wholemeal Bread: the Home and Building years: New Zealand architecture in the 1940s. Ed. Christine McArthy. Wellington: Victoria U, 2008: 29-37.

Clark, Keith. Personal Interview. 4 Feb. 2008.

Cracknell, Scott. "Prefabricated Modernity: The Solwood House." Thresholds: Papers of the Sixteenth Annual Conference of the Society of Architectural Historians Australia and New Zealand. Launceston and Hobart: SAHANZ, 1999.

Davies, Colin. The Prefabricated Home. London: Reaktion Books, 2005.

Dawson, Mark. Personal Interview. 5 May 2009.

Eldred-Grigg, Stevan. Diggers, Hatters and Whores: the story of the New Zealand gold rushes. Auckland: Random House, 2008.

Elliston, Callie, and Cheryl Nafzgar, eds. Practical Guide to Mobile Homes: an affordable home...still a reality. New York: Bantam-Hudson Idea Books, 1980.

Ferguson, Gael. Building the New Zealand Dream. Wellington: Dunmore Press, 1994.

Firth, Cedric. State Housing in New Zealand. Wellington: NZ Ministry of Works, 1949.

Gardyne, Stuart. Personal Interview. 29 Apr. 2009.

Gatley, Julia. Long Live the Modern: New Zealand's new architecture. Auckland: Auckland UP, 2008.

Giess, Juergen. Personal Interview. 2 May 2008.

Grigor, Jeff. Baches and Cribs. London: Pengun Books, 2008. 
Hansen, Jeremy. "The Futuro's Bright." New Zealand Home and Entertaining Apr/May 2006: 21-22.

Hay, David. E-mail to the author. 26 Nov. 2007.

Hay, Roger. Personal Interview. 25 Jan. 2008.

Herbert, Gilbert. The Dream of the Factory-made House: Walter Gropius and Konrad Wachsmann. Cambridge, MA and London: MIT UP, 1984.

Home Delivery: fabricating the modern dwelling. Curators Barry Bergdoll and Peter Christensen. New York: Museum of Modern Art, July 20-Oct.20, 2008.

Hoskins, Rau, and Carin Wilson. "The Whare Raupo: back to the future?" Auckland: DesignTribe-Studio Pasifica - Unitec, 2004.

Hunt, Gavin. E-mail to the author. 22 Feb. 2009.

Irving, Robert, ed. The History and Design of the Australian House. Melbourne: Oxford UP, 1985.

Juriss, Ivan. Personal Interview. 30 November 2007.

Kellaway, Laura. "The Railway House in New Zealand: a study of 1920s prefabricated houses." Thesis. U. of Auckland, 1993.

Kellaway, Tony. Austrian State Houses: Titahi Bay. Wellington: Porirua Museum, Porirua City Council, 1994.

Kelly, Burnham. The Prefabrication of Houses. New York: MIT Press and John Wiley and Sons, 1951.

Kieran, Stephen, and James Timberlake. Refabricating Architecture: how manufacturing methodologies are poised to transform building construction. New York: McGraw-Hill, 2004.

Kinsella, Fleur. Email to the author. 25 March 2008.

---. "Fifty Years of Construction Camps in the South." Draft thesis. Victoria U. of Wellington, 2009.

Knight, Tony. Personal Interview. 16 Dec. 2008.

Koshalek, Richard. Foreword. Blueprints for Modern Living: history and legacy of the Case Study Houses. Ed. Elizabeth Smith. Cambridge and London: MIT Press, 1989: 9-11.

Le Corbusier. Towards a New Architecture. Trans. Frederick Etchells. London: Architectural Press, 1946. London: J.Rodker 1927.

Lewis, Miles. "Prefabrication in the Gold Rush Era: California, Australia and the Pacific." APT Bulletin 37.1 (2006): 7-16.

Linzey, Kate. "Making a Place: Mangakino 1946-1962." From Over-Sweet Cake to Wholemeal Bread: the Home and Building years: New Zealand architecture in the 1940s. Ed. Christine McArthy. Wellington: Victoria U, 2008: 60-63.

Lockwood, John. E-mail to the author. 4 Aug. 2008.

Mace, Tania. Email to the author. 7 March 2008.

Mau, Bruce, and the Institute without Boundaries. Massive Change. London: Phaidon, 2004. 
McCarthy, Christine. "Partial architectures: post World War II New Zealand government housing." Fabrications 13.1 (2003): 33-62.

McCaul, Hamish. Personal Interview. 31 Jan. 2008.

McEwan, Ann. "Frankton Junction House Factory and Railway Housing Precinct." Long Live the Modern. Ed. Julia Gatley. Auckland: Auckland UP, 2008.

McGowan, Denis. Letter to the author. 22 Dec. 2008.

Melhuish, John. Personal Interview. 8 Apr. 2009.

Michelle Kaufmann Designs. 23 May 2009. <http://www.mkd-arc.com/>.

Mitchell, David, and Gillian Chaplin. The Elegant Shed: New Zealand architecture since 1945. Auckland: Oxford UP, 1984.

Mitchener, Allan. "Towards industrialised housing." Thesis. U. of Auckland, 1984.

Mountier, Mary. "IBS” Designscape. 50. Aug. 1973: 1-16.

--.. "IBS: an idea whose time has come." Designscape. 35. Apr. 1972: np.

Murray, Russell, and Barbara Fill. Report 152: Austrian Houses. Porirua: Porirua City Council, 2007.

Neuhart, Marilyn, and John Neuhart. Eames House. Wissenschaften Gmbh.,Germany: Ernst, Wilhelm and Sohn, Verlag fur Architektur und Technische, 1994.

Pawley, Martin. Design Heroes: Buckminster Fuller. London: Paladin, 1990.

“Prouvé Prototype Maison Troicale Realises \$4.97 Million." DesignWS 20 May 2009. $<$ http:www.designws.com/pagina/1jean.html>.

Schrader, Ben. "Labour at Home: the first Labour government and the familial suburban ideal." At Home in New Zealand: houses, history, people. Ed. Barbara Brookes. Wellington: Bridget Williams Books, 2000.

---. We Call it Home: a history of state housing in New Zealand. Auckland: Reed Publishing, 2005.

Shaw, Peter. Waitangi. Napier: Cosmos Publications, 1992.

Sheerin, Bruce. Personal Interview. 13 May 2008.

Sheridan, Marion. Dam Dwellers: end of an era. Twizel: Sheridan Press, 1995.

Smith. Elizabeth. "Extending the case study concept: newly commissioned works." Ed. Elizabeth Smith, Blueprints for Modern Living: history and legacy of the Case Study Houses. Cambridge and London: MIT Press, 1989. 213-226.

Smith, Jack. E-mail to the author. 12 Dec. 2008.

Spunt, Alexandra. "A Timeline of Prefab History.” Good. 4 Feb. 2009. 19 Feb. 2009. $<w w w . g o o d . i s / ? p=15017>$.

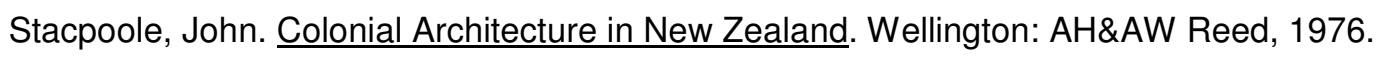

Sylvester, Michael. Personal Interview. 6 June 2008. 
Thornton, Geoffrey. New Zealand's Industrial Heritage. Wellington: Reed, 1982.

Toomath, William. Built in New Zealand: the houses we live in. Auckland: Harper Collins, 1996.

Tuohy, Phil. Personal Interview. 13 May 2008.

Vale, Brenda. Prefabs: a history of the UK temporary housing programme. London: SponChapman and Hall, 1995.

Walker, Roger. Personal Interview. 13 May 2008.

"What's Holding Back the Real Breakthrough in Modular Housing?" House and Home 1971: 8699.

White, R.B. Prefabrication: a history of its development in Great Britain. UK Ministry of Technology Building Research Station: SP 36. London: Her Majesty's Stationery Office, 1965.

Willems, Maarten. A House is not a Car. Proc. of XXXII IAHS World Congress on Housing (Sustainabilityi of the Housing Projects). Trento, 21-25 Sep. 2004. Trento: Technical University Eindhoven.

Wilson, Gordon. “Lessons in Prefabrication.” New Zealand Financial Times: 139. 1943.

Wilson, Ross. E-mail to the author. 24 Feb. 2009.

Wong, Peter. "Industrialised Building Systems: with specific reference to the domestic sector of the New Zealand building industry." Report. Victoria U. of Wellington, 1980. 


\section{Chapter 3 : Kiwi Prefabs Today}

Albert, John. E-mail to the author. 17 Feb. 2009.

Bachkit. Home Page. 20 May 2008. <http://www.bachkit.co.nz/start.html>.

Baldwin, Jonathan. "Bruce Nussbaum: are designers the enemy of design?" Blogspot, 27 July 2007. 29 July 2007. <http://jonathanbaldwin.blogspot.com/2007/07/bruce-nussbaum-aredesigners-enemy-of.html>.

Banks, Warrick. Personal Interview. 14 Aug. 2008.

Beavis, Colin. Personal Interview. 26 Feb. 2009.

Bergdoll, Barry. Personal Interview. 25 Sep. 2008.

Bergdoll, Barry, and Peter Christensen. Home Delivery: fabricating the modern dwelling. New York: The Museum of Modern Art, 2008.

Brown, David, ed. The Home House Project. Cambridge: MIT Press, 2004.

Carter Holt Harvey. Home Page. 15 July 2008. <http://www.chh.com/>.

Carters. Home Page. 15 July 2008. <http://www.carters.co.nz/>.

Caulfield, Gary. E-mail to the author. 4 Mar. 2009.

De Geest, Brian. Personal Interview. 22 Feb. 2008.

De Geest Construction. History. 28 Sep. 2007. <http://www.degeest.com/history.html>.

Durapanel Systems. Home Page. 22 May 2008. <http://www.durapanel.co.nz/>.

"Expert and Stylish: the Bachkit has caught the imagination of many." Architecture NZ. 23 July 2008. 7 Apr. 2009. <http://www.bachkit.com.au/News/news-item-2.html>.

Fox, Andrea. "Hart Attack." Unlimited. 1 Oct. 2006. 10 Feb. 2008. <http://unlimited.co.nz/unlimited.nsf/default/90E088B07C449CCECC2571E80079EE1A>.

Frame and Truss Manufacturers Association. Home Page. 15 July 2008. $<$ http://www.ftma.co.nz/>.

Freeman, Alan. Personal Interview. 26 Feb. 2009.

Future Proof Building (FPB). Home Page. 15 July 2008. <http:www.fpb.co.nz/>.

Gaiardo, Paul. "Challenges in New Zealand Truss and Frame." FTMA Conference, Wairaki. 2007.

---. E-mail to the author. 1 Mar. 2009.

Gainsford, Jennie. Lockwood: from innovation to icon in 50 years. Tauranga: Bay of Plenty Branch Committee, NZ Historic Places Trust, 2006.

Giess, Juergen. Personal Interview. 2 May 2008.

Gjerde, Morten. Residential Concrete Detailing and Specification Guide. Wellington: CCANZ, 2000.

Gladwell, Malcolm. The Tipping Point. London: Abacus-Brown Book Group, 2000. 
Hall, Kris. "Output Rockets as ‘Apollo' Launched.” Stuff. 15 June 2009. 15 June 2009. <http://www.stuff.co.nz/business/industries/2499761/Output-rockets-as-Apollo-launched>.

Harrington, Mark. "SIPs Research." E-mail to the author. 28 Apr. 2009.

Haven. Modpod. 28 Aug. 2008. <http://www.havennz.co.nz/pod_modpod.htm>.

Hossack, Glen. Personal Interview. 3 Mar. 2008.

Hotel So. Home Page. 28 Aug. 2008. <http://www.hotelso.co.nz/>.

Hunt, Graham. E-mail to the author. 6 Mar. 2009.

James, Bruce. Personal Interview. 3 Mar. 2009.

Juken New Zealand. Home Page. 4 Apr. 2008. <http://www.jnl.co.nz/>.

Keith Hay Homes. Home Page. 23 Oct. 2008. <http://www.keithhayhomes.co.nz/>.z

Kenworthy, Andy. "Anatomy of an Eco-home." Home New Zealand Aug./Sep. (2008): 158-9.

Kieran, Stephen, and James Timberlake. Loblolly House: elements of a new architecture. New York: Princeton Architectural Press, 2008.

Kirby, Alan, and Adam Leach. Personal Interview. 27 Feb. 2009.

Laing Homes. 9 Feb. 2008. <http://www.laing.co.nz/>.

Laing, Grant. Personal Interview. 22 Apr. 2008.

Leisurebuilt. Mobile Homes. 21 Feb. 2008. <http://www.leisurebuilt.co.nz/Products.asp>.

Levy, Jared. Personal Interview. 2 June 2008.

Lockwood Group. History. 17 Apr. 2008.

<http://www.lockwood.co.nz/index.asp?pagelD=2145847675>.

Lockwood Group. “Lockwood EcoSmart.” Plan-book. 2008.

Lockwood Group. Lockwood International. 22 May 2009. <http://www.lockwood.co.nz/index.asp?pagelD=2145847679>.

Lockwood Group. “Lockwood Lifestyles.” Plan-book. 2008.

Maximpanel 2007. Home Page. 11 July 2008. <http://www.maxim.co.nz/>.

McCaw, Nick. E-mail to the author. 8 July 2008.

McIntosh, Jacqueline, and Mark Harrington. "BioSIPs: a deeper shade of green?" Sustainable Building 07, Auckland. Nov. 2007.

McKenzie, Grant. Personal Interview. 22 Apr. 2008.

McRaeway Homes. Home Page. 22 June 2008. <http://www.mcraeway.co.nz/>.

Melhuish, John. Personal Interview. 8 Apr. 2009.

Millington, Gary. E-mail to the author. 4 Mar. 2008. 
Novak, Evzen. Personal Interview. 25 Jan. 2008.

Page, lan. Study Report 196: New House Price Modelling. Wellington: BRANZ, 2008.

Parker, Jeff. Personal Interview. 5 Mar. 2008.

Parrant, Lloyd. Personal Interview. 28 July 2008.

Payne, Michael. A Charmed Life. Whanganui: Michael Payne, 2008.

Portacom. Home Page. 14 Mar. 2008. <http://www.portacom.co.nz/>.

Porou, Tina. "Walking in Two Worlds." Re:think Feb. 2006. 14 Aug. 2008. <http://wms-soros.mngt.waikato.ac.nz/NR/rethink/ReThinkfeb06.pdf>.

Richardson, John. Personal Interview. 28 July 2008.

Rozbicki, Richard. Personal Interview. 7 Apr. 2009.

Savage, Melissa. E-mail to the author. 29 Aug. 2008.

Scofield, Rosemary. E-mail to the author. 18 May 2009.

Semenoff, Chippie. Personal Interview. 28 July 2008.

Senior, Grant. E-mail to the author. 8 Jan. 2009.

Solid Wood. Home Page. 2 May 2009. <http://www.solidwood.co.nz/>.

Stanley Group. Stanley Modular. 14 Apr. 2008. <http://www.stanleygroup.co.nz/page/35-Stanley-Modular>.

Stewart, lan. Personal Interview. 28 July 2008.

Sylvester, Michael. Personal Interview. 6 June 2008.

Tipa, Matt. "First Base Update." E-mail to the author. 15 June 2009.

Tipa, Matt, and Jan Keys. Personal Interview. 3 Oct. 2008.

Touchwood. History and News. 12 Aug. 2008. <http://touch-wood.co.nz/>.

"Touchwood: new options for builders." Franchise 18.1 (2009): 15.

Tristyle International. 24 Jan. 2008. <http://www.tristyle.co.nz/>.

Trower, John. Personal Interview. 7 July 2008.

Tuohy, Phil. Personal Interview. 13 May 2008.

Turner, Colin, and Martin Heere. Personal Interview. 28 July 2008.

Wakefield, Hamish. Personal Interview. 5 May 2009.

Walker, Roger. Personal Interview. 13 May 2008.

Wilco Precast. Home Page. 27 May 2009. <http://www.wilcoprecast.co.nz/>.

Wong, Peter. "Industrialised Building Systems: with specific reference to the domestic sector of the New Zealand building industry." Report. Victoria U. of Wellington, 1980. 


\section{Chapter 4 : Prefab Precedents}

Alter, Lloyd. "1947: The Acorn House Unfolds." Treehugger, 9 Jan. 2009. 23 Jan. 2009. $<$ http://www.treehugger.com/files/2009/01/the-acorn-house-unfolds.php>.

Amazon. Jennifer Siegal Search. 14 Aug. 2008. $<$ http://www.amazon.com/s/ref=nb_ss_gw?url=search-alias\%3Daps\&fieldkeywords=siegal\%2C+jennifer $\& x=17 \& y=17>$.

Apelgren, Janne. "The Shack is Back." The Weekend Australian Magazine. June 23-24, 2007: 38-40.

Archinect. "Marmol Radziner Shop offers homeowners and designers unique access to superior metal and wood shop services." 3 June 2009. 5 June 2009.

<http://www.archinect.com/news/dropbox_fullentry.php?id=89402_0_28_0_M>.

Arieff, Allison. E-mail to the author. 3 May 2008.

Arieff, Allison, and Bryan Burkhart. Prefab. Layton: Gibbs Smith, 2002.

Baufritz. "Klassikund Moderne" brochure.

Biddle, Anna. Personal Email. 10 June 2008.

Bo Klok. Home Page. 23 May 2008. <http://www.boklok.com.uk/>.

Building Research Establishment. E-mail Newsletter. 11 July 2008.

Buildoffsite. Home Page. 2 Feb. 2008. <http://www.buildoffsite.com/>.

Burke, Terry, and David Hayward. Melbourne's Housing Past, Housing Futures. Melbourne: Institute for Social Research, Swinburne University of Technology, 2000.

Construction Task Force. Rethinking Construction. London: UK Dept. Trade and Industry, 1998.

Cook, Brian. "An Assessment of the Potential Contribution of Prefabrication to Improve the Quality of Housing." Construction Information Quarterly 7.2 (2005): 50-55.

Egan, Danielle. "The Prefab Home Is Suddenly Fab.” The Tyee. 31 May 2005. 31 May 2005. <http://thetyee.ca/News/2005/05/31/PrefabHome/>.

Eli, Jay, and Patrick Giliane. Personal Interview. 6 June 2008.

Empyrean International. Empyrean: architecture, planning, fabrication. Acton: Empyrean International, 2008.

Environa Studio. House of the Future. 24 July 2008. $<\mathrm{http}: / /$ www.environastudio.com.au/house_of_the_future.html>.

Fabprefab. "Glossary." Ed. Michael Sylvester. Fabprefab. 2003. <http://www.fabprefab.com/fabfiles/glossary.htm>.

Fleetwood. About. 13 June 2008. <http://www.fleetwood.com.au/about.html>.

Fleetwood, Roy. Personal Interview. 26 Jan. 2009.

Gann, David. "Construction as a Manufacturing Process? Similarities and Differences between Industrialised Housing and Car Production in Japan." Construction Management and Economics 14 (1996): 437-50. 
Gaze, C., et al. "Modern Methods of Construction (MMC) in Housing: drivers and barriers to their use." BRE Information Paper 3.1 (2007): 1-6.

Gibb, Alistair, and Martyn Pendlebury. "Glossary of Terms V1.3." Buildoffsite. July 2006. 11 Jan. 2008. <http://www.buildoffsite.co.uk/downloads_publications.htm\#glossary>.

Gibb, Alistair. Off-Site Fabrication: prefabrication, pre-assembly and modularisation. New York: John Wiley and Sons, 1999.

Glenn, Steve. Personal Interview. 4 June 2008.

Hart, Sara. "Prefabrication, the speculative builder's tool, has been discovered by Modernist designers." Architectural Record 191.12 (2003): 123-26.

Hausbau. Sep/Oct 2007: supplement.

Hawthorne, Christopher. "Green Prefab Firm Michelle Kaufmann Designs is Closing." LA Times, 26 May 2009. 26 May 2009. <http://latimesblogs.latimes.com/culturemonster/2009/05/greenprefab-firm-michelle-kaufmann-designs-is-closing.html>.

Home Delivery: fabricating the modern dwelling. Curators Barry Bergdoll and Peter Christensen. New York: Museum of Modern Art, July 20-Oct.20, 2008.

Houses of the Future Competition. Home Page. 12 Mar. 2009.

$<$ http://www.housesofthefuture.coom.au/>.

"Housing Co-op Turns up the Volume." Communities Scotland. 10 June 2009.

<http://www.communitiesscotland.gov.uk/stellent/groups/public/documents/webpages/pub scs_011626.hcsp>.

Ikea. Home Page. 1 Aug. 2008. <http://ikea.com/>.

Jeffrey, Nancy Ann, and Nancy Keates. "Upwardly Mobile Homes: is this architecture?" The Wall Street Journal. 21 Jan. 2004. 19 Nov. 2007.

<http://www.realestatejournal.com/homegarden/20040121-jeffrey.html>.

Kaufmann, Michelle, and Molly McGrath. Prefab Green. San Francisco: Michelle Kaufmann Designs, 2006.

Kaufmann, Michelle. "Systems Building and Prefab." Dwell on Design. Los Angeles, 2008.

Keeps, David. "The Prefab Gets a Makeover." Los Angeles Times 13 Mar. 2008. 23 Mar. 2008. <http://articles.latimes.com/2008/mar/13/home/hm-prefab13>.

Kieran, Stephen, and James Timberlake. Refabricating Architecture: how manufacturing methodologies are poised to transform building construction. New York: McGraw-Hill, 2004.

Koones, Sheri. Modular Mansions. Salt Lake City: Gibbs Smith, 2005.

Levy, Jared. Personal Interview. 2 June 2008.

Marmol, Leo. Personal Interview. 3 June 2008.

Marmol Radziner Prefab (MRP). E-mail Newsletter. 20 June 2009.

Marmol Radziner Prefab (MRP). Home Page. 14 Apr. 2008.

$<$ http://www.marmolradzinerprefab.com/>.

Matsumara, Dr. Shuichi. "Prefabricated House-Building Systems in Japan." 10 Internationales Holzbau Forum, Garmish, 2004. np. 
Modular Building Institute. About. 24 July 2008.

$<$ http://www.mbinet.org/htmIPage.aspx?name=about_mbi>.

McGuigan, Cathleen, and Anna Kuchment. "Houses of the Future: now." Newsweek. 16 Oct. 2007. 3 July 2008. <http://www.newsweek.com/id/52129>.

Michelle Kaufmann Designs (MKD). Home Page. 10 July 2007. <http://www.mkd-arc.com/>

Modabode. Home Page. 24 July 2008. <http://www.modabode.com.au/pages/1home.htm>.

Ogden, Richard. Promoting Construction Offsite. London: Buildoffsite, 2008.

Paevere, P., and C. MacKenzie. Emerging Technologies and Timber Products in Construction: literature review. Melbourne: Forest and Wood Products Research and Development Corp., 2006.

Pallasmaa, Juhani, and Tomoko Sato, ed.s. Alvar Aalto: through the eyes of Shigeru Ban. London: Black Dog, 2007.

Pattison, Kermit. “Can Green Homes Be Mass Produced?" Fast Company, Dec. 2007. 8 Jan. 2008. <www.fastcompany.com/articles/2007/12/interview-kaufmann.html>.

Prebuilt. Houses. 5 Oct. 2008. <http://www.prebuilt.com.au/index.php?action=productcatalogue \&prodcat_id $=806 \&$ page $I D=6504 \&$ section $I D=6485>$.

"Prefab's Promise." Dwell, Apr/May 2005: cover.

Preston, D. "Toyota Looking to Expand Stylish Prefab Homes Unit." Jetson Green. 3 July 2008. 8 July 2008. <http://www.jetsongreen.com/2008/07/toyota-homes-lo.html>.

Quon Modular. Home Page. 13 June 2008. <http://www.prefabhouse.com.au/Quon.html>.

Radziner, Ron. Personal Interview. 2 June 2008.

Ray, Paul. "The Rise of Integral Culture.” Noetic Sciences Review (1996): 4.

Redmond, Elizabeth. "Eco-Effective Options: prefabrication and modularity." Green Options. 27 July 2007. 30 July 2007. <http://www.greenoptions.com/2007/07/27/eco_effective_options_ prefabrication_and_modularity>.

Rose, Steve. "Welcome to Ikeatown." The Guardian. Apr 13-19 (2007): 23.

Ryan, Michaela. "Kit and Caboodle." Realestate. Aug. 2006. 5 Oct. 2007. <http://www.realestate.com.au/review/aug06/article5.html>.

Rybczynski, Witold. "Houses Made in Factories". Slate. 20 Aug. 2008. <http://www.slate.com/id/2197176/slideshow/2197362/fs/0//entry/2197352/>.

Schonfeld, Erick. "Putting the 'Fab' in Prefab Housing." Business 2.0 8 Mar. 2006. 11 Mar. 2006. <http://money.cnn.com/2006/03/07/magazines/business2/fabinprefab/index.htm>.

Sekisui House. "Sekisui House Comprehensive R\&D Institute: home amenities experience studio." Brochure.

Siegal, Jennifer, ed. Mobile: the art of portable architecture. New York: Princeton Architectural Press, 2002.

---. Personal Interview. 4 June 2008. 
Smart Shax. Home Page. 24 July 2008. <http://www.smartshax.com/>.

Smith, Dakota. "Marmol Radziner Prefab Venice Home Can Be Yours." LA Curbed. 30 Jan. 2009. 10 Apr. 2009. <http://la.curbed.com/archives/2009/01/marmol_radziner_prefab_venice _home_can_be_yours.php>.

---. "Prefab Sad: Modtech Holdings files Chapter 11." LA Curbed. 28 Oct. 2008. 11 Apr. 2009. $<$ http://la.curbed.com/archives/2008/10/prefab_sad_modtech_holdings_files_chapter_11. php>.

Smith, Dana. "FAQ." Michelle Kaufmann Designs. Apr. 2008. 17 July 2008. <www.mkd-arc.com /pressroom/>.

Spunt, Alexandra. "A Timeline of Prefab History." Good. 4 Feb. 2009. 19 Feb. 2009. $<w w w . g o o d . i s / ? p=15017>$.

Staedter, Tracy. "Mobile Homes Go Green.” Discovery News. 17 Jan. 2008. 18 Jan. 2008. <http://dsc.discovery.com/news/2008/01/17/green-mobile-home-print.html>.

Stang, Alanna, and Christopher Hawthorne. The Green House: new directions in sustainable architecture. New York: Princeton Architectural Press, 2005.

Stungo, Naomi. "Home Delivery." RIBA Journal 111.4 (2004): 46-50.

Sylvester, Michael. Personal Interview. 6 June 2008.

The MAC Services Group Ltd. Construction Manufacturing. 13 June 2008. <http://www.themac.com.au/our_businesses/construction_manufacturing.php>.

United States Green Building Council (USGBC). What is LEED? 12 June 2009. $<$ http://www.usgbc.org/DisplayPage.aspx?CMSPagelD=1988>.

Venables, Tim, and Roger Courtenay. Modern Methods of Construction in Germany: playing the offsite rule. London: UK Dept. Trade and Industry (Global Watch Mission), 2004.

Waern, Rasmus. "Scandinavia: prefabrication as a model of society." Home Delivery: fabricating the modern dwelling. Eds. Barry Bergdoll and Peter Christensen. New York: The Museum of Modern Art, 2008.

"What's Holding Back the Real Breakthrough in Modular Housing?" House and Home 40 (1971): 86-99. 


\section{Chapter 5 : New Kiwi Prefabs}

Alter, Lloyd. "1947: the Acorn House unfolds." TreeHugger. 9 Jan. 2009. 23 Jan. 2009. <http://www.treehugger.com/files/2009/01/the-acorn-house-unfolds.php>.

---. "Re: Will Prefab Ever Catch On." Online posting. 26 Sep. 2008. 1 Oct. 2008. <http://freakonomics.blogs.nytimes.com/2008/09/26/will-prefab-ever-catch-on/>.

Aquabach. Home Page. 19 June 2008. <http://www.aquabach.co.nz/>.

Axis Designer Homes by PLB Group. 9 Sep. 2008. <http://www.axisdesignerhomes.co.nz/index.htm>.

Bach2go. Show Home. 4 May 2009. <http://www.bach2go.co.nz/showhome.asp>.z

Bell, Pamela. "Marketecture*: marketing an architecture via branding, fashion and media." Undergraduate Report. Victoria U. of Wellington, 2002.

Bottom, David, et al. Innovation in Japanese Prefabricated House-Building Industries. London: CIRIA, 1996.

Bowie, Charlotte. Personal interview. 6 Apr. 2009.

Brown, Cheryl. E-mail to the author. 11 Sep. 2008.

---. "K-bach Update." E-mail to the author. 2 Apr. 2009.

Brown, Cheryl, and Rocky Hawke. Personal Interview. 23 Aug. 2008.

Cassels, Ian. Personal Interview. 3 Apr. 2008.

Caulfield, Gary. Stanley Modular. E-mail to the author. 28 Apr. 2009.

Churchouse, Nick. "Fold-out Bach Makes Life at Beach a Breeze." The Dominion Post [Wellington] 5 Nov. 2007: C1.

Clark, Keith. Personal Interview. 4 Feb. 2008.

Coughlan, Kate. "Pad Fab." New Zealand Life and Leisure 17 (2008):72.

E-Homes by Maddrens. Home Page. 26 Aug. 2008. <http://www.e-homes.co.nz/>.

Frost, Tony, and Adrian Lamb. Personal Interview. 8 Aug. 2008.

Gerrard, Graham and Christine Gerrard. Personal Interview. 7 Mar. 2008.

Gibson, Rod. Personal Interview. 27 Nov. 2007.

Giess, Juergen. Personal Interview. 2 May 2008.

Giesen, William. Personal Interview. 18 Jan. 2008.

Greeks, Polly. "Bach in a Box." New Zealand Life and Leisure 17: 86-89.

Grimes, Mark. Phone-call to author. 19 June 2009.

Hansen, Jeremy. “Ipad - I Want?" Home New Zealand Dec./Jan. (2008/09): 150.

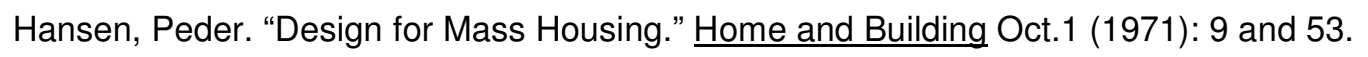


Hartley, Alan. Personal interview. 26 Feb. 2009.

Hill, Nick. Personal Interview. 28 Nov. 2008.

Hodgskin, Andre. Personal Interview. 4 Feb. 2008.

Ipad. Home Page. 22 Jan. 2008. <http://www.ipad.net.nz/>.

Kotnik, Jure. Container Architecture. Barcelona: Links Books, 2008.

Marmol, Leo. Personal Interview. 3 June 2008.

Palmer, Rebecca. "Affordable 'Model T' house for the masses." The Dominion Post [Wellington] 29 Mar. 2008: A2.

Pinecone Timber Buildings. Home Page. 9 May 2008. <http://www.ptb.co.nz/>.

Quick Living. 28 Nov. 2008. <http:www.quickliving.co.nz/>.

Salisbury, Jeff. E-mail to the author. 15 Feb 2009.

Taylor, Matt. Personal Interview. 26 Aug. 2008.

Thorn, Clem, and Bernie Gibbs. Personal Interview. 1 July 2008.

Topham, Sean. Move House. Munich: Prestel, 2004.

Tuohy, Phil. Personal Interview. 13 May 2008.

Walsh, Kat. "Town's Builders Lead the Way." Opotiki News 20 Nov. 2007: 1. 


\section{Chapter 6 : Challenges and Opportunities}

Arieff, Allison, and Bryan Burkhart. Prefab. Layton: Gibbs Smith, 2002.

Barlow, James. "From Craft Production to Mass Customisation: innovation requirements for the UK house-building industry." Housing Studies 14.1 (1999): 23-42.

Colomina, Beatriz. Domesticity at War. Cambridge (Mass.): MIT Press, 2007.

Construction Task Force. Rethinking Construction. London: UK Dept. Trade and Industry, 1998.

Davies, Colin. The Prefabricated Home. London: Reaktion Books, 2005.

De Geest, Brian. Personal Interview. 22 Feb. 2008.

Hect, Sam. "The Acceleration of Having More with Less." Simplicity: the art of complexity. ARS Electronica 2006 Catalog: Festival for Art, Technology and Society. Eds. Gerfried Stocker and Christine Schopf. Ostfildern, Hatje Cantz Verlag, 2006.

Mengisen, Annika. "Will Prefab Ever Catch On?" New York Times. 26 Sep. 2008. 1 Oct. 2008. $<$ http://freakonomics.blogs.nytimes.com/2008/09/26/will-prefab-ever-catch-on/>.

Mitchener, Allan, "Towards Industrialised Housing." Thesis. U. of Auckland, 1984.

Naumann, Stefan. "Mynewhome.com.au. Exploring New Ways of Delivering Architecture: creating a design interface for sustainable and affordable houses." Thesis. Melbourne: RMIT U., 2008.

Oxley III, David. "Role of Prefabricated Modular Housing Systems in Promoting Sustainable Housing Practices." Thesis. Melbourne: RMIT U., 2006.

Paevere, P., and C. MacKenzie. Emerging Technologies and Timber Products in Construction: literature review. Melbourne: Forest and Wood Products Research and Development Corp., 2006.

Pan, Wei, Alistair Gibb and Andrew Dainty. "Leading UK Housebuilders' Utilisation of Offsite Construction Methods." Building Research and Information 36.1 (2008): 56-67.

Weideman, Paul. "Art of Space." The New Mexican. 20 Oct. 2006. 30 Oct. 2006. $<$ www.freenewmexican.com/news/50950.htmls. 


\section{Chapter 7 : Strategies}

Alter, Lloyd. "1947: the Acorn House unfolds." TreeHugger. 9 Jan. 2009. 23 Jan. 2009. <http://www.treehugger.com/files/2009/01/the-acorn-house-unfolds.php>.

---. "On the Stands: Dwell's prefab issue." TreeHugger. 24 Dec. 2008. 6 Jan. 2009. <http://www.treehugger.com/files/2008/12/dwell-magazine-prefab.php>.

Bergdoll, Barry. Personal Interview. 25 Sep. 2008.

Bergdoll, Barry, and Peter Christensen. Home Delivery: fabricating the modern dwelling. New York: The Museum of Modern Art, 2008.

Birkbeck, David, and Andrew Scoones. Prefabulous Home: the new housebuilding agenda. London: Constructing Excellence, 2005.

Boerner, Heather. "Prefab 2.0: is prefab housing ready for primetime?" Conscious Choice. Sep. 2008. 5 Sep. 2008. <http://www.consciouschoice.com/2008/09/prefab0809.html>.

Branz. Home Page. 2 Sep. 2008. <http://www.branz.co.nz>.

BRE Innovation Park. Home Page. 14 Oct. 2008. <http://www.bre.co.uk/>.

Bright Built. "The Bright Built Manifesto." 13 Feb. 2009. <http://brightbuiltbarn.com/pdfs/BBB_press_kit_v3.2.pdf>.

Brown, David, ed. The Home House Project: the future of affordable housing. Cambridge: MIT Press, 2004.

Builder LivingHome. Overview. 6 Jan. 2009. <http://www.builderlivinghome.com/>.

The Building Exchange (BEX). Home Page. 16 Oct. 2008. <http://www.b-e-x.com/>.

Building Lab DK. Home Page. 9 Nov. 2008. <http://www.byggerietsinnovation.dk/>.

Buildoffsite. Buildoffsite Newsletter. London: Buildoffsite, May 2008.

Cannell, Michael. “Do We Really Need Architects?” FastCompany. 31 Mar. 2009. 2 Apr. 2009. $<$ http://www.fastcompany.com/blog/michael-cannell/>.

Clark, Keith. Personal Interview. 4 Feb. 2008.

Colomina, Beatriz. Domesticity at War. Cambridge (Mass.): MIT Press, 2007.

Commission for Architecture and the Built Environment. Design and Modern Methods of Construction. London: CABE, 2004.

--- (CABE). Home Page. 3 Sep. 2008. <http://www.cabe.org.uk/\#2>.

Construction Task Force. Rethinking Construction. London: UK Dept. Trade and Industry, 1998.

Craig, Anthony, Richard Laing and Martin Edge. The Social Acceptability of Prefabrication and Standardisation in Relation to New Housing. Proc. of $21^{\text {st }}$ Century: Cities, social life and sustainable development Conf., Paris: IAPS, 2000.

Davies, Colin. The Prefabricated Home. London: Reaktion Books, 2005.

Design for Manufacture Competition. 13 June 2009.

<http://www.designformanufacture.info/home.htm>. 
Foundation for Research, Science and Technology (FoRST). Current Funding Available. 20 May 2009. <http://www.frst.govt.nz/funding >.

Frame and Truss Manufacturers Association. Home Page. 15 July 2008. $<$ http://www.ftma.co.nz/>.

Free Green. Home Page. 8 Feb.2009. <http://www.freegreen.com/>.

Fuller, Louise. E-mail to the author. 2 Apr. 2009.

Gann, David. Building Innovation: complex constructs in a changing world. London: Thomas Telford, 2000.

Gibb, Alistair, and Martyn Pendlebury. "Glossary of Terms V1.3." Buildoffsite. July 2006. 11 Jan. 2008. <http://www.buildoffsite.co.uk/downloads_publications.htm\#glossary>.

Gibson, Lee. E-mail to the author. 10 Mar. 2009.

Global Innovation in Construction Conference (GIC). About. 15 May 2009. $<$ ttp://www.loughborough2009.org/index.php>.

Gorgolewski, M.T. "The Potential for Prefabrication in United Kingdom Housing to Improve Sustainability." Smart and Sustainable Built Environments. Ed.s J. Yang, P.S. Brandon, and A.C. Sidwell. Oxford: Blackwell, 2005. 121-128.

Hausbau. Sep/Oct. 2007.

Hay, Philippa. "Scholarships Update." E-mail to the author. 3 June 2009.

Insite 09. Home Page. 16 Feb. 2009. <http://www.insite09.com/>.

Jana, Reena. "Prefab Homes Get Fabulous." Business Week. 1 Nov. 2005. 24 Jan. 2008. <http://www.businessweek.com/innovate/content/oct2005/id20051026_962297.htm >.

Kelly, Burnham. The Prefabrication of Houses. New York: MIT Press and John Wiley and Sons, 1951.

Kenworthy, Andy. "A Fine Bach (of Students)." Home New Zealand Dec./Jan. 2008/9: 135.

Kieran, Stephen, and James Timberlake. Refabricating Architecture: how manufacturing methodologies are poised to transform building construction. New York: McGraw-Hill, 2004.

Kronenburg, Robert, ed. Portable Architecture: design and technology. 4th ed. Basel: Birkhauser, 2008.

Laing R., A Craig, and H. Edge. Prefabricated Housing: an assessment of cost, value and quality. Aberdeen: Robert Gordon UP, 2000.

Larsson, Nils. "Sustainable Construction." Sustainable Building 07, Auckland, Nov. 2007.

Le Corbusier. Towards a New Architecture. Trans. Frederick Etchells. London: Architectural Press, 1946. London: J.Rodker 1927.

Lifecycle Building Challenge. Home Page. 18 Jan. 2008. $<$ http://www.lifecyclebuilding.org/index.php>.

Ludeman, Chad. "Prefab Is Not the Answer to Affordable, Modern and Green Homes." Jetson Green. 16 Sep. 2008. 3 Feb. 2009. <www.jetsongreen.com/2008/09/prefab-is-not-t.html>.

Marmol Radziner Prefab (MRP). E-mail newsletter. 20 June 2009. 
McKenzie, Grant. Personal Interview. 22 Apr. 2008.

McShane, Owen. Personal Interview. 23 Jan. 2008.

Miller, Tim. Personal Interview. 11 Nov. 2008.

Modern Built Environment Knowledge Transfer Network (MBE KTN). Home Page. 18 Feb. 2009. <http://mbektn.globalwatchonline.com/epicentric_portal/site/mbektn/?mode=0>.

Modular Building Institute. About. 24 July 2008. <http://www.mbinet.org/htmlPage.aspx?name=about_mbi>.

Mtech Consult. Home Page. 19 Feb. 2009. <http://www.mtech-group.com/>.

National Modular Housing Council (NMHC). Home Page. 24 July 2008. $<$ http://www.modularcouncil.org/mc/ >.

Naumann, Stefan. "Mynewhome.com.au. Exploring New Ways of Delivering Architecture: creating a design interface for sustainable and affordable houses." Thesis. Melbourne: RMIT U., 2008.

New Zealand Wood. Home Page. 18 Feb. 2009. <http://www.nzwood.co.nz/>.

Ogden, Richard. Promoting Construction Offsite. London: Buildoffsite, 2008.

Open Prototype Initiative. Home Page. 12 May 2009. <http:www.openprototype.com/>.

Oxley III, David. "Role of Prefabricated Modular Housing Systems in Promoting Sustainable Housing Practices." Thesis. Melbourne: RMIT U., 2006.

Paevere, P., and C. MacKenzie. Emerging Technologies and Timber Products in Construction: literature review. Melbourne: Forest and Wood Products Research and Development Corp., 2006.

Page, lan. Study Report 183: Changing Housing Need. Wellington: BRANZ, 2007.

Pan, Wei, Alistair Gibb, and Andrew Dainty. Offsite Modern Methods of Construction in Housebuilding. Loughborough: Loughborough UP, 2005.

Pawley, Martin. Design Heroes: Buckminster Fuller. London: HarperCollins, 1990.

Ponoko. Home Page. 5 Feb. 2009. <http://www.ponoko.com/showroom>.

Precast New Zealand. Home Page. 15 Apr. 2009. <http://www.precastnz.org.nz/>.

Raymond, Camela. "Prefabulous." Portland Monthly. Dec. 2008. 6 Jan. 2009. <http://www.portlandmonthlymag.com/home-and-garden/articles/prefabulous/>.

"The Red Tape Chainsaw Massacre." The Dominion Post [Wellington]. 5 July 2008.

Revington, Mark. "Design?" Unlimited July (2006): 32-35.

Rewi, Adrienne. "Future Shock." New Zealand Home and Entertaining. Apr/May (2006): 46-49.

Rose, Ewen. "Off-Site Fabrication Boosted by Moves to Reduce Waste." H\&V News. 20 Nov. 2008. 6 Jan. 2009.

<http://www.hvnplus.co.uk/page.cfm/action=Archive/ArchivelD=4/EntrylD=1027 >. 
Royal Danish Academy of Fine Arts. CINARK. 9 Feb. 2009.

<http://www.karch.dk/cinark/Menu/Profil/CINARK+er+Center+for+Industriel+Arkitektur>.

Ruukki United Kingdom. "Prater and Ruukki Launch Off-Site Manufactured Solutions DVD." What's new in building (WNIBI). 3 Mar. 2008. 29 May 2008.

<http://www.ruukki.com/www/uk.nsf/O/A418AF9F25AFE922C2257516004541DF?Open Document\&lang $=1>$.

Rybczynski, Witold. "Living Smaller.” The Atlantic Monthly. Feb. 1991. 3 Mar. 2008. <http://www.theatlantic.com/issues/91feb/9102house.htm>.

Sass, Larry. Personal Interview. 25 Sep. 2008.

Scofield, Rosemary, and Suzanne Wilkinson. "Chapter 18: Offsite and Modern Methods of Construction." Management for the New Zealand Construction Industry. Auckland: Prentice Hall, 2009: proposed $2^{\text {nd }}$ edition.

Shaw, Louise. "A Woman's Place?" At Home in New Zealand: houses, history, people. Ed. Barbara Brookes. Wellington: Bridget Williams Books, 2000: 165-180.

Skilling, David. Preparing for the Future: emerging priorities for the New Zealand economy. Auckland: The New Zealand Institute, 2007.

Skinner, Robin. "Home Away: a State House in London." At Home in New Zealand: houses, history, people. Ed. Barbara Brookes. Wellington: Bridget Williams Books, 2000. 155-64.

Smith, Dakota. "Marmol Radziner Prefab Venice Home Can Be Yours." LA Curbed, 30 Jan. 2009. 2 Feb. 2009. <http://la.curbed.com/archives/2009/01/marmol_radziner_prefab_venice_ home_can_be_yours.php>.

Solar Decathlon. Home Page. 18 Jan. 2009. <http://www.solardecathlon.org/>.

Spunt, Alexandra. "A Few Words From a Legent.” Good. 4 Feb. 2009. 19 Feb. 2009. $<w w w . g o o d . i s / ? p=15095>$.

Stonyer, Heather. "Mainstreaming Sustainability in Building." Sustainable Buidling 07, Auckland, Nov. 2007.

Strachan, Dave. "Unitec." E-mail to the author. 13 Mar. 2009.

Studio 804. Home Page. 2 Feb. 2009. <http://www.studio804.com/>.

Trailer Wrap. About. 18 Jan. 2009. <http://www.trailerwrap.net/ >.

Treehugger. Home Page. 24 Apr. 2008. <http://www.treehugger.com/>.

Tuohy, Phil. Personal Interview. 13 May 2008.

Wallis, Rosemary, and Breon Gravatt. "R\&D Relief." Idealog. 19 Dec. 2007. 17 Apr. 2008. $<$ http://idealog.co.nz/workshop/rd-relief>.

"What's Holding Back the Real Breakthrough in Modular Housing?" House and Home 1971: 8699.

Whiting, Anna. "Research and Development Tax Relief Breakfast Briefing." E-mail to the author. 31 Mar. 2009. 


\section{Chapter 8 : What Now?}

Alter, Lloyd. "Thoughts on Clayton's I-House." TreeHugger. 10 Jan. 2009. 13 Jan. 2009. <http://www.treehugger.com/files/2009/01/clayton-ihome-design.php>.

Arieff, Allison. E-mail to the author. 3 May 2008.

Bahamon, Alejandro, ed. Prefab: adaptable, modular, dismountable, light, mobile architecture. New York: HarperCollins, 2002.

Bates, Susan, and Chris Kane. The Future of Housing in New Zealand. Wellington: CHRANZ and Building Research, 2005.

Bengtsson ?, Rachael Hargreaves, and lan Page. Assessment of the Need to Adapt Houses to Climate Change in New Zealand. Wellington: Building Research, 2007.

Buchanan, Michael. Prefab Home. Salt Lake City: Gibbs Smith, 2004.

Clark, Keith. Personal Interview. 4 Feb. 2008.

Construction Task Force. Rethinking Construction. London: UK Dept. Trade and Industry, 1998.

Cook, lan. "Why Off-Site Is the Future for Construction." Building the Future (Times supplement). 27 July 2007. 12.

Craig, A., R. Laing and H.Edge. The Social Acceptability of Prefabrication and Standardisation in Relation to New Housing. Proc. of $21^{\text {st }}$ Century: Cities, social life and sustainable development Conf., Paris: IAPS, 2000.

Davies, Colin. The Prefabricated Home. London: Reaktion Books, 2005.

Frame, Bob, Rhys Taylor and Kate Delaney. Four Futures for New Zealand. Wellington: Landcare Research, 2005.

Gann, David. Building Innovation: complex constructs in a changing world. London: Thomas Telford, 2000.

Gauzin-Muller, Dominique. Sustainable Living. Basel: Birkhauser, 2006.

Gibson, Anne. "New Zealand Workers Catching the Wall Street Blues." NZ Herald, 17 Oct 2009 17 Oct. 2009.

<http://www.nzherald.co.nz/unemployment/news/article.cfm?c_id=353\&objectid=10537900>.

Giess, Juergen. Personal Interview. 2 May 2008.

Glass, Dr. Jacqueline. The Future for Precast Concrete in Low-Rise Housing. Leicester: British Precast Concrete Foundation, 2000.

Goodier, Chris, and Alistair Gibb. "Future Opportunities for Offsite in the UK." Construction Management and Economics 25.6 (2007): 585-95.

Hall, Kris. "Output Rockets as 'Apollo' Launched.” Stuff. 15 June 2009. 15 June 2009. <http://www.stuff.co.nz/business/industries/2499761/Output-rockets-as-Apollo-launched>.

Hansford, David. "You Are Not Alone." Listener 15 Dec. 2007: 51.

Hawthorne, Christopher. "Green Prefab Firm Michelle Kaufmann Designs is Closing." LA Times, 26 May 2009. 26 May 2009. <http://latimesblogs.latimes.com/culturemonster/2009/05/greenprefab-firm-michelle-kaufmann-designs-is-closing.html>. 
---. "Prefab Movement Needs to Rethink its Model." LA Times, 13 June 2009. 15 June 2009. $<$ http://www.latimes.com/entertainment/news/arts/la-et-notebook132009jun13,0,7155108.story>.

Jana, Reena. "Prefab Homes Get Fabulous." Business Week. 1 Nov. 2005. 24 Jan. 2008. <http://www.businessweek.com/innovate/content/oct2005/id20051026_962297.htm >.

Kelly, Burnham. The Prefabrication of Houses. New York: MIT Press and John Wiley and Sons, 1951.

Kieran, Stephen, and James Timberlake. Refabricating Architecture: how manufacturing methodologies are poised to transform building construction. New York: McGraw-Hill, 2004.

McShane, Owen. Personal interview. 23 Jan. 2008.

Mellor, Robert. "Outlook for New Zealand Building and Construction to 2011/12.". NZ Building and Construction Forecast, Auckland: BIS Shrapnel. 24 Feb. 2009.

Pawley, Martin. Design Heroes: Buckminster Fuller. London: HarperCollins, 1990.

Rybczynski, Witold. "Home Delivery: fabricating the modern dwelling." Journal of Society of Architectural Historians 68.2 (2009): 254-6.

Skilling, David. Preparing for the Future: emerging priorities for the New Zealand economy. Auckland: The New Zealand Institute, 2007.

Steffen, Alex, ed. Worldchanging: a user's guide for the $21^{\text {st }}$ century. New York: Abrams, 2006.

Welch, Dallas. "Building Consents Issued: October 2008." Department of Statistics New Zealand. 28 Nov. 2008. 13 Jan. 2009. <http://www.stats.govt.nz/store/2008/11/buildingconsents-issued-oct08-mr.htm>.

Wong, Peter. "Industrialised Building Systems: with specific reference to the domestic sector of the New Zealand building industry." Report. Victoria U. of Wellington, 1980. 
Chapter 9 : Conclusions

Scofield, Rosemary. E-mail to the author. 18 May 2009. 
KIWI PREFAB 


\section{Appendix A}

\section{Interview Questions: Prefabricated Housing Industry Participants}

All interviews followed this question format, whether in-person, on the phone or by e-mail. The interviews were then transcribed (refer to Appendix B) and written as case studies (refer to Appendix C). Information from case studies is presented in the thesis body in the background and case study sections (refer to Chapters 2, 3, 4 and 5).

1. Please explain about how your prefabricated product / housing started:
a. Who
b. Where
c. When
d. How
e. Why

2. Please mention any key historical events (such as social, economic or political) that have had a major influence on the design and / or construction of your product / housing.

3. Please describe the type of prefabrication used in the design and / or construction of your product / housing.

4. What are the key benefits, or merits, of your product / housing?

5. What are the issues, or challenges, that your product / housing faces?

6. Can you recommend any key people, articles, or books about prefabrication in this country?

7. What are your thoughts on the role of prefabrication in your company's future?

8. How do you think we can best influence people (consumers, architecture/design profession, and construction industry) about the benefits of prefabrication?

9. Please comment on the current communication channels within the prefabrication industry (in New Zealand) - what would be your suggestions for improvements.

10. Would you be available to meet face-to-face at a time that suits you in the next few months, and would it be possible to visit your factory? 


\section{Appendix B}

\section{List of Industry Participants}

The input of all industry participants is gratefully acknowledged. Participants signed confidentiality waivers in accordance with Victoria University of Wellington Ethics Committee guidelines. They sighted and confirmed information in transcripts before case studies were written (refer to Chapters 2, 3, 4 and 5). The author can be contacted for access to interview transcripts.

Interview participants, work-place and location of interview:

Bergdoll, Barry

Brown, Cheryl

Cassels, Ian

Clark, Keith

De Geest, Brian

Eli, Jay

Fleetwood, Roy

Frost, Tony

Gardyne, Stuart

Gauthier, Douglas

Gerrard, Christine

Gerrard, Graeme

Gibbs, Bernie

Gibson, Rod

Giesen, William

Giess, Juergen

Giliane, Patrick

Glenn, Steve

Hawke, Rocky

Hay, Roger

Heere, Martin

Hodgskin, Andre

Hossack, Glenn

Kaufmann, Michelle
Museum of Modern Art, New York

Kodesign Builders, New Plymouth

The Wellington Company, Wellington

Industrialised Building Systems, Auckland

De Geest Construction, Oamaru

Empyrean, Los Angeles

Victoria University of Wellington, Wellington

HABODE IP, Nelson

Arhitecture +, Wellington

Gauthier Architects, New York

Droploc Building System, Opotiki

Droploc Building System, Opotiki

Pinecone Timber Buildings, Wellington

HABODE IP, Wellington

Atelier Workshop, Wellington

Conecta, Rotorua

Empyrean, Los Angeles

LivingHomes, Los Angeles

Kodesign Builders, New Plymouth

Industrialised Building Systems, Wellington

Tristyle / Timber Construction Solutions, Awanui

Architex, Auckland

Carters Manufacturing, Rotorua

Michelle Kaufmann Designs, Los Angeles 


\begin{tabular}{|c|c|}
\hline Keys, Jan & McRaeway Homes, Timaru \\
\hline Kirby, Alan & Cement and Concrete Association, Wellington \\
\hline Labone, Ray & Brand consultant, Wellington \\
\hline Laing, Grant & Laing Homes, Christchurch \\
\hline Lamb, Adrien & HABODE IP, Nelson \\
\hline Leach, Adam & Cement and Concrete Association, Wellington \\
\hline Levy, Jared & Marmol Radziner Prefab, Los Angeles \\
\hline Lockwood, John & Modulock / Lanwood Industries, Palmerston North \\
\hline Lovie, Del & Pod, Wellington \\
\hline Marmol, Leo & Marmol Radziner Prefab, Los Angeles \\
\hline McCaul, Hamish & Alpinehaus, Dunedin \\
\hline McKenzie, Grant & Replica Architects, Christchurch \\
\hline McShane, Owen & Industrialised Building Systems, Auckland \\
\hline Melhuish, John & Herriot and Melhuish Architecture, Wellington \\
\hline Novak, Evzen & Studio Pacific Architecture, Wellington \\
\hline Parker, Jeff & Lockwood Group, Rotorua \\
\hline Parrant, Lloyd & Juken New Zealand, Kaitaia \\
\hline Radziner, Ron & Marmol Radziner Prefab, Los Angeles \\
\hline Richardson, John & Juken New Zealand, Kaitaia \\
\hline Sass, Larry & Massachusetts Institute of Technology, New York \\
\hline Semenoff, Chippie & Juken New Zealand, Kaitaia \\
\hline Siegal, Jennifer & Office of Mobile Design, Los Angeles \\
\hline Stewart, lan & Durapanel Systems, Awanui \\
\hline Sylvester, Michael & Dwell Magazine / Fabprefab.com, Los Angeles \\
\hline Timberlake, James & KieranTimberlake, New York \\
\hline Tipa, Matt & McRaeway Homes, Timaru \\
\hline Thorn, Clem & Pinecone Timber Buildings, Wellington \\
\hline Tuohy, Phil & Tuohy Lockwood, Wellington \\
\hline Turner, Colin & Tristyle / Timber Construction Solutions, Awanui \\
\hline Walker, Roger & Vintage Homes / Pod / Strawberry Homes, Wellir \\
\hline
\end{tabular}


Further contributing participants, area of expertise and place of residence:

Albert, John

Arieff, Allison

Beavis, Colin

Bennett, Paul

Biddle, Anna

Boniface, Grant

Caulfield, Gary

Dawson, Mark

Freeman, Alan

Gaiardo, Paul

Gibb, Alistair

Gjerde, Morten

Hartley, Alan

Hay, David

Hill, Nick

Hunt, Gavin

Hunt, Graeme

Isaacs, Nigel

Keith-Brown, Judi

Kinsella, Fleur

Knight, Tony

Mace, Tania

McCarthy, Christine

McCaw, Nick

McGowan, Denis

Millington, Gary

Mountier, Mary

Neilson, Dorothy

Pankhurst, Jeremy
New Zealand Institute of Architects, Auckland

Prefabrication Expert, Los Angeles

Wilco Precast, Auckland

Housing New Zealand, Wellington

Australian Prefabricated Housing, Melbourne

Urenui bach, Auckland

Stanley Modular, Matamata

Architects Homes, Auckland

Thermomass, Christchurch

Pryda, Auckland

Offsite / Prefabrication Expert, Loughborough

Concrete Housing, Wellington

Strawberry Homes, Wellington

Keith Hay Homes, Auckland

Quick Living by Module Creative, Christchurch

Beazley Homes, Auckland

Mitek, Auckland

Colonial Housing, Wellington

Architect, Wellington

Hydro Scheme Housing, Wanaka

Light Modular Construction, Wanganui

Government Housing, Wellington

Government Experimental Housing, Wellington

Hotel SO, Christchurch

Light Modular Construction, Wanganui

Haven New Zealand, Auckland

Designscape Magazine, Waikanae

Fletcher Building Archives, Auckland

Quick Living by Module Creative, Christchurch 
Potangaroa, Regan

Rozbicki, Richard

Salisbury, Jeff

Savage, Melissa

Schrader, Ben

Scofield, Rosemary

Sheerin, Bruce

Smith, Jack

Strachen, Dave

Taylor, Matt

Toomath, William

Whiting, Anna

Wilkinson, Suzanne

Wilson, Ross
Unitec, Auckland

Carters Manufacturing, Tauranga

Bach2go, New Plymouth

MAXIM Panel, Huntly

State Housing, Wellington

Composite Structural Assemblies / Heavy Engineering Research Association, Auckland

Ministry of Education relocatables, Wellington

Architectural Historian, Rotorua

Unitec and EcoSmart series, Auckland

'e-homes' by Maddrens, Auckland

Colonial Housing, Wellington

Buildoffsite, London

Composite Structural Assemblies / University of Auckland Engineering, Auckland

Beazley, Auckland 


\section{Appendix C}

\section{Sample Interview Transcript: Keith Clark, Industrialised Building Systems (IBS)}

This is an example of an interview transcript, as written by the author, for verification by the interviewee. Subject matter is loosely grouped in question order, rather than according to when discussed during the interview.

\section{Conversation with Pamela Bell, Mission Bay, Auckland (4 February 2008)}

\section{Before IBS:}

- $\quad$ Best Bilt Homes, 1960s, Palmerston North -

- empowered (gave credits) to homeowners who did their own painting, electrical etc.

- sold off plan books with a set price (plus upgrade packages, 'up-selling', which were always used!)

- offered extra square footage at a cheap price (pound 1.50 per extra sq ft), instead of changes to design or fitting in appliances - such as eye-level oven (which was more expensive)

- gave homeowners free carpet if their home was used for 2 weekends as a showhome (great marketing)

- designed for future alterations - pre-framed in a lintel (or left stud out) so that the home-owner could put in their own double-doors and decks etc.

- also participated in "Parade of Homes"

$\circ$ and did own mini-parade, with 2 standard homes and 2 architect-designed homes (design mainly in custom window joinery), but it was hard to sell the architectdesigned homes because of the higher price (but they always re-sold at a better value and frequency, was just the initial sale which was difficult - interesting !)

- sold to low- and medium- income earners - many low-income earners and benefit recipients (who capitalized their benefits, which was possible at that time)

- didn't do 'extras' - garages, fences, paths (KC thinks people have become too obsessed with these extras and they should be doing them themselves in order to save money)

- provided affordable homes through use of cheaper claddings, such as cement board

- dabbled in 'social engineering' in terms of suburb development, and home placement for young people

- Turangi homes - asked to supply, along with Beazley and Keith Hay homes (re: transporting houses to site)

- KC built Totara Park, Wellington, with a business partner - 1100 sections and a bridge over the river

- USA visit to National Homebuilders Association in 1960s

IBS story:

- IBS Highlights:

- IBS received interest from Australian government, but a change of government put an end to that relationship

- New Zealander Ashley Rush (Carpenters and Related Trade Union) decided to take manufactured housing trades under his wing

- Bob Hawke was Trade Union leader in Australia, and was consulted together with the Secretary of Housing

- IBS received instructions to build 300 houses for the Victoria Housing Commission using the redundant premises of the Commonwealth Aircraft Corporation

- NZ govt took some ownership of IBS $-25 \%$ late 1970 s

- Appointed 2 directors, including Sir Ronald Scott (KC suggested contacting him - possibly at Chatswood, Silverstream)

- Land purchased at Rangiora to build a factory and plans drawn up 
- Ready to build the factory and go into production on government land in new Christchurch suburb of Rolleston

- But govt changed and deal fell through

- "The system was taken to Queensland by Barry Beasley then exported manufactured housing to various parts of the world." (KC letter 5 March 2008)

- Dan Reidel used the system to rebuild decaying parts of the Bronx by the New York Housing Commission. (KC letter 5 March 2008)

- US connection:

- NZ market size limiting, hence contact with Dan Reidel, of Dayton Ohio, whizzkid of manufactured housing

- Chicago marketers - Elrick and Lavidge

- IBS publicity:

- Mary Mountier, Wellington - editor of Designscape magazine in late 60s / early 70s IBS demise:

Roger Donaldson film (PB to check Archives)

- due to funding from land development business drying up (due to interest rates doubling and sales halving)

- After collapse, Sam Wright came out from Ohio, US, and was interested to learn from IBS's mistakes - he advocated the service core designs and methodology

- After collapse, Barry Beazley and his son took the IBS files and adopted many aspects of the system (but used steel structure instead of timber)

- Business and personal bankruptcy had implications for personal lives and family very difficult and contributed to break-down of marital relationship for KC

Thoughts on future of prefabrication:

- cost:

- financiers and marketers need to be in place at the beginning

- need flat roof for affordability and transportability, but concerned about cultural acceptance $-\mathrm{KC}$ thinks consumers were more discerning and conservative in 1960 s/70s, and that it wouldn't be a problem today

- idea of dealing with the poorest people, by giving them the item they can't build themselves (hence, service core)

- service core:

$\circ$ as suggested by Sam Wright (Ohio, US)

- utilizing strength of Ribsel TM flooring (therefore able to reduce number of piles)

$\circ \quad$ in combination with 'air rooms' $(\mathrm{KC})$

$\circ$ only make service core in factory

- let suppliers compete to provide appliance packages (and pay to store their appliances in the factory, so that they are accessible on demand - or can use containers of supplies dropped to corresponding points on assembly line)

- in conjunction with industry (such as Fisher and Paykel)

- use wiring loom and switch-plates for 'air rooms'

- rectangular design:

- shub and WC

- laundry and WC

- HWC Bakelite

- Open-ended kitchen

- End braced for transport

- service core as structure, on set foundations, other walls to be built off it (ME: perhaps panelized, kitset, DIY)

off-the-shelf:

- all other fittings to come off-the-shelf, none which are patented, or specially designed components

therefore, savings:

$\circ$ minimum of $25 \%$ cost savings on completed house on site ("this figure we can confirm beyond doubt" according to $\mathrm{KC}$ ) from providing service core module with air-rooms,

$\circ$ together with $25 \%$ off land costs (through revisiting consent processes - a job for OM !)

- compared with govt 'modal' - a hypothetical house for comparison purposes 
- but identified challenge of traditional valuation of property by square metre - in order for value per sq $\mathrm{m}$ to match the new cost (ie. $75 \%$ of modal), therefore $\mathrm{KC}$ would "gift" $25 \%$ deposit in order to be able to deliver a house at a lower cost - "A valuer values the modal house at say $\$ 15,000$. We receive the money from the lender after final inspection and pay the occupant family $\$ 37,500$ for the deposit. The land would be treated in exactly the same way." (KC letter 5 March 2008)

- would only work if govt agreed to provide $25 \%$ less on land value (ie. house and land values must be discounted by same amount in order to make it work...)

Other thoughts:

- 'Listener' article on low-cost housing by Roger Hay

- Eastern Europe is (or will be) in need of a refurbishment method... 


\section{Appendix D}

\section{Sample Case Study: Industrialised Building Systems (IBS)}

This is an example of a first draft case study after interview transcripts have been compiled and before editing to a sufficiently small size for inclusion in the case study research chapters (refer to Chapters 2, 3, 4 and 5).

\section{IBS story industrialised building is a system that rationalises the construction industry into a form of factory production... but to see buildings as consumer products requires a conscious shift of vision (Mountier "IBS: an idea whose time has come" np).}

Research into a New Zealand prefabricated house building system began in the late 1960s under the leadership of visionary Palmerston North property developer Keith Clark. His successful company, Best Bilt Homes (BBH), used a combination of set prices from an architectural plan book of 10-12 houses, together with cheaper outer suburban land and efficient planning of labour resources, in order to produce some of the lowest cost houses in the country at that time.

The key to affordability was in Clark's reduction of down-time on site. He did this by carefully allocating labour resources, and in organising material supplies so there were no hold-ups. Also, BBH didn't do 'extras' such as garages, fences and paths. The homeowners could do these themselves at a later date when they could afford them. Clark empowered homeowners who did their own painting or electrical work by giving financial credits. Affordability was further improved through the use of cheaper claddings, such as cement board instead of solid timber weatherboards. The BBH homes were designed for adaptability and to enable future alterations. Pre-framed lintels and left-out studs within the walls enabled the home-owner to perform their own personalisation through installing double-doors or decks.

Keith Clark had a good awareness of marketing, and gave homeowners free carpet if their home was used for two consecutive weekends as a show-home. BBH also participated in a local 'Parade of Homes' where show-homes were open to the public and provided the opportunity for prospective homeowners to 'try before you buy'.

Sometime in the 1960s BBH was invited by the government to build the Turangi hydro powerstation village along with other Bay of Plenty developers such as Beazley and Keith Hay Homes. Some experimentation into pre-built and transportable homes was carried out, but they proved to be too costly. This was because of the narrow and windy Rangitikei River Road between Turangi and the Bay of Plenty which meant the houses had to be disassembled for transport and re-assembled on site. Today the road is wider and straightened so it would be possible to carry larger modular sections intact.

The seed of Industrialised Building Systems (IBS) was sown. When Clark met Owen McShane at the Planning Department of Auckland City Council, he suggested contacting architects Bill Wilson and Ivan Juriss. Clark went on to engage Bill Wilson, a rational, highly sensitive and brilliant thinker. But tragically Wilson died of a heart attack at a surprisingly young age, tragically on the way to their first meeting. It took six months for Clark to persuade Juriss to take on the design of the prefabricated house system.

Once he had agreed, Clark, Juriss and McShane went on a three month research trip to the United States to observe businesses in the mobile home industry. This trip was crucial in providing a model for the foundation of their housing system. But it is here, that their eventual downfall first hinged. According to IBS member Roger Hay, this research trip was focussed on single businesses, rather than an overall view of how the industry operated as a system. The United States model operated as a cash business, without the need for traditional housing loans. House models were sold from a sales yard supported by dealers who held the stock and carried the financial risk. The industry was sustained by a continuous supply of homes and in turn sub-contracting and appliance industry suppliers gave excellent support. The consumer 
market was attracted to the low cost of rental land at mobile home parks, and very low cost homes with easy financing terms, essentially a hire purchase arrangement. There was also the convenience of having a house delivered from the sales yard complete with furniture and fittings within 24 hours. Clark wanted to emulate this model, but he was intent on a higher design quality, in an effort to avoid the social 'ghettos' which the United States mobile home industry was creating.

\section{IBS people}

Keith Clark assembled a very well qualified team to head the research and development of Industrialised Building Systems. This research is based on first-hand interviews with members of the IBS team, including Keith Clark (Managing Director), Ivan Juriss (Architect), Owen McShane (Research Programme Coordinator), and Roger Hay (Building Components). Ivan Juriss was one of original members of Group Construction Company (not Group Architects) with Bill Wilson, where his interest in low-cost housing developed. According to Roger Hay, Wilson and Juriss had previously experimented with a low-cost wall panel in a Green Bay house for architect Tyl Von Randow. The wall panel was a $900 \mathrm{~mm}$ factory-made structural panel. They were also influenced by the work of Richard Buckminster Fuller, as were many architects of the time.

Roger Hay, now based in Wellington, had a Design Research architect role in IBS and wrote the system specification, standards and patents. He had previously designed the standard window JMS joinery system for Jasmad. Following the demise of IBS he worked with Standards to reform building codes. Hay has an enduring passion for delivering a lower-cost house through factory production, and is considering a Doctorate research in this area. According to Roger Hay, the IBS team planned for three separate consortia in NZ and six in Australia covering manufacture, distribution, financing and land development. Each factory was forecast to produce up to 800,000 square feet of building per shift year; an astonishing 1200 homes per annum, or 25 per week (Mountier "IBS" 16).

Owen McShane led the research team. He brought experience from his US Masters in City and Regional Planning, together with experience from Auckland City Council urban renewal programme. He also shared an interest in the mobile home industry.

Tom Townson was a boat builder and joiner by trade who had previously developed a system of prefabrication and set up production in Wellington for the Housing Division of the Ministry of Works. Other key people included landscape designer Harry Turbot, first Maori engineer Harold Wallace, architectural researcher and materials tester Andrew Goodfellow, industrial designer Charles Marks, and architect Keith Hay (employee of Wilson and Juriss, not the Keith Hay associated with Keith Hay Homes).

\section{IBS system}

This method of house building was one of the most revolutionary ever undertaken in New Zealand: it involved the complete construction of houses in the factory, furnished if required, ready simply to be transported to a prepared site. Of modular construction, the IBS house could be added to or subtracted from with minimal disturbance. The company even envisaged developing a second-hand room trade, rather like the used car business. In fact the essence of IBS was its concept of a house as another product, with similar standards of manufacture and after-sales service common to reputable consumer goods makers (Mountier "100 issues" 28-30).

\section{Modular}

Ivan Juriss came up with the original late 1960s home plan on the plane back from the United States research trip. The design was linear, consisting of Bedroom, Bedroom, Bathroom / Kitchen, and Living. Modular construction was in light steel angle frame on a removable trailer, with asbestos cladding used up to 1971. He also designed a two-storey option with the basic home plan modules set at 90degrees to each other, and with a carport underneath. But this iteration "never saw the light of day... [which was the] biggest missed opportunity" according to Roger Hay.

According to Juriss, the IBS design was a sophisticated and "quite extraordinary" construction system, which offered options for multiple changes to be made. Unfortunately, in his eyes, this modular approach made it too expensive. The IBS team designed specifically for the mandate 
that "buildings must be able to be altered at will to meet varying needs - by adding, subtracting or removing altogether". They designed a system of 25 basic modules with connecting units and interchangeable components leading to over 1000 different permutations (Mountier "IBS: an idea whose time has come" np). IBS used model blocks to communicate this idea to the potential homeowner. Each model was a room module. These room modules were sized according to particle board $3.6 \times 1.8 \mathrm{~m}$ dimensions. Juriss developed a 'link' system between room modules. The central module $(7.2 \times 3.6 \mathrm{~m})$ contained the kitchen and laundry module, and other modules for living and bedrooms were attached to this.

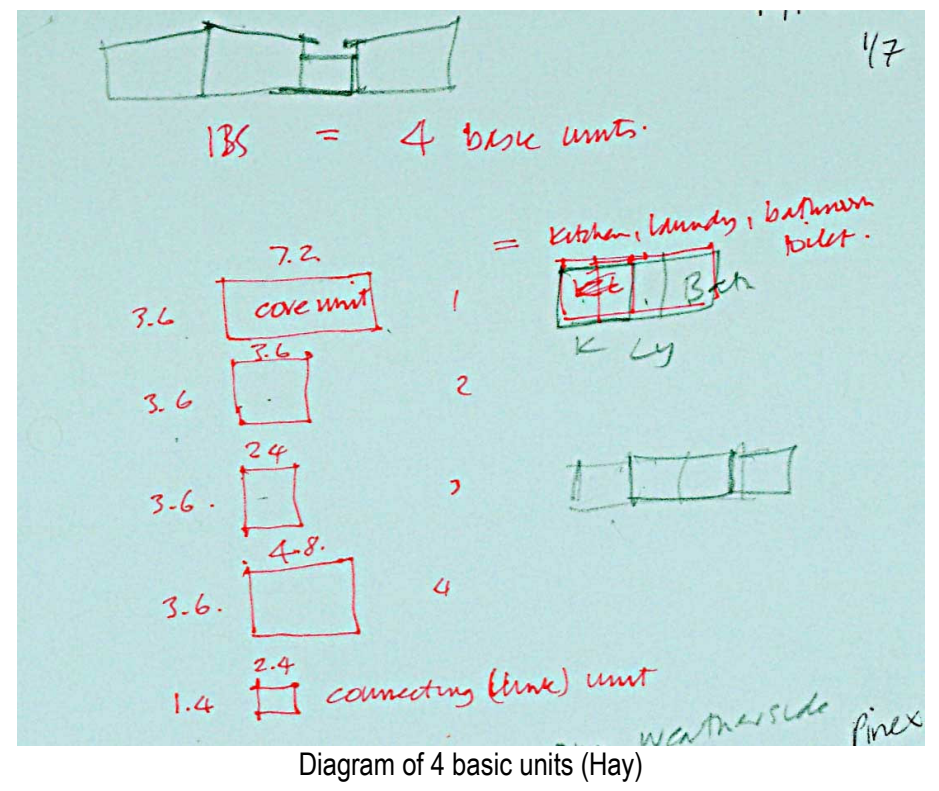

\section{Modular thinking}

The idea of room modules was unique to IBS, which enabled rooms to be sold and purchased separately. Ultimately, the idea was that "parts can be re-sold back to the factory, additional ones bought, and worn out ones replaced" (Mountier "IBS: an idea whose time has come" np). But the major downfalls in the modular system were that the jointing system was too clumsy and the electrical wiring system didn't connect easily on site.

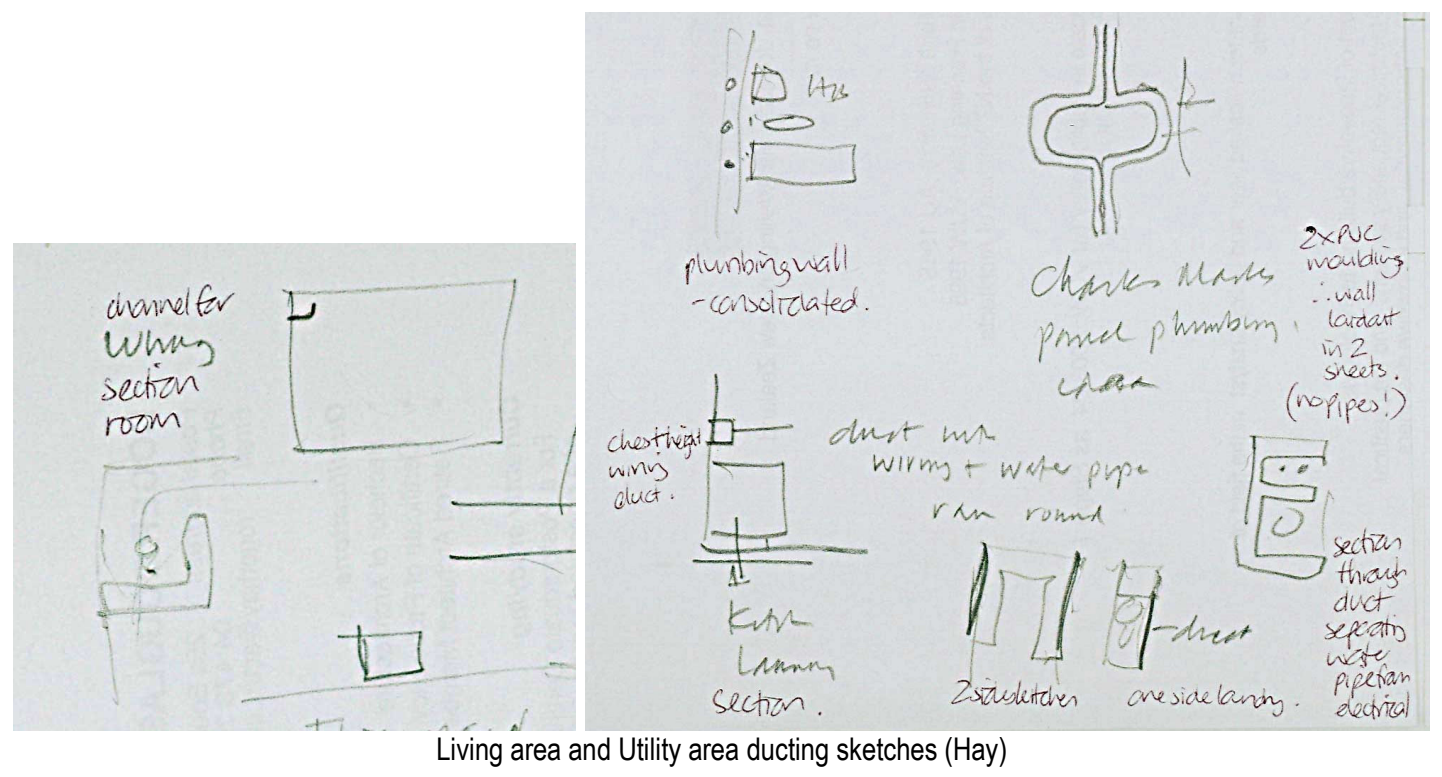

The modular system utilised prefabricated kitchens, bathrooms, and laundries, complete with appliances and fittings such as fibreglass bath and shower units. They also planned to offer a wide flexibility in interior finishings. Purchasers would be able to buy just the shell, or they could buy a fully equipped and furnished house with all furniture, floor coverings, linen, cutlery, 
crockery and curtains supplied (Mountier "IBS" 6). Beautifully detailed floor-to-ceiling built-in timber joinery was an option for bedrooms and dining areas.

\section{Construction}

The wall construction system consisted of a three-layer stressed-skin sandwich panel system, together with a specialised jointing system. The sandwich consisted of two layers of $5 \mathrm{~mm}$ hardboard, with $3 \times 12 \mathrm{~mm}$ Pinex softboard contained within, and was based on $2.4 \times 1.2 \mathrm{~m}$ sheets. Roger Hay joined IBS and developed this wall panel system with hollow jointing to carry wiring and a hollow connecting cornice. Hay and Andrew Goodfellow wrote the performance specification for these wall panels, which were subsequently supplied by Forest Products (Carter Holt Harvey, $\mathrm{CHH}$ ).

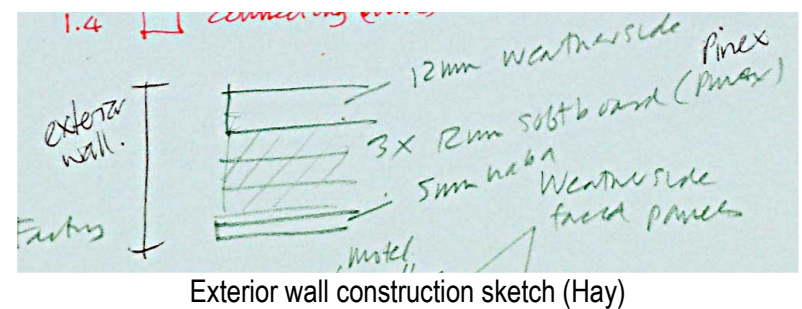

In order to provide a strong and precise platform which would withstand the stresses of loading, travel and installation, a rigid floor panel was developed. Boat builder Tom Townson developed an egg-crate system for boat decks, and suggested a cellular stressed-skin panel for the flooring. The floor panel module was based on particle board sizing of $3.6 \times 1.8 \mathrm{~m}$. The cellular panel was tested by Andrew Goodfellow and engineer Harold Wallace through loading a supported panel with a large full water tank. The panel responded with no buckling at all, and exceeded all expectations. Trademarked Ribsel and patented by Hay around 1975, this invention was a key to the dimensional accuracy of the overall system (Mountier "IBS" 9).

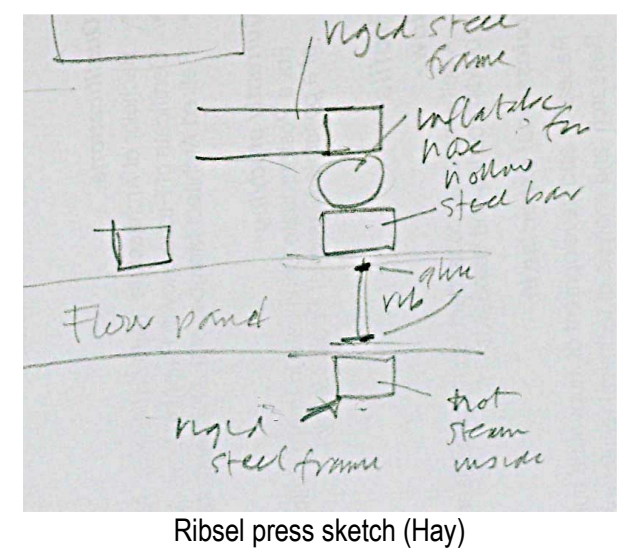

\section{IBS houses}

According to Mountier, "in 1972 a 1400 square foot family house, a motel unit and a weekend home were built in the IBS factory at Avondale" ("IBS" 5). The Avondale site houses showhomes, the design office and the factory. IBS went on to build four residential buildings, including two in Ohio, United States. The original Demonstration House from the Avondale site was relocated to Green Bay, Titirangi, Auckland. It has since been converted with a mismatched entrance, not by IBS. The Forest Products Weatherside exterior has experienced some material failure, due to the medium density fibre (MDF) panel not being sufficiently weatherproofed on its rear face. Subsequently, the lower edge of the cladding has absorbed water and turned it to 'weetbix'. The original Demonstration Unit, or Holiday Home, from the Avondale site had a plywood exterior, and was relocated to a site in Titrangi, Auckland. The original Motel Unit was the IBS design office at the Avondale site. It was made using Weatherside exterior panels, and has since disappeared. 


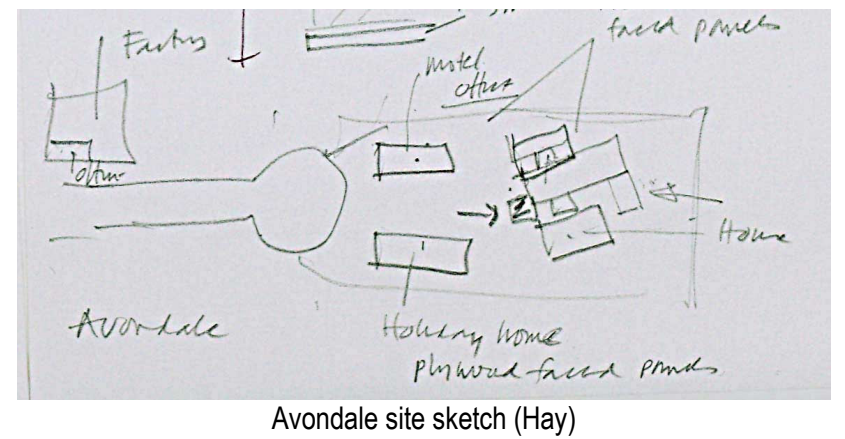

The IBS interiors were deliberately played down, neutral, and had a "slightly space-age, efficient feel" to the work areas. The three innovative bathroom designs each consisted of one-piece composite fibreglass moulds, custom-designed for home, holiday and motel applications. The motel bathroom was described as "a model of compactness and completeness, well suited to the needs of short term occupants, and of cleaning staff" (Mountier "IBS" 13).

Optional extras were planned to eventually be included, such as pergolas, balconies, paved terraces and landscaping, all in kitset form (Mountier "IBS" 6). Furthermore, IBS planned to build large retirement villages in community parks, as based on the US manufactured home park, and even presented a design for proposed resort park in Waikanae (Mountier "IBS: an idea whose time has come" np).

\section{IBS Highlights}

- IBS was instructed to build 300 houses for Australia's Victoria Housing Commission using the redundant premises of the Commonwealth Aircraft Corporation, but a change of government put an end to that relationship before work could get started (Clark, Letter).

- According to Roger Hay, the Australian Federal Government wanted to do a low-cost housing scheme for the Victorian Housing Commission using the IBS system. Eventually they decided to tackle it themselves and houses were supplied by BHP steel who copied the Russian stackable concrete box system. This was despite IBS being held up as a single-storey precedent.

- Ansett Airways expressed interest in IBS-designed Ansett houses. Roger Hay and marketing manager Peter Debreceny did an Australian cost comparison which showed they could be delivered at $12 \%$ below market costings, but the product was deemed by Ansett to be "too unconventional" (Hay, Interview, 25 Jan. 2008).

- United States Manufactured Homes Association showed a strong interest in the system, but Chicago marketing consultants Elrick and Lavidge did a consumer market survey which showed that conservative North Carolinians showed a preference for pitched roofs (Hay, Interview, 25 Jan. 2008).

- The Californian market was thought to be fertile ground for a less conventional house as its climate is closer to New Zealand's. Chicago marketing consultants Elrick and Lavidge advised that a low-cost house solution wouldn't work when land prices were so high (Hay, Interview, 25 Jan. 2008).

- According to Clark, the New Zealand government took a 25\% ownership of IBS Homes Development Ltd in the late 1970s. Two directors were appointed including Sir Ronald Scott. Land was purchased at Rangiora to build a factory and plans were drawn up by IBS. They were ready to build the factory and go into production for houses on government land in the new Christchurch suburb of Rolleston, when the government changed and the deal fell through.

- IBS publicity included articles written by Mary Mountier for New Zealand architecture and design magazine Designscape in the late 1960s and early 1970s. She also wrote for British Design magazine which featured IBS amongst ' 10 best projects of the year' in a three-page feature. According to IBS members, Peter Debreceny organised a film by Roger Donaldson on IBS.

- According to Keith Clark, Dan Reidel used the IBS system to rebuild decaying parts of the Bronx for the New York Housing Commission.

- After IBS's demise, "the system was taken to Queensland by Barry Beasley [who] then exported manufactured housing to various parts of the world" (Clark, Letter). 


\section{XIBIS (1978)}

Stage Two of IBS was the creation of Xibis (pronounced Zy-biss). The house was based on Keith Hay's two-storey model, and able to be built and delivered to site within two weeks. It consisted of ground floor modules, with roof panels installed on site to create the second storey. According to Roger Hay, four houses were built under factory management by Colin Zeff. The Keith Hay-designed model was built as a demonstration house in Manurewa, and in Napier for a family who won the house as a prize on the TV show "It's in the bag". Two houses designed by Andrew Goodfellow were built for Housing New Zealand in North Harbour.

...the two-storey houses were designed for the 'house' image wanted in the North Carolina startup market... but of course were never built there. Of course, once the IBS system went 'twostorey' it lost the 'add-on rooms, take-off rooms' facility that was the major idea that made the IBS system so attractive to the American Manufactured Housing industry. It also required the top storey to be assembled on-site, so also losing the whole point of the 'factory-made, finished and furnished' room modules, which was IBS's major evolutionary step from the mobile home industry (Hay, E-mail).

More Xibis houses were planned for production in the USA. In 1978, Mary Mountier wrote: Latest information is that with American backing, a streamlined marketing system, modified designs to suit USA conditions, and a new name (Xibis), production is now under way there, with a planned 70,000 units per year (30).

But these full-production plans never came to fruition.

\section{IBS's demise}

IBS ultimately folded in 1978 as a result of the 1970s recession when the funding from land development that was driving the research and development gradually dried up. By this stage interest rates had doubled and sales had halved. Also, the core IBS team had grown, and there were too many opinions, inputs and changes afloat. According to Ivan Juriss, there were "too many fingers in the pie". This dilution threatened to bring the design "back to the State House", away from its innovative roots.

Hay identifies "the North Carolina effect" as being partly responsible for this dilution. This United States subsidiary was partly responsible for the development of Xibis and the Keith Haydesigned two-storey house. Hay says this was decorated with 'romantic frippery' (dormer windows and a balcony) which was impossible to manufacture in a factory, and so went against IBS' initial setup premise of factory-production.

IBS went down in a blaze of glory to the tune of almost \$2.2 million, or \$12 million in today's dollars (2008) according to founder Keith Clark. Clark was acutely aware of the extent of this financial loss, as it was his development company's money which was founding the start-up of IBS. Business and personal bankruptcy had implications for the personal lives and family of the IBS members. Clark acknowledges that it was a very difficult time and contributed to the breakdown of his marital relationship.

After the collapse there were three prongs of further advancement. Firstly, according to Hay, marketing manager Peter Debreceny took over the US opportunities and invited a high-quality US mobile home manufacturer to make a two-storey house in Ohio. Secondly, according to Clark, Sam Wright came out from Ohio and was interested to learn from IBS's mistakes. He overhauled all the files and conducted an analysis which advocated for the service core designs and overall methodology. And thirdly, Barry Beazley from Beazley Homes, and his son were handed the IBS files and adopted many aspects of the system in Queensland, but they substituted steel for the timber structure (Clark, Letter).

\section{IBS challenges}

The IBS team encountered a number of challenging situations in bringing a prefabricated architectural factory-made product to the New Zealand market. The conversion from an imperial to a metric based system was concurrent with the IBS product development. At one stage they commented on the difficulty of this, while there is a clear programme for the metrication of the construction industry, there is no apparent programme for the metrication and dimensional coordination of manufactured appliances around which houses are constructed (Mountier Designscape 1973: 9). 
Ultimately they achieved the technology, but they did not achieve either the market or the finance. IBS didn't have a business plan or any market research, but they did conduct a feasibility study after the Demonstration House was built in Avondale. On a technical note, they have identified that it was too much of a challenge to have a design which depended on one-off components. Both Keith Clark and Owen McShane have identified the mistake of designing too many components from scratch, therefore incurring a high cost to bring everything to market. It is widely agreed that a better approach would have been to employ a greater number of off-theshelf components. Roger Hay has backed up these comments by advocating simplicity through a closed system for the structure, and an open system for additive components such as windows and fittings for bathroom, laundry and kitchen. For example, he thinks that the IBS timber windows should have been replaced by Aluminium off-the-shelf joinery (Hay, Interview 23 Apr. 2008).

Some IBS members have noted that the disagreement amongst the team was a challenge which contributed to its demise (refer to sub-section on IBS's demise). IBS could not afford any internal political strife, as it was difficult enough to deal with external relationships and perceptions. Roger Hay spoke of the 'tall-poppy' syndrome in New Zealand and Ivan Juriss mentioned being derided by their architecture profession peers. He said the NZIA, and Peter Middleton in particular, opposed the idea, and peers derided and laughed. This was all despite the success of the time of international architects interested in prefabrication, such as France's Jean Prouve.

It is interesting to look at the barriers that perceptions had at the time. Architecture profession perceptions were mentioned, but larger consumer market perceptions and those of the construction industry, were also hugely influential. According to Juriss, the IBS system was ahead of it's time: the "time wasn't right". In terms of consumer perceptions, people had "opposition to that sort of thing... especially people today... they like change...". According to Hay, the New Zealand financial industry wanted IBS to conform to public expectations by providing a tiled roof, or by reducing the overall cost by $25 \%$. This was an outlandish request, and goes to show that one of IBS's greatest challenges was in being ahead of their time. Their flat-roofed modernist modules were unacceptable to the New Zealand public's perceptions of 'home' at the time.

The local construction industry was not set up to be able to service and support a housing factory operation of this size. According to Hay, the Untied States mobile home industry had advantages over the local industry because of:

the nationwide network of freeways built by Roosevelt during World War 2 (to provide the ability to move war goods swiftly from coast to coast), plus the increased mobility of labour right across the States (needing cheap instant housing available on hire purchase), plus the ease of providing flat rental plots of land on which to park the mobile homes (no land shortage in the USA and no high-cost land purchases for the banking system to use as the basis for mortgages).

There were also hold-ups in the United States building regulation system where it took 12 months to process IBS's application for their prefabrication system, when it should have taken 3-4 weeks.

External factors ultimately proved to be too challenging. According to McShane, it was due to the late 1970 s recession that research and development funding ultimately dried up. Peter Wong's 1980 undergraduate thesis into industrialized building systems identified that the collapse of IBS was largely due to social, economic and political factors. The change of government was also an important determining factor, as IBS lost a lot of support and opportunities for manufacture.

Today, the industrialised, factory-produced home has not been produced to the scale that IBS envisaged. In Owen McShane's words, "the idea of the prefabricated house as manufactured product has still not been realised".

\section{IBS enduring successes}

IBS predicted their success would be based on "reshaping old attitudes towards mortgaging, building coding and land purchase and development" (Mountier "IBS: an idea whose time has come" np). In fact, their enduring successes were in the research and development focus that they took, and the technological improvements which were created as a result of this focus. 
According to Owen McShane, a number of IBS successes have fuelled research into the Building Research Association. This influence changed the thinking about some building practices which existed at that time. In 1988, ten years after the companies collapse, Roger Hay realised IBS had developed a unique technology but the original patents had since lapsed.

In their ten years of design research and development, IBS:

- Conducted extensive testing into plywood and particle board materials, which are in wide application today (McShane).

- Created the first one-piece fibreglass showers, which are standard today.

- Exploited fencing technology, in their use of the driven timber pile and the idea of treated timber in ground.

- Discovered panelised construction (which is now in use now by cool-store contractors). This was also a precursor to current structurally insulated panel construction (SIPs). IBS used two layers of hardboard together with a sandwich fill made of Pinex insulation.

- Investigated sub-floor systems (McShane).

- Utilised glued joints in-factory, which were secure, reliable, temperature and humidity controlled, and much stronger than any nail system (Hay, Interview 25 Jan. 2008).

- Employed accurate sizing through the use of a special Italian Giben saw and jigs (Hay, Interview 25 Jan. 2008).

- Developed, trademarked and patented the incredibly strong Ribsel flooring panel (Hay, Interview 25 Jan. 2008).

- Conformed to the NZ Building Standards.

IBS was the first to construct prefabricated timber buildings with no tolerances because of the incredibly accurate system. Hay claims this "has never been equalled anywhere else in the world". He believes that this is an integral component to the potential success of this, and any other, prefabricated system. The idea of room modules was unique to IBS at the time. Today it is a technique seen in the NZ bathroom module production by de Geest in Oamaru.

A major advantage of the IBS system was the estimated cost at $14 \%$ cheaper than conventional housing. At the time of their US involvement, Keith Clark knew a traditional stick-built home would cost a minimum of USD $\$ 60,000$, while a mobile home would cost USD $\$ 15,000$. The possibility to deliver more affordable housing drove Clark to set up IBS. Today, in current dollar terms, Clark estimates that an industrialised building system could save up to $25 \%$ on the cost of house construction. He advocates an affordability strategy of matching these cost savings with a $25 \%$ reduction on land costs, as supplied by government. It is a proposal worth advancing for this country's future housing needs.

\section{IBS lessons learnt}

Around 1976-7, the Vice-President of the American Manufactured Housing Industry visited IBS. According to Roger Hay, he spoke with the IBS team about the "entire structure and rationale of the mobile home industry" for nearly two house. Hay was the only one to take notes which is why his memory of this meeting is still clear. The primary advantages of the US industry were the ease of transporting on the freeway network, the large market demand for cheap instant housing, and the seemingly unlimited supply of suitable land. This was a benchmark in Hay's understanding of the differences between the New Zealand and United States industries; a difference which would prove to be insurmountable and directly attribute to the demise of IBS. This meeting was crucial according to Hay, because:

"...if Ivan Juriss and Owen McShane had properly understood that essential background from their journey around the USA in 1969/70, they would have logically turned to a prefabricated system of site-assembled components, instead of the transportable house concept." (E-mail).

A successful system in the future would respond to two key challenges; how to make the floor and roof from the same factory-made prefabricated panels; and how to swiftly and accurately assemble the components on site (Hay). The answers may be in a Ribsel-type stressed-skin panel and in an assembly and fixing system of dimensional accuracy which is yet to be determined. The future of the New Zealand prefabrication industry cannot afford to ignore the knowledge that a team of dedicated and passionate minds created 35 years ago. Many of the issues they faced then are the same as the ones we face today. Perceptions, technology and techniques have not changed dramatically in the New Zealand construction industry. We should 
heed their advice and ideas towards the future, and find an appropriate way to both protect the 'know-how' and make information available to prefabrication industry members.

\section{Works Cited}

Clark, Keith. Personal Interview. 4 Feb. 2008.

Clark, Keith. Letter to the author. 5 Mar. 2008.

Cole, Ray. Personal Interview. 20 Jul. 2007.

Hay, Roger. Personal Interview. 25 Jan. 2008.

Hay, Roger. E-mail to the author. 29 Jan. 2008.

Hay, Roger. Personal Interview. 23 Apr. 2008.

Mountier, Mary. "100 Issues: highlights from the past" Designscape 100. Mar. 1978: 27-54.

---. "IBS" Designscape 50. Aug. 1973: 1-16.

---. "IBS: an idea whose time has come." Designscape 35. Apr. 1972: np.

Juriss, Ivan. Personal Interview. 30 Nov. 2007.

McShane, Owen. Personal Interview. 23 Jan. 2008.

Western-Russell, Les. E-mail to the author. 26 Mar. 2008.

Wong, Peter. "Industrialised Building Systems: with specific reference to the domestic sector of the New Zealand building industry." BArch thesis. Victoria University of Wellington, 1980. 


\section{Appendix E}

\section{Table of Findings: New Zealand Prefabricated Housing Businesses}

The following results were gathered from first-hand interviews and subsequent research into the New Zealand prefabricated housing industry. It includes businesses and market segments, but not historical government-funded schemes. The businesses are listed alphabetically according to the name of the prefabricated product or system used. The findings were used towards the case study section of this thesis (refer to Chapters 2, 3 and 5).

\begin{tabular}{|c|c|c|c|c|c|c|c|}
\hline $\begin{array}{l}\text { Product } \\
\text { Name } \\
(\mathrm{A}-\mathrm{Z})\end{array}$ & $\begin{array}{l}\text { Company } \\
\text { Name }\end{array}$ & Year & $\begin{array}{l}\text { Prefabrication } \\
\text { Method }\end{array}$ & Merits & Challenges & $\begin{array}{l}\text { Future } \\
\text { Thoughts }\end{array}$ & Website Address \\
\hline Alpinehaus & $\begin{array}{l}\text { Alpinehaus } \\
\text { (with Clutha } \\
\text { Homes) }\end{array}$ & $\begin{array}{l}2003- \\
2005\end{array}$ & $\begin{array}{l}\text { Complete } \\
\text { building } \\
\text { (timber-frame) }\end{array}$ & $\begin{array}{l}\text { Modern design, } \\
\text { complete finish to } \\
\text { site, market interest }\end{array}$ & $\begin{array}{l}\text { Changing } \\
\text { market demand, } \\
\text { competition from } \\
\text { larger traditional } \\
\text { building } \\
\text { networks }\end{array}$ & $\begin{array}{l}\text { No longer in } \\
\text { operation }\end{array}$ & $\mathrm{n} / \mathrm{a}$ \\
\hline Bach2go & $\begin{array}{l}\text { Oulsman and } \\
\text { Spiers }\end{array}$ & $\begin{array}{l}2008- \\
\text { today }\end{array}$ & $\begin{array}{l}\text { Complete } \\
\text { building } \\
\text { (timber-frame) }\end{array}$ & $\begin{array}{l}\text { Architect-designed, } \\
\text { show-home with } \\
\text { accommodation } \\
\text { option, medium- } \\
\text { cost, some design } \\
\text { options }\end{array}$ & $\begin{array}{l}\text { Current } \\
\text { economic } \\
\text { conditions }\end{array}$ & $\begin{array}{l}\text { Eco-bach options } \\
\text { to be released in } \\
2009 \text { (information } \\
\text { from website only) }\end{array}$ & bach2go.co.nz \\
\hline Bachkit & $\begin{array}{l}\text { Developed by } \\
\text { Andre } \\
\text { Hodgskin } \\
\text { Architects } \\
\text { (with others), } \\
\text { sold to Replica } \\
\text { Homes in } \\
2001 \text { (now } \\
\text { Replica } \\
\text { Architects) }\end{array}$ & $\begin{array}{l}2000- \\
\text { today }\end{array}$ & $\begin{array}{l}\text { Component } \\
\text { (steel and } \\
\text { timber) }\end{array}$ & $\begin{array}{l}\text { Architect-designed } \\
\text { Modernist aesthetic } \\
\text { (innovative), } \\
\text { introduced new } \\
\text { customers to } \\
\text { Replica, original } \\
\text { slick marketing and } \\
\text { media interest at } \\
\text { inception, recent } \\
\text { Australian } \\
\text { distributor } \\
\text { established }\end{array}$ & $\begin{array}{l}\text { Failed research } \\
\text { and } \\
\text { development } \\
\text { partnerships, } \\
\text { limited consumer } \\
\text { demand due to } \\
\text { high-price, } \\
\text { limited design } \\
\text { offering }\end{array}$ & $\begin{array}{l}\text { International focus, } \\
\text { and explore } \\
\text { containerisation, } \\
\text { and modular } \\
\text { methods etc. }\end{array}$ & bachkit.co.nz \\
\hline
\end{tabular}




\begin{tabular}{|c|c|c|c|c|c|c|c|}
\hline $\begin{array}{l}\text { Beazley } \\
\text { Homes }\end{array}$ & $\begin{array}{l}\text { Beazley } \\
\text { Homes }\end{array}$ & $\begin{array}{l}1953- \\
\text { mid- } \\
1980 s\end{array}$ & $\begin{array}{l}\text { Component } \\
\text { (pre-cut } \\
\text { timber), and } \\
\text { Complete } \\
\text { building (steel- } \\
\text { frame) }\end{array}$ & $\begin{array}{l}\text { Pioneered pre-cut } \\
\text { methods, kitset } \\
\text { system exported, } \\
\text { local market } \\
\text { supplied direct from } \\
\text { yard via rail system }\end{array}$ & $\begin{array}{l}\text { Proliferation of } \\
\text { pre-cut } \\
\text { businesses } \\
\text { around the } \\
\text { country, } \\
\text { competition from } \\
\text { larger export } \\
\text { markets }\end{array}$ & $\begin{array}{l}\text { No longer in } \\
\text { operation }\end{array}$ & $\mathrm{n} / \mathrm{a}$ \\
\hline $\begin{array}{l}\text { Conecta } \\
\text { (Signature } \\
\text { Homes } \\
1979-1990 \text { s) }\end{array}$ & $\begin{array}{l}\text { Conecta } \\
\text { (Fletchers } \\
\text { 1979-1990s) }\end{array}$ & $\begin{array}{l}1971- \\
2006\end{array}$ & $\begin{array}{l}\text { Component } \\
\text { (solid timber) }\end{array}$ & $\begin{array}{l}\text { Flexible system, } \\
\text { lower-priced } \\
\text { housing, out- } \\
\text { sourcing }\end{array}$ & $\begin{array}{l}\text { Low consumer } \\
\text { demand, } \\
\text { misperceptions, } \\
\text { marketing and } \\
\text { communication }\end{array}$ & $\begin{array}{l}\text { No longer in } \\
\text { operation }\end{array}$ & $\mathrm{n} / \mathrm{a}$ \\
\hline De Geest & $\begin{array}{l}\text { De Geest } \\
\text { Construction }\end{array}$ & $\begin{array}{l}1955- \\
\text { today }\end{array}$ & Modular & $\begin{array}{l}\text { Pioneering Dutch } \\
\text { innovation, supply } \\
\text { to hydro-schemes, } \\
\text { current focus on } \\
\text { bathroom pods, } \\
\text { retained staff } \\
\text { knowledge, low } \\
\text { competition, direct } \\
\text { marketing, product } \\
\text { diversification }\end{array}$ & $\begin{array}{l}\text { Customer } \\
\text { misperceptions, } \\
\text { traditional tender } \\
\text { costing, } \\
\text { unwillingness to } \\
\text { invest in } \\
\text { technology }\end{array}$ & $\begin{array}{l}\text { Potential to sell } \\
\text { successful } \\
\text { bathroom } \\
\text { operations to a } \\
\text { larger business }\end{array}$ & degeest.com \\
\hline $\begin{array}{l}\text { Drop-Loc } \\
\text { Building } \\
\text { System }\end{array}$ & $\begin{array}{l}\text { Bay Property } \\
\text { Care }\end{array}$ & $\begin{array}{l}2005- \\
\text { today } \\
\text { (R\&D) }\end{array}$ & Panel (timber) & $\begin{array}{l}\text { Low-cost basic } \\
\text { housing, complete } \\
\text { closed panels to } \\
\text { site, quick assembly } \\
\text { time, durable } \\
\text { materials }\end{array}$ & $\begin{array}{l}\text { Financial } \\
\text { investment for } \\
\text { start-up period, } \\
\text { marketing }\end{array}$ & $\begin{array}{l}\text { Pursuing market } \\
\text { opportunities, } \\
\text { system has } \\
\text { potential to supply } \\
\text { large numbers of } \\
\text { low-cost housing if } \\
\text { market is } \\
\text { established }\end{array}$ & $n / a$ \\
\hline
\end{tabular}




\begin{tabular}{|c|c|c|c|c|c|c|c|}
\hline $\begin{array}{l}\text { Grove } \\
\text { Lifestyle } \\
\text { Homes }\end{array}$ & Fentech & $\begin{array}{l}1999- \\
\text { today }\end{array}$ & $\begin{array}{l}\text { Component } \\
\text { (pre-nail } \\
\text { timber), and } \\
\text { Panel (timber) }\end{array}$ & $\begin{array}{l}\text { Lower-priced } \\
\text { housing, national } \\
\text { franchise network }\end{array}$ & $\begin{array}{l}\text { Limited design and } \\
\text { material options, } \\
\text { changing building } \\
\text { code regulations }\end{array}$ & $\begin{array}{l}\text { No comments } \\
\text { (information from } \\
\text { website only) }\end{array}$ & $\mathrm{n} / \mathrm{a}$ \\
\hline $\begin{array}{l}\text { Habode and } \\
\text { i-houz }\end{array}$ & Habode IP & $\begin{array}{l}2000- \\
\text { today } \\
\text { (incl. } \\
\text { R\&D) }\end{array}$ & $\begin{array}{l}\text { Complete } \\
\text { building (steel- } \\
\text { frame) }\end{array}$ & $\begin{array}{l}\text { International focus } \\
\text { for manufacture / } \\
\text { distribution / sales, } \\
\text { extensive R\&D, IP } \\
\text { protection, clever } \\
\text { out-of-the-box } \\
\text { design, high } \\
\text { consumer interest } \\
\text { reported }\end{array}$ & $\begin{array}{l}\text { Large start-up } \\
\text { investment, R\&D } \\
\text { joint venture } \\
\text { difficulties, local } \\
\text { industry } \\
\text { uncooperative, } \\
\text { industry and } \\
\text { consumer } \\
\text { misperceptions }\end{array}$ & $\begin{array}{l}\text { Large } \\
\text { manufacturing } \\
\text { capabilities and } \\
\text { large consumer } \\
\text { demand }\end{array}$ & $\frac{\text { habode.com }}{\text { ihouz.com }}$ \\
\hline $\begin{array}{l}\text { Industrialise } \\
\text { d Building } \\
\text { Systems } \\
\text { (IBS) }\end{array}$ & $\begin{array}{l}\text { Industrialised } \\
\text { Building } \\
\text { Systems (IBS) }\end{array}$ & $\begin{array}{l}\text { late- } \\
1960 \mathrm{~s} \\
- \\
\text { late- } \\
1970 \mathrm{~s}\end{array}$ & Modular & $\begin{array}{l}\text { Innovative systems } \\
\text { (Ribsel, one-piece } \\
\text { bathrooms, } \\
\text { stressed-skin wall } \\
\text { panels), } \\
\text { international } \\
\text { research, high- } \\
\text { levels customer } \\
\text { interest }\end{array}$ & $\begin{array}{l}\text { Economic recession, } \\
\text { industry } \\
\text { misperceptions, } \\
\text { financial and } \\
\text { marketing planning }\end{array}$ & $\begin{array}{l}\text { No longer in } \\
\text { operation }\end{array}$ & $\mathrm{n} / \mathrm{a}$ \\
\hline Ipad & Architex & $\begin{array}{l}2007- \\
\text { today } \\
(R \& D)\end{array}$ & $\begin{array}{l}\text { Complete } \\
\text { building (steel- } \\
\text { frame) }\end{array}$ & $\begin{array}{l}\text { Architect-designed, } \\
\text { show-home at } \\
\text { home show, media } \\
\text { publicity, out-of-the- } \\
\text { box design, neo- } \\
\text { Modernist aesthetic, } \\
\text { iterative prototype } \\
\text { process }\end{array}$ & $\begin{array}{l}\text { Current economic } \\
\text { conditions, high } \\
\text { consumer interest } \\
\text { but low consumer } \\
\text { demand, lack of } \\
\text { industry } \\
\text { collaboration }\end{array}$ & $\begin{array}{l}\text { In start-up phase } \\
\text { of finding a market } \\
\text { for this product. }\end{array}$ & ipad.net.nz \\
\hline $\begin{array}{l}\text { Keith Hay } \\
\text { Homes } \\
(\mathrm{KHH})\end{array}$ & $\begin{array}{l}\text { Keith Hay } \\
\text { Homes }\end{array}$ & $\begin{array}{l}1949- \\
\text { today }\end{array}$ & $\begin{array}{l}\text { Component } \\
\text { (pre-cut } \\
\text { timber), and } \\
\text { Complete } \\
\text { building } \\
\text { (timber-frame) }\end{array}$ & $\begin{array}{l}\text { Pioneered use of } \\
\text { pine timber and } \\
\text { other materials, } \\
\text { supply to hydro- } \\
\text { schemes, lower- } \\
\text { priced housing }\end{array}$ & $\begin{array}{l}\text { Limited aesthetic } \\
\text { design and material } \\
\text { options, changing } \\
\text { building code } \\
\text { regulations }\end{array}$ & No comments & keithhayhomes.co.nz \\
\hline
\end{tabular}




\begin{tabular}{|c|c|c|c|c|c|c|c|}
\hline $\begin{array}{l}\text { Koastline } \\
\text { Beachouses }\end{array}$ & $\begin{array}{l}\text { Kodesign } \\
\text { Builders }\end{array}$ & $\begin{array}{l}2006- \\
\text { today } \\
(R \& D)\end{array}$ & $\begin{array}{l}\text { Complete } \\
\text { building } \\
\text { (timber-frame) }\end{array}$ & $\begin{array}{l}\text { Architect-designed, } \\
\text { durable high-quality } \\
\text { materials, clever } \\
\text { design planning, } \\
\text { indoor factory } \\
\text { construction }\end{array}$ & $\begin{array}{l}\text { Marketing to } \\
\text { convince consumers } \\
\text { of higher-price for } \\
\text { better design, } \\
\text { current economic } \\
\text { conditions and } \\
\text { regional sales } \\
\text { difficulties }\end{array}$ & $\begin{array}{l}\text { Prototype placed } \\
\text { on market, project } \\
\text { put on hold while } \\
\text { Kodesign } \\
\text { concentrate on } \\
\text { their GJ Gardner } \\
\text { design-and-build } \\
\text { franchise }\end{array}$ & $\mathrm{n} / \mathrm{a}$ \\
\hline $\begin{array}{l}\text { Laing } \\
\text { Homes }\end{array}$ & Laing Homes & $\begin{array}{l}2000- \\
\text { today }\end{array}$ & $\begin{array}{l}\text { Complete } \\
\text { building (timber } \\
\text { MAXIM panel) }\end{array}$ & $\begin{array}{l}\text { Recent architect- } \\
\text { designs, lower-cost } \\
\text { housing, yard- } \\
\text { controlled } \\
\text { conditions, strong } \\
\text { supplier } \\
\text { relationships, show- } \\
\text { homes }\end{array}$ & $\begin{array}{l}\text { Limited South Island } \\
\text { market, multiple } \\
\text { building consents } \\
\text { needed, consumer } \\
\text { misperceptions }\end{array}$ & $\begin{array}{l}\text { Suggests an } \\
\text { industry-wide } \\
\text { umbrella } \\
\text { organisation, } \\
\text { portal website, } \\
\text { deregulation, } \\
\text { subsidies, and } \\
\text { education }\end{array}$ & laing.co.nz \\
\hline $\begin{array}{l}\text { Light } \\
\text { Modular } \\
\text { Construction } \\
\text { (LMC) }\end{array}$ & $\begin{array}{l}\text { Light Modular } \\
\text { Construction }\end{array}$ & $\begin{array}{l}\text { late- } \\
1960 \text { s } \\
- \\
1978\end{array}$ & $\begin{array}{l}\text { Panel (closed, } \\
\text { structural, } \\
\text { timber) }\end{array}$ & $\begin{array}{l}\text { Precision } \\
\text { tolerances, } \\
\text { complete finishing } \\
\text { (panels contained } \\
\text { services) }\end{array}$ & $\begin{array}{l}\text { Economic recession, } \\
\text { limited designs, low } \\
\text { consumer demand }\end{array}$ & $\begin{array}{l}\text { No longer in } \\
\text { operation }\end{array}$ & $\mathrm{n} / \mathrm{a}$ \\
\hline Lockwood & $\begin{array}{l}\text { Lockwood } \\
\text { Group }\end{array}$ & $\begin{array}{l}1954- \\
\text { today }\end{array}$ & $\begin{array}{l}\text { Component } \\
\text { (solid timber) }\end{array}$ & $\begin{array}{l}\text { Flexible system, } \\
\text { established } \\
\text { marketing } \\
\text { (architect-designs, } \\
\text { show-homes and } \\
\text { plan-books), } \\
\text { national franchise } \\
\text { network, privately- } \\
\text { owned structure } \\
\text { enabling R\&D } \\
\text { investment }\end{array}$ & $\begin{array}{l}\text { Building code } \\
\text { compliance for } \\
\text { insulation and } \\
\text { structure, cultural } \\
\text { consumer shift, } \\
\text { other solid timber } \\
\text { component } \\
\text { competitors }\end{array}$ & $\begin{array}{l}\text { Move towards } \\
\text { panelised and } \\
\text { modular prefab } \\
\text { methods, CNC } \\
\text { technology etc. }\end{array}$ & lockwood.co.nz \\
\hline $\begin{array}{l}\text { Maxim } \\
\text { Panel }\end{array}$ & $\begin{array}{l}\text { Fletcher's The } \\
\text { Laminex } \\
\text { Group, re- } \\
\text { manufactured } \\
\text { by } \\
\text { Maximpanel } \\
\end{array}$ & $\begin{array}{l}1996- \\
\text { today }\end{array}$ & $\begin{array}{l}\text { Panel (timber } \\
\text { particles in } \\
\text { resin) }\end{array}$ & $\begin{array}{l}\text { Durable, structural, } \\
\text { fast installation, } \\
\text { large panel span, } \\
\text { nationwide network } \\
\text { of licensed builders }\end{array}$ & $\begin{array}{l}\text { Marketing, } \\
\text { consumer } \\
\text { misperceptions, } \\
\text { industry domination } \\
\text { by traditional timber } \\
\text { products }\end{array}$ & No comments & maxim.co.nz \\
\hline
\end{tabular}




\begin{tabular}{|c|c|c|c|c|c|c|c|}
\hline $\begin{array}{l}\text { McRaeway } \\
\text { Homes }\end{array}$ & $\begin{array}{l}\text { McRaeway } \\
\text { Homes }\end{array}$ & $\begin{array}{l}1965- \\
\text { today }\end{array}$ & $\begin{array}{l}\text { Complete } \\
\text { building } \\
\text { (timber-frame) }\end{array}$ & $\begin{array}{l}\text { Pioneered kitset } \\
\text { system, supply to } \\
\text { hydro-schemes, } \\
\text { lower-cost housing, } \\
\text { recent architect- } \\
\text { designs, show- } \\
\text { homes, R\&D }\end{array}$ & $\begin{array}{l}\text { Current economic } \\
\text { conditions, high } \\
\text { costs of R\&D, } \\
\text { consumer } \\
\text { misperceptions }\end{array}$ & $\begin{array}{l}\text { Move towards } \\
\text { more architect- } \\
\text { designed and } \\
\text { modular housing }\end{array}$ & mcraeway.co.nz \\
\hline Model T & $\begin{array}{l}\text { The } \\
\text { Wellington } \\
\text { Company }\end{array}$ & $\begin{array}{l}2007- \\
\text { today } \\
\text { (R\&D) }\end{array}$ & $\begin{array}{l}\text { Hybrid } \\
\text { (concrete panel } \\
\text { and utility } \\
\text { module) }\end{array}$ & $\begin{array}{l}\text { Architect-designed, } \\
\text { low-cost housing, } \\
\text { potential client } \\
\text { interest }\end{array}$ & $\begin{array}{l}\text { Current economic } \\
\text { conditions, high land } \\
\text { costs, multi-unit } \\
(10 x) \text { to achieve low- } \\
\text { costs }\end{array}$ & $\begin{array}{l}\text { Potential to supply } \\
\text { large numbers of } \\
\text { well-designed low- } \\
\text { cost housing }\end{array}$ & $\begin{array}{l}\text { thewellingtoncompany } \\
\text { co.nz }\end{array}$ \\
\hline Mod-pod & Haven NZ Ltd & $\begin{array}{l}2002- \\
\text { today }\end{array}$ & $\begin{array}{l}\text { Modular } \\
\text { planning (not } \\
\text { construction) }\end{array}$ & $\begin{array}{l}\text { Show-home at } \\
\text { Home Show event, } \\
\text { modern aesthetic }\end{array}$ & $\begin{array}{l}\text { Low volume built to } \\
\text { date, built work is } \\
\text { iterations of } \\
\text { prototype, modular } \\
\text { intention not fulfilled }\end{array}$ & $\begin{array}{l}\text { Further } \\
\text { prefabrication } \\
\text { methods } \\
\text { envisaged in } \\
\text { future }\end{array}$ & haven.co.nz/pod/ \\
\hline Modulock & $\begin{array}{l}\text { Modulock } \\
\text { (Lanwood } \\
\text { Industries } \\
\text { 1981-today) }\end{array}$ & $\begin{array}{l}\text { early } \\
1970 \text { s } \\
- \\
\text { mid- } \\
1990 \text { s }\end{array}$ & $\begin{array}{l}\text { Component } \\
\text { (panel and post } \\
\text { timber) }\end{array}$ & $\begin{array}{l}\text { Complete } \\
\text { component system, } \\
\text { flexible design } \\
\text { outcomes }\end{array}$ & $\begin{array}{l}\text { Cladding material } \\
\text { failure, adverse } \\
\text { publicity, legal costs }\end{array}$ & $\begin{array}{l}\text { No longer in } \\
\text { operation - name } \\
\text { used for metal } \\
\text { SIPs portable units }\end{array}$ & $\mathrm{n} / \mathrm{a}$ \\
\hline Pinespan & $\begin{array}{l}\text { Pinecone } \\
\text { Timber } \\
\text { Buildings }\end{array}$ & $\begin{array}{l}2006- \\
\text { today }\end{array}$ & $\begin{array}{l}\text { Component } \\
\text { (timber-frame) }\end{array}$ & $\begin{array}{l}\text { Use of CNC } \\
\text { technology, hands- } \\
\text { on R\&D, prototype, } \\
\text { high-visibility site }\end{array}$ & $\begin{array}{l}\text { Competition from } \\
\text { steel technology }\end{array}$ & $\begin{array}{l}\text { Offshore clients for } \\
\text { post-disaster } \\
\text { housing, continued } \\
\text { R\&D }\end{array}$ & pinespan.co.nz \\
\hline Port-a-bach & $\begin{array}{l}\text { Atelier } \\
\text { Workshop }\end{array}$ & $\begin{array}{l}2006- \\
\text { today } \\
\text { (R\&D) }\end{array}$ & $\begin{array}{l}\text { Complete } \\
\text { building (steel } \\
\text { container) }\end{array}$ & $\begin{array}{l}\text { Architect-design, } \\
\text { prototype as brand, } \\
\text { self-directed media } \\
\text { publicity, potential } \\
\text { for a sustainable } \\
\text { iterative prototype, } \\
\text { offshore } \\
\text { manufacture }\end{array}$ & $\begin{array}{l}\text { Matching high- } \\
\text { quality design with } \\
\text { manufacture, further } \\
\text { product refinement, } \\
\text { integration of } \\
\text { sustainable } \\
\text { technologies }\end{array}$ & $\begin{array}{l}\text { Looking for } \\
\text { commercial } \\
\text { partners to take } \\
\text { product to market, } \\
\text { and working with } \\
\text { Masters student to } \\
\text { research } \\
\text { sustainability }\end{array}$ & port-a-bach.com \\
\hline $\begin{array}{l}\text { Precast } \\
\text { concrete }\end{array}$ & $\begin{array}{l}\text { Manufacturers } \\
\text { represented } \\
\text { by Precast NZ }\end{array}$ & $\begin{array}{l}\text { late } \\
1990 \mathrm{~s} \\
- \\
\text { today }\end{array}$ & $\begin{array}{l}\text { Panel (concrete } \\
\text { - some with } \\
\text { insulation) }\end{array}$ & $\begin{array}{l}\text { High thermal mass } \\
\text { and durability, quick } \\
\text { installation, casting } \\
\text { design potential }\end{array}$ & $\begin{array}{l}\text { High cost due to low } \\
\text { economies of scale, } \\
\text { low use in residential } \\
\text { applications }\end{array}$ & $\begin{array}{l}\text { More } \\
\text { standardisation is } \\
\text { needed for costs } \\
\text { to come down }\end{array}$ & precastnz.org.nz \\
\hline
\end{tabular}




\begin{tabular}{|c|c|c|c|c|c|c|c|}
\hline $\begin{array}{l}\text { Pre-nailed } \\
\text { components }\end{array}$ & $\begin{array}{l}\text { Various - } \\
\text { includes } \\
\text { Carters } \\
\text { Manufacturing } \\
\text { (Rotorua) }\end{array}$ & $\begin{array}{l}\text { late } \\
1970 \text { s } \\
- \\
2008\end{array}$ & $\begin{array}{l}\text { Component } \\
\text { (pre-nailed } \\
\text { timber) }\end{array}$ & $\begin{array}{l}\text { Use of CNC } \\
\text { technology }\end{array}$ & $\begin{array}{l}\text { Current economic } \\
\text { recession, } \\
\text { construction industry } \\
\text { cyclical demand, } \\
\text { other regional pre- } \\
\text { nail suppliers }\end{array}$ & $\begin{array}{l}\text { No longer in } \\
\text { operation }\end{array}$ & carters.co.nz/trade/ \\
\hline Quick Living & $\begin{array}{l}\text { Module } \\
\text { Creative Ltd }\end{array}$ & $\begin{array}{l}2008- \\
\text { today }\end{array}$ & $\begin{array}{l}\text { Hybrid-type } \\
\text { (flat-pack } \\
\text { components } \\
\text { and modular } \\
\text { cabinetry) }\end{array}$ & $\begin{array}{l}\text { Some customer } \\
\text { choice in material } \\
\text { finishes, existing } \\
\text { suppliers packaged } \\
\text { together }\end{array}$ & $\begin{array}{l}\text { Limited aesthetic } \\
\text { design options }\end{array}$ & $\begin{array}{l}\text { Start-up phase of } \\
\text { establishing new } \\
\text { business venture }\end{array}$ & quickliving.co.nz \\
\hline $\begin{array}{l}\text { Relax } \\
\text { Series }\end{array}$ & $\begin{array}{l}\text { Developed by } \\
\text { Architects } \\
\text { Patterson, } \\
\text { later sold to } \\
\text { Architects } \\
\text { Homes }\end{array}$ & $\begin{array}{l}2002- \\
2006\end{array}$ & $\begin{array}{l}\text { Complete } \\
\text { building }\end{array}$ & $\begin{array}{l}\text { Architect-designed, } \\
\text { factory- } \\
\text { construction, high- } \\
\text { quality product }\end{array}$ & $\begin{array}{l}\text { Lack of } \\
\text { infrastructure and } \\
\text { market demand, size } \\
\text { constraints due to } \\
\text { transportation, } \\
\text { misperceptions of } \\
\text { cost by public }\end{array}$ & $\begin{array}{l}\text { No longer in } \\
\text { operation - future } \\
\text { seen to be in } \\
\text { volume housing }\end{array}$ & $\mathrm{n} / \mathrm{a}$ \\
\hline Solwood & $\begin{array}{l}\text { Natusch and } \\
\text { Sons }\end{array}$ & $\begin{array}{l}\text { early } \\
1950 \mathrm{~s} \\
\text { - late } \\
1950 \mathrm{~s}\end{array}$ & $\begin{array}{l}\text { Component } \\
\text { (solid timber) }\end{array}$ & $\begin{array}{l}\text { Flexible system, } \\
\text { use of pine timber, } \\
\text { public acceptance }\end{array}$ & $\begin{array}{l}\text { Council permit } \\
\text { process, industry } \\
\text { misperceptions, } \\
\text { financial difficulties, } \\
\text { quality of material } \\
\text { supply }\end{array}$ & $\begin{array}{l}\text { No longer in } \\
\text { operation }\end{array}$ & $\mathrm{n} / \mathrm{a}$ \\
\hline $\begin{array}{l}\text { Strawberry } \\
\text { Homes }\end{array}$ & $\begin{array}{l}\text { Globe } \\
\text { Holdings }\end{array}$ & $\begin{array}{l}2008- \\
\text { today }\end{array}$ & $\begin{array}{l}\text { Panel (timber } \\
\text { particles in } \\
\text { resin) }\end{array}$ & $\begin{array}{l}\text { Factory production, } \\
\text { durable panel } \\
\text { material, architect- } \\
\text { design (Roger } \\
\text { Walker) }\end{array}$ & $\begin{array}{l}\text { Current economic } \\
\text { recession }\end{array}$ & $\begin{array}{l}\text { Start-up phase of } \\
\text { establishing new } \\
\text { business venture }\end{array}$ & $\begin{array}{l}\text { strawberryhomes.co.n } \\
\underline{z}\end{array}$ \\
\hline $\begin{array}{l}\text { Structurally } \\
\text { Insulated } \\
\text { Panels } \\
\text { (SIPs) }\end{array}$ & $\begin{array}{l}\text { R\&D by } \\
\text { Victoria } \\
\text { University and } \\
\text { others }\end{array}$ & $\begin{array}{l}\text { early } \\
2000 \text { s } \\
- \\
\text { today } \\
\text { (R\&D) }\end{array}$ & $\begin{array}{l}\text { Panel (timber- } \\
\text { insulation } \\
\text { sandwich) }\end{array}$ & $\begin{array}{l}\text { Ease of assembly, } \\
\text { popular in Europe } \\
\text { and North America } \\
\text { for over } 50 \text { years }\end{array}$ & $\begin{array}{l}\text { Not available in NZ, } \\
\text { building code } 50 \\
\text { year durability and } \\
\text { lack of international } \\
\text { testing facilities }\end{array}$ & More R\&D needed & $\mathrm{n} / \mathrm{a}$ \\
\hline
\end{tabular}




\begin{tabular}{|c|c|c|c|c|c|c|c|}
\hline $\begin{array}{l}\text { Stanley } \\
\text { Modular }\end{array}$ & Stanley Group & $\begin{array}{l}2004- \\
\text { today }\end{array}$ & $\begin{array}{l}\text { Panel } \\
\text { (concrete), and } \\
\text { Modular }\end{array}$ & $\begin{array}{l}\text { Factory-controlled } \\
\text { conditions, quick } \\
\text { installation, } \\
\text { emphasis on R\&D, } \\
\text { international joint } \\
\text { ventures }\end{array}$ & $\begin{array}{l}\text { Multi-unit and } \\
\text { commercial } \\
\text { emphasis to date }\end{array}$ & $\begin{array}{l}\text { Material and } \\
\text { systems } R \& D \text { with } \\
\text { other businesses }\end{array}$ & stanleymodular.co.nz \\
\hline Touchwood & Touchwood & $\begin{array}{l}1998- \\
\text { today }\end{array}$ & $\begin{array}{l}\text { Panel (solid } \\
\text { timber) }\end{array}$ & $\begin{array}{l}\text { Lower-cost housing, } \\
\text { nationwide network, } \\
\text { Lockwood know- } \\
\text { how }\end{array}$ & $\begin{array}{l}\text { Marketing, code } \\
\text { compliance }\end{array}$ & No comment & touch-wood.co.nz \\
\hline Triboard & $\begin{array}{l}\text { Durapanel } \\
\text { Systems }\end{array}$ & $\begin{array}{l}1994- \\
\text { today }\end{array}$ & $\begin{array}{l}\text { Component } \\
\text { (pre-nail), and } \\
\text { Panel (timber } \\
\text { particles in } \\
\text { resin) }\end{array}$ & $\begin{array}{l}\text { CNC technology, } \\
\text { high demand from } \\
\text { dairy industry, } \\
\text { support from } \\
\text { ACTRANZ (JNL) }\end{array}$ & $\begin{array}{l}\text { Changing economic } \\
\text { conditions }\end{array}$ & $\begin{array}{l}\text { Support from } \\
\text { supplier for } \\
\text { ongoing work and } \\
\text { marketing }\end{array}$ & durapanel.co.nz \\
\hline Triboard & $\begin{array}{l}\text { Juken New } \\
\text { Zealand (JNL) }\end{array}$ & $\begin{array}{l}1991- \\
\text { today }\end{array}$ & $\begin{array}{l}\text { Panel (timber } \\
\text { particles in } \\
\text { resin) }\end{array}$ & $\begin{array}{l}\text { Durable and } \\
\text { structural, fast } \\
\text { installation, flexible } \\
\text { system, extensive } \\
\text { R\&D by privately- } \\
\text { owned company }\end{array}$ & $\begin{array}{l}\text { Marketing, } \\
\text { consumer } \\
\text { misperceptions, } \\
\text { industry domination } \\
\text { by timber products }\end{array}$ & $\begin{array}{l}\text { More direct } \\
\text { marketing, } \\
\text { pursuing offshore } \\
\text { opportunities, } \\
\text { supplying local } \\
\text { market }\end{array}$ & inl.co.nz \\
\hline $\begin{array}{l}\text { Trower } \\
\text { Panel }\end{array}$ & Trower Panel & $\begin{array}{l}1967- \\
\text { today }\end{array}$ & $\begin{array}{l}\text { Panel (timber } \\
\text { and cardboard) }\end{array}$ & $\begin{array}{l}\text { Light-weight, fast } \\
\text { installation }\end{array}$ & $\begin{array}{l}\text { Increasing } \\
\text { competition from } \\
\text { pre-nail industry }\end{array}$ & No comment & $\mathrm{n} / \mathrm{a}$ \\
\hline $\begin{array}{l}\text { Timber } \\
\text { Construction } \\
\text { Solutions } \\
\text { (TCS) }\end{array}$ & $\begin{array}{l}\text { Tristyle / } \\
\text { Timber } \\
\text { Construction } \\
\text { Solutions } \\
\text { (TCS) }\end{array}$ & $\begin{array}{l}\text { 1990s } \\
- \\
\text { today }\end{array}$ & $\begin{array}{l}\text { Component } \\
\text { (timber frame), } \\
\text { and Panel } \\
\text { (timber) }\end{array}$ & $\begin{array}{l}\text { International focus } \\
\text { (clients and } \\
\text { manufacture), local } \\
\text { marketing, joint } \\
\text { ventures }\end{array}$ & $\begin{array}{l}\text { Re-structure, cost } \\
\text { and length of job } \\
\text { procurement, } \\
\text { international } \\
\text { economies }\end{array}$ & $\begin{array}{l}\text { International focus } \\
\text { for large market } \\
\text { demand (cite } \\
\text { India) }\end{array}$ & tcs.net.nz \\
\hline $\begin{array}{l}\text { Vintage } \\
\text { Homes }\end{array}$ & Roger Walker & $\begin{array}{l}1974- \\
\text { late- } \\
1980 s\end{array}$ & $\begin{array}{l}\text { Component } \\
\text { standardisation } \\
\text { and modular } \\
\text { planning }\end{array}$ & $\begin{array}{l}\text { Flexible } \\
\text { customisable } \\
\text { system }\end{array}$ & $\begin{array}{l}\text { Lack of financial } \\
\text { planning }\end{array}$ & $\begin{array}{l}\text { No longer in } \\
\text { operation }\end{array}$ & $\mathrm{n} / \mathrm{a}$ \\
\hline
\end{tabular}




\section{Appendix F}

Chronological Index 


\section{Glossary}

This glossary has been compiled from terms used within this thesis, as derived from extensive reading on prefabrication. It expands on key terminology explained in Chapter 1 and is for reference whilst reading this thesis on prefabricated housing in New Zealand. Brand and company names can be viewed in the Table of Findings in Appendix E.

\section{bach or crib}

Bach is a colloquial term for a second-home or holiday-home in New Zealand. This term is prevalent in the North Island, while the term crib is used more commonly in the South Island.

\section{block}

A block is another term for a module, pod or unit. This term is used by prefabrication experts Stephen Kieran and James Timberlake (Loblolly House 102).

\section{box-form}

Refer to complete buildings or complete building prefabrication.

\section{building information modelling (BIM)}

BIM is the wider set of integrated software tools of which digital drawing is just one tool. Elements embedded in a three-dimensional digital model are assigned values which can be independently accessed and cross-referenced to produce useful data during the construction coordination process.

\section{cartridge}

A cartridge is a closed panel containing services, ducts, electrical conduits etc. This term is used by prefabrication experts Stephen Kieran and James Timberlake (Loblolly House 82).

\section{cassette}

A cassette is a structural floor panel usually of steel or timber that may or may not contain services (Gibb and Pendlebury).

\section{chunk}

A chunk is a grouping of pre-formed materials into a complex component or module, prior to assembly at the construction site. This term is used by prefabrication experts Stephen Kieran and James Timberlake (Refabricating Architecture 17).

\section{closed panel}

A closed panel is a panelised element that consists of framing with cladding or lining, or both. It may also include integrated services such as plumbing ducts and electrical conduits. See also open panel.

\section{complete buildings or complete building prefabrication}

These are units that enclose usable space and actually form part of the completed building or structure (units may or may not incorporate modular coordinated dimensions). They are typically fully factory finished internally (and possibly also externally), such as edge of town hotel or restaurant facilities and multi-residence housing (Gibb and Pendlebury). New Zealand complete building prefabrication includes the traditional transportable housing industry (as supplied by Laing's Homes and McRaeway Homes). Refer to Chapter 3.

\section{component-based or componentised prefabrication}

Components are relatively small scale items that are invariably assembled offsite, such as light fittings, windows, and door furniture (Buildoffsite Glossary 5). It includes structural members (trussed and frames), fittings, fixtures, and joinery that is cut, sized or shaped away from the site for assembly on site. A complete set of components is commonly referred to as a kit, kit-ofparts, or kitset. New Zealand component-based prefabrication includes pre-nailed products (as supplied by Carters Manufacturing); timber structure (as supplied by Timber Construction Systems); steel-framing, timber sub-floor and joinery components (as supplied by Replica Architects); and interlocking solid timber (as supplied by Lockwood Group). Refer to Chapter 3. 
component subassembly

Refer to component prefabrication.

\section{computer assisted design (CAD)}

Computer software that enables designs to be drawn, rendered, rotated and checked in threedimensions. Commonly-used programs include AutoCAD, ArchiCAD and Revit.

\section{computer numerically controlled (CNC)}

Cutting or machining technology that is controlled by computer programming. It is the interface between computer software and manufacturing hardware which enables designs to be directly translated from digital to physical means without manual interference. The manufacturing sectors use this technology widely, whereas the construction industry generally uses the software to produce drawings, but not physical products. CNC machinery is usually programmed with CAD software.

\section{core}

Refer to modular prefabrication.

\section{crib}

Refer to bach.

\section{Cultural creatives}

Cultural-creatives are those operating on the leading edge of cultural change, and coming up with the most new ideas in United States culture. They tend to be middle to upper-middle class, with a few more on the West Coast than elsewhere. The overall male-female ratio is forty-tosixty, or fifty percent more women than men. Cultural-creatives are a very large pool of people, forty-four million bigger than any comparable socio-economic group (Ray 4).

\section{custom home}

custom designed housing, custom-built on-site from "standard" materials with on-site labourintensive processes (Sylvester).

\section{design-and-build}

The New Zealand residential construction industry has a number of large networks of building companies that provide both design and build services. They are colloquially referred to as design-and-build contractors. Many of these networks were established through the mid-century Group Housing program which is another name that they are known by. Refer to Group Housing.

\section{flat-pack}

This is a collection of panels transported in one package to site. Refer to panelised prefabrication.

\section{green}

The term green describes materials that are designed and manufactured with exceptional regard for their environmental impact (McLendon).

\section{green-washing}

The term green-washing, or greenwashing, refers to the practice of companies deceptively using green public relations and marketing to mask a profit-making focus. One example is in presenting cost-cutting measures as resource-saving measures (Laufer).

\section{'green modern prefab'}

The term 'green modern prefab' refers to prefabricated housing that is architect-designed, has neo-Modernist design aesthetics and exhibits sustainable technologies or features.

\section{Group Housing}

The 1950s Group Housing Scheme guaranteed the government would purchase any house a builder failed to sell within two months of its completion (Ferguson 184). This term is now 
commonly used to describe large networks of design-and-build companies. Refer to designand-build.

\section{hybrid-based or hybridised prefabrication}

Hybrid-based prefabrication is also referred to as semi-volumetric prefabrication. It consists of a mixture of volumetric or modular units and non-volumetric or panelised units (module plus panel). It may also include component and site-built elements. There are currently no examples of hybrid-based prefabrication in production in New Zealand, however systems have been proposed by both The Wellington Company and Herriot and Melhuish Architecture. Refer to Chapter 3.

\section{industrialised housing}

The term industrialised housing was popular in New Zealand in the 1970s and 80s. It refers to a large-scale manufacturing-type approach to construction. Prerequisites for industrialisation include a large consumer market and high volume output. Industrialised systems may use prefabrication, but the two terms are not interchangeable (Hay).

\section{kit, kit-of-parts, or kitset}

This is the set of components prepared away from the construction site which are then assembled on site. Refer to component-based prefabrication.

\section{kit-home}

The housing kit is manufactured and packaged away from site, and assembled at the site (Sylvester).

\section{kiwi}

Kiwis is a colloquial term for New Zealand people, and a Kiwi is a New Zealander or something that is New Zealand. It is also one of New Zealand's national symbols because of the kiwi bird which is unique to New Zealand.

\section{manufactured home}

This is the current industry-preferred term for the former mobile home. Refer to mobile home.

\section{mass-customisation}

This is the use of digital technology and CAD-CAM interfaces to produce individual custom designs from standard manufacturing technologies. Refer to Chapter 1.

\section{method or methodology}

The method or methodology of prefabrication is the type of system employed. It ranges from components, panels, modules, to complete buildings. Refer to type or typology.

\section{mobile home}

This is an obsolete term for manufactured housing in the United States. It is still used in New Zealand to refer to transportable dwellings. A mobile home is manufactured away from site, and transported to the site in a largely completed state with minimal on-site labour. It is a technical term for a structure that was constructed before 15 June 1976 and meets certain criteria defined by the United States Department of Housing and Urban Development (HUD). Regulations distinguish a mobile home from a HUD-code manufactured home which is a structure constructed on or after 15 June 1976 and meeting slightly different criteria. Mobile home is frequently used in the vernacular, even by the HUD who now refers to manufactured (mobile) homes (Sylvester). A mobile home does not conform to building codes and is not necessarily fixed to permanent foundations at the site.

\section{Modern Methods of Construction (MMC)}

MMC is a British term adopted by their Housing Corporation. It refers to both offsite or prefabricated construction technologies and innovative technologies applied at site. The former are explained in this thesis (component, panel, module, hybrid and box-form). The latter include techniques such as thing-joint block-work and tunnel-form construction (Gibb and Pendlebury). 


\section{Modern or Modernist}

Modernist refers to espousing the ideals and aesthetics of Modernism. By contrast, modern is commonly used to mean contemporary. Modernist refers to a particular style of architecture which is influenced (to varying degrees) by the work of the Bauhaus and the International Style. This is a tricky definition because it can imply reverence for some of the most brutal work of the 20th century. Here is one definition of Modernism, "a twentieth-century architectural style characterized by undecorated rectilinear forms and the use of glass, steel, and reinforced concrete" (Collins English Dictionary qtd. in Sylvester).

\section{mod-lines}

After a modular home has been set in place, or assembled on site, the joints between the modular volumes are finished. This is referred to as finishing the mod-lines. This work includes exterior cladding, interior linings and any joining of wiring, plumbing or mechanical systems.

\section{modular home}

This is a house designed using pre-existing modular products or systems and built at the site using a combination of modular and standard materials (Sylvester). A modular home meets building codes and is permanently fixed to a foundation on site.

\section{module-based or modular prefabrication}

These are units that enclose usable space and are then installed within or onto a building or structure. They are typically fully finished internally, such as toilet/bathroom pods or plantrooms (Buildoffsite Glossary 5). Structural units are rooms or large parts of the building referred to as modules, volumes or sections. Non-structural units are used inside conventional buildings or modules, usually to contain utilities, and are referred to as cores or pods. New Zealand module-based prefabrication includes non-structural bathroom modules (as supplied by De Geest Construction and PLB Construction Group); and multi-unit accommodation (as supplied by Stanley Modular). Refer to Chapter 3.

\section{Neo-Modern or Neo-Modernist}

Neo-Modernism is the recent school of philosophical thought reacting to Post-Modernism. It reflects also on the mid-twentieth-century Modernist period. In purely aesthetic terms, it is a return to Modernist aesthetic concerns of purity, simplicity, open-plan, linear and semiindustrialised forms.

\section{non-volumetric preassembly}

This is a large category covering skeletal, planar and complex items which the designer has chosen to assemble in a factory prior to installation, such as above-ceiling service modules and panel systems (Gibb and Pendlebury). Refer also to panelised prefabrication.

\section{offsite or off-site or offsite manufacturing (OSM)}

Offsite is a term used to describe the spectrum of applications where buildings, structures or parts are manufactured and assembled remote from the building site prior to installation in their final position. In other words, moving operations that are traditionally completed onsite to a manufacturing environment. The offsite spectrum is extensive and, currently, the sector is diverse and fragmented (Gibb and Pendlebury).

\section{open panel}

An open panel is a panelised element that consists of framing without cladding or lining. See also closed panel.

\section{panelised home}

building designed using pre-existing panelised products/systems and built on-site using panelised prefab components and "standard" materials (Sylvester).

\section{panel-based or panelised prefabrication}

These are planar units that do not enclose usable space, such as panel systems and cladding panels (Buildoffsite Glossary 5). They may include windows, doors or integrated services, and are either open-framing or closed-in with clad and/or lining. They are transported to site as flatpacks. New Zealand panel-based prefabrication includes compressed timber sheet products 
(such as 'Triboard' and 'MAXIM'); closed panel systems (supplied by Grove Lifestyle Homes and Trower Panel); solid timber panels (supplied by Touchwood); structurally insulated panels (refer to SIPs); and precast concrete panels (supplied by members of Precast New Zealand).

\section{pattern-book}

Refer to plan-book.

pod

Refer to modular prefabrication.

\section{portable housing}

Portable buildings are generally those intended for short-term temporary applications such as utilities at events or site offices. Portable housing infers a small dwelling such as a cabin, studio or sleep-out. It is a commonly misused term, and the term transportable is more applicable to housing. Refer to transportable.

pre-

This prefix indicates any work that is carried out away from site. The specific type of work follows the prefix. For example, pre-insulated elements are insulated away from site. See other terms below.

\section{pre-assembly}

This is a comparative term with prefabrication, as used by Alastair Gibb of Loughborough University.

\section{pre-built}

Refer to prefabricated.

\section{pre-configured, pre-designed or pre-planned}

These terms refer to existing house plans which are designed prior to site knowledge. They may be presented in plan-books or pattern-books for clients to choose from.

\section{plan-book or pattern-book}

This is a collection of house plans which can be applied to various sites.

\section{pre-cut, pre-sized or pre-shaped}

This refers to materials that are cut, sized or shaped away from site for assembly at the stie. Refer to component-based prefabrication.

\section{prefab or prefabricated}

This term is wide open to interpretation but generally refers to on-site assembly from prefabricated components. The components are either generally available when the structure is designed or they are created specifically for the project or designed for reproduction (Fabprefab Glossary). For this thesis, the term prefabricated widely refers to materials or combinations of materials prepared away from the construction site, ranging from components, panels, modules and complete buildings.

\section{pre-nailed}

This refers to complex components of materials that are cut, sized or shaped and joined together using nail-plate technology. Nail-plate technology comprises engineering software, computer-controlled cutting machinery, and steel plate fasteners, as supplied by Mitek and Pryda. It is a technique commonly used for roof trusses and wall framing in traditional housing construction. Refer to component-based prefabrication and pre-engineered.

\section{ready-made}

Term referred to by Marcel Duchamp for fully prefabricated complete buildings (Colomina 68). 
relocated, relocatable housing or 'reloc's

A relocated or relocatable building can be of any style, age, or material. It does not necessarily infer a new prefabricated house. It is a dwelling that is built or assembled at one site and then transported in parts, or in whole, to an entirely different site.

\section{scaffold}

Scaffold refers to the stick or component assembly of the structure. This term is used by prefabrication experts Stephen Kieran and James Timberlake (Loblolly House 82).

\section{section}

A section is part of the building, much like a module. Refer to modular prefabrication.

\section{semi-volumetric prefabrication}

This is an interchangeable term with hybrid prefabrication. Refer to hybrid prefabrication.

\section{setting}

The process of setting a prefabricated house is the assembly at site of modular volumes transported by truck and positioned by crane. The final site-based work is construction to exposed joints between modules, or mod-lines.

\section{show-home}

This is the house built in order to show potential customers and generate further sales of the house. It is often the prototype for a particular housing design. It may be site-built, prefabricated, or built to be transportable.

\section{SIPs or Structurally Insulated Panels}

Panels are typically made using expanded polystyrene (EPS), or polyisocyanurate rigid foam insulation sandwiched between two structural skins of oriented strand board (OSB).SIPs are used as building panels for floors, walls and roofs in residential and commercial buildings. (Sylvester). SIPs are one type of panelised prefabrication.

\section{standardised}

Standardised housing utilises components, methods or processes in which there is regularity, repetition and a background of successful practice. Standardisation is useful to gain efficiencies in prefabrication, but it does not infer standardised product or system outcomes.

\section{stick-based prefabrication}

Stick prefabrication refers to lengths of timber which are pre-cut, pre-sized or pre-shaped puzzle-type pieces brought to site for assembly. Refer to componentised prefabrication.

\section{sub-assembly prefabrication}

Refer to component prefabrication.

\section{transportable housing}

Housing that is transportable includes any house that is purposely built in order to be moved to another location. In New Zealand, this includes yard- and factory-built housing which is supplied by a number of businesses.

\section{type or typology}

The type or typology of prefabrication is the method that the system employs. It ranges from components, panels, modules, to complete buildings. Refer to methodology.

\section{volumetric preassembly}

Refer to modular prefabrication. 


\section{Glossary References:}

Colomina, Beatriz. Domesticity at War. Cambridge: MIT, 2007.

Ferguson, Gael. Building the New Zealand Dream. Wellington: Dunmore Press, 1994.

Gibb, Alistair, and Martyn Pendlebury. "Glossary of Terms V1.3." Buildoffsite. July 2006. 11 Jan 2008. <http://www.buildoffsite.co.uk/downloads_publications.htm\#glossary>.

Hay, Roger. Personal Interview. Jan. 252008.

Kieran, Stephen, and James Timberlake. Loblolly House: elements of a new architecture. New York: Princeton AP, 2008.

Kieran, Stephen, and James Timberlake. Refabricating Architecture: how manufacturing methodologies are poised to transform building construction. New York: McGraw-Hill, 2004.

Laufer, William. "Social Accountability and Corporate Greenwashing." Journal of Business Ethics 43.3 (2003): 253-61.

McLendon, Sandy. Prefab Elements: adding custom features to your home. New York: HarperCollins, 2005.

Ray, Paul. "The Rise of Integral Culture.” Noetic Sciences Review 37 (1996): 4.

Sylvester, Michael. "Glossary." Fabprefab 2003. 30 Nov. 2007. <http://www.fabprefab.com/fabfiles/glossary.htm>. 



\section{Cover Images (left to right)}

1. Bachkit by Replica Architects.

Source: <http://www.bachkit.com.au/images/>.

2. Riverside by McRaeway Homes.

Source: Author's photograph, 2008.

3. Model $T$ by Fletcher Architects for The Wellington Company.

Source: R. Palmer, "Affordable 'Model T' House for the Masses" Dominion Post, 29 Mar. 2008: A2.

4. Triboard House by Opus Architects for Juken New Zealand.

Source: Image courtesy of Juken New Zealand.

5. Port-a-bach by Atelier Workshop.

Source: Image courtesy of Atelier Workshop.

6. Habode by Habode IP.

Source: Author's photograph, 2008.

7. EcoSmart range by Dave Strachan for Lockwood Group.

Source: <http://www.lockwood.co.nz/index.asp?pagelD=/>.

8. K-bach by Koastline Beachouses.

Source: <http://www.bookabach.co.nz/holiday_homes/dsp_listing.cfm?bachlD=8444>.

9. Ipad by Architex.

Source: Image courtesy of Architex.

10. Sanctuary 94 by Hill and Miles Architecture for Laing Homes.

Source: Image courtesy of Laing Homes.

11. I-houz by Habode IP.

Source: Author's photograph, 2008.

12. Axis Designer Home by Mark Frazerhurst Architects for PLB Construction Group.

Source: <http://www.axisdesignerhomes.co.nz/contact.html>. 